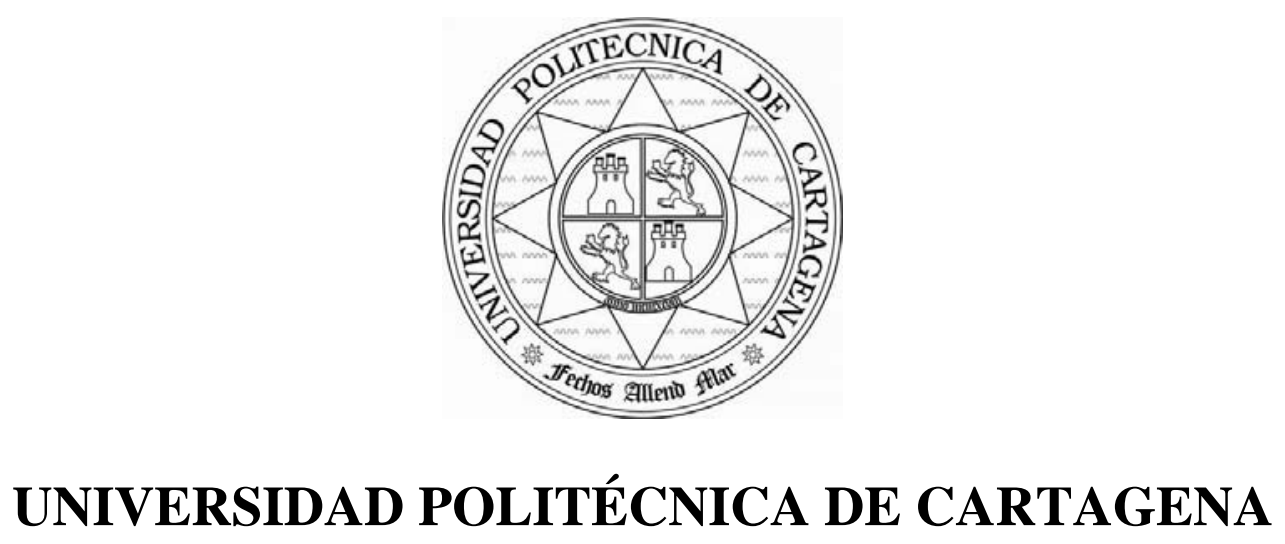

DEPARTAMENTO DE ECONOMÍA DE LA EMPRESA

"DESARROLLO DE UN MODELO DE RECURSOS HUMANOS BASADO EN LOS PROCESOS DE LA ENTIDAD DE NEGOCIO. APLICACIÓN A LOS SISTEMAS LOGÍSTICOS" 


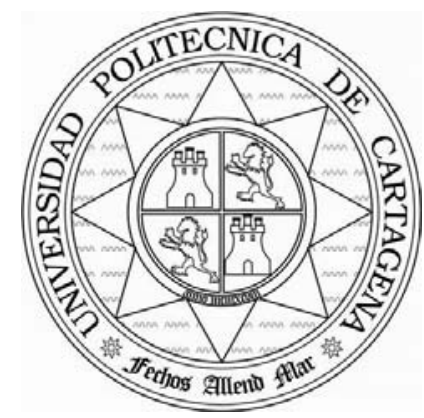

UNIVERSIDAD POLITÉCNICA DE CARTAGENA

DEPARTAMENTO DE ECONOMÍA DE LA EMPRESA

"DESARROLLO DE UN MODELO DE RECURSOS HUMANOS BASADO EN LOS PROCESOS DE LA ENTIDAD DE NEGOCIO. APLICACIÓN A LOS SISTEMAS LOGÍSTICOS"

TESIS DOCTORAL

PRESENTADA POR:

Carmen de Nieves Nieto DIRIGIDA POR

Dr. D. Lorenzo Ros McDonnell 




\section{AGRADECIMIENTOS}

Mis primeras palabras de agradecimiento son para todos aquellos amigos y compañeros que han contribuido con su ánimo y aliento a la finalización de este trabajo.

Agradecer a mis directores de tesis: Lorenzo Ros McDonnell, por el esfuerzo realizado para que este trabajo saliera a la luz, y Alejandro Domínguez Torres, cuya inestimable ayuda y enseñanzas han dado origen a lo que es ahora una Tesis Doctoral.

No puedo pasar por alto la inestimable ayuda de la Directora Técnica del Centro Español de Logística, $\mathrm{D}^{\mathrm{a}}$. Dolores Ruiz por sus ideas, conocimientos y experiencia, así como las facilidades aportadas desde su Institución.

Así mismo, he de recordar a todas las empresas que me abrieron sus puertas y dedicaron parte de su valioso tiempo, ya que con sus explicaciones y experiencias, facilitaron la contrastación del Modelo aportado.

Finalmente no puedo dejar de mencionar a Miguel, cuyo aliento, apoyo y sobre todo ilusión, han sido uno de mis principales aliados.

A todos, Gracias. 



\section{INDICE}

\section{INTRODUCCIÓN}

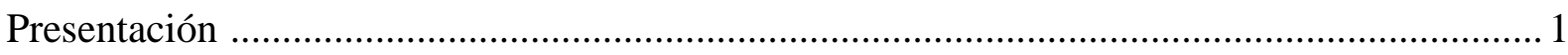

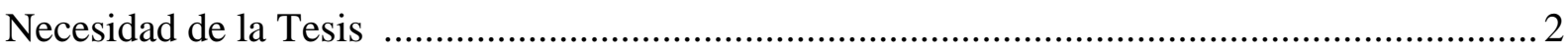

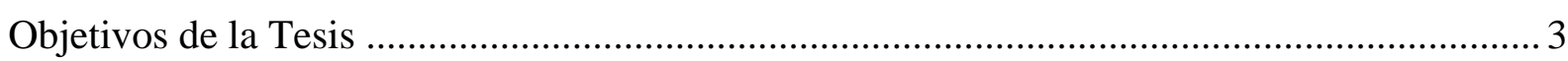

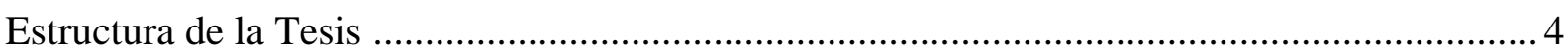

\section{Capítulo 1 INTEGRACIÓN EMPRESARIAL}

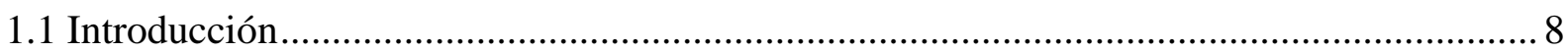

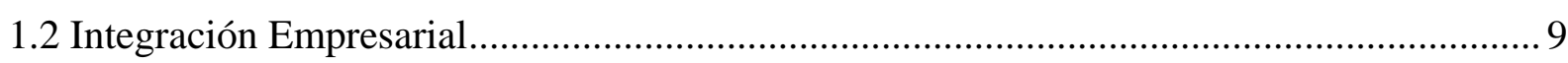

1.2.1. Definición de la Integración Empresarial ................................................................ 9

1.2.2. Tipos de Integración Empresarial ....................................................................... 12

1.2.3. Porqué de la Integración Empresarial ................................................................... 14

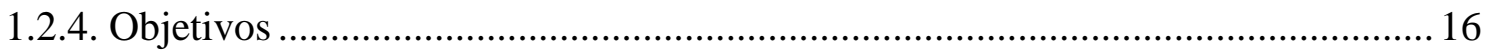

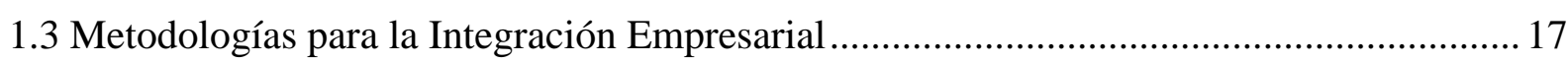

1.3.1. Metodología CIMOSA..................................................................................... 17

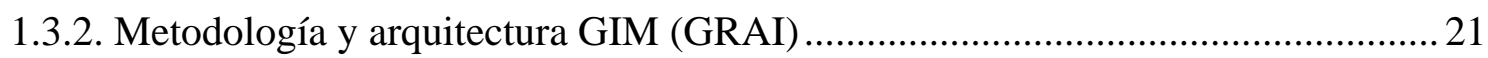

1.3.3. Metodología y arquitectura de Referencia empresarial Purdue (PERA) ............... 23

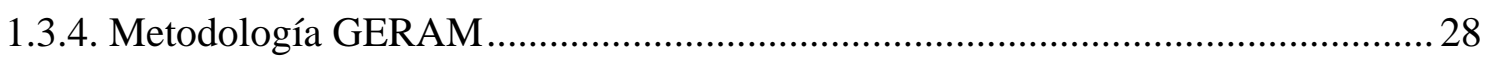

1.3.5. Metodología Zachman .................................................................................... 31

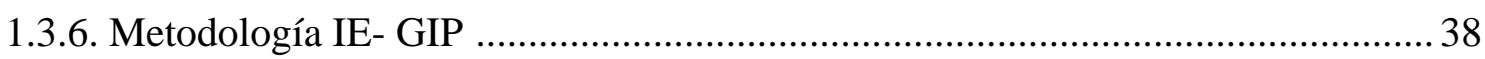

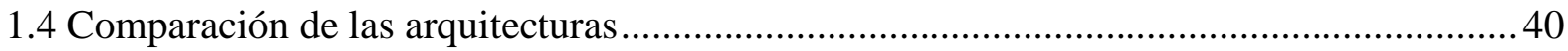

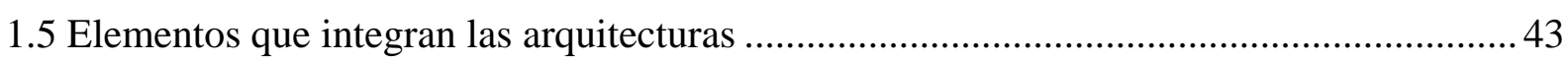

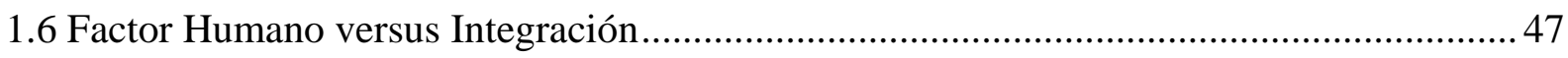

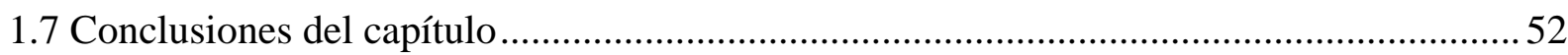

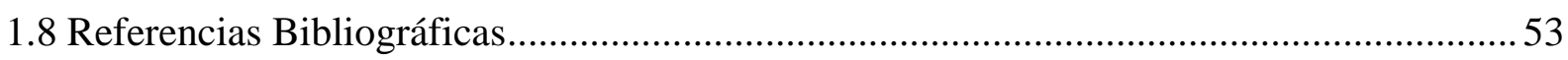

Capítulo 2 LOS ELEMENTOS EMPRESARIALES

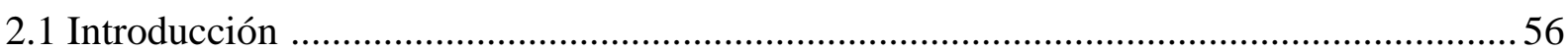

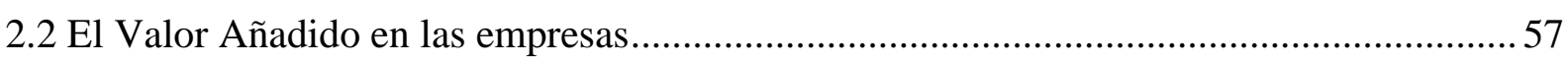

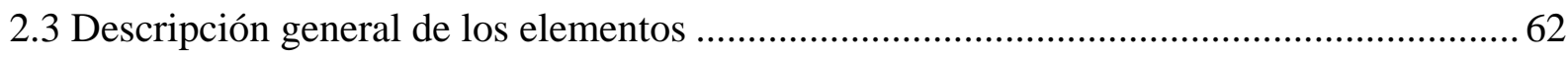

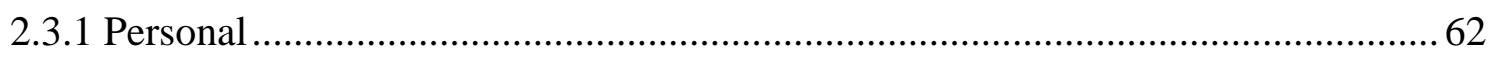

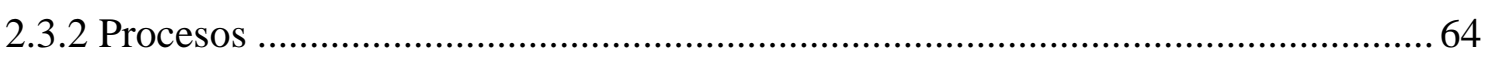

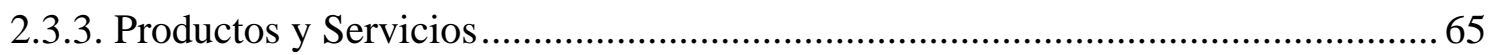

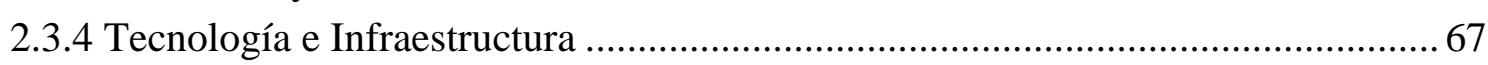

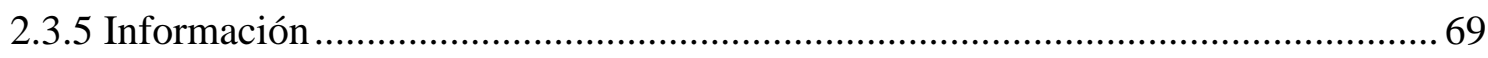

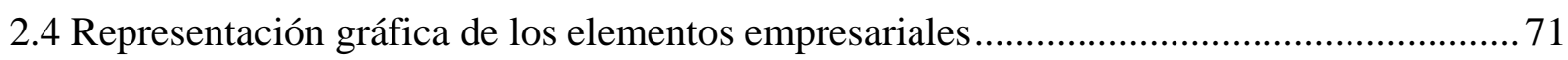

2.5 Relación entre los elementos empresariales ...................................................................... 76 


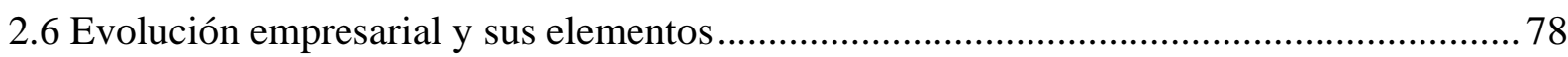

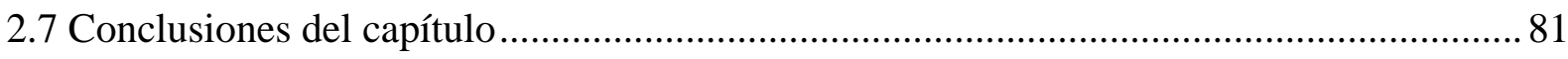

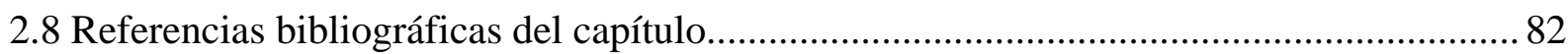

\section{Capítulo 3 CICLOS DE VIDA DE LAS ORGANIZACIONES}

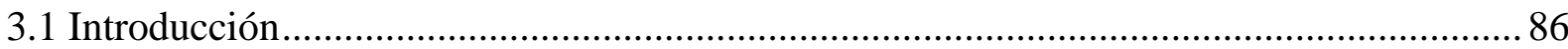

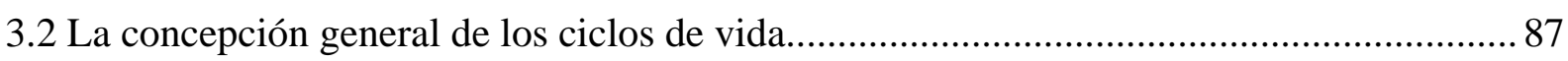

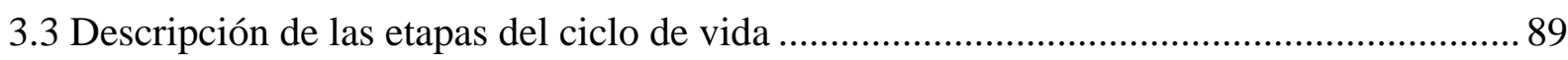

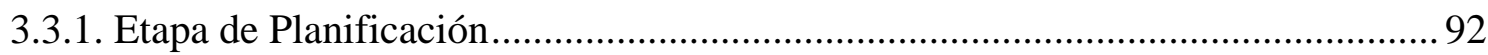

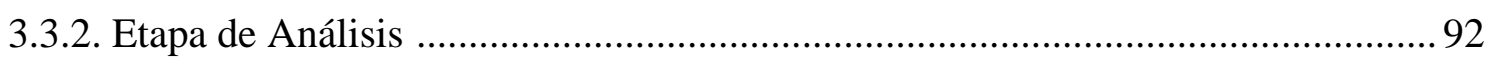

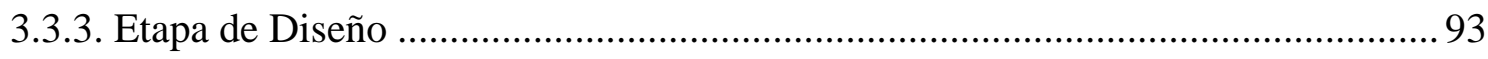

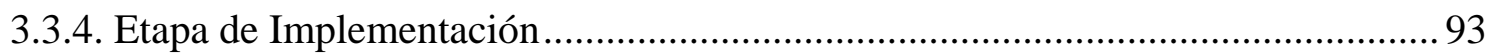

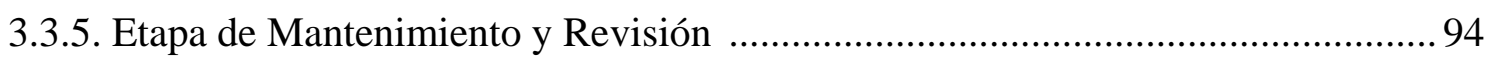

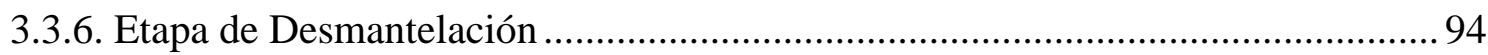

3.4 El Ciclo de Vida de los Elementos empresariales: Personal ...............................................94 94

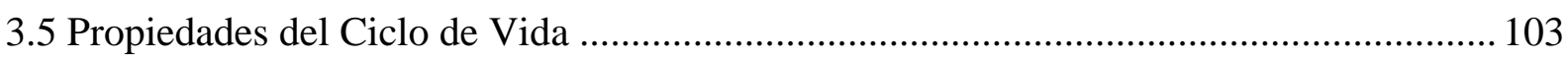

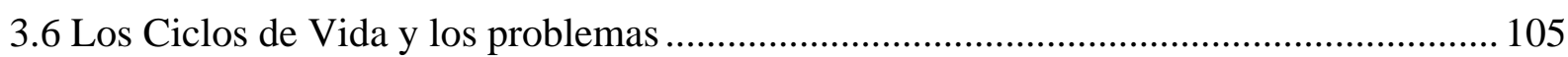

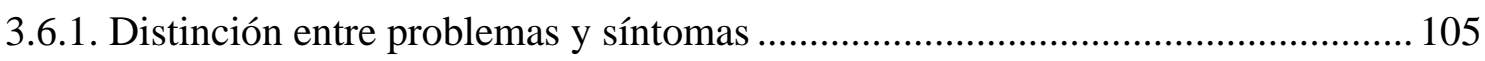

3.6.2. Situaciones del Sistema: Problemática definida o no definida ............................ 107

3.6.3. Ciclos de Vida Inversos (desde el modelo "as is") (definición del "as is") .........112

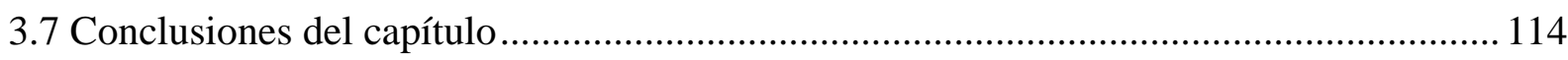

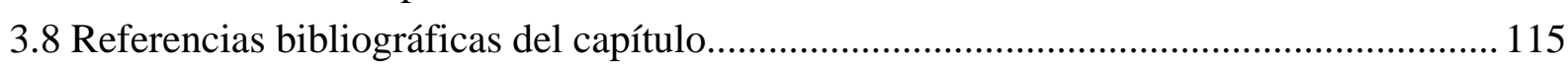

\section{Capítulo 4 LOS RECURSOS HUMANOS EN LA EMPRESA}

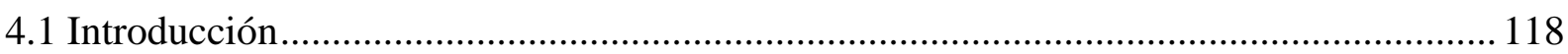

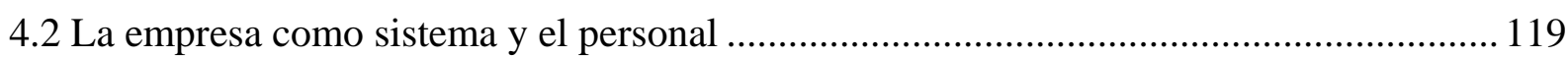

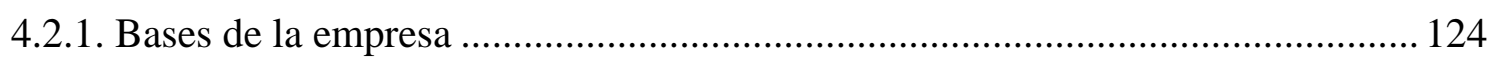

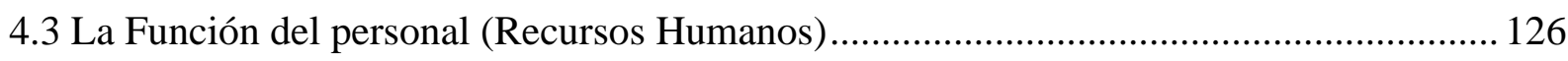

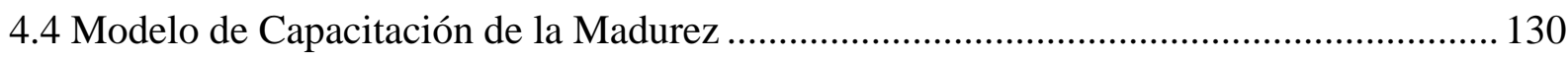

4.4.1 Los Niveles de Madurez ............................................................................... 131

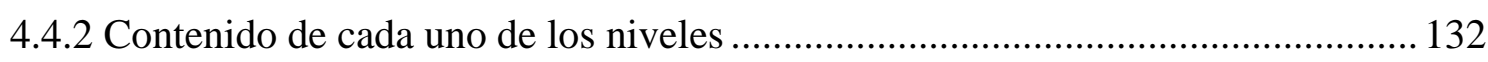

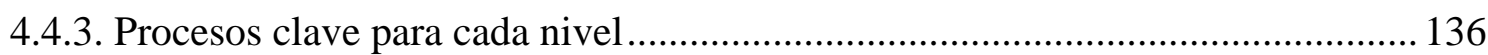

4.4.4. Aplicación del Modelo de Capacitación de Madurez para Personal ................... 140

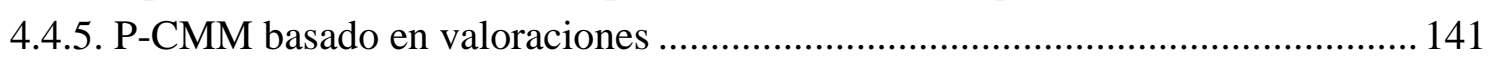

4.4.6. P-CMM como guía de mejora............................................................................ 141

4.4.7. Localización de un P-CMM basado en mejoras. ................................................... 142

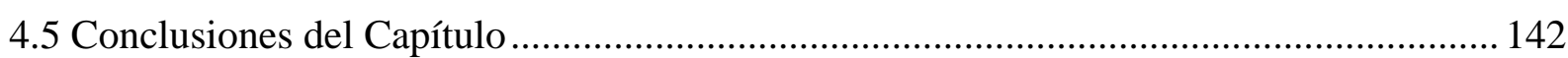

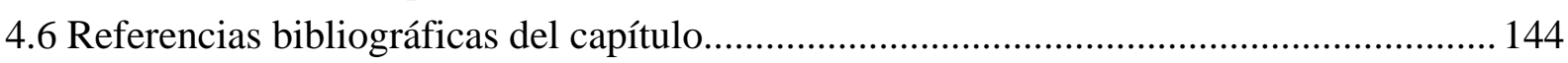

\section{Capítulo 5 Arquitectura del Modelo Propuesto de Recursos Humanos}

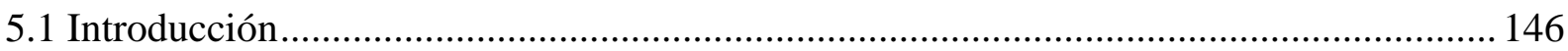

5.2 Etapa de Planificación del Nuevo Modelo de Recursos Humanos ................................... 147 
5.2.1. Etapa de Planificación. 147

5.2.2. Etapa de Planificación del Modelo de Recursos Humanos.................................. 153

5.3 Etapa de Análisis del Nuevo Modelo de Recursos Humanos ........................................... 162

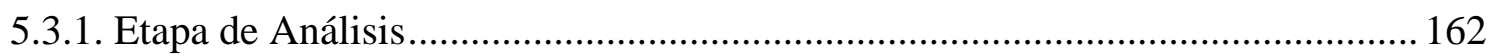

5.3.2. Etapa de Análisis del Modelo de Recursos Humanos......................................... 165

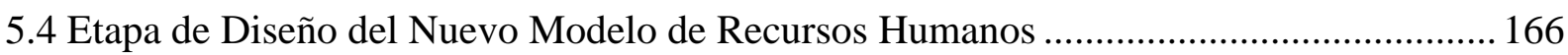

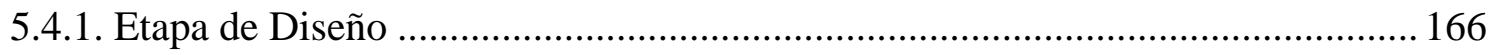

5.4.2. Etapa de Diseño del Modelo Propuesto de Recursos Humanos .......................... 167

5.5 Presentación del Modelo Propuesto de Recursos Humanos.............................................. 170

5.5.1. Contenido de los Puestos del Modelo de Recursos Humanos Propuesto ............ 176

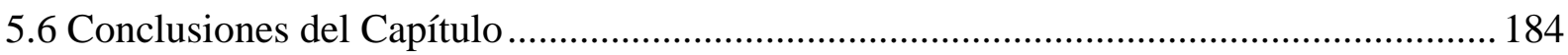

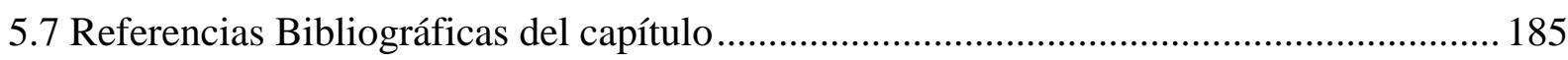

\section{Capítulo 6 LOS SISTEMAS LOGÍSTICOS}

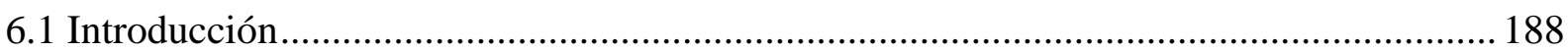

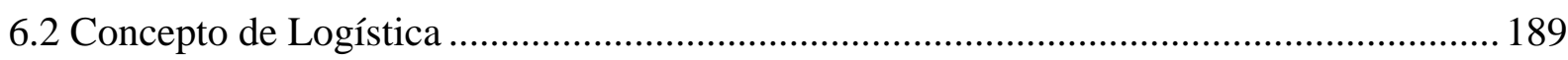

6.2.1. Evolución temporal del área de Logística en las empresas................................. 190

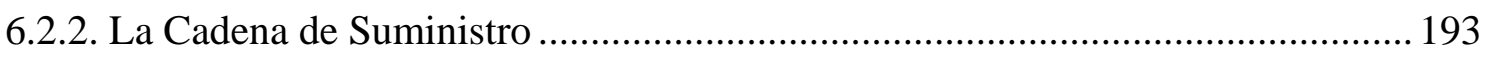

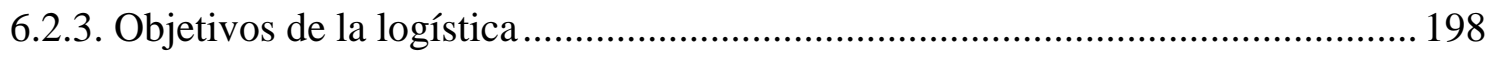

6.3 Áreas con las que se relaciona el área de logística en la empresa .....................................200

6.3.1. Actividad de Gestión de demanda ...................................................................... 202

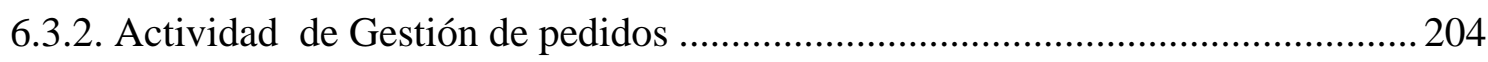

6.3.3. Actividad de Gestión de aprovisionamiento ........................................................ 207

6.3.4. Actividad de Gestión de almacenes .................................................................... 213

6.3.5. Actividad de Gestión de stocks........................................................................ 222

6.3.6. Actividad de Gestión de distribución................................................................. 228

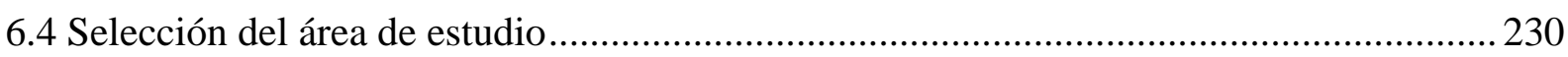

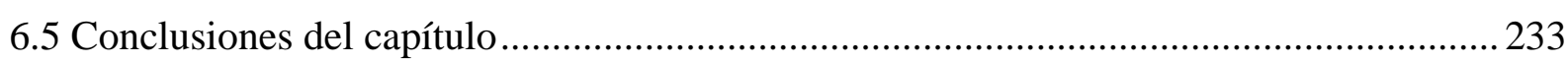

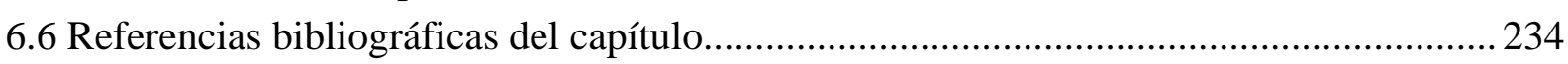

Capítulo 7 DESARROLLO DEL MODELO DE RECURSOS HUMANOS APLICADO A LOS SISTEMAS LOGÍSTICOS

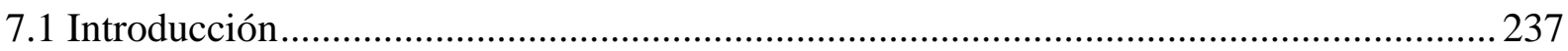

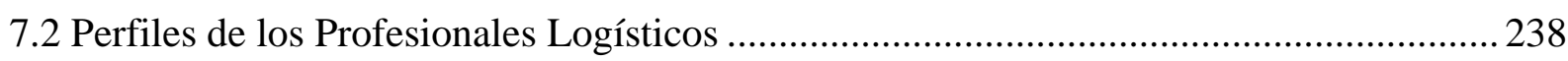

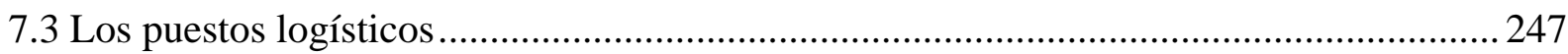

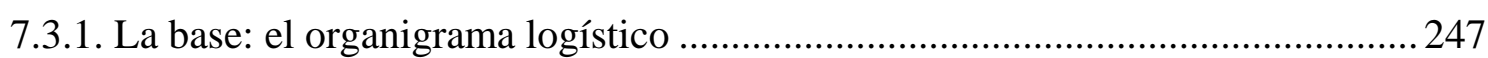

7.3.2. Los puestos logísticos según el organigrama .................................................. 248

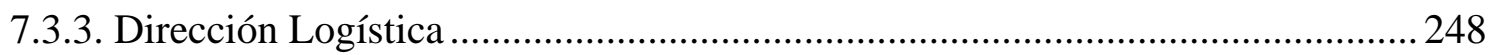

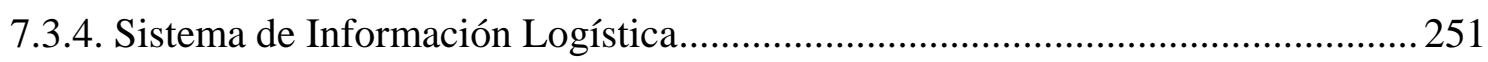

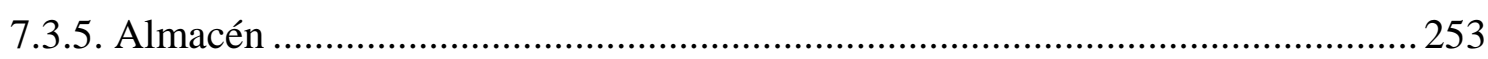

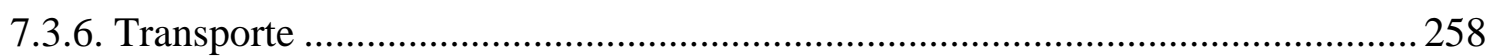

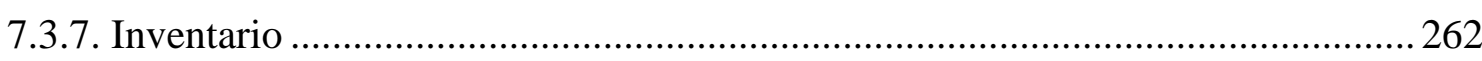




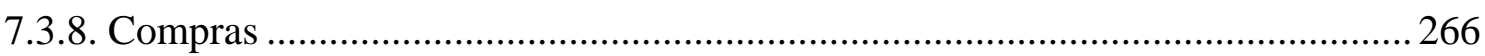

7.3.9. Servicio al cliente......................................................................................... 268

7.4 El Modelo de Recursos Humanos aplicado a los sistemas logísticos................................2. 270

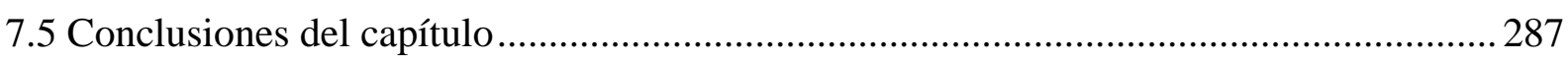

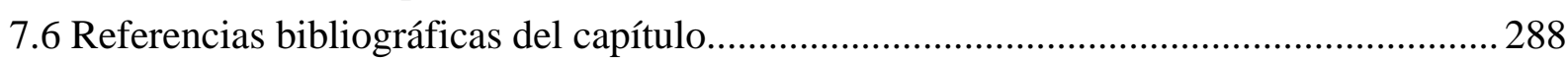

\section{Capítulo 8 APLICACIÓN DEL MODELO DE RECURSOS HUMANOS A}

\section{SISTEMAS LOGÍSTICOS}

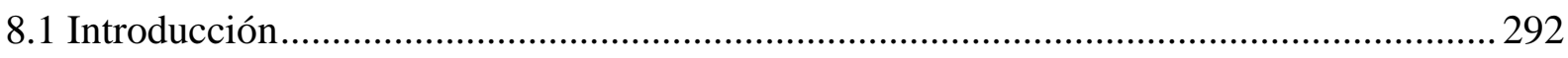

8.2 Metodología de actuación para la recogida de información............................................. 293

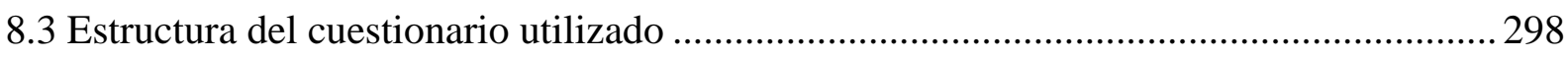

8.4 Análisis de resultados del Modelo de Recursos Humanos aplicado a los

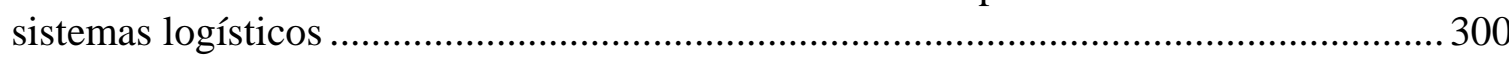

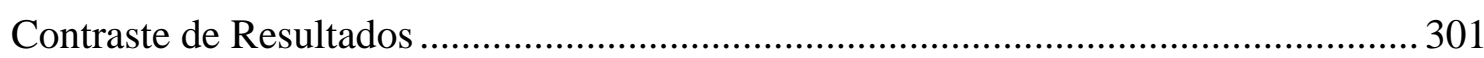

8.5 Validación del Modelo de Recursos Humanos aplicado a los sistemas logísticos............ 327

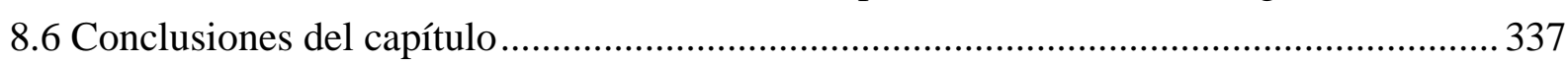

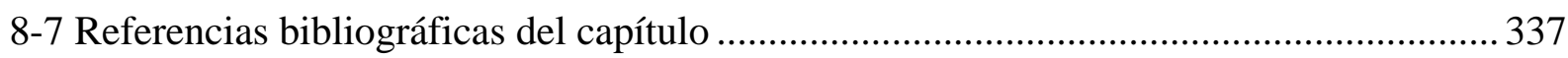

\section{Capítulo 9 CONCLUSIONES FINALES Y LÍNEAS FUTURAS DE} INVESTIGACIÓN

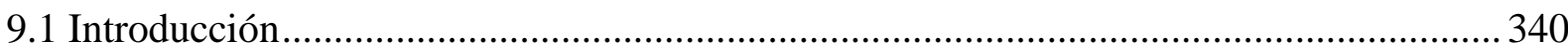

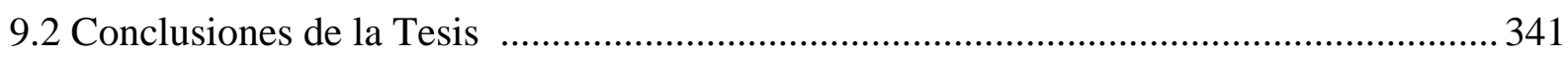

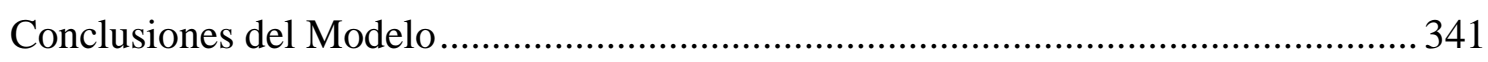

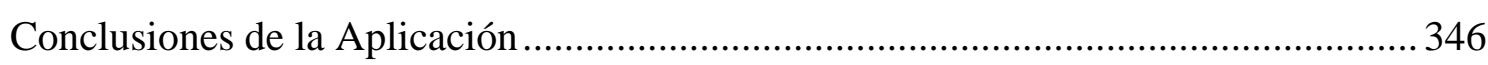

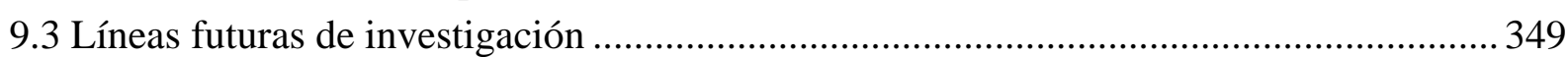

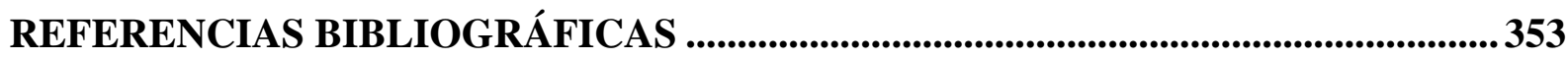

ANEXOS

Anexo I. Descripción de los Puestos de los sistemas logísticos

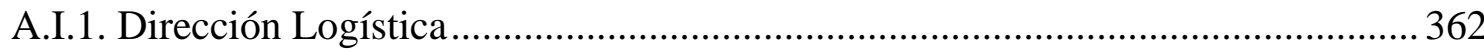

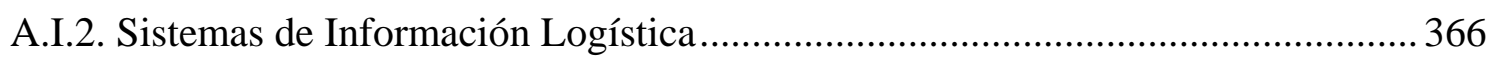

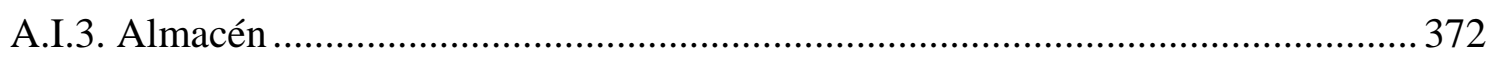

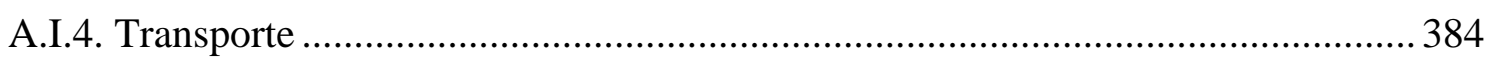

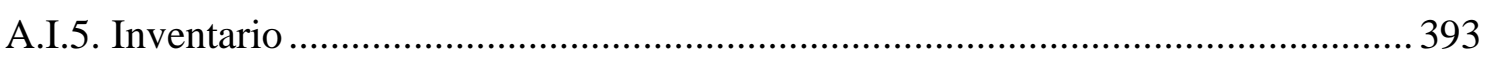

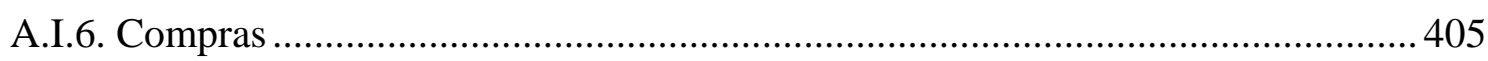

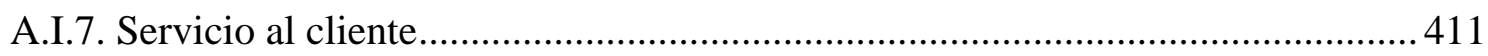

Anexo II Elaboración de los cuestionarios

A.II.1. Metodología para la recopilación de datos .......................................................... 419

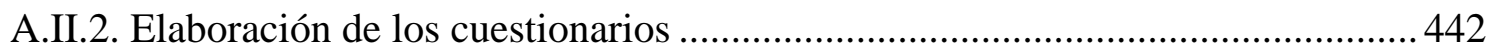

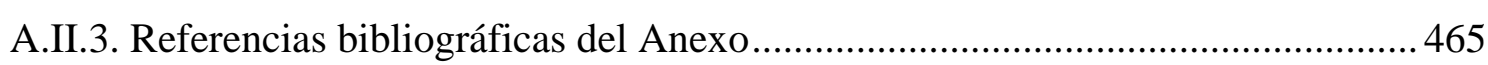

Anexo III Resultado de los Cuestionarios ....................................................................... 468 


\section{INDICE DE ILUSTRACIONES}

\section{Capítulo 1 INTEGRACIÓN EMPRESARIAL}

Ilustración 1.1: Niveles de Integración Empresarial para Kosanke [Kosanke] ......................... 14

Ilustración 1.2: Cubo de Modelización de CIMOSA. Fuente: K. Kosanke ..............................20

Ilustración 1.3: Metodología de PERA. Fuente: Hong [Hong94] ........................................... 26

Ilustración 1.4: Relación entre Automatización, Humanización y Extensión de la

Automatización. Fuente: Hong [Hong 94 p. 47, Williams p.9] ............................... 27

Ilustración 1.5: Matriz del Modelo GERAM. Fuente: Williams [Williams p.29] .................... 30

Ilustración 1.6: Marco de Arquitectura Zachman. Fuente: Zachman [Zachman] ..................... 37

Ilustración 1.7: Fase de Desarrollo de un sistema. Fuente: Ortiz [Ortiz 98 p.184] .................... 40

Ilustración 1.8: Consideraciones básicas para una correcta estructura empresarial.

Fuente: Mullins [Mullins02 p.536] ..........................................................................51

\section{Capítulo 2 LOS ELEMENTOS EMPRESARIALES}

Ilustración 2.1: Cadena de Valor de Porter. Fuente: Porter [Porter80] ..................................... 58

Ilustración 2.2: Identificación de elementos empresariales en la Cadena de Valor de

Porter. Fuente: Elaboración propia basado en M. Porter .......................................... 61

Ilustración 2.3: Relación entre personal, procesos y productos. Fuente: Phillips

[Phillips].

Ilustración 2.4: Construcción de un producto más complejo, basado en el

incremento de la capacidad del personal. Fuente: Phillips [Phillips] ........................ 72

Ilustración 2.5: Construcción de un producto más complejo, basado en el incremento de la capacidad del proceso. Fuente Phillips [Phillips]........................... 72

Ilustración 2.6: Construcción de un producto más complejo, basado en el incremento de la capacidad del personal y del proceso. Fuente: Phillips [Phillips].

Ilustración 2.7: Situación de equilibrio entre los cinco elementos empresariales.

Fuente: Elaboración propia

Ilustración 2.8: Construcción de un producto más complejo, basado en el incremento de la capacidad del personal (5 elementos). Fuente:

Elaboración propia

Ilustración 2.9: Construcción de un producto más complejo, basado en el incremento de la capacidad del proceso (5 elementos). Fuente: Elaboración propia

Ilustración 2.10: Construcción de un producto más complejo, basado en el incremento de la capacidad del personal y del proceso (5 elementos).

Fuente: Elaboración propia ... .76

Ilustración 2.11: Relaciones existentes entre los elementos empresariales. Fuente:

Elaboración Propia

Ilustración 2.12: Elementos empresariales. Fuente: Elaboración propia 
Ilustración 2.13: Ciclo de mejora del desarrollo de los elementos empresariales.

Fuente: Elaboración propia

\section{Capítulo 3 CICLOS DE VIDA DE LAS ORGANIZACIONES}

Ilustración 3.1: Etapas del ciclo de vida. Fuente: Elaboración propia 94

Ilustración 3.2: Ciclo de vida del Departamento de Recursos Humanos. Fuente:

Elaboración propia.

Ilustración 3.3: Proceso y elementos para la resolución de problemas. Fuente:

Elaboración propia basado en Domínguez [Domínguez p.50]

Ilustración 3.4: Proceso de construcción de un proyecto. Modelo To Be. Fuente:

Basado en Ortiz [Ortiz98 p.285]

Ilustración 3.5: Proceso de abstracción del Modelo As Is. Fuente: Elaboración

Propia.

Ilustración 3.6: Ciclo de vida extendido. Fuente: Elaboración Propia

Capítulo 4 LOS RECURSOS HUMANOS EN LA EMPRESA

Ilustración 4.1: Niveles de Madurez del Modelo de Capacitación de Madurez

Ilustración 4.2: Procesos clave para cada nivel del Modelo

\section{Capítulo 5 Arquitectura del Modelo Propuesto de Recursos Humanos}

Ilustración 5.1: Niveles de Mando. Fuente: E de Miguel [DeMiguel p.50].

Ilustración 5.2: Aptitudes necesarias para los distintos niveles de mando. Fuente: de Miguel [DeMiguel p.52]

Ilustración 5.3: Relación de Habilidades técnicas y Humanas. Fuente: Kerner

[Kersner p.125 fig.30]

Ilustración 5.4: Relación entre jerarquía y actividades realizadas por el personal en

la empresa. Fuente: Elaboración Propia

Ilustración 5.5: Relación existente entre los distintos niveles jerárquicos en la empresa con sus homólogos externos o de otro departamento. Fuente:

Elaboración propia

Ilustración 5.6: Niveles de Personal existentes en una entidad de negocio y las tareas relacionadas. Fuente: Elaboración propia

Ilustración 5.7: Relación entre niveles de personal, proceso, información, infraestructura, y producto/servicio. Fuente: Elaboración propia

Ilustración 5.8: Modelo de Recursos Humanos propuesto para la Entidad de

Negocio. Fuente: Elaboración Propia

\section{Capítulo 6 LOS SISTEMAS LOGÍSTICOS}

Ilustración 6.1: Proceso de gestión de la cadena de suministro: Fuente: Elaboración

Propia

Ilustración 6.2: Cadena de Valor

Ilustración 6.3: componentes de la Gestión de la Cadena de Suministro. Fuente:

Lambert [Lambert2001].

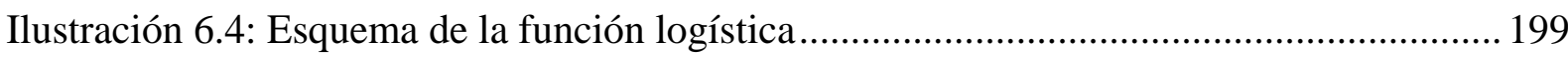

Ilustración 6.5: Alcance de la logística dentro de una empresa. Fuente: Ballou

[Ballou 91p.7] 
Ilustración 6.6: Proceso de Planificación integrado. Fuente: Kirby [Kirby2001]. 204

Ilustración 6.7: Gestión de pedido, desde el punto de vista interno y externo de la empresa. Fuente: Elaboración propia...

Ilustración 6.8: Proceso principal de la gestión externa de pedidos. Fuente: Basado en PriceWaterhouse Coopers [PwC2001 p.120]...

Ilustración 6.9: Proceso de gestión de aprovisionamiento. Fuente: Basado en PriceWaterhouse Coopers [PwC2001 p.149]

Ilustración 6.10: Proceso de gestión de almacenes. Fuente: Basado en PriceWaterhouse Coopers [PwC2001 p.67].

Ilustración 6.11: Alcance de la visión de los participantes en la cadena de suministro

Capítulo 7 DESARROLLO DEL MODELO DE RECURSOS HUMANOS APLICADO A LOS SISTEMAS LOGÍSTICOS

Ilustración 7.1: Ejemplo de Organigrama de un departamento logístico

Ilustración 7.2: Ejemplo de Organigrama general del área de logística. Basado en Le May [Le May]

Ilustración 7.3: Niveles de Mando en Logística. Fuente: Basado en E. de Miguel [DeMiguel p.50].

Ilustración 7.4: Niveles de personal existentes en el sistema logístico, entre proveedor y cliente. Fuente: Elaboración propia

Ilustración 7.5: Relación entre proveedor, sistema logístico y cliente. Fuente: Elaboración propia

Ilustración 7.6: Relación entre niveles de mando, información y tecnología, existente entre proveedor y cliente. Fuente: Elaboración propia

Ilustración 7.7: Modelo de Recursos Humanos propuesto para el desarrollo de la Cadena de Suministro entre proveedor y cliente. Fuente: Elaboración propia

\section{Capítulo 8 APLICACIÓN DEL MODELO DE RECURSOS HUMANOS A} SISTEMAS LOGÍSTICOS

Ilustración 8.1: Proceso de diseño de los cuestionarios logísticos. Fuente: Basado en Malholtra

Ilustración 8.2: Responsables de decisión y control del objetivo logístico ............................ 302

Ilustración 8.3: Motivos de desarrollo de los objetivos logísticos ...........................................303

Ilustración 8.4: Funciones de la Cadena de Suministro según tipo de sistemas logísticos

Ilustración 8.5: Reparto de decisión sobre quién informa a los distintos agentes logísticos

Ilustración 8.6: Tipo de información necesaria para dar a los clientes...................................... 309

Ilustración 8.7: Tipo de información necesaria para dar a los proveedores ............................. 309

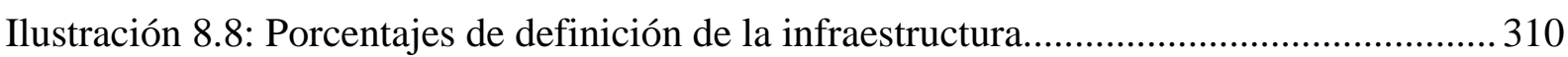

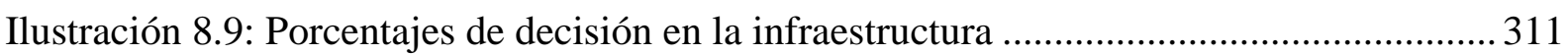

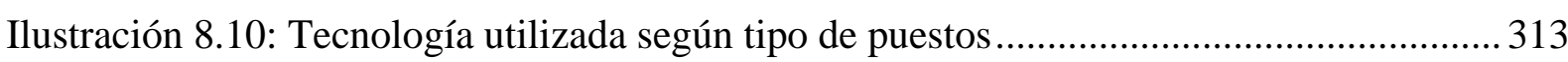




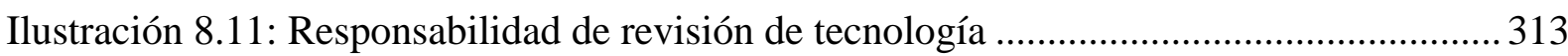

Ilustración 8.12: Distribución según niveles jerárquicos de sistemas logísticos...................... 314

Ilustración 8.13: Distribución de niveles jerárquicos según sistemas logísticos...................... 314

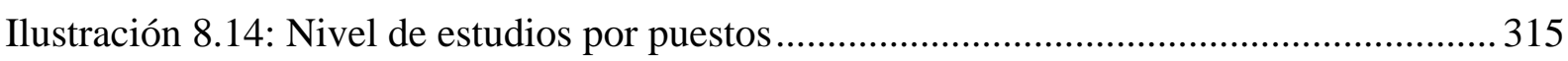

Ilustración 8.15: Conocimientos específicos del personal en los sistemas logísticos ............. 317

Ilustración 8.16: Conocimientos específicos por puestos para el personal de las

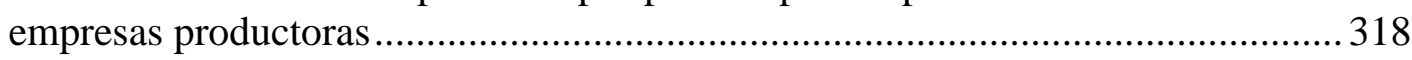

Ilustración 8.17: Conocimientos específicos por puestos para el personal de las empresas de distribución comercial ............................................................................ 319

Ilustración 8.18: Conocimientos específicos por puestos para el personal de los

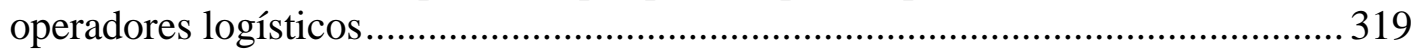

Ilustración 8.19: Nivel de idiomas requerido por puesto......................................................... 320

Ilustración 8.20: Principales habilidades requeridas por puesto en los sistemas

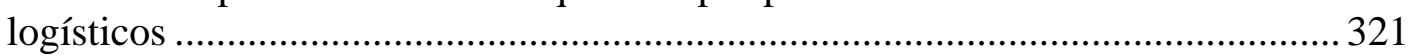

Ilustración 8.21: Perfil del manejo de tecnología para puestos logísticos................................. 322

Ilustración 8.22: Encargados de realizar la planificación del sistema logístico ........................ 322

Ilustración 8.23: Responsabilidad de asignación de personal a las tareas y

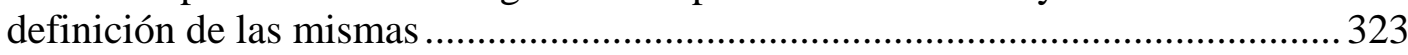

Ilustración 8.24:Vías explicativas para las actividades logísticas según tipo de

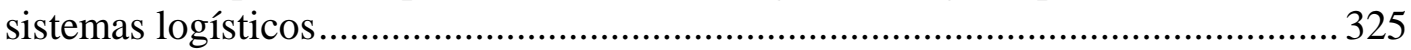

Ilustración 8.25: Periodicidad de las explicaciones de actividades y tareas en los

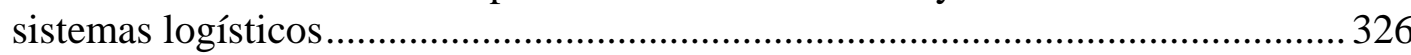

Anexo II Elaboración de los cuestionarios

Ilustración A-II.1: Proceso de diseño de cuestionarios. Basado en Malhotra 439

Ilustración A-II.2: Elementos de partida para la elaboración de cuestionarios.

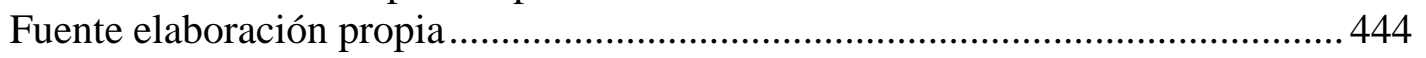

Ilustración A-II.3: Obtención de los cuestionarios para los distintos puestos logísticos ........ 445 


\section{INDICE DE TABLAS}

\section{Capítulo 1 INTEGRACIÓN EMPRESARIAL}

Tabla 1.1: Tabla comparativa del ciclo de vida de las arquitecturas de modelización. Fuente: Elaboración propia basado en Kosanke ............................. 42

Tabla 1.2: Tabla comparativa de los elementos que componen las distintas arquitecturas

\section{Capítulo 2 LOS ELEMENTOS EMPRESARIALES}

Tabla 2.1: Tabla comparativa entre actividades propuestas por la cadena de Valor de Porter y los elementos empresariales presentados

Tabla 2.2: Diferencias entre productos y servicios. Fuente: Mullins [Mullins02 p.105 extraído de J. Macdonald]

\section{Capítulo 3 CICLOS DE VIDA DE LAS ORGANIZACIONES}

Tabla 3.1: Comparación entre fases del ciclo de vida propuestas versus fases del ciclo de vida propuesto por IE-GIP.

Tabla 3.2: Tabla comparativa del ciclo de vida del Departamento de Recursos Humanos desde el enfoque de diversos autores.

Tabla 3.3: Tabla comparativa entre etapas del ciclo de vida de un sistema versus

Ciclo de vida de los Recursos Humanos

\section{Capítulo 4 LOS RECURSOS HUMANOS EN LA EMPRESA}

Tabla 4.1: Tipos básicos de estructuras formales. Fuente: Elorduy

Tabla 4.2: Postulados en política de personal de la National Industrial Conference

Board. Fuente: Peña

\section{Capítulo 5 Arquitectura del Modelo Propuesto de Recursos Humanos}

Tabla 5.1: Asignación de las principales tareas del ciclo de vida dentro de la empresa según el personal existente. Fuente: Elaboración Propia

Tabla 5.2: Presentación de las funciones del modelo de Recursos Humanos propuesto

Tabla 5.3: Funciones desempeñadas por los puestos del modelo de Recursos Humanos propuesto.

\section{Capítulo 6 LOS SISTEMAS LOGÍSTICOS}

Tabla 6.1 Objetivos de la gestión de aprovisionamiento. Fuente: PriceWaterhouse

Coopers 208

Tabla 6.2: Beneficios que ofrece la gestión de almacenes. Fuente: PriceWaterhouse Coopers

Tabla 6.3: Clases de gestión de información. Fuente: Basado en PriceWaterhouse

Coopers 


\section{Capítulo 7 DESARROLLO DEL MODELO DE RECURSOS HUMANOS APLICADO A LOS SISTEMAS LOGÍSTICOS}

Tabla 7.1: Presentación de las funciones del Modelo de Recursos Humanos logístico.

Tabla 7.2: Principales funciones desempeñadas por los puestos del Modelo de

Recursos Humanos Logístico.

\section{Capítulo 8 APLICACIÓN DEL MODELO DE RECURSOS HUMANOS A SISTEMAS LOGÍSTICOS}

Tabla 8.1: Tabla de almacenes y flota para la distribución logística 305

Tabla 8.2: Tabla con el tipo de información logística necesaria para llevar a cabo el proceso logístico

Tabla 8.3: Tabla sobre la decisión de qué tipo de información proporcionar a los agentes logísticos

Tabla 8.4: Tipo de tecnología utilizada en el proceso logístico

Tabla 8.5: Tabla de requisitos en conocimientos específicos del personal de los sistemas logísticos

Tabla 8.6: Tabla de tareas del puesto de dirección logística en las empresas visitadas

Tabla 8.7: Tabla de tareas del puesto de Gestor/ Manager logístico en las empresas visitadas

Tabla 8.8: Tabla de tareas del puesto de Administrativo / Operario logístico en las empresas visitadas

Anexo II Elaboración de los cuestionarios

Tabla A-II.1: Comparación entre entrevistas estructuradas y no estructuradas.

Fuente: Morales.

Tabla A-II.2: Ventajas e inconvenientes de la entrevista telefónica según Model.................. 432

Tabla A-II.3: Ventajas e inconvenientes de la entrevista por correo.........................................433

Tabla A-II.4: Ventajas e inconvenientes de la entrevista de grupo según Model .................... 435

Tabla A-II.5: Ventajas e inconvenientes de la entrevista In situ según Model ....................... 436

Tabla A-II.6: Etapas del Ciclo de vida en la elaboración del cuestionario .............................. 440

Tabla A-II.7: Puestos propuestos y puestos asimilados en la empresa. Fuente:

Elaboración propia basado en Le May.

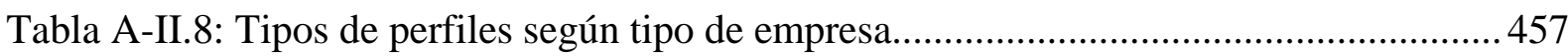

Tabla A-II.9: Puestos logísticos por tipos de empresas que aplican logística......................... 459 


\section{Introducción}





\section{INTRODUCCIÓN}

\section{PRESENTACIÓN}

La importancia que han cobrado en los últimos años los temas de Recursos Humanos se puede justificar por el carácter diferenciador de los mismos en las distintas organizaciones, y cómo éstos pueden llegar a aportar ventajas competitivas a las distintas entidades de negocio en las que participan.

La relación existente entre los trabajadores que prestan servicio en una entidad de negocio y la propia entidad en sí, surge desde el momento que se genera una relación laboral entre la entidad empresarial y los individuos que la integran, independientemente del tipo de entidad que se trate y la relación establecida.

Por tanto, ante tal situación, se puede afirmar que la Gestión de Recursos Humanos no tiene lugar de forma homogénea y constante en el tejido empresarial, sino que dependerá fundamentalmente del tipo y carácter de entidad empresarial que se esté analizando, ya que proporcionará la capacidad laboral necesaria tanto cualitativa como cuantitativamente. 
Para que dicho personal pueda desarrollarse no sólo ha de estar formado para el nivel y tareas que ha de desarrollar, sino también, debe tener especificadas todas aquellas funciones, ubicaciones, equipos, elementos, momentos e información necesaria para poder llevarlas a cabo.

Todos estos requisitos hacen que se plantee un modelo de Recursos Humanos enfocado a la realización de procesos que ha de desarrollar cada uno de los participantes en la entidad de negocio, por lo que con base a esta filosofía surge el presente trabajo.

Como resultado del mismo se obtendrá un modelo de Recursos Humanos en el cual se obtienen especificaciones sobre el ¿Qué?, ¿Cómo?, ¿Cuándo?, ¿Quién?, ¿Dónde? y ¿Porqué? ha de realizar cada participante en la entidad de negocio, y en particular la aplicación de todo ello al sector logístico, obteniendo a su vez un modelo particular para el desarrollo de los procesos logísticos.

\section{NECESIDAD DE LA TESIS}

La presente tesis aborda la problemática existente en los distintos departamentos para la adjudicación de tareas a los participantes en las actividades que realizan en la entidad de negocio. La necesidad de llevar a cabo una investigación en este campo surge como consecuencia de una revisión bibliográfica en temas de estructuras de Recursos Humanos en las empresas y la apreciación de unas estructuras obsoletas para la sociedad actual.

En la revisión bibliográfica realizada, se observa la existencia de estructuras de personal clásicas y un tanto obsoletas para los Recursos Humanos, debido a que al ser cada empresa diferente del resto, no es fácil crear un patrón válido tanto para grandes como para pequeñas empresas.

Partiendo de un modelo clásico de estructura del personal en las empresas, este trabajo plantea un nuevo enfoque de estructuración basando en los procesos que se realizan en las entidades de negocio, pudiendo dichas entidades ser desde una gran empresa a un departamento. 
Por tanto, la necesidad de esta tesis es doble:

- Por un lado, aportar un modelo de Recursos Humanos en un marco de Integración Empresarial basado en la aplicación de los procesos que realizan las entidades de negocio.

- Y por otro lado, realizar una aportación al campo de la ordenación jerárquica de puestos para la entidad de negocio, sobre la base de los procesos y funciones que desarrollan los participantes en la misma.

Así pues, esta tesis doctoral muestra en una primera parte un planteamiento genérico para cualquier entidad de negocio, para posteriormente basarse en la aplicación de dicho modelo a los sistemas que aplican logística.

\section{OBJETIVOS DE LA TESIS}

En la revisión bibliográfica realizada durante la elaboración de este trabajo, se ha detectado la ausencia de modelos de Recursos Humanos, en el marco de las metodologías de integración empresarial. Esta falta de modelos, incluso en otros marcos de estudio y análisis son debidos en parte a la dificultad que surge por el tamaño de las empresas, en parte por la diversidad de tipos de empresas existentes.

Por tanto, el objetivo principal de esta tesis se encuentra en la elaboración de un modelo genérico de Recursos Humanos que permita integrar y organizar a las entidades de negocio sobre la base de los procesos que éstas realizan. Así pues, entre los subobjetivos que permiten lograr el propósito de esta tesis se pueden señalar:

- Identificar los elementos abstractos comunes a las empresas o entidades de negocio: Basándose en las distintas metodologías de integración empresarial, se identificarán aquellos elementos comunes a todas las empresas en abstracto. 
- Desarrollar una metodología en base a los procesos para la elaboración de un modelo de Recursos Humanos. Identificando los ciclos de vida de los procesos, se identifica una metodología para la construcción de un modelo de Recursos Humanos.

- Comprobación de la validez del modelo genérico de Recursos Humanos para los sistemas logísticos: Una vez creado el modelo genérico se realizará una validación del mismo a los sistemas logísticos, debido a la escasez de estructuras para los Recursos Humanos en dicho campo.

Para realizar la aplicación del modelo genérico de Recursos Humanos a los sistemas logísticos, se ha llevado a cabo una revisión del estado actual de las estructuras de dichos sistemas, obteniendo como resultado de dicha búsqueda escasa información acerca de cómo estructuran dichos sistemas logísticos a sus participantes, por lo que uno de los objetivos de este trabajo consistirá en realizar dicha estructuración basándose en las funciones que realizan a lo largo del proceso logístico.

Finalmente y para concluir, se validará el modelo a través de la aplicación del mismo a distintas empresas o sistemas logísticos, ya sean operadores logísticos, distribuidores comerciales o empresas productoras con departamentos logísticos.

\section{ESTRUCTURA DE LA TESIS}

Los objetivos que se han expuesto en el apartado anterior son resultado de búsquedas en la literatura de la situación sobre los Recursos Humanos, y en particular en el área logística.

Por ello esta tesis doctoral sigue una estructura diferenciada en tres grandes bloques. El primer bloque supone una Identificación del Marco en el que se presentan los componentes que posteriormente se utilizarán para la construcción del Modelo de Recursos Humanos en el segundo bloque, denominado Planteamiento del Modelo. Una vez generado el modelo, se llevará a la Aplicación Práctica y validación del mismo a las áreas logísticas.

El primer bloque denominado Identificación del Marco parte en un primer capítulo de la perspectiva de la Integración Empresarial para desde ese punto justificar las etapas que señalan las distintas arquitecturas de integración presentadas, así como una identificación de 
los elementos empresariales comunes a cada entidad de negocio señalados por dichas arquitecturas. Esto se realiza para justificar cuales son los elementos comunes a las arquitecturas y para comprobar cuales son las etapas o evolución de las mismas. Una vez identificados dichos elementos, el capítulo segundo pasará a describir cada uno de elementos empresariales identificados para las entidades de negocio y las relaciones que existen entre los mismos, justificándolos no solo desde la perspectiva planteada en el capítulo primero sino que se añade una perspectiva desde la Cadena de Valor de Porter. A continuación, en el tercer capítulo se expondrán las etapas o ciclo de vida de los sistemas, y su comparación, con la ya obtenida en el capítulo primero para justificar la existencia de esas etapas. Conocidas las etapas se realiza una aplicación particular de las mismas al elemento Personal o Recursos Humanos para demostrar que se producen en los sistemas. Este bloque finaliza con el capítulo cuarto en el cual una vez demostrada la existencia del elemento personal, se hace énfasis a la importancia de dotar a dicho personal de estructuras para su funcionamiento y mejora en la realización de tareas.

Una vez identificado el marco, el segundo bloque pasará a describir a través de las etapas de ciclo de vida expuestas en el capítulo tercero un modelo de Recursos Humanos basado en los procesos que realiza el personal, apoyándose en los elementos empresariales presentados en el capítulo segundo. A este bloque se le denomina Planteamiento del Modelo, y aparece reflejado en el capítulo quinto. El modelo generado es más actual, debido a que no tiene en cuenta únicamente los niveles jerárquicos existentes en las entidades de negocio, sino que se basa en los procesos realizados en cada puesto, especificando el ¿Qué?, ¿Cómo?, ¿Cuándo?, ¿Quién, ¿Dónde? y ¿Porqué? de las tareas de cada puesto generado.

La parte final de este trabajo corresponderá a la Aplicación práctica de todo lo planteado y expuesto en las partes previas, realizando por tanto una aplicación del modelo a un área en particular: los sistemas logísticos.

Esta parte estará compuesta por el capítulo sexto el cual describirá los Sistemas Logísticos debido a que éstos son el marco de referencia de aplicación del modelo, y la logística no es un departamento aislado en las empresas sino que está relacionada con un gran número de actividades como: gestión de demanda, gestión de aprovisionamiento, gestión de almacenes, gestión de stocks, gestión de distribución. Conocido el área de estudio en el que se centrará el trabajo, en el capítulo séptimo se pasa a desarrollar el Modelo de Recursos Humanos aplicado a la Logística, debido a la falta de estructuras de personal en este ámbito, así pues siguiendo 
las pautas de actuación llevadas a cabo en la parte segunda del trabajo (Planteamiento del Modelo), se genera una modelo aplicado a los Sistemas logísticos. En este capítulo, se incluye además una breve descripción de los puestos que puede abarcar un sistema logístico.

Finalmente, el capítulo octavo expone la metodología seguida para la comprobación de dicho modelo en las empresas. Para ello se realizarán entrevistas y visitas in situ a distintas empresas que aplican logística, y mediante la realización de un cuestionario perfilar en que tipos de sistemas se cumple dicho modelo, ya que la logística puede estar aplicada tanto en empresas de distribución comercial, en operadores logísticos como en empresas productoras con departamentos de logística.

El trabajo finalizará sintetizando las aportaciones conseguidas, así como las conclusiones extraídas. Para establecer las posibles líneas futuras de trabajo en este campo y queden perfiladas pero inconclusas en este trabajo.

Además, esta tesis incluye unos anexos en los que se aporta la documentación utilizada para la elaboración del trabajo. El primer anexo (Anexo I) incluye la descripción completa de los puestos logísticos propuestos en el capítulo séptimo.

El segundo anexo (Anexo II) está compuesto de una descripción de los distintos tipos de entrevista, con sus ventajas e inconvenientes, que pueden realizarse en un trabajo de investigación, así como la metodología utilizada para la elaboración de los cuestionarios, incluyendo desde los primeros cuestionarios hasta el cuestionario final utilizado en las visitas in situ.

Finalmente, el tercer y último Anexo (Anexo III) estará constituido por las informaciones obtenidas en los cuestionarios en las visitas in-situ realizadas a las empresas. 


\section{Capítulo 1.}

\section{Integración Empresarial}




\section{CAPITULO 1}

\section{INTEGRACIÓN EMPRESARIAL}

\subsection{INTRODUCCIÓN}

El presente capítulo realiza una introducción al concepto de Integración empresarial, comenzando por las distintas definiciones aportadas, el porqué de dicha definición, los distintos tipos de integración propuestos, así como los objetivos que persigue.

Una vez definida la Integración empresarial, se realizará un repaso a las principales arquitecturas de integración existentes. Comenzando desde la arquitectura CIMOSA y la descripción de su esqueleto y dimensiones, ciclo de vida y su integración. Para proseguir con la arquitectura GIM- GRAI y la descripción de sus sistemas: físico, de decisión y de información, cómo actúan ante la toma de decisiones y que etapas cumple dicha arquitectura. A continuación se describe la arquitectura PERA y sus etapas conceptual, de definición y especificación así como los enfoques funcionales y físicos, y como afecta a la selección de tareas de personal, y las subarquitecturas que surgen. La arquitectura GERAM simplemente se muestra como combinación de las anteriores ya que toma las dimensiones de CIMOSA, el 
ciclo de vida de PERA y las vistas de GRAI y CIMOSA. Se propone como arquitectura fundamental para el desarrollo de este trabajo la Metodología de ZACHMAN, como un marco de desarrollo de empresas para el desarrollo, dirección y mantenimiento de las mismas. Finalmente se propone la arquitectura IE-GIP como propuesta para el desarrollo de sistemas, siendo a su vez una importante arquitectura de referencia en este trabajo.

Una vez presentadas las arquitecturas, el capítulo concluye con una comparación de las mismas. Este estudio se profundiza además mediante la comparación de los elementos que integran las distintas arquitecturas previamente presentadas, para observar aquellos comunes a las distintas metodologías, y en particular el factor Recurso Humano desde el punto de vista de la integración.

\subsection{INTEGRACIÓN EMPRESARIAL.}

\subsubsection{Definición de la Integración Empresarial}

Atendiendo al significado de Integración Empresarial aportado por el Diccionario de la Real Academia de la Lengua, se puede definir Integración como "la acción o efecto de integrar o integrarse", donde integrarse supone "constituir las partes de un todo. Completar un todo con las partes que le faltan. Incorporarse, unirse a un grupo para formar parte de él..." y por otro lado se define Empresarial como "perteneciente o relativo a la empresa o los empresarios", en este caso se toma lo referente a la Empresa, la cual se define como "entidad integrada por el capital y el trabajo como factores de la producción y dedicada a actividades industriales, mercantiles o de prestación de servicios generalmente con carácter lucrativo..."

Dicha definición es un tanto amplia, y en un intento de acotarla se tomará la definición aportada por Williams para la metodología PERA [Williams97], donde "la Integración Empresarial consiste en la coordinación de las operaciones de todos los elementos para alcanzar la misión tal y como la ha defendido la dirección de la empresa"

Con la Integración Empresarial lo que se pretende buscar es una dinámica de actuación adecuada, que permita a la empresa evolucionar para conseguir el objetivo de llegar a una 
verdadera integración y con ello conseguir una ventaja competitiva respecto al resto de empresas.

Ortiz [Ortiz98] señala como en temas de integración a nivel físico y de aplicaciones dentro de la empresa, hay un largo camino avanzado aunque aun quede bastante por recorrer, ya que la integración contribuye a que la integración entre la tecnología, los sistemas de información, el sistema de planificación y el control de producción, de forma que hoy en día están interactuando entre ellos sin que sea fácil distinguir o determinar cual es el más importante o no puedan trabajar unos sin otros. Por ello, el proceso de Integración Empresarial no puede plantearse sin tener en cuenta la Estrategia de la Empresa, pero a su vez la empresa debe considerar como elemento estratégico fundamental el desarrollo del proceso que llevará a la Integración efectiva de la empresa.

J.M Arnedo en su libro sobre la "Fabricación Asistida por ordenador (CIM)" [Arnedo92] señala como la palabra Integración comienza a aparecer con fuerza cuando se acuña el acrónimo CIM (Computer Integrated Manufacturing, es decir, Fabricación integrada por ordenador). Dicha fabricación supone una estrategia dinámica que integra personas, procesos, información, estructuras y tecnologías para proporcionar un método de gestión eficaz y poder ganar, una o varias ventajas competitivas para la empresa"

La International Conference on Enterprise Integration Modelling Technology (ICEIMT) [ICEIMT97] define la Integración Empresarial como el arte de entender, definir, especificar, analizar, estadarizar e implementar los procesos de negocio para la totalidad del Ciclo de Vida de la empresa, para que la empresa pueda lograr sus objetivos, ser efectiva y más competitiva en su mercado. Para ello se fundamenta en herramientas informáticas que cubran todas las fases de la empresa

En dicha conferencia [ICEIMT97] se llega a la conclusión de que la Integración Empresarial crea Arquitecturas Empresariales, plasmando el conocimiento de la organización en la utilización de estructuras e integración eficientes de las relaciones entre los distintos procesos de negocio, y consiguiendo beneficios tales como velocidad de respuesta a los cambios de 
mercado, estandarización de los procesos de negocio, facilidad y rapidez para la implementación de sistemas, competitividad y optimización de la empresa.

Para Ortiz [Ortiz97] la Integración Empresarial consiste en "la facilitación de flujos de materiales, información, decisiones, y control a través de la organización, ligando las funciones con los sistemas de información, recursos y personas, con la finalidad de mejorar la comunicación, la cooperación y la coordinación en la empresa, de tal forma que ésta se comporte como un todo, y que funcione alineada con la Estrategia de la Empresa"

En el análisis realizado por Ortiz sobre la definición de Integración Empresarial, se puede observar como al hacer referencia a la facilitación del flujo de materiales, información, decisiones, y control significa el manejo de todos los flujos de información que se producen en la empresa. Al señalar que se producen dentro de la organización, supone que se toma como organización extendida, es decir, incluyendo a los proveedores, clientes, y entorno que sean realmente significativos. Cuando tiene en consideración a los principales elementos del sistema empresa, las funciones, la información, los recursos, las aplicaciones y las personas, está tomando un enfoque de conjunto para con ello mejorar la comunicación entre los distintos elementos. Lo que implica una integración física y de aplicaciones adecuada, una cooperación y una coordinación, de forma que la empresa actúe como elemento perfectamente integrado que opera para alcanzar unos objetivos establecidos por la Estrategia de la compañía.

La definición de Empresa Extendida puede achacarse a O'Neill [ONeill95] en su tesis doctoral "Decision Support in the Extended Enterprise", donde la define como el conjunto de pequeñas y medianas empresas de productos y servicios combinadas de forma que son capaces de operar como grupos muy entrelazados en planificación y control de producción, servicio o entregas. El profesor J. Guzmán [Guzman02] de la Universidad Politécnica de Madrid define Empresa Extendida como la organización en la cual una empresa dominante extiende sus fronteras a todos o a algunos de sus proveedores, clientes y socios empresariales, lo que genera "un acuerdo a largo plazo y permanente en el que una empresa y sus suministradores y socios están unidos entre sí fuertemente por medio de flujos de información que facilitan el diseño y la producción" 
Volviendo a la definición de Integración Empresarial, para Kosanke [Kosanke] dicha Integración supone: una disminución de tiempo o desarrollo de un producto industrial, mejora de la calidad, buen ambiente empresarial y donde se produzcan los bienes demandados por el mercado de forma que todos los programas, sistemas, ordenadores, puestos de trabajo, robots, etc. estén programados para conseguir dicho objetivo. Todo ello se realiza a través de la transferencia de información entre departamentos, equipos, puestos de trabajo, empresas, participantes de la cadena de suministro, aunque puedan producirse fácilmente errores e ineficiencias.

Kosanke señala que la Integración empresarial está compuesta por cuatro palabras clave:

- Integración: hace actuar a una empresa como un conjunto de procesos, identificando las necesidades de transferir y utilizar información en el momento necesario y en el lugar adecuado: sobre productos, producción, procesos toma de decisiones.

- Personas: representan el papel más importante de la Integración ya que planifican, manejan y llevan a cabo las acciones de la Empresa: operan, programan, usan los sistemas que generan información a utilizar por diversas partes de la empresa o cadena de suministro.

- Ordenadores: Proveen el soporte tecnológico para la información. Exigen una metodología que permite trabajar de forma más eficaz y eficiente resolviendo problemas operativos en la empresa.

- Manufactura: supone las actividades necesarias para la proyección, fabricación, instalación y manutención de productos industriales o servicios.

\subsubsection{Tipos de Integración Empresarial}

Los tipos de Integración que se encuentran en el entorno empresarial según Bernus [Bernus96] son: 


\section{a. Integración Vertical- Horizontal}

La Integración Horizontal, relacionada habitualmente con la Integración física y lógica de los procesos de negocio que van desde la petición del producto, hasta que se sirve, incluyendo las relaciones fuera de los límites de la empresa e involucrando por lo tanto a proveedores y clientes. Este tipo de integración está muy relacionado con el flujo de materiales y documentos. La Integración vertical está relacionada con los distintos niveles de gestión de la empresa, el ejemplo más claro está relacionado con la Integración del flujo de decisiones.

\section{b. Integración Intra-empresa e Integración Inter-empresa}

La Integración Intra-empresa está relacionada con los procesos de negocio internos de la empresa. Mientras que la Inter-empresa, está relacionada con la integración de los procesos de negocio de una empresa con los de otras empresas, o incluso con el hecho de compartir entre varias empresas un proceso de negocio, este tipo de integración es la base de lo que se conoce como Empresa Extendida, y ya definida en el apartado anterior.

\section{c. Integración Física, Integración de aplicaciones e Integración de negocio}

Integración física: básicamente relacionada con los sistemas de comunicación y el intercambio de datos entre máquinas u ordenadores.

Integración de Aplicaciones: relacionada con la interoperatividad de aplicaciones en plataformas heterogéneas, así como al acceso de datos por parte de diversas aplicaciones, está por lo tanto relacionada con los procesos distribuidos, los servicios comunes, las infraestructuras integradoras, etc.

* Integración de Negocio: está relacionada con la Integración al nivel de empresa, por lo tanto con la Integración de los Procesos de Negocio. 
Kosanke [Kosanke] distingue a su vez tres tipos de integración empresarial, surgiendo éstos de la necesidad de resolver problemas industriales y actuar sobre aspectos operativos. Estos niveles operativos son:

- Integración de los Sistemas Físicos: Integración de las aplicaciones de proceso de datos, lo que supone una inter-operatividad entre personas y máquinas, a la vez que un fortalecimiento de la información obtenida a través de los sistemas de información.

- Integración de negocios: Integración de las funciones de gerencia, control, y dirección de los procesos de negocio. Supone un control de supervisión de los procesos operativos que coordinan acciones diarias a nivel operativo.

- Integración Empresarial: Sólo desde un enfoque de negocio en lugar del de aplicaciones o sistemas, se podrán identificar todos los aspectos de las operaciones industriales en curso y las alteraciones u optimizaciones entre sí.

Esto tipos de integración se pueden observar en la Ilustración 1.1

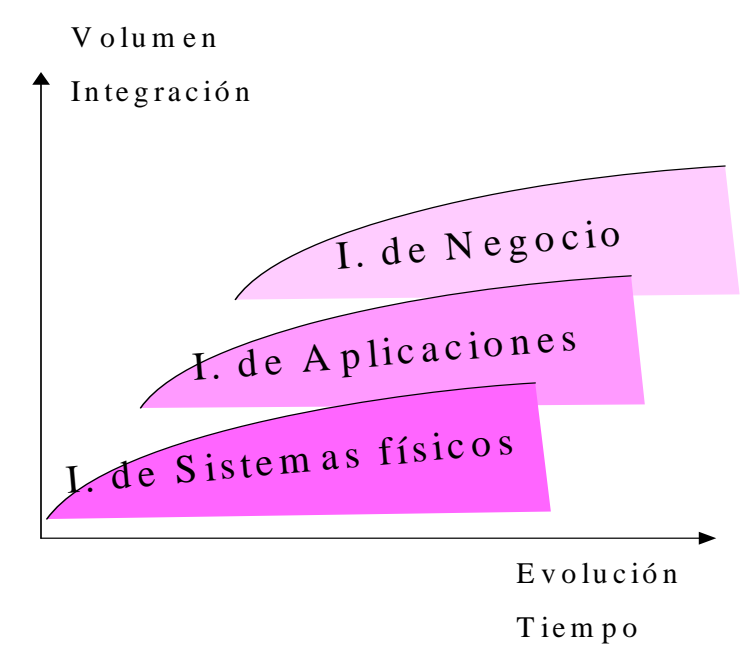

Ilustración 1. 1: Niveles de Integración Empresarial para Kosanke [Kosanke]

\subsubsection{Porqué de la Integración Empresarial}

Para Ortiz [Ortiz98 p. 112] la integración surge a raíz del objetivo de gerentes, ingenieros, personal de la industria en general y especialistas en sistemas, de relacionar y utilizar en 
cualquier momento, toda la información disponible sobre la empresa, para poder mejorar la operabilidad, economicidad, agilidad y competitividad. De ahí que la base para el desarrollo del CIM se construya sobre la capacidad del ordenador para manejar grandes cantidades de datos en períodos cortos de tiempo.

Para este autor, el diseño de un sistema CIM tiene una serie de consideraciones a tener en cuenta como:

a. El sistema es complejo y por tanto deben usarse algunas técnicas especiales para comprender esa complejidad a fin de actuar sobre ellas.

b. El sistema debe tener en cuenta los puntos de vista técnicos, económicos, sociales y humanos de forma integrada

c. El diseño requiere trabajo en equipo, no pudiendo realizarse por una única persona

d. Las condiciones iniciales del sistema han de tenerse en cuenta para comprender las limitaciones específicas con que opera el sistema y evitar los rediseños de partes que son satisfactorias.

Todo ello se realiza con el fin de modificar acciones para asegurar:

Una respuesta más rápida y mejor en los requisitos de los clientes

Elevada calidad en los productos

Aumento de la flexibilidad y respuesta cada vez más rápida en la introducción de nuevos productos y responder las necesidades del mercado.

De todo ello Ortiz [Ortiz98 p. 113]desprende que el solo uso del ordenador como elemento capaz de gestionar la información no es suficiente para responder a la problemática. Ni que el tratamiento de la información haga que se consigan ventajas competitivas, ya que hay que 
tener en cuenta los flujos de materiales, flujo de decisiones, personal, etc. y hacerlos trabajar de forma integrada para con ellos lograr la ventaja competitiva y poder cumplir los objetivos.

A su vez han surgido otros tipos de integración en el mundo, que hacen necesaria la Integración Empresarial, destacando:

- La globalización: integrando mercados, y hace que la empresa actúe en un ambiente global, aunque mantenga las características de la región.

- Integración entre proveedores y empresa: con ello se logra reducir los tiempos de aprovisionamiento y de desarrollo, logrando forzar la necesidad de integración y sincronización entre procesos de distintas compañías.

- Integración entre diferentes plataformas de hardware y software: permitiendo la interoperatividad de las distintas soluciones.

De todo ello Ortiz [Ortiz98 p. 114] desprende la idea de plantear una filosofía de carácter superior a lo desarrollado definiéndolo como Integración Empresarial.

\subsubsection{Objetivos}

Para lograr una verdadera Integración Empresarial en la que se consiga una adecuada coordinación, ha de existir fluidez en los de flujos de trabajo e información en la empresa, por lo que Ortiz [Ortiz98 p.114] señala que los motivos por los que una empresa busca la Integración Empresarial serían los siguientes:

- La necesidad de compartir información en la empresa, y no solo datos.

- $\quad$ La necesidad de que exista operatividad entre los distintos sistemas

- La necesidad de coordinación entre tareas, individuos, unidades organizacionales y sistemas que interactúan en la empresa 
- La necesidad de alinear las operaciones de la empresa con la estrategia.

Pero hay que tener presente que esto no se alcanza mediante un esfuerzo puntual, sino hay que realizar un esfuerzo continuo para lograr el objetivo empresarial. Por lo que se puede decir que es una parte de la componente de la Estrategia de la empresa.

Los objetivos que propone la perspectiva del grupo GIP, que se expondrán en el punto 1.3.6, y son aportados por Ortiz [ $\underline{\text { Ortiz98 }}$ p.167] el objetivo de la Integración Empresarial ha de conseguir que la empresa funcione bien, además de ir en la dirección correcta, y viceversa, que no sólo vaya en la dirección correcta sino que también funcione bien.

\subsection{METODOLOGÍAS PARA LA INTEGRACIÓN EMPRESARIAL}

\subsubsection{Metodología CIMOSA}

Kosanke [Kosanke] define CIMOSA (CIM Open Systems Architecture) como una metodología desarrollada por un proyecto ESPRIT que desarrolla un modelo prenormativo para el desarrollo del ciclo de vida de un sistema, junto con un lenguaje de modelización y la definición de una metodología y tecnología que lo soporte.

Para Ortiz [Ortiz98 p. 129] las motivaciones básicas que impulsaron el desarrollo de CIMOSA fueron:

La creación de un marco de modelado para las empresas CIM (o parte de ellas) que separe claramente el qué (o modelo que refleje cual debería ser la funcionalidad y el comportamiento de la empresa), del como (o modelo actual de la empresa)

La creación de un modelo particular de implementación en la empresa, que sea la base para el control por ordenador de la ejecución de los Procesos de Negocio modelados y de las actividades de empresa, proporcionando un auténtico CIM. 
Para ello, la metodología CIMOSA se basa en tres pilares fundamentales que se desarrolladan a continuación:

1. Esqueleto de Modelización de CIMOSA: En dicho esqueleto se definen tres dimensiones, con sus correspondientes subdivisiones, que reflejan todos los conceptos, mostradas en la Ilustración 1. 2 y que se exponen a continuación:

\section{Descripción de las dimensiones}

Dimensión de generación: representa el grado de participación que identifica el conjunto de modelos posibles. También se le denomina: Dimensión de los bloques constructivos

CIMOSA define tres niveles de generación: Genérico, Parcial y Particular, que a continuación se analizan:

- Nivel Genérico: en este nivel se generan una serie de estructuras que se denominan bloques constructivos arquitectónicos básicos para la construcción de cualquier modelo, pudiendo ser catálogo para cualquier referencia de construcción arquitectónica.

- Nivel Parcial: este nivel utiliza esqueletos incompletos de modelos para empresas particulares, aplicables a una amplia gama de sectores, organizaciones o estrategias industriales, acercándose a la realidad de empresa.

- Nivel Particular: representa todo el conocimiento necesario de la empresa de forma que sea utilizable por las especificaciones de un conjunto integrado de componentes de Tecnologías Industriales y de Tecnologías de información.

La arquitectura de CIMOSA distingue entre la arquitectura de Referencia, que contiene el nivel Genérico y Parcial, y la Arquitectura Particular, que contiene el Nivel Particular. 
Dimensión de las visiones: representa la estructura y comportamiento de un modelo considerado desde los distintos aspectos selectivos de una empresa. La estructura de CIMOSA contiene cuatro visiones: Función, Información, Recursos y Organización.

- Visión de Función: observa la funcionalidad de la empresa mediante la planificación, control y supervisión de las operaciones.

- Visión de la Información: permite la observación de la estructura de información requerida durante las operaciones de la empresa por procesos de planificación, control y toma de decisiones.

- Visión de Recursos: Permite la observación de los recursos de la empresa necesitados para llevar a cabo los procesos de la empresa.

- Visión Organización: responsabilidades de la toma de decisión de la empresa para los recursos de función, información y recursos y para la gestión de las excepciones y toma de decisión.

Dimensión de derivación: representa el ciclo de vida a partir de un punto de partida, que supone la representación de los requisitos del modelo.

- Nivel de definición de los requisitos: Identifica los requisitos de negocio de la empresa, que estarán relacionados con el qué hay que hacer para alcanzar los objetivos. Estos requisitos pueden descomponerse usando tipos de bloques constructivos del Nivel Genérico.

- Nivel de Especificación de diseño: Identifica y cuantifica la tecnología para ejecutar procesos identificados en la fase anterior. Estructura y optimiza los procesos según restricciones globales de la empresa y tecnología. El resultado es un modelo procesable por el ordenador con alternativas de posibles planes y que pueden evaluarse por simulación. 
- Nivel de descripción de la Implementación: Define en formato ejecutable los medios de ejecución del proceso seleccionando los actuales productos existentes en el mercado para proveer los componentes de la tecnología de la Información y Tecnología Industrial.

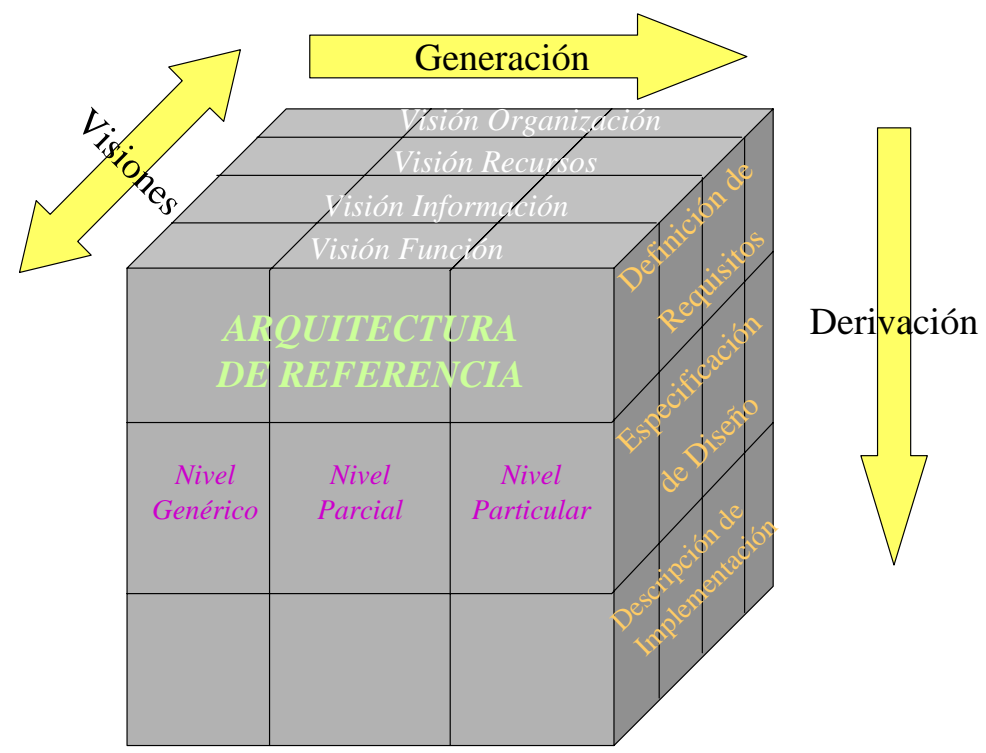

Ilustración 1. 2: Cubo de Modelización de CIMOSA. Fuente: K. Kosanke [Kosanke]

Como conclusión a todo esto, se llega a decir que la generación de modelo CIMOSA parte partir de las dimensiones analizadas, y define como se usan los bloques constructivos genéricos y los modelos parciales para crear un modelo particular de empresa.

\section{Ciclo de vida del sistema y sus ambientes: Ingeniería y Operaciones}

El ciclo de vida propuesto por CIMOSA tiene las siguientes fases principales:

1. Especificaciones de requisitos del sistema

2. Diseño del sistema

3. Descripción del sistema para su construcción y ejecución 


\section{Operaciones del sistema}

5. Cambio del sistema

Para apoyar el concepto de ciclo de vida, CIMOSA define un conjunto de ambientes interrelacionados en el se llevan a cabo tareas de modelización de la empresa, y operaciones del sistema empresa para cumplir las metas de la empresa. Con ello surgen dos ambientes: un ambiente integrado de ingeniería de empresa que proporciona soporte para la especificación, diseño, modificación y ejecución del sistema empresa, y otro correspondiente al integrado de operación de empresa, donde se proporciona soporte para la ejecución y control de los procesos de negocio, y actividades de empresa contenidas en el modelo particular de implementación.

\section{Infraestructura Integradora}

La Infraestructura integradora de CIMOSA actúa como un sistema operacional de la empresa, controlando no solo los procesos de datos, sino para todos los componentes de la empresa, incluyendo personas y máquinas, organizando y gestionando de forma dinámica las actividades de la empresa de acuerdo al comportamiento especificado en el modo particular de implementación.

\subsubsection{Metodología y Arquitectura GIM (GRAI)}

La arquitectura GIM (GRAI) comienza a ser desarrollada en los años setenta por el LAP (Laboratorio de Automatización y Producción) de la Universidad de Burdeos, para definir un sistema de producción integrada, teniendo en cuenta las compras y ventas.

Ortiz [Ortiz98] basandose en M. Roboam y su tesis doctoral por la Universidad de Burdeos "Modeles de réference et intégration des méthodes d'analyse pour la conception des systémes de production" define como objetivo principal del Enfoque Estructurado GIM el dar soporte a la fase de Análisis y/o diseño de un Sistema Avanzado de Fabricación. 
El modelo GRAI tiene como objetivo proporcionar una descripción genérica de lo que es un sistema de fabricación incidiendo en la parte de control de este sistema (la gestión de producción en un amplio sentido). Siendo el principal interés del modelo GRAI que es lo suficientemente genérico para poder utilizarse en cualquier tipo de sistema de fabricación.

El modelo GRAI se compone de tres sistemas:

* Sistema físico: debe transformar materias primas, componentes, en productos acabados creando un flujo de materiales a través de los medios organizados de acuerdo a varios criterios de agrupamiento.

* Sistema de decisión: dividido en niveles de toma de decisión de acuerdo con varios criterios, cada uno compuesto por uno o varios centros de decisión. En el sistema decisional pueden distinguirse dos partes: la parte superior dirigida a periodos, y la inferior, que suponen interfaces con el sistema físico.

* Sistema de información: contiene toda la información necesaria para el sistema de decisión. Debe estar estructurado de una forma jerárquica de acuerdo con la estructura de centros de decisión.

Un centro de decisión a cualquier nivel de la estructura puede ser descompuesto utilizando los mismos criterios de descomposición: un elemento físico, un elemento decisional, y un elemento de información.

El enfoque estructurado GIM tiene principalmente cuatro fases: iniciación análisis, diseño e implementación; dividiendo la fase de diseño en subfases, una orientada al usuario y otra orientada a la tecnología. 


\subsubsection{Metodología y Arquitectura de Referencia Empresarial de Purdue (PERA)}

La Arquitectura de Referencia Empresarial PERA (Purdue Enterprise Reference Architecture) se ha creado para llevar a cabo el desarrollo de programas de Integración Empresarial.

Dicha metodología la recoge Hong [ㅂong94] en su tesis doctoral y en el artículo extraído de la misma y referenciado, en el cual define, diseña, construye, instala y desarrolla el proceso de operación de empresas.

\section{Metodología PERA}

Hong [Hong94 p. 34] define la empresa como una entidad de negocio (EBE: Enterprise Business Entity: Entidad de negocio empresarial) constituida para producir bienes y servicios en respuesta de las necesidades de los clientes. Para ello la arquitectura Purdue considera que existen dos ambientes:

* Ambiente externo: caracterizado por rápidos cambios de las necesidades de mercado y gran competencia de otros vendedores en el mismo campo.

* Ambiente interno: caracterizado por los objetivos globales, actitudes de gestión y grandes y frecuentes cambios tecnológicos.

Las tareas propuestas por PERA (Purdue Enterprise Reference Architecture) se basan en la realización de una serie de etapas que representan un diagrama de bloques mostrado en la Ilustración 1. 3. Estas etapas son tres: La Etapa Conceptual, Etapa de Definición, Etapa de Especificación.

1. Etapa Conceptual: supone la identificación de la entidad de negocio para realizar la Integración Empresarial, tanto en el ambiente interno como externo. Esa identificación supone cual será el futuro de la empresa y así como la necesidad de llevar a cabo ciertos proyectos. 
La identificación de la unidad de negocio es lo más importante de esta etapa, ya que se describe la misión, visión y valores de la entidad junto con la filosofía operativa que se elegirá: procesos productivos, selección de clientes, etc.

A partir de esta etapa, se definen las políticas operacionales desglosándose en unidades y áreas correspondientes, clasificándose dos categorías funcionales, una para las políticas relacionadas con información y control, y otra para políticas relacionadas con producción, completando así la etapa Conceptual.

2. Etapa de Definición: en esta etapa se dan paso a los requisitos operacionales y funcionales de la entidad definida.

Los análisis realizados en la etapa de definición PERA son independientes del método específico escogido de implementación, es decir, sin importar si está basado en una máquina o en una persona.

El nivel de Definición se basa en los requisitos establecidos, realizando un enfoque funcional desde abajo hacia arriba, empezando por la definición de tareas detalladas. Las tareas se agrupan en funciones, y de los módulos construidos en bloques se conectan a una red funcional de flujo de la información en el lado izquierdo y de material en el derecho, lo que formará la red funcional de información o red funcional de producción, respectivamente.

3. Etapa de Especificación: En el nivel de Especificación se comienzan las consideraciones de implementación y se produce inmediatamente tras el nivel de Definición.

Si el sistema futuro fuera totalmente automático y no hubiera personas involucradas, las dos redes funcionales definidas (información y producción) se trasladarían directamente a la implantación. Pero al existir la necesidad de personas y participación del factor humano, surge la necesidad de definir tareas, tanto de información como de producción, a realizar por el personal. Aunque las tareas realizadas por el personal en estas arquitecturas sean diferentes, los requisitos económicos, sociales, culturales y educaciones son comunes, así 
como las capacidades físicas y psicológicas, de modo que pueden considerarse de forma conjunta todas las tareas realizadas por el personal. Todo ello supone que las dos redes funcionales se conviertan en tres subarquitecturas:

* Subarquitectura de los Sistemas de Información

* Subarquitectura Organizacional y Humana

* $\quad$ Subarquitectura del Equipo de producción

Existen dos enfoques importantes relacionados con el desarrollo de las arquitecturas descritas:

- Enfoque funcional: reúne los módulos de tareas que describen e ilustran las funciones asignadas a una entidad de negocio y sus relaciones. Comprende una serie de tareas genéricas llevadas a cabo por todas o la mayoría de las entidades de negocio de la integración empresarial.

- Enfoque físico o de implementación: reúne las organizaciones humanas y el hardware y software físico para llevar a cabo todas o parte de las funciones descritas e ilustradas por el enfoque funcional de la entidad de negocio. Este enfoque físico o de implementación es reflejado por las tres arquitecturas, desde la etapa de Especificación y a través del resto de etapas.

Para Williams [Williams94] el resultado de establecer las arquitecturas en la Especificación, hace que pueda planificarse y especificarse cual será la integración de funciones en un programa, de lo que resulta el Plan Maestro (Master Plan). Tras la etapa de Especificación, el ciclo de vida de Pera continúa a través de su fase Detallada de diseño, fase de Construcción, y Fase de Operaciones, para finalmente llegar al Desmantelamiento, en caso que se decida. Dicha evolución se denomina Ciclo de Vida de PERA y se muestra en la Ilustración 1. 3: 


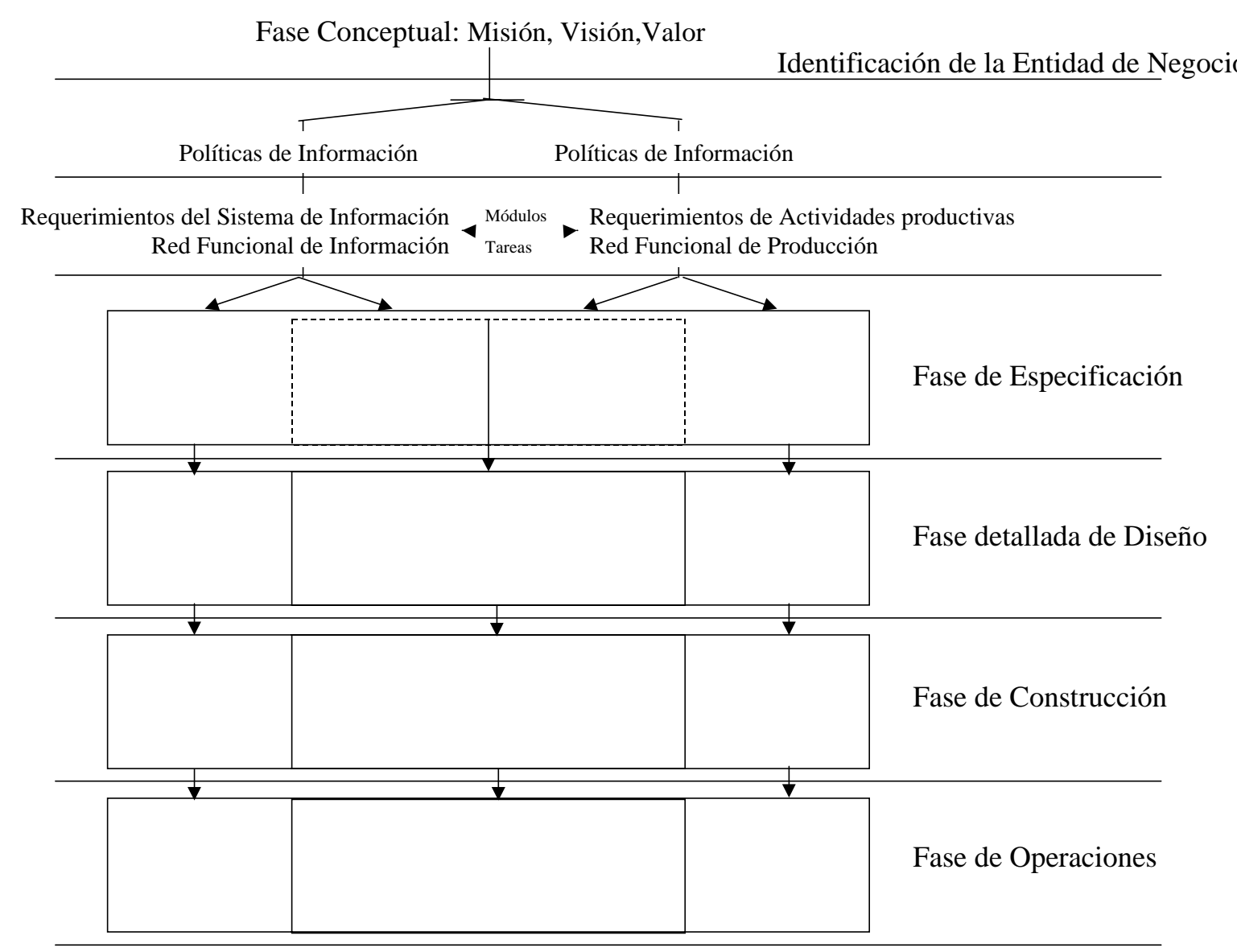

\section{Ilustración 1. 3: Metodología PERA. Fuente: Hong94 [ㅂong94]}

\section{Selección de Tareas para el Personal}

Hasta ahora se ha mostrado la estructura y las tareas más importantes, así como ciclo de vida de PERA a nivel vertical, pero a nivel horizontal PERA ha contribuido al estudio de arquitecturas de referencia a través de la división de la visión de implementación de una arquitectura en tres subarquitecturas, llegando a una discusión de los aspectos humanos de la integración en el sistema de información y producción.

Para poder asignar un lugar al personal en la realización de funciones empresariales, se necesita asignar funciones humanas propias del sistema. Para ello, habrá que definirlas y ubicarlas en la representación gráfica de la arquitectura. 
Para ello se separan las dos arquitecturas de implantación en tres, como muestra la Ilustración 1.4, para lo que hay que asignar tareas y funciones:

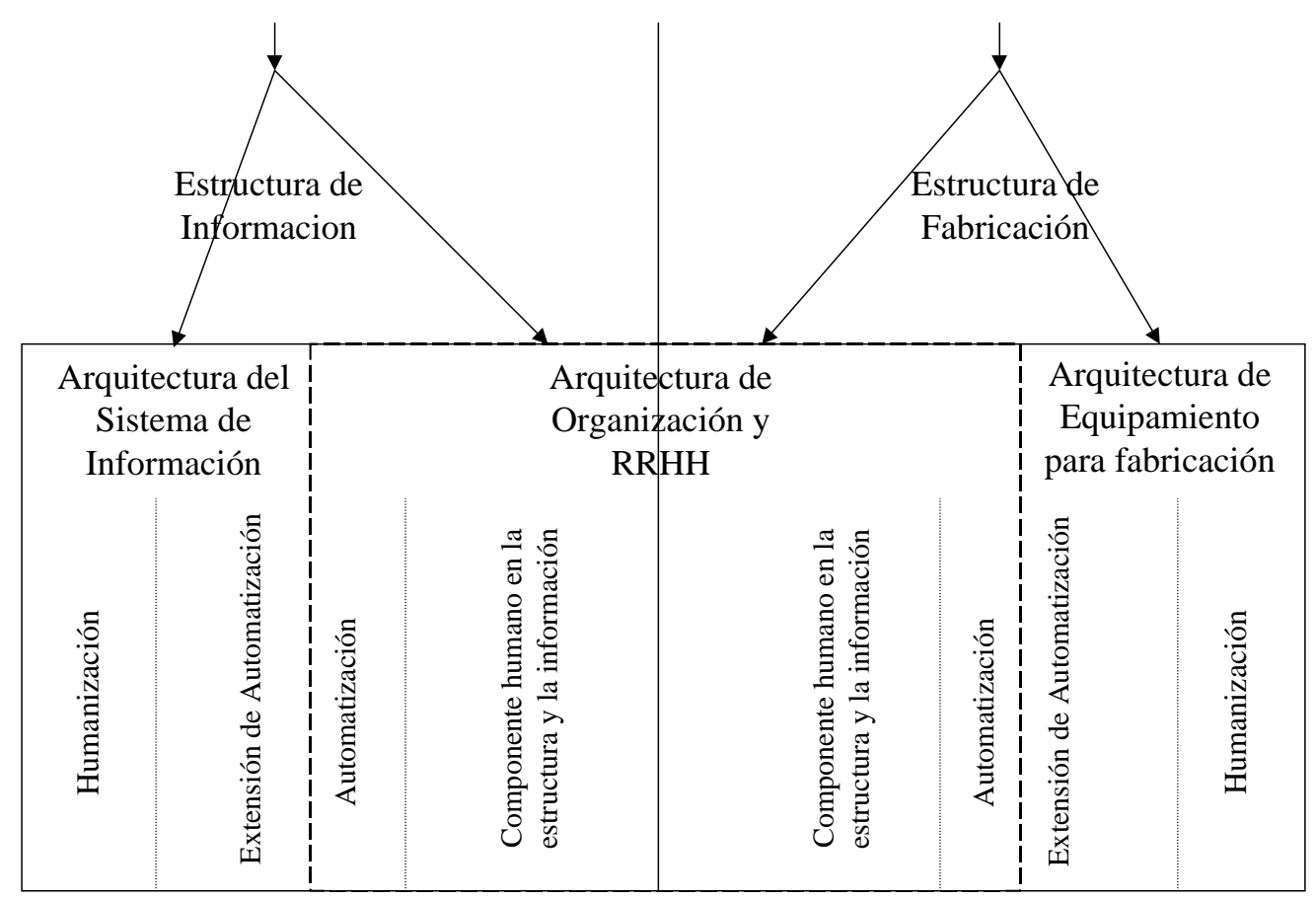

Ilustración 1.4: Relación entre Automatización, Humanización y Extensión de la Automatización. Fuente: Hong94 [ㅂong94 p.47, Williams p.9]

Para ello surgen las siguientes tres subarquitecturas:

Automatización: Muestra la extensión de la tecnología para la automatización de tareas y funciones del sistema de integración en el sistema de integración empresarial. Muchas de las tareas requieren del factor humano y no pueden automatizarse completamente con la tecnología existente en ese momento.

Humanización: Muestra la máxima extensión en la que el factor humano puede ser usado para implementar tareas y funciones del sistema de integración empresarial. La limitación procede de que muchas tareas y funciones necesitan de la innovación humana, del nivel de respuesta, de la visión del personal, e incluso de la fuerza física, etc. 
* Extensión de la Automatización: Muestra el grado actual de automatización realizado o empleado en el sistema de integración empresarial, definiendo la línea entre la arquitectura Organizacional y Humana, y la Arquitectura del Sistema de Información en el lado izquierdo, y la frontera entre la Arquitectura Organizacional y Humana y la Arquitectura del Equipo de Producción en el lado derecho.

La línea de Extensión de Automatización cuenta para su determinación y para poder ultimar la división de funciones entre humanos y máquinas con factores como: económicos, políticos, tecnológicos y sociales como costumbres, leyes, directrices, reglas....

\subsubsection{Metodología GERAM}

A la vista de las múltiples arquitecturas de integración existentes, Williams [Williams] expone la idea de crear una arquitectura universalmente aceptada dentro del campo de la integración, de forma que a través de los métodos, modelos y herramientas necesarias genere y mantenga el negocio o red de negocios integrada. Esta nueva arquitectura intentó tomar las mejores opciones y características de las arquitecturas ya existentes.

El nombre de GERAM procede de las siglas en inglés de Generalized Enterprise Reference Architecture and Methodology, es decir, Metodología y Arquitectura de Referencia Generalizada de Negocio.

La expansión de lo que cubre la Arquitectura GERAM supone una amplitud de aplicaciones:

a. Productos

b. Empresas produciendo productos o servicios

c. Empresas Integradas que realizan el desarrollo del negocio

d. Dirección Estratégica de negocio. 
La matriz del modelo GERAM se desarrolló por la combinación de las principales características de las otras arquitecturas, como:

- Dimensión genérica de CIMOSA: que aporta lo genérico, parcial y particular.

- El ciclo de vida de PERA

- Vistas de GRAI y CIMOSA

Todo ello se puede observar en la Ilustración 1. 5, correspondiendo el ciclo de vida de esta arquitectura prácticamente al de PERA, es decir: Identificación, Conceptos, definición, especificación, diseño detallado, implementación, operación 
등
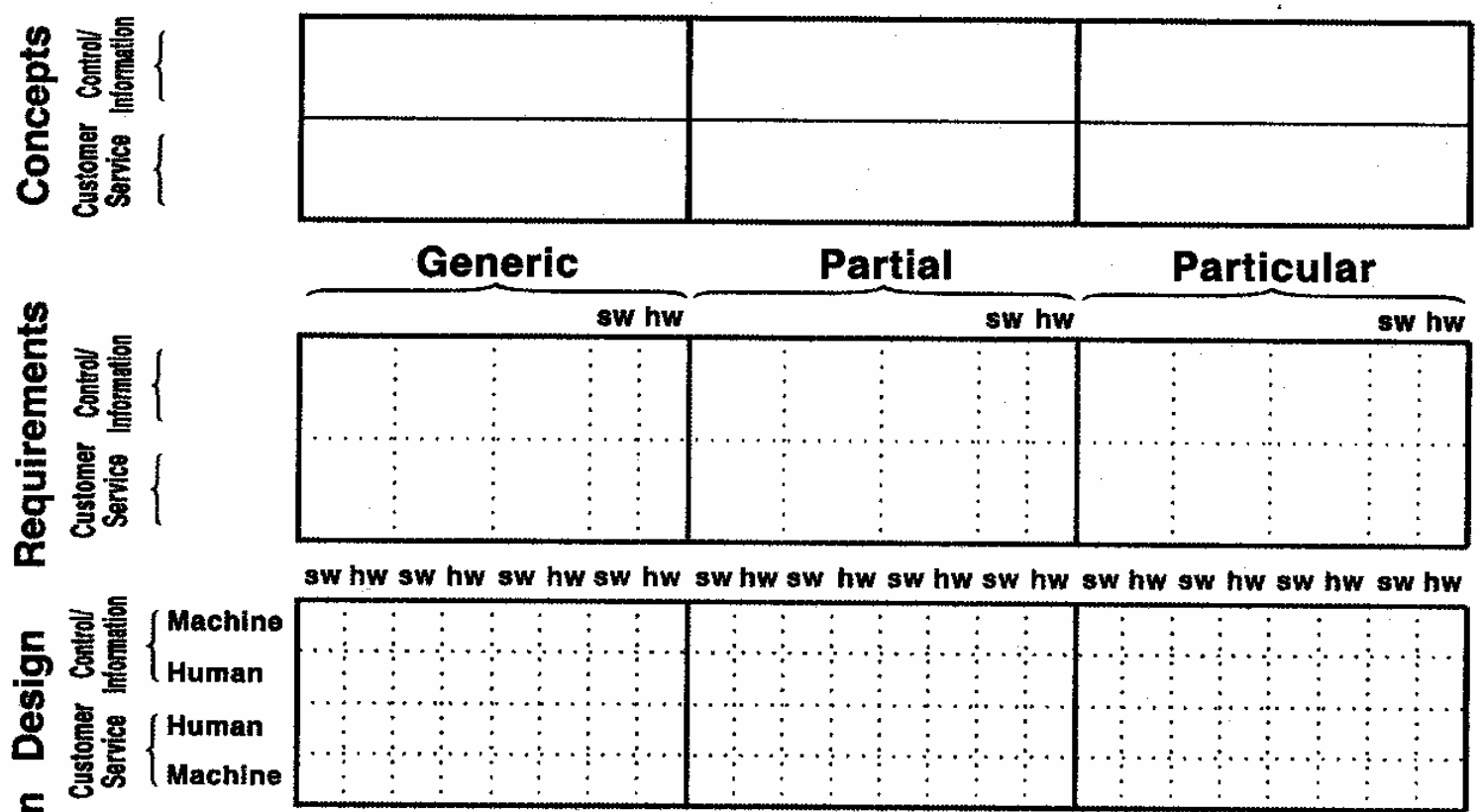

흠
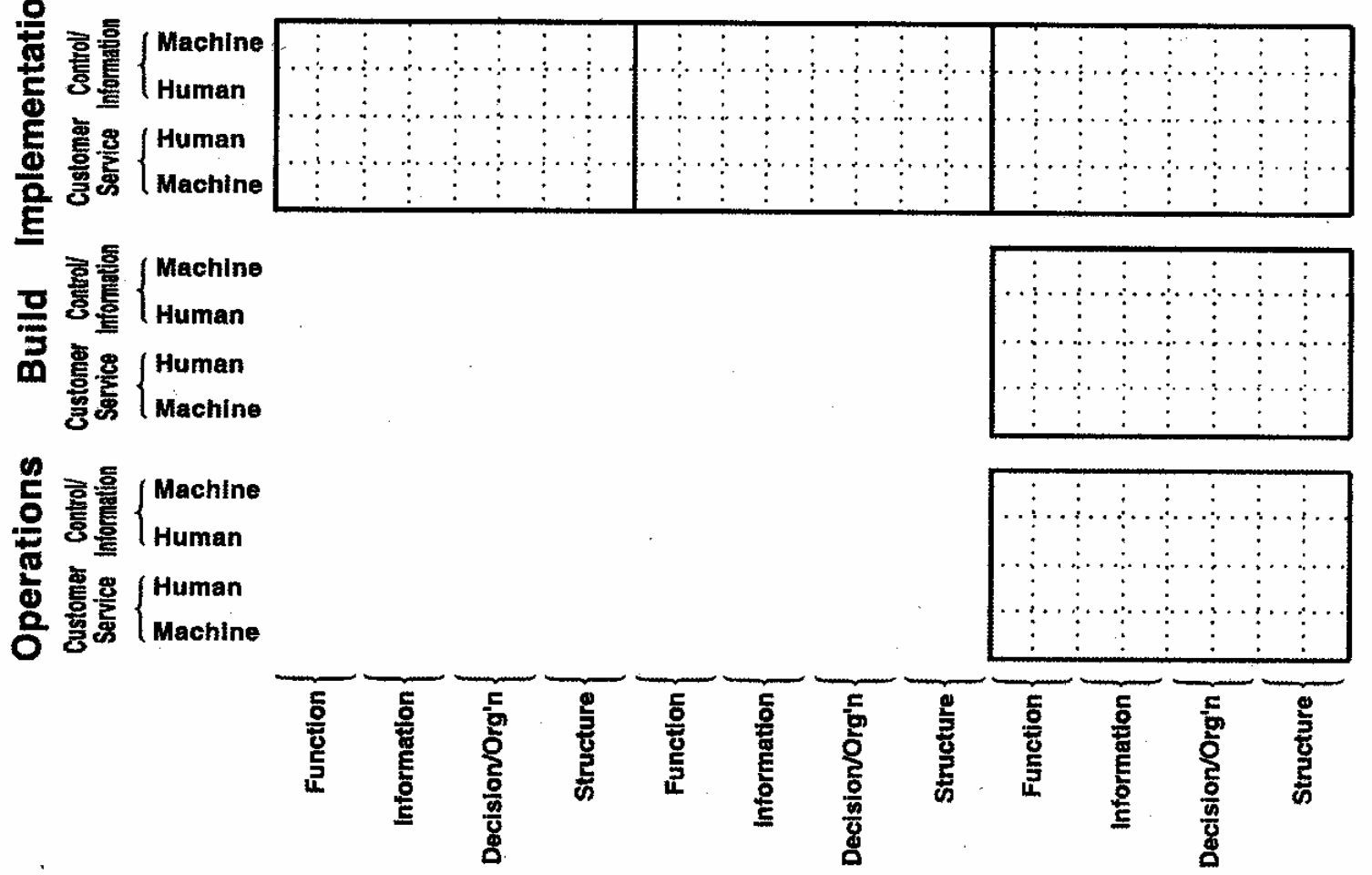

Ilustración 1. 5: Matriz del modelo GERAM. Fuente: Williams [Williams p.29] 


\subsubsection{Metodología de Zachman}

El Instituto Zachman para el Desarrollo del marco ZIFA (Zachman Institute for Framework advanced), es una red de profesionales que desarrollan las Arquitecturas de negocio de la economía del siglo XXI. La misión del grupo ZIFA es promover el intercambio de conocimiento y experiencia en el uso, implementación y desarrollo del marco Zachman para la Arquitectura Empresarial, con la idea de avanzar en el concepto e implementación de la Arquitectura Empresarial.

En 1987, John Zachman, autor de la arquitectura empresarial Zachman [Zachman], escribió "hay que mantener los negocios lejos de la desintegración, el concepto de la arquitectura de los sistemas de información se está convirtiendo más en una necesidad que en una opción". Desde que se realizó esta definición hace unos años, la arquitectura empresarial Zachman ha evolucionado y logrado ser el modelo que más empresas utilizan para la comunicación de información empresarial. La arquitectura Zachman parte desde una disciplina de arquitectura clásica al establecer un vocabulario común, un conjunto de perspectivas, y un modelo para definir y describir los sistemas de negocio actuales.

Los supuestos de partida para el marco Zachman son:

1. El éxito de la arquitectura empresarial se fundamenta en la participación en la interacción global de las empresas del siglo XXI.

2. La arquitectura empresarial es el principal mecanismo estructural para:

* $\quad$ Establecer una base de asimilación un gran número de cambios

* $\quad$ El estado del arte en el diseño empresarial

* $\quad$ Dirigir la base del conocimiento en la empresa

* Integrar la tecnología (automatizada o no automatizada) en el negocio 
3. La arquitectura empresarial es universal, lo que significa que cada negocio sea del tipo y esperanza de vida que sea, tendrá que utilizar los conceptos de arquitectura empresarial.

4. La arquitectura empresarial es interdisciplinar, requiriendo de diversas habilidades de integración, métodos y herramientas más allá de la tecnología de la comunidad.

Las metas que Zachman plantea conseguir de esta arquitectura son las siguientes:

1. Establecer el marco del modelo Zachman, como un lenguaje universal para facilitar la comunicación, investigación e implementación de los conceptos de arquitectura empresarial.

2. Lograr un entendimiento universal y competencias en cada comunidad, para implementar conceptos arquitectónicos. Estas comunidades incluyen el sector público y privado, la gestión general, los consumidores o usuarios, los suministradores, los teóricos y quienes lo practican.

3. Mantener métodos y herramientas neutrales, que hagan énfasis en la integración y posición, como oposición a la competencia.

Los objetivos a cumplir por dicha arquitectura son

1. Establecer un forum de comunicación: estrategias para lograrlo

A través de reuniones anuales

Establecer una web para el dialogo que pueda surgir en el día a día

Desarrollar una red de personas que contribuya al desarrollo de la arquitectura

Crear una asociación local ZIFA (Zachman Institute for Framework Advancement) para contactos e intercambios de ideas 
2. Identificar lo relacionado con la arquitectura y facilitar soluciones para y estrategias para lograrlo:

Iniciar y administrar proyectos de investigación

Establecer alianzas con vendedores e iniciar esfuerzos de colaboración

Realizar encuestas y otros proyectos de investigación

3. Aumentar la conciencia general de los usos de la Arquitectura empresarial. Estrategias para lograrlo:

Participar en conferencias, seminarios etc.

Preparar artículos para su publicación

Desarrollar un programa de comunicación para asequible que se pueda exponer.

4. Divulgar los conceptos, técnicas, descubrimientos, capacidades, etc. Estrategias para lograrlo:

Utilizar páginas web como vía de comunicación

Enviar un boletín mensual

Desarrollar actividades tipo seminarios, investigación retiros, etc.

Publicaciones de bibliografías, revisiones de libros, etc. 
5. Establecer una arquitectura de Calidad y desarrollo de estándares: Estrategias para su logro

Realizar unos premios anuales para los logros conseguidos

Desarrollar programas certificados de productos o ventas

El marco Zachman fue diseñado para representar las arquitecturas de los sistemas de información y sus participantes en el desarrollo, dirección, mantenimiento, y uso de dichos sistemas. La visión de esta arquitectura sigue un orden cronológico un tanto obvio, ya que pasa por las siguientes figuras: Planificador, propietario, diseñador, técnico, subcontratado y finalmente usuario. De todos modos, las perspectivas no suponen un paso delante de los detalles de la arquitectura. Cada una de estas perspectivas proporciona requisitos y límites para la arquitectura de los sistemas de información completando así la descripción de la arquitectura.

La arquitectura de Zachman genera los modelos con idea de luego implementarlos en las empresas. Por tanto la arquitectura propone una tabla de doble entrada en la que en un eje se posicionan una serie de participantes que intervendrán en la generación del sistema y la otra entrada contendrá los datos, funciones, lugares, personas, tiempo y motivación necesaria para cada participante. Esta entrada se puede explicar mediante el traslado de toda esa información a las cuestiones del ¿Qué?, ¿Cómo?, ¿Dónde?, ¿Quién?, ¿Cuándo? y ¿Por qué?, respectivamente. Toda esta representación de la arquitectura Zachman [Zachman] se puede observar en la

Ilustración 1. 6. La interacción de estos dos ejes hace surgir la toda la información necesaria para cada participante en la construcción de un sistema. Siendo esos participantes los que a continuación se definen:

Planificador: El planificador es quien realiza una descripción general de los sistemas de información y su posicionamiento en el contexto interno y externo. La planificación no 
solo identifica los principales componentes de los sistemas de información, sino también analiza su viabilidad financiera (costes y beneficios), obligaciones y alcance.

Propietario: El propietario es aquel interesado en la entrega del negocio, su funcionalidad, y su uso futuro. Una vez establecido el plan, el propietario impone los requisitos y las obligaciones específicas del sistema, como las políticas y prácticas de las empresas, y la necesidad de recuperación de datos y tiempos de respuesta.

Arquitecto/ Diseñador: El arquitecto, necesita comprender el sistema de información, tanto desde la perspectiva de negocio como desde la perspectiva técnica. El arquitecto trabaja con las especificaciones del sistema de información que se le han facilitado, con el fin de generar un diseño que cumpla las especificaciones del propietario y además pueda ser representado por el técnico. Consecuentemente, la arquitectura no debe ser capaz únicamente de interpretar los requisitos y obligaciones pero debe ser consciente tanto de las posibilidades técnicas y las limitaciones de los sistemas. Las interacciones, los sistemas existentes, las regulaciones gubernamentales, etc. podrán afectar a la implementación. Esto requiere a menudo, que el arquitecto desarrolle combinaciones de funciones y especificaciones técnicas.

Técnico: El técnico es quien gestiona el proceso de producir y montar los componentes de los sistemas. Esto requiere del conocimiento de las especificaciones de las arquitecturas del sistema. Además, el técnico debe conocer los materiales y las herramientas con los que trabajar, así como las vías con las que organizar y desarrollar el trabajo.

Subcontratista: El subcontratista construye partes específicas de un producto. A menudo, dichas partes se producen fuera del ambiente o contexto debido a que tienen unas especificaciones proporcionadas por el técnico, y es su responsabilidad proporcionar al subcontratista los correspondientes detalles de las especificaciones. A su vez, es responsabilidad del subcontratista generar los componentes según las especificaciones proporcionadas. 
Usuario: La perspectiva del usuario supone la interfaz y funcionalidad con el producto final. La perspectiva del usuario es producto de la planificación, diseño, y desarrollo de actividades previas. Cuando el sistema de información se ha completado, puede compararse con los objetivos iniciales y los requisitos del planificador y propietario. Un cambio de esos requisitos y objetivos puede justificarse o ser problemático en el futuro. 
ENTERPRISE ARCHITECTURE - A FRAMEWORK ${ }^{\text {TM }}$

\begin{tabular}{|c|c|c|c|c|c|c|c|}
\hline & DATA & FUNCTION & NETWORK & PEOPLE & TIME & MOTIVATION & \\
\hline $\begin{array}{l}\text { SCOPE } \\
\text { (CONTEXTUAL) }\end{array}$ & $\begin{array}{l}\text { List of Things Imp } \\
\text { to the Business }\end{array}$ & $\begin{array}{l}\text { List of rocesses the } \\
\text { Busine ss Performs }\end{array}$ & $\begin{array}{l}\text { List of Lo } \\
\text { the Busing }\end{array}$ & $\begin{array}{l}\text { List of Organizations } \\
\text { Important to the Business }\end{array}$ & $\begin{array}{l}\text { Iis th t f von } \\
\text { to the Bus in }\end{array}$ & List of Busin & $\begin{array}{r}\text { SCOPE } \\
\text { (CONTEXTUAL) }\end{array}$ \\
\hline Planner & $\begin{array}{l}\text { ENTITY Y Class of } \\
\text { Business thing }\end{array}$ & $\begin{array}{l}\text { Function = = lass of } \\
\text { Bustiness } \\
\text { Brocess }\end{array}$ & $\begin{array}{l}\text { Node }=\text { Major Business } \\
\text { Location }\end{array}$ & People $=$ Major Organizations & Time $=$ Major Bus iness Event & 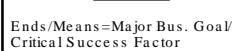 & Planner \\
\hline $\begin{array}{l}\text { ENTERPRISE } \\
\text { MODEL } \\
\text { (CONCEP TUAL) }\end{array}$ & e.g. Semantic Model & e.g. Bus iness Process Model & e.g. Logis tics Network & e.g. Work Flow Model & e.g. Master Schedule & e.g. Busines & $\begin{array}{r}\text { ENTERPRISE } \\
\text { MODEL } \\
\text { (CONCEPTUAL) }\end{array}$ \\
\hline Owner & $\begin{array}{l}\text { Ent = Busine ss Entity } \\
\text { Reln }=\text { Business Relationship }\end{array}$ & $\begin{array}{l}\text { Proc. = Bus iness Process } \\
y O=\text { Business Re sources }\end{array}$ & $\begin{array}{l}\text { Node }=\text { Business Location } \\
\text { Link }=\text { Business L Linkage }\end{array}$ & $\begin{array}{l}\begin{array}{l}\text { People }=\text { Organization Unit } \\
\text { Work }=\text { Work Product }\end{array}\end{array}$ & $\begin{array}{l}\text { Time }=\text { Business Event } \\
\text { Cycle }=\text { Busine ss Cycle }\end{array}$ & $\begin{array}{l}\text { End = Business Objective } \\
\text { Means = Bus iness Strate gy }\end{array}$ & Owne \\
\hline $\begin{array}{l}\text { SYSTEM } \\
\text { MODEL } \\
\text { (LOGICAL) }\end{array}$ & e.g. Logical Data Model & e.g. "App lica tion Archite cture" & $\begin{array}{l}\text { e.g. "Distributed System } \\
\text { Archite cure" }\end{array}$ & $\begin{array}{l}\text { e.g. Human Interface } \\
\text { Architecture }\end{array}$ & e.g. Process sing S tructure & e.g., Bus ine ss Rule Model & $\begin{array}{r}\text { SYSTEM } \\
\text { MODEL } \\
\text { (LOGICAL) }\end{array}$ \\
\hline Designer & $\begin{array}{l}\text { Ent = Data Entity } \\
\text { Reln = Data Relationship }\end{array}$ & $\begin{array}{l}\text { Proc = Application Function } \\
\text { IO =User Views }\end{array}$ & 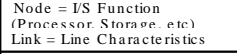 & $\begin{array}{l}\text { People = Role } \\
\text { Work = Delive rable }\end{array}$ & 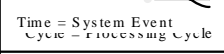 & $\begin{array}{l}\text { End = Structural As sertion } \\
\text { Means = Action Assertion }\end{array}$ & Designer \\
\hline $\begin{array}{l}\text { TECHNOLOG Y } \\
\text { MODEL } \\
\text { (PHYSICAL) }\end{array}$ & e.g. Physical Data Model & e.g. "System De sign" & 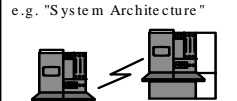 & e.g. Prese ntation Archite cure & e.g. Control Structure & e.g. Rule Design & $\begin{array}{r}\text { TECHNOLOGY } \\
\text { CONSTRAINED } \\
\text { MODEL } \\
\text { (PHYS ICAL) }\end{array}$ \\
\hline Builder & 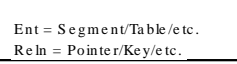 & $\begin{array}{l}\text { Proc.= = Computer Function } \\
\text { VO = Screen Device Formats }\end{array}$ & $\begin{array}{l}\text { Node }=\text { Hard ware } / \text { Sys te m } \\
\text { Soltww re } \\
\text { Link }=\text { Line } S \text { pecifications }\end{array}$ & $\begin{array}{l}\begin{array}{l}\text { People = User } \\
\text { Work = Screen Format }\end{array} \\
\text { Wort }\end{array}$ & $\begin{array}{l}\text { Time }=\text { Execute } \\
\text { Cycle }=\text { Component Cycle }\end{array}$ & $\begin{array}{l}\text { End }=\text { Condition } \\
\text { Means }=\text { Action }\end{array}$ & Builder \\
\hline $\begin{array}{l}\text { DETALEED } \\
\text { REPRESEN- } \\
\text { TATIONS } \\
\text { (OUT-OF- } \\
\text { CONTEXT) }\end{array}$ & e.g. Data De finition & e.g. "Program" & e.g. "Ne twork Archite cture" & & e.g. Timing De finition & e.g. Rule Specification & $\begin{array}{c}\text { DETALIED } \\
\text { REPREEN- } \\
\text { TAUIONS } \\
\text { (OUT-OF } \\
\text { CONTEXT) }\end{array}$ \\
\hline $\begin{array}{l}\text { Sub- } \\
\text { Contractor }\end{array}$ & $\begin{array}{l}\text { Ent }=\text { Field } \\
\text { Reln }=\text { Address }\end{array}$ & $\begin{array}{l}\text { Proc. = Language Stmt } \\
I O==\text { Control Block } \\
I,\end{array}$ & $\begin{array}{l}\text { Node }=\text { Addre sses } \\
\text { Link }=\text { Protocols }\end{array}$ & $\begin{array}{l}\text { Ponnol = Iden nity } \\
\text { Work = Job tob }\end{array}$ & & $\begin{array}{l}\text { End }=\text { Sub-condition } \\
\text { Means }=\text { Step }\end{array}$ & $\begin{array}{r}\text { Sub- } \\
\text { Contractor } \\
\end{array}$ \\
\hline $\begin{array}{l}\text { FUNCTIO NING } \\
\text { ENTER P RIS E }\end{array}$ & e.g. DATA & e.g. FUNCTION & e.g. NETWORK & e.g. ORGANIZATION & e.g. SCHEDULE & e.g. STRATEGY & $\begin{array}{l}\text { FUNCTIONING } \\
\text { ENTERPR RISE }\end{array}$ \\
\hline
\end{tabular}

Zachman Institute for Framework Advancement - (810) 231-0531

Copyright - John A. Zachman, Zachman International

Ilustración 1. 6 : Marco de Arquitectura Zachman. Fuente: Zachman [ [Zachman] 


\subsubsection{Metodología IE- GIP (Valencia)}

El enfoque proporcionado por el GIP (Gestión e Ingeniería de Producción) de la Universidad de Valencia, y en particular el enfoque aportado en la tesis de A. Ortiz titulada "Propuesta para el desarrollo de programas de integración empresarial en empresas industriales. Aplicación a una empresa del sector cerámico”, explica la propuesta del grupo GIP.

Ortiz [Ortiz98 p. 184] propone una metodología de desarrollo de programas de Integración empresarial realizada a dos niveles, uno macro y otro de detalle. Esta metodología supone el avance a través de una serie de pasos que se detallan a continuación. Estos pasos propuestos por Ortiz [Ortiz98 p. 184] son los siguientes, correspondiendo los cuatro primeros el nivel macro, y los seis restantes, al nivel de detalle:

1. Identificación de la Entidad de Negocio: Identificar donde se va a desarrollar la actuación del resolutor frente al problema, es decir, si su ámbito de actuación va a ser en toda la empresa o un departamento, sólo en algunos procesos, personas, productos.

2. Conceptualización: Establece el marco estratégico en el que se moverá el resolutor de problemas: la misión, valores, políticas, etc. convenientes.

3. Análisis de los procesos: Descripción de los procesos que se desarrollan y los que se han de desarrollar una vez resuelto el problema, es decir del modelo To Be al modelo As Is.

4. Elaboración de un plan de actuación: Plan de actuación para que el resolutor de problemas lleve a cabo su actuación.

5. Definición de requerimientos: Supone definir que características (deseables o no) ha de tener el nuevo sistema (Modelo As Is) que surgirá de la actuación del resolutor de problemas. 
6. Especificaciones de diseño: Identifica y diseña el sistema de forma que cubra los requisitos definidos en el punto anterior por el resolutor para la generación del nuevo sistema.

7. Descripción de la implementación: Selección de productos y técnicas actuales más adecuadas, que proporcionen los componentes adecuados para poner en marcha el resolutor de problemas

8. Construcción: Instalación de los requisitos en la empresa para poder ejecutar el resolutor de problemas.

9. Operación: Realización de todas las actividades especificadas en los pasos anteriores, para conseguir los objetivos de resolución del sistema.

10. Desmantelamiento: Criterios de actuación para la eliminación del sistema anterior ya en desuso.

Dichos pasos se pueden observar gráficamente en la Ilustración 1. 7, donde se observa como se sucede etapa tras etapa, para el desarrollo de programas de Integración Empresarial. 


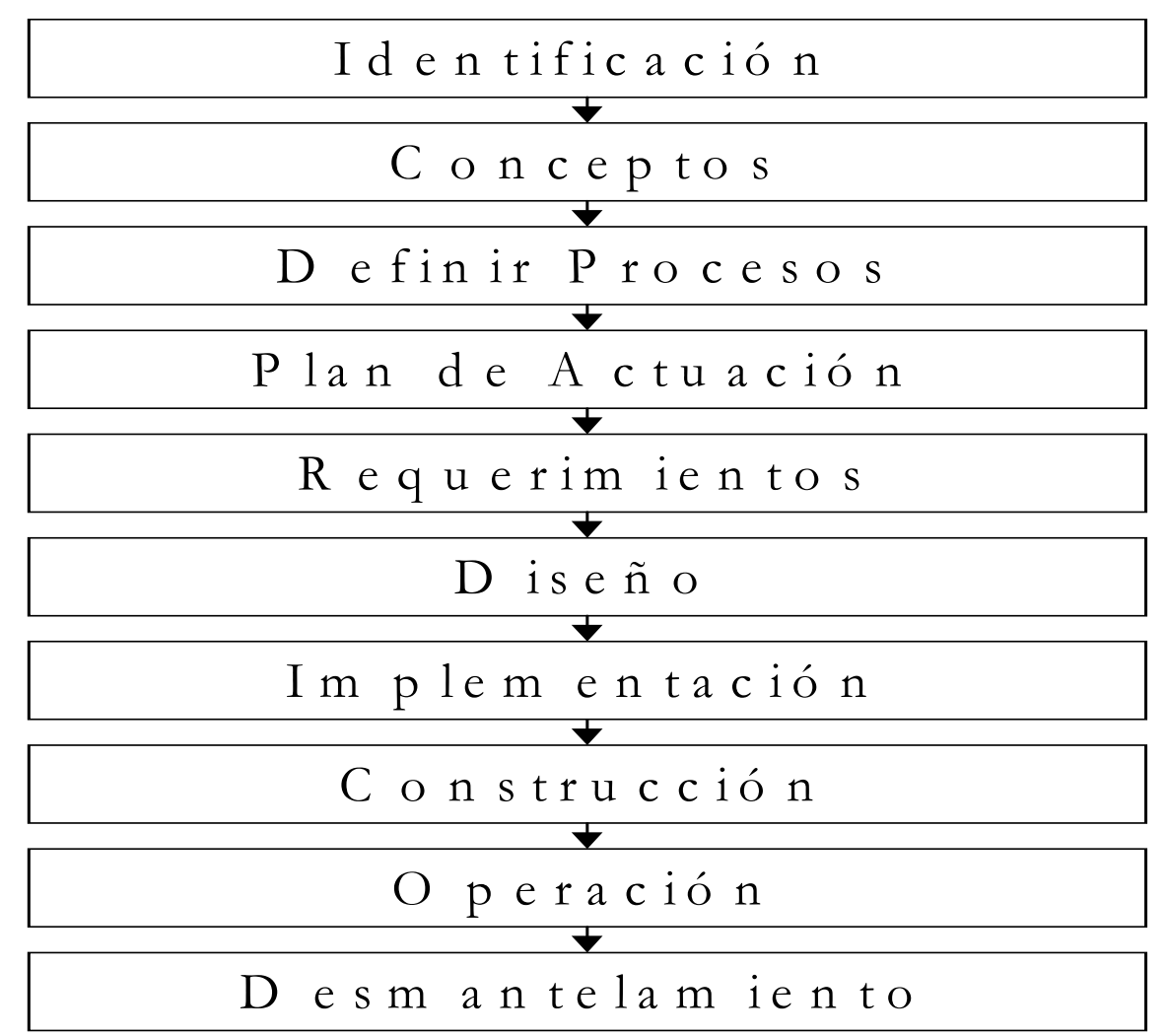

Ilustración 1. 7: Fases del Desarrollo de un sistema. Fuente: Ortiz [Ortiz98 p.184]

\subsection{COMPARACIÓN DE LAS ARQUITECTURAS}

Para K. Kosanke [Kosanke96] los esfuerzos realizados en reingeniería e integración empresarial están demostrados por las distintas metodologías de modelización. De todos modos con la cantidad de metodologías existentes, la selección de las mismas puede resultar una tarea difícil. La mayoría de metodologías se orientan hacia el concepto de ciclo de vida, pero cubriendo partes distintas del mismo.

El resultado de un análisis realizado por K. Kosanke [Kosanke96] para las principales metodologías viene reflejado en las cuatro primeras columnas de la Tabla 1. 1.

En dicha Tabla 1. 1, se observa una comparación entre las distintas arquitecturas empresariales existentes, y en particular dicha comparación se realiza basándose en el ciclo de vida que posee cada una de las arquitecturas de modelización explicadas en el punto 1.2 del presente capítulo. 
Las primeras etapas del ciclo son definidas por las arquitecturas PERA, GERAM, IE-GIP consistiendo básicamente en la Identificación (de la Entidad de Negocio), para pasar a continuación en ambas arquitecturas al Concepto (de Entidad de Negocio). Las arquitecturas CIMOSA y GRAI no definen estas etapas.

A partir de ahí, todas las arquitecturas identifican la Definición de Requisitos, o Análisis. En particular la Arquitectura IE - GIP identifica dentro de esta etapa una definición de procesos, un plan de activación, y unos requerimientos. Realizado ello, todas las arquitecturas coinciden en pasar a continuación a la etapa de Diseño, e incluso se puede observar como la arquitectura PERA señala una etapa de Diseño Detallado de la entidad de negocio.

La siguiente etapa identificada por todas las arquitecturas será la Implementación, también denominada como Manifestación por PERA, o nivel de Realización por GRAI, arquitectura que no señala más etapas.

El resto de arquitecturas (CIMOSA, PERA, GERAM, IE-GIP) señalan la Operación como la etapa siguiente, e incluso la arquitectura IE- GIP detalla como: Construcción y Operación. El ciclo de vida acaba finalmente: con las etapas de Cambio del sistema, Mantenimiento del modelo, o Actualización del modelo.

Si a dicha tabla comparativa realizada por Kosanke, se le incluye la Metodología IE-GIP realizada por el Grupo de Gestión e Ingeniería de Producción de la Universidad Politécnica de Valencia, Y la arquitectura de Zachman resultará la siguiente tabla comparativa. 


\begin{tabular}{|c|c|c|c|c|c|c|}
\hline Etapa & CIMOSA & GRAI/ GIM & PERA & GERAM & Zachman & IE GIP \\
\hline 1 & No definido & No definido & Identificación EBE & Identificación & No definido & Identificación \\
\hline 2 & No definido & No definido & Nivel de Concepto EBE & Concepto & $\begin{array}{l}\text { Planificador- } \\
\text { Planificación }\end{array}$ & Concepto \\
\hline 3 & $\begin{array}{l}\text { Definición de } \\
\text { Requisitos }\end{array}$ & $\begin{array}{l}\text { Nivel Conceptual } \\
\text { Análisis }\end{array}$ & Nivel de Definición EBE & Requisitos & $\begin{array}{l}\text { Propietario- } \\
\text { Análisis }\end{array}$ & $\begin{array}{c}\text { Definir } \\
\text { procesos } \\
\text { Plan Activación } \\
\text { Requerimientos }\end{array}$ \\
\hline 4 & $\begin{array}{l}\text { Especificaciones de } \\
\text { Diseño }\end{array}$ & $\begin{array}{c}\text { Nivel de Estructura } \\
\text { Diseño orientado al } \\
\text { usuario }\end{array}$ & $\begin{array}{c}\text { Nivel de Especificación } \\
\text { EBE }\end{array}$ & Diseño & $\begin{array}{l}\text { Diseñador- } \\
\text { Diseño }\end{array}$ & Diseño \\
\hline 5 & & & $\begin{array}{l}\text { Nivel de Diseño Detallado } \\
\text { EBE }\end{array}$ & & $\begin{array}{c}\text { Subcontratista - } \\
\text { Especificacione } \\
\text { s } \\
\end{array}$ & \\
\hline 6 & $\begin{array}{l}\text { Descripción de } \\
\text { Implementación }\end{array}$ & $\begin{array}{c}\text { Nivel de Realización, } \\
\text { Diseño técnico } \\
\end{array}$ & $\begin{array}{c}\text { Nivel de Manifestación } \\
\text { EBE }\end{array}$ & Implementación & $\begin{array}{c}\text { Técnico- } \\
\text { Implementación }\end{array}$ & Implementación \\
\hline 7 & Operación & & Nivel de Operación EBE & Operación & $\begin{array}{l}\text { Usuario- } \\
\text { Operación }\end{array}$ & $\begin{array}{l}\text { Construcción } \\
\text { Operación }\end{array}$ \\
\hline 8 & $\begin{array}{l}\text { Mantenimiento del } \\
\text { Modelo }\end{array}$ & & Actualización del Modelo & $\begin{array}{c}\text { Cambio del } \\
\text { Sistema }\end{array}$ & & Desmantelar \\
\hline
\end{tabular}

Tabla 1. 1: Tabla comparativa del ciclo de vida de las Arquitecturas de Modelización. Fuente: Elaboración propia y Kosanke [osanke96] 


\subsection{ELEMENTOS QUE INTEGRAN LAS ARQUITECTURAS}

Una vez expuestos en el punto 1.3 las visiones y desarrollos de las distintas arquitecturas empresariales introducidas en el apartado 1.2 del presente capítulo, y comparadas las etapas de las mismas en el apartado anterior, se procederá a analizar los elementos que intervienen en cada una de dichas arquitecturas.

Lo primero que se puede contrastar es el hecho de que no todas las arquitecturas denominan de igual modo a los elementos que las componen, y que a su vez, no todas aportan los mismos elementos. Con lo que puede suceder que existan algunas arquitecturas que reflejen algunos elementos, mientras que puede ocurrir que otras no los aporten.

Tal como se mostró en el punto 1.2.1, la Arquitectura CIMOSA, en su dimensión de Visión, aporta las visiones de Función, Información, Recursos y organización. Mientras que la Arquitectura GRAI, estudiada en el punto 1.2.2, hace insistencia en los Niveles Relacionales (el ¿cómo?), Niveles Estructurales (¿Quién? Y ¿Dónde?) y Nivel Conceptual (¿Qué?).

La Arquitectura PERA, presentada en el punto 1.2.3, hace hincapié en las subarquitecturas de sistemas de información, subarquitecturas de equipo de producción y subarquitecturas organizacional y humana. Mientras que la arquitectura GERAM (punto 1.2.4) utiliza las Empresas Productoras, las Empresas Integradas, y los productos.

La arquitectura Zachman, no hace referencia a los elementos directamente, sino a través de las cuestiones de: ¿Qué realizar...? Lo que correspondería al Producto, ¿Cómo realizar...? Corresponde a Procesos, ¿Dónde realizar...? corresponde a Infraestructura, ¿Quién realiza...? corresponde a Personal y ¿Por qué se realiza...? corresponde a la información. Muy similar a las cuestiones que surgen de la arquitectura GRAI.

Finalmente la arquitectura IE- GIP utiliza según Ortiz [Ortiz98 p. 164] y basándose F. Verandat, D. Brandt, K. Kosanke, J.G. Nell y su artículo de 1997 “Changes in Organisation 
and Process Structures ${ }^{1 »}$ en los siguientes elementos básicos: procesos, personas y tecnologías.

Por lo tanto, para agrupar todos esos elementos aportados por las distintas arquitecturas, se hará una asimilación a aquellos que sean más similares. Tomando como referencia la arquitectura IEGIP, se partiría de los procesos, personas y tecnología.

Los Procesos aportados por dicha arquitectura, se pueden asimilar a las funciones realizadas señaladas por CIMOSA, el nivel relacional o ¿Cómo? llevar a cabo los proceso, señalado por la arquitectura GRAI, que sería lo correspondiente a la subarquitectura del equipo de producción de PERA, o las empresas productoras de GERAM.

Las Personas señaladas por IE-GIP, son identificables con los Recursos (que pueden ser Humanos) de la arquitectura CIMOSA, el Nivel Estructural, que corresponde a ¿Quién? lleva a cabo los procesos de la arquitectura GRAI y Zachman, o la subarquitectura organizacional y humana de PERA, sin que sea especificada en la arquitectura GERAM.

La Tecnología, es el último elemento señalado por IE-GIP, pudiéndose asociar a la Organización de CIMOSA, el Nivel Estructural o ¿Dónde? se realizan los procesos de la arquitectura GRAI y Zachman, y la subarquitectura del sistema de Información de PERA. Además de los elementos señalados por la Arquitectura IE-GIP, puede hacerse otras dos divisiones para los elementos restantes. Esas divisiones corresponden a: productos e información.

Los Productos como tales son identificados por la arquitectura GERAM, pudiéndose asociar al Nivel Conceptual o el ¿Qué realizar? planteado por la arquitectura GRAI y Zachman, y que a su vez será el resultado de los procesos que llevan a cabo las empresas.

Por último, se ha de tener presente a la Información. Dicho elemento viene apuntado por la arquitectura CIMOSA directamente como una de las visiones, mientras que la arquitectura PERA

1 “Changes in Organisation and Process Structures". Enterprise engineering and Integration. Spring Verlag 1997 
lo incluye en la Subarquitectura del Sistema de Información, y pudiendo a su vez ser relacionado con las empresas integradas y la dirección de negocio de GERAM. Finalmente Zachman lo cuestiona como: ¿Por qué realizar las actividades?

Para concluir el estudio de los elementos que integran las arquitecturas, todo lo explicado en este punto se refleja en una tabla comparativa en la que se incluyen todos los elementos que componen a cada una de las arquitecturas propuestas en el punto 1.2 del presente capítulo, como se observa en la Tabla 1. 2 . En dicha tabla comparativa se pueden ver los elementos existentes y sus asociaciones correspondientes para cada arquitectura, quedando en blanco aquellas casillas donde el elemento correspondiente no queda reflejado por dicha arquitectura. 


\begin{tabular}{|c|c|c|c|c|c|c|}
\hline $\begin{array}{c}\text { Elementos } \\
\text { Empresariales }\end{array}$ & CIMOSA & PERA & GRAI/GIM & GERAM & Zachman & IE- GIP \\
\hline Procesos & Función & $\begin{array}{l}\text { Arquitectura del } \\
\text { equipo de } \\
\text { producción }\end{array}$ & $\begin{array}{c}\text { Nivel Relacional } \\
\text { ¿Cómo? }\end{array}$ & $\begin{array}{c}\text { Empresas } \\
\text { Productoras }\end{array}$ & Función: ¿Cómo? & Procesos \\
\hline Información & Información & $\begin{array}{c}\text { Arquitectura } \\
\text { Sistema de } \\
\text { Información } \\
\end{array}$ & & $\begin{array}{c}\text { Empresas } \\
\text { Integradas. Direcc } \\
\text { Negocio }\end{array}$ & $\begin{array}{l}\text { Motivación } \\
\text { ¿Porqué? }\end{array}$ & \\
\hline Personal & Recursos & $\begin{array}{c}\text { Arquitectura } \\
\text { Organizacional y } \\
\text { Humana }\end{array}$ & $\begin{array}{c}\text { Nivel Estructural } \\
\text { ¿Quién? }\end{array}$ & & $\begin{array}{l}\text { Personas } \\
\text { ¿Quién? }\end{array}$ & Personas \\
\hline Infraestr & Organización & $\begin{array}{c}\text { Arquitectura } \\
\text { Sistema de } \\
\text { Información }\end{array}$ & $\begin{array}{c}\text { Nivel Estructural } \\
\text { ¿Dónde? }\end{array}$ & & $\begin{array}{c}\text { Lugar } \\
\text { ¿Dónde? }\end{array}$ & Tecnología \\
\hline Productos & & & $\begin{array}{c}\text { Nivel Conceptual } \\
\text { ¿Qué? }\end{array}$ & Productos & $\begin{array}{l}\text { Datos } \\
\text { ¿Qué? }\end{array}$ & \\
\hline
\end{tabular}

Tabla 1. 2: Tabla comparativa de los elementos que componen las distintas arquitecturas. Fuente: Elaboración Propia 


\subsection{FACTOR HUMANO VERSUS INTEGRACIÓN}

En el punto anterior, 1.4 se han presentado aquellos elementos que son comunes a todas las arquitecturas expuestas en este capítulo. De entre esos elementos, uno de los que viene destacado por todas ellas: el Personal, por lo que se deduce la importancia que tiene en todos los enfoques de las arquitecturas estudiadas en el punto 1.2.

Como definen Goranson et al [Goranson97] una empresa integrada será aquella que logre procesos operativos, tanto internos como externos, que hagan frente a las metas de la empresa, lo que supone una optimización del sistema compuesto por personas, máquinas e información. Pero dentro de esos elementos, el factor humano supone un componente principal, debido al comportamiento especial y la sensibilidad humana frente a las máquinas y la información.

Si la modelización supone una manera de especificar el comportamiento esperado de un agente en un sistema, el problema nace cuando surgen nuevas y distintas situaciones y hay que afrontar nuevos roles y mayor complejidad, siendo en ese momento cuando se necesita la integración empresarial.

Schael [ㄷhael97] supone que la Integración Empresarial debe vincular y unir la información de las distintas actividades de las distintas etapas que se producen en la empresa: diseño, proceso, planificación de producción, control, ventas, compras, distribución, contabilidad, etc. en un sistema unitario de producción. Con ello se llegará a un sistema unificado de bases de datos que facilitará y apoyará el modelo, a la vez que reducirá el tiempo de desarrollo y producción, consiguiendo con ello que los trabajadores interactúen y coordinen sus actividades para lograr un mejor servicio.

Sin embargo, cambiar el enfoque de la perspectiva de negocio y satisfacción del cliente, a algo más que un tratamiento de material, logística, transacciones, etc. estará revelando un mayor nivel de organización, debido a que los procesos de negocio son modelados como flujos de trabajo, y por tanto se hará énfasis en las relaciones de comunicación entre las personas en las organizaciones. 
Para Smart et al [Smart97] existe la necesidad de representar metas y objetivos que aseguren la modelización empresarial en un contexto específico generando una visión y control de las operaciones que faciliten su estrategia. Además de las metas, los autores proponen identificar el papel del personal, así como la definición de cómo interactúan, habitualmente los clientes, proveedores y las relaciones que mantienen entre ellos.

Por tanto, debido a la importancia del factor humano como componente principal, este trabajo se centrará en dicho elemento en particular. Para Sánchez Barriga [SBarriga p.14] la importancia de los Recursos Humanos radica en que las empresas son realmente entes sociales, grupos de personas que poseen metas personales, metas departamentales, y metas comunes, a los que hay que aplicar principios normativos y reguladores de observancia obligatoria. Por ello,Es común que surjan unas metas frente a otras, traduciéndose en polémica o incluso destrucción del grupo. Ante esta situación surge la administración de los Recursos Humanos, fundamentada en la equidad y equilibrio en pro de los intereses del personal y la organización.

Muchos autores hablan de Recursos en las empresas, pudiendo hacer referencia a recursos materiales, técnicos o humanos, pero este trabajo hará énfasis en la importancia de los Recursos Humanos, ya que no solo comprenden el esfuerzo o actividad humana, sino los conocimientos, experiencias, intereses vocacionales, aptitudes, actitudes, habilidades, potencialidades, salud, etc. Pero su importancia radica en que pueden mejorar y perfeccionar el empleo y el diseño del resto de recursos, cosa que no ocurre al contrario.

El autor Sánchez Barriga [SBarriga p.18] señala como características de los Recursos Humanos las que se detallan a continuación:

a. No pueden ser propiedad de la organización, ya que pertenecen al patrimonio personal de cada uno. Nadie podrá ser obligado a prestar trabajos personales sin la justa retribución y sin su pleno consentimiento, salvo imposición por la autoridad.

b. Las actividades de las personas en las organizaciones son voluntarias, pero no por existir un contrato de trabajo se obtendrá el mejor esfuerzo de los miembros. Sólo 
cuando el trabajador perciba que la actividad es provechosa en alguna forma y que los objetivos concuerdan con los suyos, pondrá a disposición de la empresa sus recursos propios.

c. Las experiencias, conocimientos, habilidades, etc. son intangibles. Manifestándose solamente a través del comportamiento de las personas.

d. Los Recursos Humanos pueden ser perfeccionados a través de la preparación, mejora de los existentes, potenciando recursos; aunque también pueden ser disminuidos por las enfermedades, accidentes, etc.

e. Los Recursos Humanos son escasos, ya que no todo el mundo posee las mismas habilidades y conocimientos, con lo qué existirán personas y organizaciones dispuestas a cambiar dinero o bienes por el servicio de otros, surgiendo así el mercado de trabajo.

Para Kosanke [Kosanke] la importancia radica en que sin la participación humana, muchos proyectos, procesos productivos y funcionamiento de la empresa no podían realizarse, ya que las personas también forman parte de la ejecución de los proyectos, de las estructuras de transferencia de información necesarias para las operaciones de negocio, y por tanto, son el factor dominante en el conjunto total de los procesos operativos, aunque éstas puedan cometer fallos.

Debido por tanto a la importancia del Personal, éste ha de tener cierta estructura funcional y administrativa. Por ello Mabey et al [Mabey98 p.231] señalan que la organización de la estructura del personal y su reestructuración son fundamentales para la Dirección de los Recursos Humanos, ya que dependiendo de esas estructuras se generan distintas oportunidades, satisfacciones laborales, etc. Por lo que esto ha significado, que en los últimos años las empresas lleven a cabo comportamientos y prioridades orientadas a negocios y clientes a través de la creación de unidades de negocio estratégicas para su personal. 
Con todo ello queda patente la importancia del factor humano, y surge por tanto la necesidad de crear una estructura para la organización de los Recursos Humanos en las empresas. Para L. Mullins [Mullins02 p.530] el propósito de una estructura es la división del trabajo entre los miembros de la organización, así como la coordinación de las actividades de forma que están dirigidos hacia las metas de la organización, es decir, a la definición de tareas, responsabilidades, puestos de trabajo, relaciones y canales de comunicación.

La estructura es muy importante para cualquier organización, cualquiera que sea su tamaño, aunque en organizaciones pequeñas suele haber menos problemas de estructura que en las mayores, debido a que la distribución de tareas, la definición de autoridad y responsabilidad, así como las relaciones entre los propios miembros de la organización, pueden establecerse más fácilmente. Mientras que conforme aumenta el tamaño de la empresa, hay que ser más cuidadosos con el diseño, revisión y actualización de la estructura.

Dicho autor [Mullins02 p. 535] resalta que hay que tener en cuenta que puede pueden existir muchas variables que afecten a la estructura ideal de la organización y la dirección, incluyendo factores situacionales, así como modelos de trabajo, mayor flexibilidad, multifuncionalidad, procesos directivos, etc. Para ello surgen las estructuras como herramienta, para lograr un trabajo más productivo en ciertas tareas, bajo ciertas condiciones, y en un determinado momento.

Se puede llegar a reconocer que no hay una organización perfecta, pero lo que si se trata de paliar es la necesidad de establecer un marco para que el diseño de la estructura sea lógico. Para ello la Ilustración 1. 8 muestra las consideraciones a tener en cuenta para tal diseño. 


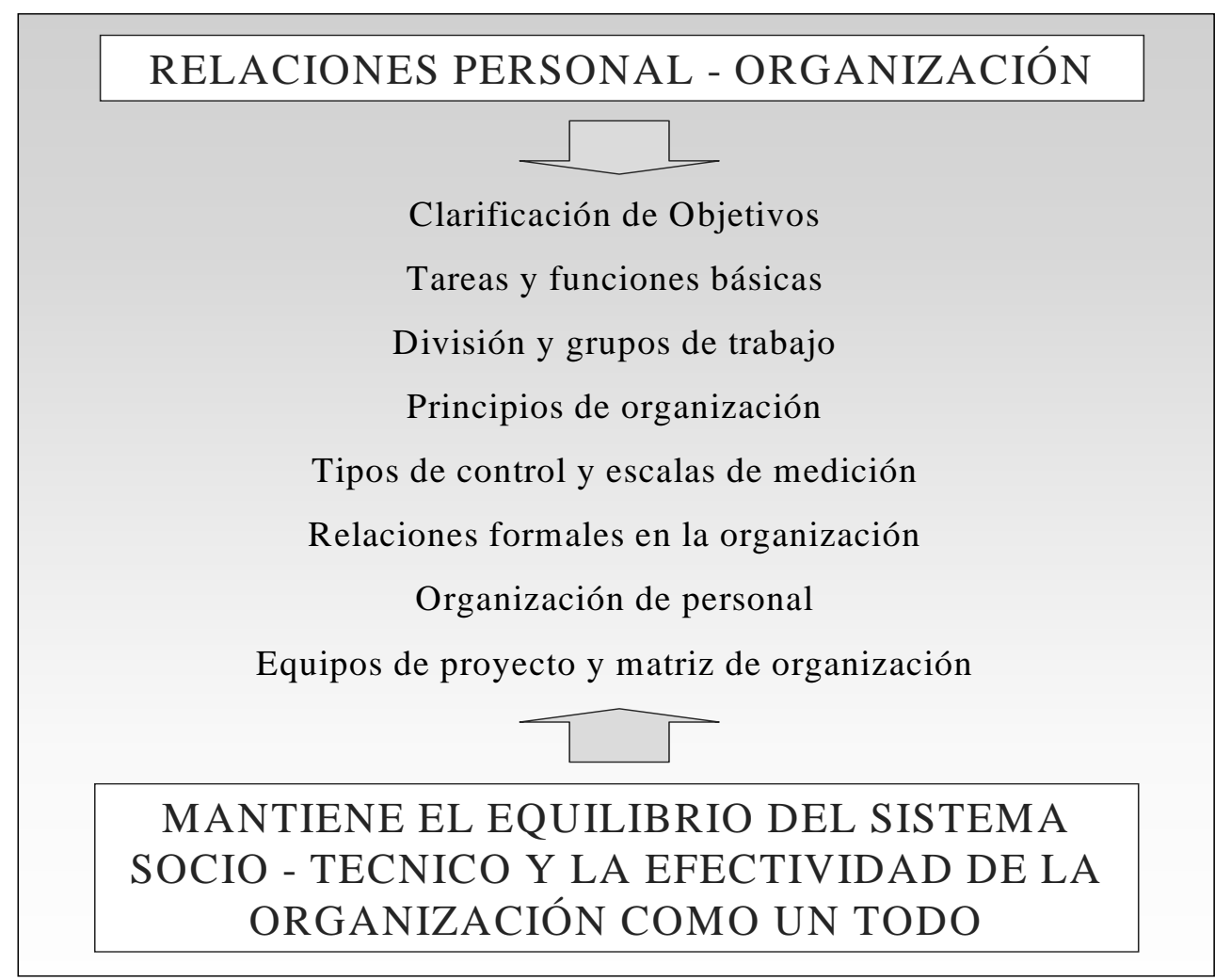

Ilustración 1. 8: Consideraciones básicas para una correcta estructura empresarial. Fuente: Mullins [Mullins02 p.536]

Las funciones de la estructura, las actividades y las relaciones dentro de la misma, existen independientemente de los miembros que trabajan en la organización, aunque las personas sean importantes para la organización. En la práctica, los objetivos de la organización dependerán del comportamiento de los trabajadores, que serán quienes le den forma y personalidad.

Pero lo más importante de las estructuras organizacionales es siempre el elemento humano, ya que los directores han de considerar a la hora de diseñar una estructura y los métodos de trabajo de una empresa, la influencia de la misma en el comportamiento y su nivel en la organización. 


\subsection{CONCLUSIONES DEL CAPITULO}

Finalizado este capítulo se puede definir claramente la Integración Empresarial, y su ámbito de funcionamiento, los tipos y objetivos de la integración, así como tener una idea de varias de las arquitecturas existentes en el campo de la integración, como lo son: CIMOSA, GRAIGIM, PERA, GERAM, Zachman, IE-GIP.

Una vez presentadas estas arquitecturas y sus principales características, se ha realizado una comparativa con ellas respecto a las distintas etapas de las que está compuesta cada una, para poder observar los distintos pasos que reflejan y las diferencias existentes en unas y otras. En dicha comparativa se ha podido observar como existe una serie de etapas o pasos que siguen las distintas metodologías en su funcionamiento. PERA, GERAM, y IE-GIP comienzan con la identificación para pasar a continuación junto con la arquitectura de Zachman a la conceptualización, y después a la etapa de definición o requisitos. Todas las arquitecturas recogen este último punto, que a continuación se refleja en la etapa de diseño que vendrá seguida de la implementación de ese diseño y su construcción u operación. Finalmente, excepto GRAI-GIM y Zachman el resto de arquitecturas señala la etapa de desmantelación del sistema o bien del mantenimiento /actualización. Basándose en esta explicación, se desarrollará posteriormente en el capítulo tercero los ciclos de vida de los sistemas, recogiendo las etapas que aquí se muestran para la arquitectura IE-GIP.

Al cuestionar el ¿Cómo? de las distintas arquitecturas, se observa que corresponde a su vez a las arquitecturas de Zachman y GRAI, la visión función de CIMOSA, la arquitectura del equipo de producción de PERA, las empresas productoras en GERAM, y los procesos de IEGIP, se puede concluir que constituyen el elemento básico "Procesos". Del mismo modo, al preguntar el ¿Porqué? planteado por Zachman, se corresponde la arquitectura del sistema de información de PERA, a las empresas integradas de GERAM, y a la información que señala CIMOSA, constituyendo a su vez el elemento "Información". El elemento "Personal", viene identificado por los Recursos en CIMOSA, la arquitectura organizacional y Humana de PERA, las Personas de IE-GIP, y el ¿Quién? planteado por GRAI y Zachman. La cuestión del ¿Dónde? que plantean Zachman y GRAI, aparece en otras arquitecturas como la visión organización de CIMOSA, la arquitectura del sistema de información en PERA, y la tecnología de IE-GIP, denominando a ese elemento "infraestructura". Finalmente, al 
cuestionar el ¿Qué? se está haciendo referencia a los "productos" o servicios de la empresa. Con esto se llega a la conclusión de la existencia de cinco elementos: procesos, información, personal, infraestructura y productos, cuya definición, desarrollo y explicación de las relaciones que existen entre ellos se explicará a continuación en el capítulo segundo.

Este primer capítulo finaliza realizando una recapitulación sobre las distintas opiniones aportadas por diversos expertos en el ámbito de la Integración Empresarial respecto a la importancia del elemento personal, es decir, de los Recursos Humanos en las empresas.

\subsection{REFERENCIAS BIBLIOGRÁFICAS DEL CAPÍTULO}

Arnedo92 Arnedo J.M. "Fabricación Asistida por ordenador (CIM)". Serie Productiva. Marcombo 1992

Bernus96 Bernus P., Nemes L. Williams TJ "Architectures for Enterprise Integration" Chapman\&Hall 1999

Goranson97 Goranson H.T., F.Fox, B.Katzy, T.J. Williams and D. Wisnosky. "Human Factor and Enterprise Integration" Enterprise Engineering. Building International Consensus. ICEIMT 97. International Conference on Enterprise Integration and Modelling Technology . Torino Italia Octubre 1997.

Guzman02 Guzmán. J. "Desarrollo de un modelo de ciclo de vida para el desarrollo de proyectos de innovación en empresas extendidas" Propuesta de proyecto de fin de carrera 2002-2003. www.getec.etsit.upm.es Consultada el 20 de diciembre de 2002

Hong94 Hong, L., Williams T. "A Formalisation and Extension of the Purdue Enterprise Reference Architecture and the Purdue Methodology." Report 158. Purdue Laboratory for Applied Enterprise Control. http://iies.www.ecn.purdue.edu/IIES/PLAIC/PERA/Report158.pdf Consultada el 4/07/2002

ICEIMT97 International Conference on Enterprise Integration Modelling Technology (ICEIMT) 1997. Enterprise Engineering. http://www.adn.com.mx/adn2/CIMOSA.htm Consultada 2/7/2002

Kosanke $\quad$ K. Kosanke. "Integración empresarial e industrial" http://www.millennium.com.br/cimosa.htm Consultada 30/6/2002

Kosanke96 K.Kosanke. "Comparation of Modelling Methodologies". http://cimosa.cnt.pl/Docs/cmm.htm Consultada el 01/07/2002

Mabey98 Mabey C., G. Salaman, J. Storey. Human Resource Management. A strategic Introduction. $2^{\text {nd }}$ Edition. Ed. Blackwell Business. 1998 U.K.

Mullins02 Mullins L. J. "Management and organisational behaviour" $6^{\text {th }}$ Ed. Financial Times. Prentice Hall. 2002 UK 
O'Neill95 O'Neill H. "Decision Support in teh Extended Enterprise". PhD Cranfield University. Año 1995.

http://www.cranfield.ac.uk/sims/cim/research/publications/doctoral_theses/ph d_theses.htm. Consultada el 29 de enero de 2003

Ortiz97 Ortiz A.. "Modelización en contexto CIMOSA. El caso de una Empresa de distribución" I Workshop International in Business Integration. Valencia 1997

Ortiz98 Ortiz A. "Propuesta para el desarrollo de programas de integración empresarial en empresas industriales. Aplicación a una empresa del sector cerámico" Tesis Doctoral. Universidad Politécnica de Valencia. España 1998

SBarriga Sánchez Barriga F.. Técnicas de Administración de RRHH. Editorial Limusa S.A. Grupo Noriega Editores. $3^{\circ}$ Edición México. 1993.

Schael97 Schael. T. "The Human Role in Enterprise Integration" Enterprise Engineering. Building International Consensus. ICEIMT 97. International Conference on Enterpise Integration and Modeling Technology . Torino Italia Octubre 1997.

Smart97 Smart P.A., J.J.P. Ferreira, K. Kosanke, T. Sachael, M. Zelm. "Enterprise Modelling - User Semantics" ICEIMT 97. International Conference on Enterpise Integration and Modeling Technology . Torino Italia Octubre 1997.

Williams94 Williams T.J. Editor “A Guide to Master Planning and Implementation for Enterprise Integration Programs, Technical Report 157, Purdue Laboratory for Applied Industrial Control Purdue University. West Lafayette, Indiana, June 1994

Williams97 Williams T.J. "Pera Metodology" I Workshop International in Business Integration. Valencia 1997

Williams Williams. T.J. "PERA and GERAM- Enterprise Reference Arquitecturas for Enterprise Integration" Institute for Interdisciplinary Engineering Studies. Purdue University. http://iies.www.ecn.purdue.edu/IIES/PLAIC/PERAGERAM_10-98.pdf . Consultada el 9/07/2002

Zachman Zachman J. "Zachman Framework for Enterprise Architecture" http://www.zifa.com . Consultada el 3 Marzo de 2002 


\section{Capítulo 2.}

Elementos Empresariales 
CAPITULO 2

\section{LOS ELEMENTOS EMPRESARIALES}

\subsection{INTRODUCCIÓN}

Tras realizar en el capítulo anterior una introducción al estudio de la Integración Empresarial: su definición, sus tipos, sus objetivos, así como una exposición de varias de las principales metodologías existentes en las distintas arquitecturas de integración, ha quedado comprobado como una parte de las mismas están formadas por unos elementos que en cierta manera son comunes en todas esas arquitecturas. Dichos elementos se han identificado en el capítulo anterior (punto1.4) aunque no sólo pueden justificarse desde la arquitectura de integración, sino que a su vez puede demostrarse desde la perspectiva del valor añadido aportado por cada empresa.

En el este segundo capítulo, se realizará una demostración de la existencia de dichos elementos desde un enfoque distinto al mostrado en el capítulo anterior, utilizando para ello la Cadena de Valor de Porter. En dicha cadena, como se muestra en el apartado 2.2, se consideran una serie de actividades primarias y otras de apoyo, siendo las primeras la logística de entrada, operaciones, logística de salida, marketing y ventas, y servicio. Y las de apoyo: Infraestructura, Recursos 
Humanos, Desarrollo de Tecnología, y Abastecimiento. Todos estos elementos pueden abstraerse llegando a obtener en dicho proceso, los elementos empresariales que se describen en apartado 2.3. En el apartado siguiente 2.4, se pasa a representar gráficamente la relación existente entre los elementos empresariales utilizando para ello un pentágono, explicitando posteriormente la relación entre ellos.

\subsection{EL VALOR AÑADIDO EN LAS EMPRESAS}

Habitualmente las organizaciones funcionan de manera que adquieren unos productos o servicios a sus proveedores, les crean un valor añadido generalmente a través de un proceso, para finalmente hacer llegar a los consumidores un producto o servicio. Ante esta situación, se entiende por Valor añadido según el Diccionario de Términos Económicos [DTE p.93] "la parte que pertenece a la empresa dentro del proceso productivo, y se calcula restando el valor de los consumos intermedios al valor total de la producción"

Porter [orter80] en 1980 publicó su libro "Competitive Strategy" en el que estudia el análisis de las empresas y sus competidores. Porter expone que hay que llevar a cabo una estrategia competitiva, consistente en crear una posición defendible para la empresa, ya que el valor definitivo que crea una empresa se mide por el precio que los compradores están dispuestos a pagar por su producto o servicio.

Las actividades que se llevan a cabo en la organización contribuyen a acrecentar el valor para el comprador, existiendo un tipo de actividades que se refieren a producir, comercializar, entrega y servicio post-venta del producto en un plano cotidiano (actividades primarias) y las que proporcionan Recursos Humanos, Tecnología e insumos comprados como apoyo para las otras actividades.

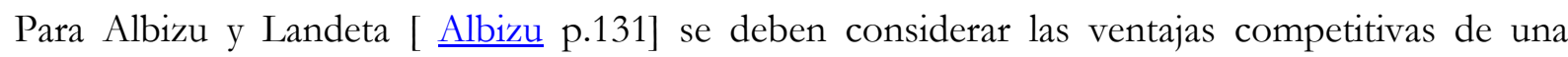
empresa, para con ello generar un valor añadido al cliente. Así los recursos cobran relevancia para la gestión de la empresa, en la medida que ésta tiene la capacidad de generar valor para el comprador a través de la conjunción de éstos.

La estrategia de cada empresa es la que marca la diferencia de gestión de sus actividades y organiza su cadena de valor. A continuación en la Ilustración 2.1 se muestra la herramienta clásica de análisis de valor: la Cadena de Valor propuesta por M. Porter. 


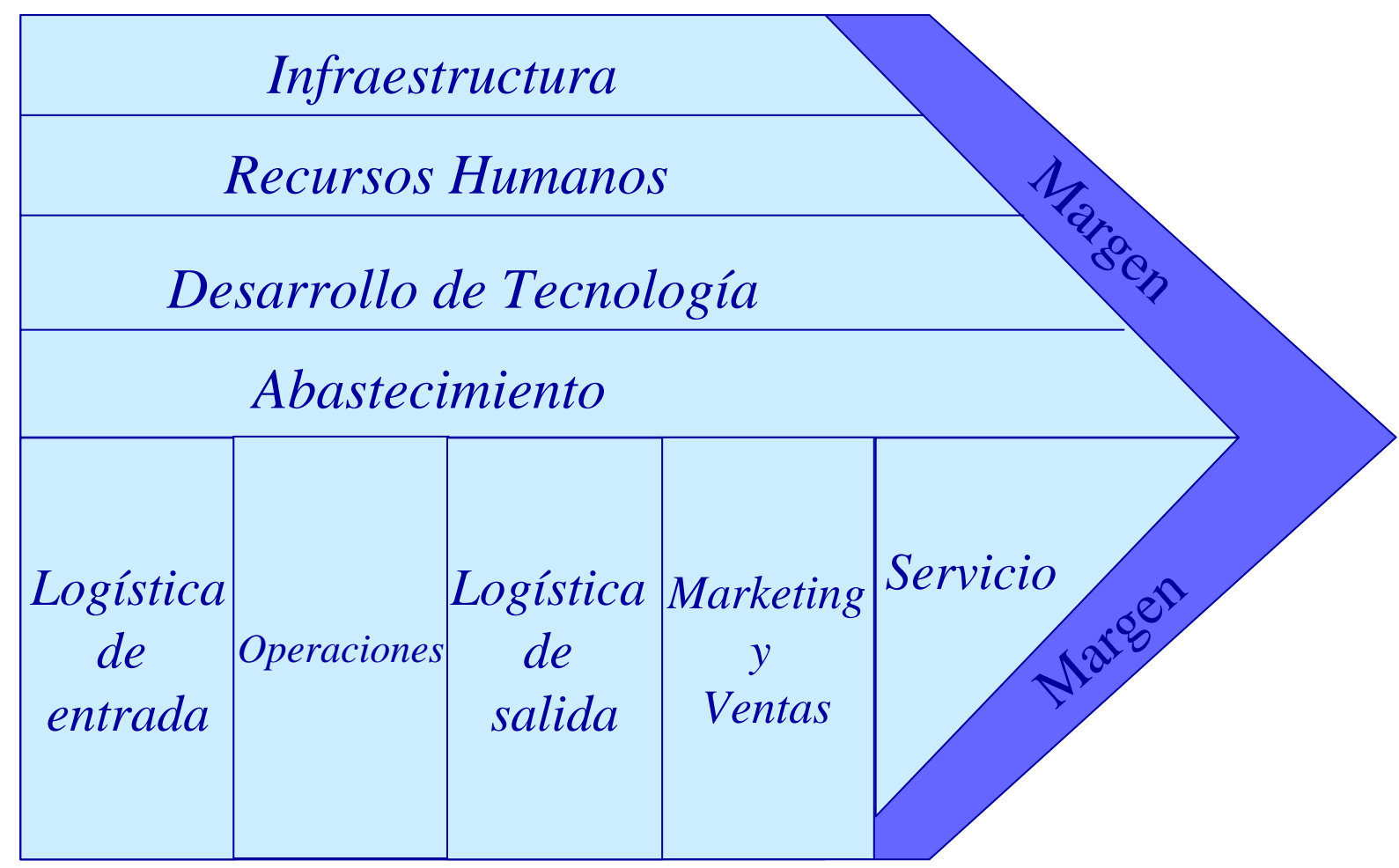

Ilustración 2.1: Cadena de Valor de Porter. Fuente: Porter [마ter80]

Realmente la Cadena de Valor de Porter supone la suma de las cadenas de valor de los clientes, los proveedores, otras unidades de negocio, canales de distribución, etc. que aportan el valor añadido diferencial de una empresa frente al resto. De modo que el valor añadido que genera una empresa, es la suma de los valores añadidos que van generándose con cada una de las actividades primarias y secundarias, dando como resultado el margen final.

Gil et al. [Gi198 p.57] señalan que "las actividades de la Cadena de Valor son los elementos con los que la empresa crea valor para el comprador de sus productos y servicios. El margen que se obtiene es la diferencia entre el valor de venta y el coste de todas las actividades de la cadena de valor. Las actividades primarias o directas son las que generan directamente valor, y las de apoyo o indirectas las que facilitan la realización de las actividades primarias. Entre las actividades de apoyo están la infraestructura de la empresa, la gestión de los Recursos Humanos, el desarrollo de la tecnología y los abastecimientos o compras. Mientras que entre las primarias están: logística de entrada, operaciones, logística de expedición, marketing, ventas y servicios".

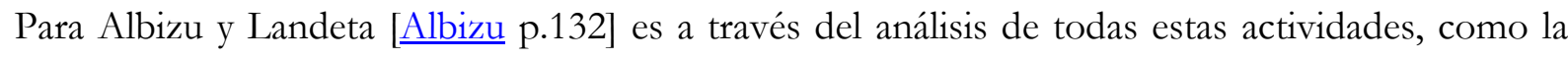
empresa puede determinar realmente: 
- Cuales de las actividades que realiza son criticas para alcanzar, sostener o mejorar su posición competitiva

- Cuales de sus actividades son las que añaden valor para el cliente y cuales no.

Por tanto, este tipo de análisis puede revelar que algunas de las actividades que efectúan las empresas, además de no añadir valor, son actividades en las que la empresa no obtiene ventajas competitivas frente a otros", por lo que hay que plantearse su eliminación, ya que estas actividades no aportar valor, pero generan costes.

Las actividades que forman parte de la Cadena de Valor de Porter son las que a continuación se detallan por Gil et al. [Gil98 p.58]

- Logística de aprovisionamiento: Recepción de los materiales, almacenamiento, y distribución a los centros

- Operaciones: Transformación de los recursos en productos terminados

- Logística de Expedición: Almacenamiento y distribución de productos

- Marketing y Ventas: Promoción y realización de ventas. Vendedores.

- Servicios: Servicio para mantener y mejorar el producto

- Infraestructura de la empresa: Apoyo para toda la cadena: dirección general, planificación, finanzas, asesoría jurídica, calidad, relaciones con la administración.

- Gestión de los Recursos Humanos: Selección, contratación, mantenimiento y formación

- Desarrollo Tecnología: Mejora del producto, técnicas de distribución y proceso productivo

- Abastecimientos: Suministros. Compras.

Si se toman las actividades y elementos señalados por Porter y se intenta realizar una abstracción hacia atrás, se pueden identificar los elementos organizacionales expuestos en el apartado 1.4 del capítulo anterior, desde la Integración Empresarial (Personal, Procesos, Productos, Tecnología, Información). Estos elementos identificados en la Cadena de Valor de Porter suponen cuatro de los cinco elementos presentados en dicho apartado, de forma que se podrían identificar en la Cadena de Valor de Porter los siguientes elementos: Infraestructura, Recursos Humanos, 
Procesos, y Servicios, mientras que quedaría por presentar un quinto elemento que será la "Información".

De tal manera que la Logística de aprovisionamiento se podría asociar a los procesos, así igualmente procesos serían las Operaciones, la Logística de Expedición, el Marketing y Ventas y los Abastecimientos.

La Infraestructura de la empresa identificada por Porter, se asociará directamente a la Tecnología (aunque también podrá denominarse Infraestructura), así como también pertenecerá a este grupo el Desarrollo de la Tecnología.

Los Servicios ofrecidos por la empresa, lógicamente pasarán al grupo de Productos y Servicios, y finalmente la Gestión de los Recursos Humanos identificada por Porter, corresponderá el elemento de Personal (Recursos Humanos)

Esto se puede apreciar en la Ilustración 2. 2, donde se muestra la Cadena de Valor de Porter, pero en lugar de las actividades propuestas por dicho autor en la casilla correspondiente, aparecen los nombres de los elementos empresariales identificados en el punto 1.4 del capítulo anterior, a excepción de la Información, que dicho autor no la contempla.

A su vez, en la Tabla 2. 1 se muestra la relación existente entre las actividades propuestas por Porter, y los elementos empresariales identificados con cada una de dichas actividades.

Dicha comparación entre la tabla de Porter y los elementos empresariales en el punto 1.4, justificará doblemente la existencia de dichos elementos, que se pasarán a estudiar en el punto 2.2 del presente capítulo. 


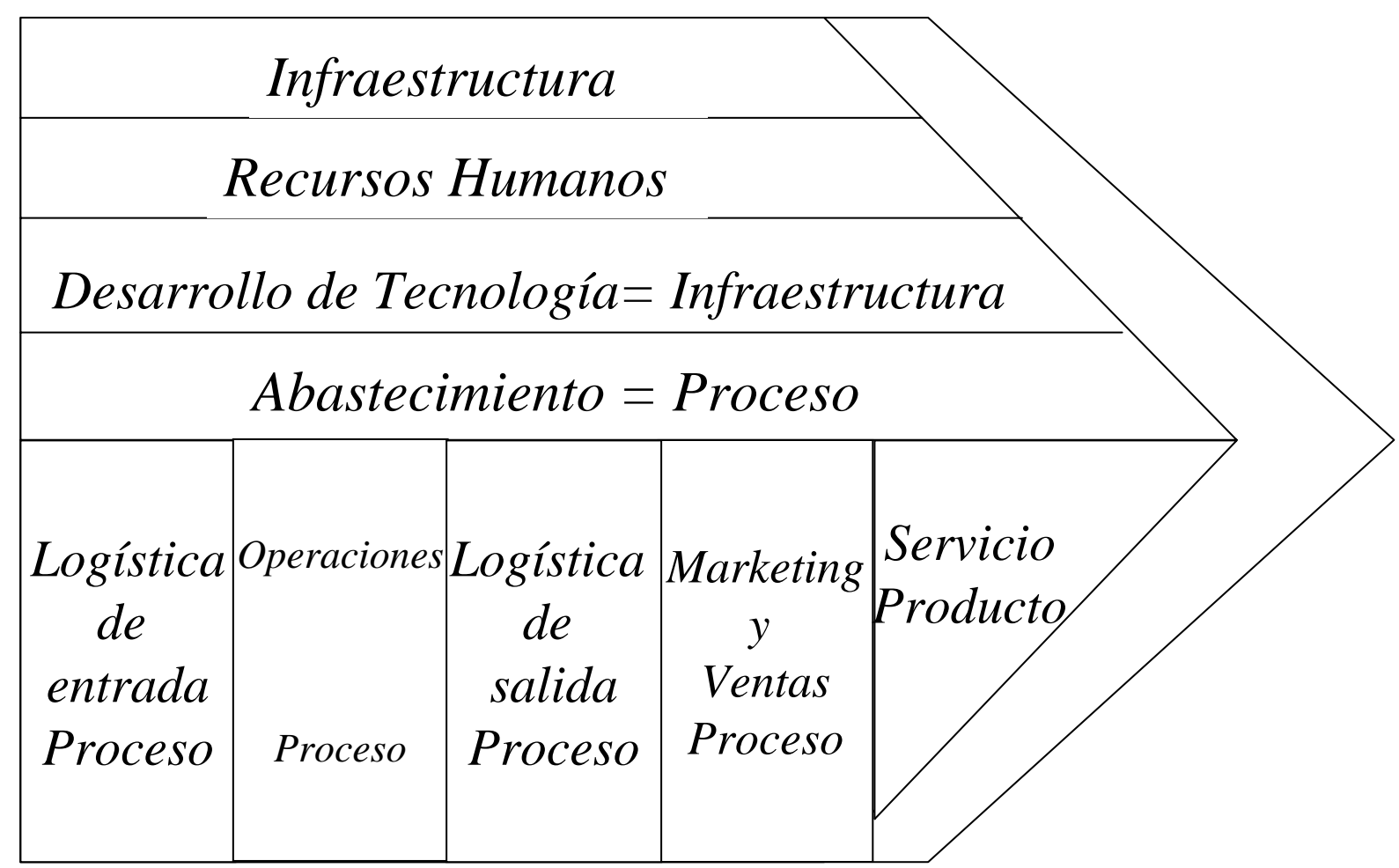

Ilustración 2. 2: Identificación de elementos empresariales en la Cadena de Porter.

Fuente: Elaboración propia basado en M. Porter

\begin{tabular}{ll}
\hline Actividad & Elementos empresariales \\
\hline Logística de aprovisionamiento & Procesos \\
Operaciones & Procesos \\
Logística de Expedición & Procesos \\
Marketing y Ventas & Procesos \\
Servicios & Productos / Servicios \\
Infraestructura de la empresa & Infraestructura / Tecnología \\
Gestión de los Recursos & Personal/ Recursos Humanos \\
Humanos & \\
Desarrollo Tecnología & Infraestructura / Tecnología \\
Abastecimientos & Procesos \\
\hline
\end{tabular}

Tabla 2. 1: Tabla comparativa entre actividades propuestas por la Cadena de Valor de Porter y los elementos empresariales. Fuente: Elaboración propia. 
Como se ha mencionado al principio de este apartado, cada empresa marcará su diferencia de gestión y de organización de su Cadena de Valor, de lo cual se deduce que cada empresa resultará diferente una de otra, debido a la visión particular de su propia filosofía empresarial que aportará cada una, en pro de la búsqueda de su particular ventaja competitiva, ya que los elementos propuestos en este trabajo son comunes a todas las empresas y la diferencia consistirá por tanto en la organización particular.

\subsection{DESCRIPCIÓN GENERAL DE LOS ELEMENTOS}

Una vez presentada la Cadena de Valor de Porter, y expuesto la importancia para las empresas de conseguir y mantener una ventaja para participar en el mundo empresarial actual, es fundamental que las empresas u organizaciones posean la infraestructura organizativa, los procesos, los recursos necesarios, la tecnología adecuada así la información suficiente para poder subsistir en un mundo tan competitivo.

Dicho proceso de generación de valor se repite en todas las empresas, independientemente de su tamaño, sector o situación, lo que queda recogido por M. Porter. Pero además, hay que hacer hincapié en los elementos empresariales comunes identificados tanto desde la Integración Empresarial en el punto 1.4, como en la Cadena de valor y que se van a describir a continuación. Dichos elementos son cinco: personal, procesos, productos, tecnología e información.

Entre los elementos presentados por M. Porter no se incluye la información, aunque si se incluye como último elemento ya que en la actualidad y la sociedad de la información en la que se hoy se está inmerso sería un error descartarla, debido a que es un elemento fundamental para la toma de decisiones.

\subsubsection{Personal}

Se puede ver a los Recursos Humanos como el elemento básico de cualquier proyecto empresarial, ya que serán las personas las que demanden, diseñen y capten las necesidades de los clientes. De manera que las empresas se servirán de estas personas para su funcionamiento, y lógicamente de aquellos que se encuentren preparados para desarrollar dichos puestos.

Esto viene reafirmado por Fernández Guerrero et al. [EdzGuerrero p.344] para quienes los Recursos Humanos constituyen el recurso estratégico más importante de las organizaciones, 
habiendo sido en muchas ocasiones infrautilizados y desaprovechados. Sin que dichos Recursos Humanso deban observarse como un gasto a minimizar, sino como un recurso fundamental en el que se debe invertir para mejorar la competitividad de la empresa a largo plazo.

Los autores citados a su vez consideran que el tipo de proceso y de tecnología existente impondrán una serie de necesidades de cualificación para el personal. De modo que la falta de adecuación, formación y aprendizaje en las cualificaciones de los trabajadores, puede resultar extremadamente costosa para la empresa.

A su vez Mullins [Mullins p.97] destaca como los objetivos y metas que ha de conseguir una empresa no se harán únicamente por personas aisladas, sino que han de unirse esfuerzos individuales para superar esas metas. Por lo que la efectividad de una organización dependerá de la calidad de su personal, y de cómo estos logran sus objetivos y metas.

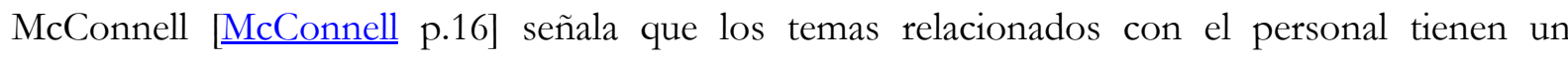
impacto muy importante en la productividad, la calidad y la eficiencia, de forma que los métodos que resultarán más efectivos serán aquellos capaces de sacar partido al potencial humano de sus desarrolladores.

Dicho autor $[$ McConnell p. 17-18] apunta que cualquier empresa que trate de mejorar seriamente la productividad, debe ocuparse primero de temas relacionados con los Recursos Humanos, a través de la motivación, el trabajo en equipo y la selección y formación:

- Desde la motivación: Una persona que carezca de motivación no estará dispuesta a renunciar a su tiempo libre por trabajo. Por lo tanto, hacer que el personal se sienta motivado e implicado con un proyecto contribuirá a que pueda realizarse con éxito.

- Desde la selección de personal: existen cinco principios básicos para la selección de personal:

1. Máximo talento: utilizar poco y buen personal

2. Trabajo adecuado: asignar tareas según la habilidad, preparación y motivación del personal disponible.

3. Progresión profesional: ayudar a la gente a actualizarse por sí mismos.

4. Equilibrado de equipo: seleccionar a la gente que se complemente y armonice con los demás, sin que cree conflicto al resto. 
5. Eliminar inadaptación: eliminar y reemplazar a los miembros problemáticos cuanto antes.

- Organización de trabajo: La forma de organizar el trabajo del personal va a influir en la eficacia con la que éste trabaje.

Dentro de este elemento, se puede incluir un punto destacado por Phillips [phillips] que no incluye McConnell, y supone la disciplina en el trabajo: esto significa que el personal ha de desarrollar su trabajo de la forma correcta, evitando todos errores que estén en su mano, y realizar los menores parones posibles, es decir, imponiendo cierta disciplina en la realización de trabajos y tareas del personal.

\subsubsection{Procesos}

Phillips [hillips] define los procesos como las "actividades que permiten llegar desde el principio al final de un diseño”. Mientras que McConnell [McConnell p.18] lo define como una “metodología, ya sea de gestión o técnica”. A su vez, puede aportarse la definición proporcionada por Domínguez Machuca et al. [DMachucaI95 p. 367] en la que se ciñe a la "transformación de los distintos factores productivos, de acuerdo con una técnica dada, para llegar a la obtención de un producto o parte de él”.

Cuando se habla de procesos empresariales se hace referencia: tanto a procesos de gestión, como a procesos técnicos, con lo que se abarca un área muy importante dentro de la empresa. Para estudiar un proceso habrá que identificar las dependencias existentes, los requisitos, así como los responsables del mismo.

Para Phillips [hillips], todo proceso puede mejorarse, como se verá más adelante en el capítulo cuarto cuando se haga referencia al Modelo de Capacitación de Madurez para el Personal, el cual ofrece cinco niveles en los que clasificar una organización, desde un nivel inicial básico hasta el último nivel denominado óptimo.

Existen además distintos modelos de procesos, todos ellos válidos a su vez; debiendo optar por el que mejor encaje en el tipo de producto que se quiera fabricar, el personal y la tecnología disponible.

McConnell [McConnell p.19] señala que puede pensarse que un proceso sea en exceso agobiante, como lo son aquellos procesos demasiado rígidos y que conllevan gran cantidad de burocracia. La 
forma más habitual de abusar de un proceso es la negligencia, resultado a menudo un personal eficaz pero que trabaja de forma ineficiente. Por lo tanto, para solucionar esta problemática,

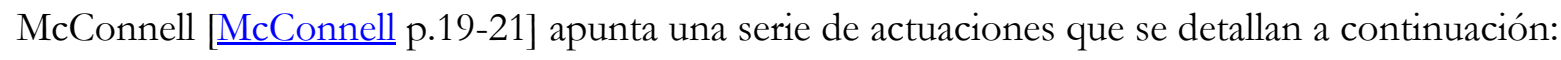

- Evitar repeticiones en el trabajo: para ello hay que orientar a los procesos a ahorrar tiempo y que no tenga que hacerse la misma cosa dos veces.

- Establecer controles de calidad: por un lado hacia el producto, ya que debe tener un nivel de calidad aceptable y por otro lado a detectar los errores de proceso, y que suponga emplear el menor tiempo posible para corregirlos.

- Gestionar los riesgos: teniendo siempre presentes los posibles riesgos, se podrán evitar o estar preparado en el momento de su aparición.

- Prestar atención a los Recursos: Realizando una gestión eficiente de los recursos de modo que ayuden a la productividad global, y no estén mal dirigidos y se usen de forma inefectiva.

- Planificar el ciclo de vida: Un modelo de ciclo de vida es útil porque describe un plan de gestión básico. Los modelos de ciclo de vida hacen que sea más fácil identificar y organizar las tareas necesarias de un proyecto.

- Orientar al cliente: Orientando los procesos a las demandas de los clientes.

\subsubsection{Productos y Servicios}

Phillips [Phillips] ve a los productos como el resultado de los procesos, ya que satisfacen las necesidades de los clientes y les hace repetir en su consumo. Su importancia se debe a la continua atención que hay que prestarles para que se produzca su salida al mercado, y de ese modo pueda conseguirse la financiación necesaria para el funcionamiento de la empresa.

Para mejorar los productos, habrá que identificar las necesidades del cliente y trasladar dichas especificaciones técnicas a la planificación, diseño, proceso y producción del producto o servicio.

El diseño de unos adecuados productos y servicios es clave de cara a la competitividad empresarial debido a que:

- Las perdidas de mercado se deben, frecuentemente a las deficiencias de diseño en los productos/ servicios 
- Todos los procesos productivos están condicionados por el diseño de los productos / servicios.

- Existen numerosos problemas técnicos relacionados con el diseño del producto/ servicios.

- Los factores coste, calidad y servicio al cliente están íntimamente ligados al producto / servicio y su diseño

- Las probabilidades de superar a los competidores son mucho mayores si se emprenden acciones de diseño que si se revisan únicamente los proyectos.

$\mathrm{Al}$ hacer referencia a los productos en este trabajo se está englobando a su vez a los servicios, debido a que lo que ofrecen las organizaciones o empresas pueden ser tanto productos como servicios, resultado de generar valor añadido. Aunque existen ciertas diferencias entre las organizaciones que ofrecen servicios y las que ofrecen productos. Entre esas diferencias Mullins [Mullins p. 104] destaca las siguientes "características en las empresas de servicios:

- El consumidor participa en el proceso de servicio: lo que requiere especial atención a todo lo que rodea y caracteriza al servicio.

- El servicio no puede ser almacenado: al no poderse almacenar un servicio, por lo que si no se usa se pierde.

- Los servicios son menos tangibles y más difíciles de explicar y comunicar. Los beneficios derivados de los servicios tienden a asociarse con sentimientos y emociones.

- Para la realización de actividades de servicio se utiliza a un personal orientado a lograr esa efectividad.

- Medir el resultado es difícil".

Mullins [Mullins p.105] hace referencia a J. Macdonald, para señalar las diferencias entre los productos y los servicios reproducidas en la Tabla 2. 2 . 


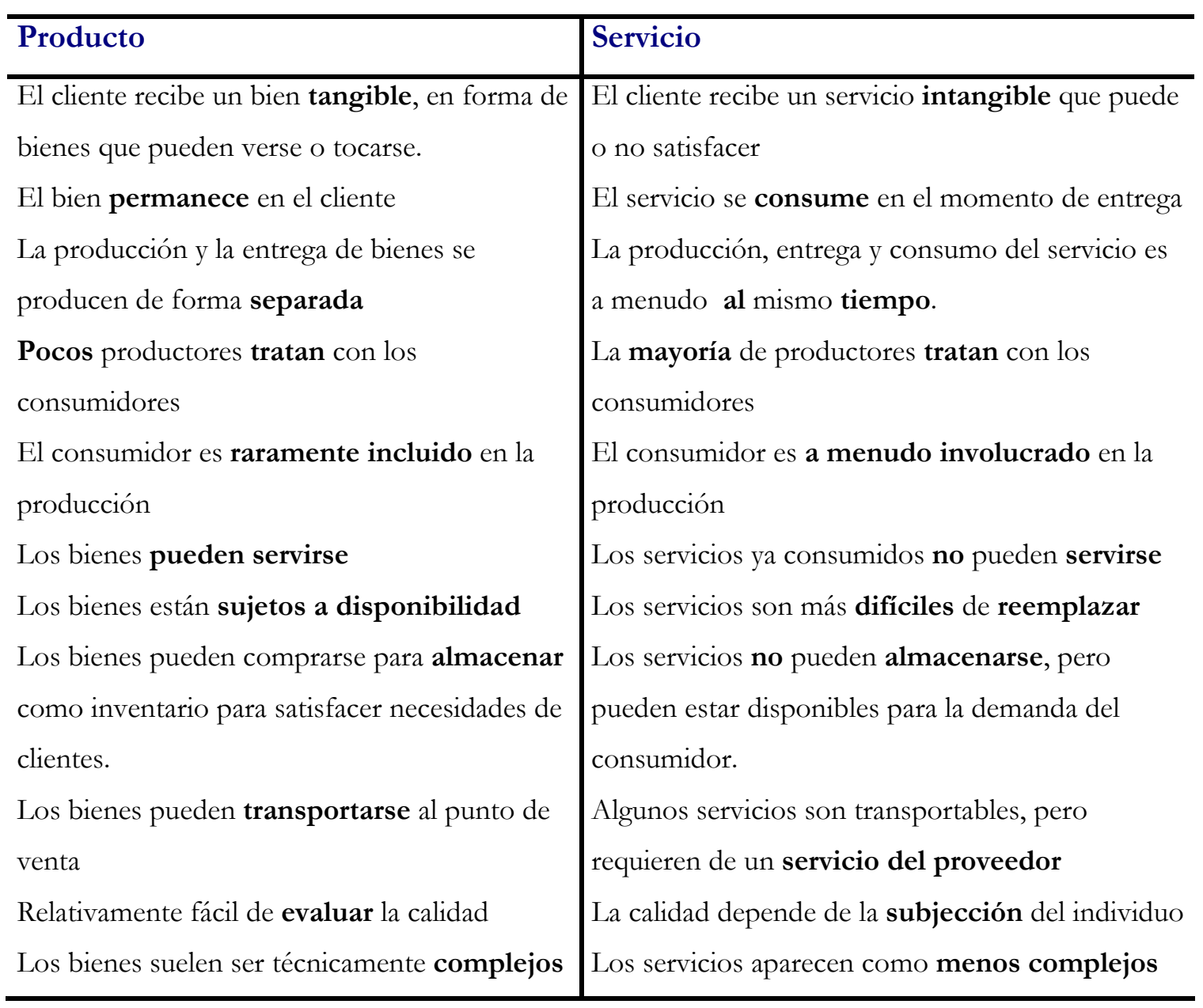

Tabla 2. 2 : Diferencias entre Productos y Servicios. Fuente: Mullins [Mullins p. 105] extraido de J. Macdonald

\subsubsection{Tecnología e Infraestructura}

Mullins [ $\underline{\text { Mullins }}$ p.114] define la Tecnología como "la forma en la que se llevan a cabo las tareas y trabajos realizados en una organización. Además de los materiales, sistemas, procedimientos, y equipamiento utilizado en el proceso de conversión"

Ruiz y Mandado la definen [ RuizMandado p.14] como "un conjunto de conocimientos aplicados y de reglas prácticas que tienen como misión: crear, modificar y valorar el entorno del hombre para satisfacer sus necesidades tal como las concibe la sociedad de la época". Para estos autores, la tecnología está ligada al progreso material, y por tanto a un conjunto de conceptos que definen el hecho tecnológico: calidad del producto, facilidad de mantenimiento, vida útil, coste del proceso productivo, normalización, etc. 
McConnell [McConnell p.22] describe como a través de la tecnología también puede mejorarse la velocidad de desarrollo, pasando de un uso de herramientas menos efectivas a otras más efectivas. La selección de dichas herramientas y la gestión de riesgos asociados son aspectos claves en una iniciativa de desarrollo tecnológico.

Pero no sólo es necesario tener la tecnología apropiada para la resolución de los problemas que se presenten, sino que hay que hacer buen uso de dicha tecnología. Para ello hay que aplicar las herramientas más efectivas para desarrollar un producto o servicio, sin que sea la tecnología la que dirija la empresa, sino que se aplique la tecnología adecuada a cada empresa, de forma que satisfaga los requisitos de la misma.

Para poner en marcha la tecnología de una empresa hay que tener presente ciertos puntos relacionados: como el aseguramiento de la adecuación a las necesidades, el soporte a la fabricación o negocio empresarial, la realización de revisiones tecnológicas para los procesos a realizar, y desarrollar formación al personal para el manejo de dicha tecnología.

Ruiz y Mandado [RuizMandado p.59] hacen referencia a como la mayoría de directivos se dan cuenta que el cambio tecnológico es relevante para ellos y que es inútil e inoperante calificar a su empresa como de alta o baja tecnología. Sin que posean una imagen clara del proceso a través del cual la tecnología se transforma en una ventaja competitiva. De tal forma, las empresas con un éxito continuado, asumen que el cambio es incesante y discontinuo, y que el nivel tecnológico no puede mantenerse fijo, sino que hay que plantearse cambiar la base tecnológica en determinadas ocasiones.

La mayor parte de problemas que surgen a raíz de que los cambios tecnológicos en las empresas aparecen por la dificultad en la adaptación de ésta. Si se logra solucionar dichos problemas, se podrá satisfacer la producción y así atender a un mayor número de clientes potenciales, ofreciendo un mayor número de productos de una misma familia y aumentando los inventarios, sin tener que elevar en exceso los costes.

La Fundación empresarial para el desarrollo del país mediante el fomento de la innovación tecnológica en la empresa y sociedad española (Cotec) [Cotec p.11] propone a la tecnología "como actividad fundamental en cualquier negocio la gestión de la tecnología, ya que ayuda a las empresas a gestionar sus operaciones de una forma eficaz y a desarrollarse estratégicamente para fortalecer sus recursos, su know-how y sus capacidades. Todo ello hace que la gestión de la 
tecnología, ayude a una organización a prepararse para el futuro reduciendo sus riesgos comerciales e incertidumbre, y aumentando su flexibilidad y capacidad de respuesta.

Además argumenta que la tecnología consiste en equipamiento, instalaciones, conocimiento y experiencia. Y a ello hay que añadir a su vez la innovación tecnológica, lo que supone el desarrollo de un modelo conceptual de cinco elementos:

- Vigilar: el entorno busca señales sobre la necesidad de innovar y sobre oportunidades potenciales que pueden aparecer en nuestra empresa, como el aumento del índice de progreso tecnológico, liberalización de mercados, globalización, cambios en el marco normativo, en la base y fuente de la competencia y en nuevas tecnologías emergentes.

- Focalizar: llevar la atención y esfuerzos en alguna estrategia particular para la mejora del negocio, o hacia una solución específica para un problema. Para ello se utiliza herramientas para realizar un análisis estratégico, herramientas de elección estratégica, y herramientas de planificación estratégica

- Capacitar: Supone la dotación de recursos y preparación de lo necesario para que la solución innovadora funcione. Para ello se combinarán conocimientos nuevos y existentes que ayuden a la innovación

- Implantar: Poner en marcha la innovación

- Aprender: de la experiencia del éxito o del fracaso."

La tecnología adaptada hoy en día en las empresas actuales es sobre todo tecnología de información y de comunicación. La primera no resuelve problemas por sí misma, sino que proporciona soluciones a determinados problemas ayudándose en todo momento de la formación y el aprendizaje. Y la segunda, ha logrado grandes progresos en reducir tiempo y recursos, pero al tener dos direcciones (la comunicación es bidireccional, las órdenes unidireccionales) la comunicación lo hace más difícil de controlar.

\subsubsection{Información}

La información se genera cuando se da o asigna significado a ciertos datos o símbolos, por ello se puede decir que "información son datos a los que se les agrega relevancia y propósito". Dicha definición es enunciada por Peter Ducker y dada por Tiwana [Tiwana p. 61]. 
Domínguez [Domínguez p.31] observa que cuando una empresa ha obtenido cierta cantidad de información, puede utilizar ésta para modificar su estructura interna y así poder afrontar cambios necesarios en una organización.

Cuando a una empresa le llegan datos, ésta ha de decidir si a los datos recibidos tienen o no significado y los convierte en información. De modo que cuando acumula cierta cantidad de información, ésta puede utilizarse para modificar su estructura y poder realizar cambios en la empresa, de ahí la importancia y el poder de este elemento.

Para Bueno Campos [ueno p.237] la información es un conjunto de datos estructurados y ordenados de acuerdo con las necesidades del usuario, que en la situación más normal de un agente económico sirven para poder tomar decisiones que le posibiliten llevar a cabo determinadas acciones.

En consecuencia, la empresa es un sistema de información- acción que transforma la primera en la segunda gracias a una función de cambio que se denomina toma de decisiones. Bueno Campos cita a J. W. Forrester para concluir que la información es siempre un input que permite generar y controlar unas acciones que volverán a generar nueva información.

Bueno Campos [Bueno p.239] hay dos tipos de información, una de tipo interno, cuya naturaleza atiende a información para la toma de decisiones y para permitir la comunicación entre los miembros de la organización, lo que constituye el sistema humano de la organización debido a que integra, motiva y facilita el desempeño de tareas. Y otra de tipo externo que va dirigida al entorno y es de tipo financiero y social.

A su vez Bueno [ $\underline{\text { Bueno }}$ p. 238] considera que la información puede generar valor añadido para la organización, ya que genera ventajas como: posibilidad de comparar magnitudes, aportación de elementos de juicio, la facilidad para tomar decisiones con rapidez, confianza que aporta, permitir la delegación de autoridad y el control de situaciones.

Lo más importante respecto a la información es que ésta debe generar un conocimiento que añada valor a la organización, ya que a menudo no suele ser suficiente con generar conocimiento, hacerlo disponible y esperar los mejores resultados, ya que esto puede llevar a proporcionar información no necesaria como señalan Tissen, Andriessen y Lekanne [Tiessen2000 p.9] 


\subsection{REPRESENTACIÓN GRÁFICA DE LOS ELEMENTOS EMPRESARIALES}

A partir de los cinco elementos empresariales descritos en el anterior apartado 2.2, se van a describir las interrelaciones existentes entre ellos.

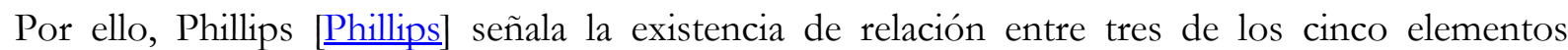
empresariales señalados en apartado anterior (apartado2.2). En particular, los elementos que este autor relaciona son: personal (apartado 2.2.1), procesos (apartado2.2.2), y producto (apartado 2.2.3).

En la Ilustración 2. 3 se muestra la gráfica creada por dicho autor para representar la relación existente entre personal, procesos y producto. Las distintas regiones señalan la complejidad del producto: lo que supone que los productos situados en una región más cercana al origen serán productos de fácil creación, debido a que no requieren mucha capacidad del personal (eje vertical) o del proceso (eje horizontal).

Mientras que cuando los productos se sitúen en una zona más alejada del origen, se convertirán en productos más complejos, y demandarán más capacidad de personal, mejores procesos o ambos.

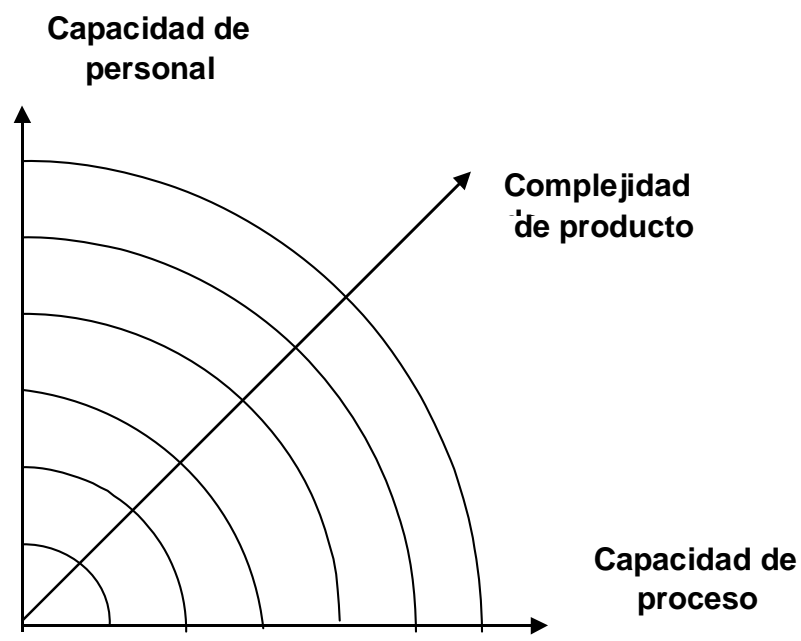

Ilustración 2. 3: Relación entre personal, procesos y productos. Fuente: Phillps [Phillips]

Para Phillips [Phillips] la capacidad necesaria para hacer un producto más complejo, puede venir desde diferentes combinaciones de mejoras, ya sea en personal, en procesos o en ambos. En la Ilustración 2. 4, se muestra como la capacidad necesaria proviene del personal, lo que en la figura 
vendrá representado por un movimiento vertical y en la realidad supondrá añadir expertos o mejorar la formación de nuestro personal.

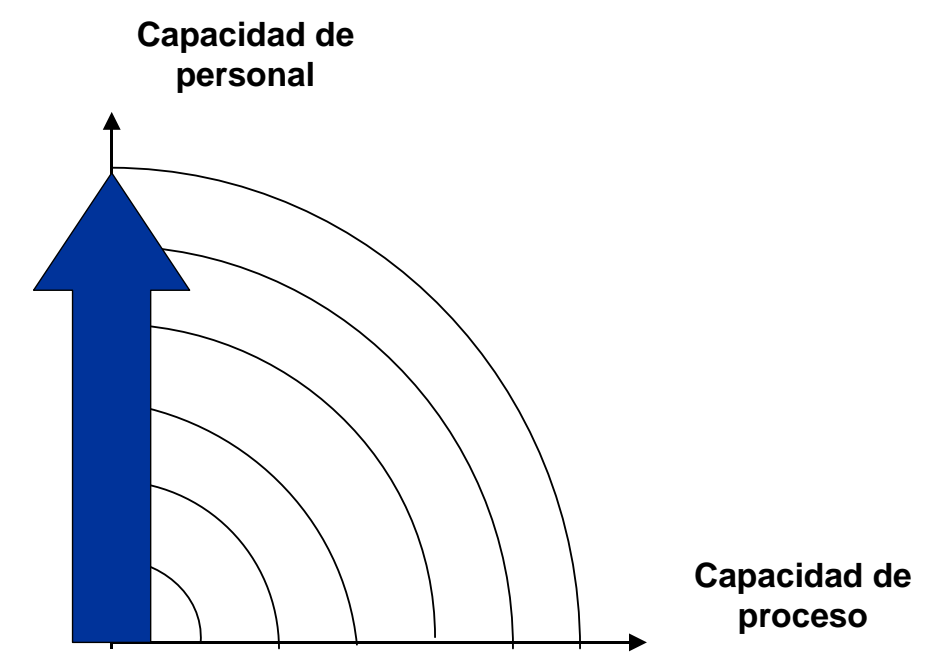

Ilustración 2. 4: Construcción de un producto más complejo, basado en el incremento de la capacidad del personal. Fuente: Phillips [Phillips]

A su vez se puede observar como Phillips en la Ilustración 2. 5 muestra como la misma capacidad extra puede venir desde los procesos en lugar del personal, lo que en la práctica supondrá utilizar un proceso mejorado, como ocurre en las entregas, evitar retrasos, etc.

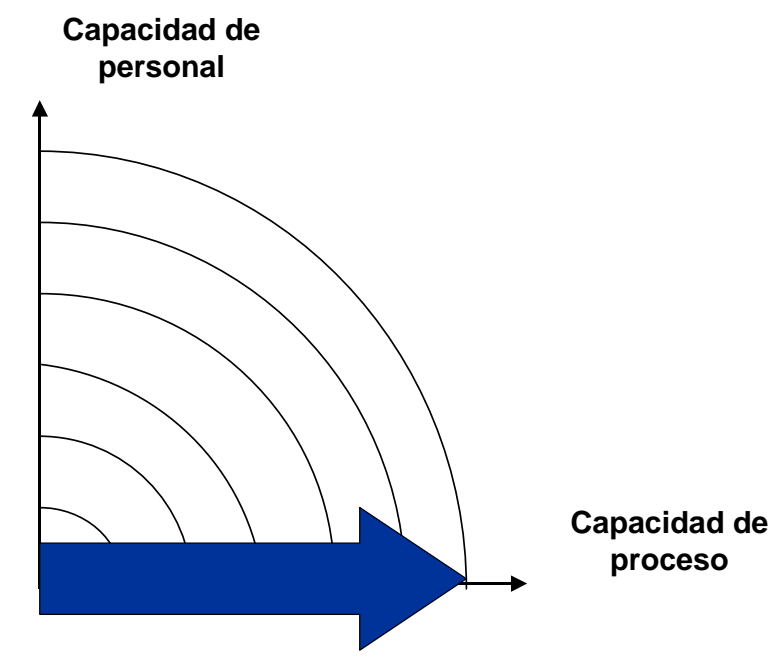

Ilustración 2. 5: Construcción de un producto más complejo, basado en el incremento de la capacidad del proceso. Fuente: Phillips [Phillips] 
Pero esa citada capacidad extra puede provenir no sólo de un elemento como se ha mostrado en las anteriores ilustraciones, sino de dos elementos como muestra la Ilustración 2. 6, en la cual el producto más complejo procede de la mejora en dos elementos: personal y procesos. Esto se podría conseguir mediante actividades conjuntas que supongan tanto una mejora en formación del personal, como la utilización de prototipos en partes del producto, o utilizar modelos de entregas, etc.

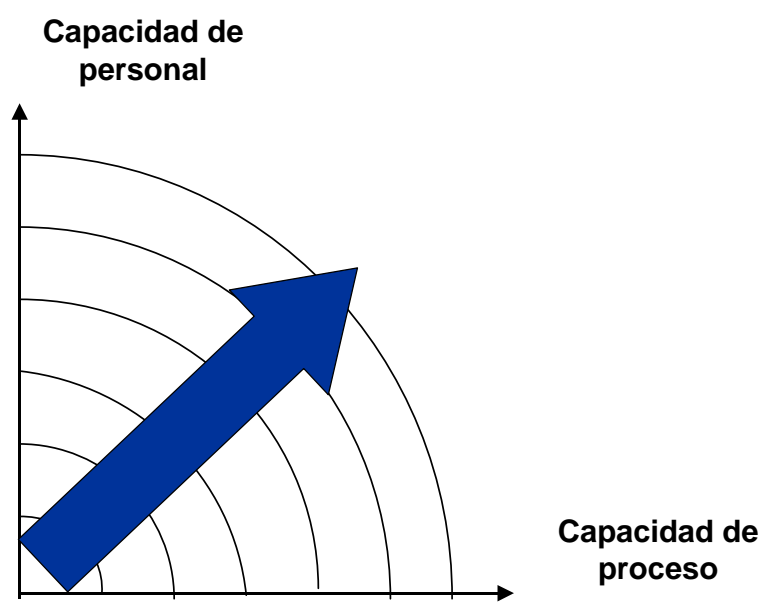

\section{Ilustración 2. 6: Construcción de un producto más complejo, basado en el incremento de la capacidad del personal y del proceso. Fuente: Phillips}

Basándose en las ideas y las relaciones mostradas por Phillips en este apartado, y extrapolándolo a los cinco elementos expuestos, se podría deducir que en lugar de representarlo en dos ejes, los cinco elementos y sus correspondientes relaciones se moverían según un pentágono regular de cinco ejes.

Dicha representación se puede observar en la Ilustración 2. 7, en la cual cada uno de los ejes representados correspondería a cada uno de los elementos empresariales expuestos en el punto 2.2 del presente capítulo. 


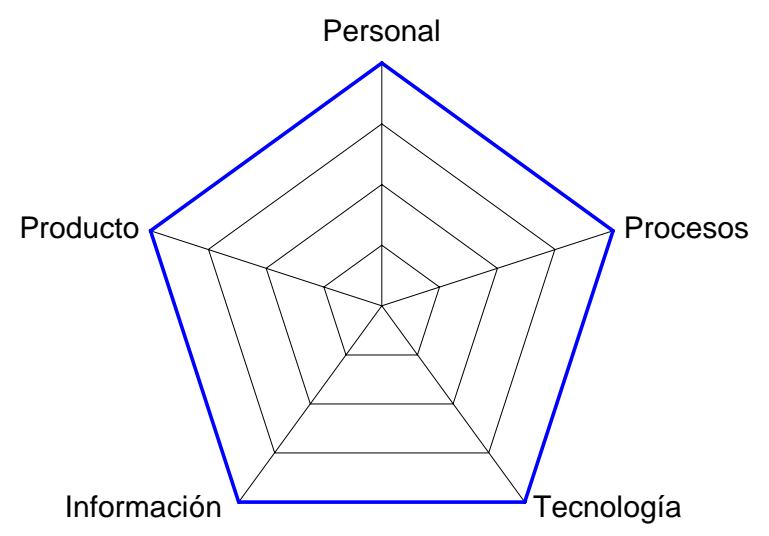

Ilustración 2. 7: Situación de equilibrio entre los cinco elementos empresariales. Fuente: Elaboración propia

Para grafiar las características de cada uno de los productos, así como las posibles mejoras a de los elementos, habría que llevar sobre el eje correspondiente, el peso proporcional del elemento a mejorar.

Por lo tanto, si se intenta representar como lo hizo Phillips en la Ilustración 2. 4, la construcción de un producto más complejo, basado en el incremento de la capacidad de personal, se obtendrá en la figura del pentágono un desarrollo en el eje del personal, y a su vez un desarrollo menor en el eje del producto de dicho pentágono, ya que la mejora se reflejará sobre esos dos ejes, y por tanto se obtendrá lo representado en la Ilustración 2. 8 que supondrá cómo hacer un producto más complejo, desde la mejora en el personal respecto de los cinco elementos. 


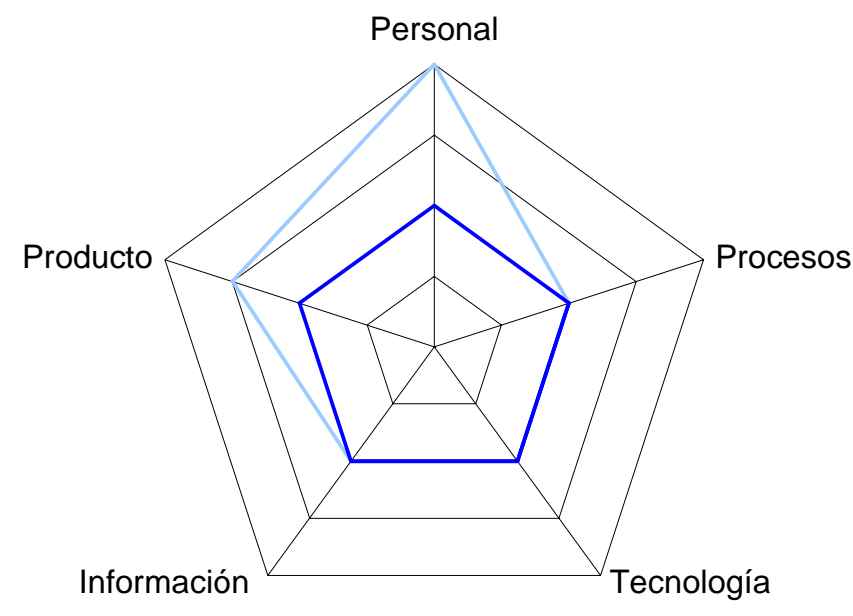

Ilustración 2. 8: Construcción de un producto más complejo, basado en el incremento de la capacidad del personal. (5 elementos). Fuente: Elaboración propia

Si por el contrario se quiere representar lo correspondiente a la figura Ilustración 2. 5, que supondría la construcción de un producto más complejo basado en un incremento de la capacidad del proceso, se puede observar en la representación del pentágono de la Ilustración 2. 9, como son los elementos de producto y proceso los que avanzan, mientras el resto permanece estable.

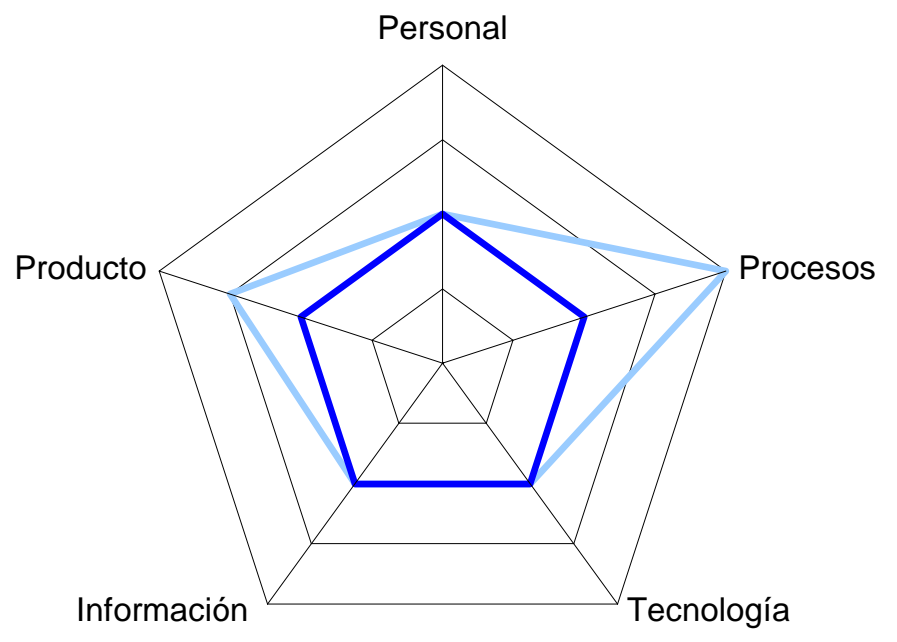

Ilustración 2. 9: Construcción de un producto más complejo, basado en el incremento de la capacidad del proceso. (5 elementos). Fuente: Elaboración Propia 
Finalmente, si se quiere representar en un pentágono correspondiente a los cinco elementos, la construcción de un producto más complejo, basado en el incremento de la capacidad de proceso y de personal, realizada por Phillips realiza en la Ilustración 2. 6, se obtendría la Ilustración 2. 10, en la que son los ejes de Personal, Procesos y Producto, los que se ven desarrollados.

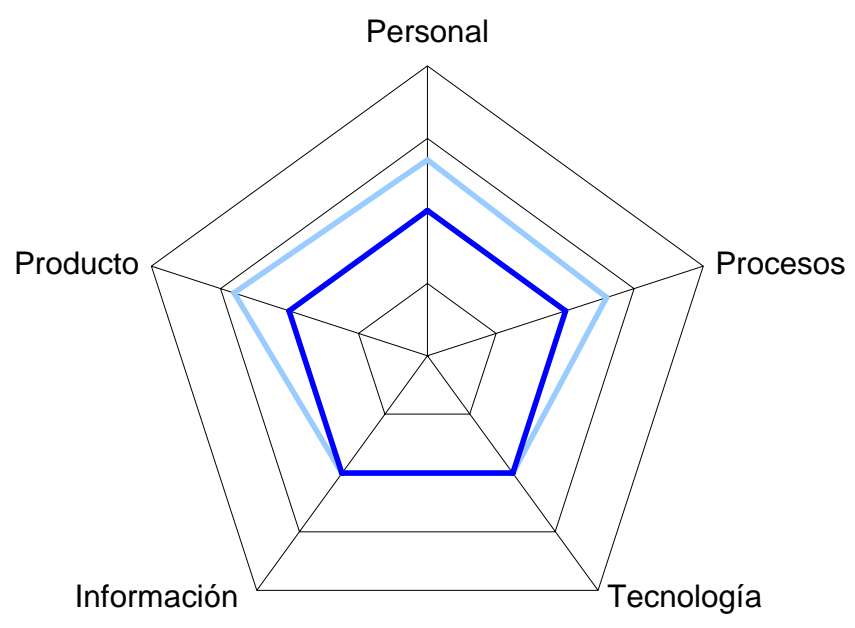

Ilustración 2. 10: Construcción de un producto más complejo, basado en el incremento de la capacidad del personal y del proceso. (5 elementos). Fuente: Elaboración Propia

Todo esto expone que los distintos elementos interactúan entre ellos, y una variación en uno de ellos conlleva a la modificación de otro u otros, por ejemplo no se puede pretender llegar a un producto más complejo si se continúa trabajando con los mismos procesos y sin proporcionar ningún tipo de mejora al personal habitual, mejoras en infraestructura o información. Con lo que para obtener productos más complejos, habrá que mejorar los elementos empresariales.

\subsection{RELACIÓN ENTRE LOS ELEMENTOS EMPRESARIALES}

Phillips [Phillips] señala que las relaciones entre los elementos se producirán a través de distintas situaciones posibles dentro del ámbito empresarial como pueden ser:

- A través de procesos y metodologías muy estrictas, pero ante un presupuesto escaso: De este modo que habrá que intentar conseguir el mejor personal posible, ya que intentar atacar un 
proceso muy rígido con un personal poco formado o novato podría tener consecuencias desastrosas.

- A través de un producto y un personal, pero sin conocer el proceso a utilizar: Aunque se tenga personal, a éste hay que proporcionarle formación suficiente y adecuada para que pueda conseguir poner en marcha los procesos.

- Teniendo el producto, y pudiendo elegir el personal y el proceso. Lo lógico es acudir a personal experimentado que haya realizado antes dichos procesos, debido a que conocen el producto y saben como organizarse para el mejor funcionamiento. La evolución de dicho personal experimentado ira limitando los vicios para finalmente eliminarlos, ya que dichos vicios surgen del estancamiento de personal en las empresas.

- Cuando la dirección de la empresa quiere seleccionar un producto nuevo de una lista de ideas, teniendo un personal a mano, y una serie de procesos a los que se puede acudir: Para ello habrá que acudir al producto que resulte más beneficioso, teniendo en cuenta el riesgo y el coste que supone. Pero teniendo también presente, cuales son los procesos conocidos y de que personal se dispone.

Todas estas posibles circunstancias hacen que se deba ser muy cuidadoso a la hora de elegir el personal y los procesos a llevar a cabo para encajar el producto a obtener.

Para conseguir que los proyectos tengan una buena base capaz de alcanzar el éxito la comunicación entre los elementos empresariales ha de ser lo más satisfactoria posible. Y con ello, se pueda llegar a un producto dado, basándose en la información precisa, consiguiendo el personal y el proceso que haga llegar a él. Para el caso de un producto y un personal dado, conseguir un proceso que encaje. Y para un personal que prefiere un tipo de proceso, tratar de obtener sólo productos que encajen. Las posibles relaciones aparecen reflejadas en la Ilustración 2. 11: 


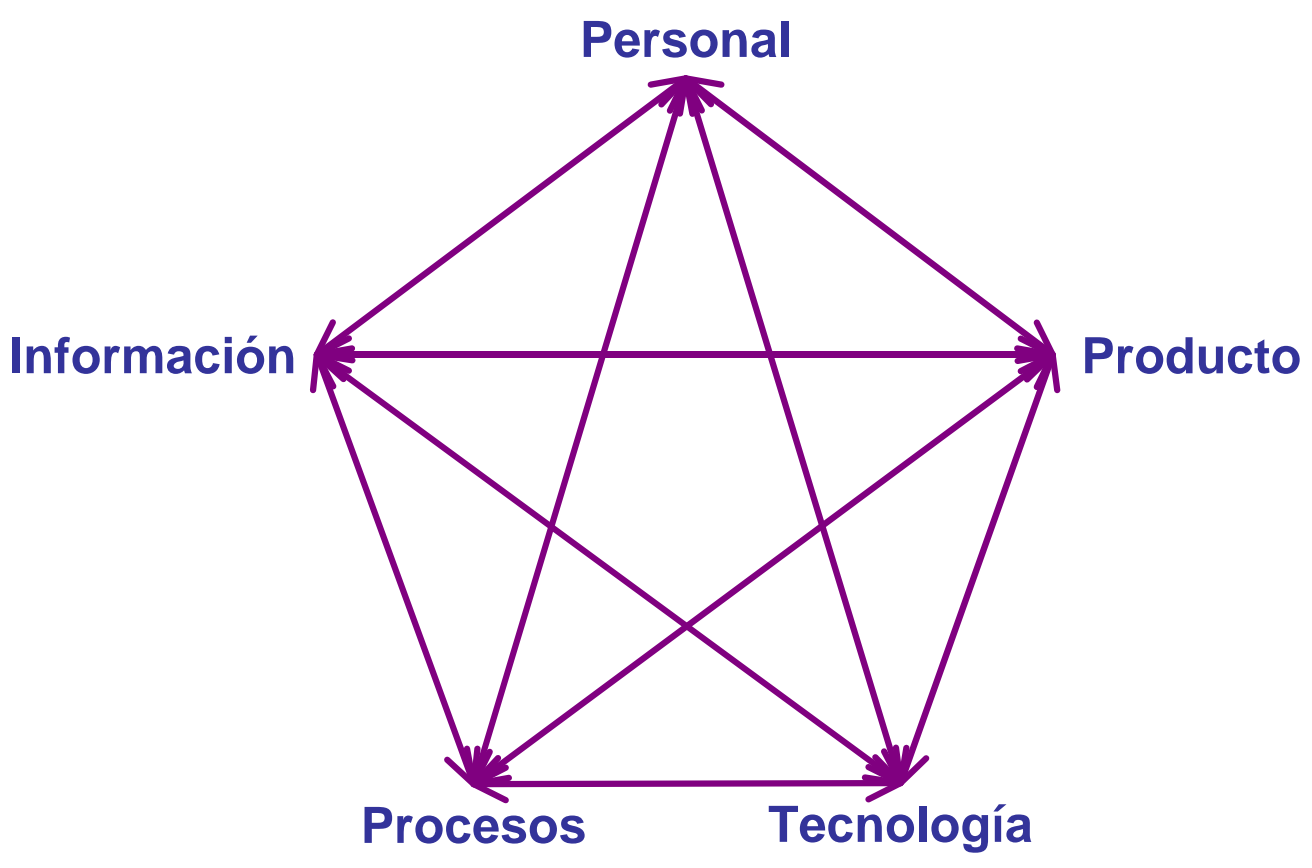

Ilustración 2. 11: Relaciones existentes entre los elementos empresariales. Fuente: Elaboración Propia

\subsection{EVOLUCIÓN EMPRESARIAL Y SUS ELEMENTOS}

El porque del estudio de estos elementos empresariales, se debe a que estos no son jijos, sino que dependiendo de como éstos evolucionen, lo hará a su vez la organización.

De forma que la importancia de la relación existente entre los elementos empresariales se debe a que si el personal es necesario para poder llevar a cabo las actividades o procesos, y a su vez éstos son necesarios o para generar valor añadido en los productos. Pero esos productos o servicios serán también importantes debido a que son el fin por el que se creo la empresa. Y por su parte, la tecnología, será el medio que utilizan las empresas para poder llevar a cabo los procesos que generan los productos.

De modo que como se ha expuesto en el apartado 2.2, las organizaciones están formadas de cinco elementos organizacionales básicos: personal, procesos, tecnología, información y productos, aspecto que se ha querido representar en la Ilustración 2. 12, donde se representan los cinco elementos empresariales del punto 2.2, relacionados en una mínima parte central, ya que mejorar uno puede suponer tener que retocar el resto. Esto indica, que no deben tomarse los 
elementos de manera aislada, puesto que modificar uno de ellos, necesariamente perturbará a los demás.

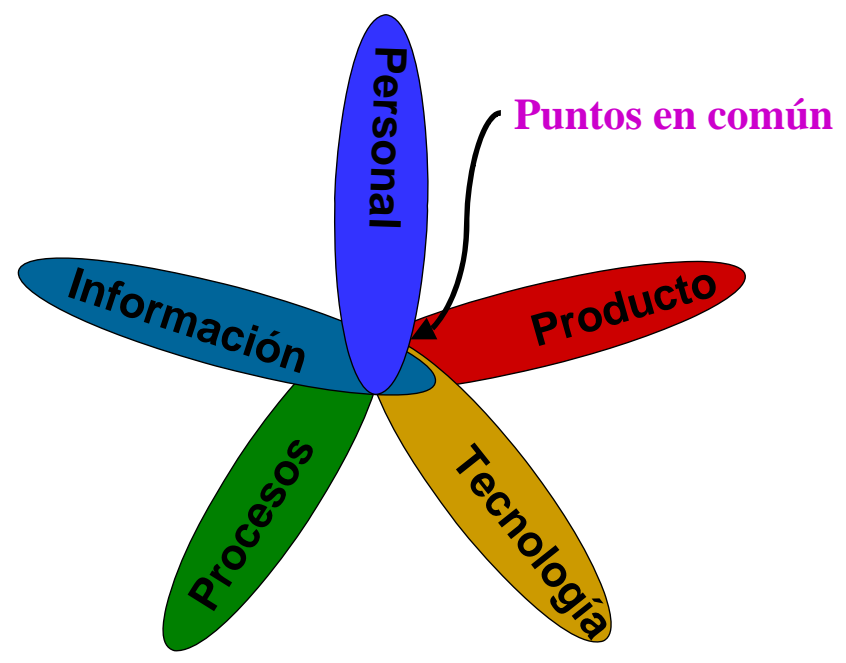

\section{Ilustración 2. 12: Elementos empresariales. Fuente: Elaboración Propia}

De tal manera que si la empresa mejora el personal a través de la realización de cursos de formación, cambiarán los procesos que el personal lleva a cabo por unos nuevos y mejores. Con ello, probablemente se produzca un mejor uso de las Infraestructuras que el personal tiene a su alcance en la empresa. Con lo que la suma de todo ello debería conseguir un producto mejorado. Generándose así un ciclo de mejora progresivo. Dicho ciclo se observa en la representación de la Ilustración 2. 13.

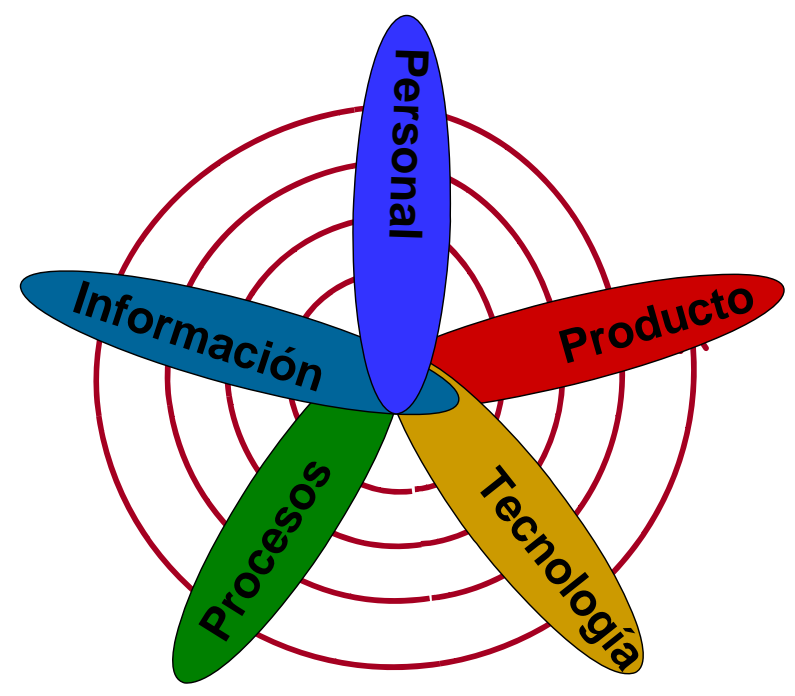

Ilustración 2. 13: Ciclo de mejora del desarrollo de los elementos empresariales. Fuente: Elaboración Propia 
Para realizar esas mejoras en las empresas, habrá que mejorar los distintos elementos empresariales que componen la empresa a través de un proceso de mejora. Dicho proceso de mejora, o ciclo de mejora, se llevará a cabo siguiendo cierto orden, que supondrá aquel aportado por su correspondiente arquitectura de integración particular.

Los distintos pasos o etapas de las distintas arquitecturas de integración ante un proceso de mejora, se mostraron en el punto 1.3 [Comparación de Arquitecturas], y en particular en la Tabla 1.1, donde se exponen los pasos a seguir según la arquitectura correspondiente.

Dichos pasos varían de una arquitectura a otra como se observó en la Tabla 1.1, pero siguen mínimamente una pauta que supone el seguimiento de una serie de etapas que se estudiarán ampliamente en el punto 3.2 (Descripción de las etapas de los ciclos de vida.) del siguiente capítulo.

Las etapas a seguir son:

- Planificación:

- Análisis

- Diseño

- Implementación

- Mantenimiento y Revisión

- Desmantelación

Estas etapas de mejora, se seguirán para la evolución de cada uno de los elementos empresariales, pero a su vez, como se ha expuesto anteriormente al principio de este apartado, entre los elementos existe una mínima relación entre sí, debido a que si por ejemplo se comienza dando una mejor formación al personal se pueden lograr cambios y evoluciones empresariales en el resto de elementos.

Esto se debe a que una vez formado el personal, se puede lograr retocar el proceso que han de realizar, con lo que se puede conseguir modificar los productos obtenidos por la empresa. Todo ello llevará finalmente a modificar la tecnología, lo que a su vez supondrá que se forme al personal para el uso de dicha tecnología, con lo que de nuevo quedarían retocados los procesos y 
así continuamente en evolución. Formándose una espiral como muestra la Ilustración 2. 13 en el desarrollo de los elementos empresariales a nivel particular, siguiendo las etapas de evolución de cada elemento, y a su vez, la espiral representará cómo se verá afectado cada uno de los elementos ante la evolución de los elementos que le rodean.

Pero a su vez, las personas pueden obstaculizar el éxito de una empresa y su combinación, ya que hay veces en las que surgen barreras desde las mismas personas de la organización. Norris et al [Norris p.120] señalan los siguientes principios para llevar a cabo en cambio del personal en las organizaciones:

$\begin{array}{ll}- & \text { Comunicar el motivo del cambio } \\ - & \text { Indicar los apoyos al cambio } \\ - & \text { Evaluar la recompensa a los diferentes líderes } \\ - & \text { Transmitir la posibilidad de realizar Feed-back } \\ - & \text { Agregar las lecciones aprendidas } \\ - & \text { Consolidar el entorno mediante posterior formación. }\end{array}$

Para estos autores, las personas cambian con una mezcla de aprendizaje y éxito, siendo el cambio flexible y dando lugar a nuevos cambios. Pero no solo cambian los aspectos de personal, Norris et al [Norris p. 120] hacen referencia a los cambios en los procesos. Para llevar a cabo esos cambios, es necesario realizar ingeniería de nuevos procesos o reingeniería de los actuales. Para ello hay que identificar todas las dependencias y nuevos requerimientos de recursos y el personal encargado de gestionar el cambio.

\subsection{CONCLUSIONES DEL CAPÍTULO}

Partiendo de los elementos empresariales presentados en el capitulo primero, en este segundo capitulo se hace una justificación de los mismos desde la perspectiva de la Cadena de Valor de Porter. En dicha cadena, como se muestra en el apartado 2.2, se consideran una serie de actividades primarias y otras de apoyo, siendo las primeras la logística de entrada, operaciones, 
logística de salida, marketing y ventas, y servicio. Y las de apoyo: Infraestructura, Recursos Humanos, Desarrollo de Tecnología, y Abastecimiento. Si estas actividades se abstraen y se intentan identificar los elementos empresariales obtenidos en el apartado 1.4 se obtendrá que dentro de los procesos se puedan incluir las actividades de operaciones, logística de expedición, marketing, ventas y abastecimiento. La infraestructura identificada por Porter, se puede asociar a la tecnología y al desarrollo de la tecnología, asi como los servicios pasarán al grupo de Productos y Servicios, mientras que la gestión de Recursos Humanos identificada por Porter, corresponderá al elemento Personal.

Una vez identificados desde esta otra perspectiva, en el apartado 2.3 se realiza una presentación y estudio en profundidad los elementos empresariales que integran las organizaciones: Personal, Procesos, Productos o Servicios, Infraestructura, e Información.

Estos cinco elementos presentados, no se encuentran aislados en las empresas, debido a que entre ellos existe relación, como lo muestra Phillips [Phillips] para tres de los cinco elementos empresariales. En el apartado 2.4, basándose en dichas relaciones se ha realizado una aproximación a cómo sería la evolución de esos mismos elementos, pero en lugar de realizarlo frente a tres de ellos como el citado autor señala se realiza frente a los cinco elementos presentados en el capítulo, utilizando para tal fin, la representación de un pentágono regular en situación de equilibrio e irregular para la evolución de los elementos correspondientes que vayan evolucionando, representándose los casos presentados por Phillips.

Finalmente el capítulo termina proponiendo en el apartado 2.6 una mejora de dichos elementos mediante una evolución, realizándose a través de un ciclo de mejora. Dicho ciclo de mejora supone una evolución que se realizará a través de etapas presentadas en el último apartado: Planificación, Análisis, Diseño, Implementación, Mantenimiento y Revisión, y Desmantelamiento, las cuales se profundizarán en el siguiente capítulo bajo el concepto de Ciclo de vida, teniendo ello referencia a lo ya presentado en la Tabla 1.1 del primer capítulo.

\subsection{REFERENCIAS BIBLIOGRÁFICAS DEL CAPITULO}

Bueno Bueno Campos, E. "Curso Básico de Economía. Un enfoque de Organización" Editorial Pirámide. España 1996

Cotec Cotec: Fundación empresarial para el desarrollo del país mediante el fomento 
de la innovación tecnológica en la empresa y sociedad española. COTEC. Pautas metodológicas en Gestión de la Tecnología y de la Innovación para Empresas. Tomo 1. Cotec Innovation. España 1999.

DTE Diccionario de Términos Económicos. Editorial Acento. España 1994

DmachucaI95 Domínguez Machuca J.A., M.A. Domínguez Machuca, S. García González, Al Ruiz Jiménez, M. J. Álvarez Gil. "Dirección de Operaciones. Aspectos tácticos y operativos en producción y servicios" Edición Mc Graw Hill. España 1995

Domínguez Domínguez Torres, A. Cambio y Conocimiento en los Sistemas. Editorial Galileo. México 2000

FdzGuerrero Fernández Guerrero R., F. Balbastre Benavent, $\mathrm{m}^{\mathrm{a}}$ T. Canet Giner, A. Redondeo Cano, L. Revuelto Taboada. "Organización y Métodos de trabajo". Editorial Civitas. España 1998

Gil98 Gil Pechúan I., J.J. Guarch Bertolín, D. Palacios Marqués. "Implantación de Sistemas y Tecnologías de Información en las Organizaciones" Servicio de Publicaciones de la Universidad Politécnica de Valencia. Colección Libro Docente. España1998.

McConell McConnell. S. Desarrollo y Gestión de proyectos informáticos. Microsoft Press. MC Graw Hill. España 1997

Mullins Mullins L.J. "Management and Organisational Behaviour" Ediciones Prentice Hall. Financial Times. 6 Edición. Reino Unido 2002

Norris Norris G., J.R. Hurley, K.M.Hartley, J.R. Dunleavy, J.D. Balls. "Del ERP al ebusiness. Transformando la empresa" Editorial Deusto S.A. Nueva Economía. PricewaterhouseCoopers Consulting. España 2001

Phillips Phillis D. People, Process, and Product. http://members.aol.com/dwaynephil/CutterPapers/ppp/ppp.htm Consultado el 24/05/2001

Porter80 Porter. M.E. (1980) Competitive Strategie The Free Press, NY. Versión Española Estrategia Competitiva. CECSA México. 1982

RuizMandado Ruiz González M., E.Mandado Pérez. "La innovación tecnológica y su gestión" Serie Productica. Marcombo. Boixareu Editores. España 1989. 
Tissen2000 Tissen R., D. Andriessen, F. Lekanne Deprez. "El valor del Conocimiento. Para aumentar el rendimiento en la empresa". Editorial Finanacial Times. Prentice Hall. España 2000.

Tiwana Tiwana, A. The knowledge management toolkit. Practical techniques for building a knowledge management system. Ed. Prentice Hall PTR. USA 2000. 
Capítulo 3.

Ciclos de vida en las

Organizaciones 
CAPITULO 3

\section{CICLOS DE VIDA EN LAS ORGANIZACIONES}

\subsection{INTRODUCCIÓN}

Una vez introducida en el primer capítulo en la Tabla 1.1 una comparativa de las distintas etapas que componen las metodologías de las arquitecturas de integración presentadas, apartado 1.4 "Comparación de las Arquitecturas de Integración", el presente capítulo va a realizar un estudio de dichas etapas. La base de partida es la arquitectura presentada por el grupo IE-GIP de la Universidad Politécnica de Valencia para lo que una vez descritas sus etapas, se realizará una comparativa de las mismas y a partir de ahí la elaboración de un ciclo de vida propio en el punto 3.3. Tras presentar el ciclo de vida propio se realizará una explicación de cada una de las etapas que lo componen: Planificación, Análisis, Diseño, Implementación, Revisión Mantenimiento y así conocer en qué consiste cada una de ellas.

Conocidas dichas etapas de ciclo de vida genérico, se realizará en el apartado 3.4 una aplicación del ciclo de vida del elemento empresarial personal, para lo que se realizará una revisión bibliográfica sobre la descripción de las etapas por las que pasa este elemento, y a través de una tabla comparativa se podrá comprobar que estas coinciden, y que el elemento empresarial Personal también sigue un ciclo de vida. 
A continuación en el apartado 3.5 se describirán las propiedades que poseen las etapas del ciclo de vida, debido a su independencia funcional, para en el apartado 3.6 reflejar como afectan los problemas a los ciclos de vida y proponer la actuación ante los mismos, ya que no es lo mismo conocer cual es el problema y realizar en ese caso ingeniería directa o reingeniería, o saber que existe el problema pero no tenerlo identificado, eso llevará a la aplicación del ciclo de vida directo e inverso, lo que llevará a realizar ingeniería inversa y pasar luego a aplicar ingeniería directa.

\subsection{LA CONCEPCIÓN GENERAL DE LOS CICLOS DE VIDA}

Ya en el capítulo segundo, al hacer referencia a los procesos en el apartado 2.2.2 McConnell [McConnell p.20] propone como una de las medidas para solucionar su problemática, una correcta planificación del ciclo de vida de los procesos. Dicha planificación responde a que los ciclos de vida describen un plan de gestión, de fácil identificación que organiza las tareas necesarias para la correcta realización de un proyecto.

Pero como se expuso en el capitulo de Integración empresarial en el apartado 1.3 Comparación de Arquitecturas, para K. Kosanke, la mayoría de metodologías se orientan hacia el concepto de ciclo de vida, cubriendo partes distintas del mismo, como se mostró en la tabla 1.1 correspondiente a la comparación de las distintas metodologías de integración y como éstas perciben cada una su ciclo de vida.

Antes de comenzar a aportar definiciones sobre el ciclo de vida de un proceso, hay que señalar que los ciclos de vida pueden aplicarse no solo a procesos sino también a cualquier sistema. Entendiendo por sistema como el "conjunto de elementos que se organizan o interactúan para cumplir objetivos, metas o un propósito específico propuesto”, siendo esta definición enunciada por De Rosnay [DeRosnay. Capitulo 2] y reflejada por Domínguez [Domínguez p. 13]

Ortiz [Ortiz p.134] a su vez propone que "si una empresa es un sistema, mientras éste esté funcionando, su sucesor está en proceso de diseño y los planes estratégicos de negocio marcan el estado para las implementaciones futuras”, lo que responde al funcionamiento de un ciclo de vida. 
Finalmente, se puede concluir con la definición de Rodríguez y Márquez [Rodríguez p.39], del ciclo de vida (ciclo de desarrollo) de un sistema, para quienes "los sistemas pasan por una serie de etapas desde su concepción hasta su desaparición; desde que surge la necesidad, pasando por la propia construcción, puesta en marcha y continuas revisiones hasta su abandono o reemplazo".

Trasladando estas definiciones al mundo empresarial, podría identificarse a la empresa como el sistema, pudiendo desglosarla en subsistemas, que serían los departamentos o áreas funcionales, que a su vez llevarán a cabo una serie de actividades relativas a las tareas desarrolladas dentro de la empresa. Estas actividades serán las actividades del ciclo de vida para el desarrollo de productos o proyectos.

Para poder desarrollar e implementar un sistema ha de seguirse una metodología que proporcione las técnicas a llevar a cabo en cada una de las etapas. Entendiendo por metodología [Rodríguez p.40] "el enfoque para organizar, dirigir y realizar actividades del ciclo de vida de desarrollo de un sistema”. Existen distintas metodologías generales e independientes según el tipo de empresas y organizaciones. Dentro de cada organismo pueden y deben adaptarse los métodos existentes, para construir así su propio método o un enfoque práctico de construcción de sistemas.

En muchas empresas la metodología ha llegado a formalizarse en un conjunto de etapas estandarizadas que definen la secuencia y documentación necesaria en cada una de ellas, para poder llevarla a cabo de la manera más práctica y eficiente.

Cuando se trate de una metodología para el desarrollo de los ciclos de vida de los sistemas, se estará preparando una estructura para desarrollar los sistemas en todas sus fases, desde la planificación y diseño hasta la implementación y desarrollo. Por ello a partir de ahora se utilizará la definición de metodología como el método para construir sistemas de calidad más rápidos, a menores costes y con menores riesgos. Ejemplos de ciclos de vida, se encuentran en todas las actividades vitales, desde una empresa y su desarrollo de productos y procesos, la cadena de suministro para el aprovisionamiento de bienes o servicios, o el proceso de selección en un Departamento de Recursos Humanos, cada uno de estos ejemplos sigue un proceso que siempre se repite, en pro de conseguir el objetivo planteado. 


\subsection{DESCRIPCIÓN DE LAS ETAPAS DEL CICLO DE VIDA}

Si como se ha expuesto en el apartado anterior, para desarrollar un sistema ha de seguirse una determinada metodología que contribuya a la construcción del sistema, el Departamento de Dirección y Presupuestos de Maryland en su Plan Tecnológico [Maryland] señala que "existe un gran número de metodologías aceptadas para la creación de sistemas, cada una con sus conceptos básicos y prácticos del desarrollo o mantenimiento del sistema. Cada metodología aplicada ha de ser la apropiada para cada sistema, tanto en tamaño, tipo y alcance del proyecto, con lo que hace que cada autor identifique un número de etapas que variará según enfoque, aunque estudiando distintos autores se puede concluir que las etapas son las mismas, pudiendo estar éstas más o menos desglosadas”.

Tomando como referencia la metodología propuesta por la arquitectura IE-GIP, Ortiz [Ortiz98 p. 184] propone una metodología de desarrollo de programas de Integración empresarial realizada a dos niveles, uno macro y otro de detalle. Las etapas de ciclo de vida propuestas por Ortiz [Ortiz98 p. 184] son los siguientes, correspondiendo los cuatro primeros el nivel macro, y los seis restantes, al nivel de detalle:

11. Identificación de la Entidad de Negocio: Identificar donde se va a desarrollar el programa de Integración, es decir, donde se desarrollará el sistema: si su ámbito de actuación será en toda la empresa o un departamento, sólo en algunos procesos, personas, productos.

12. Conceptualización: Supone establecer el marco estratégico en el que se mueve la entidad definida en el paso anterior, especificando la misión, valores, políticas, etc. convenientes para el sistema.

13. Análisis de los procesos: Descripción de los procesos que se desarrollan y los que se han de desarrollar en la entidad objeto del programa, es decir del modelo To Be al modelo As Is.

14. Elaboración de un plan de actuación: Plan de actuación para abordar la transición entre un modelo y otro. 
15. Definición de requerimientos: Supone definir que características (actuales o deseables) que está desarrollando (o deberá desarrollar) dentro de cada uno de los Procesos.

16. Especificaciones de diseño: Identificar y diseñar los sistemas que van a permitir que se cubran los requerimientos definidos por el usuario en la fase anterior.Por lo que pueden diseñarse acciones que conduzcan a mejorar condiciones en trabajo, diseño, formación, etc.

17. Descripción de la implementación: Selección de productos y técnicas actuales más adecuadas, que proporcionen los componentes adecuados en una realización integrada y efectiva, pudiendo ejecutar los procesos.

18. Construcción: Instalación de los requisitos en la empresa para poder ejecutar el sistema.

19. Operación: Realización de todas las actividades especificadas en los pasos anteriores, con los recursos instalados en dichos pasos, para conseguir los objetivos deseados.

20. Desmantelamiento: Criterios de actuación para la eliminación del sistema ya en desuso.

Si todas estas actividades propuestas por Ortiz, se relacionan con el ciclo de vida propuesto en este capítulo, se puede comprobar que forman un ciclo de vida similar más resumido, debido a que Ortiz presenta diez etapas, y el ciclo de vida aquí presentado presenta seis, como se explicará detalladamente desde el apartado 3.2.1 en adelante.

Estas etapas fundamentales que forman parte del ciclo de vida de un sistema son: Planificación, análisis, diseño, implementación, mantenimiento y revisión, y desmantelamiento, que se detallan a continuación y muestran en la Ilustración 3. 1 corresponden a las siguientes etapas propuestas por Ortiz y su arquitectura como se detalla a continuación y se muestra en la Tabla 3. 1. 
La etapa de Planificación correspondería a la identificación de la entidad de negocio, así como los conceptos que hacen referencia a la visión, misión, etc. de la empresa en el modelo propuesto por Ortiz.

El Análisis propuesto, supone para Ortiz la Definición de procesos a realizar, la elaboración de un plan de actuación, así como los requisitos y características que ha de poseer el nuevo sistema.

La etapa de Diseño coincide debido a que en ella se especificará el diseño del sistema para que cumpla con los requisitos.

La Implementación es a su vez identificada por Ortiz, como Implementación y Construcción. Ya que supone una elección de productos y técnicas adecuadas, para poner en marcha del sistema, y su construcción.

La Revisión supone la Operación y consecución de los objetivos propuestos por el sistema.

Y Finalmente la etapa de Mantenimiento que supondrá el mantener el sistema o deshacerse del mismo mediante el Desmantelamiento

\begin{tabular}{cl}
\hline Etapa del ciclo de vida del sistema & \multicolumn{1}{c}{ Etapas propuestas por Ortiz } \\
\hline Planificación & Identificación \\
& Conceptos \\
\hline Análisis & Definir procesos \\
& Plan de Actuación \\
& Requerimientos \\
\hline Diseño & Diseño \\
\hline Implementación & Implementación \\
& Construcción \\
\hline Revisión & Operación \\
\hline Mantenimiento & Desmantelamiento \\
\hline
\end{tabular}

Tabla 3. 1 : Fases propuestas para el ciclo de vida versus fases del ciclo de vida propuesto por IE-GIP. Fuente: Elaboración propia 


\subsubsection{Etapa de Planificación}

La planificación es la primera etapa del ciclo y supone la iniciación y primer contacto con el sistema. Sundaresan [Sundaresan] identifica esta primera etapa como "aquella en la que se realiza la investigación preliminar, se definen los objetivos a alcanzar y se lleva a cabo un estudio de viabilidad".

Esto supondrá conocer cual es la situación en que se encuentra el sistema y conocer las necesidades y prioridades que se quieren obtener. Para ello el autor propone "realizar un estudio de viabilidad, o bien un análisis coste-beneficio, etc. para comprobar si realmente es conveniente o no llevar a cabo lo proyectado. Si el resultado es positivo, a continuación se pasaría a hacer una planificación de cómo será el sistema, definiendo las metas a alcanzar y el plan de trabajo a alto nivel con el fin de obtener las aprobaciones correspondientes dentro de la empresa para su puesta en marcha”.

Puede ocurrir que se encuentren autores que a la etapa de Planificación la denominen como etapa de Análisis, o bien, que incluso unifiquen las dos etapas en una única, denominada etapa de Análisis.

\subsubsection{Etapa de Análisis}

Una vez conocidas las necesidades del sistema y el plan de trabajo marcado, ha de decidirse como plantea González [González] lo qué se va a hacer, cómo se va a hacer, cuando se va a hacer, con qué frecuencia, hasta dónde, qué requerimientos y a qué problemas se enfrentará.

Todo ello supone partir de un modelo AS-IS para llegar al modelo TO BE. Es decir, estudiar como está realmente el sistema en ese momento para poder llegar al modelo propuesto o a como debería ser, para lo cual se recolectan los datos, informes, requerimientos y prioridades.

Para poder llevar esto a cabo, Thistle [Thistle] propone "analizar cuales son los problemas, oportunidades y objetivos, para obtener una visión del sistema y sus consecuencias y determinar las oportunidades de mejora”.

En esa línea, y para llevar a cabo el análisis, la Universidad del Estado de Pennsylvania [Pennsylvania] propone "realizar un análisis coste-beneficio, y una revisión de necesidades y requisitos. Todo ello supone realizar un estudio del impacto que supondrá el nuevo sistema en 
todos los niveles de la organización, y un plan detallado de los estadios siguientes a desarrollar”.

\subsubsection{Etapa de Diseño}

La siguiente es la etapa de diseño en la que González [González] señala que "se diseñará un nuevo sistema según los requerimientos, datos, detalles específicos etc. solicitados, lo que supondrá llevar a cabo el diseño técnico, de las distintas partes o módulos en que se subdivide el sistema, y las unidades de trabajo".

Thistle [Thistle] propone que "el diseño lo lleve a cabo un especialista ayudándose de herramientas, gráficos, programas etc. y estructurará los procedimientos a realizar para llevar a cabo un sistema sin errores, que cumpla con los requerimientos iniciales, para lo cual deberá diseñar también un sistema de verificación, seguridad y control”.

Con frecuencia, ocurrirá que quien implante los sistemas y quien los diseñe no sea la misma persona, para ello el diseño deberá codificarse en un lenguaje lo más universal posible de manera que pueda ser interpretado por cualquier persona que conozca dicho lenguaje.

\subsubsection{Etapa de Implementación}

El hecho de implantar un sistema para González [González] supone "tomar el diseño, y si cumple con los requisitos solicitados, instalarlo”. Pero puede ocurrir que ese nuevo sistema necesite como apuntan Sundaresan [Sundaresan] y Thistle [Thistle] una "cierta instrucción y conocimiento por parte de quienes lo ejecuten”, de modo que la preparación e instrucción de éstos será también parte de la implementación.

Estos dos últimos autores hacen hincapié en que "el sistema hay que dejarlo validado y comprobado que funciona para aquello que se diseñó, y en caso negativo realizar correcciones hasta conseguirlo, para lo cual debe probarse el sistema”.

El principal problema que plantea la Implementación es como llevar a cabo la transición de un viejo sistema en funcionamiento a uno nuevo. Para ello hay que asegurarse de que el nuevo sistema que se va a implantar funciona correctamente, cumple con los requisitos, y los usuarios del nuevo sistema saben como funciona. 


\subsubsection{Etapa de Mantenimiento y Revisión}

Para finalizar, la última etapa será el mantenimiento y la revisión, que según propone el Departamento de Dirección y Presupuestos de Maryland en su Plan Tecnológico [Maryland] supondrá "realizar las modificaciones correspondientes para que sistema cumpla con los requisitos y correcciones solicitadas por los usuarios una vez que éstos han probado el sistema”. González [González] lo presenta como "otra etapa denominada Evaluación, contenida dentro del mantenimiento y la revisión”.

\subsubsection{Etapa de Desmantelación}

La desmantelación de un sistema según la Universidad del Estado de Pennsylvania [Pennsylvania], se llevará a cabo "cuando un sistema existente quede obsoleto y haya que eliminarlo, entonces, es cuando se produce dicha desmantelación. No siempre se lleva a cabo esta etapa ya que cuando un sistema es nuevo, no se puede reemplazar por ningún otro, y por tanto no existe desmantelación de ninguno”.

A continuación se muestra en la Ilustración 3. 1, donde aparecen todas las actividades que integran el ciclo de vida explicado en el presente apartado 3.2.

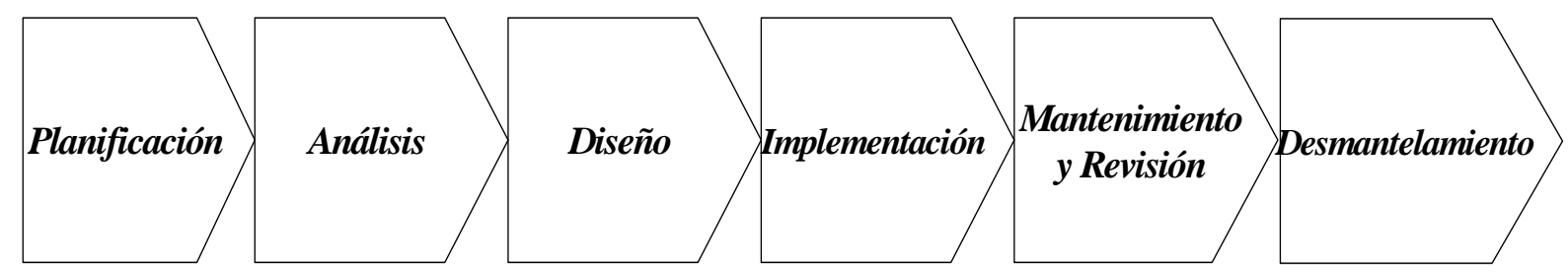

Ilustración 3. 1: Etapas del Ciclo de Vida. Fuente: Elaboración Propia

\subsection{EL CICLO DE VIDA DE LOS ELEMENTOS EMPRESARIALES: PERSONAL}

Una vez presentadas y explicadas cada una de las etapas que componen el ciclo de vida, si se aplican todas estas etapas descritas para un sistema como la Gestión de un Departamento de Recursos Humanos de una organización, se obtendrá que el proceso es similar al explicado debido a que se produce un discurrir a través de las etapas presentadas, pero adaptadas a la estructura y tareas que realiza de dicho departamento de personal. 
Existen diversos autores que recogen las etapas que se producen a lo largo del ciclo de vida del funcionamiento de los departamentos de Recursos Humanos. En la Tabla 3. 2 se puede observar una comparación entre las distintas etapas señaladas por distintos autores. En ella se aprecia como la mayoría de autores señalan etapas muy similares, aunque puede ocurrir que las presenten de forma desordenada.

Gil et al [Gil97] proponen la existencia de las siguientes etapas en la dirección de las personas, definiendo ésta como una actividad empresarial encaminada a conseguir la utilización óptima de los trabajadores desde el punto de vista empresarial, integrándolos en el proyecto empresarial.

1. Planificación de Plantillas: La planificación y gestión de las necesidades del personal procede de la planificación que realiza la organización. Por tanto, un análisis detallado de las necesidades futuras del personal se extraerá de los planes de la organización.

2. Análisis, Descripción y Valoración de los puestos de trabajo: El análisis de puestos es un procedimiento que consiste en determinar mediante estudios rigurosos los elementos o características inherentes a cada puesto. Debiendo aparecer los requisitos y cualificaciones necesarias para el desempeño de responsabilidades y obligaciones inherentes al puesto y condiciones físicas y ambientales en que se va a desarrollar el trabajo.

3. Búsqueda y selección de personal: Esta etapa supone conseguir un número suficiente de candidatos interesados en el puesto a cubrir. Y la selección realizada tras el reclutamiento, primero con una preselección de una muestra de candidatos entre los que estarán los finalistas y a continuación con la selección final.

4. Formación de personas en la organización: a su vez, la formación supone en si misma un nuevo ciclo de vida, ya que estaría compuesta de :

* Formación

* Análisis de las necesidades formativas 
* $\quad$ Programación de las Actividades formativas

* Impartición de las Actividades formativas

* Evaluación de la formación

5. Evaluación de las personas: La evaluación del rendimiento supone una técnica para apreciar sistemáticamente la actuación de una persona durante un determinado tiempo, en relación a su trabajo actual y sus características personales, así como su contribución a los objetivos previstos. Sirviendo además, para proyectar actuaciones futuras en orden a una posibilidad de desarrollo personal y de la organización.

Gan et al. [Gan95] confirman que la Etapa de Formación se puede a su vez clasificar como uno ciclo de vida, en si que desglosan en las siguientes etapas:

* Detección de las necesidades formativas: marco de referencia de los instrumentos de apoyo a la detección, organización de listados de necesidades.

* Elaboración de Planes de formación: Políticas de formación y elaboración de un plan de formación.

* Elaboración de programas formativos: Programa para la acción interna y los instrumentos a utilizar.

* Selección de participantes: según el tipo de acción formativa y la homogeneidad o heterogeneidad de los grupos.

* Selección de formadores: si éstos pertenecen a la estructura interna o externa de la organización , apoyo a su tarea, contenidos básicos, etc.

* Gestión económica de la formación: criterios a utilizar, presupuestos, etc. 
* Técnicas de Impartición: metodologías, formación a distancia, formación en el puesto de trabajo, utilización de nuevas tecnologías,...

* Evaluación de la formación: evaluación de los recursos, auditoría de la formación, ...

La clasificación de las etapas de gestión de Recursos Humanos se repite en diversos autores como muestra Gary Dessler en su libro “Administración del Personal” en el que se exponen las siguientes etapas:

1. Planificación estratégica del personal: [Dessler2001 p.21] "Supone la unión de la administración del personal con las metas y objetivos estratégicos, a efecto de mejorar el desempeño de un negocio y desarrollar la cultura de la organización, que propicie la innovación y la flexibilidad”. Dicha definición la aporta Dessler, en el citado libro pero el autor la extrae de Catherine Truss y Lynda Gratton de "Strategic Human Resource Management: A conceptual approach”. The International Journal of Human Resources Management. Volumen 5. №3, Septiembre 1994. P. 663

2. Análisis del puesto de trabajo: [Dessler2001 p. 84] Procedimiento para determinar las obligaciones correspondientes a los puestos y las características de las personas que se contratarán para ocuparlos.

3. Descripción de puestos: Lista de las obligaciones de un puesto, responsabilidades, relación, condiciones laborales, responsabilidades de supervisión; siendo el resultado el análisis del puesto.

4. Reclutamiento: [Dessler2001 p.123] Supone obtener una reserva de candidatos para los puestos, pudiendo proceder dichos candidatos del interior o exterior de la organización.

5. Pruebas y selección de candidatos: [Dessler2001 p.174] Para poder poner en marcha las pruebas de selección, éstas deberán tener validez y fiabilidad. Además habrá que seleccionar el tipo de pruebas que se van a llevar a cabo: de capacidad congnoscitiva, de 
capacidad física o motora, de personalidad o interés, de rendimiento, grafológica, examen médico, consumo de drogas.

6. Capacitación y desarrollo de empleados: [Dessler2001 p. 249] Proceso que proporciona a los empleados nuevas habilidades básicas que necesitan saber para desempeñar su trabajo de la forma más eficaz.

7. Evaluación del desempeño: [Dessler2001 p. 321] Supone calificar a un empleado comparando su actuación presente o pasada, con las normas establecidas para su desempeño.

8. Administración de Carreras: (Planificación y Desarrollo) Proceso mediante el cual una persona adquiere conciencia de atributos relacionados con su carrera personal, así como etapas de la vida que contribuye la realización de esa carrera.

El mismo orden y clasificación siguen Gómez-Mejía et al [GómezMejía2001] al enumerar las etapas como: gestión de los flujos de trabajo, análisis del puesto de trabajo, reclutamiento y selección, gestión del rendimiento y desarrollo de carrera.

De Cenzo y Robins coinciden en las etapas propuestas hasta ahora, aunque cambia cierto orden en ellas, ya que propone antes el desarrollo de la carrera laboral que la evaluación del desempeño:

1. Planificación de Recursos humanos: [Decenzo2001 p.130] Proceso en el que se encuentra una organización cuando pretende determinar sus necesidades de Recursos Humanos, debiendo estar vinculada con la estrategia general de la empresa.

2. Análisis de Puestos de trabajo: [Decenzo2001 p.139] Exploración sistemática de las actividades que conforman un Puesto de Trabajo. Es un procedimiento técnico que se utiliza para definir deberes y responsabilidades de un puesto de trabajo 
3. Reclutamiento y Selección: [Decenzo2001 p. 169] Proceso que decide y termina la contratación. Supone las siguientes etapas:

Entrevista inicial

Llenado de la solicitud

Pruebas de empleo

Entrevista ampliada

Investigación de antecedentes

Oferta condicional de empleo

Exámenes físico - médicos

- Oferta definitiva de empleo.

4. Desarrollo de empleados: [Decenzo2001 p.232]: Desarrollo hacia el futuro en pro de la educación y capacitación para el puesto de trabajo.

5. Carrera laboral [Decenzo2001 p.254] Supone la trayectoria laboral del empleado El desarrollo de la Carrera Laboral busca la eficacia y éxito del personal de una organización a largo plazo.

6. Evaluación del desempeño [Decenzo2001 p.288] Deben orientarse hacia los aspectos relativos a la retroalimentación, el desarrollo y la documentación.

La propuesta que realizan Dolan et al. supone además del cambio propuesto por DeCenzo y Robins una pequeña alternación en las dos etapas iniciales, quedando por tanto: 
1. Análisis: [Dolan99 p.27] Proceso que describe y registra el fin de un puesto de trabajo, cometidos, actividades, condiciones: Habilidades, conocimiento y aptitudes.

2. Planificación: [Dolan99 p.53] Supone prever las necesidades de Recursos Humanos en la organización, y fijar los pasos para cubrirlas

3. Reclutamiento: [Dolan99 p.77] Conjunto de actividades y procesos que se realizan para conseguir un número suficiente de personas cualificadas, de forma que la organización pueda seleccionar a aquellas más adecuadas para realizar el trabajo.

4. Selección: [Dolan99 p.91] Recopilación de información sobre candidatos a un puesto, así como la decisión de a quién deberá contratarse.

5. Formación y perfeccionamiento: [Dolan99 p.127] Conjunto de actividades cuyo propósito es mejorar un rendimiento presente y futuro, incrementando su capacidad a través de la mejora de sus conocimientos, habilidades y aptitudes.

6. Planificación y Gestión de la carrera profesional: [Dolan99 p.161] Sucesión de actividades laborales y de puesto de trabajo desempeñados por una persona a lo largo de su vida, junto con actitudes y reacciones asociadas, proporcionando una perspectiva en movimiento entre el individuo y la organización.

7. Evaluación del rendimiento: [Dolan99 p.191] Procedimiento estructural y sistemático para medir, evaluar e influir sobre los atributos, comportamientos y resultados relacionados con el trabajo, así como el absentismo para descubrir en que grado afectará al rendimiento futuro. 


\begin{tabular}{|c|c|c|c|c|}
\hline Gil, Ruiz, Ruiz [Gil97] & Dessler [Dessler2001] & $\begin{array}{l}\text { De Cenzo, Robins } \\
\text { [Decenzo2001] }\end{array}$ & $\begin{array}{l}\text { Dolan, Schuler, Valle } \\
\text { [Dolan99] }\end{array}$ & $\begin{array}{c}\text { Gómez Mejía, Balkin, } \\
\text { Candy } \\
\text { [GómezMejía2001] }\end{array}$ \\
\hline 1. Planificación de Plantillas & $\begin{array}{l}\text { 1. Planificación estratégica del } \\
\text { personal }\end{array}$ & $\begin{array}{l}\text { 1. Planificación de los Recursos } \\
\text { Humanos }\end{array}$ & 1. Análisis & $\begin{array}{l}\text { 1. Gestión de flujos de } \\
\text { trabajo }\end{array}$ \\
\hline $\begin{array}{l}\text { 2. Análisis, descripción y } \\
\text { valoración de puestos }\end{array}$ & $\begin{array}{l}\text { 2. Análisis y Descripción de } \\
\text { Puestos de Trabajo }\end{array}$ & 2.Análisis de Puestos de trabajo & 2. Planificación & $\begin{array}{l}\text { 2. Análisis de Puestos de } \\
\text { trabajo }\end{array}$ \\
\hline 3. a. Búsqueda del Personal & 3. Reclutamiento & 3. Reclutamiento & 3. Reclutamiento & 3.a.Reclutamiento \\
\hline 3. b Selección del Personal & 4. Selección & 4. Selección & 4. Selección & 3.b Selección \\
\hline $\begin{array}{l}\text { 4. Formación de la persona en } \\
\text { la organización }\end{array}$ & $\begin{array}{l}\text { 5. Capacitación y Desarrollo de } \\
\text { los empleados }\end{array}$ & 5. Desarrollo de los empleados & $\begin{array}{l}\text { 5. Formación y } \\
\text { Perfeccionamiento }\end{array}$ & \\
\hline \multirow[t]{2}{*}{ 5. Evaluación de las personas } & 6. Evaluación y desempeño & 6. Carrera laboral & $\begin{array}{l}\text { 6. Planificación y gestión de la } \\
\text { carrera profesional }\end{array}$ & 5. Desarrollo de Carrera \\
\hline & 7. Administración de Carrera & 7. Evaluación del desempeño & 7. Evaluación del Rendimiento & 4. Gestión del Rendimiento \\
\hline
\end{tabular}

Tabla 3. 2 : Tabla comparativa del Ciclo de vida del Departamento de Recusos Humanos desde el enfoque de distintos autores. Fuente:

Elaboración propia 
Una vez expuestos algunos de los puntos de vistas de los distintos autores, puede concluirse que todos ellos coinciden en las actividades o etapas que ha de llevar a cabo el departamento de Recursos Humanos, y el orden en que estas etapas se disponen es prácticamente el mismo para casi la totalidad de autores, y en los casos que varía, no es singularmente importante.

De modo a que cuando en el ciclo de vida de un sistema se hace referencia a la planificación, se corresponde a la planificación realizada en un departamento de recursos humanos en pro de conocer cuales serán las necesidades de personal que tendrá el citado departamento.

El análisis realizado en un sistema se corresponde con el realizado por los departamentos de recursos humanos debido a que se estudiarán los requisitos, procedimientos y obligaciones que ha de afrontar un puesto de trabajo.

A continuación, se pasa a la etapa de Implementación que llevado al departamento de recursos humanos, supone el reclutamiento y la selección de personal, ya que corresponderá a la puesta en marcha de aquello que se ha planificado, es decir el personal necesario, y se ha analizado, lo que supone el estudio de cómo se realizarán las tareas de cada puesto.

La etapa de revisión corresponderá a la Capacitación y Evaluación del desempeño, que supone estar al corriente de cómo evoluciona cada empleado en su trabajo y en el desempeño de su trabajo.

Finalmente, el mantenimiento de un sistema podrá llevarse al terreno de personal como la administración de la carrera laboral del empleado, por un lado para su formación y mejora, y por otro para evitar su fuga a otra empresa.

Por lo tanto, el ciclo de vida de un departamento de Recursos Humanos quedaría como muestra la Tabla 3. 3. 


\begin{tabular}{cc}
\hline Etapa del ciclo de vida del sistema & Etapa de los Recursos Humanos \\
\hline Planificación & Planificación de los Recursos Humanos \\
\hline Análisis & Análisis de Puestos de Trabajo \\
\hline Diseño & Descripción y Diseño de Puestos de trabajo \\
\hline Implementación & Reclutamiento y Selección \\
\hline Revisión & Capacitación y Evaluación del Desempeño \\
\hline Mantenimiento & Administración de la Carrera Laboral \\
\hline
\end{tabular}

Tabla 3. 3: Tabla comparativa entre etapas del Ciclo de Vida de un sistema versus Ciclo de vida de los Recursos Humanos. Fuente: Elaboración Propia

En una ilustración gráfica de las etapas del ciclo de vida de un sistema de Recursos Humanos se mostrará como se sucede una etapa tras otra como se ha expuesto en este apartado y en resumen, en la tabla anterior, quedando representado en la Ilustración 3. 2

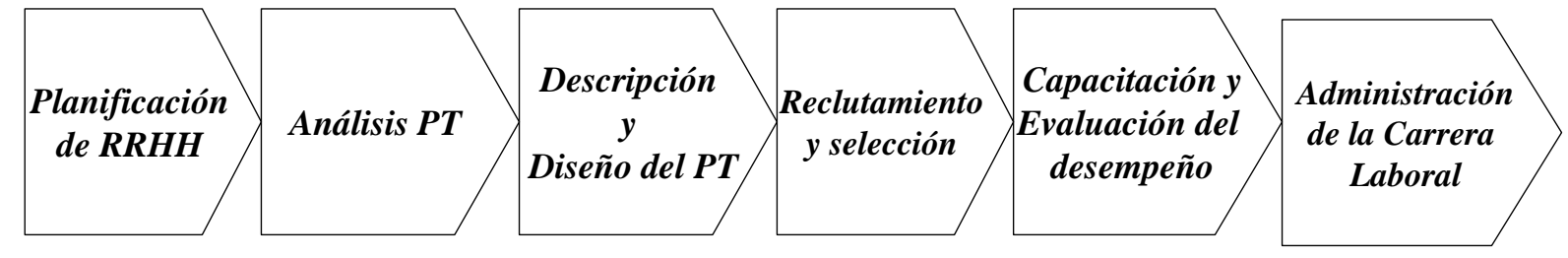

Ilustración 3. 2 : Ciclo de Vida del Departamento de Recursos Humanos. Fuente:

Elaboración Propia

\subsection{PROPIEDADES DE LAS ETAPAS DEL CICLO DE VIDA}

Una vez conocidas las etapas que constituyen el ciclo de vida de un sistema, así como las tareas o actividades principales en que consiste cada una de esas etapas, ha de señalarse que éstas poseen la cualidad de independencia funcional, lo que supone realizar una serie de funciones específicas pero con cierta interacción entre las otras etapas. De forma que si se produjera un cambio en una de las etapas, los efectos secundarios de dicho cambio se verían amortiguados por dicha independencia.

Domínguez [Domínguez p. 137] señala que la independencia funcional se mide sobre dos criterios: el acoplamiento y la cohesión, definidos como: 
* Acoplamiento: número y complejidad de conexiones entre dos subsistemas, es decir, medida de la interdependencia relativa entre ellos.

* Cohesión: medida de la fuerza relativa funcional de un subsistema, fuerza interna de los procesos y tareas dentro de un subsistema.

De modo que en una situación en la cual se produce acoplamiento entre etapas del proceso, deberá existir un nivel mínimo de cohesión, así como una máxima independencia posible, en las etapas del proceso. En esta situación, Domínguez [Domínguez p.140] señala que el efecto producido será:

- Menores posibilidades de trasladar problemas de una a otra.

- Mayor facilidad para el cambio, debido a que no se verán afectadas unas y otras

- Mayor sencillez, debido a que las entidades serán más simples y que se podrán cambiar, alterar o modificar sin afectar al sistema.

- Evitar el efecto Ola: cuando ocurren problemas en una etapa, se propagan al resto.

Si la cohesión es la extensión natural de la información propia de cada entidad, una etapa cohesionada realizará una sola tarea dentro de un proceso, con poca interacción en los procedimientos realizados por otras etapas. De modo que cuanto más cohesiva sea una etapa, más relacionadas estarán las tareas que han de realizarse a lo largo de ella; al igual que el acoplamiento, la cohesión podrá ubicarse en distintos niveles: desde más a menos acoplada. 


\subsection{LOS CICLOS DE VIDA Y LOS PROBLEMAS}

Un sistema puede estar funcionando a lo largo ciclo de vida sin generar ningún tipo de problema. Pero cuando éstos aparecen hay que detectar cual son los síntomas que se han generado y como resolver los problemas.

Ante el surgimiento de un problema en un sistema, lo primero que hay que plantearse es si dicho problema proviene de una problemática conocida, es decir, se sabe porqué surge, o bien el problema se detecta pero no se conoce el motivo. Ante esta última posibilidad, habrá que abstraer cada una de las etapas para detectar donde está realmente el problema. Este apartado, estudiará todas estas posibilidades.

\subsubsection{Distinción entre problemas y síntomas}

Para distinguir entre problemas y síntomas, lo primero que se hará será definir uno y otro. La definición más acorde de problema la aporta por $M_{c L e o d}{ }^{2}$ en su libro denominado Management Information Systems, que Domínguez [Domínguez p.50] resume como “condición, que tiene el potencial de provocar bien daños o bien beneficios excepcionales".

De tal forma, cuando surja un problema en un sistema, en primer lugar habrá que determinar los síntomas que generan cambios en el sistema. Pudiendo definir los síntomas como las señales o indicios de algo que está sucediendo o va a suceder.

Cuando en un sistema surja un problema, habrá que detectar y estudiar cual son sus síntomas. Una vez conocidos éstos, el siguiente paso será estudiar la estructura de los sistemas para poder plantear posibles estrategias de solución a dicho problema.

Para Domínguez [Domínguez p.50] la resolución de un problema, supone "responder a los problemas con el fin de eliminar los efectos de los daños, o capitalizar las oportunidades que se presentan". Dicho autor propone además, que para resolver el problema debe existir un sistema resolutor de problemas, que actuará cuando se genere un síntoma o un problema.

2 Mc Leod, R. "Management Information Systems". 7th Edición. Prentice Hall, Inc. New Jersey. 1998 
El resolutor de problemas actuará a su vez como un sistema, debido a que llevará a cabo una serie procesos (que compondrán el ciclo de vida del resolutor de problemas) que obtendrán finalmente una solución. Dicho resolutor se apoyará en información sobre el estado actual existente y el estado deseado al que se quiere llegar, así como de las restricciones propias del sistema para encontrar soluciones, que procedan del personal y la tecnología. Todo ello puede verse representado en la Ilustración 3. 3, donde aparecen reflejados los elementos que actúan en la resolución del problema y su proceso:

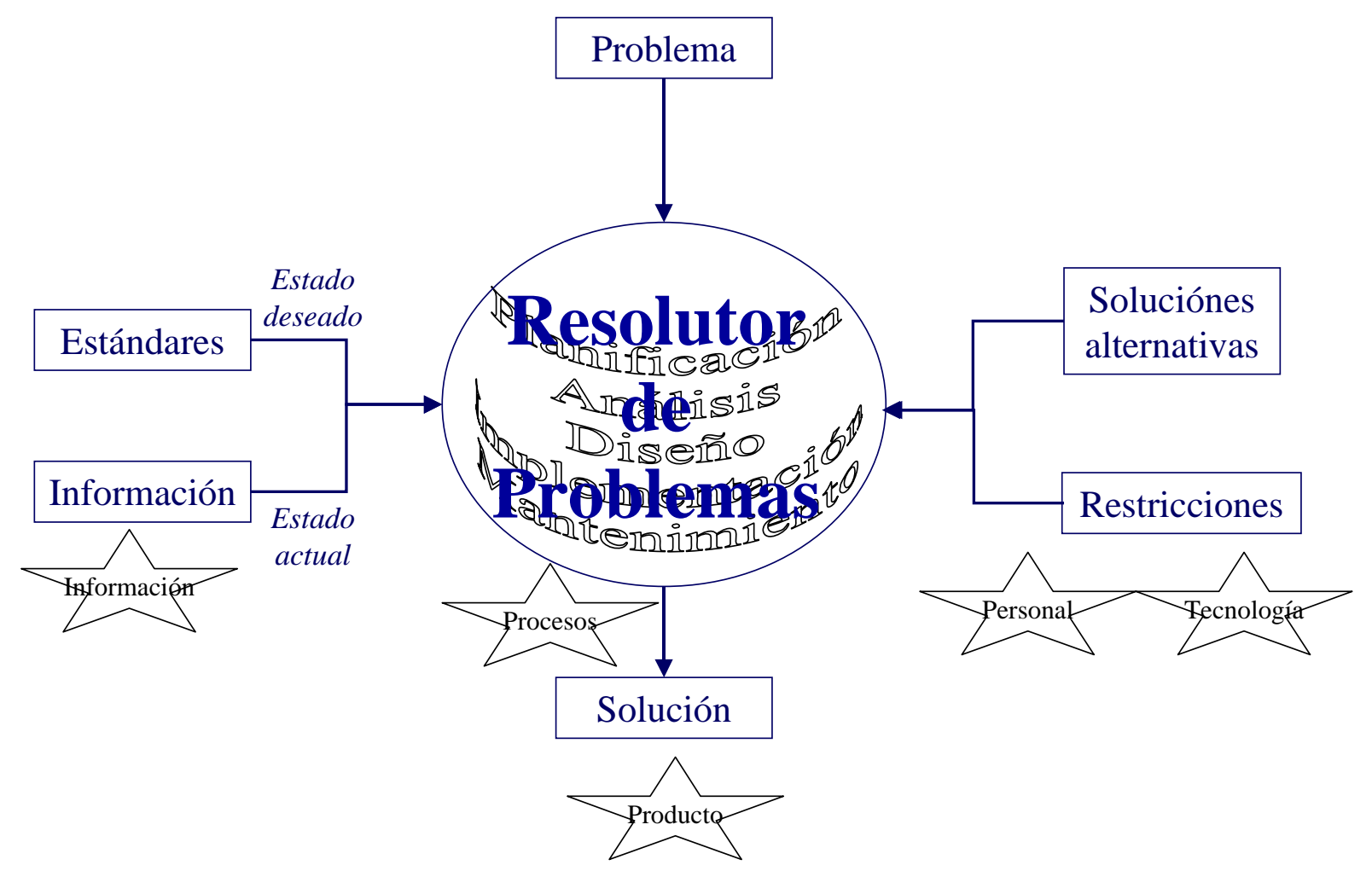

Ilustración 3. 3: Proceso y elementos para la resolución de problemas. Fuente:

Elaboración Propia basado en Domínguez [Domínguez p.50] 


\subsubsection{Situaciones del sistema: Problemática definida o no definida}

Cuando un sistema se encuentra frente a un problema, pueden producirse dos situaciones que llevarán a una actuación distinta según sea un caso u otro. La primera situación es que la problemática esté definida, y por tanto se conozca cual es el problema, y la segunda situación es que esa problemática no se conozca o no esté definida, con lo que habrá que averiguar cual es el verdadero problema.

\section{La problemática está definida (se tiene el modelo "To be")}

Cuando un sistema tiene un problema conocido y definido, y se sabe claramente la solución a la que se quiere llegar, la forma de actuar del resolutor de problemas será a través de un proceso de Reingeniería, la cual tratará de conseguir un nuevo estatus para el sistema (también denominado Modelo To Be).

Dicha Reingeniería supone poner en marcha un ciclo de vida para el proceso de construcción de un nuevo sistema, lo que según se ha explicado en el presente capítulo, supondrá llevar a cabo una serie de etapas encadenadas que se coordinan en pro de conseguir la construcción de ese nuevo sistema. (Modelo To Be)

Por lo tanto, ante un problema conocido, un sistema seguirá las siguientes etapas para su resolución, como se puede observar en la Ilustración 3. 4,

- Estudio de las especificaciones del nuevo sistema y elaboración del plan de actuación (planificación del sistema),

- Definición de los requisitos (análisis),

- Diseño

- Implementación: construcción y puesta en marcha 
- Mantenimiento y revisión

- Desmantelación del sistema anterior.

En la que dichas etapas se suceden desde arriba hacia abajo en cascada, denominando a este proceso Reingeniería

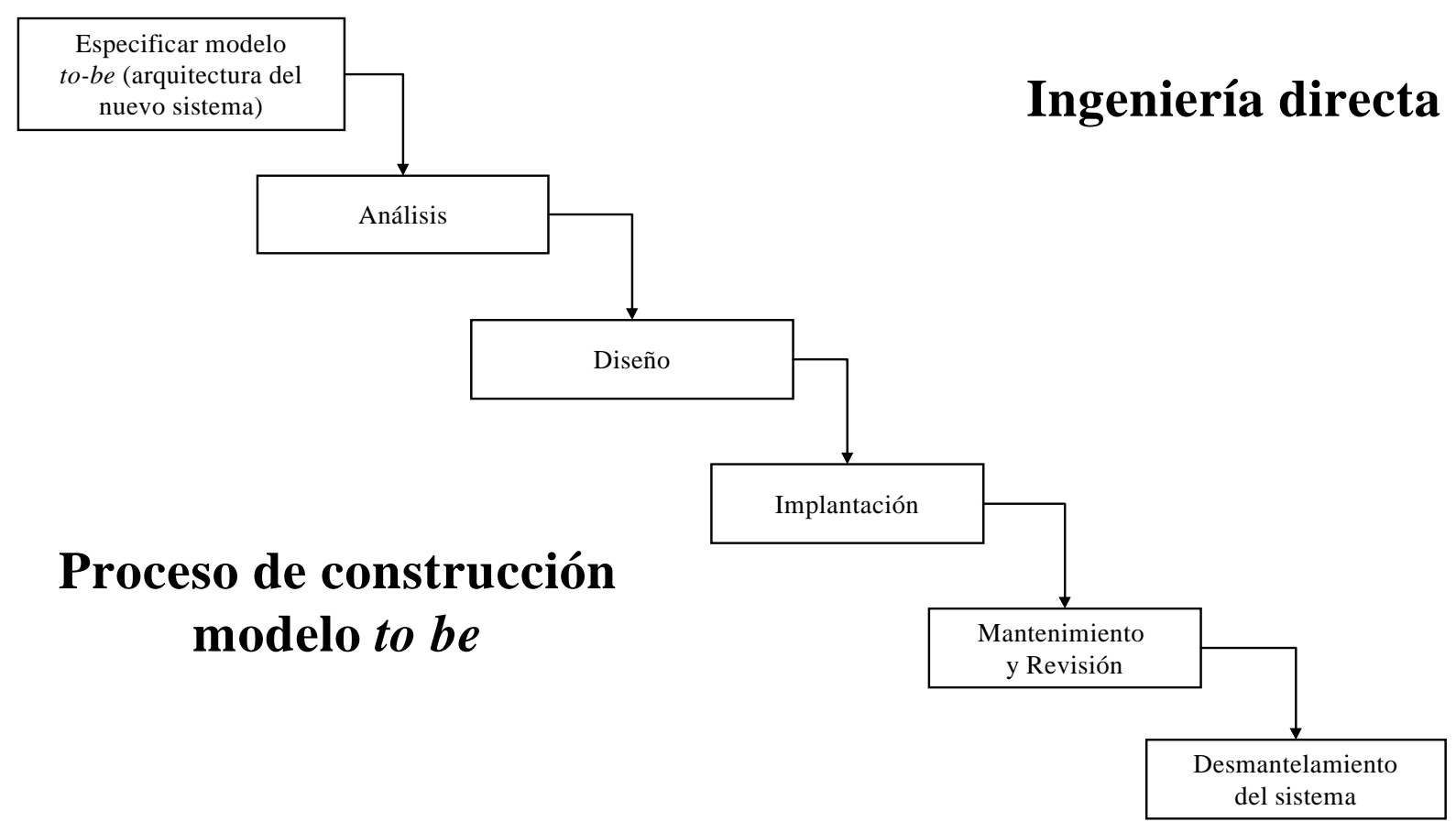

Ilustración 3. 4: Proceso de construcción de un proyecto. Modelo To be. Fuente: Basado en Ortiz [Ortiz98 p.285]

La definición de Reingeniería la proporciona M. Hammer ${ }^{3}$ y recogida por J.A. Pérez Fernández de Velasco [Pérez1996 p. 250] como "la revisión fundamental del negocio y el rediseño radical de sus procesos para alcanzar mejoras espectaculares en medidas críticas y contemporáneas de rendimiento, tales como costes, calidad, servicio y rapidez." El autor, señala a su vez que la reingeniería es un objetivo "per se" y sin límites, por lo que se habla de "Reingeniería puntual".

${ }^{3}$ M. Hammer "Reenginering the Corporation" (Harper Bussiness, Nueva York 1993 
Otra definición completa la da J. Arenas [Arenas] como" técnica para efectuar cambios radicales en la manera en que una organización define sus objetivos, realiza su trabajo y satisface las necesidades de sus clientes. Enfatiza el logro de mejoras espectaculares en los resultados (medidos en términos de costo, tiempo de ciclo, calidad y servicio al cliente) mediante el análisis fundamental y el cambio radical del sistema completo (procesos de trabajo, definición de cargos, estructura organizacional, sistemas de medición y administración, y valores y creencias). Con la Reingeniería, la organización ya no se ve en términos de funciones, divisiones o productos, sino más bien en términos de procesos clave de negocios que satisfacen las necesidades del cliente."

Este proceso de Reingeniería, se aplica también a los Recursos Humanos, ya que a su vez Gómez-Mejía et al [GómezMejía2001 p. 61] citan a Hammer y Champy y su libro, en el ejemplo que "una empresa se encuentre ante un problema de excesivos niveles de dirección y quiera eliminarlos, que se estaría ante un proceso de reingeniería. Para ello, hay que replantearse la empresa, realizar un nuevo diseño radical de los procesos empresariales para lograr mejoras en considerables en costes, calidad, servicio y velocidad... La reingeniería utiliza el análisis de los flujos de trabajo para identificar las tareas que pueden eliminarse o combinarse con otras para mejorar el rendimiento de la empresa”.

Dichos autores [GómezMejía2001 p. 61], citan a su vez a S. Greengard ${ }^{4}$ y J. Verity ${ }^{5}$ para los que "la reingeniería analiza la forma en que la empresa lleva a cabo sus actividades, prestando una atención minuciosa a los procesos centrales implicados en la producción de productos o entrega de servicios, aprovechando la tecnología informática y las distintas maneras de organizar los recursos humanos, con lo que la empresa puede ser capaz de volver a inventarse a si misma.”

Por tanto, ante situaciones donde se conoce el problema que se está produciendo y a su vez se conoce a donde se quiere llegar, se han de llevar a cabo proyectos de reingeniería, para lograr esa solución.

${ }^{4}$ S. Greengard (1993 diciembre. Reenginering: out of the rubble. Personal Journal 48B-48O 
Cuando no se conoce la problemática (No se tiene el Modelo As Is)

La otra situación de un problema en un sistema se produce cuando no se tiene identificado y se desconoce cual es el realmente problema existente.

En este caso, lo primero que hay que cuestionarse, es la identificación del problema. Para lograr identificar cual es el verdadero problema, habrá que prestar atención tanto a los síntomas que se generan, como al funcionamiento del sistema.

Para C. Gutierrez [Gutiérrez], aunque sea desde la óptica muy distinta del humanismo, aporta unas definiciones tales que "la Ingeniería Directa es un arte constructor que va desde un conjunto de planos de construcción, mediante un proceso tecnológico, hasta un producto terminado. Ese producto puede ser un edificio, un barco u otra clase de vehículo, o un mecanismo de distintos grados de complejidad, por ejemplo una computadora (en el caso del ingeniero electrónico). Pero es posible también para un ingeniero trabajar "al revés": comenzar por la observación de un artefacto cualquiera (que él no haya construido y cuyos planos no estén disponibles) y tratar de llegar a una posible definición de esos planos constructivos, lo que sería la Ingeniería Inversa."

Por tanto, para poder descubrir el problema y lograr su definición, habrá que realizar un proceso de Ingeniería Inversa y así lograr abstraer cómo está el sistema (modelo AS IS). Dicha Ingeniería Inversa supone recorrer una serie de etapas en sentido descendente de la Ilustración 3. 5, lo que se asemeja a la realización de Ingeniería Directa pero en el sentido inverso.

De ese modo, se conseguirá abstraer cual es el problema existente, y a través de:

- La identificación el problema

${ }^{5}$ J. Verity (1993 junio.Getting work to go with the flow. Business Week 156-61 
- Conceptualización del problema,

- Descripción del sistema- problema

- Especificar el diseño del sistema- problema,

- Llegando así a la situación de conocimiento del sistema actual y el problema (Modelo AS IS)

- Conocimiento de a donde se quiere llegar (Modelo TO BE)

lo que nos situará en el punto de partida del apartado anterior, es decir, en la resolución de problema conocido, para lo que habrá que aplicar lo expuesto en ese apartado. La representación gráfica de estas etapas de Ingeniería Inversa puede observarse en la Ilustración 3. 5.

\section{Ingeniería inversa}

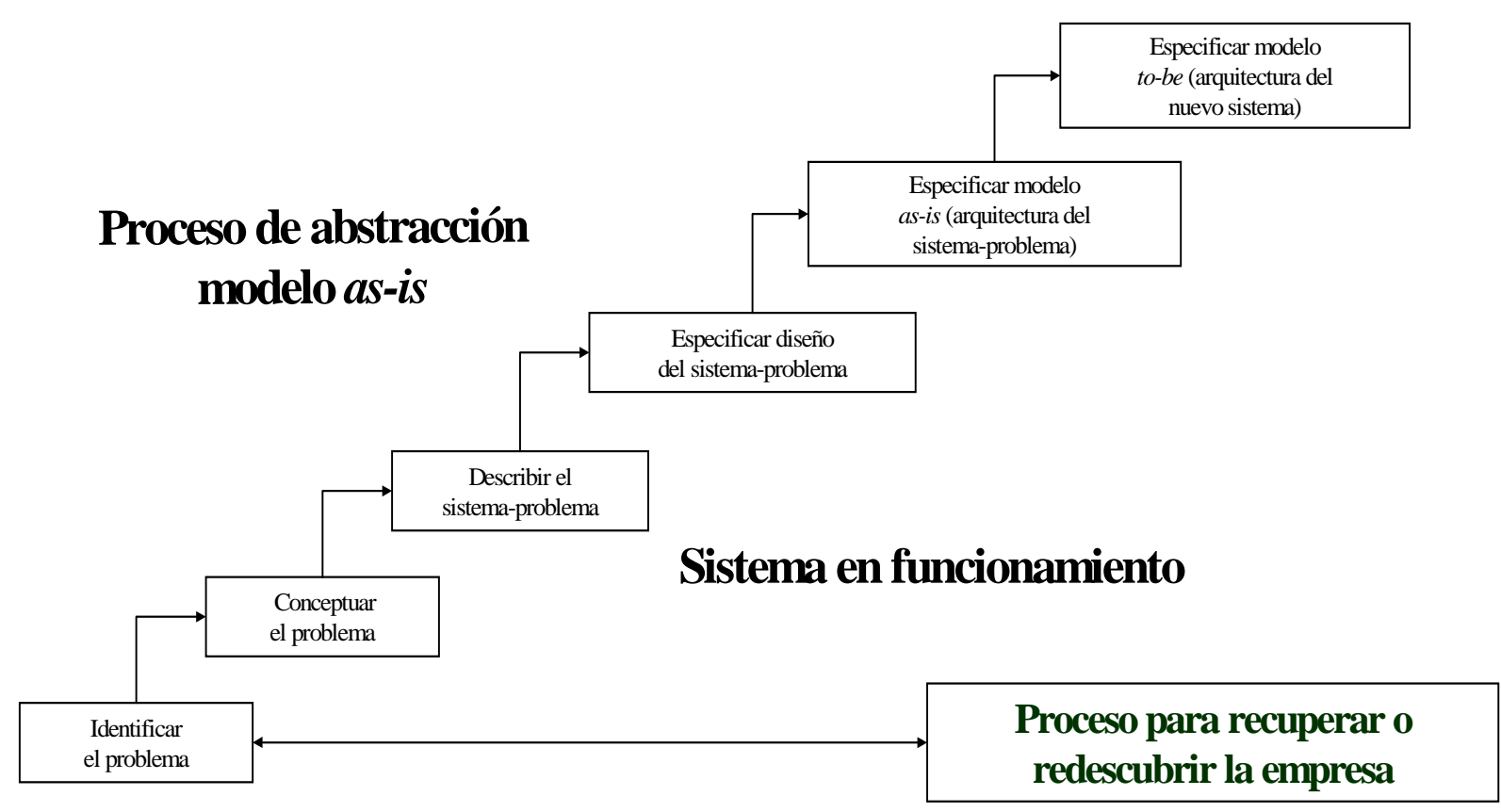

Ilustración 3. 5: Proceso de Abstracción del modelo As- Is. Fuente: Elaboración Propia 


\subsubsection{Ciclos de vida inversos (desde el modelo "as is") (definición del "as is")}

Si en el apartado anterior se recomienda hacer Ingeniería inversa en el caso de que no se conozca realmente el problema que se está produciendo en un sistema, con ese procedimiento de se conseguiría recuperar el valor de los componentes participantes en el proceso, que serán información, productos, servicios o una combinación de todos ellos.

La realización de un proceso completo tanto de Ingeniería Inversa como Directa, puede contemplarse en la Ilustración 3. 6, en la que se observa como a partir de un proceso de creación de un sistema mediante Ingeniería Directa, puede retrocederse de forma que se vaya abstrayendo el porque del sistema- problema hasta llegar a la verdadera identificación del problema, lo que ayudará a su vez a redescubrir la empresa.

Con todo ello se consigue saber si se ha logrado cumplir con objetivos y los estándares fijados, tanto por el sistema como por el entorno. Si no se han logrado dichos niveles propuestos, habrá por lo tanto que realizar la mejora de procesos en el sistema mediante un proceso de Reingeniería, que suponga retocar los procesos existentes una vez conocidos cuales son los problemas y las propuestas de soluciones.

A todo el proceso completo de abstracción e Ingeniería Inversa y Regingeniería, se le denomina, Ciclo de vida Extendido, y se muestra en la Ilustración 3. 6. 


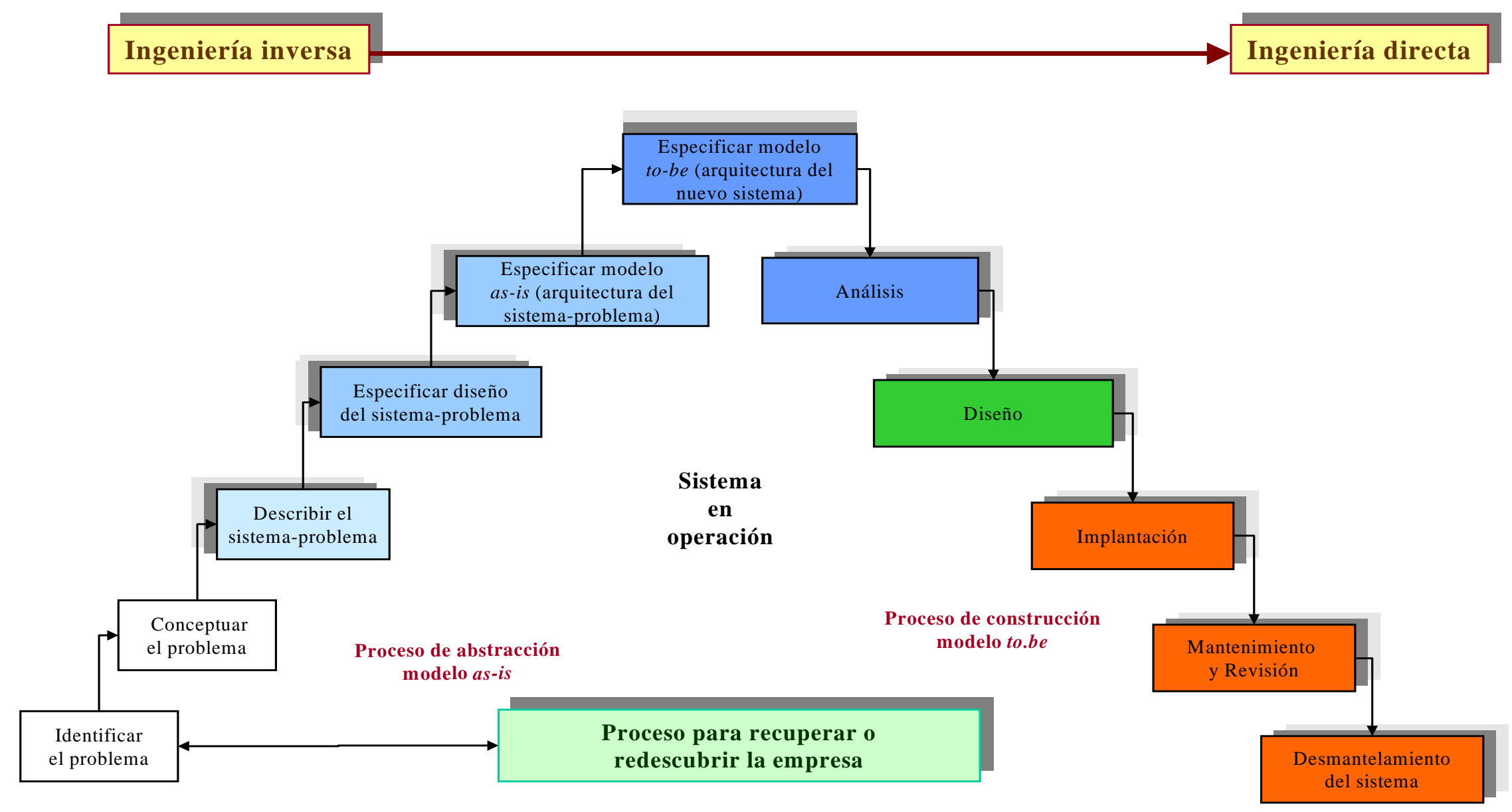

Ilustración 3. 6: Ciclo de vida extendido. Fuente: Elaboración Propia 


\subsection{CONCLUSIONES DEL CAPÍTULO}

Partiendo de las etapas de las que estaban compuestas las arquitecturas de integración presentadas en el punto 1.4 del primer capítulo, se realiza en este una aproximación a las mismas desde la Metodología de IE-GIP de la Universidad Politécnica de Valencia. A partir de este enfoque se describen en el apartado 3.2 lo que son los sistemas, para pasar en el 3.3 a describir las etapas de la propuesta IE-GIP y elaborar un ciclo de vida propio válido para cualquier sistema.

Las etapas que componen el ciclo de vida propuesto parten de la planificación, que se constituye como primera etapa y supone conocer cuales son las necesidades y prioridades del sistema, a través de un estudio de viabilidad o un análisis coste -beneficio. Conocidas las necesidades del sistema y el plan de trabajo hay que decidir que se va a hacer, como y cuando, lo que se decidirá en la etapa de Análisis, a partir de la etapa de Diseño, se diseñará un nuevo sistema basándose en los requisitos solicitados, para a continuación en la etapa de Implementación tomar el diseño e instalarlo. Por último hay que mantener y revisar las posibles modificaciones del sistema y finamente hay tener presente si los sistemas hay que eliminarlos en la etapa de Desmantelación si éstos han quedado obsoletos. Pueden encontrarse autores que denominen del mismo modo a las mismas etapas, e incluso autores que incluyan a unas en otras, por ello se propone este modelo como referencia en este trabajo.

Una vez conocido el ciclo de vida para un sistema, se ha centrado el estudio en el apartado 3.4 en el ciclo de vida existente para el Elemento Empresarial Personal (denominado también en las organizaciones actuales como Recursos Humanos, como se explicará en el siguiente capítulo). Para ello se han descrito las etapas por las que pasan los Recursos Humanos en las empresas, realizando una comparativa de éstas con las del ciclo de vida genérico a la vez que se han comparado varios autores que las reflejan, quedando por tanto las etapas del ciclo de vida de personal como: planificación de plantillas, análisis, descripción y valoración de puestos, búsqueda y selección de personal, formación de 
personas en la organización y evaluación de personal. Se ha tomado este elemento para su estudio y posterior propuesta de un modelo, para lo que se realizará en el capítulo cuarto una aproximación a los Recursos Humanos y su función en las empresas.

El capítulo avanza para en el apartado 3.5 describir las propiedades de las etapas del ciclo de vida, ya que sobre la base de su independencia funcional, han de basarse en la cohesión como medida de la fuerza entre ellas y el acoplamiento como número de conexiones existentes. Finalmente, en el apartado 3.6 realiza una disertación de lo que son problemas o síntomas, y cómo éstos afectan los problemas a los ciclos de vida. Distinguiendo primero que hacer en el caso de que surja un problema, ya que la operativa ha de ser diferente si el problema es conocido, donde habrá que generar un nuevo sistema a través de una ingeniería directa o reingeniería, o bien donde el problema no es conocido para lo que hay que realizar un proceso de ingeniería inversa y poder así detectar cual el verdaderamente el problema y realizar a continuación el proceso de reingeniería una vez conocido y detectado cual era el problema.

\subsection{REFERENCIAS BIBLIOGRÁFICAS}

Arenas

Decenzo2001

DeRosnay

Domínguez

Dolan99

Dessler2001

Gan95

Gil97
Arenas Herrera, J. "Glosario de Reingeniería" http://www.alfinal.com/consultor/management/reingenieriaglosario.sht ml Consultada el 12/08/2002

DeCenzo D.A., S.P. Robins. "Administración de Recursos Humanos” Editorial Limusa S.A. de C.V. México. 2001

De Rosnay J. "The macroscope, a new world scientific system" Web Edition, Principa Cibernetica Web Project. http://pespmc1.vub.ac.be/macroscope/chap2.html Consultada en septiembre de 2002

Domínguez Torres, A. Cambio y conocimiento en los sistemas. Editorial Galileo. México 2000.

Dolan S., R. S. Schuler, R. Valle. "La Gestión de los Recursos Humanos” Mc Graw Hill. España 1999

Dessler G. “Administración del Personal” Octava Edición. Prentice Hall. México. 2001

Gan F., B. Alonso, E. De Francisco, S. Puyol. "Manual de técnicas e instrumentos de Formación en la empresa” Editorial Apóstrofe. España 1995

Gil I., L. Ruiz, j. Ruiz. "La Nueva dirección de Personas en la 
Empresa” Mc Graw Hill. España 1997.

GómezMejía200 Gómez Mejía L. R., D. B. Balkin, R. L. Candy. "Dirección y Gestión de 1 Recursos Humanos”. Editorial Prentice Hall. Tercera Edición. España

González 2001.

González, C. "Systems development life cycle". www.andrew.cmu.edu/user/conzalez/Teaching/ISW1/Lifecycle.html. Consultada 15/02/2001

Gutiérrez Gutiérrez C. "Ensayos sobre el nuevo humanismo" http://cariari.ucr.ac.cr/ claudiog/El_genoma_25.html Consultada el $14 / 08 / 2002$

Hammer Hammer M. y J. Champy " http://www.issa.int/span/domact/om/reengin.htm

Maryland Maryland Department Budget \& Management. Structured systems development life-cycle methodology Apendix A. www.dbm.state.md.us/mdplan/apdx-a.htm Consultada 15/02/2001

Ortiz98

Ortiz, A. "Propuesta para el desarrollo de programas de integración empresarial en empresas industriales. Aplicación a una empresa del sector cerámico." Tesis Doctoral. Universidad Politécnica de Valencia. Departamento de Organización de Empresas. Valencia. España. 1998.

Pennsylvania Pennsylvania State University. Stages of the Systems Life Cycle. www.ist.psu.edu/courses/110_content/topic_10/lesson_04/10_04_02.ht ml. Consultada el 27/02/2001

Pérez1996 Pérez Fernández de Velasco, J.A. "Gestión de Procesos. Reingeniería y mejora de los procesos de empresa." Editorial ESIC (Escuela Superior de Gestión Comercial y Marketing) España. 1996

Rodríguez Rodríguez Cuadrado A., A. Márquez Serrano. Técnicas de Organización y Análisis de Sistemas. Organización de los servicios informáticos. Mc Graw Hill. España 1993

Sundaresan Sundaresan, S. Information systems processing and design. Systems development life cycle.

http://www2.smeal.psu.edu/courses/mis430.sundaresan/protected/notes/ sdlc_ho.pdf Consultada el 21/02/2001

Thistle Thistle, D.A. Systems development life cycle- SDLC. http://cs104cs.uwinsor.ca/develop.htm Consultada el 22/02/2001 


\section{Capítulo 4.}

\section{Los Recursos Humanos en}

la empresa 
CAPITULO 4

\section{LOS RECURSOS HUMANOS EN LA EMPRESA}

\subsection{INTRODUCCIÓN}

Una vez presentados en el segundo capítulo los elementos empresariales, y justificada la importancia del factor humano, correspondiente al elemento "Personal" tanto en las aportaciones expuestas en el punto 1.5 de este trabajo, como en las etapas analizadas en el punto 3.3 por las cuales evoluciona el personal en una empresa, en el presente capitulo se justificará la importancia que tiene este elemento empresarial en las organizaciones.

En este capitulo se comenzará analizando en el apartado 4.2 a las empresas como sistemas, con sus departamentos como subsistemas y compuestas de personal, al cual hay que dotar de estructura. Dichas estructuras pueden ser de carácter informal o formal, pudiendo a su vez subclasificarse en otros tipos. La importancia de dicha estructuración se debe a que es en base a ésta sobre la cual se realiza la división del trabajo, por ello se destaca la importancia de los Departamentos de Recursos Humanos en las empresas, debido a que aportan y realizan una 
serie de tareas orientadas a facilitar el funcionamiento empresarial y la gestión del personal dentro de la organización.

Para ello las empresas han de plantearse cual es su estructura y situación, y como pueden mejorar su capacidad en su evolución empresarial, para lo que este capítulo propone como modelo a utilizar el Modelo de Capacitación de Madurez, en el cual través de la mejora en las tareas desarrolladas por la organización se va mejorando de nivel: desde un nivel inicial, pasando al de repetición, definición, dirección y finalmente nivel óptimo, obteniendo así un mayor nivel en las tareas, en la capacidad, en la motivación y en la preparación de los trabajadores de la organización.

\subsection{LA EMPRESA COMO SISTEMA Y EL PERSONAL}

Como punto de partida, se toma la definición de sistema proporcionada en el apartado 3.1 de este trabajo, donde se definió como un "conjunto de elementos que se organizan o interactúan para cumplir objetivos, metas o un propósito específico propuesto” aportada por De Rosnay [DeRosnay] y reflejada por Domínguez [Domínguez2000 p.13]. Dicha definición también puede aplicarse a una empresa, donde se supone un conjunto de elementos, ya definidos en el punto 2.2, que se organizan o interactúan para cumplir los objetivos, metas o propósitos por los que se creó la empresa.

Werther y Davis [Werther p. 17] proponen un modelo para la administración de Personal, basado en el modelo de sistemas, donde "las actividades están interrelacionadas formando un sistema con elementos que interactúan, pero con límites claros y precisos. Para lo hay que limitar las actividades inicialmente, lo que supondrá un punto de principio al entorno externo, muy importante por ser sistemas abiertos, y por tanto se verán afectados por dicho entorno.

Partiendo de dicha definición de sistema, pueden encontrarse autores como Huse y Bowditch [ informal. La organización formal se establece con arreglo a las políticas, reglas, procedimientos prescritos, etc. presentándose mediante organigrama, que supone la estructura o armazón oficialmente prescrito por la organización como sistema formal". 
Por lo tanto, para conseguir los objetivos, metas o propósitos, la empresa ha de estar organizada. Por ello J.I. Elorduy [Elorduy p. 105] señala que una empresa es una organización compleja formada por personas. Sus objetivos no pueden ser alcanzados por una sola persona, lo que obliga a establecer una división y especialización de trabajos y trabajadores. Esta división y especialización es lo que da origen a la estructura interna y reparto de tareas dentro del proceso de negocio.

La estructura de la empresa se distribuye en funciones y responsabilidades entre los diferentes departamentos, unidades o personas que integran la organización. No sólo es necesario que a partir de la estrategia se diseñe una estrategia coherente, sino que aun es más importante que con la estructura diseñada se puedan alcanzar los resultados estratégicos esperados. Es similar pero completamente distinto, ya que la primera es condición necesaria y la segunda condición suficiente.

A su vez, Gil et al. [Gil] señalan que en el diseño de la estructura han de considerarse dos componentes: el técnico y el humano. El técnico ha de establecer las técnicas y operatividad para facilitar la aplicación de estrategias, flujo de trabajo, control, factibilidad de tareas y medición. Mientras que el humano ha de conseguir el ajuste de las personas, organizar el poder entre grupos, compatibilizar los valores y creencias de las personas con la organización y definir un estilo de dirección.

De ahí surgen la estructura formal y la informal. Para Elorduy [Elorduy p.105] la estructura formal corresponde a la distribución de funciones comunicada y establecida por la dirección entre las diferentes unidades y personas que componen la empresa. Mientras que la estructura informal corresponde a las tareas y relaciones que se desarrollan y mantiene y no están definidas por la dirección de la empresa, siendo necesaria para conseguir un funcionamiento adecuado. Hay incluso quien la define como "lubricante de la estructura informal”.

Los distintos tipos de estructuras formales pueden venir clasificados según se expone a continuación y se muestra en la Tabla 4.1:

El tipo funcional agrupa las actividades entorno a las funciones típicas que tienen lugar en la empresa: producción, comercial, administración, finanzas, etc. Este tipo de agrupación es el 
más utilizado tradicionalmente, encontrándose en cualquier estructura organizativa, por lo que el criterio utilizado es el de la especialización en funciones o conocimiento.

El tipo de Territorialidad se basa en la ubicación geográfica, agrupándose en función de las zonas geográficas donde desarrollen esta actividad. Esta estructura tiene un gran atractivo para grandes empresas cuyas actividades estén muy dispersas físicamente.

El tipo Divisional se basa en unidades operativas de negocio. Es la forma que cobra una mayor importancia. Cuando las empresas comienzan a diversificarse, consiste en agrupar las actividades en función de los productos o líneas de productos realizados por la empresa. Se dice que es el paso lógico de una estructura funcional cuando la empresa se diversifica.

El tipo Matricial supone dos criterios habituales, la zona geográfica y la división. El tipo Híbrido supone una mezcla de criterios, pudiendo combinar las unidades de negocio de las divisiones con las áreas funcionales.

Un resumen de todos estos tipos puede observarse en la Tabla 4. 1:

\section{Tipos básicos de estructuras formales}

\begin{tabular}{ll}
\hline Funcional & Criterio de especialidad funcional y conocimiento \\
Territorialidad & Zona de ubicación geográfica \\
Divisional & Unidad de operativa de negocio \\
Matricial & Dos criterios, habitualmente se unen zona geográfica y división. \\
Híbrida & Mezcla de criterios, pudiendo combinar Unidades de negocio con \\
& Areas funcionales. \\
\hline
\end{tabular}

Tabla 4. 1: Tipos básicos de estructuras formales. Fuente: Elorduy [Elorduy]

Huse y Bowditch [Huse] citan a Koontz y O’Donnell ${ }^{6}$ para señalar que la estructura de una organización no implica sólo el armazón departamental; sino también los procedimientos para asignar actividades formales a las unidades departamentales. La organización informal se

${ }^{6}$ Koontz y O’Donnell “Principles of Management: An Analysis of Managerial functions".Ed. McGraw Hill 4ª 1968 
desarrolla a partir de los modos en que los empleados en todos los niveles de la organización interactúan y trabajan uno con otro. Muchas de éstas interacciones no están prescritas por la organización y son de un carácter mucho más formal.

El concepto de estructura formal e informal está implícito en las tres perspectivas que plantean los autores, ya que tanto la perspectiva formal como la informal existen simultáneamente en la organización dentro de cada perspectiva y cada perspectiva representa un modo distinto de contemplar la organización como sistema.

Las perspectivas propuestas por Huse y Bowditch [use p.45 y ss.] son:

A. Perspectiva Estructural: en ella se subraya la estructura formal y las líneas predeterminadas de autoridad y responsabilidad. En ella el sistema es vertical, como por ejemplo: el departamento de marketing, el departamento de fabricación, el departamento de finanzas y contabilidad, la organización en su conjunto.

B. Perspectiva del Flujo de Trabajo: es esencialmente horizontal, ya que se centra en los modos mediante los que el trabajo fluye a través de la organización. A medida que las organizaciones continúan aumentando en tamaño y complejidad, y los límites entre ellas y su entorno exterior se hacen más vagos y difusos, a medida que aumenta la diversidad de productos e importancia de los ordenadores y el sistema de información de gestión, se debe prestar una atención mayor al modo de trabajo de la organización.

Los autores citan a J. W. Forrester ${ }^{7}$ en su libro Industrial Dynamics quién señala que existen por lo menos cinco subsistemas interactuantes conectados entre sí principalmente por flujos de información y por una red de toma de decisiones, que es necesario considerar en el proceso de flujo de trabajo.

1. Flujo de información: Corriente de ideas e información desde y hacia el entorno, que influye en decisiones presentes y futuras.

${ }^{7}$ J. W. Forrester "ndustrial Dynamics" (editado por MIT Press. Cambridge. Massachusetts. 1968 
2. Flujo de materiales: Proceso del input de materias primas procedentes del exterior, de la transformación y del output, además de comprender áreas organizacionales como compras, fabricación, contabilidad y finanzas.

3. Flujo de dinero: subsistema relacionado con la circulación del dinero y abarca todos los departamentos.

4. Flujo de pedidos: seguimiento del papeleo de pedidos desde que entra en la organización hasta que sale, mediante albaranes, ordenes de expedición, conocimiento del estado en almacén, embarques...

5. Fuentes y empleos de medios de producción: proceso para determinar si se necesitan dichos medios de producción, el pedido y compra, así como su uso.

C. Perspectiva Humana: centrada en los seres humanos y los modos en que éstos interactúan.

El individuo con sus motivos, necesidades y deseos. Puede considerarse como un subsistema propio o como parte de un subsistema más grande.

El grupo: está en un nivel de complejidad más alto que el individuo. Facilita la actuación de los individuos y con impacto en la organización.

La organización: sistema humano total, compuesto de subsistemas de individuos y grupos, cada uno de los cuales afecta al otro y a la organización.

De lo que se trata es de comprender la organización y ayudar a su eficacia considerando las tres perspectivas. 


\section{Contenido de la organización}

Manuel Peña Baztán [Peña] señala como: "la división del trabajo se realiza en tareas y funciones, lo que ayudará a concebir y estudiar la estructura de la organización. La división horizontal: se suele dividir en departamentos como producción, administración, ventas, logística, personal, etc., cada uno con sus subdivisiones correspondientes y en cada una de ellas las tareas y funciones concretas y delimitadas.

Por otro lado para definir la división vertical Peña Baztán [Peña] acude a Simon $^{8}$, quien se orienta hacia:

- Lograr y coordinar entre tipos especializados de trabajo

- Influir y adiestrar para la toma de responsabilidades

- Establecer autoridad necesaria para la asunción de responsabilidades.

Ambas divisiones generan actividades horizontales y verticales que aseguran que los distintos objetivos estén coordinados y dirigidos hacia un objetivo final, que dependerá del objetivo general de la empresa.

\subsubsection{Bases de la empresa}

Manuel Peña Baztán recoge en su libro Dirección de Personal, los postulados de la National Industrial Conference Board (Studies in Personnel Policy. Número 139 de 1953). Dichos postulados determinan una validez general a efectos organizativos, es decir, que son aplicables a cualquier tipo de estructura empresarial y se detallan en la Tabla 4. 2:

\footnotetext{
8 Simon "Administrational Behaviour". The McMillan Company. Nueva York 1959
} 


\section{Postulados en Políticas de Personal}

1. Deben existir líneas definidas de autoridad, desde los niveles más altos a los más bajos.

2. Nadie en la organización debe depender de más de un supervisor de línea. Todo el mundo debe saber a quién debe informar y de quién debe recibir información y directrices.

3. La responsabilidad de cada mando, así como la autoridad, deben definirse por escrito

4. La responsabilidad debe ir siempre unida a la correspondiente autoridad

5. La responsabilidad de los mandos por actos de los que ellos dependen es absoluta

6. La autoridad debe delegarse hasta donde sea posible.

7. El número de niveles de autoridad debe establecerse en cantidades necesarias pero no mínimas

8. El trabajo de cada persona en la organización debe limitarse hasta donde sea posible, a la ejecución de una sola función capital.

9. Siempre que sea posible, las funciones de línea deben separarse de las funciones de asesoramiento, debiendo señalar claramente las que corresponden a cada punto.

10. Existe un límite en el número de posiciones o puestos que pueden coordinarse por un solo ejecutivo o mando.

11. La organización debe ser lo suficientemente flexible para que pueda ajustarse sin dificultad a los cambios que puedan producirse

12. La organización debe concebirse y mantenerse tan sencilla como sea posible.

Tabla 4. 2: Postulados en Política de Personal de la National Industrial Conference

Board. Fuente: Peña [Peña]

Este conjunto de reglas se compendia perfectamente con los requisitos a tener en cuenta a la hora de preparar el esquema de cualquier tipo de estructura organizativa. 
La atribución de funciones concretas, el establecimiento de cauces de información y comunicación, la delimitación de niveles jerárquicos, entre otros, son postulados que desde el elemento empresarial: Personal se pueden y se deben aplicar, porque facilitan el desarrollo de la administración y conducción de los empleados. En una empresa mediana es difícil dar misión al director si la estructura de la empresa carece de los principios básicos.

\subsection{LA FUNCIÓN DEL PERSONAL (RECURSOS HUMANOS)}

En un sentido amplio como destacan Albizu y Landeta [Albizu p.19] la función de Recursos Humanos contempla el conjunto de actividades orientadas a canalizar las relaciones que se generan entre una organización y los individuos que la integran, constituyéndose en el eje de la actividad organizativa.

En particular, estos autores se basan en la definición de Weiss para la Función de Recursos Humanos como: "área de gestión empresarial responsable de las decisiones y acciones que afectan a la relación entre la empresa y los trabajadores que prestan sus servicios en ella, adoptadas para la consecución de los objetivos empresariales”. Por tanto, dicha función empresarial existe desde el mismo momento en que la actividad empresarial genera una relación laboral entre la empresa y una o más personas, independientemente de las características de la empresa (tamaño, situación mercantil, actividad que desarrolla, etc.) y de la relación establecida (tipo de contratación, duración de la prestación, remuneración, etc.)

El desarrollo de la función de los Recursos Humanos no tiene lugar de forma homogénea en el conjunto del tejido empresarial, sino que se circunscribe, principalmente, a las grandes empresas debido a que la actividad empresarial es sustancialmente mayor que en las pequeñas y medianas empresas.

La finalidad principal que destacan Albizu y Landeta [ $\underline{\text { Albizu }}$ p.20] es proporcionar a la organización la capacidad laboral necesaria, tanto cuantitativa como cualitativamente, en el momento oportuno y bajo el principio de economicidad. Por ello la dirección de Recursos Humanos debe tomar las decisiones pertinentes para obtener, desarrollar, evaluar, utilizar, 
retener o prescindir de los perfiles y cantidades correctos de trabajadores, a fin de conseguir tanto la eficiencia económica como social. Este doble objetivo hace a la empresa asumir responsabilidades sobre la motivación, comunicación y participación de las personas de la empresa, el cambio social y la gestión cultural, de forma que la organización cuente con el grupo humano necesario en cuanto a capacidades, conocimiento y actitudes, lo que lleva a que las personas de la organización sepan, aporten y evolucionen en el sentido que necesita la organización, el cual debe ser compatible con sus propios intereses.

La dirección de los Recursos Humanos desarrollará su actividad general guiada por s objetivos básicos que se pueden resumir en:

Eficiencia económica: implica el mejor cumplimiento de los programas de rendimiento material de una empresa por las aportaciones de los operarios sobre la base de la productividad del trabajo, la economicidad, la calidad, y la flexibilidad y adaptabilidad para contribuir de manera continua a la eficacia y eficiencia de la organización.

> Eficiencia social: mejora en el grado de satisfacción de las expectativas, necesidades e intereses de las personas en la organización, lo que repercutirá en el compromiso e identificación de los empleados con su organización

Integración: hace referencia a tres aspectos

- Necesidad de que las políticas y objetivos de Recursos Humanos sean congruentes con el resto de políticas de la empresa, es decir, que la capacidad laboral que se pretenda conseguir se corresponda con lo que la organización necesita para desarrollar sus estrategias y objetivos generales.

- La necesidad de alcanzar la debida congruencia de las diferentes políticas y objetivos en Recursos Humanos entre sí

- La búsqueda conjunta de la eficacia económica y de eficacia social, la integración de los fines de la organización y de sus trabajadores. 
El éxito de una empresa ha de trabajarse a través del desarrollo de sus profesionales y trabajadores. El grado de madurez de una organización marca la prioridad de ésta en los trabajos que realizan sus trabajadores. Pero a su vez, la función de los Recursos Humanos trata de desarrollar a sus profesionales de forma que la evolución de los mismos, colabore en el desarrollo de la empresa.

Los Recursos Humanos de las empresas realizan una serie contribuciones muy importantes a las funciones estratégicas empresariales, pasando así de una gestión del personal a una gestión de los Recursos Humanos. Estas contribuciones realizadas por los Recursos Humanos son:

1. Administración del Personal

2. Relaciones Laborales

\section{Selección}

\section{Formación}

\section{Desarrollo}

\section{Seguridad y Salud}

Por tanto, se dice que la función de Recursos Humanos ha venido sufriendo una evolución desde los años ochenta, debido a que hasta entonces lo más importante en las empresas eran los departamentos que suponían un área estratégica para la empresa, entendiéndose como tales los departamentos de finanzas, operaciones, etc. y quedando los Recursos Humanos en otro nivel. Pero en los últimos años se ha incrementado la importancia de este departamento debido a que los Recursos Humanos son quienes hacen funcionar realmente a la empresa, ya que desarrollan actividades estratégicas en la administración del personal, las relaciones laborales, la selección, formación y desarrollo del personal, la seguridad y salud y la integración plena en la estrategia general de la organización. Para 
ello se ha de crear una estrategia de Recursos Humanos congruente con la estrategia de negocio a seguir por la empresa.

En la estrategia de Recursos Humanos se debe tender a atraer al personal cualificado necesario, desarrollarlo en la empresa, para finalmente fidelizarlo. En la atracción del personal, la parte más importante la constituye la selección, siendo clave en este proceso el conocimiento de la realidad de la organización, y la estrategia de negocio para lo que hay que estudiar las necesidades a corto, medio y largo plazo, y actuar para cubrir las necesidades en esos plazos. Esto se ha de tener presente a la hora de realizar la selección debido a los errores que se producen al incorporar personal, seleccionarlo y sobre todo los errores que causa la falta de definición en las necesidades de la empresa o definición del perfil buscado.

Los costes en que incurren las organizaciones por realizar una inadecuada política de selección son los siguientes:

$>$ Coste económico: coste tanto de la realización de todo el proceso de selección como el coste de salida del personal en caso que haya que prescindir de alguna de las personas contratadas.

Coste Social: costes de oportunidad asociados a la perdida de imagen para la organización o bien al mal clima que puede llegar a generarse.

Costes de Organización: debido al impacto producido en la generación de los flujos en la empresa.

Rentabilidad: Con toda esta situación de error en la selección y contratación pueden generarse situaciones de lucro cesante.

Debido al alto coste que supone la necesidad de buscar las máximas garantías de personal tanto a corto como a largo plazo, las organizaciones tienden a realizar una selección por 
competencias. Para ello se orienta hacia el perfil buscado y se seleccionan los comportamientos que encajen en el mismo.

El siguiente paso será la formación, que debe generar siempre una mejora de resultados. Para proporcionar una formación adecuada al personal de una empresa, se han de detectar las necesidades operativas, la estrategia de la empresa, así como una adecuación de la persona al puesto. Una vez detectadas esas necesidades, habrá que realizar el Plan de Formación, dando estructura y procedimiento de la metodología que se seguirá y determinando quién proporcionará esa formación. A su vez se establecerá la forma de evaluar y como se realizará el control, para ello se verificará la cobertura de la necesidad, la asistencia a dicha formación, la calidad de quien la proporciona. Finalmente habrá que observar el impacto en los resultados: tanto en rentabilidad, en el análisis coste -beneficio y los modelos econométricos.

Dicha formación deberá resultar en un cambio para la organización. Dicho cambio ha de venir liderado desde la organización, que debe apoyar con los medios y la formación adecuada, así como disponer de las condiciones adecuadas para que los trabajadores entiendan la utilidad del mismo.

\subsection{MODELO DE CAPACITACIÓN DE LA MADUREZ}

Una vez presentada la importancia de la formación y el cambio en la organización, se propone como modelo de gestión de los Recursos Humanos, el Modelo de Capacitación de Madurez para el Personal. Dicho modelo (MCM) [PCMM] hace énfasis en el continúo desarrollo del activo humano dentro una organización, ejerciendo como guía de desarrollo de una organización cuyas costumbres, trabajos, y tareas mejoran de manera continuada la capacidad de sus trabajadores. Así, las organizaciones mejoran su capacidad atrayendo, desarrollando, motivando, organizando y reteniendo el talento necesario para incrementar su capacidad.

El Modelo de Capacitación de Madurez para el Personal (PMCM) es una herramienta práctica creada para mejorar la administración del personal en una organización, ya que suministra el marco correspondiente para motivar, reconocer, estandarizar y mejorar las tareas 
bien hechas en la empresa. Además enfatiza la necesidad de reconocer la importancia de los individuos como personas y desarrollar sus capacidades. Por tanto, este modelo es una guía para lograr mejoras en la capacidad de desempeño del personal en las organizaciones.

Por lo tanto, se pueden definir como objetivos estratégicos de este modelo:

- La Mejora de la capacidad de las organizaciones a través de la mejora en la capacidad de su fuerza laboral

- Asegurar que la capacidad de desarrollo empresarial, es un atributo de la organización más que de los propios individuos.

- Alinear la motivación de los individuos con la de la organización

- Retener al activo humano preparado dentro de la organización (Ej. Personal preparado y con conocimientos específicos)

\subsubsection{Los Niveles de Madurez}

El modelo de capacitación de madurez proporciona a las empresas unas líneas de actuación para la estabilización y mejora de las tareas a realizar por los trabajadores a través de cinco niveles de madurez.

Así partiendo de uno de los niveles del modelo, y mediante la institucionalización y generación de capacidades que logren mejorar el conocimiento y preparar a los trabajadores, a la vez que se consigue una mejora para toda la empresa, se asciende en el nivel de madurez a través de cambios en el desarrollo de las tareas y la mejora de la cultura empresarial.

Los cinco niveles de madurez existentes en este modelo son los que a continuación se detallan y se observan en la Ilustración 4.1: 


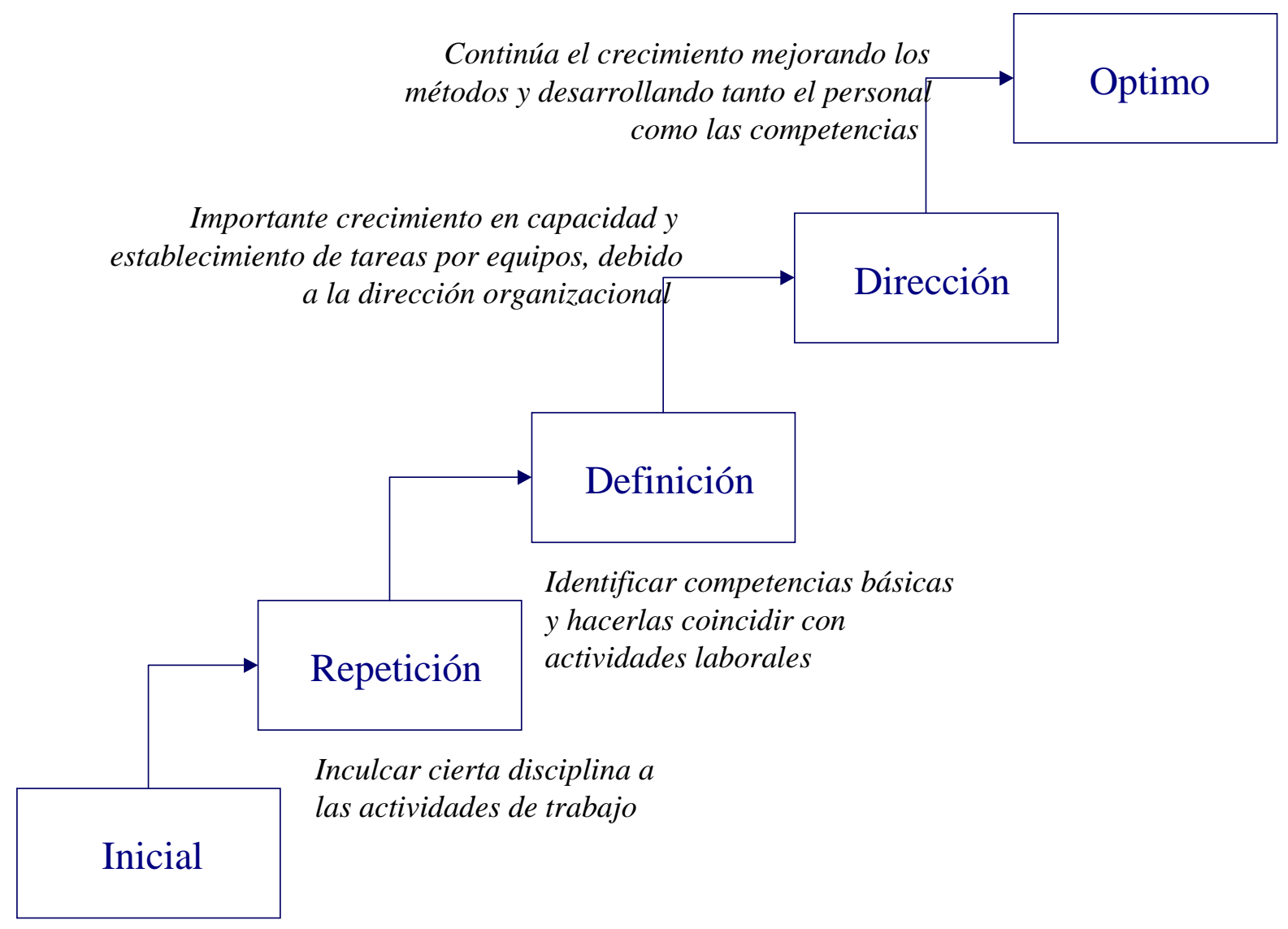

Ilustración 4. 1: Niveles de Madurez del Modelo de Capacitación de la Madurez

\subsubsection{Contenido de cada uno de los niveles}

\section{Nivel 1: Nivel Inicial}

Las tareas que se realizan los trabajadores en el nivel inicial son muy inconsistentes. Y las empresas apenas ofrecen guías de cómo han de realizarse dichas tareas. Así pues, este tipo de empresas no es excesivamente exigente con el trabajo de sus empleados, ya que tampoco tienen capacidad de desarrollar programas de mejora para las actividades que realizan.

Los directivos o mandos de este tipo de empresas, no están preparados para cumplir ciertas responsabilidades, y su dirección se produce casi siempre a través de otras experiencias anteriores. Suelen ser esos directivos quienes realizan las entrevistas y valoraciones a los candidatos, para lo cual no están preparados, por lo que resultarán decisiones pobres, falta de decisiones de promoción y por tanto, empleados descontentos. 
Se impondrán formas de realizar las tareas importadas de otras áreas, secciones o empresas, sin realizar antes ningún análisis de si conviene o no hacerlo.

Se desconoce la capacidad laboral de una empresa del Nivel 1, debido a que no se han hecho esfuerzos ni en medirla, ni mejorarla. El problema se percibe cuando la empresa siente que tras producir mejoras, el nivel de conocimiento y preparación disponible en la empresa no crece, debido en muchos casos a la gran rotación del personal existente y el conocimiento perdido del personal que va abandonando la empresa.

\section{Nivel 2: Nivel de Repetición}

Los objetivos principales del Nivel de Repetición supondrán fundamentalmente hacer que el personal cumpla con sus responsabilidades laborales de forma efectiva así como establecer actividades de mejora continua para el desarrollo de dicho personal. Los problemas que ocurren en este nivel, provienen de: distracciones medioambientales, objetivos no aclarados, falta de conocimiento o preparación, o escasez de comunicación.

Una empresa situada en el Nivel de Repetición, debe establecer las políticas que contribuyan a desarrollar su personal, siendo uno de los objetivos principales el establecimiento de responsabilidad y disciplina en la realización de tareas básicas. Éstas asegurarán que el personal de dicho departamento o sección tendrá el conocimiento y preparación para cumplir lo asignado. Conforme esas tareas se vayan institucionalizando en la empresa, se irán mejorando los métodos, prácticas y tareas.

Aquellos que tengan responsabilidades, deberán establecer que hay que hacer y como cumplirlo eficientemente. Si lo consiguen, se estará aceptando el crecimiento y desarrollo como responsabilidad primordial del puesto. En ese punto, comienzan a producirse métodos de repetición de actividades. Los individuos son conscientes de la consistencia de las tareas que realizan, aunque cada grupo utilice métodos más o menos específicos pudiendo existir pequeñas diferencias entre ellos. 
Las mejoras en las actividades comienzan cuando los directores se comprometen con la organización en realizar mejoras en conocimiento, preparación, motivación y tareas para los trabajadores. Hasta que esas tareas básicas de trabajo no se institucionalicen, la organización tendrá dificultades en adoptar otras más sofisticadas.

En el Nivel de Repetición aunque las empresas realicen tareas básicas, suele haber cierta inconsistencia entre como las llevan a cabo los distintos departamentos. Así las empresas no capitalizan las oportunidades que tienen de estandarizar sus mejores procesos, debido a que no se han identificado ni el conocimiento, ni la preparación, ni la mejor forma de llevar a cabo dichas tareas

\section{Nivel 3: Nivel de definición}

Una empresa estará motivada para alcanzar el Nivel de Definición cuando con la definición y realización de sus principales tareas pretenda obtener alguna ventaja competitiva. Así, a través del análisis, la especificación tanto de la formación necesaria como de las tareas a realizar, la empresa identificará cuales son las características más importantes para adoptar aquellas que permitan desarrollar el conocimiento específico.

Para ello, habrá que analizar el proceso de negocio, y determinar las capacidades, conocimiento y preparación necesaria para que se puedan realizar eficientemente las tareas.

En el Nivel de Definición puede desarrollarse una buena cultura de empresa, debido a que dicha cultura adquiere importancia por un lado debido al crecimiento en la capacidad organizativa de las principales competencias y por otro a que los trabajadores comienzan a compartir la responsabilidad de dicho crecimiento. Por tanto, dicha cultura se reforzará cuando se adapten tareas que consigan y recompensen el crecimiento en las principales capacidades de la empresa.

La capacidad de las empresas en este nivel se basa en disponer de trabajadores con el suficiente conocimientos y preparación para que ayuden a cumplir con las principales actividades de la empresa. Así, el conocimiento y la preparación se extenderán más y mejor en la empresa. Con ello se consigue mejorar la capacidad, nivel de preparación y conocimiento de sus trabajadores. 
Así como, establecer un grupo de mejora que genere un desarrollo continúo de conocimiento y preparación.

\section{Nivel 4: Nivel de dirección}

En este cuarto nivel, las empresas comienzan a capitalizar sus capacidades en ventajas competitivas. Para ello, se establecen unos objetivos cuantitativos que ayuden a aumentar dichas capacidades, así como un incremento cualitativo en función de las actividades a realizar a través de individuos, equipos, unidades, y niveles de la organización. Además, pretende maximizar la efectividad de aplicar estas capacidades para el desarrollo de equipos que integren conocimiento y preparación complementaria.

En el Nivel de Dirección, el personal tendrá unos conocimientos y una preparación complementaria además de condiciones que una vez desarrolladas hagan que se mantenga su función.

Existen unos "Mentores" disponibles tanto para, equipos como para individuos, que se basan en la utilización de su experiencia para apoyar al personal, darle guía, potenciar el desarrollo de habilidades e incluso proporcionar caminos para retener lo aprendido dentro de la empresa.

El crecimiento de la organización en cada una de sus principales capacidades está dirigido de forma cualitativa. Los datos a nivel de las principales capacidades de la empresa, se analizan para determinar acuerdos y capacidades. Estos acuerdos de capacidad se utilizan para evaluar la efectividad de las capacidades relacionadas con actividades laborales. En resumen, manejar esos datos supone recolectarlos y analizarlos para llegar a acuerdos de cumplimento tanto individual, de equipo, y de la organización. Los acuerdos sirven para evaluar la efectividad del cumplimiento de las actividades laborales.

La capacidad laboral de las empresas situadas en el Nivel 4, es predecible, debido a que se conoce cuantitativamente la capacidad laboral del momento. Las empresas han desarrollado un mecanismo para que se aumenten las capacidades de forma efectiva a través actividades de cierto nivel como acuerdos para aumentar la capacidad laboral y futuros cumplimientos, mejorando así el conocimiento y preparación de los trabajadores y su formación. En este nivel 
la formación que poseen los trabajadores proporciona una predicción de acuerdos a la empresa.

\section{Nivel 5: Nivel Óptimo}

En el Nivel Óptimo se produce una continua mejora en las capacidades individuales y una búsqueda de vías mediante las que mejorar la motivación y capacidad. La organización utiliza el esfuerzo que realizan sus trabajadores hacia un continuo desarrollo de las competencias que desarrollan. Los supervisores estarán provistos del soporte para desarrollo de capacidades, tanto personales como de equipo.

Se utilizan datos relativos a la efectividad de las actividades laborales, para identificar donde están las necesidades de innovación: tanto en tareas como en tecnología, evaluándose aquellas más prometedoras que se explorarán mediante pruebas. Aquellas innovaciones que presenten mejores resultados se transferirán y utilizarán en la empresa.

La capacidad laboral de las organizaciones en el Nivel Óptimo mejora continuamente debido a que se produce un desarrollo continuo en las tareas. Las mejoras se producen, tanto por los avances en las tareas existentes, como por la adopción de nuevas tareas y métodos que puedan tener un impacto considerable. La cultura que generan las empresas de Nivel Óptimo, será tal que todos sus miembros se esforzarán para su mejoría personal, la de sus equipos, su conocimiento y formación, así como la motivación, que supondrá la mejora de toda la organización, de modo que se orientarán las tareas hacia la creación de una cultura de empresarial hacia la excelencia.

\subsubsection{Procesos clave para cada nivel}

Existen unas tareas claves para el paso de uno a otro nivel, éstas son las que a continuación se detallan y vienen recogidas en la Ilustración 4. 2, que se muestra a continuación: 


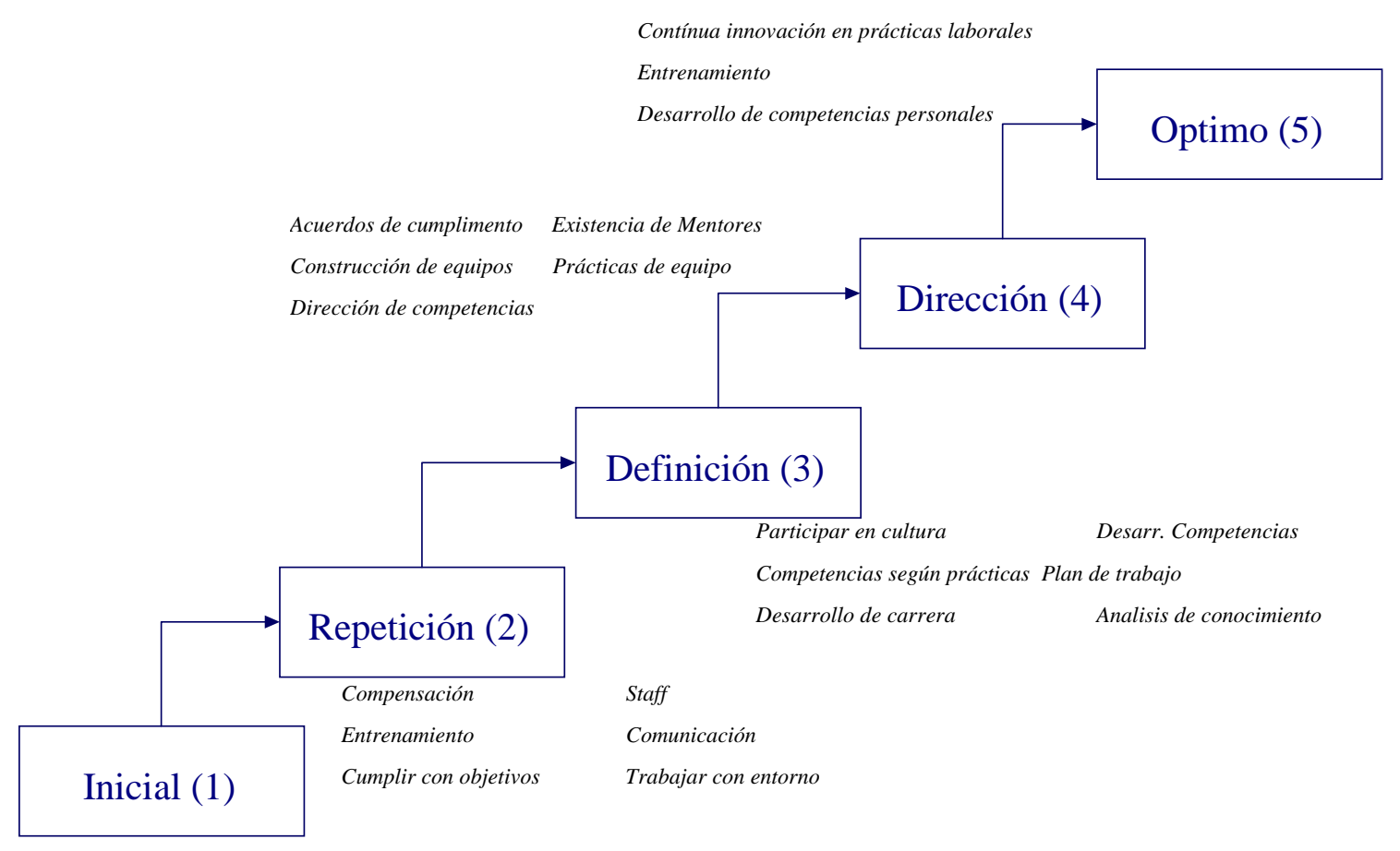

Ilustración 4. 2: Proceso clave para cada nivel del Modelo

Procesos clave del Nivel Inicial al Repetible

- Ambiente de trabajo: El ambiente de trabajo permitirá a los trabajadores concentrarse en sus tareas sin distracciones innecesarias, cumplir todas las leyes y regulaciones, eliminando impedimentos y minimizando restricciones.

- Comunicación: La comunicación aporta interacción y asegura que los trabajadores estén preparados para compartir información, se coordinen de forma efectiva, realicen revisiones eficientes, resuelvan problemas, y aseguren la preparación de los trabajadores.

- Reclutamiento: El reclutamiento es el proceso formal mediante el cual se recluta, selecciona y transiciona el talento en activo para la empresa.

- Administración del desempeño: Establece los objetivos con los que medir las actividades realizadas por unidades e individuos, a través de retroalimentación y aumentando la actividad de forma continua. 
- Capacitación: La capacitación asegura una preparación suficiente de todos los individuos.

- Compensación: La compensación propone dar a todos los individuos la remuneración y beneficios según su contribución y valor aportado a la empresa.

\section{Procesos clave del Nivel Repetible al Definido}

- Análisis de conocimiento y habilidades: Identifica el conocimiento y la preparación requerida para llevar a cabo los procesos y utilizarlos como base.

- Planificación de los trabajadores: La planificación de los trabajadores coordina la actividad laboral con las necesidades de negocio actual y futuro. Incluye el desarrollo de un plan estratégico laboral así como el desarrollo de planes a corto plazo.

- Desarrollo de competencias: Diseñado para aumentar la capacidad de los trabajadores de manera constante en la realización de las responsabilidades y tareas asignadas, etc.

- Desarrollo de carrera: Asegura la motivación y oportunidades para el desarrollo de nuevas habilidades que hagan aumentar la consecución de objetivos de carrera planteados.

- Tareas basadas en la formación: Aseguran que las tareas a realizar se basen en el desarrollo del conocimiento y habilidades de los trabajadores.

- Cultura participativa: La cultura participativa asegura el flujo de información dentro de la empresa, conocimiento de los procesos, apoyo de los participantes. Para ello se basa en la creación de equipos cualificados y supone el establecimiento de una comunicación efectiva, toma de decisiones, acuerdos.

\section{Procesos clave del nivel definido al administrado}

- Asesoramiento: Guía que incluye el desarrollo de conocimiento y habilidades, a través de la mejora de las actividades, manejo de situaciones difíciles, y toma de decisiones de carrera. Incluye además el establecimiento de objetivos, diseño de actividades de asesoría, 
la selección y formación a los asesores apropiados, así como la asignación de asesores a cada individuo o grupo de individuos, estableciendo relaciones y evaluación de la eficacia de los programas de asesoría.

- Formación de equipos: Se diseña para capitalizar las oportunidades de creación de equipos que maximicen la integración del conocimiento y las habilidades en las funciones empresariales. Supone la comprobación de miembros potenciales con conocimiento y las habilidades requeridas, así como la formación a nuevos miembros, la adaptación de procesos, y revisiones periódicas de actividades.

- Prácticas basadas en equipos: Se diseñan para adaptar las prácticas laborales de la empresa de modo que den soporte, motivación y funcionamiento a los equipos.

- Administración de la competencia organizacional: Aumenta la capacidad de la empresa en relación con sus competencias principales y determinar la efectividad del desarrollo en sus actividades logrando mejorar metas competitivas específicas

- Alienación del desempeño organizacional: trata de aumentar la alienación de los resultados de cumplimiento de los individuos, equipos, unidades y niveles organizativos, con las metas apropiadas y cuantitativamente valorar la efectividad de las prácticas que permitan lograr dicha alienación.

\section{Procesos clave del nivel administrado al nivel optimizado}

- Desarrollo de las capacidades de personal: Se diseña para proporcionar el desarrollo profesional, a través de un programa voluntario para la mejora continua en los procesos de trabajo mediante el desarrollo de metas y planes para las actividades laborales, estableciendo y definiendo procesos personales, midiendo y analizando la efectividad de esos procesos de personal, e implementando mejoras.

- Asesoramiento: Provee de asistencia externa para aumentar la formación de equipos o individuos. Los asesores guían el desarrollo de habilidades que mejoren las actividades. 
- Mejora continua para el desarrollo de personal: La mejora continua en el desarrollo de personal, incluye el establecimiento de un mecanismo para la mejora de actividades de personal, identificando las necesidades y evaluando las prácticas más innovadoras y conduciendo a pruebas exploratorias en las nuevas prácticas e implementando las más beneficiosas en las empresas.

\subsubsection{Aplicación del Modelo de Capacitación de Madurez para Personal( P-CMM)}

El Modelo de Capacitación de Madurez para Personal (P-CMM) adapta la arquitectura y el marco de madurez del Modelo de Capacitación de Madurez (CMM) para utilizarlo en relación con el personal y sus mejoras. El Modelo de Capacitación de Madurez (CMM) ayuda a las organizaciones a mejorar al desarrollo de los procesos. Y por la adaptación del marco de madurez y arquitectura, las actividades del Modelo de Capacitación de Madurez para Personal (P-CMM) pueden integrarse de forma más fácil en los procesos y como guía en aspectos relacionados con el personal y su mejora.

El Modelo de Capacitación de Madurez para Personal (P-CMM) puede utilizarse de dos modos:

Como estándar para asesorar las actividades de los trabajadores

Como guía en la planificación e implementación de actividades de mejora.

Cada área clave en los procesos del P-CMM se organiza en cinco subsecciones denominadas características comunes, siendo éstas las siguientes:

- Compromiso de cumplimiento,

- Capacidad de cumplimiento,

- Actividades realizadas, 
- Medida y análisis,

- Verificación de la implementación, especificando las prácticas claves,

Cuando se consiguen de forma colectiva se consiguen las metas de los procesos claves del área. Para conseguir algunas de esas características comunes se realizan una serie de tareas, mientras que otras establecen el soporte necesitado para institucionalizarlas. Dichas prácticas son las contenidas en el Modelo de Capacitación de Madurez para Personal (P-CMM).

\subsubsection{P-CMM basado en valoraciones}

El P-CMM proporciona un estándar frente al cual se valoran las tareas realizadas en la organización. El equipo de valoraciones del P-CMM incluye al menos alguien preparado en conductas de valoración, así como alguien relacionado en mejoras del P-CMM, y alguien que provenga del departamento de Recursos Humanos, aunque una sola persona pueda ocupar más de uno de estos roles.

La idea es que el Modelo de Capacitación de Madurez para Personal (P-CMM) ayude a la organización a comparar la madurez de sus prácticas laborales con el estado de prácticas en la industria. Utilizando el P-CMM como marco, requerirá que el P-CMM basado en la valoración sea sometido una reposición, como el Proceso del Sistema de Valoración de Información. Estos datos indican acuerdos en la industria además de proveer el marco.

\subsubsection{P-CMM como guía de mejora}

El Modelo de Capacitación de Madurez para Personal (P-CMM) proporciona una guía para implementar prácticas en un programa de mejora de la organización. Existen dos niveles de guías propuestas por el modelo: por un lado una guía estratégica para desarrollar la organización a lo largo del tiempo, y por otro lado una guía de prácticas que la organización puede utilizar para resolver problemas explícitos o defectos existentes.

Respecto a dichas guías, el Modelo de Capacitación de Madurez para Personal no especifica explícitamente las que han de implementarse, sino el marco para seleccionar y confeccionar prácticas en la organización, cultura, y medio ambiente. 


\subsubsection{Localización de un P-CMM basado en mejoras. Programa en la organización}

El Consejo Consultivo del Modelo de Capacitación de Madurez para Personal (P-CMM) recomienda que los profesionales de Recursos Humanos se sumen al grupo de ingeniería de procesos para trabajar en el P-CMM basado en mejoras. El programa de mejoras supone realizarlas en procesos, tecnología y personas, siendo el P-CMM parte de ese programa de mejora, y es donde se realizan las practicas relacionadas con temas de personal.

Muchos profesionales de los Recursos Humanos se consideran frustrados por no ser considerados como parte principal de la organización. Según ello, les afecta que un programa de mejora que venga de Recursos Humanos sea considerado como parte crítica de los esfuerzos de mejora. Así pues, incluir mejoras en el P-CMM como parte del programa de mejoras que mantiene el desarrollo de la organización provee de un vehículo para los Recursos Humanos profesionales como parte del esfuerzo de la principal oleada para mejorar el negocio. Más adelante, la coordinación basada en las mejoras puede incluir a trabajadores a los que les afecte directamente, lo que les hace sentir un gran sentido de importancia por participar en la mejora de esas prácticas.

\subsection{CONCLUSIÓN DEL CAPÍTULO}

Tras definir en este capítulo a la empresa como un sistema y como una organización formada por personas cuyos objetivos no pueden alcanzarse únicamente por un individuo sino por un grupo, conlleva a proporcionar a la empresa de una estructura de la cual emanen tanto funciones como responsabilidades para sus integrantes, de modo que con ello se logre alcanzar una estructura coherente y unos resultados estratégicos. Dicha estructura puede ser de tipo formal, entre los que se encuentran las estructuras básicas: funcional, territorial, divisional, matricial o híbrida, o bien estructura de tipo informal, en la que dependiendo del modo de trabajar y la interacción de los empleados surge la estructura.

Las estructuras de Recursos Humanos aparecen para orientar y canalizar las relaciones existentes entre la organización y los individuos que la componen, así como para estructurar 
la división del trabajo, con ello se logra ajustar las capacidades laborales existentes, así como la eficiencia económica y social.

Así pues, para lograr fijar una situación y estructura en las empresas, y como mejorar su capacidad en la evolución empresarial, este capítulo ha utilizado el Modelo de Capacitación de Madurez, que arrancando de las tareas desarrolladas por la empresa, propone una serie de recomendaciones para mejorar tanto su nivel como el de los empleados.

El Modelo de Capacitación de Madurez hace énfasis en el desarrollo continuo del activo humano en la organización, actuando como guía de mejora continua que motiva, reconoce, estandariza y mejora al personal. Dicha mejora se lleva a cabo a través de la evolución a lo largo de los niveles de madurez que propone el modelo, los cuales se alcanzan mediante la implantación de procesos clave que le hacen evolucionar de un nivel al siguiente nivel. Como punto de partida todas las empresas se sitúan en el primer nivel o Nivel Inicial, y a partir de inculcar cierta disciplina a las actividades de trabajo logran pasar al segundo nivel denominado Nivel de Repetición. Una vez en éste, habrá que identificar las competencias básicas y hacerlas coincidir con las actividades de la empresa para pasar al tercer nivel o Nivel de Definición. Para pasar de este tercer nivel al cuarto denominado de Dirección, será necesario realizar un crecimiento importante en capacidad, establecimiento tareas, por equipos desde la dirección empresarial. Finalmente para acceder al quinto y último nivel, denominado Nivel Óptimo habrá que continuar creciendo, a través de la mejora de métodos y desarrollo tanto del personal como de las competencias.

Por tanto, una vez propuestos los elementos empresariales, su evolución y conocida la importancia tanto del elemento personal, como de la estructura del mismo, este trabajo tratará a partir del próximo capitulo de confeccionar un modelo de Recursos Humanos que identifique todas aquellas funciones que han de realizar los participantes en la entidad de negocio, dependiendo de su ubicación jerárquica y teniendo en cuenta todos los aspectos señalados hasta ahora. 


\subsection{REFERENCIAS BIBLIOGRAFICAS DEL CAPÍTULO}

Albizu Albizu Gallastegi E. Y J. Landeta Rodríguez. "Contextualización de la función de los Recursos Humanos". Capítulo correspondiente al libro "Dirección Estratégica de los Recursos Humanos" Ediciones Pirámide. España 2001

PCMMV2 Curtis B., W.E. Heley, S. Miller. Overview of the People Capability Maturity Model. Versión 2 http://www.sei.cmu.edu/cmmp/version2/part1.pdf. Consultada el 2 de noviembre de 2001

CMM-P Curtis B., W.E. Heley, S. Miller. Overview of the People Capability Maturity Model September 1995.

http://phillips.rmc.ca/archive/cficse/resources/sei-p-cmm-overviewmm001_95.pdf.Consultada el 15 de julio 2001

DeRosnay De Rosnay "The macroscope, a new world scientific system" Web edition. Principia Cibernetica Web Proyect. http://pespmc1.vub.ac.be Consultada el 15 de octubre de 2002

Domínguez200 Domínguez Torres, A. Cambio y conocimiento en los sistemas. 0 Editorial Galileo. México 2000.

Elorduy $\quad$ Elorduy Mota, Juan Ignacio. "Estrategia de empresa y Recursos Humanos. Una visión dinámica de la empresa” Ediciones Mc Graw Hill. Serie Mc Graw Hill del Management. Instituto de Empresa. España 1997.

Gil Gil Ignacio, Ruiz Leonor, Ruiz Jesús. "La nueva dirección de personas en la empresa” Mc Graw Hill. España 1997

Huse $\quad$ Huse E.F., Bowditch J.L. "El comportamiento humano en la organización” Editorial Deusto. España 1986

Peña Peña Baztán, Manuel . "Dirección de Personal en la Organización y técnicas” Colección ESADE. 6ª Edición. España 1990

TQM_EFQM1 TQM-EFQM 1999. El Modelo EFQM de Excelencia.

$999 \quad$ http://www.tqm.es/TQM/ModEur/ModeloEuropeo.htm Consultada el 20 Noviembre 2002

Werther Werther W.B., K. Davis. “Administración del Personal y Recursos Humanos" Mc Graw Hill. 3ª Edición . Mexico 1991 


\title{
Capítulo 5.
}

Arquitectura del Modelo

\section{Propuesto de Recursos}

\author{
Humanos
}


CAPITULO 5

\section{ARQUITECTURA DEL MODELO PROPUESTO DE RECURSOS HUMANOS}

\subsection{INTRODUCCIÓN}

En la primera parte de la tesis introducida hasta ahora y denominada como Identificación del marco, se ha mostrado un planteamiento teórico de los elementos empresariales y sus etapas, haciendo hincapié en la situación de los Recursos Humanos dentro de las empresas. La principal conclusión que se puede extraer de esta primera parte es que los Recursos Humanos constituyen un elemento fundamental (apartado 2.2.1) e importante dentro de la empresa (apartado 1.5 y capítulo 4). Por lo tanto, una vez presentadas en el apartado 1.2 algunas arquitecturas descritas desde el marco de Integración empresarial, y conocidos los elementos empresariales (apartado 2.2) que integran la empresa, este capítulo propone la construcción de un Modelo de Recursos Humanos sujeto a dicho marco de referencia.

En este quinto capítulo se generará el modelo haciendo un recorrido a lo largo de las etapas del ciclo de vida expuestas en el capítulo tercero, partiendo en el punto 5.2 de la Etapa de Planificación, para pasar a continuación en el 5.3 a realizar la Etapa de Análisis del mismo y finalmente en el 5.4 realizar el Diseño del modelo propuesto. 
El capítulo se estructura en base a las etapas del ciclo de vida, y cada una de ellas se subdivide: primero en un desarrollo teórico, que contenga los pasos y requisitos a realizar en dicha etapa, para pasar a continuación a una aplicación práctica de implantación de lo expuesto, e ir generando etapa tras etapa el Modelo de Recursos Humanos.

Dicho modelo parte de los cinco elementos empresariales ya estudiados en el capítulo segundo y su aplicación a las etapas a realizar a lo largo del ciclo de vida, explicadas en el capitulo tercero. A partir de esos cinco elementos empresariales, y basándose en la importancia del elemento personal, como se mostró en el capítulo cuarto, se creará una estructura de puestos, n la que se definirán el ¿Qué? ¿Cómo? ¿Cuándo? ¿Quién? ¿Dónde y ¿Porqué? para cada puesto presentado, generando así un nuevo modelo de Recursos Humanos.

\subsection{ETAPA DE PLANIFICACIÓN DEL NUEVO MODELO DE RECURSOS HUMANOS}

\subsubsection{Etapa de Planificación}

El primer paso necesario para realizar la planificación del Modelo de Recursos Humanos supone como bien se apuntó en el apartado 3.2.1, Realizar una investigación preliminar de la conveniencia o no del modelo, definiendo los conceptos estratégicos a alcanzar y realizando un estudio de viabilidad de dicho modelo. Esto supondrá conocer cual es la situación en que se encuentra el sistema y conocer las necesidades y prioridades que se quieren obtener.

Para ello hay que comprobar la conveniencia de cumplir con lo proyectado, es decir, si conviene o no implementar el nuevo modelo. Si el resultado es positivo, se pasa a continuación a hacer una planificación de cómo será el modelo, definiendo los conceptos estratégicos a alcanzar y el plan de trabajo a realizar a alto nivel con el fin de obtener las aprobaciones correspondientes dentro de la empresa para su puesta en marcha. 
Para comenzar con la planificación, el primer hecho que ha de realizarse es la elección del sistema o Entidad de negocio. Dicha entidad de negocio es definida por Ortiz [Ortiz98 p.196] como "la parte de la empresa, que posteriormente puede ir expandiéndose a través de añadir nuevos procesos si son oportunos". En este caso, la entidad de negocio será la empresa, el departamento o área en que se vaya a desarrollar el modelo. Por lo tanto, ha de elegirse la entidad de negocio en la cual se va a actuar y desarrollar el modelo para la misma en particular.

Una vez definida la entidad de negocio, hay que estudiar como va a afectar el nuevo modelo a los aspectos estratégicos de la empresa, así como tener presentes los procesos que se van a llevar a cabo para lograr esos objetivos estratégicos.

Por lo tanto, a la hora de establecer el nuevo modelo, se tendrán en cuenta los puntos de partida para la generación del mismo, controlando que toda la empresa esté de acuerdo con su generación, su ejecución y desarrollo, así como disponer de recursos disponibles y capaces para lograr dicho desarrollo de forma adecuada, así como prever la evolución de los elementos que integran el modelo.

Una vez definida la Entidad de Negocio, hay que especificar tanto los conceptos estratégicos relacionados con la empresa como los relacionados con la entidad de Negocio. A este proceso Ortiz [Ortiz98 p.201] le denomina Conceptualización.

Dichos Conceptos Estratégicos son los siguientes:

- Misión: Para Bueno [Bueno96 p.408] la misión es manifestación de la filosofía o política general de la empresa, es decir, los objetivos de negocio a los que se va a dedicar. Mientras que Menguzzato [Menguzzato95 p. 105] la define como "la expresión general de los objetivos que quiere ser la empresa, de sus aspiraciones sociales, filosofía, valores, creencias, etc."

- Visión: Para Bueno [Bueno96 p. 407] es "la forma de anticipar el futuro, o de proyectar la empresa en dicho futuro, o definir una determinada filosofía de la empresa" 
- Valor: Albizu [Albizu p.99] acude a Campell y Tawadey ${ }^{9}$, para definirlos como " las convicciones que sostienen el estilo de dirigir la organización, su relación con los empleados y los demás partícipes en la actividad empresarial, y su ética.

- Metas: Para Bueno [Bueno96 p.409] son "la máxima concreción de los objetivos"

- Acciones: Para Bueno [ㅂeno96 p.409] son "las reglas, pautas, recomendaciones, procedimientos o políticas concretas que se definen para que la base operativa de la organización cumpla con lo pretendido"

- Estrategia: Para Albizu [ y pone en marcha, en una situación de competencia para la consecución de los objetivos planteados"

- Objetivos: Para Bueno [Bueno96 p.408] son la concreción en el tiempo, en el espacio y en la cuantía de lo pretendido por la misión. Es decir, son las guías y propósitos del sistema de dirección para poder cumplir con su misión. Dentro de la clasificación de objetivos, puede haber Objetivos Individuales [Bueno96 p.409] que serán los que pretendan alcanzar las personas o grupos componentes de la organización, según la expresión de preferencia.

- Planes: definidos por Ortiz [Ortiz98 p. 200] como la forma en que las metas se deben alcanzar.

- Políticas: definidas por Ortiz [Ortiz98 p. 201] como los métodos seleccionados entre las diversas alternativas que marcan las condiciones para guiar las decisiones.

Por lo tanto, en esta fase habrá que especificar como han de combinarse todos estos elementos para lograr los objetivos de la Entidad de negocio, y de la empresa, mientras se desarrolla el modelo.

\footnotetext{
${ }^{9}$ Campbell, A y Tawadey, K. (1992): La misión de los negocios. Díaz de Santos. Madrid
} 
Para Ortiz [Ortiz98 p.201] lo primero que hay que definir es la Misión, Visión y Valores de la empresa, para hacerlo a continuación de la Entidad de Negocio, debido a que éstos sólo tienen cabida una vez definidos los de la empresa.

Así mismo han de definirse los Objetivos para la entidad de negocio en términos de crecimiento, rentabilidad, perspectivas de futuro, etc., así como el resto de los conceptos estratégicos identificados, que permitirá ubicar perfectamente la entidad de negocio donde se va a desarrollar el modelo.

Ortiz [Ortiz98 p.201] propone que "la Estrategia de la empresa debe definir la mejor vía para alcanzar las Metas de la Entidad, cumpliendo con la Misión de ésta, y teniendo en cuenta las restricciones existentes. Esta estrategia debe definirse en el marco de un Plan orientado a conseguir los Objetivos planteados. La documentación adecuada de este proceso es fundamental, ya que en la mayoría de las empresas muchos de estos conceptos se pasan por alto, lo cual hace que los programas difícilmente cumplan con las expectativas creadas, ya que se desconoce exactamente cuales son las metas y objetivos a alcanzar, así como la estrategia y factores críticos de éxito que permitirán alcanzar éstos."

Por lo tanto, en esta primera fase, la Alta Dirección, ha de documentar los conceptos estratégicos de la empresa y así como los de la entidad de negocio seleccionada para su completa coherencia. A su vez, la Alta Dirección ha de aprobar y establecer restricciones a los dichos planes.

Finalmente hay que realizar una definición de los procesos necesarios para poder llevar a cabo el nuevo modelo, lo que supondrá definir cuales han de ser los procesos que se están desarrollando y los que se quieren o se van a desarrollar, así como las medidas de control que se utilizarán. Esto permitirá tener una visión de cual es el estado actual del Modelo de Recursos Humanos de la entidad (Modelo AS -IS), y cual será el estado futuro del Modelo, denominado Modelo TO BE. 
Por lo tanto, Ortiz [Ortiz98 p. 222] propone que esta fase, la cual denomina: Definición de Procesos, y que en este trabajo está incluida en planificación, concluya con los siguientes resultados:

- "Generación del Modelo AS-IS (como se encuentra la organización en ese momento), para este caso particular supondrá un estudio de cual es el modelo de Recursos Humanos que aplica la entidad de negocio en ese momento

- $\quad$ Listado de los procesos que han de llevarse a cabo: Tener claro cuales son los procesos que ha de desarrollar el nuevo modelo.

- Identificación de los objetivos actuales: Identificación de objetivos tanto para la empresa, el sistema o la entidad de negocio.

- Definición de cómo apoya cada proceso a la Estrategia de la entidad: Definir como afecta el modelo al cumplimiento del objetivo y la estrategia de la empresa.

- Clasificación de los procesos: Tener en cuenta los procesos que ha de realizar y en que nivel jerárquico han de implementarse, lo que afectará a los puestos del modelo

- $\quad$ Identificación de los parámetros que permitan medir los resultados del modelo.

- $\quad$ Representación gráfica de los procesos identificando las actividades que desarrollan cada uno de ellos en el modelo de Recursos Humanos, así como las entradas, salidas, eventos y relaciones que tiene cada uno.

- Primera aproximación a la aceptabilidad o no del proceso en el marco de la entidad: realización de tanteos de si el nuevo modelo tendrá o no aceptabilidad de implementación.

- $\quad$ Modelo TO BE: Modelo futuro a desarrollar e implantar en la entidad de negocio. 
- Definición de los objetivos del modelo: Hay que definir que objetivo persigue el nuevo modelo de Recursos Humanos, sobre la base de los anteriores y la identificación de los parámetros.

- $\quad$ Representación gráfica del modelo, identificando las actividades que desarrollará cada uno de los integrantes del mismo, así como las actividades, eventos y relaciones. Esto supondrá realizar un flujograma o esquema de los pasos o procesos por los que evolucionará el modelo, así como la definición de actividades para cada uno de sus integrantes.

- Definición de cómo apoya a la estrategia de la entidad, es decir, como el nuevo modelo de Recursos Humanos, afectarán a la estrategia general de la entidad.

- Definición de los parámetros que van a permitir medir los resultados y evolución de la entidad de negocio: Lo que supone definir como los elementos empresariales descritos en el capítulo segundo (apartado 2.2) afectan y son necesarios para definir los resultados a obtener y los procesos a realizar.

Todo ello tiene una gran importancia, ya que el conocer y definir los procesos que han de realizar los Recursos Humanos, ayudará a desarrollar el futuro modelo ( Modelo TO BE) lo que supondrá un avance en la integración de la empresa o entidad con el resto de elementos.

Lo que esta tesis doctoral persigue es la identificación de los procesos que realizan de Recursos Humanos, para generar el modelo TO BE que permita profundizar en la Integración Empresarial, para lo que se utiliza el trabajo presentado por Ortiz [Ortiz98], aunque dicho trabajo contempla únicamente las vistas de los procesos, personas y tecnología, dejando fuera los elementos presentados en el capítulo segundo correspondientes a producto o servicio, e información. 


\subsubsection{Etapa de Planificación del Modelo de Recursos Humanos}

La primera etapa necesaria para la construcción de un modelo de Recursos Humanos es la planificación. Dicha planificación surge de la importancia de contar con personal adecuado en cada lugar y momento de forma que permita y facilite llevar a cabo los objetivos por los que se creó la empresa.

Como señalan Huse y Bowditch [Huse86 p.192] "el establecimiento de los objetivos organizacionales determina los fines organizacionales y el empleo de recursos para conseguir esos objetivos." Por lo tanto, en la etapa de Planificación se establecerán los objetivos principales de la organización, empresa, o entidad de negocio, así como la planificación de los elementos empresariales expuestos en el apartado 2.2. (Personal, procesos, productos o servicios, infraestructura e información) y como se acaba de exponer en el apartado anterior 5.2.1 (Etapa de Planificación).

Los autores Menguzzato y Renau [Menguzzato95 p.227] señalan a Besseyre des Horts (en "Typologies des pratiques de gestion des ressources humanies" Revue Francaise de Gestion, noviembre- diciembre 1987, y Vers une gestion strategique des ressources humanies, Les Editions d'Organisation, Paris 1998), quien señala como "las características de las distintas funciones que componen la Gestión de Recursos Humanos, varían según el tipo de estrategia elegida, ya que las estrategias variarán dependiendo de si la empresa se encuentra en la fase de crecimiento inicial, la fase de crecimiento sostenido, la fase de madurez o la fase de declive".

Estos autores, Menguzzato y Renau [Menguzzato95 p.226], señalan que "un proyecto de empresa, es la expresión de una voluntad compartida por los miembros de la empresa y suele presentar los siguientes componentes

Una visión de futuro: manifestación de lo que la empresa quiere llegar a ser en el futuro. 
Una voluntad de alcanzar la meta futura: a pesar de las amenazas, implica que la voluntad de la empresa debe ser compartida y dar lugar a un esfuerzo colectivo de todos sus componentes.

> Prioridades y líneas de acción: que permitirán alcanzar los objetivos aceptados por la organización.

Valores compartidos: que guiarán los comportamientos de las personas

Es decir, que todo el proyecto empresarial enuncia grandes fines y opciones de la empresa en relación con su entorno general y competitivo, así como los principios de acción y/o de comportamiento. El proyecto de empresa persigue crear una voluntad colectiva, un sentimiento de pertenencia a la empresa y de identificación con los objetivos, valores y comportamientos, alrededor de los cuales se movilizan los esfuerzos de todos los miembros de la empresa. Pretendiendo dar un sentido a la actividad de cada uno, ayudar a ir más allá de las dificultades cotidianas para creer en los objetivos del proyecto y asociarse personalmente al desafío"

Huse y Bowditch [ $\underline{\text { Huse86 }}$ p.192] señalan que "una vez fijados los objetivos de la organización se hace posible planear la estructura de la misma. El plan estructural de la organización influye considerablemente en la planificación de los puestos de trabajo dentro de ella".

Para finalizar, estos autores señalan que respecto al elemento empresarial personal [ㅂuse86 p.192] "La planificación del potencial humano es necesaria para determinar el número y tipo de personas en la organización y el modo de utilizarlas. Como la estructura organizacional influye en la planificación del puesto de trabajo, las organizaciones difieren en la combinación de personal y en los estilos de liderazgo que puedan llevar al máximo su capacidad para satisfacer los objetivos organizacionales."

Así pues, para realizar la planificación del personal, se parte de la estructuración clásica para cualquier departamento, empresa o entidad de negocio, definida por E. De Miguel [DeMiguel 
p. 50] en cuatro grandes grupos: Alta Dirección, Mandos Intermedios, Mandos Operativos y Operarios como muestra la pirámide de los niveles de mando de la Ilustración 5. 1. Dicha estructura clásica supondrá el Modelo AS - IS del que parte la propuesta de modelo de Recursos Humanos.

Dichos grupos vienen definidos por E. de Miguel [DeMiguel p.50], como se detalla a continuación, exponiendo a su vez las tareas y procesos que desempeñar cada uno de los niveles de mando:

Alta dirección: compuesta por los mandos que ocupan el nivel superior. Son los responsables del conjunto de la empresa o departamento.

Mandos Intermedios: son los responsables de los principales departamentos o divisiones de la empresa.

> Mandos Operativos: Son los mandos operativos o de primera línea. Siendo responsables directos de los bienes y servicios producidos.

Operarios: Son los que ejecutan las ordenes de los mandos operativos generando la creación de bienes y servicios ofertados.

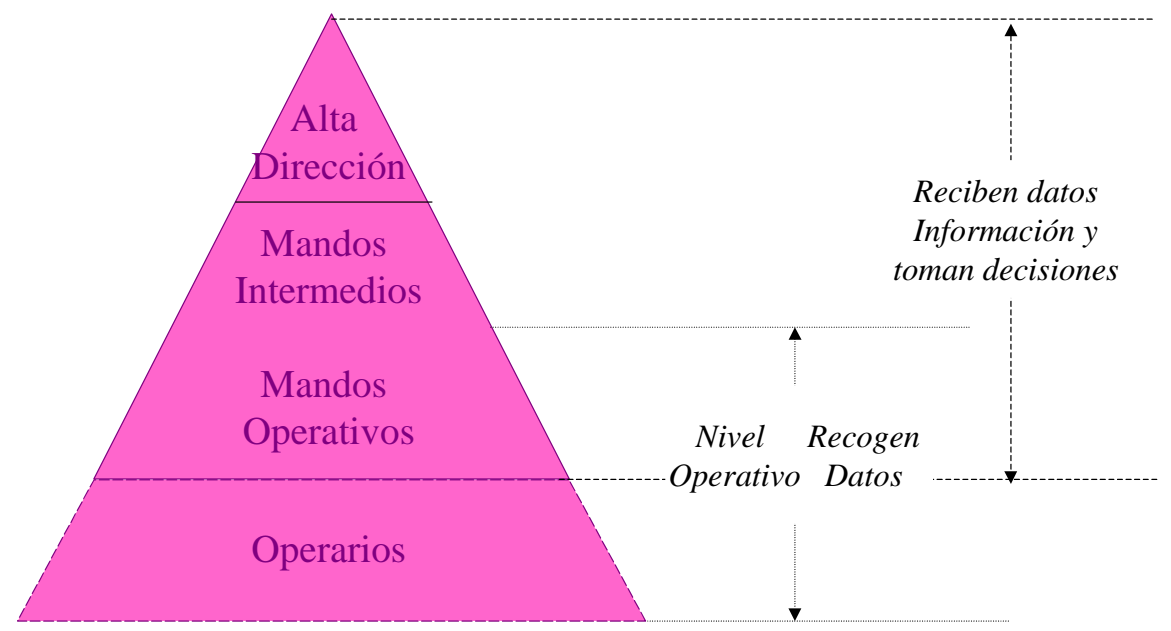

Ilustración 5. 1: Niveles de Mando. Fuente: E. de Miguel [DeMiguel p.50] 
Para el autor E. de Miguel [de Miguel p. 52] según el nivel que se ocupe dentro de la pirámide, los mandos deberán poseer en mayor o menor medida unas aptitudes o habilidades que clasifica en las siguientes y se pueden observar en la Ilustración 5. 2:

- Aptitudes Técnicas: conocimientos y habilidades para la ejecución de trabajos o tareas determinados. Son decisiones que afectan al área de finanzas, producción y marketing. Estas son fundamentales en el caso de los mandos operativos.

- Aptitudes humanas: habilidades del mando para trabajar con sus compañeros y subordinados, tanto en el ámbito individual como grupal. Son fundamentales para la función de dirección, que dentro de la gestión actual fomenta la participación de los subordinados mediante una comunicación fluida.

- Aptitudes conceptuales: relacionadas con la capacidad de los mandos para conocer el sistema de la empresa y su entono, pronosticar la evolución futura y adaptar el sistema a las amenazas y oportunidades del medio.

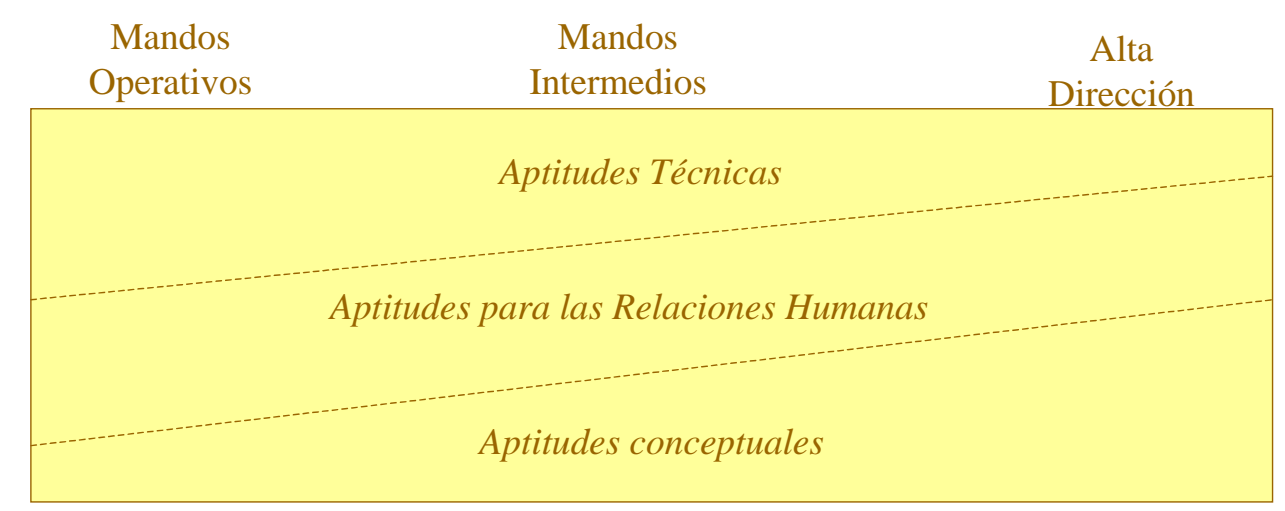

Ilustración 5. 2: Aptitudes necesarias para los distintos niveles de mando. Fuente: de Miguel [DeMiguel p.52]

Estos mandos expuestos por E. de Miguel, se tomarán a partir de ahora como base para el modelo de Recursos Humanos que desarrollará este trabajo.

A su vez, Kerzner [Kerzner pag.125] plantea una relación entre habilidades técnicas y humanas necesarias para ocupar el puesto correspondiente. Para este autor, hay una relación 
entre las habilidades necesarias según el puesto y su ubicación dentro de la pirámide de puestos, como se muestra en la Ilustración 5. 3.

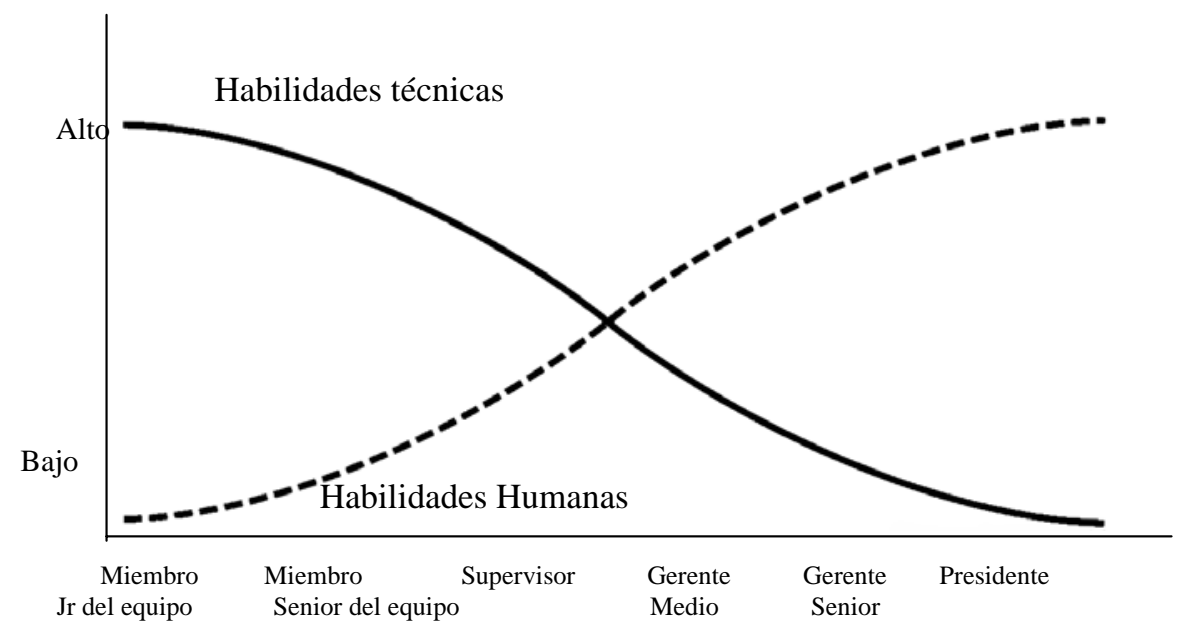

Ilustración 5. 3: Relación de Habilidades Técnicas y Humanas. Fuente: Kersner [ $\underline{\text { Kersner }}$ p.125 fig. 3.10]

Así pues, según E. De Miguel [DeMiguel p.50], se pueden adjudicar las siguientes tareas correspondientes a cada grupo expuesto en la pirámide de la Ilustración 5. 1. Así, y según lo expuesto en esa clasificación y basándose en los atributos de cada puesto,

Alta dirección: Sus principales tareas son:

- Pronosticar el futuro, fijando los grandes objetivos y desarrollando planes de conjunto y a largo plazo.

- Valorar el rendimiento global del departamento

- Conocer bien a los mandos intermedios, con el fin de seleccionar a personas idóneas para futuros ascensos. 
- Definir la política de Recursos Humanos e influyen sobre la cultura del departamento.

- Tratar con los mandos intermedios los asuntos y problemas de ámbito general del departamento.

Mandos Intermedios: Sus principales tareas son:

- Desarrollar planes a medio plazo en función de la planificación a largo plazo establecida por la alta dirección.

- Coordinar las actividades entre los diversos departamentos.

* Analizar el rendimiento de los subordinados con vistas a los futuros ascensos.

* $\quad$ Establecer las políticas del departamento

* $\quad$ Liderar los equipos de trabajo y resuelven conflictos.

* Revisar, diaria y semanalmente, los informes correspondientes a su departamento y a otros que sena de su interés.

* Aconsejar a los mandos subordinados sobre personal, producción u otros problemas del departamento.

Mandos Operativos: Sus principales tareas son:

- Hacer planes detallados a corto plazo, basándose en los planes de los mandos intermedios

- Preocuparse de que los subordinados observen las normas y procedimientos del departamento 
- Vigilar el rendimiento de los subordinados

- Supervisar las operaciones

- Asignar tareas específicas a los trabajadores que se hallan bajo su mando.

- Mantener relaciones estrechas y cordiales con los trabajadores, motivándoles para lograr que se cumplan eficaz y eficientemente los objetivos marcados.

Operarios: Son los que ejecutan las ordenes de los mandos operativos generando así la creación de bienes y servicios ofertados.

Por lo tanto, se puede decir, que las principales tareas que desarrollarán cada unos de estos niveles jerárquicos, corresponderán básicamente a tareas de Análisis y Planificación para quienes ocupen puestos de Alta Dirección. Realizarán de forma habitual tareas de Diseño del sistema, aquellos que se encuentren situados en puestos de Mandos Intermedios, mientras que de forma general realizarán las tareas de Implementación y Supervisión los que se sitúen en puestos de Mandos Operativos y Operarios. Esto no indica que cada nivel jerárquico realice sólo estas tareas, sino que realizarán todo tipo de ellas, aunque se centrarán principalmente en aquellas que correspondan a cada una de las etapas del proceso citada, como muestra la Ilustración 5. 4. 


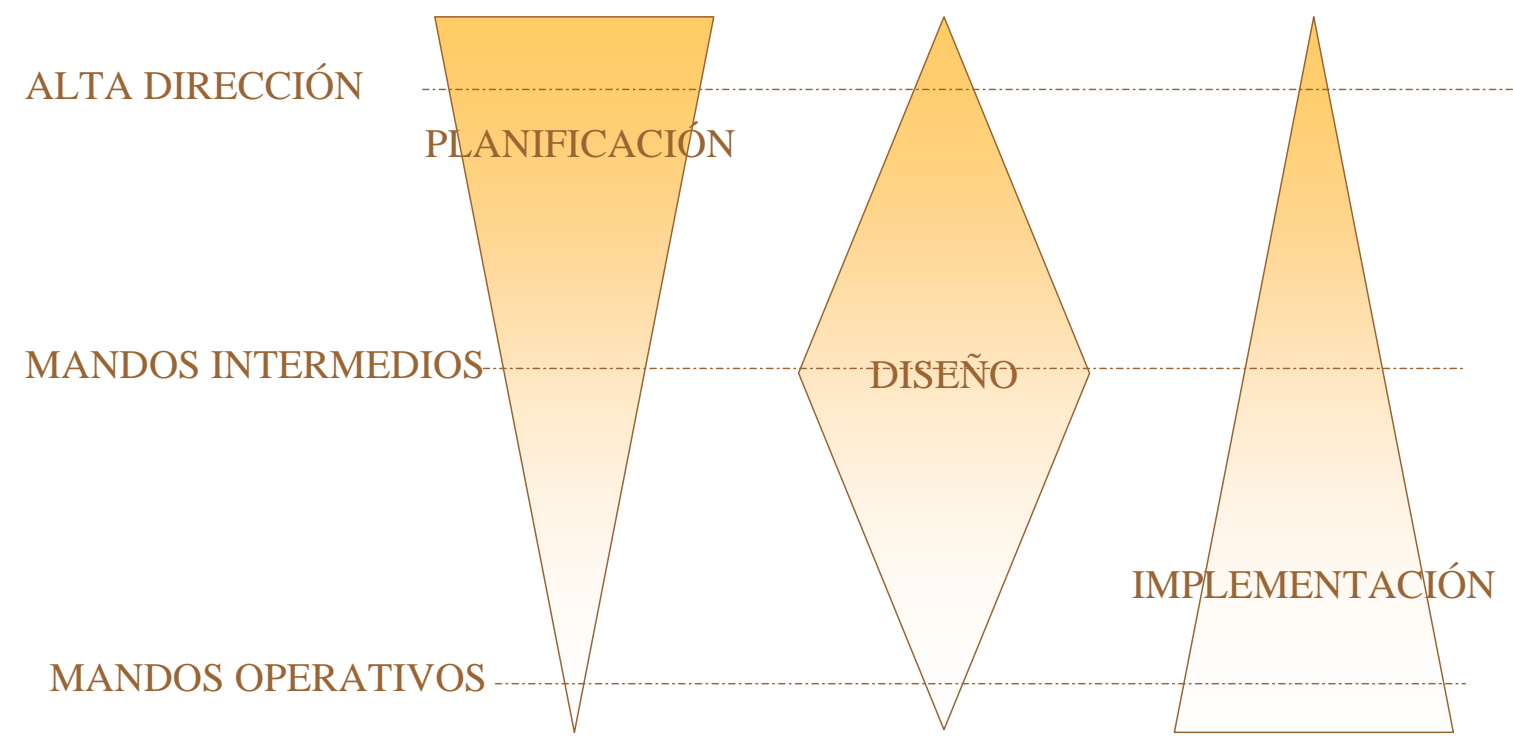

Ilustración 5. 4 : Relación entre jerarquía y actividades realizadas por el personal en la empresa. Fuente: Elaboración Propia

A su vez, estas tareas corresponderían básicamente con las actividades o etapas desarrolladas según el ciclo de vida presentado en el apartado 3.2 del capitulo tercero. Por lo tanto, la Alta Dirección se ubicaría en tareas de Planificación y Análisis, los mandos Intermedios en tareas de diseño y quedarían los Mandos Operativos y los Operarios como aquellos encargados de llevar a cabo las tareas de implementación, control y supervisión. Esta ordenación puede observarse en la Tabla 5.1

\begin{tabular}{ll}
\hline Etapa de Ciclo de Vida del proceso & Personal que la desarrolla básicamente \\
\hline Planificación & Alta Dirección \\
Análisis & Alta Dirección \\
Diseño & Mandos Intermedios \\
Implementación & Mandos Operativos y Operarios \\
Mantenimiento y Revisión & Mandos Operativos y Operarios \\
Desmantelación & Mandos Operativos y Operarios \\
\hline
\end{tabular}

Tabla 5. 1: Asignación de las principales tareas del ciclo de vida dentro de la empresa según personal existente. Fuente: Elaboración propia

Todas estas tareas y procesos que ha de desarrollar el personal de la empresa o entidad de negocio, han de estar en permanente coordinación con los conceptos estratégicos de la empresa. 
Partiendo de esta situación de modelo AS IS, donde existe una pirámide clásica dividida jerárquicamente en los niveles expuestos en este apartado, donde se sitúa la Alta Dirección en lo alto de la pirámide, y los Mandos Operativos y operarios en la base, Ross [Ross2000 p. 289-296] expone como los cambios sociales producidos en las empresas en las últimas décadas tales como: la producción en masa, la mejora de la distribución, los bienes estandarizados, el comportamiento directivo, los cambios en los consumidores, el uso de los ordenadores, de competencias asociadas, etc. hizo que a primero de los años noventa se aplicaran enfoques de mejora que tuvieron respuesta desde el JIT y desde procesos de reingeniería. Todo ello hizo que hubiera un cambio en cuanto a la orientación del personal, y en lugar de enfocarse hacia la tarea, la cual necesita personal y proponer objetivos, se propone la orientación al proceso, la cual requiere una reorientación y aumento de esfuerzo del personal hacia el logro de los objetivos de negocio asociados a la realización del proceso.

A partir, de esta situación, este trabajo plantea la creación de un nuevo modelo de Recursos Humanos (Modelo TO BE), en el que basándose en los conceptos estratégicos de la empresa o entidad de negocio acordes a los objetivos del departamento y las etapas que cada uno ha de desarrollar a lo largo del ciclo de vida de los procesos, surjan los puestos y los correspondientes procesos que cada uno ha de llevar a cabo

Para la realización y delimitación de las tareas de planificación, habrá que cuestionarse cuales han de ser los objetivos necesarios para poder llevar a cabo todo el proceso de negocio. En el caso de los directivos que ocupan puestos de Alta Dirección de una empresa, supondrá decidir cuales son y como afectarán a los elementos empresariales de la misma, por lo que realizará un listado de tareas o ciclo de vida del negocio o empresa, señalando tanto los lugares donde se realizará cada una de las tareas señaladas, como quién ha de cumplir o realizar dichas tareas. La descripción de las mismas supone también detallar cuando se producirá el desarrollo del ciclo de vida y así como una explicación lógica del porqué se producen esas actividades y como afectan a la misión de la empresa.

En el caso en que se tome un departamento o área de una empresa en lugar de una empresa completa, la Alta Dirección pasará a estar formada por su Director, el cual tendrá que decidir que elementos empresariales existirán y las relaciones existentes entre ellos, describiendo así el ciclo de vida de las tareas empresariales, su interactuación, donde habrá que realizar cada tarea, así como el organigrama del departamento y tareas a realizar por cada uno en el 
momento preciso y con los equipos existentes (infraestructura), todo ello se realiza para poder hacer cumplir la visión, misión y objetivos correspondientes al aspecto empresarial.

\subsection{ETAPA DE ANÁLISIS DEL NUEVO MODELO DE RECURSOS HUMANOS}

\subsubsection{Etapa de Análisis}

La fase de Análisis supone la realización de las actividades, que identifican la relación entre el modelo AS-IS y el TO BE, teniendo siempre presente los objetivos definidos en la fase de Planificación (y en concreto en la conceptualización) expuesta en el apartado anterior. Dichas actividades se enumeran a continuación y para Ortiz [마tiz98 p.224] son las correspondientes a la etapa por él denominada "Elaboración del Plan de Actuación".

- Identificación de las diferencias entre el modelo AS - IS y TO BE: El objetivo será conocer las diferencias entre uno y otro, a través del chequeo entre los distintos procesos de un modelo y otro.

- $\quad$ Planteamiento de la transición: Elección de entre varias alternativas de la mejor vía para pasar de un modelo a otro.

- Establecer las prioridades de cada uno de los caminos propuestos para realizar la transición: supone hacer unas prioridades de clasificación de procesos, análisis económicos, análisis de inversión, etc. que finalizará en una priorización de opciones.

- Definir los equipos de procesos: Definir los Elementos empresariales para el proceso, ya que puede ocurrir que necesiten de unas habilidades y características específicas para el personal, o que desaparezcan una serie de procesos por otros más nuevos, etc. Todo ello habrá de definirse básicamente en este punto. 
- Planificar la Gestión del cambio: Con ello se alude a abordar todos los aspectos relacionados con los cambios en el sistema organizativo.

- Realizar el documento del plan de actuación: este documento reflejará todo el trabajo realizado que ha de entregarse a la Alta Dirección de la empresa, para que conozca la situación de la entidad, propuestas planteadas, evalúe las oportunidades, etc.

Ortiz [Ortiz98 p. 238] señala que en esta fase de análisis, pueden terminar ocurriendo tres cosas:

Aprobar la propuesta: lo que supone seguir con el resto del proceso

Denegar la propuesta: Lo que llevaría a suspender el proceso, de forma momentánea o definitiva.

Solicitar información adicional: la Alta dirección puede no tener clara la decisión y solicitar información adicional para tomar la decisión. En este caso ha de aportarse documentación hasta desembocar en uno de los dos supuestos anteriores.

Ortiz [Ortiz98 p.238] propone que en esta fase que denomina como "Elaboración del Plan de actuación", es necesario generar un informe que clarifique cual es el estado actual del problema, la solución que se propone, y lo que ello supone, además de realizar todo el trabajo con detalle de las siguientes fases mediante la definición de requerimientos.

En el informe emitido, la empresa podrá apreciar la cuantificación real del problema, ya sea en excesivos recursos, tiempo, etc. Y si finalmente se aprueba el plan de Actuación, es cuando se abordan las fases que darán lugar a que los procesos se desarrollen hasta ser operativos en la empresa.

A partir de aquí se realiza una Definición de Requerimientos. Ya que una vez finalizado y aprobado el plan de actuación, han de definirse los requerimientos que permitan la generación del proceso necesario para alcanzar los objetivos estratégicos. 
Para ello, Ortiz [Ortiz98 p.268] propone que ha de realizarse:

Ordenación jerárquica de funciones: Procesos de Dominio, Procesos de negocio (nivel jerárquico inferior) y Actividades de la empresa.

Asignación de objetivos y restricciones para cada una de las funciones

Análisis del proceso dinámico de los procesos, es decir, su ejecución

Detalle de las actividades de la empresa: definiendo la información necesaria para ejecutarse, tomar decisiones, y desarrollar cada actividad y recursos necesarios para su realización.

Análisis de consistencia: que comprobará si la generación del modelo es correcta, y en caso contrario identificar las inconsistencias, analizarlas y solucionarlas

Estas actividades que componen la etapa de Análisis, suponen la comprobación de los modelos AS IS - TO BE y sus diferencias, además de como afectan los distintos procesos de cada modelo a los objetivos estratégicos, identificando las diferencias entre ellos, y proponiendo distintas alternativas de transición.

A continuación se identifican los beneficios potenciales que puede proporcionar cada alternativa de entre los posibles modelos, optándose por una de ellas, dándole prioridad, pero a su vez, teniendo en cuenta los tipos de procesos, los recursos que consumen, la línea de actuación, y otros posibles puntos.

Con los objetivos bien claros, se definen los elementos empresariales necesarios para su resolución: Infraestructura, información, personal, productos o servicios que se quieren ofertar, y como se realizarán los posibles cambios, y finalmente la generación de un informe descriptivo del problema actual, y solución propuesta sobre la base de los requisitos establecidos. 


\subsubsection{Etapa de Análisis del Modelo de Recursos Humanos}

Una vez realizada en la Etapa de Planificación, la conceptualización de los conceptos estratégicos tanto de la empresa como del área de Recursos Humanos (entidad de negocio), la etapa de Análisis, ha de realizarse como se ha propuesto en la parte teórica precedente. Es decir, a través de la realización de un Análisis de las actividades a que se dedica la empresa, así como una asignación de los objetivos y restricciones de cada una de las funciones que se lleven a cabo. Además de ello, hay que realizar principalmente una ordenación jerárquica de funciones, establecer un proceso de ejecución y finalmente estudiar la consistencia.

Para ello se comenzará con la primera etapa propuesta en la parte teórica del apartado anterior 5.3.1, donde se propone la identificación de las diferencias entre el modelo AS IS y el modelo TO BE. En el caso del modelo de Recursos Humanos, se parte de un modelo AS IS que supone únicamente una serie de puestos ordenados jerárquicamente según la pirámide clásica propuesta por De Miguel en la Ilustración 5. 1, para llegar a un modelo TO BE más complejo, donde la ordenación jerárquica se base en el ciclo de vida que ha de desarrollar un departamento o entidad de negocio y las funciones que ha de realizar cada uno de los puestos dentro del modelo.

Finalmente, en esta etapa hay que analizar como se gestionará el cambio, para ello se elaborará un documento con el plan de actuación propuesto que será presentado a la dirección para su aprobación, reflejando dicho documento el trabajo resumen de lo elaborado en las etapas de planificación y análisis.

Dicha tarea corre a cargo del Analista, que será quien defina los modelos del sistema de negocios en términos rigurosos y técnicos. Para ello, el analista se basará en los elementos empresariales ya presentados (procesos, productos o servicios, personas, información e infraestructura) definiendo la funcionalidad (eficacia y eficiencia) de cada uno de ellos.

Para ello, el analista deberá describir la forma en que cada uno de ellos funciona y se ejecuta, así como los componentes del ciclo de vida. Así pues, crea en base a los elementos empresariales una arquitectura para los elementos empresariales, definiendo las características que ha de tener el personal y los equipos que intervienen, y los eventos que causan transformación y cambio en el proceso de negocio para cumplir siempre los objetivos. 


\subsection{ETAPA DE DISEÑO DEL NUEVO MODELO DE RECURSOS HUMANOS}

\subsubsection{Etapa de Diseño}

El propósito de esta etapa es definir como los requisitos del sistema definidos en la etapa anterior (apartado 5.3) pueden llegar a ser implementados. Zelm, Vernadat, y Kosanke [Zelm95]. Pero hay que tener en todo momento presente tanto las políticas de la empresa, como los objetivos y restricciones planteados por ésta. De modo que los bloques constructivos que se definieron en la fase anterior, se amplían con extensiones.

Otra característica de esta fase, es que las etapas anteriores de planificación y análisis, fueron llevadas a cabo por la Alta Dirección, esta etapa comienza a incorporar especialistas en el diseño para su conclusión con éxito. Dichos especialistas serán capaces de cumplir con los requisitos definidos por la Alta Dirección a través de la correcta definición de los elementos empresariales necesarios. De modo que se añaden atributos adicionales al modelo como el tiempo, localización, etc.

Con lo que el objetivo final es generar un modelo implementable a partir del modelo generado por la fase de Análisis. Las subfases que propone Ortiz [Ortiz98 p.271] en esta etapa, la cual denomina "Especificaciones de diseño", son:

Consolidación de la Fase de Definición de Requerimientos

Diseño del comportamiento

Diseño Operacional

Diseño del Sistema de Información

Diseño del Sistema de Recursos 


\section{Diseño Organizacional}

Diseño del Sistema de Tecnologías de la información

Verificación del Diseño:

Por lo tanto, el resultado de esta fase supondrá la generación de un modelo que cubra las expectativas de los requerimientos, así como los objetivos principales establecidos por la organización.

\subsubsection{Etapa de Diseño del Modelo Propuesto de Recursos Humanos}

La etapa de Diseño del Modelo de Recursos Humanos llevará a definir como los requisitos propuestos en los anteriores apartados pueden llegar a ser implementados.

A partir de aquí, el modelo de Recursos Humanos diseñado, ha de evolucionar por las siguientes etapas:

- Consolidación de la fase de definición de requerimientos: a través de la incorporación de personal de diseño, denominando a dicho puesto Diseñador, y su principal tarea será definir la estructura de los componentes del sistema.

- Diseño del comportamiento: Los diseñadores deberán especificar cual ha de ser el comportamiento real para cada uno de los puestos y para el desarrollo de las distintas actividades. Para ello, este trabajo propone la utilización de la propuesta de Zachman [Zachman], presentada en el capítulo primero.

- Diseño operacional: Este tipo de diseño supondrá la descripción de las operaciones y como se ejecutarán de forma puntual las tareas de cada elemento, su acoplamiento y ubicación para obtener los productos o servicios. 
- Diseño del Sistema de Información: Es claro que cada puesto dentro de un sistema ha de recibir una cantidad de información, que no ha de ser la misma que reciba otro de los puestos de esa misma empresa. Por ello, hay que diseñar la cantidad de información que recibe cada puesto y de que nivel o categoría ha de ser ésta. Es en este momento del diseño, cuando se establece el diseño del tipo y cantidad de información que recibirá cada uno de los puestos propuestos, ya que no ha de ser la misma para la Alta Dirección, que para un operario, debido a que los primeros necesitarán un tipo de información para la planificación general de la empresa, mientras que los segundos, necesitarán una información mucho más puntual de cómo cumplir con sus obligaciones y actividades. Como se muestra en la Ilustración 5.5

- Diseño del Sistema de Recursos y de Sistemas de Tecnologías de información: En este caso, tanto los recursos como la tecnología, pueden englobarse en el elemento empresarial identificado en el apartado 2.2 como: Infraestructura. El diseño de la misma va a ser a su vez importante, ya que dependerá de su buen uso, el que las actividades se puedan realizar de forma eficaz y eficiente, igual que el apartado anterior, no necesitará la misma tecnología un directivo para su planificación y toma de decisiones, que un operario.

- Diseño Organizacional: Éste se hará partiendo de las relaciones de responsabilidad y autoridad. Para ello, el modelo del modelo AS IS mostrado en el apartado 5.2.1 con la pirámide clásica de puestos, de modo que se mantiene la línea jerárquica y las relaciones existentes entre los puestos.

El diseño supondrá por tanto definir los modelos tecnológicos y de infraestructura con qué operarán los modelos planificados y analizados. Para ello hay que definir estructuralmente cada uno de los componentes del proceso de negocio con base a los elementos empresariales, es decir, comprobar la robustez de cada uno de los componentes. Hay que describir la ejecución puntual de cada una de las tareas de los componentes del proceso de negocio y como acoplar éstas para que se genere producto o servicio, a la vez que se define la situación física de los elementos y funciones de cada uno de los puestos. 
El proceso de negocio se convierte en mensajes y operaciones, para lo que es preciso diseñar todo de forma detallada, incluido el momento en que se llevarán a cabo cada una de las tareas. Todo ello se realiza en pro de conseguir unos objetivos específicos de cada uno de los componentes del proceso de negocio.

Pero hay que tener presente cómo se producirán las relaciones a la hora de diseñar el modelo. En la Ilustración 5. 5, se puede observar como ha de mantenerse la línea jerárquica en las relaciones que se producen entre los miembros del mismo grupo dentro de la misma. Así, las relaciones que mantienen los Altos Directivos como puede ser un Director General, suelen producirse con otro Director General, mientras que son los operarios de un departamento o sección quienes se relacionen de forma habitual con los de otro departamento o sección.
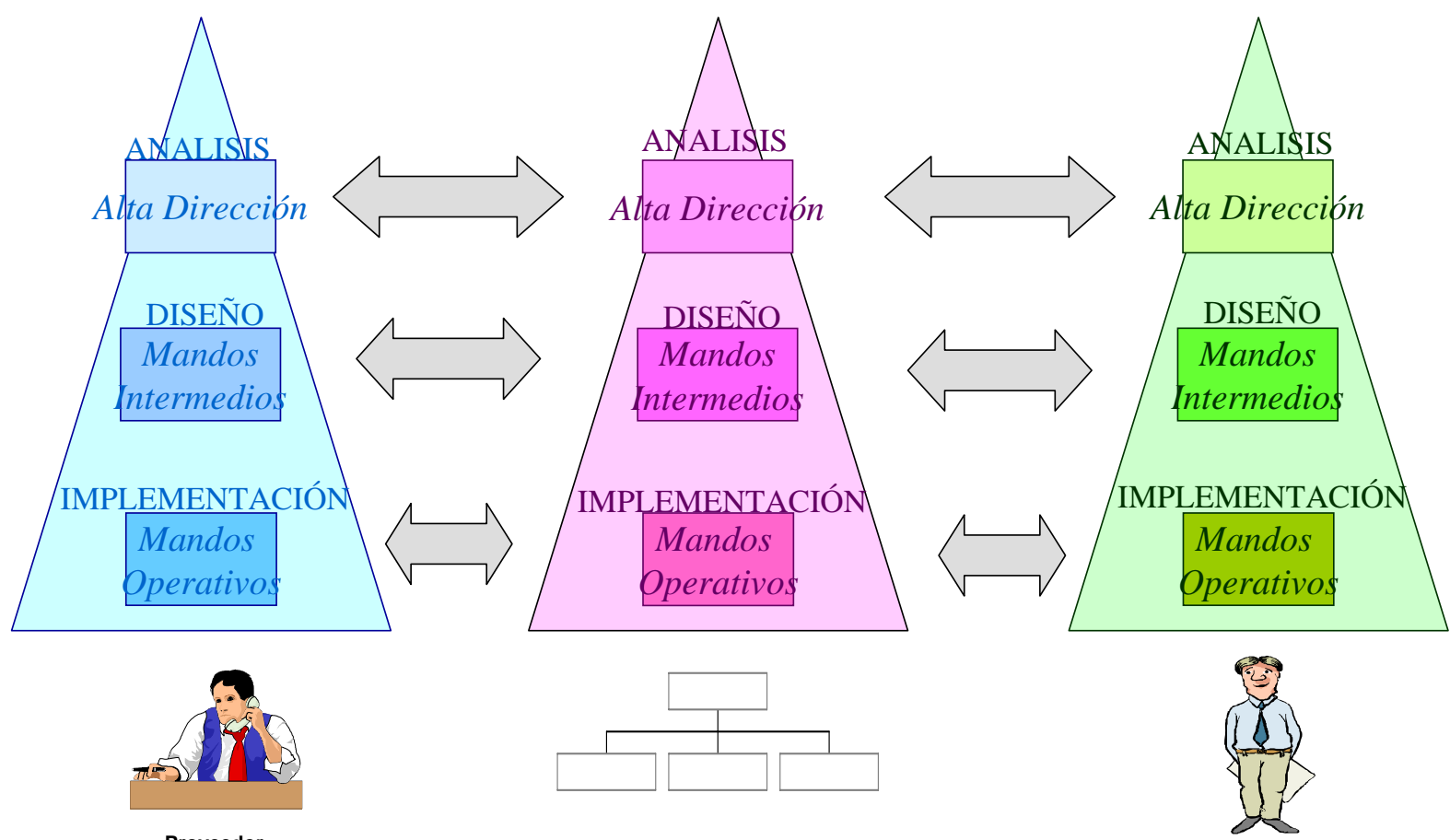

Ilustración 5. 5: Relación existente entre los distintos niveles jerárquicos en la empresa con sus homólogos externos o de otro departamento. Fuente: Elaboración Propia

Finalmente, la última de las etapas que ha de cumplir el diseño del Modelo de Recursos Humanos, es la simulación de que el modelo funciona y existe. 
Cumpliendo todas estas etapas, se logrará generar un modelo que cubra las expectativas de los requerimientos y los principales objetivos establecidos en las etapas anteriores.

Una vez diseñado el modelo y realizada la simulación, habrá que implementarlo. Para ello, intervendrán tanto los mandos operativos como los operarios. Los mandos operativos serán quienes definan lo representado en el modelo en un lenguaje específico de comprensión para quién tiene que ejecutar las órdenes. Mientras que los operarios, serán quienes ejecuten las tareas definidas en el modelo.

Los Mandos Operativos definen la forma en que cada una de las tareas del proceso se implementa de forma real. Para ello deberá describir operativamente como se realizan las tareas en cada paso del proceso de negocio. Esto supone realizar especificaciones sobre donde se realizará cada una de las tareas del proceso, que persona realizará cada tarea, y en que momento puntual la llevará a cabo. Todo ello con el objetivo de que se cumplan las tareas asignadas a cada componente de negocio empresarial.

Los operarios por su parte, ejecutarán las tareas asignadas basándose en las indicaciones proporcionadas. Para ello, se tendrán que encontrar en las ubicaciones definidas para cada tarea y en el momento indicado y con ello lograr ejecutar las tareas del proceso de negocio.

\subsection{PRESENTACIÓN DEL MODELO PROPUESTO DE RECURSOS HUMANOS}

Para comenzar a discutir el modelo de Recursos Humanos propuesto, se utilizará una representación gráfica de la evolución del mismo, que supondrá partir del modelo AS IS de niveles jerárquicos propuestos en la Ilustración 5. 1. Por lo tanto, partiendo de la existencia de tres niveles básicos correspondientes a: Alta Dirección, Mandos Intermedios y Mandos Operativos y Operarios, y conociendo quienes participan principalmente en cada una de las distintas etapas del ciclo de vida, como se ha ido explicando en el apartado 5.2.2 y en 
particular la Tabla 5. 1, surge el primer planteamiento del nuevo Modelo, que se muestra en la Ilustración 5. 6.

En dicha ilustración se muestran los niveles de personal propuestos en la Ilustración 5.1 y las etapas del ciclo de vida asociadas, proponiéndose en ésta ilustración una agrupación de las distintas etapas del ciclo de vida expuestas en el capítulo tercero, en tres grandes bloques, según quién las lleve a cabo y por asociación genérica de las mismas. De tal modo, quedaría, un primer bloque de Planificación y Análisis, que se le denominará ANALISIS, un segundo bloque de DISEÑO, y un tercer bloque de IMPLEMENTACIÓN, que incluye la implementación, mantenimiento y control. Y como se ha planteado en la Tabla 5. 1, cada uno de estos grandes bloques sería ejecutado por los siguientes grupos de personal respectivamente: Alta dirección, Mandos Intermedios, y Mandos operativos y Operarios.

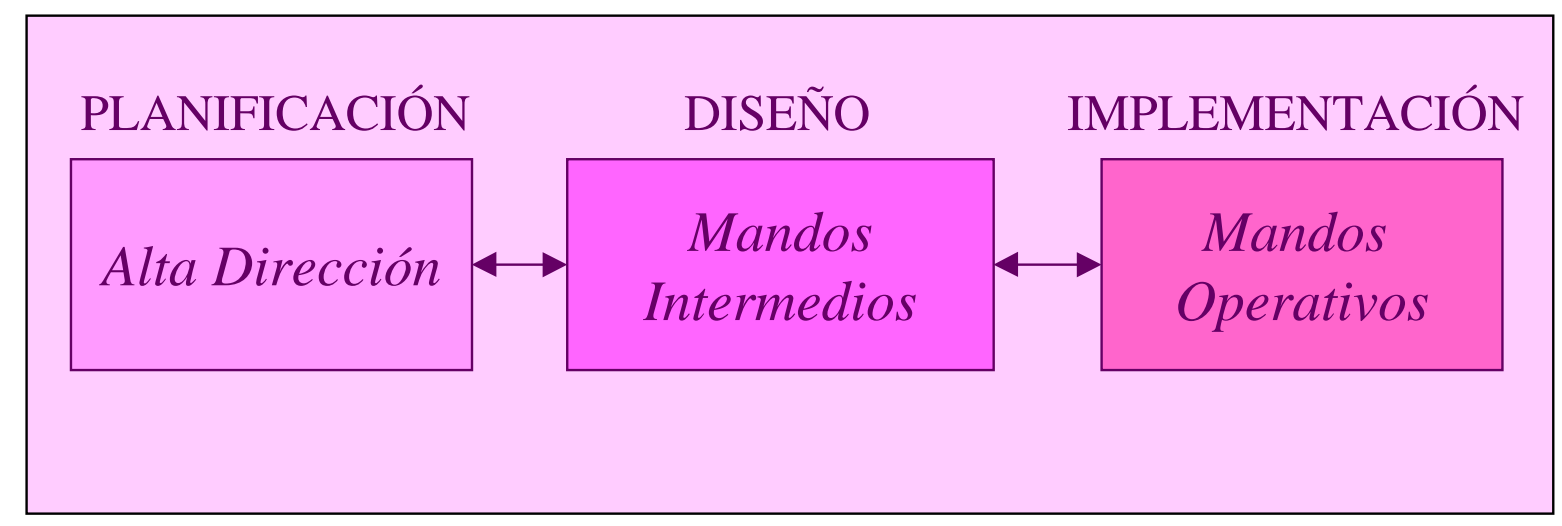

Ilustración 5. 6: Niveles de personal existente en una entidad de negocio y las tareas relacionadas. Fuente: Elaboración Propia

Pero esto es realmente más complejo, debido a que el personal que interviene en las organizaciones desarrollando las etapas de un proceso (que supondrán un ciclo de vida de dicho proceso), a su vez se han de apoyar del resto de elementos necesarios para conseguir bienes y/o servicios. Por ello, dichos puestos necesitan de Información e Infraestructura para poder desarrollar sus tareas y colaborar en la producción de bienes y/o servicios.

Pero según se puede apreciar en la Ilustración 5. 2 y Ilustración 5. 3, donde se muestran Aptitudes y Habilidades técnicas y humanas necesarias para cada tipo de mando. Así quienes ocupen puestos en la Alta Dirección, necesitarán de más aptitudes conceptuales y humanas, y de menores aptitudes técnicas. Mientras que por el contrario, quienes desempeñen mandos 
operativos o sean operarios, deberán disponer de mayores aptitudes técnicas y menores aptitudes conceptuales.

Esto es importante debido a que a la hora de disponer de los elementos empresariales Información e Infraestructura, éstos no serán utilizados igualmente por las distintas categorías de personal: Alta Dirección, Mandos Intermedios, Mandos Operativos y Operarios, mostradas en la Ilustración 5. 1.

Por lo tanto, para el desarrollo de los puestos correspondientes a la Alta Dirección se requerirá de un bloque de información distinto al necesario para el resto de puestos. Es necesario tener información para la toma de decisiones, planificación de la empresa y recursos disponibles con los que puede contar la empresa. Igualmente la Alta Dirección hará uso de una Infraestructura para el desarrollo de sus tareas, que puede no ser la misma infraestructura o incluso siendo la misma puede ser utilizada de forma distinta a la que utilizan el resto de puestos dentro de la organización.

Por su lado, los Mandos Intermedios requieren así mismo de un bloque de información y recursos necesarios para el desarrollo de sus tareas. Aunque dicha información no será la misma que la necesaria por la Alta Dirección, sino información de un modo más puntual, ya que se requerirá en forma de datos más específicos, como por ejemplo información correspondiente al tamaño de los almacenes, depósitos, naves, rutas existentes, etc. de modo que no sólo necesitan saber quien es el cliente, sino toda la información disponible respecto a dicho cliente en lo que a logística se refiere: capacidad, rutas, almacenes, etc.

Por último, los Mandos Operativos requieren información más puntual de la empresa o cliente en lugar de una información genérica. Esto generará la creación de la Ilustración 5. 7, en la que se muestra la relación del elemento personal asociado al proceso correspondiente, y la relación existente con la información y la Infraestructura.

Las líneas de distinto grosor que relacionan la Información con las distintas casillas correspondientes a personal, suponen la cantidad distinta de información que recibe cada uno de los bloques de personal.

Lo mismo ocurre con la Infraestructura, ya que los elementos necesarios para llevar a cabo las tareas correspondientes no han de ser los mismos o ser utilizados de forma distinta según los 
puestos. La justificación de líneas de distinto grosor que relacionan la casilla de Infraestructura y las casillas correspondientes al personal, proceden de la distinción realizada al principio de este apartado, debido a que los mandos operativos y operarios tienen un mayor componente técnico, por lo que se verán relacionados con más tecnología o infraestructura.

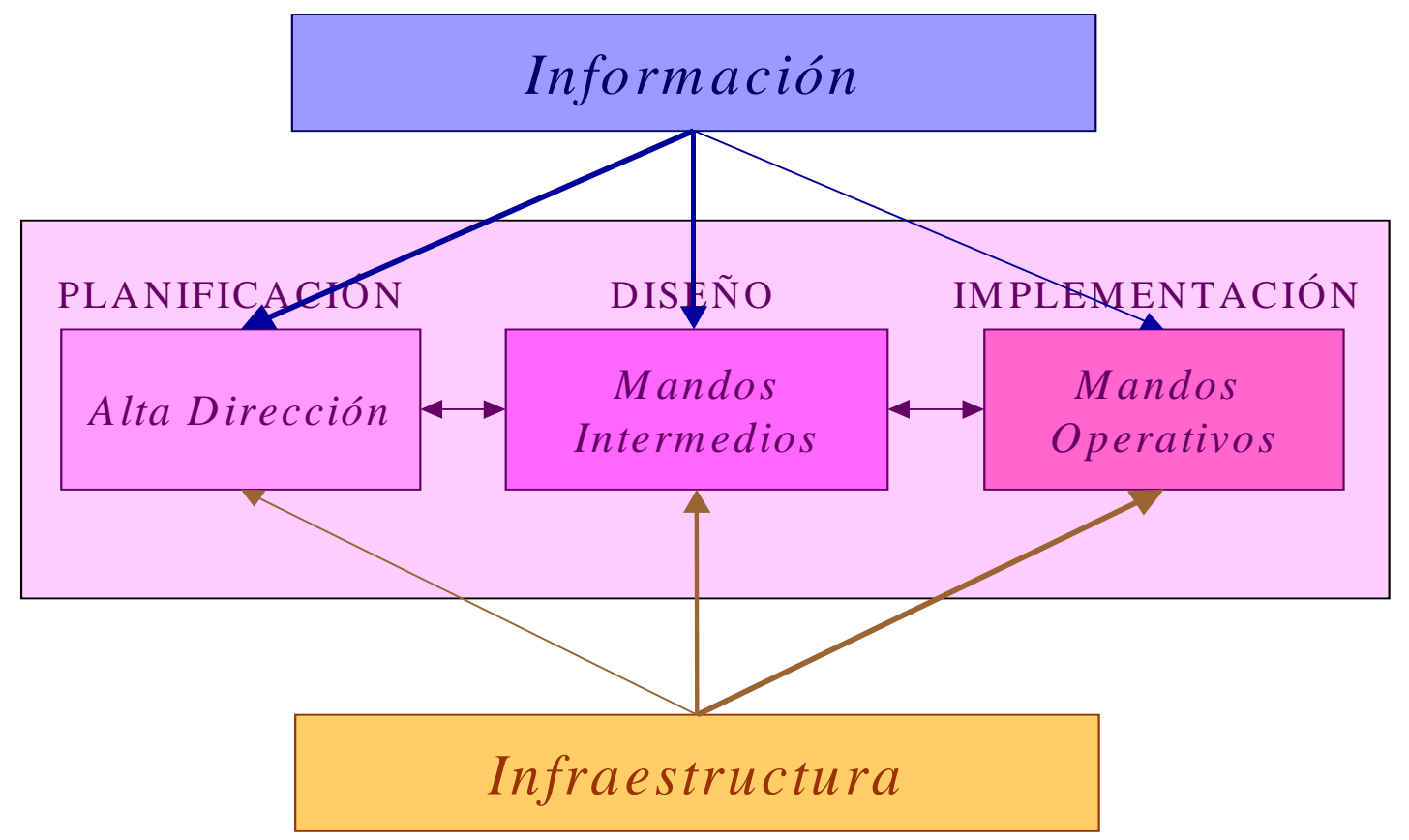

Ilustración 5. 7: Relación entre niveles de personal, proceso, información, infraestructura, y producto/servicio. Fuente: Elaboración Propia.

Como se puede comprobar en esta Ilustración 5. 7, aparecen relacionados, los cinco elementos empresariales ya comentadas el capítulo 2, apartado 2.2: la información que será necesaria para que los distintos puestos realicen sus tareas, la tecnología o infraestructura necesaria para el desarrollo de las tareas del personal, el personal propiamente dicho, reflejado en los distintos niveles jerárquicos, el proceso, que supondrá el recorrido a través de las etapas del ciclo de vida y finalmente el producto y/o servicio obtenido que se verá como el servicio prestado, y será el resultado del proceso realizado.

Finalmente logra consolidarse el modelo de Recursos Humanos propuesto basado en los procesos que han de desarrollar en un departamento o entidad de negocio. Y respaldado por arquitecturas sólidas como la de Ortiz y Zachman con lo que la expresión gráfica de dicho modelo quedaría representada en la Ilustración 5.8 : 


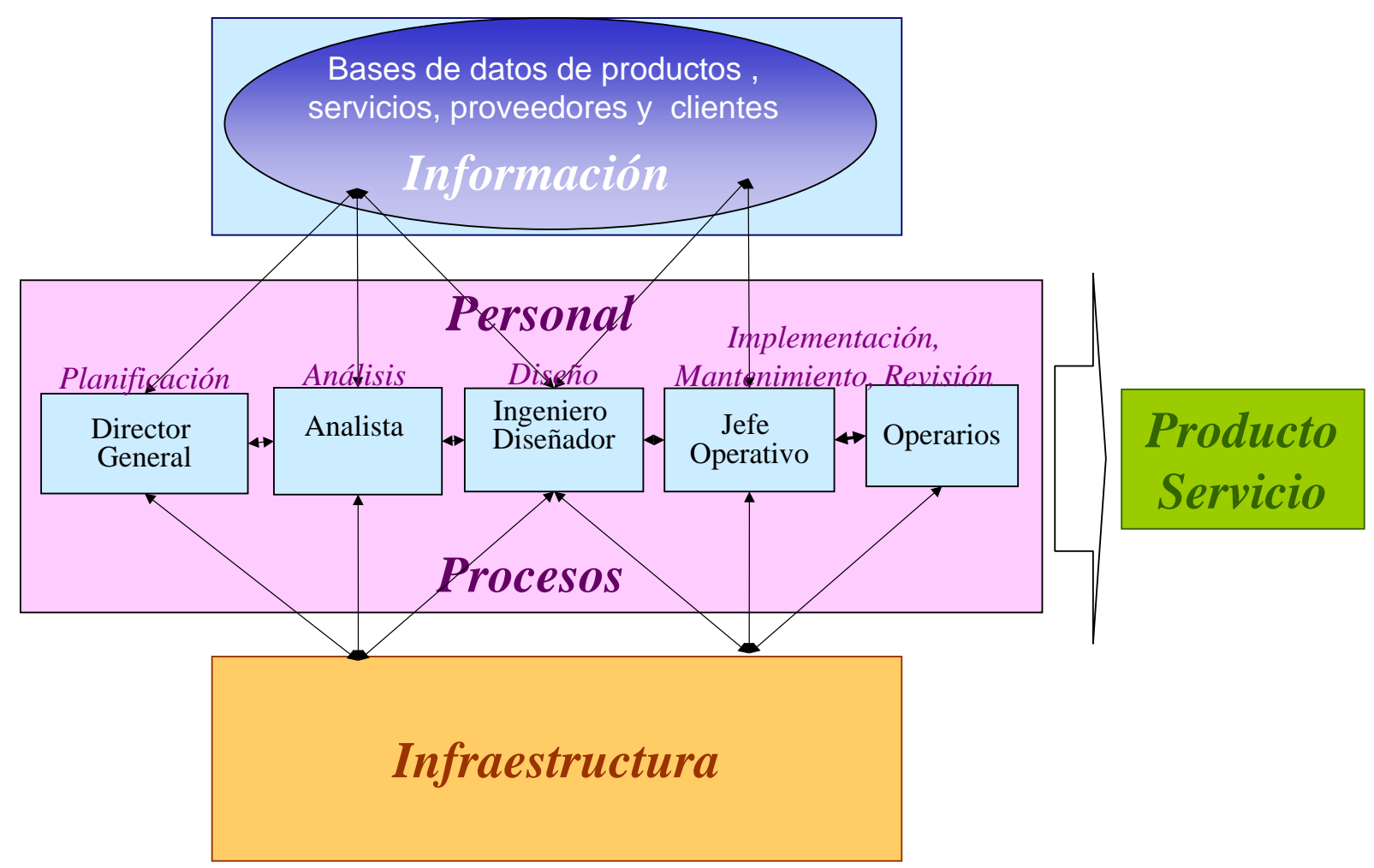

Ilustración 5. 8: Modelo de Recursos Humanos propuesto para la Entidad de Negocio.

Fuente: Elaboración Propia

Esta ilustración muestra como a lo largo de un departamento o entidad de negocio se definen una serie de puestos encargados de cumplir con las etapas existentes a lo largo del proceso que ha de llevarse a cabo (Ciclo de vida).

Por ello se propone el puesto de Director General como aquel que realiza funciones básicamente de Planificación, ya que es quién tiene la visión del proceso empresarial completo y decide la gestión que se llevará a cabo en la empresa, hacia el interior y exterior. Planifica y aporta la visión, misión, objetivos y metas a alcanzar, lo que supondrá según Mullins [Mullins02 p.175] "Ilevar a cabo actividades de dirección, como la planificación, control, coordinación y comunicación”.

El Analista realizará un estudio en profundidad de la funcionalidad empresarial, decidiendo a través del análisis que realiza si los procesos son factibles, y que utilidad tendrán en la organización. Siguiendo con la planificación establecida por el Director, el analista es quién define los requisitos del sistema, así como las políticas, prácticas y datos necesarios. 
El Ingeniero será encargado de generar un modelo empresarial solicitado basándose en las especificaciones que surgen de la planificación y análisis realizados por el director general y analista. Dicho diseño se realizará partiendo de los recursos, estándares y restricciones existentes dentro de la organización.

El Jefe Operativo será quién implemente los modelos obtenidos a partir de las fases de análisis y diseño realizados anteriormente. Debe conocerse la infraestructura disponible para poner en marcha los procesos, y por tanto ha de tenerse para ello información precisa y puntual de las tareas que han de realizarse. Por último, los Operarios llevan a cabo cada una de las tareas necesarias para realizar la implementación de los procesos, de manera puntual y personalizada, a través de las tareas impuestas por el jefe operativo.

Para el Instituto de Dirección de Proyectos (Project Management Institute) [PMI Capitulo 10], esta relación se debe a que "todo el personal de una organización que desarrolla un proceso, debe estar preparado para enviar y recibir información, y entender como afecta dicha información a todo el proceso. Además será muy importante tener una perspectiva del modelo de comunicación, ya que a su vez seguirá un ciclo de vida, debido a que tiene una parte de planificación, distribución de la información, realización y cierre."

En dicha planificación, se estudia quien necesita que información para cada puesto, cuando se necesita y cómo se proporciona a cada quién la información. La distribución de la información se realizará de modo que ésta llegue de forma puntual y en el momento preciso a cada nivel de la organización involucrada en el proyecto. Esto se implementará recogiendo y distribuyendo información al personal, teniendo en cuenta que recursos hay que proporcionar para lograr los objetivos del proyecto. Una vez finalizado el proceso, se cierra. Básicamente el esquema de todo ello se muestra en la Ilustración 5.5

Aplicado a la empresa, supondrá que hay que planificar la información necesaria para realizar los procesos en cada uno de los puestos, detallando: quién necesita qué información, cuando se necesita, cómo se proporcionará a cada puesto, etc.

Por tanto, la comunicación y relación que se produce entre el personal de una entidad de negocio y el personal correspondiente a otras entidades de negocio como pueden ser: los proveedores, clientes u otros departamentos, se producirá básicamente entre los mismos niveles jerárquicos, es decir, que seguirá aproximadamente la misma estructura de mandos, de 
forma que la Alta Dirección de proveedores, clientes y departamentos se relacionará principalmente con la alta Dirección del departamento correspondiente, los mandos operativos de proveedores, clientes o departamentos dentro de la empresa se relacionarán con los mandos operativos del departamento en cuestión, y lo mismo ocurrirá con los operarios de unos y otros, lo que se presentó en la Ilustración 5. 5.

\subsubsection{Contenido de los Puestos del Modelo de Recursos Humanos Propuesto}

Una vez presentados los puestos y sus principales tareas básicas en función al ciclo de vida, hay que pasar a desarrollar las principales tareas y procesos a llevar a cabo por cada uno de esos puestos propuestos.

Para delimitar cuales son las tareas y procesos principales que ha de realizar cada uno de estos puestos dentro del modelo de Recursos Humanos propuesto, se toma como base las arquitecturas expuestas en el capítulo primero y en particular la arquitectura creada por J. Zachman [Zachman y Zachman2], ya que permite su presentación de forma adecuada al desarrollo que se ha venido realizando.

Por ello la primera columna vertical donde aparecen los puestos del personal, es decir, aquella donde se identifican para Zachman los puestos existentes en las arquitecturas empresariales, aparecerán ahora los puestos propuestos por el nuevo Modelo de Recursos Humanos Propuesto, es decir, los puestos de Director General, Analista, Ingeniero Diseñador, Jefe Operativo y Operarios, todos ellos mostrados en la Ilustración 5. 8, donde además aparecen asociados a las principales tareas que desempeñan a lo largo del ciclo de vida.

El Director General puede serlo tanto de la empresa como del Departamento. En el primer caso será quién defina el modelo contextual de negocios, es decir la dirección de la empresa y el propósito del negocio, mientras que en el segundo caso será quien defina los modelos de negocio del departamento, caso que suele venir representado por una única persona. El Analista, será el encargado de definir los modelos de la entidad de negocio en términos más rigurosos y técnicos, pudiendo en este caso estar representado por más de una persona, o bien que sea una persona ocupando además de este, otro puesto. Por su parte, el Ingeniero definirá los modelos tecnológicos y de infraestructura necesarios para ejecutar los modelos que han 
definido anteriormente el director y analista, pudiendo ser este puesto mayor en número que el analista, y a su vez una única persona estar ocupando el puesto de diseñador, analista e incluso dirección. Los puestos de Jefe Operativo corresponden al encargado de definir las representaciones realizadas por los anteriores pudiendo habitualmente ser mayor en número al diseñador. Finalmente el Operario será quien ejecute las tareas definidas por el Jefe Operativo, siendo mayor en número a éste.

En el sentido horizontal aparecen las principales cuestiones que se plantean para cada uno de los puestos, es decir: ¿Qué?, ¿Cómo?, ¿Dónde?, Quién?, ¿Cuándo?, ¿Porqué?. Utilizando una tabla de doble entrada y haciendo un cruce de todas estas casillas se obtendrá que tareas realizan cada uno de los puestos, como las lleva a cabo, donde se realizan, quién las realiza, cuando y el motivo de realización a través del porqué. Todo ello supondrá un análisis con profundidad de las tareas y procesos que han de desarrollarse en la entidad de negocio, y a su vez, se irán definiendo el resto de elementos empresariales necesarios para generar esos procesos. El resultado queda reflejado en la Tabla 5. 2.

De forma que al cuestionar ¿Qué? se plantea la descripción de objetos físicos, conceptuales o de información que han de llevarse a cabo. Para lo que hay que dirigir el conocimiento y la información de cada puesto en pro de conseguir esos objetivos. Especificando ese ¿Qué? en el caso del Director General de la empresa supondrá proporcionar una lista de elementos empresariales importantes para la empresa y como afectan a su dirección y propósito. Mientras que el director de departamento, ese qué se convierte en el listado de los elementos empresariales del departamento o entidad de negocio. Posicionándose en la figura del Analista, el qué supondrá definir las funciones, en términos de eficacia y eficiencia, de cada uno de los componentes de la entidad de negocio desde el punto de vista interno y externo. Mientras que para el Ingeniero, supondrá definir la estructura de cada uno de los componentes de la entidad de negocio basándose en los elementos empresariales y proporcionando robustez a los componentes. El Jefe operativo tomará la definición proporcionada y dará forma a como implementar cada una de las tareas, para finalmente los Operarios ejecutar las operaciones de los procesos con los elementos empresariales disponibles.

El ¿Cómo? describirá aquellas acciones necesarias para llevar a cabo la misión de la empresa a través de la definición de operaciones detalladas. Esto supone por parte del Director General de la empresa realizar una lista de tareas desde el punto de vista de la empresa, mientras que 
para el Director de Departamento supone describir el modelo de negocio que sirva para ejecutar cada una de las tareas empresariales del departamento. El Analista, describirá desde el punto de vista funcional la forma en que se ejecutan cada uno de los componentes de la entidad de negocio (ciclo de vida). Mientras que el Ingeniero, describirá como se ejecutan puntualmente cada una de las tareas de los componentes del proceso de negocio y como acoplar estas tareas para que se genere producto o servicio. Por su parte, el Jefe Operativo describirá operativamente la realización de las tareas en cada paso del proceso de negocio, y los operarios ejecutarán cada una de las tareas de dicho proceso de negocio.

Por su parte, el ¿Dónde? describirá la ubicación geográfica de las entidades y actividades empresariales. Por lo que el Director General de la empresa decidirá los lugares donde opera la entidad de negocio basándose en los elementos empresariales, y el Director de Departamento describirá como interactúan las localizaciones desde el punto de vista de los negocios y funcional, basado siempre en los elementos empresariales. El Analista, creará la arquitectura de distribución de los componentes de la entidad de negocio y su funcionalidad, mientras que el Ingeniero define la distribución puntual de los elementos empresariales utilizados en cada uno de los procesos de negocio. Basándose en ello, el Jefe Operativo definirá las especificaciones de ubicación de cada una de las tareas del proceso para lo que el Operario se encontrará en dichas ubicaciones definidas para cada una de las tareas del proceso de negocio.

La definición del ¿Quién? supone describir aquellos objetos con cierto nivel de inteligencia (personas, ordenadores, etc. ) involucrados en el proceso empresarial. Para ello el Director General proporcionará la lista de unidades o departamentos de la empresa, así como la misión de cada uno de ellos. El Director de Departamento definirá el organigrama funcional del personal y equipos inteligentes (infraestructura) de la entidad de negocio. El Analista por tanto, definirá las características del personal y equipos del organigrama, para que sea el Ingeniero quién determine la ubicación geográfica puntual y las funciones a realizar en cada puesto. Por ello, el Jefe Operativo será quién asigne personas a las tareas del diagrama funcional y el Operario ejecutará las tareas de dicho diagrama.

El Análisis del ¿Cuándo? supondrá describir el momento en el cual se llevan a cabo las acciones en la entidad de negocio, así como los efectos que tendrá el tiempo. Por ello, el Director General describe el ciclo de desarrollo de la entidad de negocio y los eventos 
empresariales, mientras que el Director de Departamento define cuando ocurrirán las etapas del ciclo de vida del negocio empresarial. Por ello el Analista define los eventos que causan transformación y cambio en el proceso de negocio empresarial. El Ingeniero será quien convierta el proceso en mensajes y operaciones, diseñando el momento en el cual se llevarán a cabo cada una de las tareas. Con esta información, el Jefe Operativo definirá puntualmente el momento de llevar a cabo cada tarea en la entidad de negocio y por tanto los Operarios serán quienes ejecuten las tareas del proceso empresarial en el momento indicado.

Finalmente queda plantear el ¿्टorqué? lo que significa describir los motivos por los cuales se dan las anteriores actividades o cuestiones, trasladando las metas estratégicas a fines específicos. Por ello, al cuestionar el Porqué se actúa de ese modo, el Director General de la empresa se justifica que es para estar acorde a la misión, visión y objetivos de la empresa, mientras que el Director de Departamento lo hace para cumplir la visión, misión y objetivos correspondientes al aspecto empresarial. El Analista hará cumplir los objetivos de la entidad de negocio correspondiente, mientras que el Ingeniero pretende hacer cumplir los objetivos específicos de cada uno de los componentes de la entidad de negocio. Por su parte, el Jefe Operativo busca hacer cumplir las tareas de cada uno de los componentes del negocio empresarial, y finalmente los operarios tratarán de ejecutar las tareas de los componentes del proceso de negocio. 


\begin{tabular}{|c|c|c|c|c|c|c|}
\hline & $\begin{array}{l}\text { QUÉ } \\
\text { Describe objetos físicos, } \\
\text { conceptuales o de } \\
\text { información. Cada fila dirige } \\
\text { el conocimiento y tratamiento } \\
\text { de la información del negocio, }\end{array}$ & $\begin{array}{l}\text { CÓMO } \\
\text { Describe las acciones. } \\
\text { Describe el proceso de } \\
\text { translación de la misión de la } \\
\text { empresa a definición de las } \\
\text { operaciones de forma detallada } \\
\end{array}$ & \begin{tabular}{|l|} 
DÓNDE \\
Describe la ubicación \\
geográfica de las entidades y \\
las actividades empresariales.
\end{tabular} & $\begin{array}{l}\text { QUIÉN } \\
\text { Describe objetos con cierto } \\
\text { nivel de inteligencia (personas, } \\
\text { ordenadores, etc.) } \\
\text { involucrados en el negocio } \\
\text { empresarial.. } \\
\end{array}$ & $\begin{array}{l}\text { CUÁNDO } \\
\text { Describe el momento en cual } \\
\text { se llevan a cabo las acciones; } \\
\text { así como los efectos del } \\
\text { tiempo en el negocio }\end{array}$ & $\begin{array}{l}\text { PORQUÉ } \\
\text { Describe los motivos por el } \\
\text { cual se dan todas las } \\
\text { anteriores. Es el traslado de las } \\
\text { metas estratégicas a fines } \\
\text { específicos. }\end{array}$ \\
\hline $\begin{array}{l}\text { ANALISTA } \\
\text { Define los modelos de la } \\
\text { entidad de negocio, en } \\
\text { términos más rigurosos y } \\
\text { técnicos. Puede estar } \\
\text { representado por más de una } \\
\text { persona }\end{array}$ & $\begin{array}{l}\text { Con base en los elementos } \\
\text { empresariales define la } \\
\text { funcionalidad (eficiencia y } \\
\text { eficacia) de cada uno de los } \\
\text { componentes de la entidad de } \\
\text { negocio desde el punto de } \\
\text { vista interno (algunas veces } \\
\text { desde el externo) }\end{array}$ & \begin{tabular}{|l} 
Describe desde el punto de \\
vista funcional la forma en \\
que se ejecutan cada uno de \\
los componentes del negocio \\
empresarial (ciclo de vida)
\end{tabular} & $\begin{array}{l}\text { Con base en los elementos } \\
\text { empresariales crea la } \\
\text { arquitectura de distribución de } \\
\text { los componentes de la entidad } \\
\text { de negocio empresarial y su } \\
\text { funcionalidad }\end{array}$ & $\begin{array}{l}\text { Define las características del } \\
\text { personal y equipos inteligentes } \\
\text { del organigrama funcional }\end{array}$ & $\begin{array}{l}\text { Define los eventos que causan } \\
\text { transformación y cambio en el } \\
\text { proceso de negocio }\end{array}$ & $\begin{array}{l}\text { Para hacer cumplir los } \\
\text { objetivos de la empresa o } \\
\text { departamento }\end{array}$ \\
\hline $\begin{array}{l}\text { JEFE OPERATIVO } \\
\text { Define las representaciones } \\
\text { detalladas de los modelos } \\
\text { anteriores por medio de un } \\
\text { lenguaje específico. Su } \\
\text { número puede ser mayor al del } \\
\text { Ingeniero. }\end{array}$ & $\begin{array}{l}\text { Tomando como referencia los } \\
\text { elementos empresariales, } \\
\text { define la forma en que cada } \\
\text { una de las tareas del proceso } \\
\text { de negocio se implementa (en } \\
\text { firme) }\end{array}$ & $\begin{array}{l}\text { Describe operativamente la } \\
\text { realización de las tareas en } \\
\text { cada uno de los pasos del } \\
\text { proceso de negocio. }\end{array}$ & $\begin{array}{l}\text { Define las especificaciones de } \\
\text { ubicación de cada uno de las } \\
\text { tareas del proceso, tomando } \\
\text { como base los elementos } \\
\text { empresariales. }\end{array}$ & $\begin{array}{l}\text { Asigna personas a las tareas } \\
\text { del diagrama funcional }\end{array}$ & $\begin{array}{l}\text { Define puntualmente el } \\
\text { momento de llevar a cabo cada } \\
\text { tarea del negocio. }\end{array}$ & $\begin{array}{l}\text { Para hacer cumplir las tareas } \\
\text { de cada uno de los } \\
\text { componentes del negocio } \\
\text { empresarial. }\end{array}$ \\
\hline $\begin{array}{l}\text { OPERARIO } \\
\text { Ejecuta las tareas definidas por } \\
\text { el jefe operativo. Su número } \\
\text { puede ser mucho mayor que el } \\
\text { de los jefes operativos }\end{array}$ & $\begin{array}{l}\text { Ejecuta las operaciones del } \\
\text { proceso desde el punto de vista } \\
\text { de los elementos } \\
\text { empresariales. }\end{array}$ & $\begin{array}{l}\text { Ejecuta cada una de las tareas } \\
\text { del proceso de negocio. }\end{array}$ & $\begin{array}{l}\text { Se encuentra en las } \\
\text { ubicaciones definidas para } \\
\text { cada una de las tareas de cada } \\
\text { uno de los componentes de la } \\
\text { entidad de negocio }\end{array}$ & $\begin{array}{l}\text { Son las personas que ejecutan } \\
\text { las tareas del diagrama } \\
\text { funcional }\end{array}$ & $\begin{array}{l}\text { Ejecuta las tareas del proceso } \\
\text { de negocio en el momento } \\
\text { indicado }\end{array}$ & $\begin{array}{l}\text { Para ejecutar las tareas de los } \\
\text { componentes del proceso de } \\
\text { negocio }\end{array}$ \\
\hline
\end{tabular}

Tabla 5. 2: Presentación de las funciones del Modelo de Recursos Humanos Propuesto. 
Una vez planteadas todas las especificaciones al modelo respecto al ¿Qué? ¿Cómo? ¿Dónde? ¿Quién? ¿Cuándo? y ¿Porqué?, podría sintetizarse de forma más simple por puestos. Por tanto el Director General de la empresa o Director de Departamento será el encargado de aportar la visión, misión y los objetivos empresariales, describiendo a grandes rasgos que elementos empresariales presentados en el punto 2.2. de este trabajo, son necesarios para desarrollar el negocio empresarial y las distintas relaciones existentes. Por ello, al presentar el proceso empresarial, deberá dar las líneas de las actividades que han de realizarse y bajo que modelos ha de hacerse. En la planificación que ha de realizar este puesto, ha de aportar las líneas de cuando sucederá cada una de las etapas del proceso, así como donde se llevarán a cabo y a grandes rasgos el organigrama necesario para ello.

El Analista, será quien realice el Análisis de la situación, para lo que deberá describir la funcionalidad de cada uno de los elementos del modelo, tanto desde el punto de vista interno, como externo. Por ello, dicha funcionalidad supondrá un detalle de la creación de la estructura, el funcionamiento y ejecución de los elementos que intervienen en el proceso, así como las características necesarias de quienes intervienen en cada etapa del proceso. Y finalmente debe apuntar a su vez, aquellos elementos que causen transformación y cambio dentro del proceso.

El Diseñador, se ocupará del diseño del proceso a través de la definición de la estructura de cada elemento empresarial basado en el proceso de negocio. Es decir, define la ejecución puntual de las tareas que componen el proceso de negocio empresarial, su distribución puntual, la puntualización de la distribución geográfica y funciones de cada puesto. La principal característica que desarrolla este puesto consiste en la conversión del proceso en mensajes y operaciones más simplificadas, así como el diseño del momento correcto para su realización.

El Jefe Operativo será quién defina cada una de las tareas del proceso de negocio, describiendo operativamente la realización de cada uno de los elementos empresariales que intervienen en el negocio: lo que supone definir la ubicación de cada actividad de 
forma puntual, la asignación de personal para cada una de las tareas puntuales, así como su momento de realización.

Los Operarios son los encargados de realizar y ejecutar las operaciones y tareas del proceso, para lo que seguirán las indicaciones de los Jefes Operativos realizando dichas tareas en las ubicaciones definidas para cada una de ellas, y utilizando los recursos que les vienen impuestos para la realización de las tareas correspondientes.

Estas especificaciones realizadas de forma más resumida para cada uno de los participantes en el nuevo modelo de Recursos Humanos, se recogen en la Tabla 5. 3, donde se presentan un desglose de las principales tareas que ha de realizar cada uno de ellos. La elaboración de la presente tabla viene derivada de la Representación de las funciones del Modelo de Recursos Humanos Propuesto mostrada en la Tabla 5. 2. 


\begin{tabular}{|c|c|}
\hline ENTIDAD & FUNCIONES \\
\hline Alta Dirección & $\begin{array}{ll}\checkmark & \text { DESCRIBE LOS PROCESOS, INFORMACIÓN, PERSONAL Y TECNOLOGÍA NECESARIA PARA } \\
& \text { DESARROLLAR EL NEGOCIO EMPRESARIAL Y SUS RELACIONES } \\
\checkmark & \text { DETALLA LAS ACTIVIDADES DE NEGOCIO A REALIZAR Y BAJO QUE MODELO SE EJECUTARÁN } \\
\checkmark & \text { DETERMINA LA UBICACIÓN DE LAS DISTINTAS ACTIVIDADES DEL PROCESO DE NEGOCIO } \\
\checkmark & \text { DEFINE EL ORGANIGRAMA, PERSONAL Y EQUIPOS PARA CADA ACTIVIDAD } \\
\checkmark & \text { ESPECIFICA CUANDO SUCEDERÁ CADA ETAPA DEL PROCESO DE NEGOCIO } \\
\checkmark & \text { DESCRIBE LA VISIÓN, MISIÓN Y OBJETIVOS EMPRESARIALES }\end{array}$ \\
\hline ANALISTA & $\begin{array}{ll}\checkmark & \text { DESCRIBE LA FUNCIONALIDAD DE CADA COMPONENTE DEL PROCESO (DESDE EL PUNTO DE } \\
& \text { VISTA INTERNO Y EXTERNO PARA LA ORGANIZACIÓN) } \\
\checkmark & \text { DESCRIBE EL FUNCIONAMIENTO Y EJECUCIÓN DE LOS ELEMENTOS DEL PROCESO } \\
\checkmark & \text { CREA LA ARQUITECTURA DE LOS ELEMENTOS DEL PROCESO } \\
\checkmark & \text { DEFINE LAS CARACTERÍSTICAS DEL PERSONAL Y EQUIPOS INTELIGENTES QUE } \\
& \text { INTERVENDRÁN EN CADA ETAPA DEL PROCESO } \\
\checkmark & \text { DEFINE LOS EVENTOS EMPRESARIALES QUE CAUSAN TRANSFORMACIÓN Y CAMBIO }\end{array}$ \\
\hline INGENIERO & $\begin{array}{ll}\checkmark & \text { DEFINE LA ESTRUCTURA DE CADA COMPONENTE DEL PROCESO DE NEGOCIO BASADO EN } \\
& \text { LOS ELEMENTOS EMPRESARIALES } \\
\checkmark & \text { DESCRIBE LA EJECUCIÓN PUNTUAL DE LAS TAREAS DE LOS COMPONENTES DEL PROCESO } \\
& \text { EMPRESARIAL } \\
\checkmark & \text { DEFINE LA DISTRIBUCIÓN PUNTUAL UTILIZADA PARA CADA COMPONENTE EMPRESARIAL } \\
\checkmark & \text { DETERMINA PUNUTALMENTE LA UBICACIÓN GEOGRÁFICA Y FUNCIONES DE CADA PUESTO } \\
\checkmark & \text { CONVIERTE EL PROCESO EN MENSAJES Y OPERACIONES, DISEÑANDO EL MOMENTO DE } \\
& \text { REALIZACIÓN }\end{array}$ \\
\hline JEFE OPERATIVO & $\begin{array}{ll}\checkmark & \text { DEFINE COMO SE IMPLEMENTA CADA TAREA DEL PROCESO DE NEGOCIO } \\
\checkmark & \text { DESCRIBE OPERATIVAMENTE LA REALIZACIÓN DE TAREAS DE CADA UNO DE LOS } \\
& \text { ELEMENTOS EMPRESARIALES } \\
\checkmark & \text { DEFINE LAS ESPECIFICACIONES DE UBICACIÓN DE CADA TAREA A REALIZAR DEL PROCESO } \\
\checkmark & \text { ASIGNA PERSONAL A CADA TAREA FUNCIONAL } \\
\checkmark & \text { DEFINE EL MOMENTO PUNTUAL DE REALIZACIÓN DE CADA TAREA }\end{array}$ \\
\hline OPERARIO & $\begin{array}{ll}\checkmark & \text { EJECUTA LAS OPERACIONES Y TAREAS DEL PROCESO } \\
\checkmark & \text { SE ENCUENTRA EN LAS UBICACIONES DEFINIDAS PARA CADA UNA DE LAS TAREAS DEL } \\
& \text { PROCESO } \\
\checkmark & \text { UTILIZA LOS RECURSOS QUE SE LE IMPONEN PARA LA REALIZACIÓN DE LAS TAREAS } \\
\text { CORRESPONDIENTES. }\end{array}$ \\
\hline
\end{tabular}

Tabla 5. 3: Funciones desempeñadas por los puestos del Modelo de Recursos

\section{Humanos Propuesto.}

Una vez generado el modelo de Recursos Humanos para una entidad de negocio cualquiera, se puede demostrar su validez aplicándolo a un sector particular.

En este trabajo, y debido a la escasez de referencias bibliográficas se realizará la aplicación del mismo a los sistemas logísticos. Por lo tanto, en los capítulos siguientes se realizará primero una aproximación a los sistemas logísticos, para pasar a 
continuación a realizar una aplicación del Modelo de Recursos Humanos creado en este capítulo a dichos sistemas logísticos, para finalmente comprobar su validez en dicho sector.

\subsection{CONCLUSIONES DEL CAPITULO}

Finalizado este capítulo puede concluirse que se ha logrado generar un modelo de Recursos Humanos (Modelo To Be) basado en los procesos realizados por los participantes en la entidad de negocio.

Dicho modelo se ha creado basándose en las etapas estudiadas en el capítulo tercero correspondiente a los ciclos de vida, y por tanto, comenzando en la Etapa de planificación se han estudiado los requisitos de creación del modelo para posteriormente pasar a su aplicación, con ello se ha conseguido saber cual es el modelo de partida (Modelo AS IS), así como el que se quiere obtener (Modelo TO BE), modelo basado en los procesos realizados por cada uno de los participantes, donde la Alta dirección realizará básicamente tareas de Planificación y Análisis, los Mandos intermedios realizan tareas de Diseño, y los Mandos Operativos y Operarios, tareas de Implementación.

A continuación, en la etapa de análisis, se han identificado las diferencias entre los modelos existentes y el modelo al cual se quiere llegar, sus prioridades, modo de realizar la transición, plan de actuación etc., que en este caso supone identificar al modelo de partida como unos puestos ordenados jerárquicamente según la pirámide clásica, para pasar a una ordenación basada en los procesos que se realizan a lo largo del ciclo de vida, a su vez que se detalla como se gestionó el cambio.

Finalmente, llega la etapa de diseño, que tras la definición de los requisitos supone diseñar la consolidación de los requerimientos, los comportamientos, operaciones, sistemas de información, recursos, infraestructura y organización, es decir, el diseño detallado de la realización de las tareas.

La generación del modelo concluye en el apartado 5.5 donde se Define y concreta el modelo. Por ello siguiendo la línea jerárquica de partida de Alta Dirección, Mandos Intermedios y Mandos Operativos, se han ido añadiendo los elementos empresariales. 
En el caso de los Procesos, se les han asociado los principales procesos que realizan, que para las categorías citadas corresponden básicamente la Planificación, el diseño y la Implementación. Estos niveles realizarán dichos procesos apoyándose en dos importantes bases: el elemento infraestructura, y el elemento información, los cuales serán utilizados en su justa medida dependiendo del nivel jerárquico y puesto a desarrollar para obtener el último elemento: Producto o Servicio. Si desarrollamos más los procesos en base al ciclo de vida expuesto en el capítulo tercero, los puestos que surgen asociados a cada etapa son: Director General realizando tareas básicamente de Planificación, Analista para tareas de Análisis, Ingeniero diseñador para tareas de Diseño, Jefe Operativo y Operarios para tareas de Implementación, Mantenimiento y Revisión. Una vez obtenidos los puestos, se ha elaborado la descripción de ¿Qué?, ¿Cómo?, ¿Cuándo? ¿Dónde? ¿Quién? y ¿Porqué? actúa cada uno de los puestos.

Este modelo de Recursos Humanos obtenido en este capítulo para cualquier entidad de Negocio, se aplicará a partir del siguiente capítulo a un área concreta, la logística. Para ello se realizará en el siguiente capítulo una aproximación a los Sistemas Logísticos y las áreas con las que éstos se relacionan, para pasar en el capítulo séptimo a la generación de un Modelo de Recursos Humanos aplicado a los sistemas logísticos.

\subsection{REFERENCIAS BIBLIOGRÁFICAS DEL CAPITULO}
Albizu
Albizu Gallastegi E. Y J. Landeta Rodríguez. "Contextualización de la función de los Recursos Humanos". Capítulo correspondiente al libro "Dirección Estratégica de los Recursos Humanos" Ediciones Pirámide. España 2001
Bueno96 Bueno Campos, E. "Curso Básico de Economía. Un enfoque de Organización" Editorial Pirámide. España 1996
DeMiguel De Miguel. Introducción a la gestión (Management) I. $8^{\circ}$ Edición. Servicio de Publicaciones de la Universidad Politécnica de Valencia. España 1993
Domínguez2 Domínguez, A. Modelos Curriculares de Postgrado en Informática/Computación, Soluciones Avanzadas, Año 7, Número 68, pp. 50-56, septiembre de 1999
Huse86 Huse E. F., J.L. Bowdich. El Comportamiento humano en la organización. Ediciones Deusto. España 1986
Kersner H. Kersner. Project Management. $7^{\text {a }}$ Edición. Editorial John Wiley. Año 2000. USA
Menguzzato9 Menguzzato M., J.J. Renau. "La dirección estratégica de la empresa. Un 
5

enfoque innovador del management". Ediciones Ariel Economía. $2^{\mathrm{a}}$

Reimpresión . España. 1995

Mullins02 L. J. Mullins. "Management and organisational behaviour" $6^{\text {th }}$ Ed.

Financial Times. Prentice Hall. 2002 UK

Ortiz98 Ortiz A. "Propuesta para el desarrollo de programas de integración empresarial en empresas industriales. Aplicación a una empresa del sector cerámico" Tesis Doctoral. Universidad Politécnica de Valencia.

España 1998

PMI Project Management Institute. (PCI) USA. Chapter 10: Project Communications Management. www.pmi.org Consultada el 10/04/2002

Ross2000 Ross, D.F. "Competing through Supply Chain Management: Creating Market- winning strategies through Supply Chain Parternships" Materials Managment. Logistics Series. Kluwer Academic Publishers $3^{\text {a }}$ Edición. USA año 2000

Zachman Zachman. The Zachman Framework. www.zifa.com .Consultada el 27/09/2001

Zachman2 Zachman. Enterprise Architecture. A framework http://www.istis.unomaha.edu/isqa/vanvliet/arch/isa/isa-rows.htm Consultada el 19/09/2002

Zelm95 Zelm M.; Vernadat F.; Kosanke K. "The CIMOSA Business Modelling Process" Computers in Industry. Volume 27 n $^{\circ} 2.1995$ 


\title{
Capítulo 6.
}

\author{
E1 área de Logística
}


CAPITULO 6

\section{LOS SISTEMAS LOGÍSTICOS}

\subsection{INTRODUCCIÓN}

Una vez presentado en el capítulo quinto la arquitectura del modelo Recursos Humanos Propuesto se comenzará en esta parte de la tesis denominada Validación de la Propuesta su aplicación a un área concreta. El modelo obtenido en el capítulo anterior es de tipo genérico aplicable a cualquier entidad de negocio, pero es a partir de este punto del trabajo donde se procederá a aplicar y confirmar su funcionamiento en una parcela del mundo empresarial.

Dicha parcela se aplicará a los sistemas logísticos, pero antes de comenzar dicha aplicación se realizará una aproximación a los mismos, a través de definiciones que clarifiquen los conceptos logísticos básicos como logística, logística inversa, cadena de suministro etc., así como una introducción histórica de la evolución de la logística en el tiempo, y cuales son los objetivos que persigue la logística.

A continuación en el apartado 6.3, se realiza un recorrido a lo largo de las etapas con las que se relaciona la logística: la gestión de demanda, gestión de pedidos, gestión de aprovisionamiento, gestión de almacenes, gestión de stocks, gestión de distribución. Y 
finalmente en el apartado 6.4 exponer el área de estudio en la cual se centrará este trabajo.

\subsection{CONCEPTO DE LOGÍSTICA}

Desde el principio de la humanidad, las mercancías que la gente deseaba, bien no se producían donde la gente deseaba consumirlas, o bien no estaban disponibles en el momento que les apetecía, por lo que consumían los productos en sus zonas, o los trasladaban a su lugar predilecto, y almacenaban para su posterior consumo; y debido a la dificultad del transporte, se limitaba a lo que cada persona pudiera acarrear.

Ballou [Ballou91 p.1] explica como “con el tiempo, los sistemas logísticos y los puntos de consumo y producción comenzaron a separarse geográficamente. Cada área empezó a especializarse en aquellos bienes que podían producir más eficientemente, trasladando los excesos de producción a otras zonas o mercados, mientras se importaba lo que no se producía localmente.”

La logística comercial, surge como un campo novedoso en comparación con el resto de áreas de la empresa más tradicionales, aunque actividades de transporte y almacenamiento de mercancías se vienen realizando desde siempre. La novedad que apunta Ballou [Ballou91 p. 3] dentro de este campo se centra en "el tratamiento coordinado de las actividades de transporte y almacenamiento de mercancías, en lugar de hacerlo por separado.”

La logística es una ciencia tan nueva que como apunta Ballou [Ballou91 p. 3] "hay que esperar a 1961, para que se produzca la aparición del primer libro de Edward W. Smaykay, Donald J. Bowersox y Frank H. Mossman, "Physical Distribution Management: Logistics Problems of the Firm”. (New York: McMillan, 1961), que sugiere los posibles beneficios de una gestión logística coordinada."

Por lo tanto, al buscar la definición de logística en el diccionario, éste, remite a la ciencia militar. El término de logística comenzó a utilizarlo el ejército francés durante el siglo XVIII, para hacer referencia a la obtención de la impedimenta, armamento y munición que necesitaba para cumplir una misión. No obstante, en la actualidad, tal y como se expuso en el Congreso PILOT de Logística en Zaragoza en 2001, el concepto 
de logística hace referencia a "la gestión de flujos tanto físicos como de información que comienzan en la fuente de aprovisionamiento y acaban en el punto de consumo." [CELPilot2001 p.6].

La logística inversa hace referencia al flujo de vuelta de artículos y elementos de embalaje, incluido el servicio al cliente y la retirada final de los artículos devueltos. Estas devoluciones pueden realizarse sin aviso al proveedor, o con previa comunicación a éste.

La logística inversa incluye la retirada de desechos, productos reciclables, productos perecederos o materiales absolutos. Por lo que supone una parte importante y costosa dentro de la cadena de suministro, ya que requiere que se le dediquen recursos adecuados para poder controlarla.

Debido a la relación actual entre proveedores y clientes, deben considerarse que ha de existir una mayor flexibilidad y atención hacia los clientes, así como considerar las barreras existentes. Para poder llevar con todo ello una gestión eficiente de la Logística Inversa, las organizaciones deben apoyarse en: almacenes (en los cuales se realizarán movimientos bidireccionales) e información para gestionar adecuadamente el problema.

La logística inversa es un tema de creciente actualidad, debido a que por presiones a clientes, costes de obsolescencia, leyes medioambientales, etc. hace que las empresas se cuestionen seriamente la importancia de tratamiento de los artículos.

\subsubsection{Evolución temporal del área de Logística en las empresas}

\section{Primera Época: Los años del letargo}

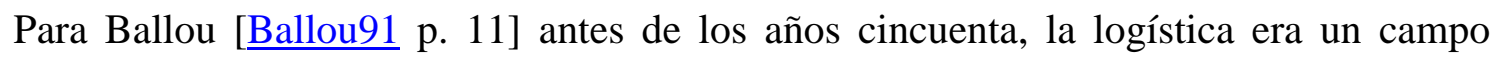
aletargado dentro de la gestión empresarial. Aunque las actividades logísticas se consideraban importantes, no se favoreció un ambiente favorable de reconocimiento de la importancia logística en la empresa. 
Dicho autor señala como desde los inicios de la Revolución Industrial hasta la década de los años veinte, hubo sobre todo en Estados Unidos, una rápida expansión de mercados, que sumado a la expansión tecnológica, especialización del trabajo, inversión, recursos naturales, y un escaso control del sistema político, llevó a una rápida expansión de la economía, debido a que la producción creció rápidamente para satisfacer a una creciente demanda. En estas condiciones, la preocupación principal de los directivos era la producción, que permitía vender fácilmente todo lo que se fabricaba, por lo que áreas como la ingeniería y los procesos de fabricación captaban todo el interés.

Durante los años veinte, surge el marketing como nueva disciplina dentro de la gestión empresarial, pasándose a estimular una demanda que absorbiera toda la producción disponible, y aunque los especialistas de marketing incluían la distribución física, le prestaban poca atención. Durante el desarrollo de la II Guerra Mundial, las actividades logísticas constituyeron una de las primeras aplicaciones de muchos de los conceptos sobre logística actuales, pero el mundo empresarial no los puso en práctica hasta varios años después. Por tanto, hasta los años cincuenta, hubo un predominio de las ventas y la producción, presentando mayor deficiencia en las actividades logísticas por quedar ocultas debido a mercados en expansión que ofrecían grandes beneficios.

\section{0-1960: Los años de desarrollo}

El periodo entre 1950 y 1960 marcó una época de desarrollo de la teoría y práctica de la logística, ya que se dio un clima adecuado para la puesta en marcha de actividades de logística empresarial.

Además de estudios sobre los costes de la puesta en marcha de la logística y los servicios generados, Ballou [Ballou91 p.14-17] señala cuatro factores que ayudaron a su despegue:

* Cambios en la actitud y distribución de los consumidores: Con el cambio tecnológico, se produjo a su vez un cambio en las costumbres, consumos de la población, y cambios migratorios hacia las ciudades, con lo que hubo que cambiar a su vez los sistemas de suministros a las ciudades de una mayor cantidad de 
productos. Todo ello, a su vez, se tradujo en mayores costes de almacenamiento y transporte, lo que llevó a que cambiara el modo de realizar el almacenaje, como por ejemplo a centros de almacén, lo que hizo que se diera mayor importancia a temas como distribución, control de inventarios, servicio de entrega, etc.

Presión de los costes de la industria: Debido la crisis económica tras la II Guerra Mundial, las empresas tuvieron que buscar fórmulas para mejorar su productividad, y muchas lo hicieron a través de la logística, y reconociendo la importancia de los costes logísticos.

Progreso de la tecnología de los ordenadores: Con el paso del tiempo los problemas logísticos se hicieron más complejos debido a que había más diseños alternativos a considerar, la tecnología trajo nuevos servicios de transporte a elegir, mayor variedad de productos en inventario, planificación logística, demandas del consumidor, etc. Afortunadamente, el aumento de la complejidad fue contrarrestado por una nueva tecnología que surgía a mediados de los años cincuenta: el ordenador, y se comenzaron a utilizar modelos matemáticos y estadísticos para tratar modelos logísticos reales como: programación lineal, teoría sobre control de inventarios, simulación, muy valiosos para resolver problemas logísticos de ubicación, asignación de clientes a almacenes, control del nivel de existencias, trazado de itinerarios, programación de servicios de transporte.

Influencia de la experiencia militar: Antes de que las empresas mostraran un interés general en administrar las actividades logísticas de un modo coordinado, el ejercito ya estaba organizado para llevar a cabo estas actividades logísticas, lo que sirvió de experiencia contrastada para el mundo empresarial.

\section{De los setenta hasta el presente: los años del despegue}

A principios de los años setenta aun se consideraba la logística empresarial como un área en estado de semimadurez, ya que había empresas que si contabilizaban los beneficios de las aplicaciones en el área de logística pero su aceptación era lenta, ya que las empresas prestaban más atención a la generación de ingresos vía control de costes. 
Un cambio desencadenante en la situación existente se debió a la crisis del petróleo de los años setenta y el crecimiento de la inflación, lo que llevó a un cambio en la filosofía económica, pasándose de estimular la demanda a realizar una mejora en gestión de los recursos.

Este interés dio lugar a que las empresas optaran por reducir sus inventarios sin que se disminuyera el servicio prestado a los clientes. Ante esta perspectiva surgió la necesidad de planificar y gestionar de forma integrada la distribución, producción y el aprovisionamiento.

Ya en los años ochenta Rushton y Oxley [Rushton89 p.7] señalan como “se produce un aumento en la profesionalización dentro de la distribución. Con ella se ha logrado que se realice una planificación logística a largo plazo, centralización en la distribución, reducciones en el mantenimiento de stocks, así como el uso de ordenadores que ayudan a la mejora en el tratamiento de información y control."

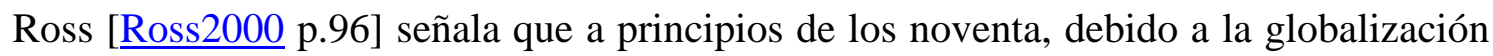
económica mundial, y el impacto de las tecnologías de comunicación y la información, las empresas fueron más allá de una simple integración logística para conseguir ventajas estratégicas. Gracias a los sistemas de Respuesta Rápida, surge un cambio importante debido a la nueva forma de gestionar las ventajas que se obtienen de la integración de participantes y empresas a lo largo de la Cadena de Suministro.

En España, el concepto de logística surgió en el ámbito comercial e industrial a mediados de los años setenta, pero no se generalizó hasta los ochenta, y aunque ya ha comenzando a cambiar, lo ha hecho de forma paralela y complementaria a la gestión de inventarios.

\subsubsection{La Cadena de Suministro}

Todo ello supuso que las empresas tuvieran que buscar una ventaja competitiva respecto a sus competidoras, haciendo que se desarrollara la logística como vía de mantener a largo plazo dicha ventaja. Para conseguirlo, debe producirse una coordinación de flujos 
materiales entre empresas que permitan formar una cadena logística continua y sin interrupciones, dando lugar así a la cadena de suministro, y siendo su objetivo: conseguir una cadena de suministro más eficaz y eficiente que la del resto de sus competidoras. El Council of Logistics Management [CLM2000 p.4] define la Gestión de la Cadena de Suministro como "la coordinación sistemática y estratégica de las funciones tradicionales y estratégicas a través de las funciones de negocio dentro de la cadena de suministro, con el objetivo de mejorar la realización de las actividades que realiza cada empresa a largo plazo de la cadena". Por lo tanto, la gestión de la cadena implicará coordinar las actividades y estrategias de todas las empresas participantes, como se muestra en la Ilustración 6. 1, donde se presentan las posibles empresas, como: el proveedor del proveedor, el proveedor, el cliente, el usuario final, y como cada uno realiza sus operaciones tras otro, y como todos ellos han de ir coordinados y gestionados de forma única.

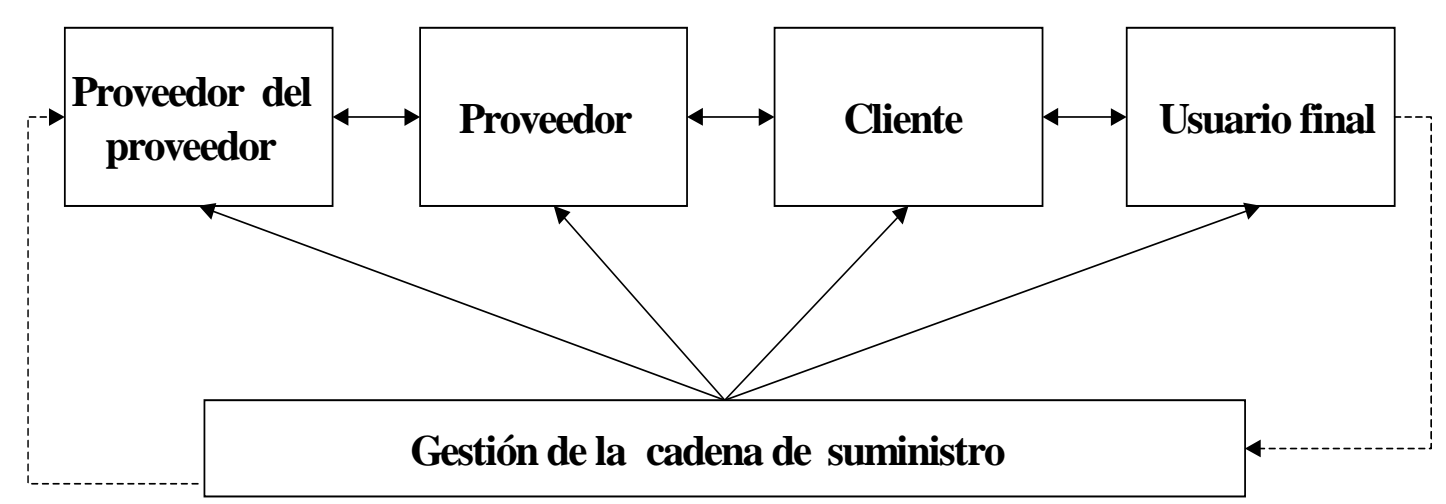

Ilustración 6. 1: Proceso de gestión de la cadena de suministro. Fuente: Elaboración

\section{Propia}

La Gestión de la Cadena de Suministro incorpora además de las operaciones logísticas, otro tipo de actividades que no están directamente vinculadas al campo de la logística, como la gestión de los Recursos Humanos, la tecnología, las infraestructuras, el servicio al cliente, la administración o el mantenimiento entre otras.

Como se explicó en un capítulo segundo, Porter aportó el concepto de Cadena de Valor, y los autores Prida y Gutierrez [Prida p.66] señalan en referencia al autor como " la obtención de una ventaja competitiva no se puede entender si no se mira la empresa 
como un todo o como un sistema ${ }^{10}$. Dicha ventaja parte de las actividades que realiza la empresa diseñando, produciendo, comercializando, entregando y apoyando el producto. Cada una de estas actividades contribuye a generar un coste, y crea a su vez una base para la diferenciación del producto. La cadena de valor desagrega una empresa en sus actividades estratégicamente relevantes, para entender el comportamiento de los costes y de las fuentes actuales y potenciales de diferenciación. Una empresa obtiene ventaja competitiva haciendo sus actividades estratégicamente importantes mejor que sus competidores o a un coste menor que ellos..."

A su vez, Mayo [Mayo] señala que "la técnica de la Cadena de Valor de Porter tiene por objetivo, identificar las actividades que se realizan en una institución, las cuales se encuentran inmersas dentro de un sistema denominado: Sistema de Valor, conformado por la Cadena de Valor de los Proveedores, Cadena de Valor de otras unidades de negocio, Cadena de Valor de los canales de distribución, Cadena de valor de los clientes... Con lo que se consigue una ventaja competitiva cuando se logra que la empresa desarrolle e integre las actividades de su Cadena de Valor de forma menos costosa y más diferenciada que la de sus rivales. La Cadena de valor de la logística estará formada por todas sus actividades generadoras de valor agregado y por los márgenes que éstas aportan."

El curso de Gestión de Inventarios del Centro Español de Logística [CELFormación p.27] a su vez, hace referencia a Porter, señalando que "la percepción del negocio como cadena de valor, se observa como una serie de elementos que se combinan para producir productos, que se perciben de gran valor para el cliente. Si un proceso no da valor, de alguna manera se percibe como un derroche.”

Por tanto, se puede decir que la cadena de valor logística está constituida por una serie de procesos que crean valor mediante la entrega de productos y servicios a los clientes, tras manejarlos desde su concepción hasta la comercialización. Las actividades que componen esa cadena de valor logística, serán la suma de las actividades tales como: la gestión de los aprovisionamientos, la fabricación o conversión a través de operaciones de servicio, la gestión de órdenes de compra, la logística y distribución, las operaciones

\footnotetext{
${ }^{10}$ Ver definición de Sistema en el capítulo 3.
} 
de venta y finalmente, puede incluirse como parte de la cadena de valor, el servicio post- venta ofrecido por la empresa. Todo ello puede observarse en la Ilustración 6. 2.

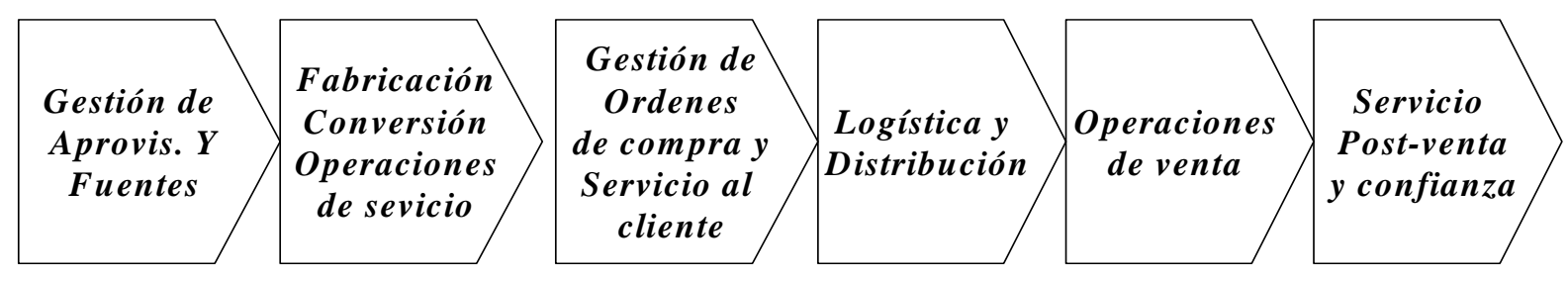

Ilustración 6. 2 : Cadena de valor.

El Council of Logistics Management [CELConsorci2002 p.8] define la Logística como

"la parte del proceso de gestión de la cadena de suministro encargada de planificar, implementar y controlar de forma eficiente y efectiva el almacenaje y flujo directo e inverso de los bienes, servicios y toda la información relacionada con éstos, entre el punto de origen y el punto de consumo, con el propósito de cumplir con las expectativas del consumidor". De ello se deduce que la misión de la logística es planificar y coordinar las actividades necesarias para conseguir niveles de servicio y calidad al menor coste posible. De tal manera que lo que realiza es una actividad de enlace entre el mercado y la empresa, llevando a cabo actividades que van, desde la gestión de la materia prima hasta la entrega del producto terminado. De forma que cuando se hable de Cadena de Suministro, se haga referencia a la unión de todas las empresas que participan en la producción, distribución, manipulación, almacenamiento y comercialización de un producto y sus componentes, es decir, que integra todas las empresas que hacen posible que un producto salga al mercado en un momento determinado, teniendo en cuenta a los proveedores de materias primas, fabricantes, distribuidores, transportistas y detallistas.

Por tanto, la Gestión de la Cadena de Suministro la define el Global Supply Chain Forum 1998, y aportada por Lamberty Orbson [Lambert2001], como la integración de los procesos clave de negocio desde los proveedores iniciales al consumidor final, proporcionando productos, servicios e información de forma que añadan valor para clientes y participantes, lo que supone una integración en dirección y procesos a lo largo de la cadena de Suministro. 
Para poder llevar a cabo la gestión de la cadena de suministro, hacen falta ciertos componentes de gestión, que se pueden dividir en dos grandes bloques: por un lado los físicos y técnicos, y por otro los de gestión y comportamiento. Los primeros estarán compuestos de actividades correspondientes a planificación, control, actividades a realizar (flujos de trabajo), estructura organizativa, información y comunicación y apoyo estructural. Mientras que los componentes directivos de gestión y comportamiento, aportan métodos directivos, conceptos de poder y liderazgo, riesgos y recompensas, y la cultura y las distintas actividades. El desglose gráfico de cada bloque se aprecia en la Ilustración 6. 3:

\section{GESTIÓN DE LA CADENA DE SUMINISTRO}

Principales componentes de Gestión
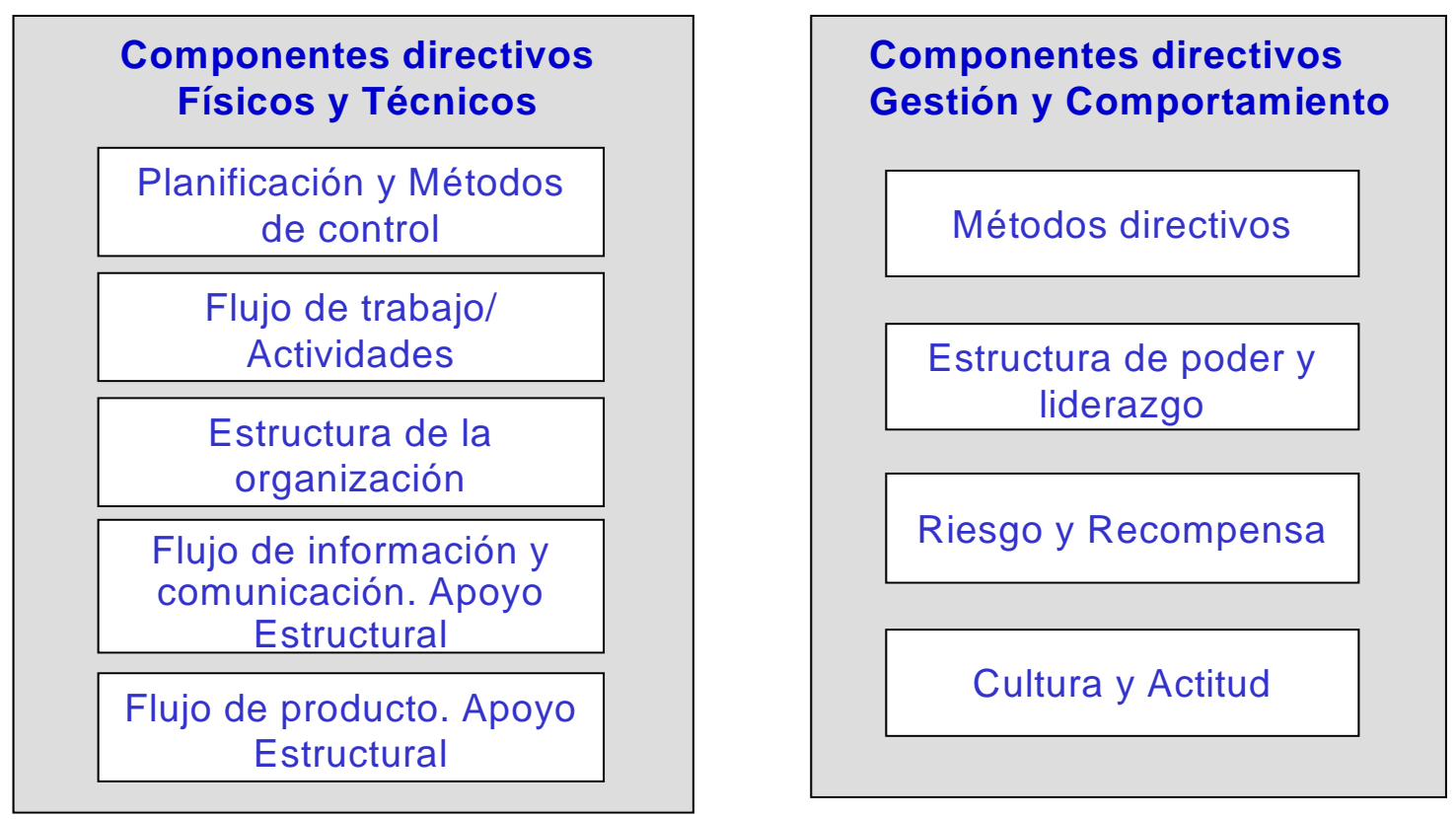

Ilustración 6. 3: Componentes de la Gestión de la Cadena de Suministro. Fuente:

\section{Lambert [Lambert2001]}

Detallando la definición expuesta en el apartado 6.2.1, y teniendo en cuenta todo lo anterior, el concepto de Logística estará constituido por "el proceso de planificar, desarrollar y controlar el movimiento y almacenamiento tanto de flujos físicos como de información, a lo largo de la cadena de valor”, es decir, el proceso que consigue poner a disposición de los clientes los productos y servicios procedentes de las empresas. 


\subsubsection{Objetivos de la logística}

Los objetivos de la logística han de integrarse en los objetivos generales de la empresa, por ello se puede decir que el objetivo de la logística es satisfacer las necesidades (expresadas o no) en las mejores condiciones prestando cierto nivel de servicio. La empresa deberá poner a disposición del consumidor los productos o servicios, a través de una serie de etapas u operaciones en las que intervendrán una serie de actores con intereses dispares. Estas etapas corresponderán a su vez a un ciclo de vida del proceso logístico, y en un nivel abstracto podrán representarse como las que se indicaron en el capitulo tercero (apartado 3.2).

Carrallo en su libro "Logística Comercial” [Carrallo78 p.145] señala como objetivos del sistema logístico, la Eficacia y el Coste Total del sistema:

- Eficacia: alcanzar el nivel de servicio a los clientes, establecido en forma de:

- Plazos de respuesta acordados: tiempo que transcurre desde que el cliente pasa su pedido hasta que recibe la mercancía.

- Lugar de entrega acordado

- Cantidad estipulada: disponibilidad de los productos que corresponderá al porcentaje de la cantidad pedida, entregada en las condiciones estipuladas.

- Coste Total del sistema: que estará formado por

- Coste de funcionamiento del sistema: coste de las operaciones de servicio, de comunicaciones, aprovisionamiento, etc.

- Coste del capital invertido: en stocks principalmente. 
Por lo tanto, habrá que poner a disposición del consumidor los productos o servicios en condiciones de máxima eficacia y mínimos de costes, donde el papel fundamental de quienes operan con la logística se convierte en primordial, debido a que ponen en contacto a proveedores y productores, productores y distribuidores, distribuidores con los consumidores, haciéndoles llegar tanto materias primas (insumos) como productos terminados. Como viene representado en la Ilustración 6. 4.

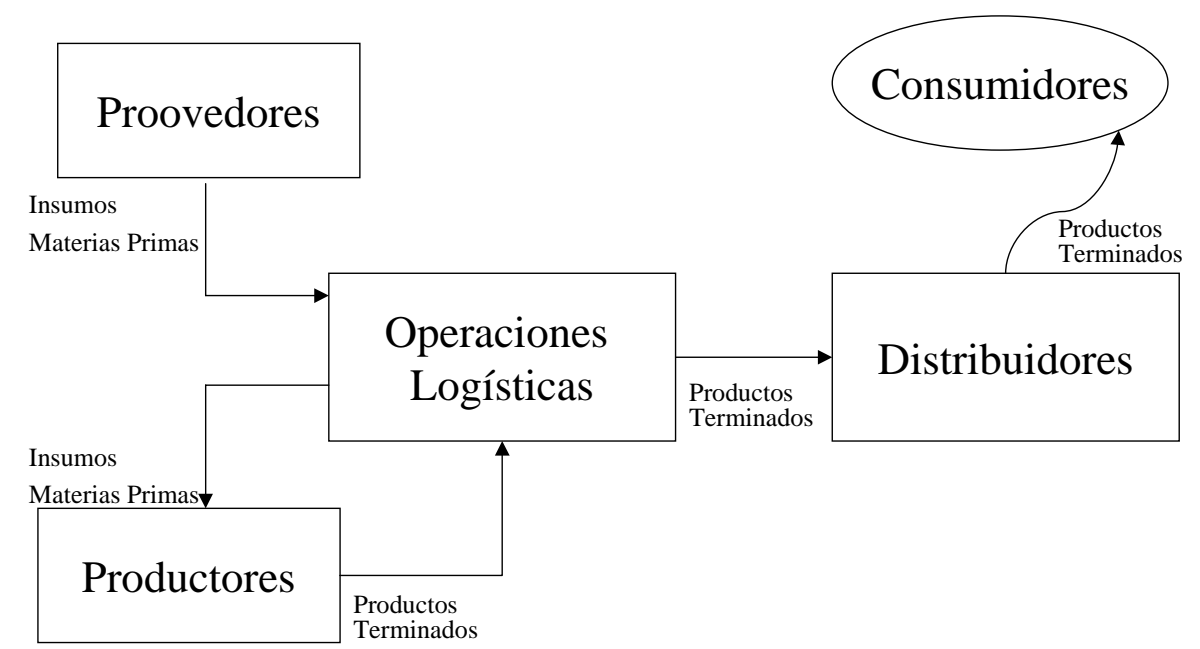

Ilustración 6. 4: Esquema de la función logística

Gibson et al [Gibson]señalan entre los motivos de la importancia de la logística los siguientes

- El gran impacto en las economías domésticas y globales: debido a que facilita gran cantidad de intercambios y favorece las grandes compras de material.

- Ser de gran importancia para la supervivencia humana: ya que proporciona disponibilidad continuada de bienes, agua, medicinas...

- El impacto en la calidad de vida: ayuda a la distribución de bienes local y globalmente.

- Por afectar a gran variedad de contactos: impactar en las actividades, el flujo industrial y los productos de consumo. 


\section{3 ÁREAS CON LAS QUE SE RELACIONA EL ÁREA DE LOGÍSTICA EN LA EMPRESA}

Una vez expuesto el concepto de logística y los conceptos fundamentales en que se apoya dicha definición: como cadena de valor, cadena de suministro, importancia de la logística y los objetivos principales, en el apartado 6.2. Se realizará un desglose de lo que supone la gestión logística en la empresa; para ello se entrará en explicar la gestión de demanda y su predicción, el aprovisionamiento, la gestión de almacenes, de stocks, de pedidos, los recursos humanos e incluso logística inversa.

La gestión logística busca dirigir el flujo de materiales desde su fuente hasta el usuario exigiendo que todas las actividades que unen el mercado proveedor con el de demanda estén interconectadas y tengan presente que una decisión tomada en una parte, impactará en todo el sistema.

Ballou [Ballou91 p.7] señala que "las actividades empresariales que forman parte de la logística, variarán de empresa a empresa, dependiendo de características como: la estructura de la organización, las diferentes opiniones de los directivos sobre lo que debe ser el alcance de la logística o la importancia de cada actividad dentro del ámbito de las operaciones de la firma.” Por ello, las actividades que se van a presentar, constituyen una lista global de todas las funciones que la logística puede abordar. El citado autor, propone la división de las tareas logísticas en dos grandes bloques, uno correspondiente a los suministros o gestión de materia prima, que se situará entre el suministro de materia prima y las fábricas, y otro bloque denominado de Distribución, que se situará entre las fábricas y los clientes. En el primer bloque correspondiente a los Suministros o gestión de la materia prima, se realizarán actividades de transporte, proceso de pedidos, compras, tratamiento de mercancías, almacenaje, mantenimiento de inventarios, almacenaje de información, o empaquetado de protección orientada hacia las fábricas. Mientras que en el bloque de Distribución, las actividades logísticas que van realizarse son las mismas pero encaminadas desde la fábrica, hacia los clientes de las mismas. La representación gráfica de ello se puede observar en Ilustración 6. 5, con las actividades propuestas por Ballou para la logística empresarial. 


\section{LOGISTICA EMPRESARIAL}

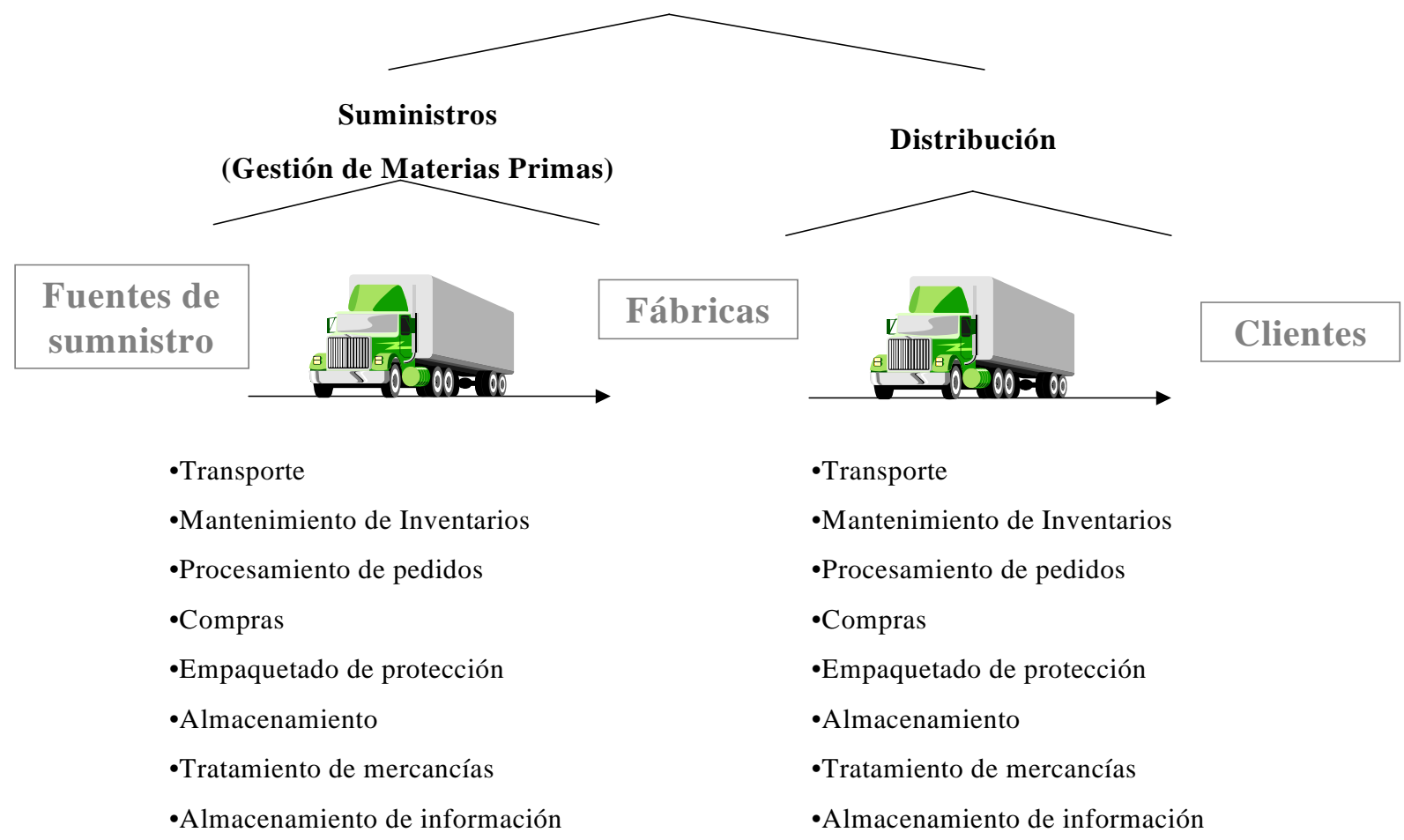

Ilustración 6. 5: Alcance de la logística dentro de una empresa.

Fuente: Ballou [Ballou91 p. 7]

A partir de estas distinciones se pasará en el presente apartado, a realizar un repaso a las grandes áreas de la logística, sin hacer distinción entre quiénes se producen. Dichas áreas engloban y amplían las propuestas por Ballou ya que dicho autor propone una serie de actividades sueltas, mientras que la clasificación que a continuación se expone realizará un recorrido a lo largo de la cadena de suministro partiendo desde la gestión de demanda para terminar con la gestión de un pedido, aunque incluyan las actividades de la Ilustración 6. 5 . Con ello podrían asociarse las actividades propuestas por Ballou de Proceso de pedido y de compras a la gestión de aprovisionamiento, las actividades de almacenamiento y almacén de información a la gestión de almacenes, las actividades de gestión de stocks como mantenimiento de inventario y tratamiento de mercancías, y el proceso de pedido de clientes y el empaquetado de protección como la gestión de pedidos de distribución.

Por lo tanto, en los epígrafes siguientes se hace una descripción de dichas áreas pertenecientes a la logística. 


\subsubsection{Actividad de Gestión de demanda}

Como ya se estudió en las etapas del ciclo de vida, (y en particular en el punto 3.2.1 Etapas de Planificación) en el capítulo tercero, y se recalcó en el apartado 5.2 de Planificación del Modelo de Recursos Humanos, la importancia de dicha etapa es fundamental, ya que en todas las áreas de las organizaciones es obligado realizar una adecuada planificación.

Para el caso particular de la demanda, habrá que realizar una estimación de la misma, denominada también como previsión, incluso conocida en el mundo empresarial internacional como Forecasting, que "consiste en la estimación y el análisis de la demanda futura para un producto, componente o servicio, utilizando una serie de inputs como: ratios históricos de venta, estimaciones de marketing e información promocional, a través de diferentes técnicas de previsión."[PwC2001 p.23]

Ballou [Ballou91 p.89] señala la "previsión de la demanda como una de las actividades generales de mayor importancia para cualquier empresa, ya que proporciona los datos básicos de entrada para la planificación y el control de todas las áreas funcionales, incluida la logística, comercialización, producción y finanzas. Para la logística estos problemas se centran en la naturaleza espacial y temporal de la demanda, en su variación y en el grado de arbitrariedad de la misma.”

Si se traslada esta definición al campo de la logística, realizar esa predicción supondrá poseer información y poder estar preparado para soportar operaciones futuras del área logística (con medios técnicos, humanos y financieros) como la estimación de compras, producción, necesidades de almacenaje, transportes, etc. y a su vez poder estimar los beneficios que conlleve todo ello.

La importancia de tener información sobre la previsión de ventas para la empresa dentro del campo de la logística se debe a que está relacionada con otras áreas de la empresa como son: 
- Gestión de Aprovisionamiento: su importancia radica en que una buena previsión facilitará realizar la previsión de compras y ayudará a negociar con proveedores.

- Gestión de Transporte: Planificar los medios humanos y materiales que necesitará el proceso.

\section{- $\quad$ Planificación de la producción}

- Gestión de stocks y almacenes: ayuda a determinar el nivel de stocks y planificar las necesidades de almacenaje.

- Finanzas y comercial, etc.

Por todo ello, debe considerarse la gestión de la demanda como un factor fundamental para el éxito de la empresa y con unas grandes consecuencias en el área logística.

Los tipos de planificación que señalan Kirby y Planas [Kirby2001] son las que a continuación se detallan y pueden observarse en la Ilustración 6. 6:

- Previsión de demanda

- Planificación de distribución

- Planificación de Producción

- Planificación de aprovisionamiento

- Planificación de transporte 


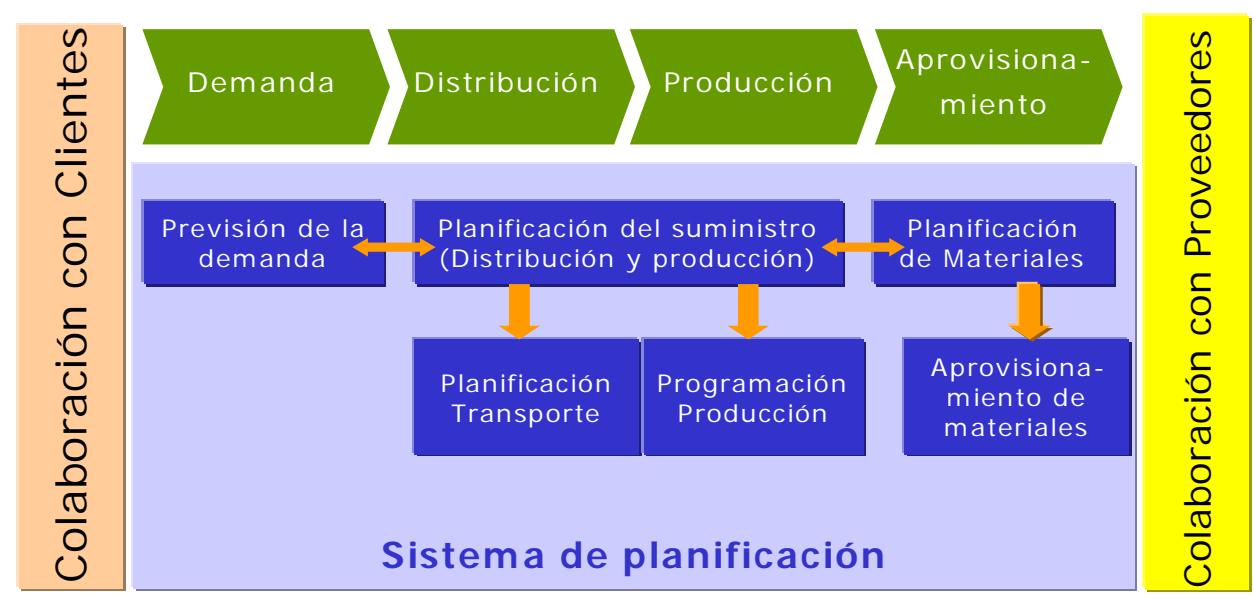

Ilustración 6. 6 : Proceso de Planificación integrado. Fuente: Kirby [Kirby2001]

\subsubsection{Actividad de Gestión de pedidos}

La gestión de pedidos [PwC2001 p.119], consiste en la cumplimentación de órdenes de pedido del cliente, a la vez que se asegura el máximo valor de la cadena de suministro y el servicio al cliente.

Un pedido se define como un encargo o petición hecha a un fabricante o vendedor de géneros, que supone a su vez un compromiso entre el proveedor y el cliente de las condiciones mínimas para que la relación comercial se produzca. La diferencia de éste con la intención de compra es fundamentalmente que no implica compromiso de compras, sólo sería válido a nivel previsión.

El proceso de gestión de pedido puede dividirse en dos bloques, uno para la logística interna de la empresa y otro la logística externa, como se muestra en los dos circuitos señalados en la Ilustración 6. 7. En dicha ilustración, se muestra como existe un circuito de gestión de pedidos que proceden del exterior y darán lugar a la logística externa de la empresa. Dicho circuito se representa con números en la citada ilustración y abarca desde la solicitud de pedido por parte de los clientes a las oficinas comerciales de las empresas al servicio al cliente. Dicha logística externa abarca una serie de etapas que se desglosan a continuación y están reflejadas en la Ilustración 6. 8: 


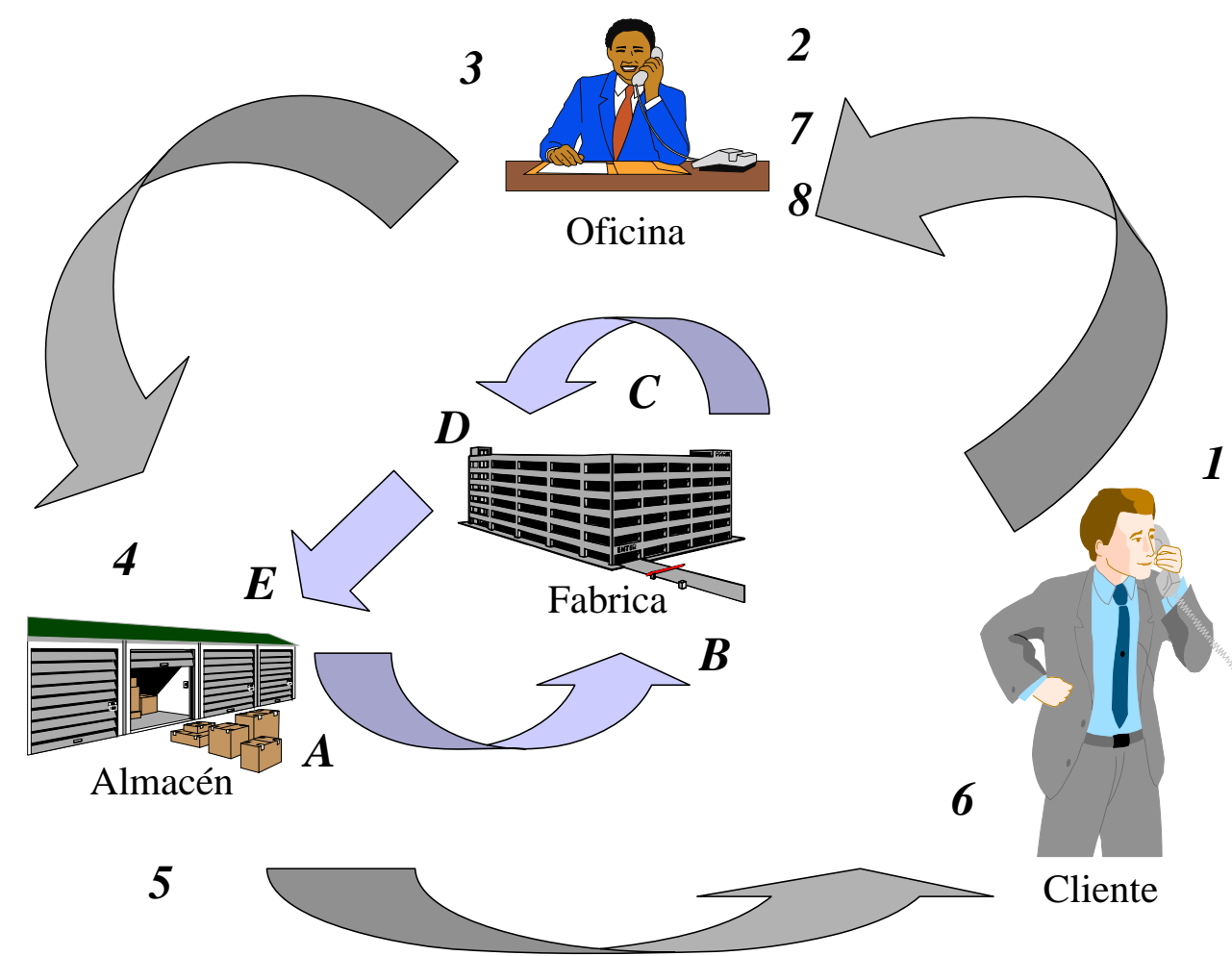

Ilustración 6. 7: Gestión de pedido, desde el punto de vista interno y externo de la empresa. Fuente: Elaboración propia

1. Entrada de pedidos: la entrada del pedido comienza cuando el cliente emite su pedido y éste queda registrado y aceptado por el proveedor. El tiempo de la operación dependerá del canal utilizado: fax, teléfono, Internet, correo postal, etc.

2. Comprobar el crédito: implicará contactar y hacer seguimiento de las solicitudes según la modalidad de pago elegida por los clientes, es decir, comprobar si están o no capacitados los clientes para pagar los productos que desean adquirir, para lo que las empresas establecen unos límites de crédito, lo que supone distintas condiciones de venta para cada cliente o pedido.

3. Comprobar la disponibilidad de existencias: Para poder gestionar un pedido se necesitará poder dar cobertura, para lo cual hay que asegurar que se puede entregar la cantidad en el plazo acordado. Para poder dar respuesta a esa disponibilidad, hay que mantener registros de inventario actualizados y precisos, además de contar con lo que existe en esos momentos en inventario y lo que hay planificado. En caso de no disponer de existencias suficientes, se han de negociar plazos de entrega adaptables a la disponibilidad o bienes sustitutos 
4. Priorizar los pedidos: Supone la reserva o priorización de existencias para diferentes clientes en base a segmentación según el tipo de cliente.

5. Preparar los pedidos: En esta etapa habrá que incluir la elección del almacén, centro de distribución, etc. más adecuado. Supone realizar una recogida de material y preparación de los items que compondrán el pedido.

6. Enviar y entregar: Actividades que comienzan al retirar las mercancías de las existencias, seguidas por las de decisión del medio de transporte al cliente (barco, avión, tren, tubería, camión, cisterna). En esta etapa hay que incluir el proceso de embalaje, que consistirá en la preparación de las cajas o envases que contendrán el pedido, junto con la generación de etiquetas identificativas de cada pedido. Para terminar se realiza finalmente la entrega en las condiciones pactadas adjuntado al pedido los documentos propios de dicha entrega: albaranes y recibos de transporte del pedido.

7. Facturar: Dependerá de la elección del cliente o de la opción de la compañía, es decir, ser facturado por pedido o por entrega, o elegir una opción como pagos mensuales, pago al uso, pago al recibo. Suelen aparecer problemas cuando en una misma factura se unen muchas líneas de productos o cuando incluyen productos en promoción con otros, surgiendo así cierto conflicto que termina requiriendo esfuerzos especiales por ambas vías.

8. Cobrar el pedido: La gestión de pedidos es responsable de coordinar facturas, envíos y documentos de ventas de los productos entregados. El ciclo de pedido finaliza cuando éste es cobrado, ya que es lo que mantiene a las organizaciones.

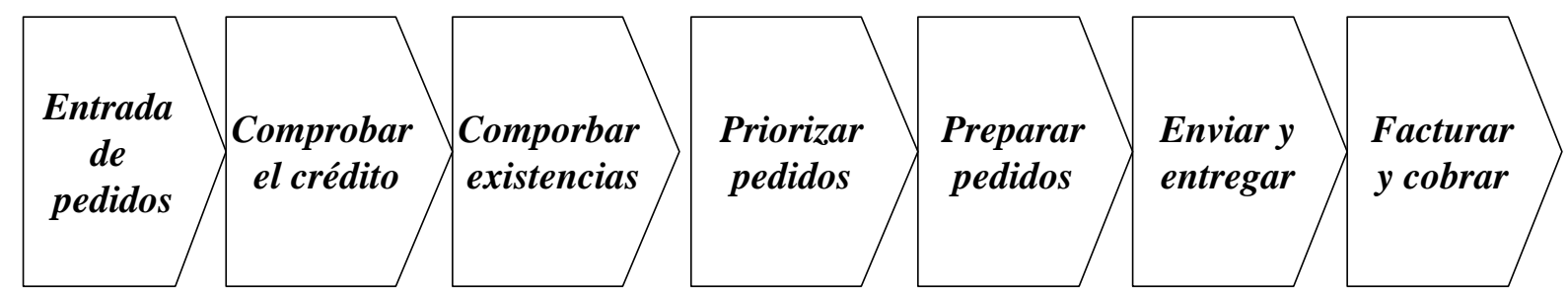

Ilustración 6. 8: Proceso Principal de la gestión externa de pedidos. Fuente: Basado en PriceWaterhouseCoopers [ $\underline{\mathrm{PwC} 2001}$ p.120] 
Por otro lado se desarrolla la logística interna de la empresa, en la cual el sistema de logística interna estará basado en la Dirección de Operaciones, producción y abastecimiento para el almacén y los clientes. Las etapas que sigue este proceso denominado por Logística Interna son:

A. Generación de una orden de suministro de planta a almacén de materia prima

B. Lanzamiento de una orden de fabricación, ya sea sobre pedido o de planificación

C. Fabricación de pedido

D. Envío a almacén

E. Recepción en almacén

Por tanto, los principales problemas a los que se enfrenta la gestión de pedidos provienen por un lado de la necesidad de eliminar el mayor número de errores posible, y por otro utilizar únicamente información precisa y adecuada, obtenida mediante los representantes de servicio, que han de encargarse de tomar nota de los pedidos, datos, reclamaciones y dar información al cliente. Por lo que estos representantes de servicio, dependerán del departamento comercial o gestor de clientes.

\subsubsection{Actividad de Gestión del aprovisionamiento}

Realizar una buena gestión de aprovisionamiento es un punto fundamental para poder reducir costes en la cadena de valor de la empresa. Para conseguirlo las empresas realizan una selección y gestión de proveedores de mercancías y negocios, negociación de precios y términos de compra, y la adquisición de mercancías y servicios de calidad, siempre con los objetivos de mejorar la calidad y reducir sus costes.

Los objetivos generales de la gestión del aprovisionamiento según

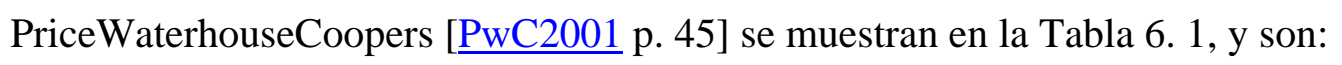


- Apoyar la consecución de objetivos estratégicos

- Minimizar el coste total de la gestión de compras según el plan de negocio de la organización

- Mejorar la calidad y el flujo de bienes y servicios

- Encontrar una fuente de suministro competente y fiable

- Soportar y responder a la demanda de clientes

- Minimizar el riesgo de aprovisionamiento o fluctuación de los precios

- Gestionar a los proveedores para reducir el gasto y mejorar la calidad de las mercancías y servicio

- Establecer relaciones de participación con los proveedores clave

- Optimizar el coste del aprovisionamiento en base al riesgo a asumir

Tabla 6. 1: Objetivos de la Gestión de aprovisionamiento. Fuente:

PriceWaterhouseCoopers [ $\underline{P w C 2001}$ p.45]

Con todo ello, se puede concluir que una buena gestión de aprovisionamiento logra una reducción de los costes de compra, lo que llevará a mejorar los márgenes de beneficios, y hacer por tanto, que los clientes ahorren sin que la calidad de los productos se vea afectada o dañada.

Más aun PriceWaterhouseCoopers [PwC2001 p.47-48] señala como "toda compañía debe disponer de una estrategia de compras y aprovisionamiento que debe estar en línea con la estrategia global de la compañía. Es además recomendable que la compañía disponga de una política de compras, que debe incluir los siguientes aspectos:

- Parámetros de decisión: precio, plazo, calidad, servicio requerido 
- Búsqueda de nuevas fuentes de suministro y selección de proveedores: características de los productos, modo de identificación de suministradores potenciales, petición de ofertas, numero de proveedores a seleccionar, etc.

- Negociación: tipo de información, tiempo de espera, reglas básicas, etc.

- Relación con las áreas funcionales de la compañía

- Criterios de ética profesional"

Para Soret [Soret97 p.258] "es el departamento de compras quien debe conocer perfectamente al mercado proveedor mediante su adecuada valoración, y cubrir todas las labores administrativas que implican la emisión, seguimiento y recepción de pedido, para lo que tendrá que estar en contacto con otros departamentos empresariales como producción, finanzas, comercial, logística y dirección general. Los cuatro parámetros principales de compra son:

- Precio: debe ser claro y unitario, incluyendo los conceptos de transporte, manipulación etc. Y ya que hay productos que no los consideran, como los de exportación e importación, debiéndose de detallar entonces los seguros, recepción, impuestos, divisas, etc.

- Calidad: el objetivo no es comprar lo más barato posible, sino optimizar el conjunto, precio, calidad, servicio. Hay veces que una calidad excesiva puede ser innecesaria, lo que hace incrementar los precios sin aportar valor añadido para el consumidor.

- Condiciones de compra: Otros factores que pueden afectar al precio son aquellos que provienen de descuentos por volumen de compra, contratos establecidos, formas de pago, etc. Hay que tener en cuenta las promociones a bajo precio, ya que pueden hacerse para dar a conocer algún producto, o que se esté vendiendo artículos de stocks almacenados mucho tiempo o de baja calidad. 
- Plazo de entrega: Es fundamental su consideración para no incurrir en rupturas de stock, o en la paralización del proceso productivo, ya que si no lo fuera, habría que mantener mayores niveles de stock, que se traduce en mayores costes de mantenimiento, mayor capacidad de almacén. Para ello se debe conocer la evolución de la demanda de la empresa y poder acordar y negociar la cantidad y frecuencia de los pedidos.”

Para Soret [Soret97 p.267] hay que tener clasificados a los proveedores según estas características, es decir, conociendo el número de defectuosos que envía, los retrasos en los que incurre, y su precio, valorando y ponderando todas ellas, se obtendrá al mejor proveedor.

La manera correcta de llevar a cabo el proceso de gestión de aprovisionamiento según PriceWaterhouse-Coopers es la que se muestra a continuación [PwC2001 p. 49]:

1. Identificar las necesidades: Detectar las necesidades de bienes o servicios del departamento, comunicarla al director del mismo, y cuando se autorice pasar un aviso formalizado (normalmente por escrito) al departamento de compras.

2. Seleccionar las fuentes de suministro: Al objeto de conocer los suministradores y seleccionar los idóneos. Hay que realizar una segmentación de las citadas compras basándose en los criterios establecidos, para luego establecer un criterio de selección de proveedores, que dependerá del tamaño, naturaleza del negocio, estrategias, necesidades... Una vez seleccionados los proveedores, se formulará la petición y comparación de ofertas.

3. Contratar y negociar: En base al poder de negociación (grado de poder entre proveedor y comprador, y la posición relativa para llegar a un acuerdo), el tiempo y la información existente de compradores y vendedores se llegará a realizar el contrato previas negociaciones. 
4. Emitir y seguir los pedidos: A continuación el comprador emite una orden que ha de ser aceptada por el proveedor pudiéndose realizar esta tarea por correo, teléfono, fax, Internet..., finalizando esta etapa cuando el proveedor acepta el pedido.

5. Recepcionar e inspeccionar los pedidos: Supone: aceptar el material, descargarlo, depositarlo, verificar con la documentación su cantidad y condición, e introducir toda la información en el sistema de inventarios.

6. Aprobar y pagar facturas a proveedores. Para ello se compararán los albaranes entregados con la mercancía con los pedidos de compra y con las facturas del proveedor. En ellos vendrá la cantidad y precio acordado por ambos, debiendo estar conformes antes de que se realice el pago al proveedor.

7. Controlar los resultados: El control de resultados supondrá una evaluación a posteriori, que incluirá las incidencias con proveedores, las reclamaciones, el nivel de servicio prestado... etc. Hay empresas que remiten esa información a los proveedores para su conocimiento.

Todas estas etapas quedan reflejadas gráficamente en la Ilustración 6. 9, donde se observa como se realizan secuencialmente actividades para lograr alcanzar una adecuada gestión de aprovisionamiento. 


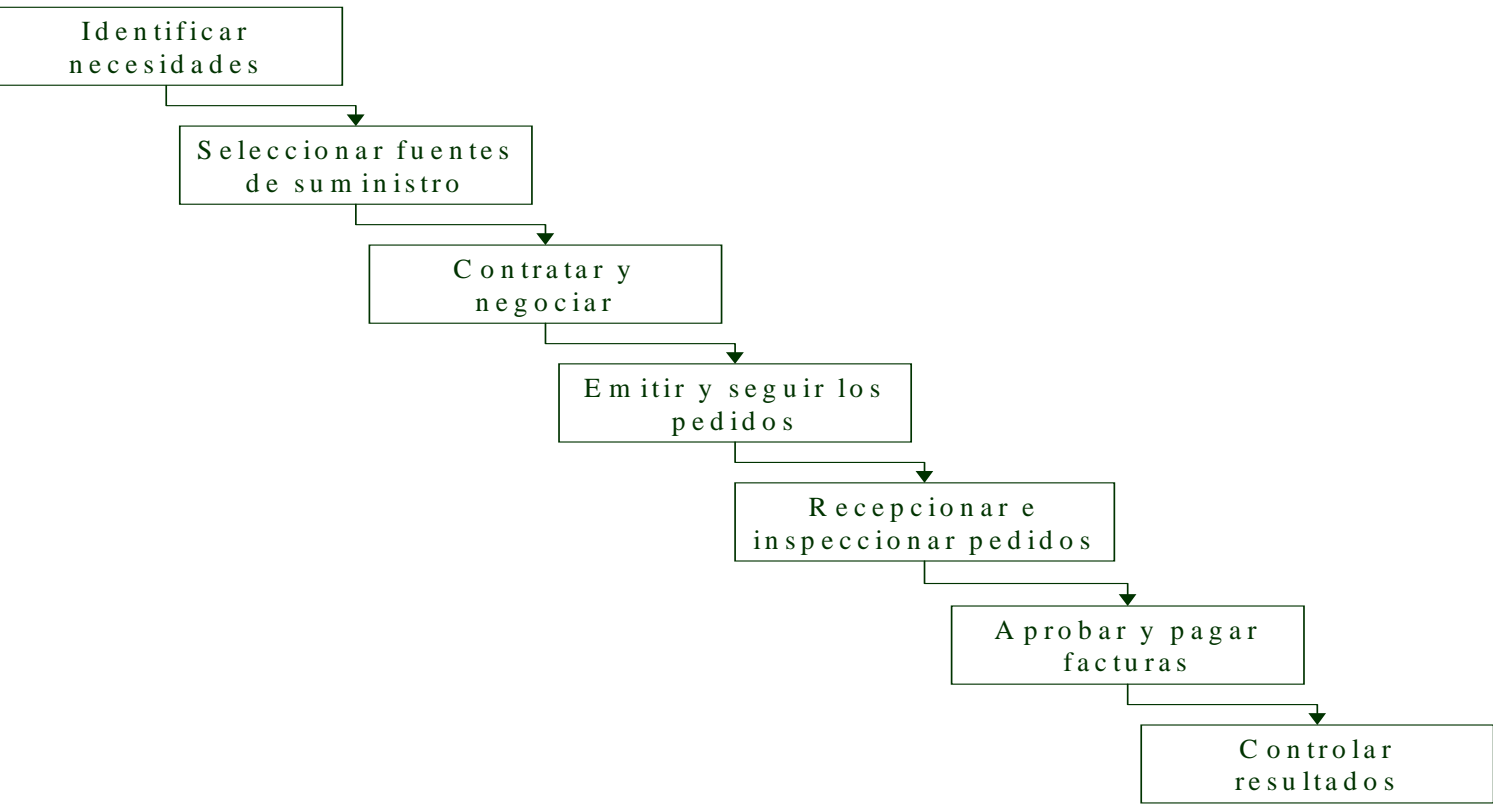

Ilustración 6. 9: Proceso de gestión de aprovisionamiento. Fuente: Basado en

PriceWaterhouseCoopers [PwC2001 p.49]

No se puede concluir este apartado sin hacer referencia a gestión de compras realizada desde Internet. El gran crecimiento experimentado por este medio ha favorecido la gestión de compras y las relaciones con proveedores logrando reducciones en los costes, debido a que la información en Internet puede replicarse a coste cero sin limite, factor muy importante en el área de la Logística al ser una función intensiva en información.

El E-procurement consiste en la compra de bienes y servicios necesarios para las actividades diarias de la empresa realizado desde Internet. Los beneficios que aporta esta nueva vía de aprovisionamiento son los que se destacan a continuación:

- Gestión eficiente y controlada de las compras de una empresa: mejor intercambio de información respecto a la marcha de los pedidos

- Mayor integración con los gestores de compras

- Facilidad para aumentar a los proveedores, incluso con gestores internacionales 
- Reducción del ciclo de tiempo de la compra: ya que se eliminan tiempos de comunicación, llamadas, localizar a personas, etc.

- Reducción importante de los costes: por devoluciones, demoras, cantidades erróneas, etc.

- Actualización de catálogos e información de los proveedores

- Flujos de información (certificaciones, condiciones, propuestas, pedidos)

\subsubsection{Actividad de Gestión de almacenes}

La Gestión de Almacenes consiste en "un proceso de la función logística que trata la recepción, almacenamiento y movimiento desde dentro de un almacén hasta el punto de consumo de cualquier material, ya sean materias primas, semielaboradas y/o terminadas, así como el tratamiento e información de los datos generados”. Como se observa gráficamente en la Ilustración 6. 10:

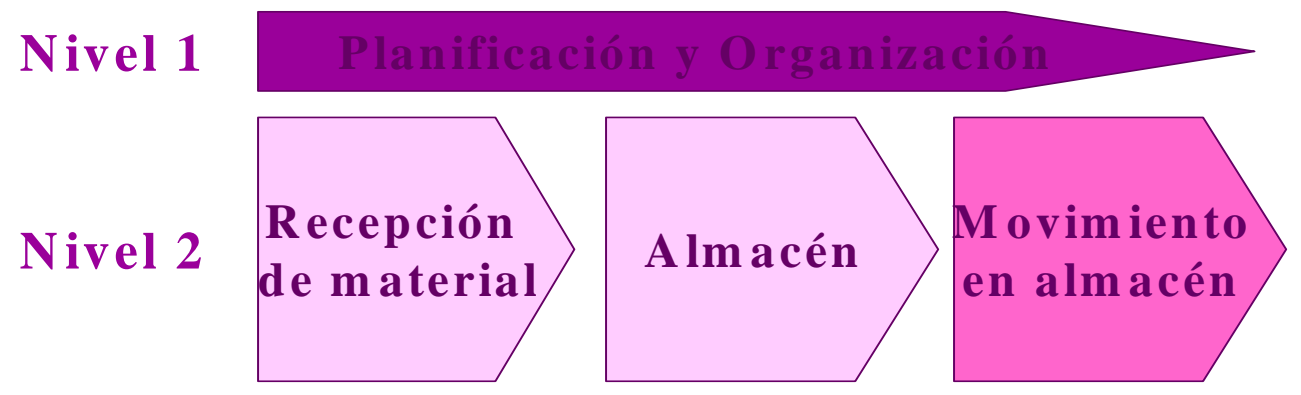

Nivel 3

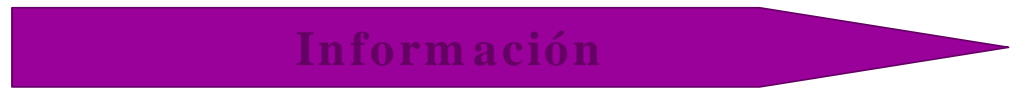

Ilustración 6. 10: Proceso de Gestión de Almacenes. Fuente:

PriceWaterhouseCoopers [ $\underline{P w C 2001}$ p.67] 
Las razones señaladas por Rushton y Oxley [ㄴushton89 p. 40] para considerar la necesidad de los almacenes son las siguientes:

"Mantener bajos los costes de producción, lo que permite altos niveles de producción, mientras que se minimiza el tiempo empleado en la puesta a punto de las máquinas.

Mantener el vínculo entre requisitos de demanda y capacidades productivas, para lograr la eficiencia operativa.

Estar preparado ante grandes demandas estacionales y poder proveer eficientemente.

Proporcionar un buen servicio al cliente

Permitir reducir los costes de comercio con el sistema de transporte (entrega de bultos)

Facilitar orden en las reuniones”

Una de las características principales de la gestión de almacenes es la ausencia de actividades que supongan valor añadido a los materiales manejados. Aun así, llevar a cabo esa gestión se realiza debido a los beneficios generados como los que muestra la Tabla 6. 2: 
- Reducción de tareas administrativas

- Agilidad en el desarrollo de procesos logísticos

- Optimización de la gestión del nivel de inversión del circulante

- Mejora de la calidad del producto

- Optimización de costes

- Reducción de tiempos de proceso

- $\quad$ Nivel de satisfacción del cliente

Tabla 6. 2 : Beneficios que ofrece la Gestión de Almacenes. Fuente:

\section{PriceWaterhouseCoopers [PwC2001 p.70]}

Pina [Pina2000] señala la existencia de cuatro zonas en el marco general del almacenaje, correspondientes a:

Almacén: lugar donde se guarda el material, productos intermedios, productos terminados, etc.

Área de Picking: lugar donde se seleccionan y recogen los productos para los diferentes pedidos

Área de consolidación: lugar donde se preparan los pedidos y se expiden

Sistema informático y administrativo: área en la que se realiza el control y la gestión de las operaciones.

Por otro lado, la clasificación de los procesos que genera la gestión de almacenes se puede subdividir en niveles:

* Nivel 1: Actividades de planificación y organización, Para PricewaterhouseCoopers [PwC2001 p.71-78] suponen las actividades de 
carácter estratégico y táctico, como gestión de almacenes, ubicación, recursos técnicos y humanos necesarios o la planificación del siguiente nivel (recepción, almacén y movimiento).

Roux [Roux2002 p.141] señala que una planificación correcta, ayudará a su vez a organizar el trabajo y las tareas de los almaceneros, y si son unidades de distribución grandes, la planificación puede exigir que las entregas se efectúen dentro de un horario muy preciso, llegando incluso a registrar citas entre repartidores y almaceneros.

* Nivel 2:Recepción, almacén y movimiento

- Recepción de Material: Parte del proceso de planificación que se ocupa de las entradas de mercancías, descarga y verificación tal y como se solicitaron, actualizando los registros de inventario. Este proceso no añade valor añadido.

Roux [Roux2002 p.140] distingue en función de que las entradas a almacén procedan de producción o procedan del exterior. En el primer caso, se realiza una comparación entre la entrega real y la prevista, comprobando que todo se desarrolle correctamente. Si las entradas proceden del exterior, se compara a su vez la cantidad esperada y su calidad, y con lo que se logrará conocer qué productos están disponibles en el almacén, y a su vez informar a compras de si hay que hacer alguna variación en el pago, en los documentos comerciales, en los asientos contables y de gestión o incluso la realización de un envío devuelto.

Para la asignación de ubicación a los artículos, Roux [Roux2002 p.142] establece varios criterios como: 
- "Clase de producto: dependiendo de la clase de producto puede asignársele una zona determinada en función de sus características físicas, peso o volumen.

- Tipo de rotación: Si tiene mucha rotación se le ubicará lo más cerca posible de la salida par minimizar los tiempos totales de desplazamiento.

- Artículos Vecinos: Puede ser interesante almacenar productos juntos cuando son opciones posibles de la referencia principal. O lo contrario, separarlos para evitar confusión de productos que parecen el mismo.

- Entrega inmediata: Un agotamiento de existencias o un pedido urgente de un producto que en principio estaba destinado a stock, puede hacer que ciertos artículos transiten sin entrar físicamente en stock, y solo se contemple la anotación.

- Completar un pedido retenido: Pedidos importantes y especiales requieren a menudo de tratamientos particulares. Al necesitar un largo periodo para su preparación se comenzará a realizar aunque todos los artículos no estén disponibles y se llevarán los productos directamente al contenedor o zona de preparación de ese pedido. "

Una vez realizadas las operaciones de entrada y asignadas las direcciones a los artículos, el traslado no tiene porque ser inmediato, pero no suele demorarse mucho debido a la falta de espacio en los muelles.

- Almacén: Parte del proceso en el que se guardan y conservan los productos con los mínimos riesgos tanto para el producto, como personas u organización, optimizando el espacio físico en el almacén.

Para ello los almacenes tienen unas zonas divididas en: recepción, almacenamiento, preparación de pedidos, salida o verificación, paso y oficinas. 
Los tipos de almacén se pueden clasificar en:

Racking: utiliza de manera eficiente el espacio vertical, aunque la recogida puede requerir mayor trabajo y ser más caro, ya que es necesario utilizar sistemas automáticos de elevación.

Por Zonas: despacha la recogida, permanencia y envío agrupando las existencias de características comunes en lugares de fácil acceso. Este tipo puede resultar menos eficiente y llegar a malgastarse el espacio.

Aleatorio: agrupa productos de acuerdo al tamaño de los lotes y el espacio disponible sin relacionar las características de los productos. El almacenamiento aleatorio no ayuda a la recogida rápida, especialmente cuando se trata de grandes cantidades.

De temporada: los productos sujetos a temporalidades son ubicado en áreas de fácil recogida y abastecimiento para minimizar los costes de manipulación.

Cuarentena de alto riesgo: la existencia de algo de valor como por ejemplo armas de fuego requieren condiciones especiales de almacenamiento, incluyendo el acceso restringido y supervisión para la recogida y el envío, así como un seguimiento especial de la trazabilidad dentro del almacén para prevenir robos y posibles problemas.

De temperatura controlada: para productos que requieren una temperatura controlada es importante tener en cuenta la seguridad de los empleados y protegerlos de los choques térmicos. La manipulación de los productos también puede ser más lenta debido al tiempo limitado que se puede pasar en el entorno de la temperatura controlada. 
Cross-docking: utilización de instalaciones intermedias para el almacenamiento de mercancías, sobre todo entre los muelles de carga y descarga. El más típico es el muelle, donde el material es transferido de un camión a otro sin necesidad de ser almacenado. Suele ser considerado más un modelo de distribución que de almacenaje.

La actividad realizada en el almacén supone dos tipos de operaciones, por un lado el tratamiento de pedidos que llegan del servicio comercial, y por otro, las acciones de responsabilidad local como reorganizaciones o mantenimiento.

Una vez que los productos entran en el almacén constituyen el stock, y es indispensable conocer su ubicación para poder encontrarlos. Para ello la forma habitual de hacerlo es conociendo la referencia completa de cada artículo.

- Movimiento de Almacén: Supone el traslado de materiales o productos de una zona a otra en un mismo almacén. Los criterios utilizados normalmente son LIFO (Last in First Out: la última mercancía que entra en el almacén es la primera que sale para la expedición), FIFO (First in First Out, la primera mercancía que entra en el almacén es la primera mercancía que sale, con lo que se evitan obsolescencias), FEFO (First Expired- First Out el producto cuya fecha de caducidad esté más próxima es el primero en salir).

En un principio, la operación de picking o preparación de pedidos, consistía en tener mucha paciencia y mucho tiempo, ya que el operario guiado por una lista de referencias, nombres, unidades y otros datos, recogía las unidades que conformaban los pedidos pudiendo éstas encontrarse ubicadas de forma dispersa en los almacenes.

Esta labor aparentemente sencilla, se traducía en resultados bastante negativos, ya que solamente un $20 \%$ del tiempo real se invertía en picking, 
mientras el resto se empleaba en leer, memorizar y recordar las ubicaciones de los diferentes productos

Pina [Pina2000] destaca como la importancia relativa del picking y preparación de pedidos supone un conjunto de operaciones de alto coste, que llega a ser hasta del $60 \%$ de los costes operativos y más del 50\% de los costes de mano de obra en algunas empresas. Dicho picking puede realizarse: por pedidos, por referencias, por zonas, multizonal.

La llegada de los pedidos debe hacerse a través del departamento comercial, registrando los pedidos de los clientes. Una vez aceptado el pedido, y comprobada la disponibilidad de artículos, se procede a su preparación. Para optimizar ésta se suelen dividir en líneas de pedido e incluso por zonas de carga.

Lo más habitual es que se elija entre las distintas direcciones donde estén ubicados los mismos artículos. El almacén puede también tener que elegir entre artículos que lleven la misma referencia pero que poseen algunas características diferentes como la fecha de entrada en stock, número de lote, fecha límite de venta, fecha límite de utilización óptima, fecha de caducidad, entre otras.

Para Roux [Roux2002 p.156] una vez decididas todas las ubicaciones en las que hay que recoger items, hay que reagruparlas para formar rondas de carga de forma lógica. Los factores que deciden este reagrupamiento son:

- El volumen y peso conjunto de las cargas de cada ronda

- La pertenencia a una misma zona de almacenamiento

- La accesibilidad con un sistema de manipulación 
- Las horas de las próximas salidas.

Si la actividad de almacén incluye el embalaje de artículos antes de su envío, habrá que determinar el tamaño de los mismos antes de comenzar. Además se debe editar y pegar etiquetas de envío cuando se preparen las cajas u otro tipo de envases ya que en dichas etiquetas se presentan instrucciones de carga, lo que permite ganar en productividad y limita el número de errores posibles.

Roux [Roux2002 p.159] apunta como debe obrarse para realizar la gestión de las salidas de almacén. Primero hay que consolidar el pedido a través de la confirmación de éste se ha agrupará por línea o por destino. Una vez reagrupado el pedido, se embalará y etiquetará para el envío, y se enviará a expediciones para su carga. Además hay que generar los documentos de envío: los albaranes de envío de entrega (que suelen llevarlos los transportistas), los que acompañan a los paquetes, los recibos de transporte o recepción (a firmar por los destinatarios) y la carta de porte para los controles del chofer.

* Nivel 3: Información. [PwC2001 p. 84] Este proceso es de vital importancia y se extiende a todos los anteriormente citados, desarrollándose de manera paralela a través de: la información para la gestión, como son la configuración de almacén, los medios disponibles, las mercancías almacenadas, informes de actividad, indicadores, instrucciones de trabajo, perfiles y requisitos, ubicaciones como estanterías, pasillos y alturas, e identificación y trazabilidad de mercancías ya sea a través de códigos de barras o etiquetas electrónicas, como muestra la Tabla 6.3. 


\section{Información para la Identificación de ubicaciones gestión}

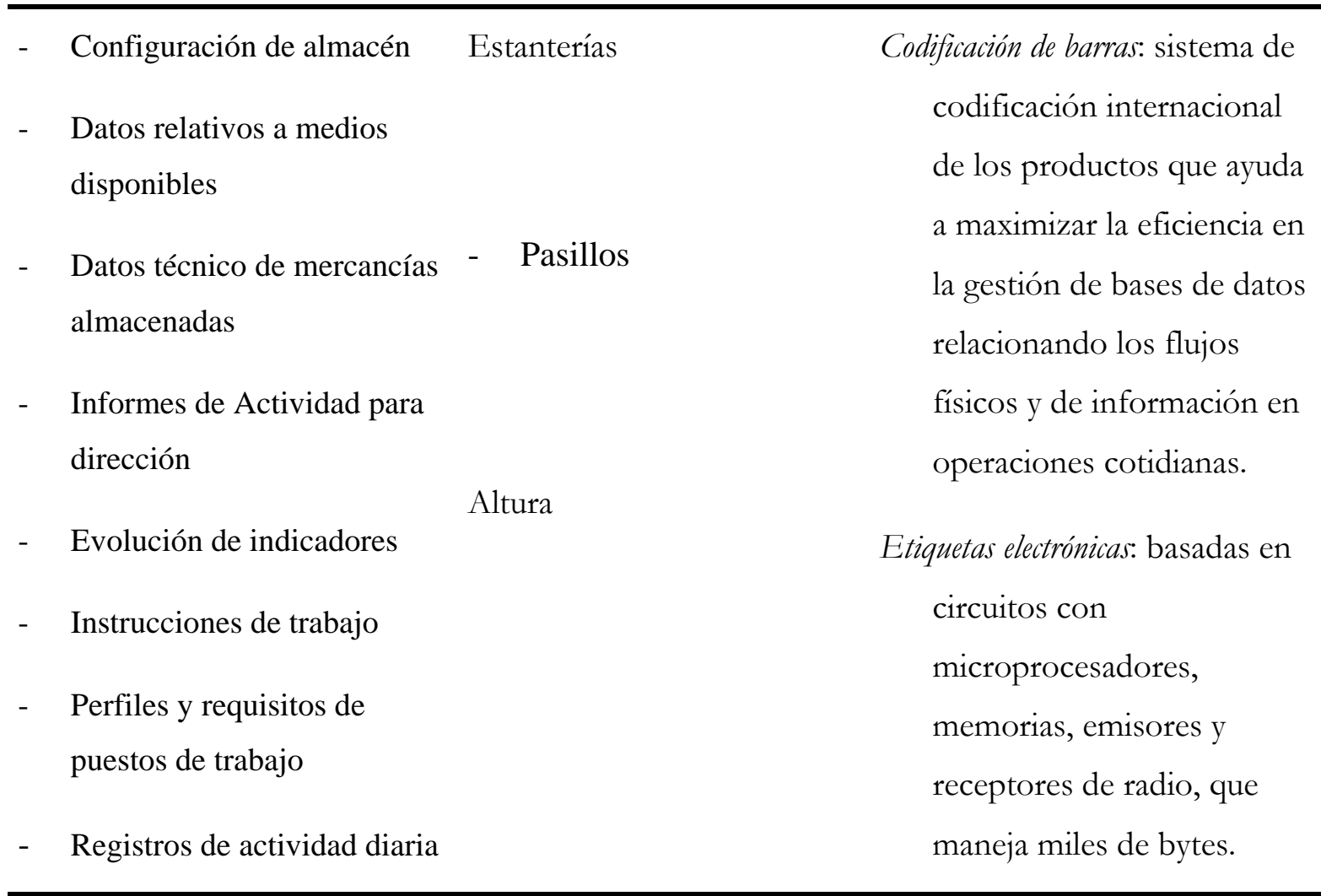

Tabla 6. 3: Clases de Gestión de información. Fuente: Elaboración propia basada en PriceWaterhouse Coopers [ $\underline{P w C 2001}$ p, 84-89]

\subsubsection{Actividad de Gestión de stocks}

Para PriceWaterhouseCoopers [ $\underline{\mathrm{PwC2001}}$ p.99], la gestión de stocks constituye una de las actividades principales dentro de la gestión de la cadena de suministro, ya que el nivel de stocks puede llegar a suponer la mayor inversión de la compañía llegando a ser incluso más del 50\% del total del activo de distribución. De esta manera el gestor de la cadena de suministro tendrá a su cargo al gestor de stocks. 
Roux [ $\underline{\text { Roux} 2002}$ p.150] define los "inventarios como la enumeración precisa de lo que contiene el almacén. Pudiendo ser : Inventario Intermitente, Inventario Permanente o Inventario en Movimiento "

Para PriceWaterhouseCoopers [PwC2001 p.99] el disponer de inventarios surge de la dificultad que existe para coordinar y gestionar en el tiempo las necesidades y requerimientos de los clientes con el sistema productivo y las necesidades de producción con la habilidad de los proveedores de suministrar los materiales en el plazo acordado.

Mantener esos inventarios de materiales supone para la empresa un aspecto positivo, ya que le permite tener flexibilidad operativa para poder producir y emitir pedidos a un ritmo diferente, mientras que por otro lado existe un aspecto negativo debido el gran número de costes: que acarrea: administrativos, de espacio, operativos, financieros y económicos.

Los objetivos principales de la gestión de stocks son: la reducción al mínimo posible de los niveles de existencias y el asegurar el suministro de producto en el momento adecuado al área de producción o al cliente.

Para Roux [Roux2002 p.131] "la gestión de stocks permite decidir un cierto número de principios estratégicos y tácticos, como:

Determinar que artículos hay que tener en almacén y en qué cantidad

Elegir los modos de reabastecimiento

Optar por una manera de valorar el stock".

La importancia de la gestión de stocks se debe a que gracias a ellos, las empresas poseen una inversión ya realizada que se valora periódicamente a través de métodos contables, (LIFO FIFO, precio medio...) y por ello ha de tenerse conocimiento del 
valor económico de cada tipo de material almacenado, ya sea materia prima, producto en curso y producto terminado, y sobre éste calcular el coste financiero de la inversión.

A su vez las tareas operacionales que Roux [Roux2002 p.132] señala que hay que llevar a cabo para la gestión de stocks son:

- Grabación de todos los movimientos: las entradas y salidas

- Conocer el estado del stock (inventario permanente)

- Vigilar permanentemente el nivel de los stocks y compararlo con los puntos de pedidos o de fabricación

- Comprobar la procedencia de un pedido

- Administrar las entregas parciales

- Administrar los restos que van a quedar

- Ayudar a elegir la fuente de abastecimiento y realizar los pedidos.

- Elegir el tipo de fuente de abastecimiento y realizar los pedidos.

- Elegir el tipo de inventario que se efectuará, sobre qué referencias, en qué fecha y dar las instrucciones correspondientes a la gestión del almacén para lanzar las operaciones de recuento.

Una correcta gestión de stocks, constituye uno de los pilares básicos en los cuales se apoyan las nuevas tendencias logísticas en la empresa. Además, el alto nivel competitivo con que se mueve actualmente el mercado, obliga a las empresas a reducir sus costes operativos, uno de cuyos componentes más importantes está ligado al 
llamado "Capital cautivo" que las empresas mantienen como consecuencia de las inversiones en stocks necesarias para dar el servicio que el mercado requiere.

En resumen, la gestión de stocks es responsable del "Qué", del "cuanto", del "cuándo" y del "a qué precio". Exigiendo intervención de la dirección general de la empresa y de las direcciones de marketing, comercial, fabricación y compras."

\section{Tipos de Stocks}

Los stocks pueden clasificarse de varias maneras

Por su grado de transformación

- Materias primas. Materiales utilizados para hacer los componentes del producto terminado.

- Componentes. Partes o submontajes que se incorporan al producto final.

- Productos en curso de fabricación. Se trata de materiales y componentes que están experimentando transformaciones o que están en la planta entre dos operaciones consecutivas.

- Productos semiterminados. Los que han sufrido ya parte de las operaciones de producción y cuya venta no tendrá lugar hasta que no se complete dicho proceso productivo.

- Productos terminados. Los artículos finales destinados a su venta.

- Subproductos. De carácter accesorio y secundario a la fabricación principal.

- Materiales para consumo y reposición. Tales como combustibles, repuestos, material de oficina. 
- Embalajes y envases. Los necesarios para el transporte en condiciones adecuadas.

\section{Por su categoría funcional}

- Inventarios de ciclo. En la mayoría de las ocasiones, no tiene sentido producir o comprar artículos a medida que van siendo demandados. En estos casos, se lanza una orden de pedido de un tamaño superior a las necesidades del momento, dando así lugar a un inventario que es consumido a lo largo del tiempo. Así, por ejemplo, un supermercado realizará un pedido de un determinado número de tambores de detergente, en lugar de esperar a que se produzca la demanda del cliente, para pedir el tambor que satisficiera dicha demanda. Este inventario recibe el nombre de inventario de ciclo, ya que se presenta periódicamente, dando lugar a una pauta de comportamiento cíclica.

- Stocks de seguridad. Constituidos como protección frente a la incertidumbre de la demanda y del plazo de entrega del pedido. Evitando, dentro de lo posible, la inexistencia de inventarios en un momento dado.

- Inventarios estacionales. Su objeto es hacer frente a un aumento esperado de las ventas, por ejemplo, el material escolar a principios de septiembre que acopia una papelería situada junto a un colegio.

- Inventarios en tránsito. Se denomina así a los artículos que están circulando entre las diferentes fases de producción y de distribución, como, por ejemplo, entre el almacén de productos terminados y un almacén regional de distribución, o entre distintas fases del montaje.

En la mayoría de las ocasiones, un mismo artículo presentará situaciones de inventarios que corresponden a varias de estas categorías funcionales, puesto que un inventario de ciclo también puede serlo estacional, y además de seguridad, etc. Lo importante es saber con la mayor exactitud posible y a un coste razonable, cuánto vale la globalidad del 
almacén de una empresa. Para ello, cada empresa debería establecer un control de stocks que le permita conocer en cada momento el estado de su stock, la ubicación, así como cuando realizar la reposición de elementos del mismo. Dicha reposición dependerá del tipo de producto, los tiempos de reposición, las fechas de recepción programada, los itinerarios, los controles, etc. lo que se realiza a través de cálculos mediante algoritmos.

Para Rusthon y Oxley [Rushton89 p. 239] el objetivo de un sistema de reposición de inventario supone llevar a cabo un balance entre el coste de mantener los niveles de stock y el servicio prestado a los clientes. La decisión consiste en decidir si tener altos niveles de stock, que proporcionarán altos niveles de servicio a los clientes, o tener bajos niveles de stock, que generará unos costes bajos. Las desventajas de los bajos niveles de stocks provienen de que los pedidos no pueden terminarse, lo cual lleva a una perdida tanto de clientes en curso y futuros. $\mathrm{Y}$ aquellos pedidos que se realizan frecuentemente, pueden generar altos costes de entrega. Por su parte mantener altos niveles de inventario supone mayores desventajas debido a que el capital que está almacenado podía estar invertido en otro sitio más productivo. Además hay un riesgo de deterioro de productos o caducidad de tiempo. A lo que hay que sumar otra desventaja adicional que supone el gasto adicional de espacio.

Los sistemas de reposición de inventarios se diseñan para minimizar los efectos de esas ventajas o desventajas de los niveles de stocks. Existe una gran variedad de sistemas, pero los más utilizados para Rusthon y Oxley [Rushton89 p. 240] son el sistema de revisión periódica y el sistema de pedido en punto fijo. Los sistemas de revisión periódica funcionan bajo la idea de que el nivel de stock de productos se revisa en intervalos regulares de tiempo, y dependiendo de la cantidad de stock se lanza la orden de pedido de reposición de material. El pedido dependerá del nivel predeterminado para los stocks. En el sistema de pedido en punto fijo, se determina un nivel de stock y la cantidad a pedir cuando se alcanza ese nivel de stock, por lo que el tiempo de pedido varía. Estos sistemas se han utilizado durante años con un buen rendimiento, pero el principal inconveniente es que pueden crear altos o bajos niveles de stock innecesarios. 
El problema que surge entonces es cuanto pedir. Pero la respuesta a dicho problema no es fácil de contestar, ya que hay diferentes visiones. Un método particular de calcular la cantidad adecuada es el Método de Cantidad económica de pedido. Dicho método es un intento de estimar la cantidad adecuada de pedido a través del estudio de los costes de mantener el stock y de situar las órdenes de reposición. El efecto de la cantidad de pedido en los costes de mantenimiento de stocks supone que a mayor pedido de un item, mayor será el tiempo de almacén, y mayores los costes de almacenamiento. Por otro lado, realizar un gran número de pedidos en pequeñas cantidades genera una media baja de stock, pero unos altos costes en función de la localización de los pedidos así como costes administrativos y de entrega. Por tanto, hay que llegar al punto medio entre los costes de almacén de un item y los costes de pedido del mismo. Aunque hay que considerar factores operativos, de control de los sistemas de stock como: pedidos pendientes, pedidos mínimos, cantidades paletizables, temporalidad, etc.

\subsubsection{Actividad de Gestión de distribución}

Rushton y Oxley [Rushton89 p.41] señalan los siguientes tipos de costes asociados a la distribución:

* Costes de Producción: varían según los requerimientos de los distintos tipos de estructura de distribución, requiriendo ciertos productos de salida de fábrica. Además está relacionado con los métodos de almacenamiento y manejo.

Costes de empaquetado: Principalmente relacionados con la relación comercial entre el tipo de empaquetado, el manejo y costes de transporte. El trabajo con unidades puede ser importante.

Costes de manejo de información: cubren gran amplitud del área desde la orden de recibo a la dirección del sistema de información. El tipo de depósito en red afectará a muchos de los costes. 
Costes de perdidas de ventas: puede ocurrir que debido a un inadecuado servicio al cliente. Muy importante con respecto a la proximidad del depósito al cliente, junto con la responsabilidad y rapidez en servicio.

Costes de Inventario: Incluyen los costes de capital invertidos en inventario así como los costes por obsolescencia, etc. Una relación fundamental con el la red de depósitos en términos de número de puntos de almacenamiento y jerarquía involucrada.

Costes de Transporte: Estos costes están afectos significativamente por el número y localización de los depósitos dentro de la estructura de distribución, y asociados a los productos de salida Ambos costes de manipulación y entrega final se verán afectados.

Costes de almacén: Estos costes varían según el tipo de almacén y sistema de manejo utilizado, junto con el volumen y productos de salida del depósito. El tamaño será a su vez importante, así como la localización.

Una vez preparado el pedido y pasados los últimos controles en la empresa, habrá que editar los documentos que acompañan al envío, que pueden ser según Roux [Roux2002 p. 162]:

- "Albaranes de envío o albaranes de entrega: documentos que el transportista deberá firmar al margen y formaliza la transferencia de responsabilidad.

- Albaranes de envío para los destinatarios: albaranes de envío que acompañan a los paquetes y que deben entregarse a los destinatarios.

- Recibos de transporte: recibos de recepción que deben ser firmados por el destinatario y entregado al transportista 
- Carta de porte: para los que el chofer pueda hacer los controles y sirva de justificante en caso de accidente. "

\subsection{SELECCIÓN DEL ÁREA DE ESTUDIO}

Una vez expuestas en este capítulo tanto la definición de logística como las actividades que la componen, hay que resaltar la importancia de la integración de la misma en la empresa. Dicha importancia viene reflejada en el artículo titulado "Logistics and Interdepartmental Integration" propuesto por Kahn y Mentzer [Kahn1996 p. 6-14] donde se muestra como los departamentos logísticos tienen una relación con el resto de la empresa o departamentos basadas en el nivel de interacción y colaboración, pero que para situaciones puntuales como el lanzamiento de un nuevo producto, nuevos requisitos de clientes, incertidumbre, producciones a muy corto plazo, requerirán mayor colaboración, o bien si se está ante productos y órdenes más complejas, situaciones criticas, o clientes clave, se requerirá de mayor colaboración y mayor interacción. Por todo ello, conviene tener siempre presente la importancia de las relaciones entre los departamentos o áreas de la empresa. Y en particular tener en cuenta que todas estas relaciones las llevan a cabo los trabajadores de la empresa, por ello, serán quienes den el carácter único a la misma.

En los siguientes capítulos, este trabajo va a proponer como deben estructurarse los Recursos Humanos en el área logística a partir del modelo Propuesto de Recursos Humanos expuesto en el capítulo quinto, para su aplicación de forma eficaz y eficiente, suponiendo en todo momento que una adecuada gestión de Recursos Humanos aumentará la efectividad global del trabajo e incrementar los beneficios empresariales.

Debido a la gran expansión e importancia de la logística en el marco socioeconómico actual, cada vez son más las empresas que están prestando un interés creciente a sus departamentos logísticos, debido a que están ayudando a que las organizaciones alcancen ciertas ventajas competitivas respecto a sus competidoras. Para conseguir todo ello, hay que realizar adecuadas selecciones y reclutamiento de personal, gestionar adecuadamente el trabajo en los departamentos, dar la adecuada importancia a las personas dentro de la estrategia logística, previsión de los cambios, etc. 
Existen diversas barreras para la mejora de los departamentos logísticos en las empresas como: la falta de comunicación interdepartamental en las empresas, el bajo nivel en técnicas de gestión y la falta de apoyos de la alta dirección a las áreas operativas, etc.

C. West [West] señala en su artículo " SCM is about People, not Technology" cómo la importancia del personal en logística es fundamental ya que será el personal quién desarrolle la Gestión de la Cadena de Suministro, jugando un papel importantísimo en el conocimiento y relaciones que suponen para el personal. Las empresas logísticas comienzan a darse cuenta que el valor real de lo que el personal aporta al proyecto no es sólo el proceso en sí, sino en el conocimiento aportado, lo que facilita las complejas relaciones entre clientes, el flujo de información, etc. "

Además se han ido creando nuevos puestos en las empresas conforme éstas han ido creciendo, es decir por evolución común, ya que al crecer surgen nuevas necesidades, por lo que hay que plantearse esa creación de puestos nuevos. Hoy en día dentro de los departamentos logísticos es difícil describir una jerarquía común para todas las empresas que aplican logística, debido a que sus integrantes proceden de distintos departamentos o han ido ascendiendo desde dentro del mismo, logrando ocupar una posición más importante debido a la experiencia y saber hacer dentro del mismo. Por lo tanto, se puede intuir que existe una falta de orden jerárquico y madurez dentro de dichos departamentos. Así pues, la creciente importancia de los Recursos Humanos en logística y la necesidad de describir como son realmente los trabajos específicamente logísticos y como encajan dentro del mundo de la logística hace que se plantee el particular enfoque de este trabajo. El problema que surge se debe a la falta de concreción existente en los puestos y tareas logísticas, por lo que hay que proveer de organización a esos departamentos logísticos, para lo que habrá que crear una estructura de puestos en la que habrá que especificar la formación y requisitos que han de cumplir esos trabajadores así como una especificación de que tareas ha de desarrollar cada uno de los puestos en el modelo.

La cadena de suministro logística (apartado 6.2.2), objeto del área de estudio de éste trabajo, está compuesta de etapas en las cuales se han de realizar una serie de actividades considerándose que en cada actividad participarán únicamente dos 
entidades principales: el proveedor y el cliente, entendiendo con ello que lo que suceda detrás de ellos no va a interesar al otro, como viene reflejado en la Ilustración 6. 11:

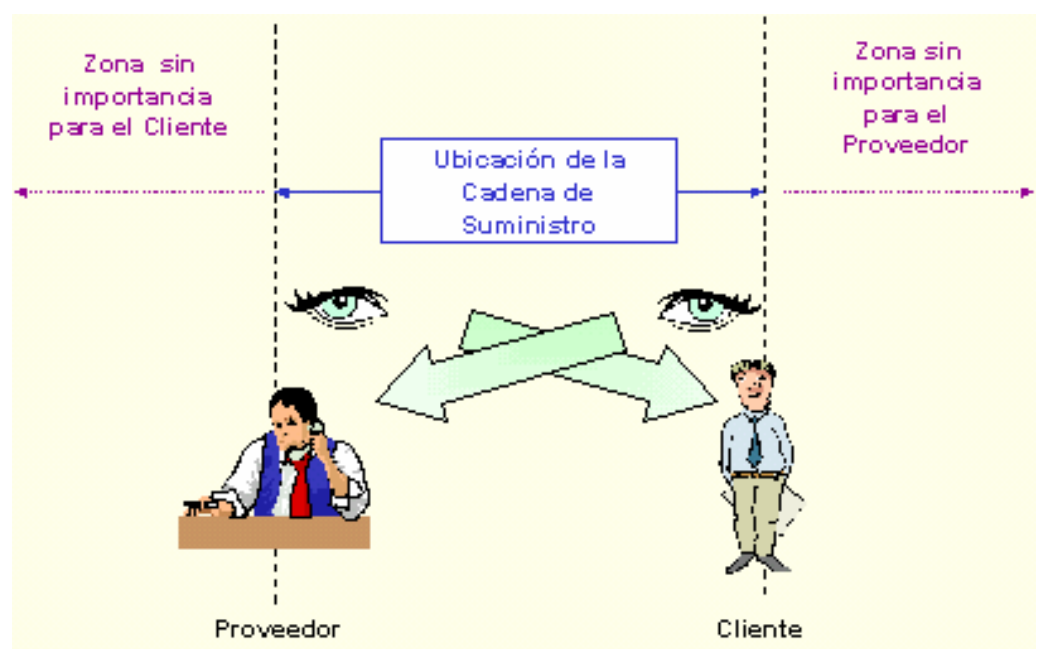

Ilustración 6. 11: Alcance de la visión de los participantes en la cadena de suministro

Por tanto, estas actividades pueden definirse como elementales, en el sentido de que participan sólo dos entidades, el proveedor y el cliente, y si se desplaza a lo largo de la cadena, el proveedor actual pasará a ser el cliente de otra cadena, pudiendo ser el proveedor. Obviamente la cadena se puede ampliar incluyendo más entidades participantes, o repitiéndose entre cada par la cadena de suministro antes señalada. Sin embargo aunque se extienda la cadena, la interacción siempre será entre dos entidades: el proveedor y el cliente. Entre estas dos entidades citadas (proveedor y cliente) va a ser entre las que se sitúen los trabajadores logísticos y por tanto donde hay que definir los puestos, tareas, formación y habilidades.

Para la aplicación del un Modelo de Recursos Humanos logístico, este trabajo se va a basar en el modelo desarrollado en el capítulo 5, pero aplicado a los sistemas logísticos, para posteriormente realizar su aplicación práctica a las empresas. Una vez presentada en este capítulo sexto una introducción a lo que es la logística y lo que abarca, a partir del siguiente capítulo se propone el desarrollo del modelo de Recursos Humanos logístico teniendo en cuenta todo lo presentado hasta ahora. 


\subsection{CONCLUSIONES DEL CAPÍTULO}

Una vez obtenido en el capítulo quinto el modelo de Recursos Humanos Propuesto, se procederá a su aplicación a un área determinada de las organizaciones. Esa área es la logística, por lo que antes de aplicar realmente el modelo, se ha procedido a introducir este capítulo como presentación de los principales conceptos logísticos y de que están compuestos.

Para ello, en el apartado 6.2 se ha comenzado a definir el concepto de logística, logística inversa, y pasar a continuación a realizar un recorrido histórico por la evolución de la logística: desde los años del letargo, hasta los años del despegue, pasando por los años de desarrollo de los cincuenta y sesenta. Este apartado se ha completado con la definición de Cadena de Suministro como la coordinación de funciones de negocio a lo largo de una cadena logística continua y sin interrupciones, todo ello con el objetivo de satisfacer las necesidades de los clientes en las mejores condiciones y prestando un nivel de servicio.

Se ha expuesto una descripción de las áreas que componen la logística, es decir, un recorrido por la gestión de demanda, gestión de pedidos, gestión de aprovisionamiento, gestión de almacenes, gestión de stocks, así como gestión de distribución. Finalmente el capítulo hace una reflexión sobre el área de estudio que se va a analizar a partir del próximo capítulo para realizar una aplicación del Modelo de Recursos Humanos, y poder generar un modelo de Recursos Humanos aplicado a los Sistemas Logísticos.

A partir de este capítulo se realizará la aplicación del modelo expuesto a la logística y así generar la denominación de los puestos en los sistemas logísticos, y poder definir el ¿Qué?, ¿Cómo?, ¿Cuándo?, ¿Quién?, ¿Dónde? y ¿Porqué? de cada uno de los puestos obtenidos. 


\subsection{REFERENCIAS BIBLIOGRÁFICAS DEL CAPITULO}

Ballou91 Ballou, R.H. “Logística empresarial. Control y Planificación” Editorial Díaz de Santos. España. 1991

Carrallo78 Carrallo Méndez, A. “Logística Comercial”. Ediciones ESIC. Escuela Superior de Gestión Comercial y Marketing. España. 1978.

CELPilot2001 CEL - Foro Pilot. "Estudio de situación logística en las empresas de Aragón 2001". Centro Español de Logística. Mayo 2001.

CELConsorci20 Centro Español de Logística. El Consorci de la Zona Franca de 02 Barcelona. La Situación de la logística en España. Estudio de situación 2001.España 2002

CELFormación CEL- Formación. Formación en Logística Integral. Curso de Gestión de Inventarios II.

CLM2000 Council of Logistics Management. "What is all about? Publicación del Council of Logistics Management. USA. Año 2000

Gibson Gibson B, M. Gibson, Rutner S. "Careers in Logistics". Georgia Southern University. Council of Logistics Management (CLM) www.clm1.org

Kahn1996 Kahn K.B., Mentzer J.T. "Logistics and Interdepartmental Integration" International Journal of Physical distribution \& Logistics Management. Vol. 26. No 8 USA. University Press 1996

Kirby2001 Kirby C, J.M. Planas. “Un caso de logística estratégica: ¿Cómo optimizar la red logística: centralizar o descentralizar”. Idom Ingeniería, Trace Logístics XXIII Jornadas de logística. Salón Internacional de la logística. Barcelona. Junio 2001

Lambert2001 Lambert DM (The Raymond E. Mason Chair in Transportation and Logistics. The Ohio State University). PF Osborn III (Eminent Scholar Chair in Logistics. University of North Florida). "Supply Chain Management”. XXIII Jornadas de Logística. Salón Internacional de Logística. Barcelona Junio 2001

Machuca Domínguez Machuca J. A., S. García González, MA Domínguez Machuca, A. Ruiz Jimenénez, M.J. Álvarez Gil.. Dirección de Operaciones: Aspectos tácticos y operativos en la producción y los servicios. Mc Graw Hill. España. 1995

Mayo J.C. Mayo. "Cadena de Valor: El análisis de la Cadena de Valor, técnica de M. Porter para obtener ventaja competitiva". 
http://www.gestiopolis.com/recursos/experto/catsexp/pagans/eco/no 12/cadenavalorporter.htm Consultada el 22/04/2002

Pina2000 Pina Barrios, Rafael. Director General de Shitake Corp. "Nuevas tecnologías para la automatización de almacenes". I Foro Logístico de la Región de Murcia. INFO - CEL. 2000

Prida Prida Romero B., G. Gutiérrez Casas. "Logística y aprovisionamiento". Mc Graw Hill de Management. España. 1996

PwC2001 PriceWaterhouseCoopers. Manual práctico de logística- Foro Pilot. Zaragoza. España 2001

Ross2000 Ross, D. F. "Competing through Supply Chain Management: Creating Market-winning strategies through Supply Chain Partnerships" Materials Management. Logistics Series. Kluwer Academic Publishers. Tercera Edición. Estados Unidos Año 2000

Roux2002 Roux M. "Manual de Logística para la Gestión de Almacenes". Edición Gestión 2000. Segunda Edición. España. Año 2002

Rushton89 Rushton A., J. Oxley. "Handbook of Logistics and Distribution Management” Editorial Kogan Page. Reino Unido. 1989

Soret97 Soret los Santos, I. "Logística Comercial y Empresarial” Colección Universidad. ESIC (Escuela Superior de Gestión Comercial y Marketing). 2º Edición. España 1997.

West Carol West. "SCM is about People, not Technology" Logistics Quarterly. Volume 7. Issue 3. Summer 2001. www.lq.ca/issues/fall2001/articles/article15.html Consultada el $30 / 05 / 2002$ 


\section{Capítulo 7.}

Desarrollo del Modelo de

Recursos Humanos

Aplicado a los Sistemas

Logísticos 
CAPITULO 7

\section{DESARROLLO DEL MODELO DE RECURSOS HUMANOS APLICADO A LOS SISTEMAS LOGÍSTICOS}

\subsection{INTRODUCCIÓN}

En el capítulo quinto se ha expuesto el modelo de Recursos Humanos Propuesto, y realizado en el capítulo sexto una aproximación a los sistemas logísticos, su concepto y áreas que los componen. En el presente capitulo, se desarrollará una aplicación del Modelo Propuesto al área particular de los sistemas logísticos.

Para ello se comenzará aportando las ideas que tras una revisión bibliográfica aportan los expertos sobre el perfil que ha de cumplir un profesional logístico.

En el apartado 7.3 se realizará una descripción de los distintos puestos que pueden llegar a encontrarse en los departamentos logísticos tanto de una empresa como de un operador logístico, para posteriormente, en el apartado 7.4 proceder a la aplicación del modelo de Recursos Humanos Propuesto a los sistemas logísticos y generar así un modelo de Recursos Humanos Logísticos.

La generación de este modelo seguirá los pasos propuestos en el capítulo quinto, y obtendrá igualmente los puestos que componen los sistemas logísticos, procediendo a continuación a 
general el ¿Qué?, ¿Cómo?, ¿Cuándo?, ¿Quién?, ¿Dónde? y ¿Porqué? de cada uno de los puestos que se proponen.

\subsection{PERFILES DE LOS PROFESIONALES LOGÍSTICOS}

Antes de comenzar a analizar los perfiles de los puestos de los profesionales logísticos, hay que señalar las peculiaridades que como tal posee dicho sector. San Cristóbal [SanCristobal2001] en su ponencia "Los Recursos Humanos de un Operador Logístico" señala como peculiaridades del sector las siguientes:

Inexistencia de Formación Académica Ad Hoc

Número escaso de profesionales

Perfiles diferentes no muy especificados trabajando conjuntamente

Desconfianza hacia el Headhunter

Alto grado de comunicación entre los profesionales

Venta desequilibrada del puesto y/o sector

Poca atención al anuncio en prensa y escasa respuesta"

Pero cuando se habla en general de perfiles, se tiende a hablar de puestos de trabajo, con sus características propias que les hacen ser diferentes unos de otros, incluidos los de su mismo ámbito. Un puesto de trabajo tiene una serie de exigencias y particularidades a distintos niveles, lo que se traduce en características que ha de reunir una persona para desarrollar dicho puesto de forma eficiente. 
Cada puesto tiene una serie de exigencias formativas y de conocimientos específicos; dicha formación supone el uso de un lenguaje, una base, etc., junto con otro tipo de formación, creatividad, y aspectos tales como las habilidades personales, la personalidad propia, y la motivación, hacen que se desarrolle la competencia profesional. Todo ello permite que se complete el perfil, y ayude a la selección del personal para un determinado área específica, a través del análisis de puestos y desarrollo de manuales de funciones, que contendrán desde la identificación del puesto a la descripción de tareas (tanto habituales como ocasionales), relaciones con otros puestos de trabajo, así como conocimientos y experiencias requeridas.

Realizando una aproximación al perfil que han de cumplir los profesionales logísticos se han de tener en cuenta las ideas expuestas por M. A. McIntryre [McIntryre2002] en la conferencia realizada en el "53 Annual Salzberg Medallion Lecture" en la cual se apunta como los profesionales logísticos no realizan sólo un trabajo, sino que más bien el desarrollo de una carrera.

Esto demuestra el interés creciente hacia los puestos logísticos y su desarrollo, ya que son quienes planifican todo el proceso, trabajando cada detalle con anterioridad según los planes diseñados para la cadena de suministro y permaneciendo muy a menudo a la sombra para el gran público, quién no se pregunta como llegan productos del otro lado del mundo a cualquier comercio se encuentre donde se encuentre.

Como señala McIntrye [McIntryre2002 p.9], hasta hace no demasiados años, "en las empresas existían para el desarrollo de la logística los llamados Jefes de Tráfico, quienes se encargaban de enviar o embarcar los productos. Éstos eran prácticamente administrativos ejecutivos encargados de llevar a cabo las políticas referentes a la logística, en lugar de ser un ejecutivo con la autoridad y la misión de diseñar la mejor manera de realizar las tareas. Éstas consistían en estar en su oficina revisando tarifas de transporte, vuelos, costes de embarque, dando órdenes de transporte y pagar a los transportistas, etc. Sin llegar a tener autoridad en la toma de decisiones, ni poder ejercitarla.

...Pero hoy en día los profesionales de la logística no sólo se dedican a consultar un libro de tarifas, sino que han de analizar todos los elementos que permitan tomar decisiones a lo largo 
de la Cadena de suministro, e ir modelizando en los distintos escenarios posibles...lo que hace que se produzcan importantes huecos para el desarrollo de estas carreras logísticas."

Dicha autora [McIntryre2002 p.15] hace un pequeño repaso sobre las características que ha de tener un profesional logístico señalando las siguientes: " habilidad, formación, profesionalidad, y no sólo estar dedicado a planificar, diseñar y ejecutar los procesos logísticos, sino también trabajar con directivos de la empresa para integrar el proceso en la búsqueda, desarrollo de productos, ingeniería, financiación y producción.

...Los profesionales logísticos necesitan preparación en análisis de datos para poder tomar las decisiones correctas, así como capacidad negociadora para sacar adelante acuerdos multiparte antes de que el sistema empiece a funcionar. Los antiguos Jefes de Expediciones o Tráfico se han quedado fuera, quedando únicamente para realizar las entregas. Los profesionales logísticos ya no están al final del proceso esperando a que les digan que hacer con el producto, sino que participan junto con el resto de los directivos desde que nace la idea del nuevo producto, ya que pueden apoyar y dar idea de si el producto podrá o no venderse en algunos mercados, siendo por tanto de gran responsabilidad y requiriendo gran compromiso con las empresas a las que pertenecen, y acercándose más al perfil de ejecutivo de negocios"

M. Cooper, A. Gillyard y Sandu [Cooper2002] en su estudio sobre "Modelos de Carreras Logísticas para Mujeres", señalan como características para el perfil logístico: "el ser bien educado, trabajar largas jornadas, viajar, poseer habilidad interpersonal, preparación analítica, tratamiento de información y tecnología, tener apoyos, y ambientes positivos."

En el estudio realizado por Gibson et al.[Gibson1998 p.4], titulado "Carrers in Logistics" los autores señalan como: "los profesionales de la logística han aumentado la importancia de las actividades de análisis, estrategia y tecnológicas, lo que hace que se convierta en una carrera más atractiva, y proporcione perfiles de todo tipo: un amplio número de mujeres e incluso minorías sociales. Pero la carrera logística de cada uno dependerá de sí mismo, aunque esté relacionado con las habilidades, conocimientos del proceso logístico y experiencia, lo que proporcionará probablemente la oportunidad de comenzar como un directivo si se pueden demostrar dichas capacidades directivas. 
Gibson et al. [Gibson1998 p.8] apuntan que "las áreas de la logística a ocupar son muchas, tales como: planificación logística, análisis, transporte, dirección de almacenes, planificación y control de inventarios, compras, logística internacional, planificación de producción, Cadena de Suministro, Servicio al cliente, Sistemas de información, Marketing y ventas, ingeniería logística, etc. pudiendo ser combinadas dichas áreas bajo la responsabilidad de un único jefe logístico."

Mientras, el estudio realizado por la Universidad del Estado de Ohio en el 2001 "Estado de los Modelos de Carrera en Logística" de La Londe y Ginter [LaLonede2002 p.6] incluye en su encuesta las áreas más importantes de la logística para los trabajadores del sector. El resultado obtenido es:

- 89 \% consideró como principal actividad la dirección de tráfico,

- $83 \%$ los almacenes

- $\quad 74 \%$ logística en general

- 61\% Fábricas

- 59 \%Control de inventario

- 57\% Dirección general

- $\quad 40 \%$ Servicio al cliente

- $\quad 40 \%$ Embalaje

- $38 \%$ Proceso de Pedidos

- $29 \%$ Compras 
- 21\% Planificación de producción

- $\quad$ 17\% predicción de ventas

- $17 \%$ otros

El perfil presentado para el profesional logístico por Gibson et al. [Gibson1998 p.10] incluye unas características más específicas como conocimientos logísticos, habilidades funcionales, conocimiento de operaciones, marketing, estadística, análisis cuantitativo, finanzas, así como conocimiento de la situación internacional, relaciones humanas, y por supuesto, experiencia en el sector. Mientras que dentro del otro tipo de características más universales, pueden incluirse la habilidad social, capacidad analítica, comunicación, flexibilidad, informática.

Los autores Gibson et al. [Gibson1998 p.29] a su vez señalan que un grado universitario no es fundamental para comenzar el desarrollo de la actividad logística, pero puede ser muy útil a lo largo de la carrera logística, ya que puede mejorar la experiencia, así como la planificación estratégica, la dirección financiera así como la habilidad analítica, aunque muchos de los profesionales actuales hayan llegado a donde están a través de la experiencia.

Murphy y Poist, [Murphy1998 p.284] en su artículo sobre " Skill requirements of senior-level logisticians: Practitioner perspectives ", señalan como los directivos logísticos se enfrentan cada vez más, hacia un entorno completamente diferente al de hace unos diez años, debido a los cambios acontecidos en el sector del transporte, el uso de los ordenadores, y la globalización mundial. Los estudios realizados por LaLonde y Cooper en la Universidad del estado de Ohio en 1980, encontraron que los directores logísticos de los años ochenta poseían formación de gestión, estudios financieros, y de logística, mientras que la encuesta realizada por Masters y LaLonde en 1989 las materias eran finanzas, informática y comercio internacional. Basándose en dichos estudios, el correspondiente a 1980 señaló los costes de distribución, costes de energía y la regulación como los principales factores que influenciaban en el coste de la logística, mientras que los factores más influyentes en 1989 fueron los costes 
de control, el servicio al cliente, y Intercambio electrónico de datos (EDI -Electronic Data Interchange).

Lynch [Lynch1998] por su parte señala en su artículo "Leadership in Logistics", como los líderes logísticos lo son hoy más que nunca, pero no solo como profesionales, sino también como líderes y estar preparado para ello no solo en aprendizaje (títulos, lecturas, seminarios, etc.) sino también en tareas a realizar, y en el momento preciso. Para ello han de rodearse de personal competente, ya que un buen líder dirige una buena organización a través de una buena comunicación, ya que de otro modo no se encontraría en ese puesto. Por tanto un buen líder ha de ser honesto, ético, y con gran sentido de la integridad"

En el estudio realizado por Murhpy y Poist [Murphy1998 p.287-288] se señalaban como atributos logísticos más importantes: el transporte y la logística, la administración general de empresas, la dirección de los Recursos Humanos, la comunicación y los sistemas de información. Y entre los menos importantes, los idiomas extranjeros (aunque al ser un estudio americano, el idioma en que se realiza es el inglés), la planificación urbana y regional, la Ingeniería civil, los discursos, los seguros y el historial de negocios. Por tanto, entre los requisitos más importes que se piden a los Senior en logística son: primero, el servicio al cliente, y segundo, la gestión de transporte, aunque teniendo siempre claro que primero han de ser gestores y luego logísticos, eso supone que sean primero generalistas y luego especialistas, para lo que se requiere habilidad directiva.

El estudio realizado por Dadzie [Dadzie1998 p.269] señala como "habilidades requeridas para los profesionales logísticos: el transporte, la gestión de inventario, el control financiero, marketing y los sistemas informáticos".

Finalmente hay también que considerar hacia donde apunta la logística, ya que sus profesionales han de estar preparados para ello. En la encuesta realizada por La Londe y Ginter [LaLonede2002 p.12] se señala entre los factores que afectan al desarrollo y crecimiento de la logística a la:

- Información tecnológica (19\%) 
- Integración de la cadena de suministro (14\%)

- Creación de valor del intermediario (14\%)

- E- Commerce (13\%)

- Crecimiento internacional (8\%)

- Control de costes (7\%).

Dentro del e-commerce y la Cadena de Suministro Electrónica, Williams, Esper y Ozmet [Williams2002 p. 703-719] señalan al líder logístico como un líder dinámico, que se sitúa en el centro de un círculo de actividades logísticas, en lugar de lo alto de la pirámide de mandos, animando a sus subordinados a lograr la excelencia y comprendiendo las interdependencias entre ellos y la organización. El líder ha de ayudar a los empleados a darse cuenta del potencial que tienen y cómo pueden superar cualquier obstáculo, con optimismo contagioso, por ello poseen un gran carisma, estimulación intelectual, respeto y consideración hacia sus empleados.

Puede realizarse una mención a la Cadena de Suministro Global, en la cual dicha cadena supone una integración de actividades y procesos entre entidades organizativas en múltiples países, generándose por tanto la Cadena de Suministro Global. En dicha cadena se intenta sacar el máximo valor a través de los vínculos y sinergias que existen en el sistema. Para ello, Harvey [Harvey2001 p.110-111] señala como "los trabajadores que desarrollan sus trabajos en las cadenas de suministro global, han de mejorar las economías de escala y su alcance en la cadena. Dichos gestores se mueven entre barreras competitivas, basadas en tiempo, barreras comerciales, barreras de transporte, de reestructuración y barreras específicas por países"

En España, Pérez [Pérez2001 p.24-26] señala como "Hace diez años, un responsable logístico administraba la dirección del servicio de transporte y la gestión de stocks. Progresivamente su campo de actuación y responsabilidad se ha extendido a la preparación de pedidos, a la gestión de los flujos de producción, a la gestión de los abastecimientos, a la gestión de los 
flujos de información e incluso a la tele-venta y a la previsión de ventas. Los responsables de las empresas han tomado progresivamente conciencia de la importancia de una gestión global de los flujos físicos, pero también de los flujos de información, con lo que así consiguen mayor control sobre la Cadena de Suministro.

Por tanto, los puestos logísticos más requeridos en los últimos años, son aquellos relacionados con la gestión de proyectos, que aporten conocimientos de CRM (Customer Relationship Management). Otro perfil requerido es el de la persona orientada a la gestión del conocimiento, lo que supone una persona con conocimientos financieros y de control interno, que al mismo tiempo pueda comprender la segmentación de las operaciones y crear y transmitir conocimiento, lo que aunaría la búsqueda de la rentabilidad y de la implementación de nuevos procesos logísticos. Todo ello sin olvidar los perfiles ya conocidos de dirección comercial, marketing, control de operaciones y calidad, tan importantes en el sector logístico."

Todo ello, justifica el porqué de que los buenos profesionales de logística estén tan buscados y tan bien pagados, ya que necesitan una amplia formación y experiencia, así como preparación para afrontar el futuro, y las universidades y centros de enseñanza no pueden formar a todos los buenos profesionales que demandan las empresas.

San Cristóbal [SanCristobal2001] en su ponencia "Los Recursos Humanos de un Operador Logístico" señala cinco competencias que ha de desarrollar el profesional logístico español, siendo éstas las que a continuación se señalan:

Iniciativa: predisposición a la proactividad, a la capacidad de anticiparse y actuar.

Capacidad de análisis: como la habilidad para desglosar los problemas, simplificándolos y solucionándolos.

Orientación al cliente: es la sensibilidad para comprender y comprometerse con las necesidades del cliente. 
Trabajo en equipo: Supone una realidad en la colaboración con los demás, aportando y creando sinergias.

Flexibilidad: Capacidad para adaptarse y ser eficaz en las distintas situaciones que se puedan producir, valorando así otros enfoques.

Así pues San Cristóbal [SanCristobal2001] hace referencia a como el cambio en el sector ha hecho que se produzca un cambio y reciclaje en los profesionales veteranos con experiencia ya que éstos poseen un conocimiento profundo del sector, tienen un talante resolutivo basado en la experiencia, trato cercano y una orientación a los clientes, a ello se le ha incorporado mandos de nueva generación, surgiendo con ello, un sector profesionalmente más sólido, generándose poco a poco una formación más reglada y de postgrado, que conlleva una visión global de la empresa, teniendo en cuenta en todo momento tanto la visión del análisis y la planificación como las nuevas tecnologías aplicables. Entre los profesionales de nueva generación San Cristóbal señala puestos como el Jefe de Proyecto en el área de Operaciones, encargado de desarrollar los proyectos orientados a la optimización de las operaciones y racionalización de las operaciones y procesos con el fin de orientar la actividad a criterios de rentabilidad, calidad y valor añadido. Mientras que en el área comercial señala al Encargado de Grandes Cuentas, como un profesional encargado de llevar las grandes cuentas de los grandes clientes de los operadores logísticos, puesto que compartirá la visión, necesidades y responderá con rapidez a las demandas de los clientes.

Finalmente, a lo que hay que prestar mucha atención por parte de las empresas es a la fidelización de los trabajadores de los sistemas logísticos, debido a que ante la escasez de buenos profesionales formados debe realizarse un proceso de fidelización, motivación y adecuación del entorno profesional para que no se produzca fuga de profesionales de la compañía. Para ello las empresas han de llevar a cabo una estrategia de Recursos Humanos basada en el liderazgo y la gestión óptima del talento de cada uno de los profesionales logísticos 


\subsection{LOS PUESTOS LOGÍSTICOS}

\subsubsection{La Base: el organigrama logístico}

En el capítulo anterior se expusieron (epígrafe 6.3) las áreas con las que se relaciona la logística, sobre la base de dichas áreas se puede realizar una clasificación de los puestos correspondientes al departamento logístico.

Atendiendo a la clasificación realizada en el epígrafe 6.3, se puede decir que la gestión de aprovisionamientos la realizará el área de compras, la gestión de almacenes llevará a la realización de tareas de almacén, la gestión de stocks supondrá realizar tareas de inventario, y la gestión de pedidos y distribución realizará tareas de transporte y servicio al cliente. A esto hay que sumarle la importancia de la información, ya destacada en el capítulo segundo, en el epígrafe 2.2.5 y que en lo que a logística se refiere hay que incorporarla en el departamento a través del Sistema de Información Logística.

Todo ello vendrá coordinado desde la dirección del departamento logístico, o dirección de la empresa en el caso de ser un operador logístico y siguiendo los objetivos estratégicos del propio departamento, o de la dirección. Dicha dirección realizará tareas de liderazgo, así como dirección, coordinación y planificación logística.

Por lo tanto, el organigrama que surge de la división comentada en el párrafo anterior es el expuesto en la Ilustración 7. 1, donde se puede apreciar la división en tareas de información logística, almacén, transporte, inventario, compras y servicio al cliente, dependiendo todas ellas de la Dirección Logística.

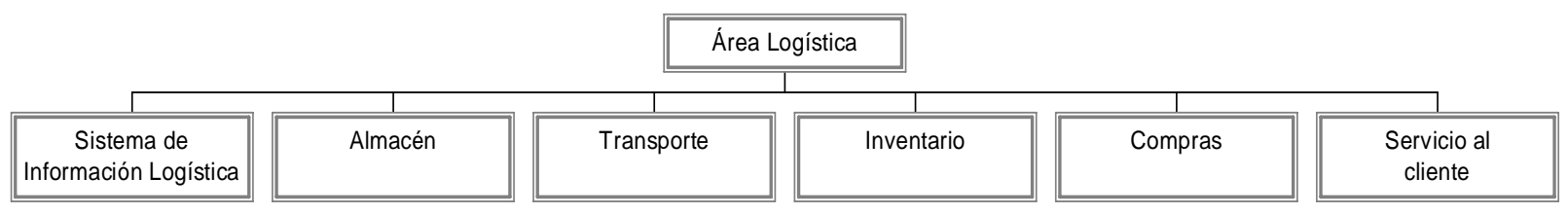

Ilustración 7.1 : Ejemplo de Organigrama de un departamento logístico

El problema que puede surgir al observar dicho organigrama nace de la cantidad de ramas o subáreas que lo componen. Dicha cantidad de ramas proviene de la inclusión de todas las posibles áreas relacionadas con la logística, pudiendo existir o no en cada caso particular de empresa. 
Por lo tanto, dependerá en gran medida del tipo de empresa ante la que se esté, el incluir o no todas las subáreas aquí presentadas. No será lo mismo hablar de una mediana empresa productora con un departamento logístico, que hablar de un operador logístico dedicado exclusivamente a realizar la gestión de la Cadena de Suministro, o un distribuidor comercial.

Los puestos logísticos que a continuación se presentan en el siguiente epígrafe, surgen del desarrollo del organigrama presentado en el actual. Pero habrá que tener en cuenta en todo momento el tipo y el tamaño de empresa que se va a analizar.

\subsubsection{Los puestos logísticos según el organigrama}

Una vez conocida y presentada la división de los distintos puestos que se pueden encontrar en un departamento logístico, se pasará a describir cada uno de los posibles puestos que pueden encontrarse según las distintas áreas que aparecen en la Ilustración 7. 1, y que corresponderán a los sistemas de información logística, almacén, transporte, inventario, compras y servicio al cliente, dependiendo en todo momento de la dirección Logística.

En esta parte de la tesis doctoral se realiza una breve descripción de los puestos logísticos, realizándose el análisis en profundidad en el Anexo I de este trabajo, donde se analiza puesto a puesto de forma más exhaustiva.

\subsubsection{Dirección Logística}

En el área de Dirección de un departamento logístico, se encontrará habitualmente el directivo logístico. Esta idea la muestra Persson [Persson1997 p.282] al mencionar en su artículo "Organization design strategies for business logistics" como se ha sido necesaria la figura de un Director Logístico situado en la línea de mando de la organización y que dirija al departamento logístico. Esta filosofía logística, basada en el director logístico, se desarrolla proporcionando responsabilidades a dicho puesto como coordinador profesional del área o departamento, coordinador de personal del área o departamento y como coordinador de la matiz de la organización en dicho área.

La tarea principal de dicho puesto consiste en implementar las políticas logísticas de la empresa, así como realizar la estrategia de servicio al cliente. El detalle correspondiente a este puesto se muestra en la siguiente descripción aportada desde el libro del Council of Logistics 
Management realizado por Le May et al [LeMay99 p.54] "The Growth and Development of Logistics Personnel" 


\subsubsection{Dirección Logística}

\begin{tabular}{|c|c|}
\hline Área de Información & Contenido \\
\hline $\begin{array}{l}\text { Denominación y localización del } \\
\text { puesto: }\end{array}$ & $\begin{array}{l}\text { Vicepresidente de Operaciones logísticas, } \\
\text { Presidente logístico, director general en logística, } \\
\text { etc. }\end{array}$ \\
\hline Categoría & Alta Dirección \\
\hline Relación organizativa: & $\begin{array}{l}\text { Ascendente: Director General de la empresa } \\
\text { Descendente: analista logístico, ingeniero logístico, } \\
\text { jefe operativo, operarios - empleados de } \\
\text { operaciones logísticas, gestor y especialista en } \\
\text { bases de datos, gestor y especialista en redes y } \\
\text { comunicaciones. } \\
\text { Horizontal: resto de jefes de áreas como el jefe de } \\
\text { marketing, jefe de producción, jefe comercial, } \\
\text { finanzas, y jefe de compras } \\
\text { Relaciones internas: directores de medio nivel, alto } \\
\text { administrativos y personal de apoyo. Supervisores } \\
\text { de primera línea, profesionales y técnicos } \\
\text { especialistas. } \\
\text { Relaciones externas: directores, ejecutivos, } \\
\text { proveedores, clientes, contratistas, solicitantes de } \\
\text { empleo, y en menor grado: org. de caridad, } \\
\text { inspecciones, prensa ... }\end{array}$ \\
\hline Resumen del puesto: & $\begin{array}{l}\text { Define los modelos de negocio a llevar a cabo en } \\
\text { logística y el control sobre directores, supervisores, } \\
\text { profesionales, y autoridad presupuestaria }\end{array}$ \\
\hline $\begin{array}{l}\text { Información sobre exigencias del } \\
\text { puesto: }\end{array}$ & $\begin{array}{l}\text { Formación: Recursos Humanos, informática (bases } \\
\text { de datos), base de matemáticas y estadística, } \\
\text { compras-ventas, presupuestos, contabilidad, } \\
\text { control de almacenes, transporte, supervisión... } \\
\text { Conocimiento de idioma ingles, planes } \\
\text { estratégicos, conocimiento del sector privado, } \\
\text { público y empresarial, tablas de decisión, reuniones } \\
\text { de dirección, redacción de informes. } \\
\text { Experiencia: Negociación, reuniones de dirección, } \\
\text { toma de decisiones... }\end{array}$ \\
\hline
\end{tabular}




\subsubsection{Sistema de Información Logística}

\subsubsection{Gestión del Sistema de información logística}

\begin{tabular}{|c|c|}
\hline Área de Información & Contenido \\
\hline $\begin{array}{l}\text { Denominación y localización del } \\
\text { puesto: }\end{array}$ & $\begin{array}{l}\text { Director de tecnología, Director de planificación de } \\
\text { sistemas logísticos, director de arquitectura del } \\
\text { sistema logístico, director del sistema logístico, } \\
\text { director de proyecto del sistema logístico }\end{array}$ \\
\hline Categoría & Mando Intermedio \\
\hline Relación organizativa: & $\begin{array}{l}\text { Relaciones internas: técnicos, especialistas, } \\
\text { ejecutivos, administrativos, directivos intermedios, } \\
\text { supervisores, personal de marketing y ventas, } \\
\text { Relaciones externas: clientes, proveedores, } \\
\text { directores y ejecutivos externos }\end{array}$ \\
\hline Resumen del puesto: & $\begin{array}{l}\text { Toma de decisiones y responsabilidad para la } \\
\text { implementación de sistemas de información } \\
\text { logística. Para ello desarrolla una faceta de } \\
\text { estrategia de RRHH y otra de especialista en } \\
\text { cuestiones logísticas y tecnológicas. }\end{array}$ \\
\hline $\begin{array}{l}\text { Información sobre exigencias del } \\
\text { puesto: }\end{array}$ & $\begin{array}{l}\text { - Formación: Conocimiento en dirección } \\
\text { tecnológica e informática: bases de datos, } \\
\text { cuestionarios, lenguajes informáticos, } \\
\text { conocimiento y desarrollo de aplicaciones } \\
\text { logísticas (control de inventarios, almacén y } \\
\text { transporte), desarrollo de personal, idioma } \\
\text { inglés (hablado y escrito). Dirección de } \\
\text { proyectos y organización de reuniones, equipos } \\
\text { específicos (hardware y software de la } \\
\text { empresa, así como disponibilidad de } \\
\text { aplicaciones logísticas), movilidad } \\
\text { interpersonal (dirección, estrés, supervisión, } \\
\text { desarrollo empresarial, implementación de } \\
\text { proyectos, reclutamiento), conocimiento } \\
\text { (prácticas logísticas, dirección de operaciones } \\
\text { logísticas) }\end{array}$ \\
\hline & \\
\hline
\end{tabular}




\subsubsection{Operaciones del Sistema de información logística}

\begin{tabular}{ll}
\hline \multicolumn{1}{c}{ Área de Información } & \multicolumn{1}{c}{ Contenido } \\
\hline penominación y localización del & Especialista en Información logística, Diseñador de \\
& Sistemas de Información logística, Técnico de \\
& Sistemas y procesos, administrador de sistemas, \\
& Director de Servicio Técnico, programador. \\
\hline Categoría & Mando Operativo/ Operario \\
\hline Relación organizativa: & Relación ascendente: Director de Sist. Inf. \\
& Logística \\
& Relaciones internas: técnicos, especialistas, \\
& ejecutivos, administrativos, directivos intermedios, \\
& supervisores. \\
& Relaciones externas: clientes, proveedores, \\
& directores y ejecutivos externos \\
\hline Resumen del puesto: & Coordinan la realización de los sistemas de \\
& información logística. Realizan la adquisición, \\
& instalación e implementación del software para \\
& mejorar el sistema de información logística. \\
\hline Información sobre exigencias del & Operaciones informáticas, Gestión de información \\
puesto: & y tecnología, Programación, Administración de \\
& bases de datos, proceso de trabajo, reuniones y \\
& comunicaciones, control de inventarios y \\
& almacenes, conocimientos de transportes aéreos, \\
& marítimos y terrestres. Conocimientos de logística \\
básica.
\end{tabular}




\subsubsection{Almacén}

Para cualquier profesional del sector logístico, conocer y saber gestionar un almacén supone buena parte del éxito del negocio. La evolución de la logística ha provocado que funciones como gestión de inventarios y de almacén hoy se encuentren prácticamente solapadas, ya que como cita la Revista "Operadores Logísticos"[OpLogisticos27 p. 55], en su especial "Manipulación y almacenaje", aparecido en su tercer año, Junio 2002, n 27, un almacén nace por la necesidad de albergar en un lugar cerrado una serie de mercancías, tanto de productos acabados como de elementos que formarán la manufactura", proceso que se aplica tanto a necesidades de consumo como a necesidades internas entre áreas. Por ello, entre las principales características del almacén se destaca no generar valor añadido, pero a pesar de ello, los beneficios que reporta una buena gestión son: apuntar a la reducción de tareas administrativas, agilidad en el desarrollo del resto de procesos logísticos, optimización de la gestión del nivel de inversión del circulante, mejora de la calidad del producto, optimización de costes, reducción de tiempos de proceso, nivel de satisfacción del cliente. 


\subsubsection{Gestión de almacén}

\begin{tabular}{ll}
\hline \multicolumn{1}{c}{ Área de Información } & \multicolumn{1}{c}{ Contenido } \\
\hline penominación y localización del & $\begin{array}{l}\text { Supervisor de Distribución, Director de almacén y } \\
\text { transporte, Director de producción de almacén, } \\
\text { Director de recepción. }\end{array}$ \\
\hline Categoría & Mando Intermedio \\
\hline Relación organizativa: & - Relaciones internas: Supervisor de primera línea, \\
& alta dirección, administrativos, Directores \\
& intermedios, empleados. \\
& - Relaciones externas: Altos directivos, \\
& proveedores, clientes. \\
\hline Resumen del puesto: & $\begin{array}{l}\text { Vigilar las facilidades que gobiernan la realización } \\
\text { del sistema logístico. Su trabajo gira entorno a la } \\
\text { toma de decisiones clave basadas en la información } \\
\text { que se deriva del análisis, informes e interacción } \\
\text { con sus empleados a todos los niveles: } \\
\text { proveedores, clientes, clientes internos, altos } \\
\text { directivos. }\end{array}$ \\
\hline Información sobre exigencias del & Formación: Almacenes y control de almacén, \\
puesto: & distribución, compras, Recursos Humanos, \\
& Seguridad y Salud. Supervisión, comunicación, \\
& escritura, presentación, presupuestos. \\
& Experiencia: Supervisión, toma de decisiones, \\
& reuniones, seguridad y salud \\
& Perfil deseable: Contabilidad, auditoria, \\
& presupuestos, Recursos Humanos y otros temas \\
& relacionados, control de estrés, supervisión. \\
\hline & \\
\hline &
\end{tabular}




\subsubsection{Planificación de almacén}

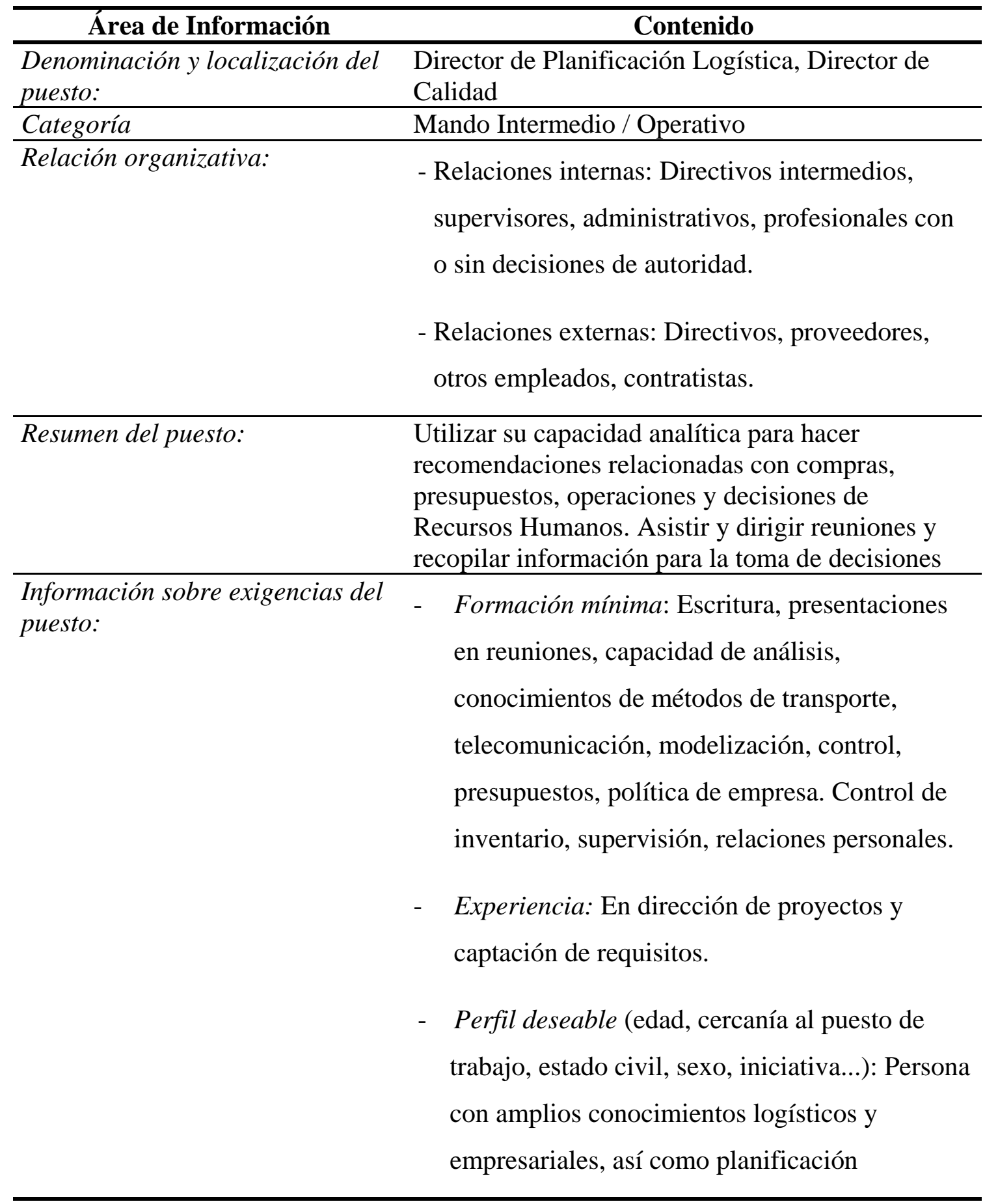




\subsubsection{Operaciones de Almacén}

\begin{tabular}{|c|c|}
\hline Área de Información & Contenido \\
\hline $\begin{array}{l}\text { Denominación y localización del } \\
\text { puesto: }\end{array}$ & $\begin{array}{l}\text { Supervisor del equipo de almacén, supervisor de } \\
\text { recepción/embarque de productos, jefe de equipo, } \\
\text { líder de almacén, planificador de material. }\end{array}$ \\
\hline Categoría & Mando Operativo /Operario \\
\hline Relación organizativa: & $\begin{array}{l}\text { - Relaciones internas: Directivos intermedios, } \\
\text { supervisores, administrativos, profesionales con } \\
\text { o sin decisiones de autoridad. } \\
\text { - } \quad \text { Relaciones externas: Directivos, proveedores, } \\
\text { otros empleados, contratistas. }\end{array}$ \\
\hline Resumen del puesto: & $\begin{array}{l}\text { Operaciones de almacén realizando más funciones } \\
\text { de las propias de operarios, como reuniones y } \\
\text { ejercicio de la prudencia y liderazgo como } \\
\text { supervisor }\end{array}$ \\
\hline \multirow[t]{3}{*}{$\begin{array}{l}\text { Información sobre exigencias del } \\
\text { puesto: }\end{array}$} & $\begin{array}{l}\text { - Formación mínima: supervisión, reuniones, } \\
\text { tareas de almacén, seguridad interna }\end{array}$ \\
\hline & $\begin{array}{l}\text { - Formación aconsejable: Informática o proceso } \\
\text { de datos con ordenador }\end{array}$ \\
\hline & - Experiencia: Carga y descarga de material \\
\hline
\end{tabular}




\subsubsection{Operaciones de Almacén}

\begin{tabular}{|c|c|}
\hline Área de Información & Contenido \\
\hline $\begin{array}{l}\text { Denominación y localización del } \\
\text { puesto: }\end{array}$ & $\begin{array}{l}\text { Trabajador de Muelle, asociado a carga, sostenedor } \\
\text { de material, procesador de mercancías, equipo de } \\
\text { almacén. }\end{array}$ \\
\hline Categoría & Operario \\
\hline \multirow[t]{3}{*}{ Relación organizativa: } & $\begin{array}{l}\text { - } \\
\text { Ascendente: Supervisores y capataces, } \\
\text { supervisores de primera línea, directivos } \\
\text { intermedios, administrativos }\end{array}$ \\
\hline & - $\quad$ Descendente: no hay \\
\hline & $\begin{array}{l}\text { - Horizontal: entre compañeros, elevadores, } \\
\text { transportadores, ... }\end{array}$ \\
\hline Resumen del puesto: & $\begin{array}{l}\text { Trabajo centrado en operaciones con máquinas de } \\
\text { tipo de (carretillas, elevadoras...) }\end{array}$ \\
\hline \multirow[t]{4}{*}{$\begin{array}{l}\text { Información sobre exigencias del } \\
\text { puesto: }\end{array}$} & $\begin{array}{l}\text { - Formación mínima: supervisión, reuniones, } \\
\text { tareas de almacén, seguridad interna }\end{array}$ \\
\hline & - Formación aconsejable: Informática o proceso \\
\hline & de datos con ordenador \\
\hline & - Experiencia: Carga y descarga de material \\
\hline
\end{tabular}




\subsubsection{Transporte}

Como refleja el Estudio realizado por la Fundación para la Formación Continua (FORCEM) [FORCEM2000] en la convocatoria de 1999 de Ayudas al desarrollo de Acciones Complementarias y de Acompañamiento a la Formación, en el que participó el Departamento de Organización Industrial y Gestión de Empresas de la Escuela Superior de Ingenieros de Sevilla, el Instituto de Formación y Estudios Sociales (IFES), la Asociación de Investigación y Cooperación Industrial de Andalucía (AICIA), PRINCA S. Coop. And., la Federación Regional de Transportes, Comunicaciones y Mar de la U.G.T., finalizado en Febrero de 2000, son "las grandes empresas las que cuentan con personal dedicado a tareas o funciones especializadas, aunque se pueden encontrar con que faltan herramientas para desempeñar la complejidad de la función encomendada o conocimientos específicos sobre el sector, para aplicarlos y mejorar la eficacia del transporte. Los principales niveles profesionales que componen este sector están muy condicionados al tamaño de la empresa, ya que para grandes empresas existen profesionales especializados para cada una de las funciones o niveles, y para pequeñas empresas es frecuente que una sola persona sea la que desempeñe todas las funciones (administración, labor comercial, función de ventas, etc." 


\subsubsection{Dirección de Tráfico}

\begin{tabular}{|c|c|}
\hline Área de Información & Contenido \\
\hline $\begin{array}{l}\text { Denominación y localización del } \\
\text { puesto: }\end{array}$ & $\begin{array}{l}\text { Director de tránsito, Director de Servicios de } \\
\text { Exportación e Importación. }\end{array}$ \\
\hline Categoría & Mando Intermedio \\
\hline Relación organizativa: & $\begin{array}{l}\text { - Relaciones internas: Personal Administrativo, } \\
\text { superiores de Primera línea, Supervisores } \\
\text { intermedios. } \\
\text { - Relaciones externas: Proveedores, clientes, } \\
\text { directivos. }\end{array}$ \\
\hline Resumen del puesto: & $\begin{array}{l}\text { Asumir la máxima responsabilidad de operaciones, } \\
\text { Recursos Humanos, compras y decisiones } \\
\text { presupuestarias. Dirigir las funciones de tráfico y } \\
\text { transporte en la empresa, Selección de rutas }\end{array}$ \\
\hline $\begin{array}{l}\text { Información sobre exigencias del } \\
\text { puesto: }\end{array}$ & $\begin{array}{l}\text { - Formación: Buen uso del lenguaje (hablado y } \\
\text { escrito), uso de Bases de Datos, macros, } \\
\text { operaciones con vehículos y mantenimiento, } \\
\text { equipos de telecomunicación. Toma de } \\
\text { decisiones, trato con clientes, conocimiento de } \\
\text { costes de explotación y precio de transporte, } \\
\text { calidad de servicio }\end{array}$ \\
\hline & $\begin{array}{l}\text { - Experiencia: En transporte, telecomunicación, } \\
\text { dirección de personal, logística, redes. }\end{array}$ \\
\hline & $\begin{array}{l}\text { - Perfil deseable: Conocimiento del mercado, } \\
\text { conocimiento de leyes y regulaciones de } \\
\text { transporte, rutas, redes y telemática. }\end{array}$ \\
\hline
\end{tabular}




\subsubsection{Gestión de Expediciones}

\begin{tabular}{|c|c|}
\hline Área de Información & Contenido \\
\hline $\begin{array}{l}\text { Denominación y localización del } \\
\text { puesto: }\end{array}$ & $\begin{array}{l}\text { Especialista en operaciones de carga, planificador } \\
\text { de carga, coordinador o especialista de embarque, } \\
\text { Técnico de transporte }\end{array}$ \\
\hline Categoría & Mando Operativo \\
\hline Relación organizativa: & $\begin{array}{l}\text { - Relaciones internas: Directivos intermedios, } \\
\text { superiores de Primera línea, trabajadores y } \\
\text { administración. } \\
\text { - Relaciones externas: Clientes. }\end{array}$ \\
\hline Resumen del puesto: & $\begin{array}{l}\text { Cargar vehículos y coordinar su movimiento para } \\
\text { la mejor distribución de facilidades, asegurando } \\
\text { que vaya al cliente correcto en vehículo } \\
\text { correspondiente, en el paquete correcto y la } \\
\text { cantidad indicada }\end{array}$ \\
\hline $\begin{array}{l}\text { Información sobre exigencias del } \\
\text { puesto: }\end{array}$ & $\begin{array}{l}\text { - Formación mínima: Carga y manejo manual de } \\
\text { material, conocimiento de leyes y regulación de } \\
\text { carga, procedimiento de carga.. Tratamiento de } \\
\text { datos de almacén, operativa de oficina, } \\
\text { matemáticas básicas. }\end{array}$ \\
\hline & $\begin{array}{l}\text { - Perfil deseable: Conocimiento de las redes de } \\
\text { los clientes, conocimiento de leyes y }\end{array}$ \\
\hline & $\begin{array}{l}\text { Regulación de transporte, Control de inventario } \\
\text { y de gamas de productos, Políticas, } \\
\text { procedimientos y prácticas empresariales, } \\
\text { conocimiento de redes y telemática }\end{array}$ \\
\hline
\end{tabular}




\subsubsection{Actividades de Transporte}

\begin{tabular}{|c|c|}
\hline Área de Información & Contenido \\
\hline $\begin{array}{l}\text { Denominación y localización del } \\
\text { puesto: }\end{array}$ & $\begin{array}{l}\text { Encargado de envíos, conductor, transportista, } \\
\text { inspector de transporte }\end{array}$ \\
\hline Categoría & Operario \\
\hline Relación organizativa: & $\begin{array}{l}\text { - } \quad \text { Relaciones internas: Directivos intermedios, } \\
\text { superiores de Primera línea, trabajadores y } \\
\text { administración. } \\
\text { - } \quad \text { Relaciones externas: Clientes. }\end{array}$ \\
\hline Resumen del puesto: & Realizar el transporte de mercancías \\
\hline $\begin{array}{l}\text { Información sobre exigencias del } \\
\text { puesto: }\end{array}$ & $\begin{array}{l}\text { Formación: Conocimientos de transporte: } \\
\text { vehículos, su mantenimiento, inspección, } \\
\text { Licencias de transporte, telecomunicación } \\
\text { que le mantiene unido a la } \\
\text { Central/Terminal, carga-descarga. } \\
\text { Matemáticas básicas, habilidad social. } \\
\text { - Experiencia: En transporte y } \\
\text { telecomunicación. } \\
\text { - Perfil deseable: estar en posesión de las } \\
\text { licencias requeridas para poder conducir los } \\
\text { vehículos requeridos, Experiencia, } \\
\text { mantener el control en situaciones de estrés, } \\
\text { etc. }\end{array}$ \\
\hline
\end{tabular}

A los puestos aquí presentados, el estudio de FORCEM [FORCEM2000], les señala como puestos relacionados en el Consejero de Mercancías Peligrosas y Delegado de Prevención de Riesgos Laborales. El puesto de Consejero de Seguridad de Mercancías peligrosas está encargado de llevar un registro de documentación al día, de la manipulación, la seguridad e inspección, los sistemas de calidad, estar al día de la Reglamentación general de conductores de mercancías peligrosas, la prevención de incendios, actuaciones en situaciones de emergencia, y la conducción de ese tipo de vehículos. 


\subsubsection{Inventario}

\subsubsection{Gestión de la Cadena de Suministro}

\begin{tabular}{ll}
\hline \multicolumn{1}{c}{ Área de Información } & \multicolumn{1}{c}{ Contenido } \\
\hline $\begin{array}{l}\text { Denominación y localización del } \\
\text { puesto: }\end{array}$ & $\begin{array}{l}\text { Planificación de negocio de la Cadena de } \\
\text { Suministro, Director de estrategia de la Cadena de } \\
\text { Suministro e Inventario, Director del Control de } \\
\text { Calidad de material. Director de Operaciones, } \\
\text { Director de Producción }\end{array}$ \\
\hline Categoría & Alta Dirección /Mando Intermedio \\
\hline Relación organizativa: & Relaciones internas: Alta dirección, \\
& administrativos, mandos intermedios, \\
& supervisores de primera línea. \\
& Relaciones externas: Representantes de ventas, \\
& proveedores, contratistas consultores. \\
\hline Resumen del puesto: & Coordinar y dirigir la Cadena de Suministro \\
\hline puesto: & $\begin{array}{l}\text { Formación: Selección de empleados, supervisión, } \\
\text { desarrollo, Dirección de producción, compras, } \\
\text { matemáticas, estadísticas, comunicación, hablar en } \\
\text { público, habilidad para mantener y dirigir } \\
\text { reuniones. Toma de decisiones. } \\
\text { Experiencia: Con equipos: ordenadores, otros } \\
\text { equipos, operaciones de máquinas y maquinaria de } \\
\text { oficina. } \\
\text { Con Personal: Comunicación oral y escrita, hablar } \\
\text { en público, conducir reuniones efectivas } \\
\text { En Conocimiento: Selección de empleados, } \\
\text { Control de inventario y almacén, dirección de } \\
\text { producción, planificación estratégica. }\end{array}$ \\
\hline & \\
& \\
& \\
&
\end{tabular}




\subsubsection{Gestión de Producción}

\begin{tabular}{|c|c|}
\hline Área de Información & Contenido \\
\hline $\begin{array}{l}\text { Denominación y localización del } \\
\text { puesto: }\end{array}$ & $\begin{array}{l}\text { Director de producción, coordinador del proceso, } \\
\text { Director de Control de Calidad, Director del } \\
\text { programa de producción, Director Logístico al por } \\
\text { menor }\end{array}$ \\
\hline Categoría & Alta Dirección /Mando Intermedio \\
\hline \multirow[t]{2}{*}{ Relación organizativa: } & $\begin{array}{l}\text { - Relaciones internas: Dependerá de ejecutivos, } \\
\text { mandos intermedios, supervisores de primera } \\
\text { línea. }\end{array}$ \\
\hline & $\begin{array}{l}\text { - Relaciones externas: Personal de ventas, } \\
\text { representantes, proveedores, contratistas, } \\
\text { subcontratistas o agentes.. }\end{array}$ \\
\hline Resumen del puesto: & $\begin{array}{l}\text { Coordinar el proceso de fabricación: Tareas, } \\
\text { productos y líneas de productos que satisfagan a } \\
\text { los clientes con el mínimo coste. Encargado del } \\
\text { inventario: entradas de materiales y su } \\
\text { transformación en productos solicitados por los } \\
\text { clientes. Participación en la coordinación logística } \\
\text { principal. }\end{array}$ \\
\hline $\begin{array}{l}\text { Información sobre exigencias del } \\
\text { puesto: }\end{array}$ & $\begin{array}{l}\text { Formación: Auditoria y control de inventario, } \\
\text { operaciones productivas y transporte, } \\
\text { coordinación de la cadena de suministro. En } \\
\text { cuanto a los Recursos Humanos han de tener } \\
\text { una formación en Selección, Supervisión y } \\
\text { Desarrollo. Conocimiento de contabilidad, } \\
\text { inventario, almacén, matemáticas (estadística), } \\
\text { transporte y también en cuanto a la realización } \\
\text { de Planes Estratégicos y Dirección de } \\
\text { reuniones (fomentar la comunicación). }\end{array}$ \\
\hline & $\begin{array}{l}\text { Experiencia: Operación con máquinas y } \\
\text { mantenimiento, ordenadores, periféricos, } \\
\text { material de oficina. Con personal: } \\
\text { Comunicación oral y escrita, hablar en público, } \\
\text { dirigir reuniones, toma de decisiones. } \\
\text { Conocimiento: Operaciones, control de } \\
\text { inventarios y archivos, contabilidad práctica, } \\
\text { selección de formación de empleados y formas } \\
\text { de transporte }\end{array}$ \\
\hline
\end{tabular}




\subsubsection{Supervisión de Inventario}

\begin{tabular}{|c|c|}
\hline Área de Información & Contenido \\
\hline $\begin{array}{l}\text { Denominación y localización del } \\
\text { puesto: }\end{array}$ & Supervisor de Inventario \\
\hline Categoría & Mando Operativo / Operario \\
\hline Relación organizativa: & $\begin{array}{l}\text { - Relaciones internas: Mandos intermedios, } \\
\text { supervisores inmediatos, administrativos de } \\
\text { producción. } \\
\text { - Relaciones externas: Clientes.. }\end{array}$ \\
\hline Resumen del puesto: & $\begin{array}{l}\text { Supervisan el trabajo de los operarios de } \\
\text { inventario. Entran entre los especialistas de } \\
\text { inventario y los jefes de producción, realizan la } \\
\text { supervisión última y decisiones de su área }\end{array}$ \\
\hline $\begin{array}{l}\text { Información sobre exigencias del } \\
\text { puesto: }\end{array}$ & $\begin{array}{l}\text { - Formación: Matemáticas, supervisión, trato de } \\
\text { personal, producción, informática para el } \\
\text { manejo de Base de datos. Recursos Humanos, } \\
\text { producción y áreas operativas, inventarios, } \\
\text { almacén, transporte, supervisión. }\end{array}$ \\
\hline & $\begin{array}{l}\text { Experiencia: Con equipos: ordenadores, } \\
\text { periféricos, material de oficina estándar, } \\
\text { operaciones con carretillas. Con Personal: }\end{array}$ \\
\hline & $\begin{array}{l}\text { Supervisión, comunicación (oral y escrita), } \\
\text { hablar en público, dirección de reuniones, } \\
\text { dirección con estrés. De Conocimiento: }\end{array}$ \\
\hline & $\begin{array}{l}\text { Producción, informática, Recursos Humanos, } \\
\text { transporte, almacenes, seguridad, compras- } \\
\text { ventas. }\end{array}$ \\
\hline
\end{tabular}




\subsubsection{Control de Inventario}

\begin{tabular}{ll}
\hline \multicolumn{1}{c}{ Área de Información } & \multicolumn{1}{c}{ Contenido } \\
\hline $\begin{array}{l}\text { Denominación y localización del } \\
\text { puesto: }\end{array}$ & $\begin{array}{l}\text { Empleados de Control de Material/Inventario. } \\
\text { Administrador del control de inventario, } \\
\text { Especialista en Control de Inventario, Supervisor } \\
\text { de material }\end{array}$ \\
\hline Categoría & Operario \\
\hline Relación organizativa: & Relaciones internas: Mandos intermedios, \\
& supervisores inmediatos, Administrativos de \\
& producción. \\
\hline Resumen del puesto: & $\begin{array}{l}\text { Recoger la carga - mercancía y entregar. Mayor } \\
\text { rango de personal relacionado con movimientos de } \\
\text { material. Mueven material dentro y fuera de la } \\
\text { empresa, se escanea un código de barras y entra al } \\
\text { sistema de inventario de la empresa (cantidad, } \\
\text { control de calidad, lugar de la empresa). Colocan } \\
\text { en un lugar del almacén, informando de su } \\
\text { localización (informa al sistema de esa } \\
\text { reubicación). }\end{array}$ \\
\hline $\begin{array}{l}\text { Información sobre exigencias del } \\
\text { puesto: }\end{array}$ & Formación: Entrada de datos al sistema, \\
& preparación física, habilidad interpersonal. \\
& Operaciones con carretillas, grabación de datos. \\
& Procedimientos seguros de carga - descarga, \\
& habilidad para hablar y escribir. \\
& Experiencia: Certificado manejo de carretillas, \\
& cursos de informática \\
& \\
& \\
& \\
& \\
&
\end{tabular}




\subsubsection{Compras}

\subsubsection{Gestión de Compras}

\begin{tabular}{|c|c|}
\hline Área de Información & Contenido \\
\hline $\begin{array}{l}\text { Denominación y localización del } \\
\text { puesto: }\end{array}$ & $\begin{array}{l}\text { Compradores, Especialista en compras, } \\
\text { Coordinador de Compras, Analistas de la Cadena } \\
\text { de Suministro. }\end{array}$ \\
\hline Categoría & Mando Intermedio \\
\hline Relación organizativa: & $\begin{array}{l}\text { - Relaciones internas: Administrativos y personal } \\
\text { de apoyo, mandos intermedios, especialistas no } \\
\text { supervisores, supervisores de primera línea, altos } \\
\text { ejecutivos. } \\
\text { - Relaciones externas: Empleados de dirección, } \\
\text { ejecutivos, contratistas, proveedores, } \\
\text { representantes de ventas. }\end{array}$ \\
\hline Resumen del puesto: & $\begin{array}{l}\text { Desarrollar la función de compras y coordinar y } \\
\text { dirigir la cadena de suministros }\end{array}$ \\
\hline $\begin{array}{l}\text { Información sobre exigencias del } \\
\text { puesto: }\end{array}$ & $\begin{array}{l}\text { Formación: Desarrollo de empleados, } \\
\text { supervisión, Selección, Compras, Planificación } \\
\text { estratégica, Presupuestos, Bancos, acuerdos } \\
\text { comerciales, acciones comerciales } \\
\text { internacionales, búsqueda de operaciones, } \\
\text { transporte, contabilidad, habilidad de } \\
\text { comunicación oral y escrita, de organización y } \\
\text { capacidad de negociación y aptitud numérica y } \\
\text { técnica. Programas informáticos. } \\
\text { - Experiencia: propia del trabajo desarrollado. } \\
\text { - Perfil: conocimiento de Equipos específicos: } \\
\text { operaciones con ordenadores, otros equipos y } \\
\text { equipo de oficina. Habilidad personal: } \\
\text { Dirección de proyectos, organización, técnicas } \\
\text { de dirección con stress, supervisión y desarrollo } \\
\text { de empleados. Prácticas presupuestarias, } \\
\text { Dirección de RRHH, comercio internacional, } \\
\text { control de inventario y almacenes, transporte. }\end{array}$ \\
\hline
\end{tabular}




\subsubsection{Compras}

\begin{tabular}{|c|c|}
\hline Área de Información & Contenido \\
\hline $\begin{array}{l}\text { Denominación y localización del } \\
\text { puesto: }\end{array}$ & $\begin{array}{l}\text { Empleados de Control de Material/Inventario. } \\
\text { Administrador del control de inventario, } \\
\text { Especialista en Control de Inventario, Supervisor } \\
\text { de material }\end{array}$ \\
\hline Categoría & Operario \\
\hline Relación organizativa: & $\begin{array}{l}\text { - Relaciones internas: Mandos intermedios, } \\
\text { personal administrativo, supervisores de primera } \\
\text { línea. } \\
\text { - Relaciones externas: Clientes, representantes de } \\
\text { ventas, ejecutivos. }\end{array}$ \\
\hline Resumen del puesto: & $\begin{array}{l}\text { Coordinar el proceso de compra, generar } \\
\text { información, desarrollar y evaluar alternativas (tras } \\
\text { un proceso de selección, selecciona una alternativa } \\
\text { y realiza la compra). }\end{array}$ \\
\hline $\begin{array}{l}\text { Información sobre exigencias del } \\
\text { puesto: }\end{array}$ & $\begin{array}{l}\text { Formación : Compras, control de inventario y } \\
\text { almacén, nociones de informática, transporte, } \\
\text { control de archivos, contabilidad, buen uso del } \\
\text { lenguaje (oral y escrito), relaciones } \\
\text { interpersonales, aptitud técnica y numérica, } \\
\text { habilidad negociadora. Capacidad de } \\
\text { comunicación, comunicación electrónica } \\
\text { (redes, Internet, bases de datos y otras } \\
\text { aplicaciones específicas). }\end{array}$ \\
\hline & $\begin{array}{l}\text { Experiencia: Con equipos: ordenadores, } \\
\text { periféricos, material de oficina estándar. Con } \\
\text { personal: Comunicación (oral y escrita), } \\
\text { dirección de reuniones efectivas, técnicas de } \\
\text { dirección con estrés. Conocimiento de Compras } \\
\text { inventario, almacenes, transporte, control de } \\
\text { archivos y mantenimiento de libros }\end{array}$ \\
\hline
\end{tabular}




\subsubsection{Servicio al cliente}

\subsubsection{Gestión de Servicio al Cliente}

\begin{tabular}{|c|c|}
\hline Área de Información & Contenido \\
\hline $\begin{array}{l}\text { Denominación y localización } \\
\text { del puesto: }\end{array}$ & $\begin{array}{l}\text { Director de cuentas de clientes, Asistente de } \\
\text { operaciones de servicio al cliente, Representante de } \\
\text { productos de servicio al cliente. }\end{array}$ \\
\hline Categoría & Mando Operativo / Operario \\
\hline Relación organizativa: & 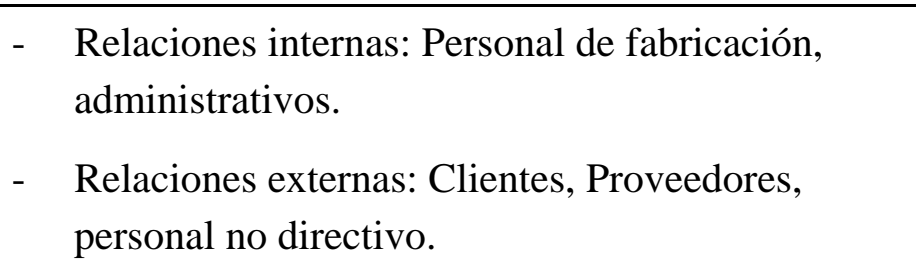 \\
\hline Resumen del puesto: & $\begin{array}{l}\text { Dirigir el programa de servicio al cliente, supervisar } \\
\text { que las solicitudes del cliente se convierten en } \\
\text { servicios y productos }\end{array}$ \\
\hline $\begin{array}{l}\text { Información sobre exigencias } \\
\text { del puesto: }\end{array}$ & $\begin{array}{l}\text { Formación: Conocimiento de la función } \\
\text { logística, Core-business, supervisión de } \\
\text { empleados y desarrollo de los mismos. Excelente } \\
\text { comunicación oral y escrita, habilidad en el } \\
\text { manejo del material de oficina, capacidad para } \\
\text { trabajar de forma independiente. Capacidad para } \\
\text { trabajar en situaciones de estrés y aptitud } \\
\text { matemática. } \\
\text { Experiencia: Propia del puesto de trabajo, con } \\
\text { equipos: ordenadores, periféricos, equipos } \\
\text { estándar de oficina, equipos de telecomunicación. } \\
\text { Con Personal: Desarrollo y Supervisión de } \\
\text { empleados, habilidad directiva y comunicativa. } \\
\text { De conocimiento: Marketing, llevar libros de } \\
\text { empresa, operaciones informáticas, control de } \\
\text { inventario, Seguridad y Salud, compras, } \\
\text { Auditoria, presupuesto, ventas, búsqueda de } \\
\text { información, contabilidad, análisis del trabajo, } \\
\text { beneficios de empleados, selección de personal, } \\
\text { Planificación estratégica. Español hablado y } \\
\text { escrito correctamente, inglés, lenguajes } \\
\text { informáticos. }\end{array}$ \\
\hline
\end{tabular}




\subsubsection{Servicio al Cliente}

\begin{tabular}{|c|c|}
\hline Área de Información & Contenido \\
\hline $\begin{array}{l}\text { Denominación y localización del } \\
\text { puesto: }\end{array}$ & $\begin{array}{l}\text { Asistente administrativo, analista desarrollo de } \\
\text { negocio }\end{array}$ \\
\hline Categoría & Operario \\
\hline Relación organizativa: & $\begin{array}{l}\text { - Relaciones internas: mandos intermedios, alta } \\
\text { dirección o ejecutivos, empleados } \\
\text { administrativos, personal de apoyo, personal de } \\
\text { marketing. } \\
\text { - } \quad \text { Relaciones externas: Proveedores y clientes, } \\
\text { empleados de dirección, representantes de } \\
\text { compras y ventas. }\end{array}$ \\
\hline Resumen del puesto: & $\begin{array}{l}\text { Relación con los clientes cuando una relación es } \\
\text { mantenida, establecida o acabada para asegurar la } \\
\text { satisfacción de clientes, contestar dudas, controlar } \\
\text { estado del proceso }\end{array}$ \\
\hline $\begin{array}{l}\text { Información sobre exigencias del } \\
\text { puesto: }\end{array}$ & $\begin{array}{l}\text { - Formación: Formación oral y escrita, } \\
\text { utilización de equipos de oficina estándar, } \\
\text { nociones sobre informática y aptitud } \\
\text { matemática. Formación en informática para } \\
\text { poder obtener toda la información de forma } \\
\text { rápida } \\
\text { - Experiencia: Con Equipos específicos: PC’s, } \\
\text { otros equipos, equipos estándar de oficina, } \\
\text { equipos de telecomunicación. De Habilidad } \\
\text { interpersonal: Dirección de proyectos, } \\
\text { organización, pensamiento crítico, } \\
\text { comunicación oral y escrita. De Conocimiento: } \\
\text { operaciones de transporte, geografía local y } \\
\text { regional, prácticas de control de inventario, } \\
\text { control de archivos y mantenimiento de libros, } \\
\text { planificación estratégica, ambiente de } \\
\text { marketing empresarial. }\end{array}$ \\
\hline
\end{tabular}




\section{Resumen de puestos logísticos}

Para concluir, el análisis de todos los puestos de trabajo descritos en los epígrafes anteriores se puede ver reflejado en forma de un organigrama general en la Ilustración 7. 2, donde aparecen las principales áreas de la logística como son: los sistemas de información logística, almacén, transporte, inventario, compras y servicio al cliente y colgando de cada una de ellas, los puestos más comunes que pueden existir dentro de esas áreas.

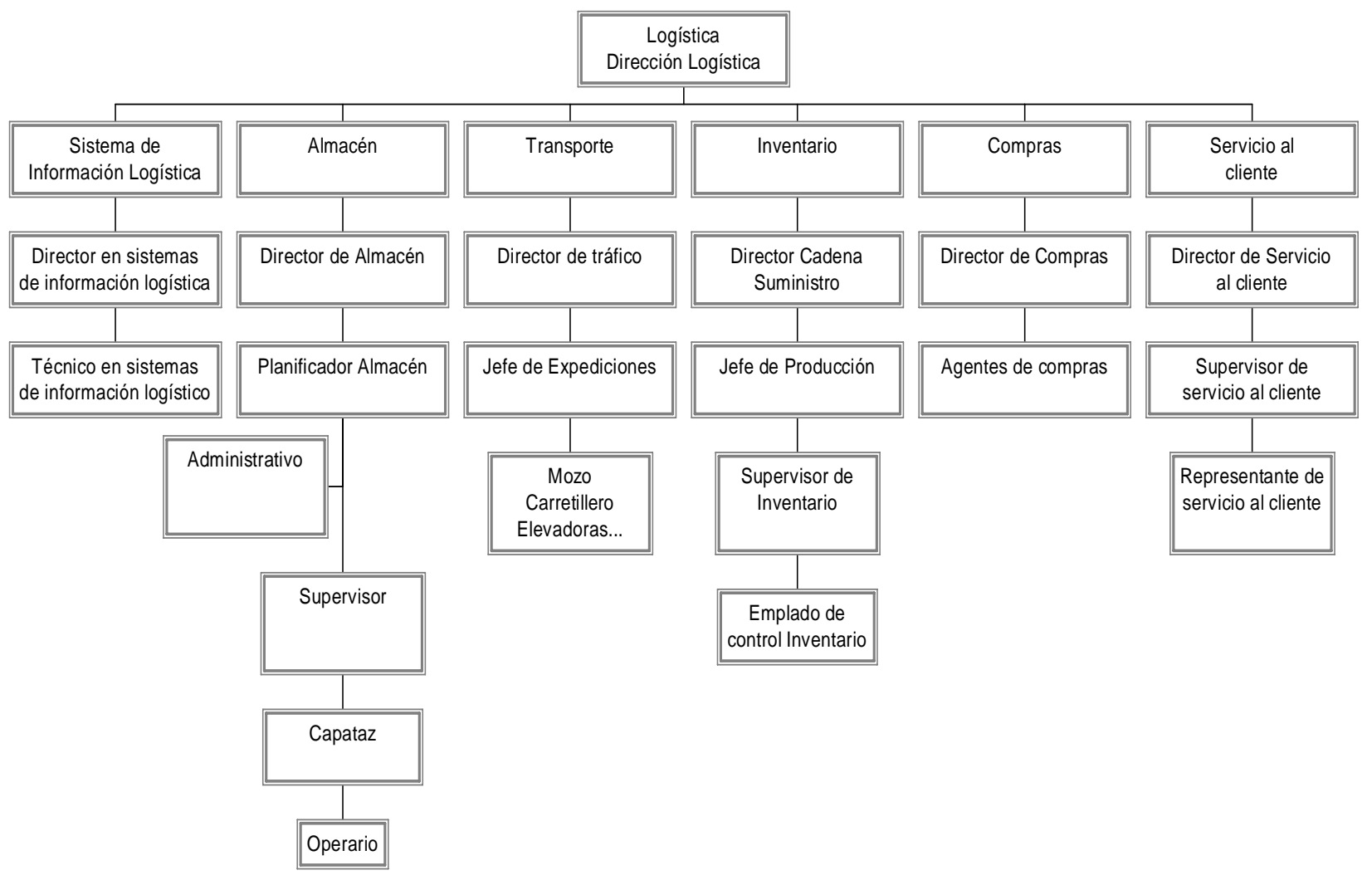

Ilustración 7. 2 : Ejemplo de Organigrama general del área logística. Basado en Le May [LeMay99]

\subsection{EL MODELO DE RECURSOS HUMANOS APLICADO A LOS SISTEMAS LOGÍSTICOS}

En el apartado anterior se ha realizado una descripción de los distintos puestos logísticos que pueden existir en un área, departamento u operador logístico, desde un único punto de vista: la estructura de un organigrama. Esta presentación se ha realizado en base a la propuesta 
realizada por Le May et al. [LeMay99] en el libro "The Growth and development of logistics personnel". La propuesta realizada en dicho libro por Le May et al. [LeMay99], junto con otra propuesta que nace desde el análisis de las Carreras logísticas de Gibson et al. [Gibson1998] donde no se sigue ningún orden, y finalmente las propuestas del informe TC/273 de CEN (AENOR) que presentan una descripción para unificar los puestos de trabajo en la Unión Europea, hace que se pueda pensar que existe una falta de modelos para los Recursos Humanos en los sistemas logísticos, donde se incluyan todos los elementos empresariales presentados en el capítulo segundo, apartado 2.

Para implementar la logística, es necesario (aunque no suficiente) contar con personal adecuado que permita y facilite llevar a cabo cada una de las fases reflejadas en el capítulo tercero y el ciclo de vida aplicado a la logística.

De modo que este trabajo propondrá un modelo de Recursos Humanos para las áreas logísticas que contemple los elementos empresariales del capítulo segundo, y sirva a su vez para desarrollar la logística atendiendo a quién lleva a cabo cada una de las etapas del proceso logístico. Teniendo en cuenta a su vez que todo esté integrado en la empresa, como se proponía en el primer capítulo. Kohn y McGinnins [KohnMcGinnis1997] en su artículo "Advanced Logistics Organization Structures: Revisited", indican como existen dos dimensiones que describen la logística, siendo una de ellas la integración debido a que ésta propicia la gestión del flujo logístico, la coordinación y la complejidad dentro de la organización y la otra dimensión correspondería a la orientación al proceso en busca de la eficiencia, control y reducción de costes.

Por lo tanto, esta tesis doctoral propone tomar el modelo teórico de Recursos Humanos generado en el capítulo 5 pero proporcionándole una aplicación al área logística, y generar así un modelo de recursos humanos logístico desde el enfoque de los procesos que sigue ese departamento o empresa.

En el epígrafe 6.4 del capítulo sexto, al explicar el área de estudio se concluyó que la Cadena de Suministro puede definirse como elemental, en el sentido que la relación será siempre entre un proveedor y un cliente, independientemente del momento o de la etapa en que se encuentre dentro de la cadena de suministro. 
Para llevar a cabo ese eslabón en la Cadena de Suministro entre ambos participantes, intervendrá un sistema logístico, ya sea un departamento u operador logístico, que contará con un personal logístico, dividido como se mostró en la figura 5.1 según de Miguel [DeMiguel p. 50] en Alta Dirección, Mandos Intermedios, Mandos Operativos y Operarios como muestra la pirámide de los niveles de mando logísticos de la Ilustración 7. 3, en la cual quedaría la Alta dirección logística en la cima de la pirámide, los mandos intermedios logísticos a continuación para seguir con los mandos operativos logísticos y en la base de la pirámide los operarios logísticos.

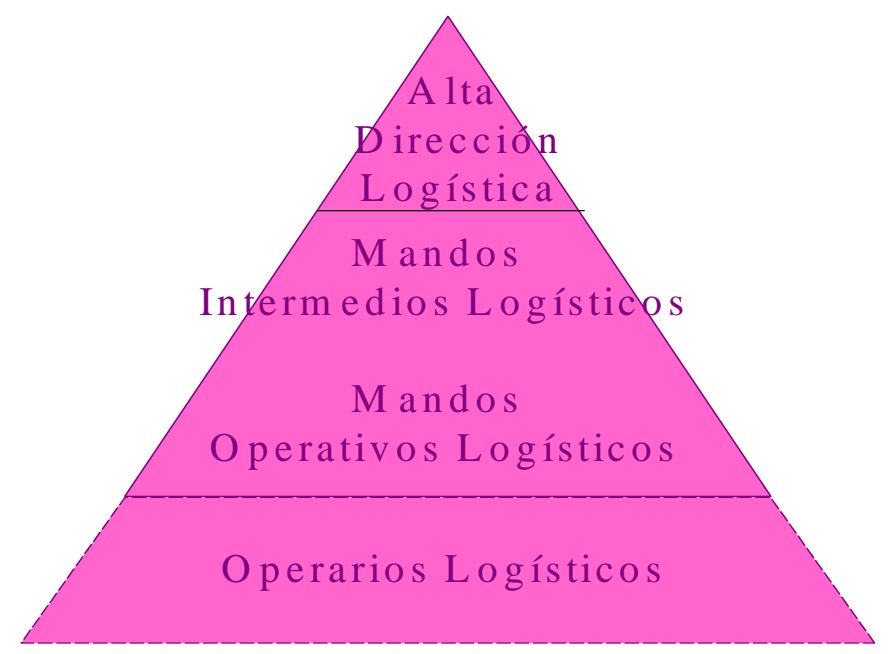

Ilustración 7. 3: Niveles de Mando en Logística. Fuente: Basado en E. de Miguel [DeMiguel p.50]

De Miguel [DeMiguel p.50], a su vez expone las siguientes tareas como básicas para cada uno de los nivel de mando, como se vio en el capítulo 5, pero que aplicadas a la logística suponen:

Alta dirección: los mandos que ocupan el nivel superior son los responsables del conjunto del departamento logístico, siendo sus principales tareas:

- Pronosticar el futuro, fijando los grandes objetivos del departamento logístico y desarrollando planes de conjunto empresa- departamento logístico a largo plazo.

- Influyen sobre la cultura del departamento logístico

- Valoran el rendimiento global del departamento logístico 
- Tratan con los mandos intermedios los asuntos y problemas de ámbito general del departamento logístico, así como realizan trabajos/reuniones de forma conjunta.

- Conocer bien a los mandos intermedios que pertenecen al departamento logístico con el fin de seleccionar a personas idóneas para futuros ascensos.

- Definen la política de Recursos Humanos del área logística

\section{Mandos Intermedios Logísticos:}

- Desarrollan planes y diseñan proyectos logísticos a medio plazo en función de la planificación logística establecida por la dirección del departamento logístico.

- Coordinan las actividades dentro del departamento logístico y con otros departamentos.

- Analizan el rendimiento de los subordinados con vistas a los futuros ascensos en el propio departamento logístico.

- Establecen las políticas de funcionamiento del departamento

- $\quad$ Lideran los equipos de trabajo y resuelven conflictos.

- Revisan, diaria y semanalmente, los informes correspondientes a su departamento o área y a otros que sean de su interés y puedan afectar al departamento logístico.

- Aconsejan a los mandos subordinados sobre personal, producción u otros problemas del departamento.

Mandos Operativos: Los mandos o de primera línea son los responsables directos del servicio logístico ofrecido. 
- Hacen planes detallados a corto plazo, basándose en los planes de los mandos intermedios, sobre las actividades y tareas que tienen que cumplir los operarios logísticos.

- Se preocupan de que los subordinados observen las normas y procedimientos elaborados dentro del departamento logístico.

- Vigilan el rendimiento de los subordinados para que sean eficientes y cumplan las normas establecidas por el propio departamento

- Supervisan las operaciones logísticas

- $\quad$ Asignan tareas específicas a los trabajadores que se hallan bajo su mando.

- Mantienen relaciones estrechas y cordiales con los trabajadores, motivándoles para lograr que se cumplan eficaz y eficientemente los objetivos marcados.

Estos mandos expuestos por de Miguel, se tomarán a partir de ahora como base para el modelo de personal logístico que desarrollará este trabajo.

Por lo tanto, como se dijo al generar el modelo en el capítulo 5, las principales tareas que desarrollarán cada unos de estos niveles de mando logístico, corresponderán básicamente a Tareas de Análisis y Planificación Logística para la Alta Dirección, Tareas de Diseño del sistema logístico para los Mandos Intermedios y Tareas de Implementación y Supervisión Logística para los Mandos Operativos. Esto se muestra en la Ilustración 7. 4: 


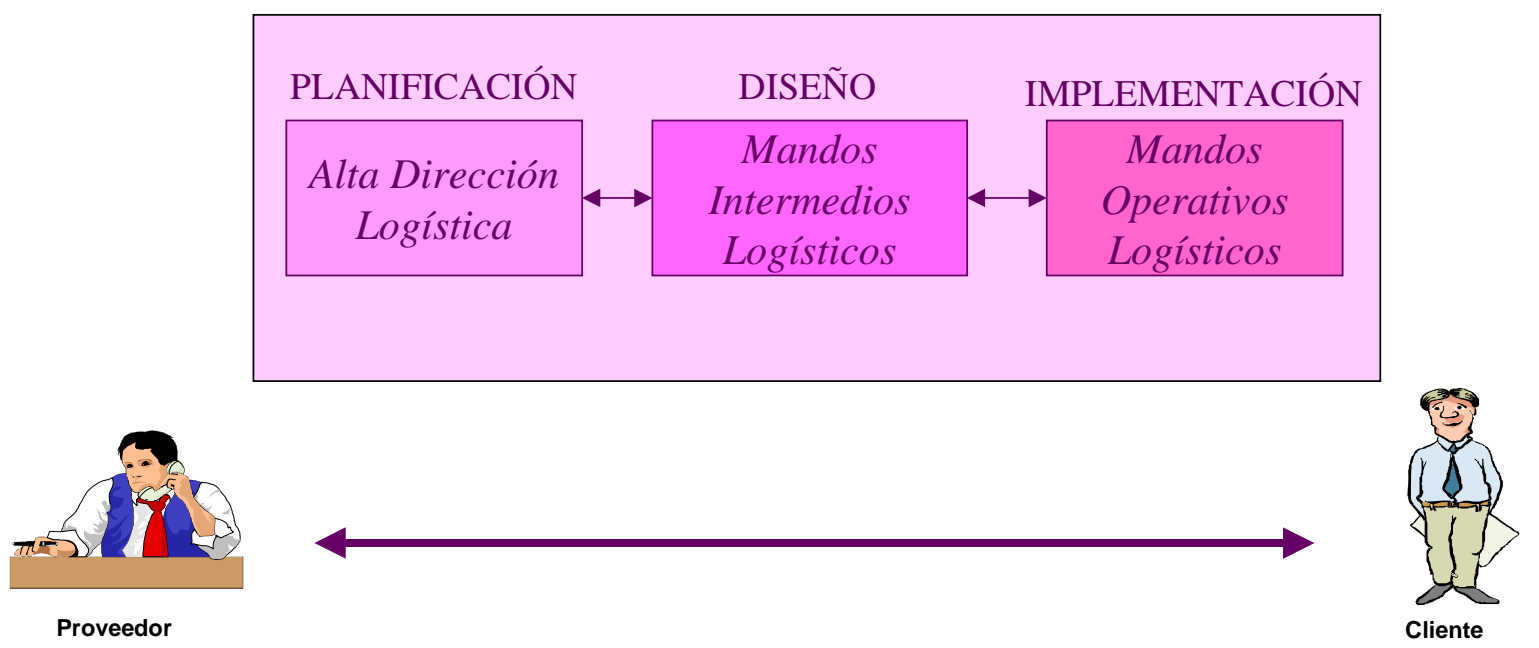

Ilustración 7. 4: Niveles de personal existentes en el sistema logístico, entre proveedor y cliente. Fuente: Elaboración Propia

Pero esta relación es realmente más compleja, debido a la existencia de más elementos empresariales ya explicados en el apartado 2.2. Por tanto, a los elementos presentados en la Ilustración 7. 4 : que corresponden a proceso, y personal, hay que añadirles el resto de elementos empresariales: servicio logístico, información e infraestructura. Esto supondrá como se explicó en el apartado 5.4 y la Ilustración 5.4 "el nivel de información correspondiente para cada puesto dentro de un sistema ha de recibir una cantidad de información, que no ha de ser la misma que reciba otro de los puestos de la misma empresa", al igual que ocurre con la tecnología y los recursos, el nivel necesario de los mismos para el desarrollo de cada puesto es distinto según el nivel jerárquico que ocupe en la pirámide de puestos logísticos.

Para el Instituto de Dirección de Proyectos (Project Management Institute) [PMI Capitulo 10], esta relación se debe a que todo el personal de una organización que desarrolla un proceso, debe estar preparado para enviar y recibir información, y entender como afecta dicha información a todo el proceso. Además será muy importante tener una perspectiva del modelo de comunicación, ya que a su vez seguirá un ciclo de vida, debido a que tiene una parte de planificación, distribución de la información, realización y cierre.

Al realizar la planificación del área logística, se estudia quien necesita qué información para el desarrollo de cada puesto, cuando se necesita y cómo se proporciona a cada quién la información. La distribución de la información se realizará de manera que llegue de forma 
puntual y en el momento preciso a cada nivel de la organización involucrada en el proyecto. Esto se implementará recogiendo y distribuyendo información al personal, teniendo en cuenta que recursos hay que proporcionar para lograr los objetivos del proyecto.

Por tanto, la comunicación y relación que se produce entre el personal de los departamentos logísticos y el personal correspondiente a los proveedores y clientes, se producirá básicamente entre los mismos niveles jerárquicos de personal, es decir, que seguirá aproximadamente la misma estructura de mandos, de forma que la Alta Dirección de proveedores y clientes se relacionará principalmente con la Alta Dirección del departamento u operador logístico, los mandos operativos de proveedores y clientes se relacionarán con los mandos operativos de los departamentos u operadores logísticos, y lo mismo ocurrirá con los operarios de unos y otros. Todo ello se aprecia en la Ilustración 7.5
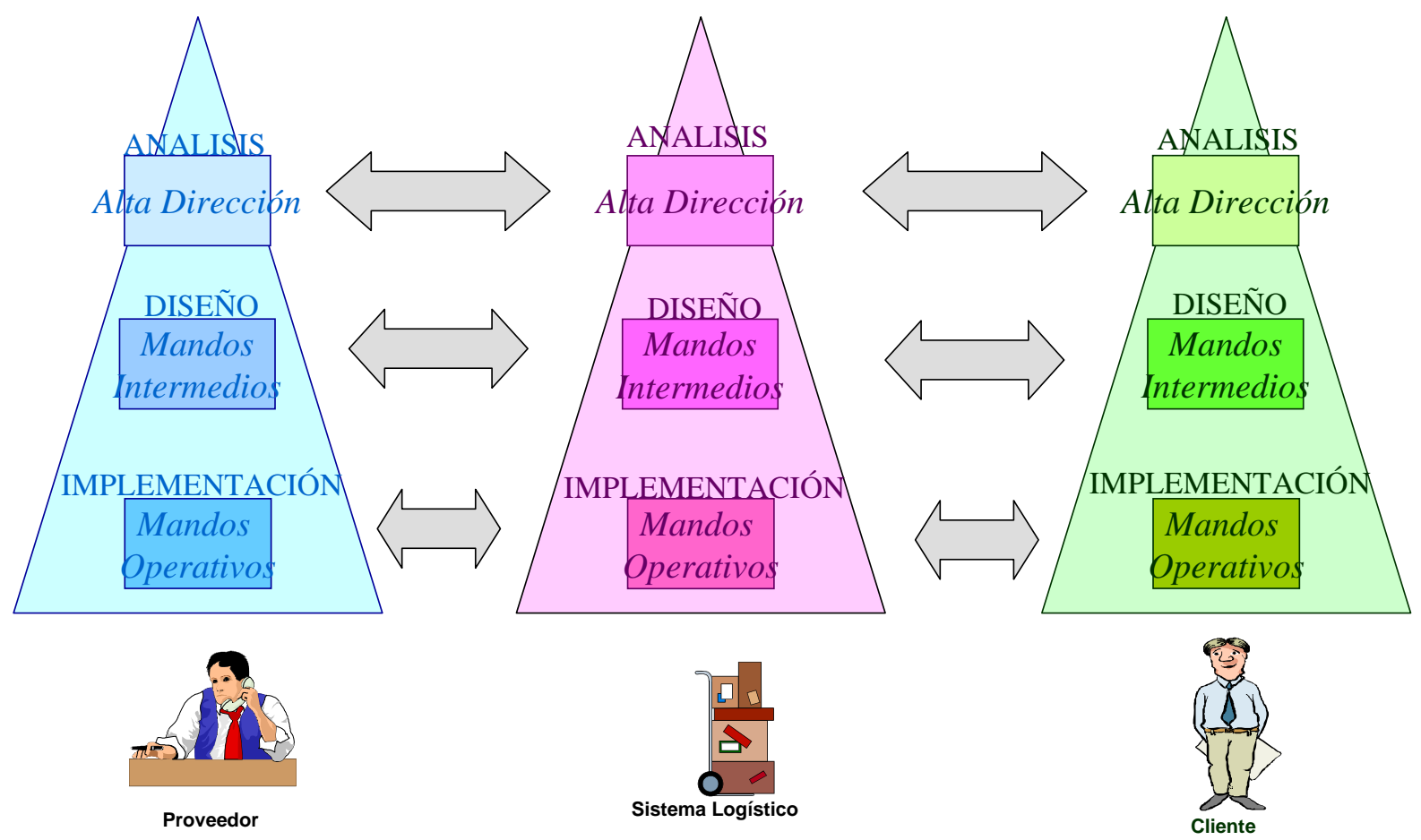

Ilustración 7. 5: Relación entre proveedor, sistema logístico y cliente. Fuente:

\section{Elaboración Propia}

Por lo tanto, la Alta Dirección Logística requiere de un bloque de información de proveedores y clientes, así como conocer con qué recursos de distribución puede contar. Por su lado, los Mandos Intermedios Logísticos requieren así mismo de información y recursos pero de un modo más puntual, ya que dicha información se requiere en forma de datos más específicos, como por ejemplo información correspondiente al tamaño de los almacenes, 
depósitos, naves, rutas existentes, etc. de modo que no sólo necesitan saber quien es el cliente, sino toda la información disponible respecto a dicho cliente en lo que a logística se refiere: capacidad, rutas, almacenes, etc. Por último, los Mandos Operativos Logísticos requieren información mucho más puntual de la empresa, proveedores o clientes en lugar de una información genérica. Esto generaría la Ilustración 7. 6 en la que se muestra con líneas de distinto grosor la cantidad de información que recibe cada bloque de personal, así como la ubicación de los elementos empresariales existentes en un departamento logístico, ya que para poder generar su trabajo o servicios se llevará a cabo un proceso logístico, existirá un personal (Alta Dirección, Mandos Intermedios y Mandos Operativos), una tecnología y una información, fundamental según el nivel de que se trate.

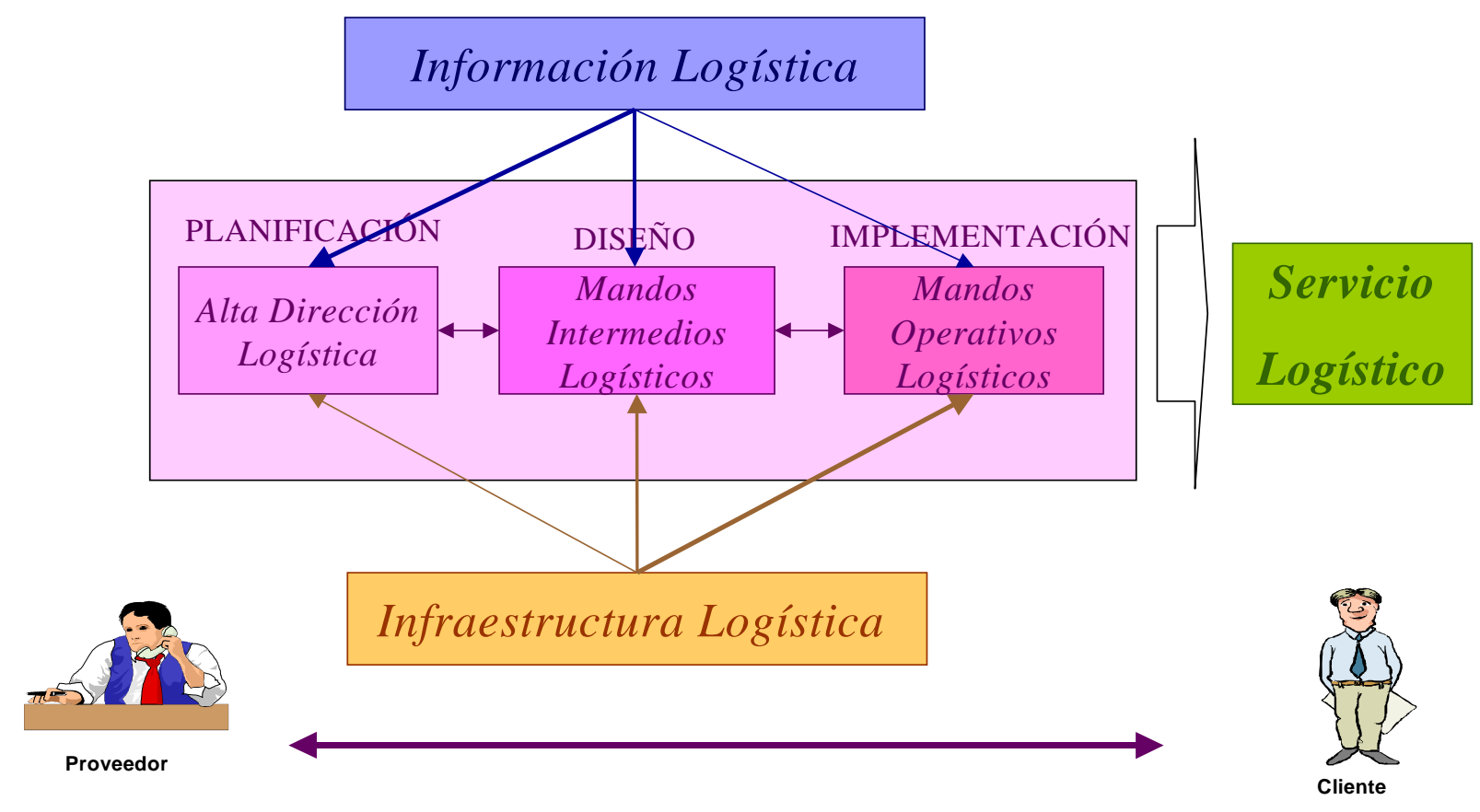

Ilustración 7. 6: Relación entre niveles de mando, información y tecnología, existente entre proveedor y cliente. Fuente: Elaboración Propia.

En esta Ilustración 7. 6, se puede observar de forma completa los cinco elementos empresariales descritos en el capítulo segundo: la información logística que llega a los mandos según las necesidades de cada uno de dicha información, la tecnología o infraestructuras necesarias para el desarrollo de la logística, el personal reflejado en los distintos niveles (Alta Dirección Logística, Mandos Intermedios Logísticos, Mandos Operativos Logístico), el proceso logístico o ciclo de vida logístico, que será la Cadena de Suministro, representado en la figura por las etapas de planificación, diseño, e 
implementación y finalmente el producto o servicio, que para el caso logístico será el servicio logístico.

Atendiendo a todos estos elementos y conociendo las etapas del ciclo de vida extendido presentado en el capítulo tercero surge el modelo final de Recursos Humanos propuesto para un sistema logístico. El modelo de ciclo de vida extendido, no tendrá que ver con el modelo de ciclo de vida presentado por Beier ${ }^{11}$ y recogido por Perrson [Persson1997 p.284-285], donde señala que la logística forma un ciclo de vida para el sistema logístico cuyas etapas son: Prelogística, Inicio a la Coordinación Logística, Departamentalización, Integración de la información y la logística, y finalmente Estado de Sistemas programados.

Pero el modelo aquí propuesto, parte del modelo de Recursos Humanos presentado en el capítulo quinto, pero adaptado al personal necesario para desarrollar la Cadena de Suministro, y se puede observar su representación en la Ilustración 7. 7 :

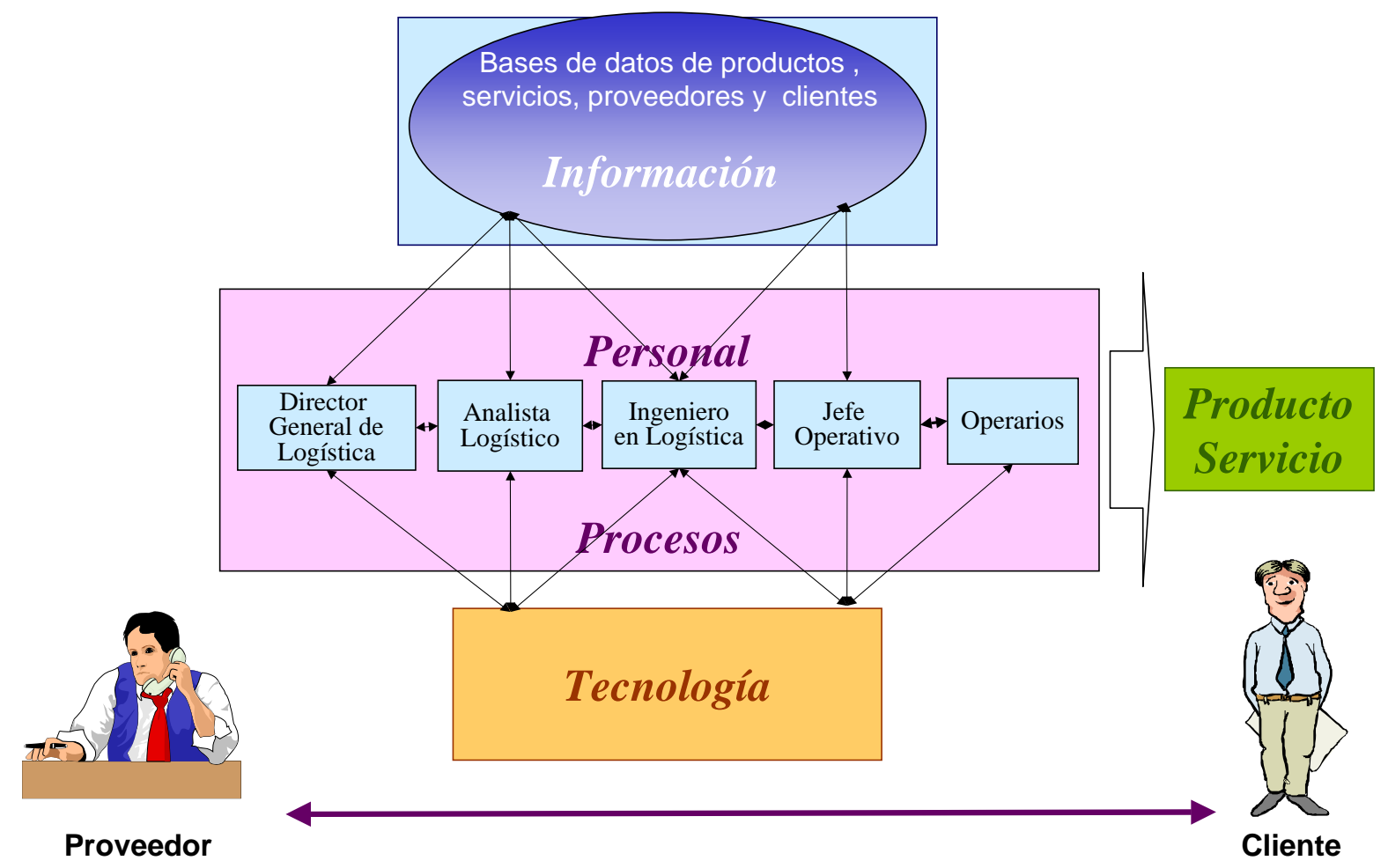

Ilustración 7. 7: Modelo de Recursos Humanos propuesto para el desarrollo de la Cadena de Suministro entre proveedor y cliente. Fuente: Elaboración Propia

\footnotetext{
11 Beier F.J., "Information Systems and the life cycle of logistics departments" International Journal of Physical Distribution Vol. 3.1973
} 
Esta ilustración muestra como entre proveedor y cliente se definen una serie de puestos encargados de cumplir con las etapas existentes en cada eslabón de la Cadena de Suministro y llevar a cabo las tareas logísticas. Los puestos que surgen son una aproximación a los puestos presentados en la arquitectura de Zachman [Zachman] mostrada en el capítulo primero como presentación, y en la aplicación del Modelo de Recursos Humanos Propuesto realizada en el capítulo quinto.

Al generar el modelo de Recursos Humanos aplicado a los sistemas logísticos, surgen unos puestos basados en los procesos que lleva a cabo cada uno de dichos puestos.

El primer puesto corresponde al Director General de la empresa. Este puesto no puede decirse que sea un puesto logístico, sino más bien será el puesto correspondiente a quien esté al mando de toda la empresa, ya que será quien defina el modelo contextual del negocio, es decir la dirección de la empresa y del negocio. En el caso que la empresa sea un operador logístico este puesto si tendrá relación con la logística, pero en caso de se una empresa productora con departamento de logística, este puesto supondrá aquel a quien le rindan cuentas los directores de logística.

El Director General de la empresa o similar, será el encargado de proporcionar las líneas de actuación para los elementos empresariales debido a que según las líneas de actuación proporcionadas por la empresa variará la dirección y el propósito de la misma, incluyendo la parte logística. Por tanto, tendrá que proporcionar la lista de tareas que ha de realizar la empresa desde el punto de vista de los negocios, así como una lista de donde opera la empresa y sus negocios, basado siempre en los elementos empresariales. A su vez ha de proporcionar la lista de unidades o departamentos de la empresa que se ven afectados por dichas tareas y así como el momento en que hay que realizar los negocios o eventos empresariales para que todo esté acorde con la misión, visión y objetivos de la empresa.

Centrándose en el Departamento o Área logística de la empresa, la máxima autoridad en dicho área corresponde al puesto denominado Director General de Logística, quien se encargue de definir los procesos de negocio para el área logística, siendo este puesto ocupado por una única persona. Para ello, proporcionará la lista de elementos empresariales necesarios para el desarrollo del negocio logístico, estableciendo los componentes de la cadena de suministro y las relaciones de negocios entre ellos: nombres, atributos, operaciones, etc. 
Una vez que el Director Logístico ha dado las pautas de actuación, el Analista logístico será el encargado de definir los modelos de negocio, de forma rigurosa y técnica para alcanzar esos objetivos, misión y visión propuesta por el Director logístico. Con lo que basándose en los elementos empresariales existentes, tendrá que definir la funcionalidad de cada uno de ellos en la Cadena de suministro.

Una vez el Analista logístico ha definido los modelos de negocio logístico, el Ingeniero o Diseñador Logístico será el encargado de definir los modelos tecnológicos y de infraestructura necesarios para operar, pudiendo ocupar estos dos últimos puestos una única persona, e incluso que esa única persona desarrolle además las tareas correspondientes a dirección, es decir: Planificación, más las correspondientes al analista e ingeniero. El Ingeniero Logístico, por tanto definirá las tareas de los componentes de la cadena de Suministro, proporcionando solidez a las operaciones que se realicen.

Una vez diseñada la estructura logística, el Jefe Operativo Logístico definirá las representaciones de los modelos definiendo como se implementará cada tarea de los componentes de la Cadena de suministro tomando como referencia los elementos empresariales y describiendo operativamente como se realizarán las tareas. Por último, el Operario Logístico ejecutará las tareas logísticas definidas por el Jefe Operativo Logístico, según como se haya definido.

De manera que al cuestionar ¿Qué? tareas realizan los puestos presentados para los sistemas logísticos, se estarán describiendo los objetos físicos, conceptuales o de información que realizan cada uno de los participantes en el proceso logístico, dirigiendo el conocimiento y tratamiento de la información del negocio logístico. Para ello, el Director General de la Empresa generará la lista de elementos empresariales importantes y necesarios para la empresa, que afectan a la dirección y al propósito, tanto de la empresa como de la parte logística.

Mientras, el Director Logístico proporcionará la lista de elementos empresariales necesarios para establecer la cadena de suministro, así como las relaciones de negocios existentes entre la empresa y los clientes, proporcionando: nombres, atributos y operaciones. 
Para el Analista Logístico supondrá una vez definidos por el Director los elementos empresariales, definir la funcionalidad: tanto en eficacia como en eficiencia, de cada uno de los componentes de la cadena de suministro (desde el punto de vista interno de la empresa).

El Ingeniero en Logística, definirá estructuralmente cada uno de los componentes de la Cadena de Suministro basado en los elementos empresariales, es decir, la robustez de las operaciones de cada uno de los componentes

El Jefe Operativo definirá la forma en la que cada una de las tareas de los componentes de la Cadena de Suministro se implementan teniendo en cuenta los elementos empresariales. Para finalmente, el Operario Logístico ejecutar las operaciones de la Cadena de Suministro desde el punto de vista de los elementos empresariales disponibles.

Al cuestionar ¿Cómo? se realizan las actividades, se estará describiendo la forma de llevar a cabo las acciones logísticas. A través de la descripción de procesos de traslación de la misión de la empresa a la definición de las operaciones de forma detallada.

Para ello el Director General de la Empresa proporcionará la lista de tareas principales a realizar por la empresa desde el punto de vista de los negocios. Mientras el Director Logístico describirá el modelo de negocio para poder ejecutar cada una de las tareas de los componentes de la Cadena de Suministro, incluyendo el ciclo de vida de ejecución de la Cadena de Suministro.

El Analista logístico describirá desde el punto de vista funcional la forma en que se ejecuta cada uno de los componentes de la Cadena de Suministro, mientras que el Ingeniero Logístico describirá cómo se ejecutan cada una de las tareas de los componentes de la Cadena de Suministro, y cómo acoplar estas tareas para que resulten el servicio o producto a ofrecer.

El Jefe Operativo describirá operativamente la realización de las tareas en cada uno de los componentes de la Cadena de Suministro. Siendo el Operario Logístico, aquel que ejecuta cada una de dichas tareas.

Al cuestionar ¿Dónde?, se describirá la ubicación geográfica de las entidades y acciones logísticas. Para lo que el Director de la Empresa proporcionará la lista de lugares donde opera la empresa y los negocios empresariales tomando como base los elementos empresariales. Mientras que el Director Logístico proporcionará un gráfico más detallado describiendo como 
interactúan las distintas localizaciones desde el punto de vista de los negocios y funcional de la Cadena de Suministro en relación con los clientes y servicios.

El Analista Logístico tomará como base los elementos empresariales y creará la arquitectura de distribución logística de los componentes de la Cadena de Suministro en base a la funcionalidad. El Ingeniero Logístico definirá la distribución puntual de cada uno de los elementos en cada componente de la Cadena de Suministro.

El Jefe Operativo definirá las especificaciones de ubicación de cada uno en las tareas de los componentes de la Cadena de Suministro, es decir, las rutas requeridas, comunicaciones necesarias, etc. tomando como base los elementos empresariales. Por último, los Operarios logísticos han de encontrarse en las ubicaciones definidas por cada una de las tareas de cada uno de los componentes de la Cadena de Suministro.

Al cuestionar ¿Quién? se describirán los objetos con cierto nivel de inteligencia, ya sean personas, ordenadores, etc. involucrados en el negocio de la logística para poder llevar a cabo la Cadena de Suministro. Por ello, el Director General de la Empresa proporcionará la lista de unidades o departamentos de la empresa, así como la misión de cada unidad. Mientras que el Director Logístico define el organigrama funcional del personal y los equipos inteligentes sobre la base de la Cadena de Suministro.

El Analista logístico define las características del personal y los equipos inteligentes que son necesarias dentro del organigrama funcional para poder llevar a cabo las actividades logísticas dentro de la Cadena de Suministro, y a partir de ahí, el Ingeniero Logístico determinará puntualmente la ubicación geográfica y las funciones de cada uno de los puestos dentro del organigrama funcional de la empresa o departamento. Finalmente el Jefe Operativo asignará personal a las tareas del diagrama funcional, y serán los Operarios Logísticos aquellos que ejecuten las tareas de dicho diagrama.

Al cuestionar ¿Cuándo? han de llevarse a cabo las tareas, se estará describiendo el momento en el cual se han de realizar las acciones, así como los efectos del tiempo en el negocio. Por ello el Director General de la empresa describirá el ciclo de desarrollo del negocio y los eventos empresariales, mientras que la tarea del Director Logístico será definir cuando ocurrirán las etapas del ciclo de vida logístico o Cadena de Suministro. Para ello el Analista 
logístico definirá los eventos logísticos que han de ocurrir y causar transformación y cambio en la Cadena de Suministro.

El Ingeniero Logístico convierte la Cadena de Suministro en mensajes y operaciones, diseñando detalladamente el momento en que se lleve a cabo cada una de las actividades de dicha cadena. Para ello el Jefe Operativo define puntualmente el momento en que realmente se llevarán a cabo las actividades y los Operarios logísticos ejecutarán las tareas de la cadena en el momento indicado.

Por último ante la cuestión del ¿Porqué?, se plantea describir los motivos por los cuales se han producido todas las actividades anteriores, suponiendo un traslado de las metas logísticas estratégicas a fines específicos con cierto significado. Por lo que Director de la empresa actuará de modo que esté acorde a la misión, visión y objetivos de la empresa. El Director Logístico hará cumplir la visión y los objetivos correspondientes a su departamento logístico o área logística, mientras que el Analista logístico buscará mediante la definición del modelo hacer cumplir los objetivos de la Cadena de Suministro.

El motivo por el cual el Ingeniero Logístico actúa acorde con dicha conducta es debido a que han de cumplirse los objetivos específicos de cada uno de los componentes de la Cadena de Suministro, para lo que el Jefe Operativo hará cumplir las tareas de cada uno de los componentes y que los Operarios Logísticos cumplan con la ejecución de dichas tareas de los componentes. 


\begin{tabular}{|c|c|c|c|c|c|c|}
\hline & $\begin{array}{l}\text { QUÉ } \\
\text { Describe objetos físicos, } \\
\text { conceptuales o de } \\
\text { información. Cada fila dirige } \\
\text { el conocimiento y tratamiento } \\
\text { de la información del negocio } \\
\text { logístico }\end{array}$ & $\begin{array}{l}\text { CÓMO } \\
\text { Describe las acciones } \\
\text { logísticas (verbos). Describe el } \\
\text { proceso de translación de la } \\
\text { misión de la empresa a } \\
\text { definición de las operaciones } \\
\text { de forma detallada }\end{array}$ & $\begin{array}{l}\text { DÓNDE } \\
\text { Describe la ubicación } \\
\text { geográfica de las entidades y } \\
\text { las acciones logísticas }\end{array}$ & $\begin{array}{l}\text { QUIÉN } \\
\text { Describe objetos con cierto } \\
\text { nivel de inteligencia (personas, } \\
\text { ordenadores, etc.) involucrado } \\
\text { en el negocio de la logística }\end{array}$ & $\begin{array}{l}\text { CUÁNDO } \\
\text { Describe el momento en cual } \\
\text { se llevan a cabo las acciones; } \\
\text { así como los efectos del } \\
\text { tiempo en el negocio }\end{array}$ & $\begin{array}{l}\text { PORQUÉ } \\
\text { Describe los motivos por el } \\
\text { cual se dan todas las } \\
\text { anteriores. Es el traslado de las } \\
\text { metas logísticas estratégicas a } \\
\text { fines específicos con } \\
\text { significado }\end{array}$ \\
\hline $\begin{array}{l}\text { DIRECTOR GENERAL DE } \\
\text { LA EMPRESA } \\
\text { Define el modelo contextual } \\
\text { de negocios: la dirección de la } \\
\text { empresa y del negocio }\end{array}$ & $\begin{array}{l}\text { Lista general de elementos } \\
\text { empresariales importantes } \\
\text { para la empresa y que afectan } \\
\text { su dirección y propósito } \\
\text { (incluyendo la parte logística) }\end{array}$ & $\begin{array}{l}\text { Lista de tareas a realizar por la } \\
\text { empresa desde el punto de } \\
\text { vista de negocios }\end{array}$ & $\begin{array}{l}\text { Lista de lugares donde opera la } \\
\text { empresa y los negocios } \\
\text { tomando como base los Elem } \\
\text { Empres. }\end{array}$ & $\begin{array}{l}\text { Lista de unidades o } \\
\text { departamentos de la empresa, } \\
\text { así cómo la misión de cada } \\
\text { unidad. }\end{array}$ & $\begin{array}{l}\text { Describe el ciclo de desarrollo } \\
\text { del negocio y los eventos } \\
\text { empresariales. }\end{array}$ & $\begin{array}{l}\text { Para estar acorde a la misión, } \\
\text { visión y objetivos de la } \\
\text { empresa }\end{array}$ \\
\hline $\begin{array}{l}\text { DIRECTOR DE } \\
\text { LOGÍSTICA } \\
\text { Define los modelos del } \\
\text { negocio. Esta representado por } \\
\text { una sóla persona }\end{array}$ & $\begin{array}{l}\text { Lista general de Elem. } \\
\text { Empres. del negocio logístico } \\
\text { (propio y del cliente), } \\
\text { establece los componentes de } \\
\text { la cadena de suministro y las } \\
\text { relaciones de negocios entre } \\
\text { ellos (nombres, atributos y } \\
\text { operaciones) }\end{array}$ & $\begin{array}{l}\text { Describe el modelo de } \\
\text { negocios para ejecutar cada } \\
\text { una de las tareas de los } \\
\text { componentes de la cadena de } \\
\text { suministro, incluyendo el ciclo } \\
\text { de vida de ejecución de la } \\
\text { cadena de suministro }\end{array}$ & $\begin{array}{l}\text { Gráfico más detallado, } \\
\text { describiendo cómo interactúan } \\
\text { las distintas localizaciones } \\
\text { desde el punto de vista de } \\
\text { negocios y funcional de la } \\
\text { cadena de suministro (en } \\
\text { relación con los clientes y } \\
\text { servicios) }\end{array}$ & $\begin{array}{l}\text { Define el organigrama } \\
\text { funcional del personal y } \\
\text { equipos inteligentes en base a } \\
\text { la cadena de suministro }\end{array}$ & $\begin{array}{l}\text { Define cuando ocurrirán las } \\
\text { etapas de ciclo de desarrollo } \\
\text { de la cadena de suministro }\end{array}$ & $\begin{array}{l}\text { Para hacer cumplir la visión, } \\
\text { misión y objetivos } \\
\text { correspondientes al aspecto } \\
\text { logístico }\end{array}$ \\
\hline $\begin{array}{l}\text { ANALISTA LOGÍSTICO } \\
\text { Define los modelos del } \\
\text { sistema de negocios en } \\
\text { términos más rigurosos y } \\
\text { técnicos. Puede estar } \\
\text { representado por más de una } \\
\text { persona }\end{array}$ & $\begin{array}{l}\text { Con base en Elem Empres. } \\
\text { define la funcionalidad } \\
\text { (eficiencia y eficacia) de cada } \\
\text { uno de los componentes de la } \\
\text { cadena de suministro desde el } \\
\text { punto de vista interno }\end{array}$ & $\begin{array}{l}\text { Describe desde } \\
\text { funcionalmente la forma en } \\
\text { que se ejecutarán cada uno de } \\
\text { los componentes de la cadena } \\
\text { de suministro (ciclo de vida de } \\
\text { la cadena de suministro) }\end{array}$ & $\begin{array}{l}\text { Con base en Elem Empres. } \\
\text { crea la arquitectura de } \\
\text { distribución logística de los } \\
\text { componentes de la cadena de } \\
\text { suministro y su funcionalidad }\end{array}$ & $\begin{array}{l}\text { Define las características del } \\
\text { personal y equipos inteligentes } \\
\text { del organigrama funcional }\end{array}$ & $\begin{array}{l}\text { Define los eventos logísticos } \\
\text { que causan transformación y } \\
\text { cambio de la cadena de } \\
\text { suministro }\end{array}$ & $\begin{array}{l}\text { Para hacer cumplir los } \\
\text { objetivos de la cadena de } \\
\text { suministro }\end{array}$ \\
\hline $\begin{array}{l}\text { INGENIERO EN } \\
\text { LÓGÍSTICA } \\
\text { Define los modelos } \\
\text { tecnológicos y de } \\
\text { infraestructura para operar los } \\
\text { modelos anteriores. Su número } \\
\text { puede ser mayor al de los } \\
\text { analistas logísticos }\end{array}$ & $\begin{array}{l}\text { Define estructuralmente cada } \\
\text { uno de los componentes de la } \\
\text { cadena de suministro con base } \\
\text { en Elem Empres. (robustez de } \\
\text { las operaciones de cada uno de } \\
\text { los componentes) }\end{array}$ & $\begin{array}{l}\text { Describe como se ejecutara } \\
\text { puntualmente cada una de las } \\
\text { tareas de los componentes de } \\
\text { la cadena de suministro y } \\
\text { como acoplar estas tareas para } \\
\text { que resulten el servicio o } \\
\text { producto a ofrecer }\end{array}$ & $\begin{array}{l}\text { Define la distribución puntual } \\
\text { de Elem Empres. utilizada en } \\
\text { cada uno de los componentes } \\
\text { de la cadena de suministro }\end{array}$ & $\begin{array}{l}\text { Determina puntualmente la } \\
\text { ubicación geográfica y las } \\
\text { funciones de cada puesto del } \\
\text { diagrama funcional }\end{array}$ & $\begin{array}{l}\text { La cadena de suministro se } \\
\text { convierte en mensajes y } \\
\text { operaciones y se diseña } \\
\text { detalladamente el momento de } \\
\text { que se llevarán a cabo }\end{array}$ & $\begin{array}{l}\text { Para hacer cumplir los } \\
\text { objetivos específicos de cada } \\
\text { uno de los componentes de la } \\
\text { cadena de suministro }\end{array}$ \\
\hline $\begin{array}{l}\text { JEFE OPERATIVO } \\
\text { Define las representaciones } \\
\text { detalladas de los modelos } \\
\text { anteriores por medio de un } \\
\text { lenguaje específico. Puede ser } \\
\text { mayor en número al del } \\
\text { Ingeniero en Logística }\end{array}$ & $\begin{array}{l}\text { Define la forma en que cada } \\
\text { una de las tareas de los } \\
\text { componentes de la cadena de } \\
\text { suministro se implementan (de } \\
\text { forma robusta) tomando como } \\
\text { referencia los Elem Empres. }\end{array}$ & $\begin{array}{l}\text { Describe operativamente la } \\
\text { realización de las tareas en } \\
\text { cada uno de los componentes } \\
\text { de la cadena de suministro }\end{array}$ & $\begin{array}{l}\text { Define las especificaciones de } \\
\text { ubicación de cada uno de las } \\
\text { tareas de los componentes de } \\
\text { la cadena de suministro (rutas } \\
\text { requeridas, comunicaciones } \\
\text { necesarias, etc.) tomando } \\
\text { como base los Elem Empres. }\end{array}$ & $\begin{array}{l}\text { Asigna personas a las tareas } \\
\text { del diagrama funcional }\end{array}$ & $\begin{array}{l}\text { Define puntualmente el } \\
\text { momento de llevar a cabo cada } \\
\text { tarea de la cadena de } \\
\text { suministro }\end{array}$ & $\begin{array}{l}\text { Para hacer cumplir las tareas } \\
\text { de cada una de los } \\
\text { componentes de la cadena de } \\
\text { suministro }\end{array}$ \\
\hline $\begin{array}{l}\text { OPERARIO LOGÍSTICO } \\
\text { Ejecuta las tareas logísticas } \\
\text { definidas por el jefe operativo. } \\
\text { Su número puede ser mucho } \\
\text { mayor que el de los jefes } \\
\text { operativos }\end{array}$ & $\begin{array}{l}\text { Ejecuta las operaciones de la } \\
\text { cadena de suministro desde el } \\
\text { punto de vista de los Elem } \\
\text { Empres. }\end{array}$ & $\begin{array}{l}\text { Ejecuta cada una de las tareas } \\
\text { en la cadena de suministro }\end{array}$ & $\begin{array}{l}\text { Se encuentra en las } \\
\text { ubicaciones definidas por cada } \\
\text { una de las tareas de cada uno } \\
\text { de los componentes de la } \\
\text { cadena de suministro }\end{array}$ & $\begin{array}{l}\text { Son las personas que ejecutan } \\
\text { las tareas del diagrama } \\
\text { funcional }\end{array}$ & $\begin{array}{l}\text { Ejecuta las tareas de la cadena } \\
\text { de suministro en el momento } \\
\text { indicado }\end{array}$ & $\begin{array}{l}\text { Para ejecutar las tareas de los } \\
\text { componentes de la cadena de } \\
\text { suministro }\end{array}$ \\
\hline
\end{tabular}

Tabla 7. 1 : Presentación de las funciones del Modelo de Recursos Humanos en los Sistemas Logísticos. Elaboración propia 
Una vez presentado el Modelo de Recursos Humanos propuesto para los sistemas logísticos, puede hacerse un resumen que defina las responsabilidades y funciones correspondientes a cada uno de los puestos propuestos en el modelo que se presenta en este trabajo. Con lo que de forma más breve a la expuesta en la Tabla 7. 1. Por lo tanto, en una rápida descripción de los puestos se pueden enunciar como:

- Director General de Logística: tiene la visión del proceso logístico completo, y posee información de la importancia de la logística, de los procesos a realizar, de los lugares donde opera, las empresas colaboradoras y las mentas a alcanzar

- Analista Logístico: diseña la parte funcional logística, que comprende: modelos de procesos de negocios, modelos de red logística, modelos de flujo de trabajo y un modelo del plan general de negocio.

- Ingeniero en logística: encargado de generar un modelo de datos necesarios para implementar la logística, aplicando los modelos diseñados por el analista, diseña la arquitectura de distribución, el personal y los procesos requeridos para llevarla a cabo, aplicando estándares y restricciones existentes.

- Jefe Operativo: implementa los modelos obtenidos a partir de las fases de análisis y diseño.

- Operarios: llevarán a cabo cada una de las tareas físicas a realizar, de manera puntual y personalizada.

Dichos puestos corresponderán al elemento empresarial denominado desde el capítulo segundo como "Personal". A su vez, se ha mostrado en el modelo final (Ilustración 7. 7) que existen otros elementos empresariales relacionados con el personal y los procesos. Estos elementos son la Infraestructura o Tecnología y la Información. Las personas que componen estas áreas no estarán dentro de los departamentos o áreas logísticas, sino que pueden pertenecer a otros departamentos. Entre los puestos que se pueden encontrar 
dentro del denominado hasta ahora como elemento información podrían nombrarse puestos como:

- Mando en bases de datos: Determina como deben ser las bases de datos y la gestión de la información.

- Operario en bases de datos: Implanta las bases de datos y accesos a la información.

Y dentro del personal que puede ocupar los puestos que conforman el elemento de Infraestructura o tecnología se pueden citar:

- Mando en redes de distribución: Define los recursos de red y la comunicación en la empresa.

- Operario en redes de distribución: Implanta la comunicación y el mantenimiento de red para la empresa y el departamento logístico.

- Operario en redes de comunicación: Detecta las necesidades, los recursos, y las redes de comunicación.

Éstos últimos, estarían encargados del control de la flota de transporte, que en los últimos tiempos y con la adaptación de tecnologías de GPS mantienen un enlace entre los vehículos y la empresa a través de Internet. Además de mediante un terminal GSM se pueden realizar mensajes cortos SMS, con lo que pueden obtener información sobre su posición y alarmas de los vehículos en tiempo real, la velocidad, la población más cercana, e incluso el control de la carga, grabación de datos para la creación de un fichero de históricos cada cierto tiempo.

Un resumen de las principales tareas que han de realizar los principales puestos logísticos propuestos en el modelo creado se desglosan a continuación en la Tabla 7. 2: 


\begin{tabular}{|c|c|}
\hline ENTIDAD & FUNCIONES \\
\hline $\begin{array}{l}\text { DIRECTOR GENERAL EN } \\
\text { LOGÍSTICA }\end{array}$ & $\begin{array}{ll}\checkmark & \text { DESCRIBE LOS PROCESOS, INFORMACIÓN, PERSONAL Y TECNOLOGÍA NECESARIA PARA } \\
& \text { DESARROLLAR LA LOGÍSTICA A LO LARGO DE LA CADENA DE SUMINISTRO Y SUS RELACIONES } \\
\checkmark & \text { DETALLA LAS ACTIVIDADES LOGÍSTICAS A REALIZAR Y BAJO QUE MODELO SE EJECUTARÁN } \\
\checkmark & \text { DETERMINA LA UBICACIÓN DE LAS ACCIONES LOGÍSTICAS DE LA CADENA DE SUMINISTRO } \\
\checkmark & \text { DEFINE EL ORGANIGRAMA, PERSONAL Y EQUIPOS PARA CADA ACTIVIDAD } \\
\checkmark & \text { ESPECIFICA CUANDO SUCEDERÁ CADA ETAPA DE LA CADENA DE SUMINISTRO } \\
\checkmark & \text { DESCRIBE LA VISIÓN, MISIÓN Y OBJETIVOS LOGÍSTICOS } \\
\end{array}$ \\
\hline ANALISTA LOGÍSTICO & $\begin{array}{ll}\checkmark & \text { DESCRIBE LA FUNCIONALIDAD DE CADA COMPONENTE EN LA CADENA DE SUMINISTRO } \\
& \text { (DESDE EL PUNTO DE VISTA INTERNO Y EXTERNO) } \\
\checkmark & \text { DESCRIBE EL FUNCIONAMIENTO DE EJECUCIÓN DE LOS COMPONENTES DE LA CS } \\
\checkmark & \text { CREA LA ARQUITECTURA DE DISTRIBUCIÓN LOGÍSTICA DE LOS COMPONENTES DE LA CS } \\
\checkmark & \text { DEFINE LAS CARACTERÍSTICAS DEL PERSONAL Y EQUIPOS INTELIGENTES } \\
\checkmark & \text { DEFINE LOS EVENTOS LOGÍSTICOS QUE CAUSAN TRANSFORMACIÓN Y CAMBIO EN LA CS }\end{array}$ \\
\hline INGENIERO EN LOGÍSTICA & $\begin{array}{ll}\checkmark & \text { DEFINE LA ESTRUCTURA DE CADA COMPONENTE DE LA CS BASADOS EN LOS ELEMENTOS } \\
& \text { EMPRESARIALES } \\
\checkmark & \text { DESCRIBE LA EJECUCIÓN PUNTUAL DE LAS TAREAS DE LOS COMPONENTES DE LA CS (PARA } \\
& \text { ACABAR EN UNA OFERTA DE SERVICIO) } \\
\checkmark & \text { DEFINE LA DISTRIBUCIÓN PUNTUAL UTILIZADA PARA CADA COMPONENTE DE LA CS } \\
\checkmark & \text { DETERMINA PUNUTALMENTE LA UBICACIÓN GEOGRÁFICA Y FUNCIONES DE CADA PUESTO } \\
\checkmark & \text { CONVIERTE LA CS EN MENSAJES Y OPERACIONES, DISEÑANDO EL MOMENTO DE } \\
& \text { REALIZACIÓN }\end{array}$ \\
\hline JEFE OPERATIVO & $\begin{array}{ll}\checkmark & \text { DEFINE COMO SE IMPLEMENTA CADA TAREA DE LOS COMPONENTES DE LA CS } \\
\checkmark & \text { DESCRIBE OPERATIVAMENTE LA REALIZACIÓN DE TAREAS DE CADA UNO DE LOS } \\
& \text { COMPONENTES DE LA CS } \\
\checkmark & \text { DEFINE LAS ESPECIFICACIONES DE UBICACIÓN DE CADA TAREA DE COMPONENTES } \\
\checkmark & \text { ASIGNA PERSONAL A CADA TAREA FUNCIONAL } \\
\checkmark & \text { DEFINE EL MOMENTO PUNTUAL DE REALIZACIÓN DE CADA TAREA }\end{array}$ \\
\hline OPERARIO & $\begin{array}{ll}\checkmark & \text { EJECUTA LAS OPERACIONES Y TAREAS DE LA CS } \\
\checkmark & \text { EJECUTA LAS TAREAS DEL DIAGRAMA LOGÍSTICO } \\
\checkmark & \text { SE ENCUENTRA EN LAS UBICACIONES DEFINIDAS POR CADA UNA DE LAS TAREAS }\end{array}$ \\
\hline
\end{tabular}

Tabla 7. 2. Principales funciones desempeñadas por los puestos del Modelo de

Recursos Humanos aplicado a los sistemas logísticos. Fuente: Elaboración propia

\subsection{CONCLUSIONES DEL CAPÍTULO}

Una vez presentado en el capítulo quinto el Modelo de Recursos Humanos para la entidad de negocio, y realizada en el capítulo sexto una aproximación al área de estudio, se ha pasado a aplicar el Modelo Propuesto a los Sistemas Logísticos, obteniendo con ello un Modelo de Recursos Humanos Logísticos. 
Para ello, se ha comenzado definiendo desde la bibliografía existente cual ha de ser el perfil de los profesionales logísticos. A continuación en el apartado 7.3 se ha procedido a describir los posibles puestos que pueden existir en un sistema logístico, describiéndose puestos existentes en las áreas de dirección logística, sistema de información logística, almacén, transporte, inventarios, compras e incluso servicio al cliente, ampliándose las descripciones en el Anexo I.

Una vez presentados todos estos puestos con una breve descripción de los mismos, se ha procedido a generar en el apartado 7.4, el modelo de Recursos Humanos Logístico. Dicha generación se ha obtenido siguiendo las etapas y pautas que se propusieron en el capítulo quinto para la generación del modelo de Recursos Humanos de Entidad de Negocio, mientras que ahora se ha enfocado particularmente la Logística, obteniéndose los puestos de Director General Logístico, Analista logístico, Diseñador Logístico, Jefe Operativo y Operarios Logísticos. Estos puestos se apoyarán en la información e infraestructura logística, y obteniendo con todo ello un servicio logístico. A su vez se ha obtenido la información correspondiente al ¿Qué?, ¿Cómo?, ¿Cuándo?, ¿Quién?, ¿Dónde? y ¿Porqué? de cada uno de los puestos logísticos propuestos.

A partir de este capítulo en el que ya se tiene un Modelo de Recursos Humanos Logístico, se pasará a comprobar si el mismo se puede validar en los sistemas logísticos, para ello el capítulo siguiente propone una metodología de comprobación, así como la comprobación propiamente dicha a través de cuestionarios y visitas a varios sistemas logísticos.

\subsection{REFERENCIAS BIBLIOGRÁFICAS DEL CAPITULO}

Cooper2002 Cooper M., A. Gillyard, A. Sandu. "2001 Carrer Patterns of Women in Logistics" http://www.clm1.org/career/downloads/2002WIL.pdf. Consultada en septiembre de 2002

Dadzie1998 Dadzie K.Q. "Management education for physical distribution and logistics" International Journal of Physical Distribution \& Logisitcs Management. Vol 28. No 4, 1998 Pp: 259-271

DeMiguel De Miguel. Introducción a la gestión (Management) I. $8^{\circ}$ Edición. Servicio de Publicaciones de la Universidad Politécnica de Valencia. España 1993

FORCEM2000 Fundación para la Formación Continua. Departamento de Organización Industrial y Gestión de Empresas de la Escuela 
Superior de Ingenieros de Sevilla, el Instituto de Formación y Estudios Sociales (IFES), la Asociación de Investigación y Cooperación Industrial de Andalucía (AICIA), PRINCA S. Coop. And., la Federación Regional de Transportes, Comunicaciones y Mar de la U.G.T. http://io.us.es/Formacion_Logistica.htm Consultada el 1 de octubre de 2002

Gibson1998 Gibson B., M. Gibson, S.Runter. "Carrers in Logistics" Georgia Southern Univesity. Council of Logistics Management.1998. http://www.clm1.org/career/downloads/careerstudy.pdf Consultada el 20 de agosto 2002

Harvey2001 Harvey M.G., R. Glenn Richey. "Global supply chain management. The selection of globally competent managers" Journal of International Management. 7 año 2001. Páginas 105- 128

Kersner H. Kersner. Project Management. $7^{\text {a }}$ Edición. Editorial John Wiley. Año 2000. USA

KohnMcGinnis19 Kohn J.W., M. A. McGinnis, "Advanced logistics organisation 97 structures: revisited" Journal of Business Logistics 1997, Vol 18. Issues2 P.147 $16 \mathrm{p}$

LaLonde2002 La Londe B.J., J.L. Ginter. "2001 Survey of Career Patterns in Logistics" The Ohio State University. http://www.clm1.org/career/downloads/2002careerpatterns.pdf Consultada el 15 junio 2002

LeMay99 Le May S.A, J.C. Carr, J.A. Periatt, R.D. McMahon.. "The Growth and Development of Logistics Personnel" Mississipi State University. Council of Logistics Management. 1999. USA

Lynch1998 Lynch C.F. "Leadership in Logistics" Journal of Business Logistics 1998. Vol 19 Issue 2, pp 3-5.

McIntryre2002 McIntyre M.. "Today's Logistics Professional: It's not a Job - It's a carrer" Executive Vice President and Chief Operating Officer. 53

Annual Salzberg Medallion Lecture. 5/04/2002.

http://www.clm1.org/career/downloads/salzbergfull.pdf .Consultada el 1 de Octubre de 2002

Murphy1998 Murphy P.R., R. F. Poist Jr. "Skill requirementes of senior-level logisticians" International Journal of Phisical Distribution \& Logistics Management. Vol 28. Nº4. p. 284-301. MCB University Press. 1998

OpLogisticos27 Operadores Logísticos.

Pérez2001 Pérez, Carlos. "En un entorno cada vez más competitivo. La imprescindible figura del director logístico". Revista: Logística Profesional. Especial Operadores logísticos 2001. Grupo Tecnipublicaciones.

Persson1997 Person G., "Organisation design strategies for business logistics" International Journal of Physical Distribution \& Logistics Management" Vol. 27. N 5/6. 1997 pag. 282-291. MCB University Press.

PMI Project Management Institute. (PCI) USA. Chapter 10: Project Communications Management. www.pmi.org Consultada el $10 / 04 / 2002$ 
SanCristobal2001 San Cristóbal Espiga A., Director de Recursos Humanos SDF Ibérica S.A. Ponencia "Los Recursos Humanos de un Operador Logístico" II Foro Logístico de la Región de Murcia. Noviembre 2001

Williams2002 Williams L.R., T. L. Esper, J. Ozment. "The electronic Supply Chain. It's impact on the current and future structure of strategic allinaces, parternships and logistics leadership" International Journal of Phisical Distribution \& Logistics Management. Vol 32 Issue 8.

Zachman Zachman. Enterprise. The issue of the century http://www.zifa.com/zifajz01.htm. Consultada el 27/09/2001

Zachman2 Zachman. Enterprise Architecture. A framework http://www.zifa.com/zifajz02.htm. Consultada el 27/09/2001 


\section{Capítulo 8.}

Aplicación del Modelo de

Recursos Humanos a

Sistemas Logísticos 
CAPITULO 8

\section{APLICACIÓN DEL MODELO DE RECURSOS HUMANOS A SISTEMAS LOGÍSTICOS}

\subsection{INTRODUCCIÓN}

Una vez planteado en el capítulo quinto un modelo de Recursos Humanos desde el punto de vista de la integración empresarial, en el cual se proporcionan una serie de puestos basados en los procesos, responsabilidades y funciones a realizar para cumplir con las etapas existentes a lo largo del ciclo de vida, se ha realizado en el capítulo séptimo una plasmación de dicho modelo para el ámbito logístico, generándose así un modelo de Recursos Humanos para los Recursos Humanos de los sistemas logísticos.

Una vez aplicado dicho modelo a los sistemas logísticos en el capítulo séptimo, en el presente se procederá a verificar y comprobar si el mismo se puede aplicar realmente a los departamentos y empresas que aplican logística.

Para ello, el capítulo comienza explicando la metodología seguida para la recopilación de datos, detallando las etapas del proceso de obtención de información. Conocido esto, 
a partir de aquí, se realiza una explicación de la estructura del cuestionario, así como el proceso de elaboración de los mismos, para pasar a continuación al estudio de los resultados obtenidos y posteriormente validar el modelo propuesto.

\subsection{METODOLOGÍA DE ACTUACIÓN PARA LA RECOGIDA DE INFORMACIÓN}

Ante la situación de comprobar la validez del modelo que surge en el capítulo séptimo, este trabajo propone el estudio de diversas empresas que aplican logística. Para ello, se realizarán entrevistas siguiendo una estructura de preguntas, realizadas a través de un cuestionario, de forma que guíe la entrevista. La decisión de realizar entrevistas basadas en preguntas cerradas y abiertas al realizar visitas in situ, se toma una vez estudiadas y analizadas las características de los distintos métodos existentes de recogida de información: entrevistas telefónicas, encuestas por correo, entrevistas en grupo, visitas in situ, así como la filosofía y principios que rigen los cuestionarios. En el Anexo II se exponen todas estas metodologías, así como las ventajas e inconvenientes de las mismas, para dentro del análisis de la entrevista, estudiar: sus partes, pautas de actuación, errores a evitar, cuestionarios, etc. así como las opciones

Por tanto, habrá que planificar la información que se va a buscar y se determinará el contenido de cada pregunta a través del diseño de los cuestionarios. La realización y obtención de cuestionarios que recojan en pocas preguntas mucha información es una laboriosa tarea, debido a que hay que realizar unos cuestionarios iniciales e ir realizando posteriormente una serie de tamizaciones a los mismos, para finalmente seleccionar aquellas preguntas que logren sacar el máximo conocimiento de los sistemas a analizar.

Las etapas a seguir en esta metodología son tomadas de Malholtra [Malhotra97 p. 321] y pueden observarse en la Ilustración 8. 1, suponiendo estas un ciclo de vida como se expuso en la explicación teórica. 


\begin{tabular}{|c|}
\hline \multicolumn{2}{|c|}{ Información de los puestos de trabajo logísticos } \\
\hline Modelo de entrevista a realizar: Entrevista in Situ \\
\hline Contenido de las preguntas: Qué, Cómo, Cuando, Dónde, Quién Porqué, \\
\hline Diseñar la pregunta:Servicio, Procesos, Personal, Infraestructura e Información \\
\hline \multicolumn{2}{|c|}{$\mid$} \\
\hline Redacción de las preguntas \\
\hline Ordenar las preguntas, la forma y disposición: de lo general a lo particular \\
\hline \\
\hline \\
\hline
\end{tabular}

Ilustración 8. 1: Proceso de diseño de los cuestionarios logísticos. Fuente: Basado en Malholtra p.321

A continuación se presenta la explicación de las distintas etapas expuestas en la Ilustración 8. 1

1. Información de los puestos de trabajo logísticos: Antes de pasar a realizar los cuestionarios ha de tenerse una idea sobre qué consiste la logística, qué procesos son necesarios para llevarla a cabo, y qué personas intervienen en esos procesos. Esta etapa se ha realizado con la elaboración del capítulo sexto donde se hace una incursión en lo que es logística y las áreas relacionadas con la logística.

2. Especificar el modelo de entrevista a realizar: Para realizar las entrevistas se realizarán visitas In -Situ. La explicación y comparación de los distintos tipos de entrevista, aparecen expuestas en el Anexo II. Esto supone llevar a cabo las siguientes acciones:

- Realizar un primer contacto con las empresas, contacto que se ha realizado a través del Centro Español de Logística, a través de su Dirección Técnica. 
- Obtener citas con los distintos puestos a entrevistar: una vez seleccionadas las empresas a entrevistar junto con la Dirección Técnica del Centro Español de Logística (CEL), se obtendrán citas con los responsables de logística de dichas empresas.

- Acudir a las distintas empresas físicamente

- Realizar los cuestionarios preparados y verificados previamente.

Estas acciones, a su vez se desarrollan como un ciclo de vida, en el que se produce un análisis en el primer contacto con las empresas, un diseño del sistema al obtener citas con los distintos puestos a entrevistar y finalmente una implementación al acudir a distintas empresas y realizar los cuestionarios preparados y verificados.

3. Contenido de las preguntas: Para realizar los cuestionarios se utilizará el material y las ideas propuestas en la primera parte de éste trabajo, en concreto en la parte de Identificación del Marco, debido a que analizarán las dimensiones empresariales para cada uno de los puestos, es decir, hacer un análisis sobre el servicio generado, los procesos realizados, el personal necesario y su capacitación, así como la infraestructura e información necesaria para desarrollar correctamente cada uno de los puestos.

4. Diseñar las preguntas: Además de tener presente los puestos y las dimensiones empresariales, se emplearán las ideas de Zachman [Zachman] propuestas a su vez por Domínguez [Domínguez2000 p.37] sobre división conceptual del conocimiento, obteniendo de esta forma las siguientes categorías:

- Información (el "Qué"): se refiere al entendimiento y compromiso que representa la información en y del sistema. Es decir, hace referencia a la importancia de la información dentro del sistema logístico de la empresa para poder realizar correctamente sus tareas. 
- Funciones (el "Cómo"): describe el proceso de traducción del propósito del sistema a definiciones detalladas a las operaciones a realizar. Cuya aplicación a la logística supone explicar como se realizarán y levarán a cabo las tareas logísticas

- Redes (el "Dónde"): se refiere a la distribución geográfica de las actividades del sistema. Es decir, detallar el lugar donde se llevarán a cabo las actividades logísticas.

- Sistemas de Respaldo (el "Quién"): Describe a los sistemas involucrados en el sistema, y cómo éstos se relacionan con la tecnología. Esto supone especificar quien ha de desarrollar determinadas tareas y con qué infraestructura lo realizará.

- Tiempo (el "Cuando"): Describe los efectos del tiempo en el sistema. Es decir, detalla el momento en que se realizarán las tareas logísticas.

- Motivación (el "porqué): describe el proceso de traducción de las metas y estrategias del sistema a significados y esfuerzos específicos. Explica el motivo por el cual han de realizarse esas tareas y de esa forma determinada.

Si se cruzan el Qué, el Cómo, el Quién, el Cuándo, el Dónde, y el Porqué con los elementos empresariales (Procesos, Servicio, Personal, Tecnología e Información), y con cada uno de los puestos logísticos propuestos (Director General Logístico, Analista Logístico, Diseñador Logístico, Jefe Operativo, y Operario), se obtendrán unos cuestionarios muy amplios que servirán para analizar con profundidad y con el máximo rigor cada uno puestos logísticos. Dichos cuestionarios se adjuntan en el Anexo II.

Con las respuestas a esos cuestionarios se puede lograr dominar la totalidad de las áreas del conocimiento dentro del núcleo principal del sistema logístico. 
5. Redacción de las preguntas: ha de utilizarse un estilo sencillo, evitando palabras grandilocuentes, de modo que sea fácil de entender y responder. Si no se realiza de tal modo puede ocurrir que los entrevistados no respondan o lo hagan de forma incorrecta. En este caso se utilizó un lenguaje claro y sin utilizar excesivos términos técnicos. Se realizaron preguntas más estratégicas a los puestos más altos y más técnicas u operativas a los operarios.

6. Ordenar las preguntas, la forma y disposición: En este caso se sigue la estrategia de embudo propuesta por Morales [Morales] y Malhotra [Malhotra97 p. 337] de manera que se comenzará con preguntas generales seguidas por preguntas cada vez más específicas, tocando en todo momento como afecta a ese puesto las dimensiones empresariales.

El problema surge a la hora de visitar y encuestar a los puestos logísticos de las empresas, ya que si brindan la oportunidad de acceder a las entrevistas, habrá que intentar obtener la máxima información con la menor molestia y de la forma más breve posible, con lo que habrá trabajar para acortar esos cuestionarios.

7. Reproducir el cuestionario: Se realizarán preguntas que sean fáciles de leer y responder. Con tipografía grande y clara, sin que su lectura suponga una limitación. En este caso al utilizarse entrevistas in-situ el entrevistador será quien administre el cuestionario y tome notas sobre las respuestas que vayan ofreciendo los entrevistados sobre un formato ya establecido.

8. Eliminar los problemas mediante una prueba piloto: Supondrá hacer una prueba previa a algún compañero o conocido perteneciente a una empresa que aplique logística. Para ello se llevarán a cabo todos los pasos señalados a modo de ensayo, y se pedirá opinión al entrevistado como guía para la mejora. Esta prueba permitió revisar el cuestionario, las preguntas, las reacciones de los entrevistados, su duración etc. con ello se pudo reducir el número de preguntas y comprobar la escasa disponibilidad de las empresas a permitir entrevistar a muchos de sus empleados. Ante tal situación desde el Centro Español de Logística (CEL) y su asesora técnica se 
colaboró con la confección del cuestionario aportando tanto ideas como experiencia en el campo logístico. Finalmente se optó por elaborar un único cuestionario mostrado en el Anexo II, que surge tras varias tamizaciones de los elaborados en primer lugar.

\subsection{ESTRUCTURA DEL CUESTIONARIO UTILIZADO}

Una vez conocida la metodología de actuación presentada en el apartado anterior, en éste se explicará la estructura del cuestionario utilizado en las entrevistas in situ a las empresas. Inicialmente y como se explica en el Anexo II se propusieron cuestionarios para todos los puestos propuestos en el modelo, pero tras diversas depuraciones y entrevistas previas en las empresas, se optó finalmente por realizar un único cuestionario aplicable a cualquiera de los puestos entrevistados en las visitas. A través del citado cuestionario se obtendrán, las distintas aportaciones de cada uno de los trabajadores de la organización, bajo las mismas cuestiones lo que a su vez facilita la recogida de información.

El cuestionario final es el resultado de la depuración de los cuestionarios iniciales obtenidos para cada uno de los puestos propuestos en el capítulo séptimo, en los que se casaban preguntas relacionadas con los elementos logísticos y las cuestiones del ¿Qué?, ¿Cómo? ¿Dónde? ¿Cuándo?, ¿Quién? y ¿Porqué? como se muestra en el Anexo II.

El cuestionario final supone un esfuerzo de aunar todo ello en un único cuestionario adaptado a la realidad empresarial donde a su vez se muestran tres niveles de puestos asociados a los presentados en el capítulo séptimo, pasando de los cinco niveles propuestos a tres grandes bloques debido a una mayor facilidad de identificar desde las empresas. Estos niveles corresponden a: Dirección, Gestión y Operarios o Administrativos.

Con la visita y la contestación de las cuestiones planteadas, así como las aclaraciones y explicaciones obtenidas en las entrevistas, se pretende confirmar la validez total o parcial del modelo expuesto en el capítulo séptimo. 
El cuestionario proporciona opciones de respuesta cerrada a lo largo del mismo, para conseguir con ello la mayor facilidad de respuesta de los entrevistados. A la vez se han realizado visitas in-situ a las empresas con el fin de poder discutir y profundizar en algunas de las respuestas facilitadas en cada caso.

La primera información que recoge el cuestionario además de la fecha, el nombre de la empresa y el cargo de la persona entrevistada, supone comprobar quienes están dedicados a la planificación y establecimiento de los objetivos empresariales, así como su cumplimiento. Para ello se establece un bloque de cuatro preguntas referentes a los objetivos logísticos de las empresas, haciendo referencia a quién se encarga de desarrollar dicho objetivo, quién controla el cumplimiento del mismo, cada cuanto tiempo se establecen dichos objetivo y porqué es importante desarrollar esos objetivos. A partir de este punto el cuestionario realiza un recorrido por los distintos elementos empresariales presentados en el capítulo segundo de este trabajo: los procesos, la información, la tecnología y el personal, dando por hecho que el producto corresponderá al servicio logístico proporcionado por la organización.

El análisis de los procesos se realiza cuestionando qué funciones de la Cadena de Suministro se llevan a cabo en la empresa y quién realiza estas tareas. Para ello, se proporcionan las opciones de: Gestión de pedidos, gestión de aprovisionamiento de materia prima, planificación de la producción, gestión de la distribución, servicio al cliente, gestión de inventario y compras, mientras que las opciones que se ofrecen para la realización de las tareas son los tres grados que aparecen en los organigramas: Director, Gestor/Manager y Operario/ administrativo.

En este punto también se solicita información sobre el número total de empleados del departamento y de la empresa.

Llegados a este punto, se cuestiona quién diseña la Cadena de Suministro, si es la propia empresa, si se deja en manos de una consultora, si se acude a seminarios, si la reciben impuesta desde la Casa Madre, lo hacen sobre la base del Benchmarking (mejores prácticas), y en el caso señalado, especificar quién diseña la Cadena de Suministro, quién define los procesos, quién detalla las tareas y quién define las ubicaciones. 
Otra cuestión interesante para conocer como se realiza la logística en las empresas visitadas, es saber si tanto los almacenes como la flota son propios o subcontratados, debido a que de dicha información se podrá conocer la existencia de ciertos puestos relacionados con esas áreas.

A continuación, se pasa a realizar unas cuestiones referidas al elemento Información, conociendo qué información manejan las empresas, quién decide que información dar a cada bloque con los que se relaciona la empresa, y de la información existente cual es fundamental dar a proveedores y clientes.

El bloque siguiente hace referencia a la Tecnología, para conocer cual es la infraestructura utilizada, quien la define y quien la decide, y quién se encarga de su revisión.

Finalmente, el último elemento que se analiza es el personal, en el cual se comienza cuestionando cuantos niveles jerárquicos existen en las empresas. A continuación se analiza el perfil de los Recursos Humanos Logísticos según los bloques de puestos propuestos, con lo que se analiza el nivel de estudios, el nivel de conocimientos específicos, el nivel de idiomas, las habilidades, la experiencia previa, el conocimiento informático.

Conocida esta información, se pasa a confirmar el funcionamiento o área del departamento logístico en cuanto al personal se refiere: la planificación, la asignación de tareas al personal, la definición de las tareas por puesto, el conocimiento de las mismas, quién, cómo, cuando, donde y qué tareas se realizan en las actividades de los puestos logísticos, e información referente a la formación.

\subsection{ANÁlisis DE RESUltados DEL MODELO DE RECURSOS HUMANOS APLICADO A LOS SISTEMAS Logísticos}

A partir de la creación de este Modelo de Recursos Humanos para los sistemas logísticos, se realizará una verificación de la consistencia del mismo y de la existencia 
de dichos puestos y tareas en distintas empresas que posean departamentos o áreas logísticas. Dicha comprobación se realizará mediante entrevistas y cuestionarios a aquellos que participen en el proceso logístico. Mediante dichos cuestionarios y visitas se confirmará si existe una estructura de puestos como la definida en el modelo presentado en este trabajo, así como las funciones que lleva a cabo cada puesto. A este proceso se le llamará Verificación del Modelo de Recursos Humanos logístico.

Para poder realizar esa verificación, se realizaron visitas a distintas empresas en las que existan departamentos logísticos, así como operadores logísticos con el fin de obtener información al respecto y poder identificar dentro del caos estructural, cuales son las estructuras existentes en las empresas, así como las principales actividades realizadas para cada uno.

El análisis se ha centrado en la visita a nueve empresas en las cuales llevan a cabo actividades de logística. Estas empresas pertenecen a todos los tipos de sistemas logísticos, ya que cuatro de ellas son distribuidoras comerciales, tres de ellas son empresas productoras con departamentos logísticos y dos de ellas son operadores logísticos. Las empresas visitadas están situadas en la Región de Murcia (1), Comunidad Autónoma de Madrid (6) y Aragón (2). Estos resultados obtenidos se pueden observar en el Anexo III de este trabajo, donde quedan recogidas las respuestas obtenidas de cada empresa al cuestionario, siendo estas empresas las siguientes: Sistemas Logísticos Integrados, Grupo Logístico Santos, Procter \& Gamble, Amena, Editorial Bruño, Silvestre Autobat, Sabeco, Transportes Carreras, Dia Alimentación. Dedicadas a todos los sectores de la economía, desde recambios de automóviles, telefonía móvil, alimentación, servicios, productos de higiene y limpieza, libros, etc.

A su vez, con ese trabajo de campo, se permitirá conocer cual es el perfil de empresas a las que se les puede aplicar el modelo propuesto en este capítulo.

\section{Contraste de Resultados}

\section{Objetivos logísticos}

Al plantear en las distintas empresas estudiadas la cuestión de los objetivos logísticos y sobre quién recae la responsabilidad de los mismos en las empresas que desarrollan 
logística, se obtuvo un resultado unánime. Dicho objetivo recae sobre la responsabilidad del Director del área en cuestión, ya sea departamento logístico o empresa, siendo a su vez responsabilidad suya el control del cumplimiento de esos objetivos estratégicos de la empresa o departamento. Mientras que los objetivos tácticos son supervisados habitualmente por el Gestor o Manager. Como se muestra en la Ilustración 8. 2. En dicha figura se muestra como el Responsable del objetivo logístico es siempre el director y el gestor lo será en un 10\% de los casos, que puede producirse por actuar de forma colegiada con la dirección. Esta tendencia cambia al observar quién es encargado de realizar el control de ese objetivo, ya que aunque sigue apareciendo el director como responsable principal en un 89\% de los casos, ya aparece la figura del gestor o manager con cierta importancia en un $55 \%$ de los casos.

Dichos objetivos logísticos se desarrollan en todos los casos entrevistados de forma anual cada 12 meses y con revisiones también de tipo anual.

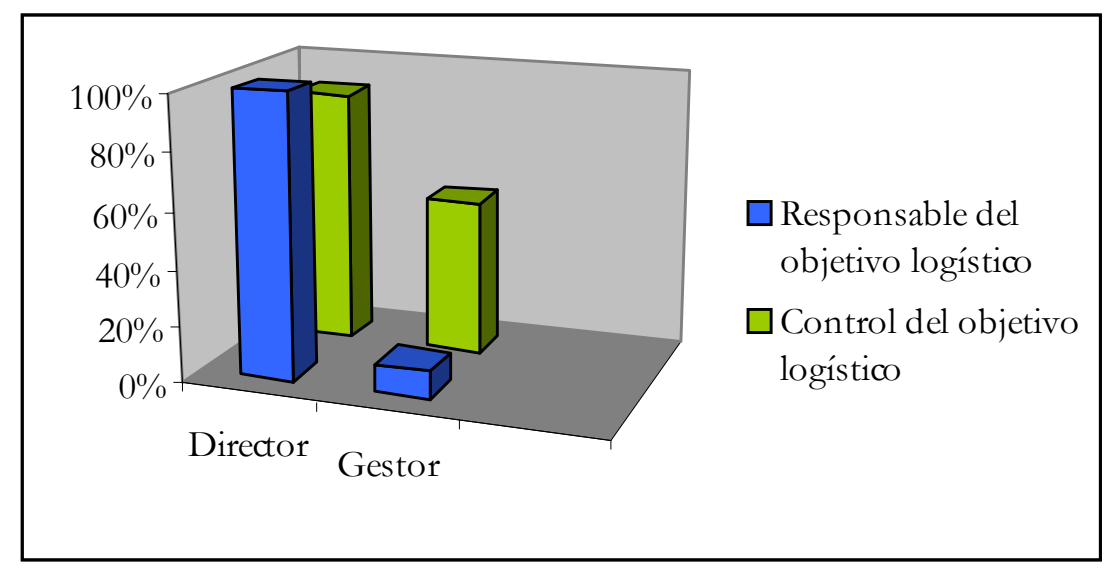

Ilustración 8. 2: Responsables de decisión y control del objetivo logístico

Estos objetivos logísticos se desarrollan por los motivos que a continuación se señalan y ordenados según la importancia señalada para las empresas de mayor a menor:

1. Ayudar a cumplir los objetivos estratégicos de la empresa, todas las empresas

2. Ser más competitivos que la competencia

3. Entender la logística como modelo de lograr el crecimiento de la empresa El primer objetivo fue señalado por todas las empresas como la línea de actuación de todos los sistemas logísticos principalmente. Siendo el segundo de ellos el que le sigue 
en importancia para un 90\% de las empresas. Y sólo un 65\% de las empresas señalaron como objetivo el tercero de los propuestos, ya que para algunas grandes empresas productoras internacionales ya han superado esta fase, mientras que para otras más pequeñas si que es un objetivo de carácter principal, incluso más que el segundo de los propuestos. Esto se muestra en la Ilustración 8.3

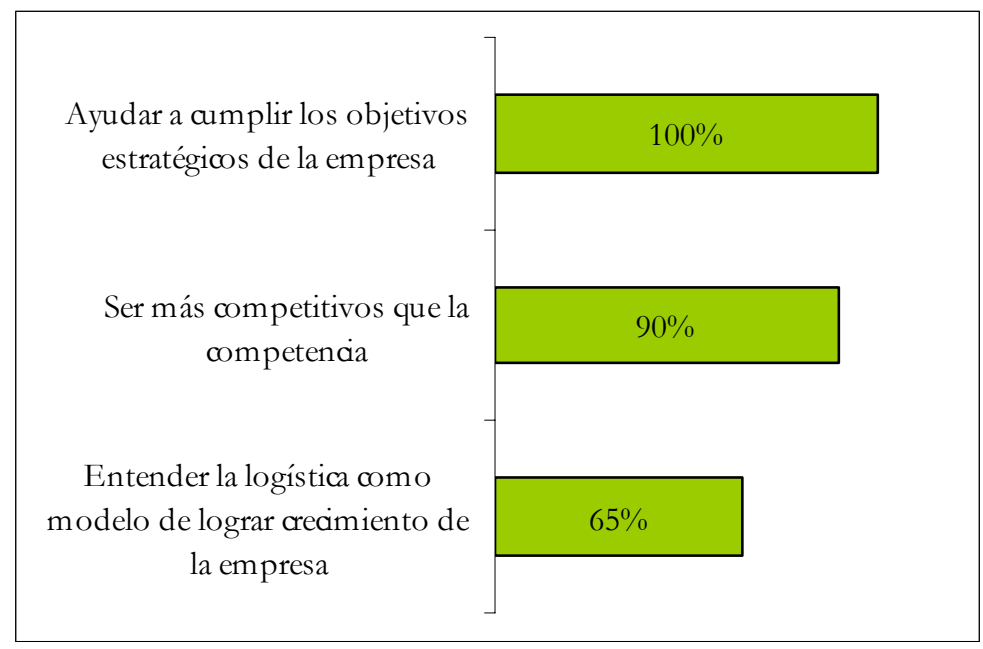

Ilustración 8. 3: Motivos de desarrollo de los objetivos logísticos

\section{Cadena de Suministro}

$\mathrm{Al}$ estudiar la Cadena de Suministro en las empresas entrevistadas, lo primero que se cuestiona son las actividades que componen dicha cadena para cada una de las empresas, ya que no todas las Cadenas de Suministro están compuestas por las mismas actividades para todas las empresas.

Las actividades propuestas en el cuestionario que forman parte de la Cadena de Suministro, y entre las que las empresas han ido seleccionando cuales forman parte de la suya propia son: gestión de pedidos, gestión de aprovisionamiento de materias primas/ productos empaquetados a producción, planificación de la producción, gestión de la distribución (reparto), Servicio al cliente (donde se subdivide en comercial y atención al cliente), y por último la actividad de compras.

Analizando según tipo de sistemas logísticos, se obtiene que los Operadores logísticos realizan principalmente actividades de gestión de pedidos, gestión de aprovisionamiento de materias primas y productos empaquetados a producción, planificación de producción, gestión de la distribución, servicio de atención al cliente y gestión de 
inventario y almacén, quedando pendiente de realizar la actividad de compras, si es subcontratada por el cliente.

En las empresas de Distribución Comercial, se encuentra que no todas ellas realizan gestión de pedidos ni compras en las áreas logísticas ya que pueden constituir parte de otro departamento o área de la empresa denominada habitualmente como Departamento Compras. Al no ser empresas productoras, apenas participan en el aprovisionamiento de materias primas, ni la planificación de producción, sino que centran en actividades de distribución, de servicio al cliente, de gestión de inventario y almacén, como se observa en la última y penúltima columna de la Ilustración 8. 4.

Las Empresas Productoras realizan actividades de gestión de pedidos, planificación de producción, gestión de distribución, servicio al cliente y gestión de inventario principalmente, quedando en menor medida para los departamentos de logística de este tipo de empresas los asuntos de compras y gestión de aprovisionamiento debido a que en las empresas entrevistadas ocurre en gran parte de los casos que existen áreas o departamentos de compras encargados de realizar estas tareas.

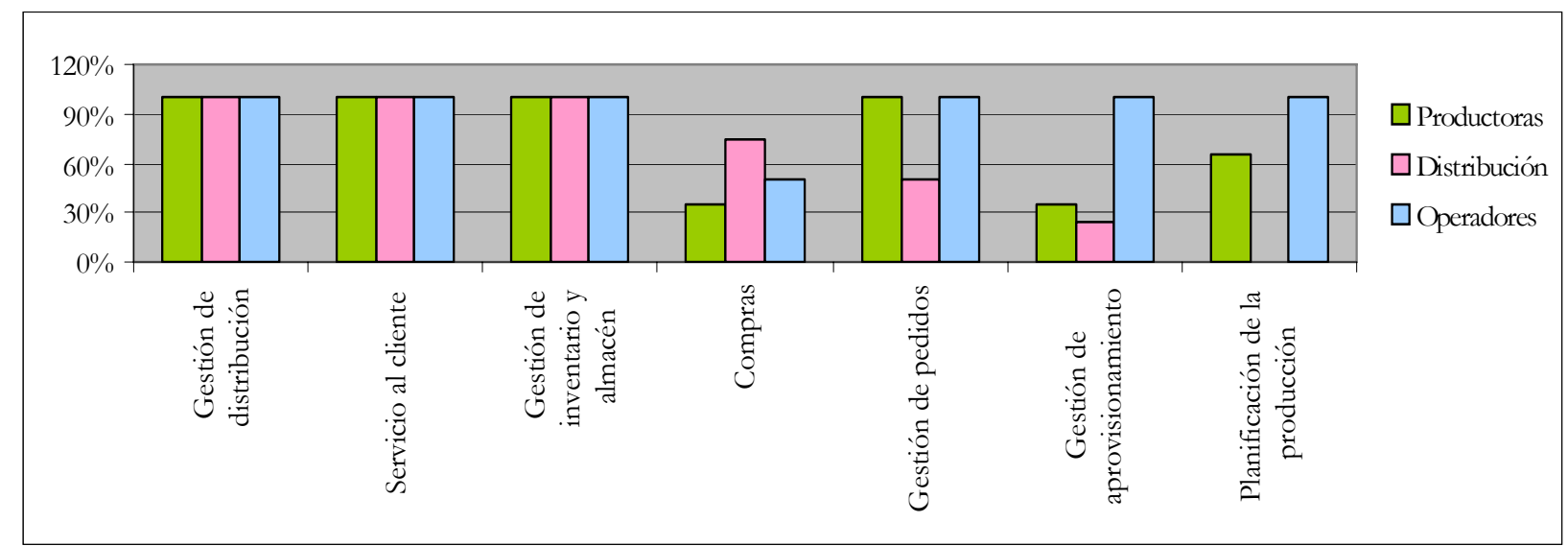

Ilustración 8. 4: Funciones de la Cadena de Suministro según tipo de sistemas logísticos

La Cadena de Suministro se diseña en las propias empresas en un $100 \%$ de los casos analizados, aunque puede ocurrir que dicho diseño venga esbozado desde la Casa Madre en casos de grandes empresas internacionales, o bien por parte de los clientes para el caso de ciertos Operadores logísticos. 
Los procesos se definen siempre desde la propia empresa, siendo a su vez ésta la que detalla qué tareas han de realizarse en los departamentos o áreas logísticas. Al igual que es la propia empresa en todos los casos analizados, quién define las ubicaciones necesarias de cada una de las tareas a realizar. En la mayoría de casos donde se subcontratan operadores logísticos todos estos detalles se diseñan, definen y detallan junto con los clientes debido a las exigencias que éstos imponen, quedando únicamente en el caso de los operadores logísticos la definición de las ubicaciones como tareas de la propia empresa.

Esos procesos logísticos los llevan a cabo las empresas en almacenes tanto propios como subcontratados, y a su vez la flota de la que se valen puede ser propia o subcontratada. Respecto a las Empresas Productoras, cabe destacar que solo un tercio de las mismas poseen almacenes propios, siendo por tanto un $66 \%$ de ellas las que subcontrata los almacenes, mientras que la flota de transporte es en todos los casos estudiados subcontratada.

Para Operadores logísticos, suelen hacer uso indistintamente de almacenes propios como subcontratados, mientras que el uso de flota propia solo se encuentra en la mitad de los mismos, el uso de flota subcontratada es una característica que se encuentra en todos los operadores logísticos estudiados.

Finalmente, las empresas de Distribución Comercial, se caracterizan por tener todas ellas almacenes propios, mientras que la mitad de ellas posee además almacenes subcontratados. La flota para la realización de la distribución es en todas estas empresas subcontratadas, pudiéndose encontrar que además sólo en un 25\% de ellas existe flota propia.

Los datos numéricos de lo explicado se pueden observar en la Tabla 8. 1, donde se aprecian las diferencias entre los distintos tipos de sistemas logísticos.

\begin{tabular}{lcccc}
\hline & A. Propios & A. subcontratado & Flota Propia & Flota subcontratada \\
\hline Productoras & $33 \%$ & $66 \%$ & $0 \%$ & $100 \%$ \\
\hline Operadores & $50 \%$ & $50 \%$ & $50 \%$ & $100 \%$ \\
\hline $\begin{array}{l}\text { Distribución } \\
\text { comercial }\end{array}$ & $100 \%$ & $50 \%$ & $25 \%$ & $100 \%$ \\
\hline
\end{tabular}

Tabla 8. 1: Tabla de almacenes y flota para la distribución logística. 


\section{Información}

El elemento información presentado en el capítulo segundo, se justifica a través de la cuestión referente al tipo de información logística necesaria para llevar a cabo el proceso logístico. Las respuestas obtenidas son similares según los distintos grupos de sistemas logísticos presentados, debido a que la información referente a los niveles de inventario es fundamental en todos los sistemas logísticos, al igual que los datos de producción y los datos de demanda, aunque puede ocurrir que exista alguna empresa dentro del grupo de la distribución comercial que no dependa de la demanda en sí, debido a que son meros distribuidores de mercancías y no tienen en cuenta este tipo de información, siendo este grupo bastante reducido.

La información referente a los costes es a su vez muy importante sobre todo para la toma de decisiones logísticas, opción señalada por todas las empresas. Al igual que aquella información referente a la capacidad de producción, almacén y transporte, que supone unos datos de gran importancia para la toma de decisiones logísticas.

La información que hace referencia a los clientes es muy importante en el caso de las empresas productoras, y las distribuidoras comerciales, aunque para éstas últimas muchas veces son ellas mismas o las tiendas de su cadena sus propios clientes. Es en el caso de los operadores logísticos cuando esa información no se vuelve tan relevante. Mientras que la información de datos de los proveedores se vuelve importante para un $70 \%$ de las empresas productoras, un 50\% de los operadores comerciales, y un $75 \%$ de las distribuidoras comerciales.

La información referente a las distintas rutas que han de realizarse, es muy importante para los distribuidores comerciales, ya que estos son encargados de realizar dicha distribución, y menos para los operadores logísticos y empresas productoras. Y los datos de embalaje suponen una información considerable señalada por hasta un $70 \%$ de las empresas.

Finalmente, se puede destacar como las empresas productoras son las únicas que señalan como información importante los datos referidos a otras empresas.

Toda esta información se puede observar en la Tabla 8. 2 


\begin{tabular}{cccc}
\hline & Productoras & Operadores & Distr. Comercial \\
\hline Niveles de Inventario & $100 \%$ & $100 \%$ & $100 \%$ \\
\hline Datos de Demanda & $100 \%$ & $100 \%$ & $75 \%$ \\
\hline Datos de Producción & $100 \%$ & $100 \%$ & $100 \%$ \\
\hline Datos de Costes & $100 \%$ & $100 \%$ & $100 \%$ \\
\hline Bases de Datos de clientes & $100 \%$ & $50 \%$ & $100 \%$ \\
\hline Bases de Datos de proveedores & $70 \%$ & $50 \%$ & $75 \%$ \\
\hline $\begin{array}{c}\text { Capacidades de producción, almacén y } \\
\text { transporte }\end{array}$ & $100 \%$ & $100 \%$ & $100 \%$ \\
\hline Rutas & $70 \%$ & $50 \%$ & $100 \%$ \\
\hline Datos de otras empresas (e ideas) & $100 \%$ & - & - \\
\hline Datos de embalaje & $70 \%$ & $50 \%$ & $75 \%$ \\
\hline
\end{tabular}

Tabla 8. 2: Tabla con el tipo de Información logística necesaria para llevar a cabo el proceso logístico.

Una vez conocida en la Tabla 8. 2 qué tipo de información es necesaria según el sistema logístico para tomar decisiones, hay que aclarar quién es encargado de proporcionar esa información a los distintos agentes de la Cadena de Suministro, debido a que no todos poseen ni el mismo tipo de información, ni con la misma responsabilidad. Por ello en la Tabla 8. 3, se muestra como los puestos directivos son habitualmente quienes proporcionan información, principalmente hacia el personal de la empresa y hacia los clientes. Repartiéndose la tarea de proporcionar dicha información a los proveedores junto con los gestores y managers en.

Información proporcionada a\ desde Director Gestor/Mng Administrativo

\begin{tabular}{lccc}
\hline Personal de la empresa & $89 \%$ & $44 \%$ & $10 \%$ \\
\hline Proveedores & $55 \%$ & $44 \%$ & $0 \%$ \\
\hline Clientes & $89 \%$ & $55 \%$ & $33 \%$ \\
\hline
\end{tabular}

Tabla 8. 3: Tabla sobre la decisión de que tipo de información proporcionar a los agentes logísticos. 


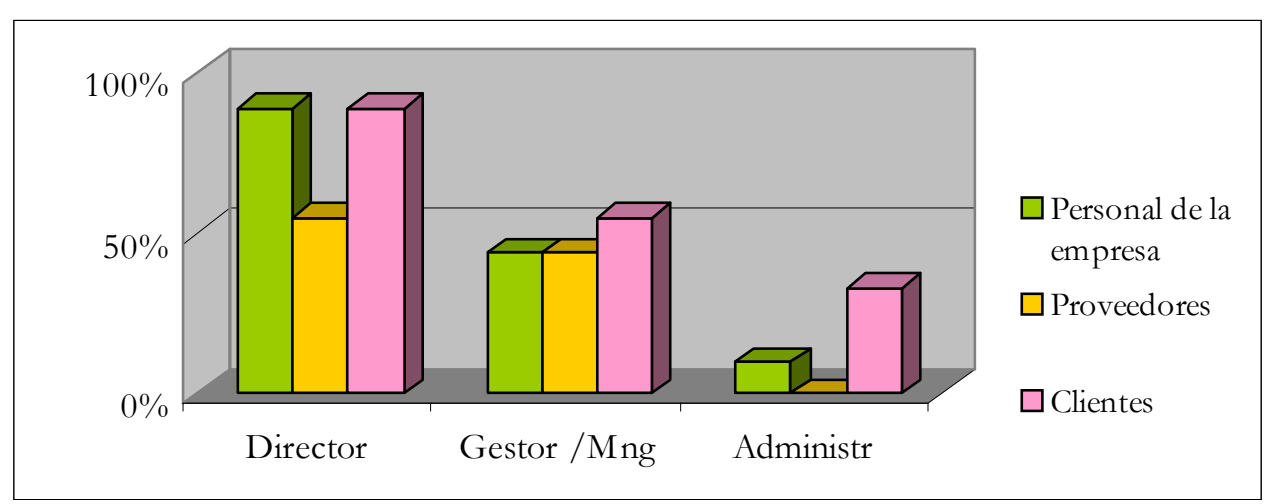

Ilustración 8. 5: Reparto de decisión sobre quién informa a los distintos agentes logísticos.

Realizando esta comparación por tipos de sistemas logísticos, son los directores de los operadores logísticos los que siempre dan información al personal de la empresa y a los clientes, así como algunos de los gestores y managers colaboran en dar información a dichos grupos y a su vez se encargan de dar información a proveedores, quedando los administrativos como informadores de cara a los clientes.

En el caso de Empresas Productoras, los directivos deciden que información proporcionar al personal de la empresa, a los proveedores y clientes en una gran mayoría de los casos, apoyándose de los gestores y managers para proporcionar esa información a clientes y personal de la empresa, y en algunos casos son los administrativos con cierta responsabilidad lo que pueden llegar a dar esa información a dichos grupos.

El tipo de información que se proporciona a los clientes es siempre la fecha de entrega del pedido, así como el lugar de entrega. Entre las empresas entrevistadas, el precio no fue un factor fundamental de conocimiento para los clientes, ya que estos precios vienen muy a menudo fijados previamente desde otros departamentos, al igual que las posibles tasas que surjan de la gestión del pedido. Respecto a las disponibilidades de referencias, un 75\% aproximadamente de las empresas señaló que consistía en una información proporcionada a los clientes, siendo más habitual proporcionar información referente a las características de carga y descarga, no comunicándose en un 10\% de los casos, en los que esta operación se encuentra subcontratada a un operador logístico y sea él quién lo gestione, como se muestra en la Ilustración 8. 6. 


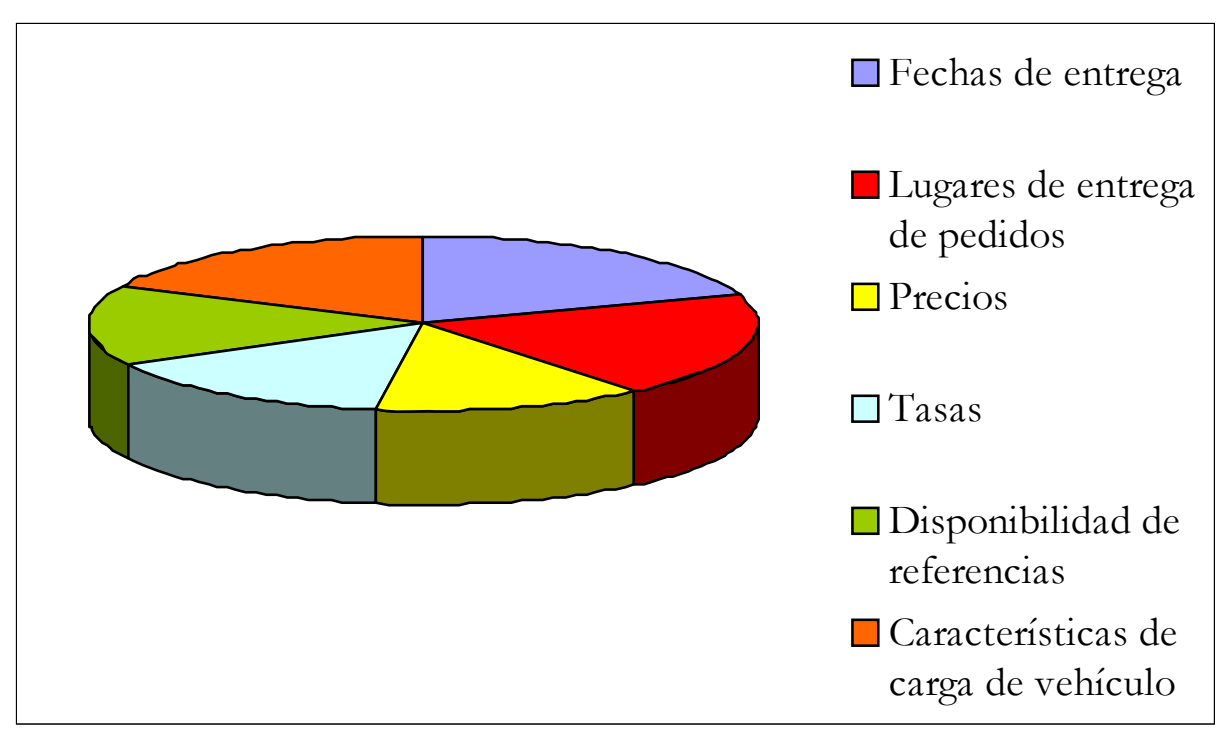

Ilustración 8. 6 : Tipo de información necesaria para dar a los clientes

Si por el contrario se analiza la información proporcionada por las empresas a los proveedores, la información fundamental a dar a conocer son las fechas de recepción y lugares. En el caso de empresas en las que haya subcontratado un operador en logística, será dicho operador el encargado de dar al proveedor las fechas de recepción y lugares.

Los precios y tasas no son información relevante a dar a los proveedores, al igual que la disponibilidad de referencias, mientras que si que se suelen proporcionar las características de carga y descarga de los vehículos en poco más del $75 \%$ de las empresas, como se muestra en la Ilustración 8. 7.

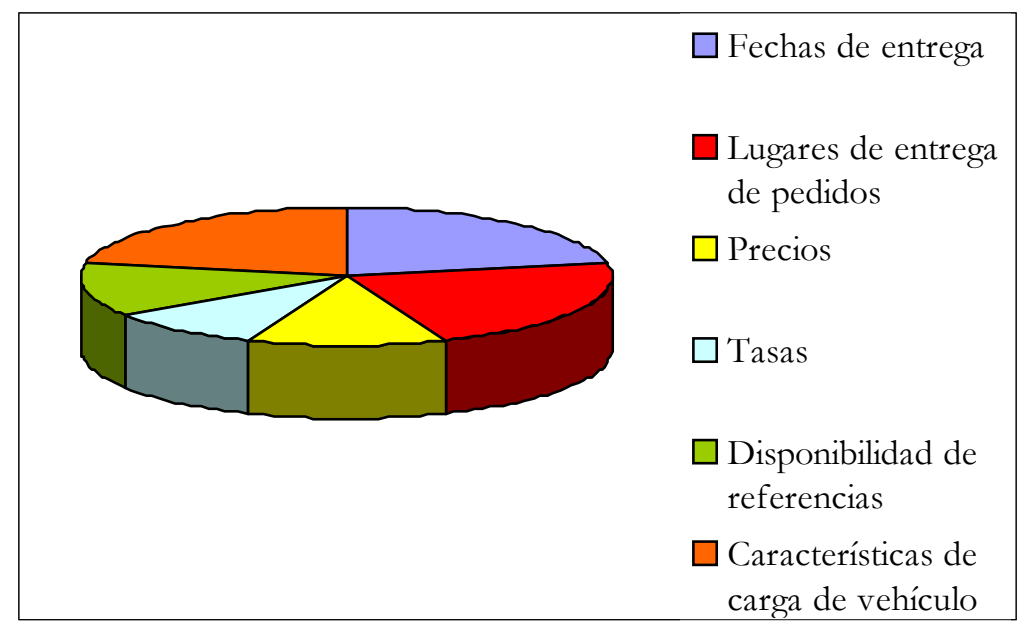

Ilustración 8. 7: Tipo de información necesaria a dar a los proveedores 


\section{Tecnología}

Una vez analizado el elemento información y los procesos que se realizan a lo largo de la Cadena de Suministro, la tecnología es el próximo elemento a analizar. Para definir quién se encarga de la definición de la tecnología o infraestructuras, utilizadas o a utilizar en el proceso logístico, en los resultados se obtiene que un 66\% de las ocasiones es el director, apoyado en un 44\% de los Gestores y Managers en algunas de las empresas desde las consultoras, y si la decisión se toma de forma colegiada en la empresas, pueden llegar a existir administrativos en esa estructura colegiada, siendo esta situación reflejada en muy pocos casos. La representación gráfica se puede contemplar en la Ilustración 8. 8.

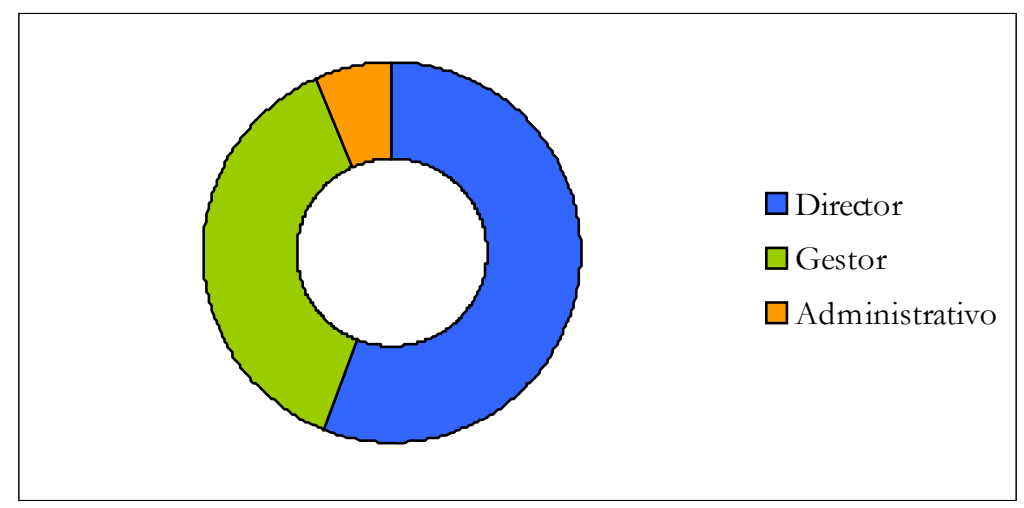

Ilustración 8. 8: Porcentajes de definición de la infraestructura

El porcentaje de Directores encargados de la definición tecnológica, se produce en un $50 \%$ de los Operadores logísticos estudiados, en un 75\% de los distribuidores comerciales y un 33\% de las empresas productoras respectivamente. Siendo para los managers la distribución por tipos de empresa, un 50\% de operadores logísticos y de empresas de distribución, y un 30\% de las productoras.

La decisión tecnológica se toma siempre desde la dirección, sea el tipo de sistema logístico que se analice, apoyada en un $20 \%$ de gestores que refuerzan las propuestas realizadas, siendo estos casos en empresas de distribución y productoras y nunca en operadores logísticos, como se puede observar en la Ilustración 8. 9 


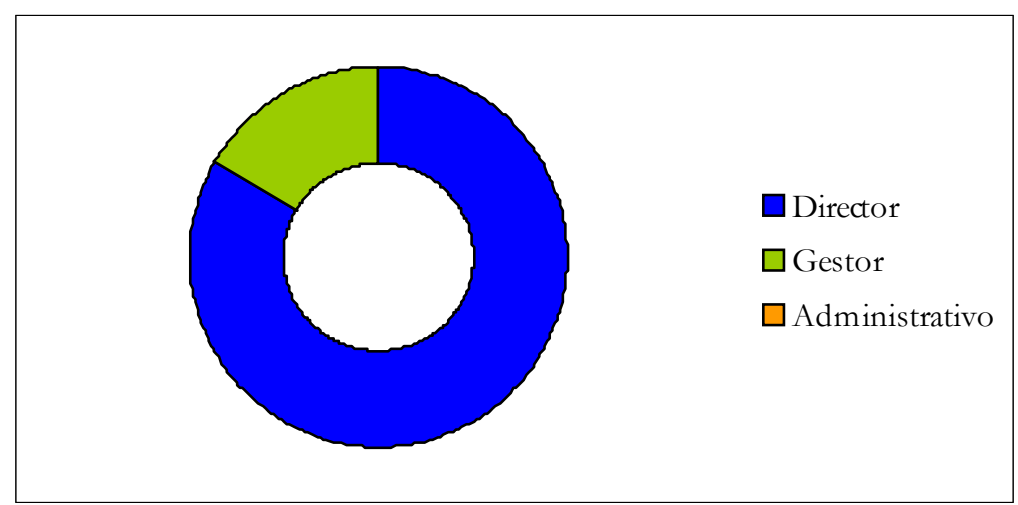

Ilustración 8. 9: Porcentajes de Decisión de la infraestructura

Analizando las necesidades y tipo de tecnología que se utiliza para poder desarrollar el proceso logístico, se obtiene que el ordenador, el teléfono, fax y las redes de comunicaciones, son infraestructuras utilizadas en todas las empresas estudiadas a todos los niveles administrativos. Sin embargo la utilización de escáners y códigos de barras se produce solo para operarios de almacén en un $65 \%$ de las empresas estudiadas, utilizándose en todos los operadores logísticos y la mayoría de grandes distribuidores comerciales, siendo menos frecuente el uso de los mismos en empresas productoras.

El uso de etiquetadoras, ensacadoras o embaladoras, vehículos remolques, apiladoras y carretillas es función de jefes y operarios de almacén. Estas infraestructuras se encuentran por tanto en los almacenes, y son los puestos que se desarrollan en dicho ámbito las que manejan toda esa maquinaria.

El uso de etiquetadoras se produce en un 65\% de las empresas, sobre todo en Distribuidoras Comerciales y Operadores Logísticos, siendo menos común en empresas productoras.

Las ensacadoras o embaladoras son máquinas que se encuentran en poco más de la mitad de las empresas estudiadas, por lo que del $55 \%$ de las mismas se produce en operadores logísticos y empresas productoras, mientras que no todas las distribuidoras comerciales contestaron afirmativamente poseerlas.

Los vehículos, remolques y carretillas son infraestructuras que casi todas las empresas reconocieron poseer. 
Finalmente, solo un $45 \%$ de las empresas estudiadas posee transporte automático, siendo las empresas productoras y operadores logísticos quienes poseen esta tecnología, mientras que los distribuidores comerciales no se destacan por esta maquinaria.

El reparto numérico de los porcentajes obtenidos se muestran en la Tabla 8. 4, y la comparativa por puestos de forma gráfica se muestra en la Ilustración 8. 10, donde se muestran las infraestructuras y los distintos puestos que hacen uso de la misma.

\begin{tabular}{|c|c|c|c|}
\hline & Director & Gestor & $\begin{array}{l}\text { Admvo } \\
\text { operario }\end{array}$ \\
\hline Ordenador & $100 \%$ & $100 \%$ & $100 \%$ \\
\hline Teléfono & $100 \%$ & $100 \%$ & $100 \%$ \\
\hline Escáner & $0 \%$ & $0 \%$ & $65 \%$ \\
\hline Intercomunicador & $45 \%$ & $45 \%$ & $77 \%$ \\
\hline Fax & $100 \%$ & $100 \%$ & $100 \%$ \\
\hline Redes de comunicación & $100 \%$ & $100 \%$ & $100 \%$ \\
\hline Etiquetadoras & $0 \%$ & $0 \%$ & $75 \%$ \\
\hline Ensacadoras & $0 \%$ & $0 \%$ & $55 \%$ \\
\hline Vehículos & $0 \%$ & $0 \%$ & $90 \%$ \\
\hline Remolques & $0 \%$ & $0 \%$ & $90 \%$ \\
\hline Apiladoras & $0 \%$ & $0 \%$ & $90 \%$ \\
\hline Carretillas & $0 \%$ & $0 \%$ & $90 \%$ \\
\hline Transporte automático & $0 \%$ & $0 \%$ & $50 \%$ \\
\hline
\end{tabular}

Tabla 8. 4 : Tipo de tecnología utilizada en el proceso logístico 


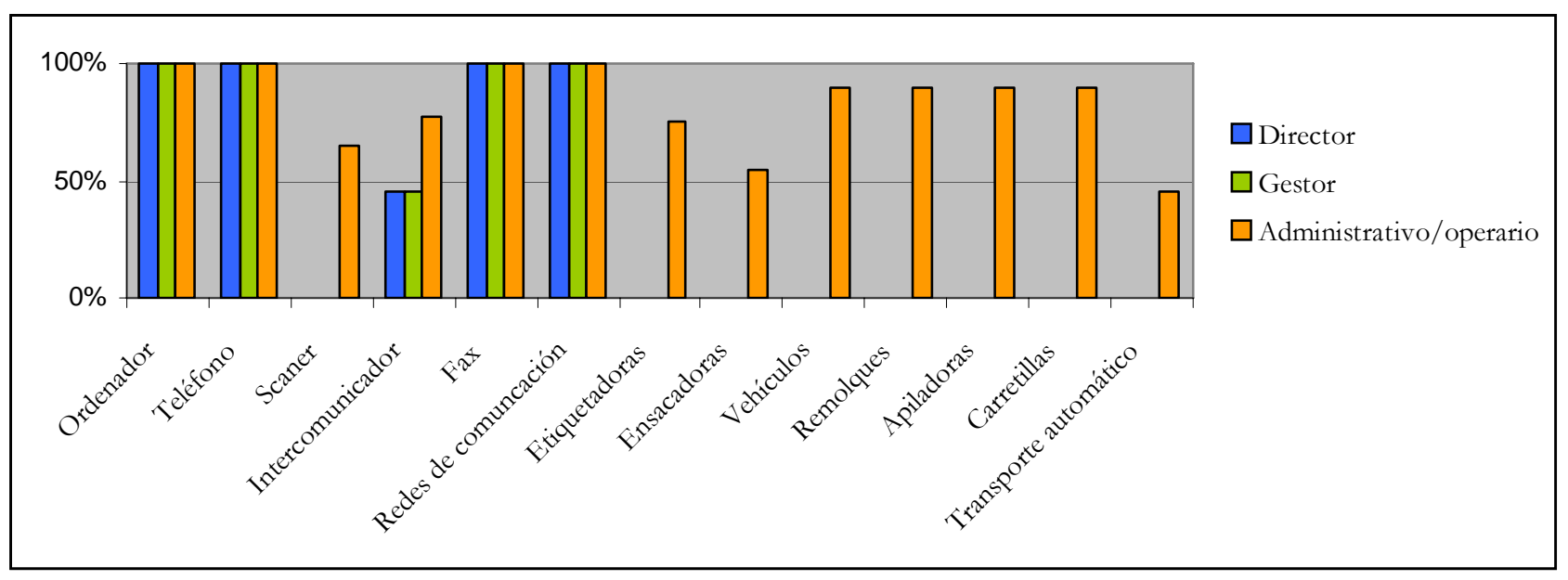

Ilustración 8.10 : Tecnología utilizada según tipos de puestos

Una vez definida la infraestructura que utiliza cada uno de los puestos analizados en el cuestionario, se plantea quién es encargado de realizar la revisión tecnológica. Dicha tarea es realizada por los Gestores o Managers en un 90\% de los casos, siendo en el resto de casos realizada desde dirección, como representa la Ilustración 8. 11. Esta tarea se realiza por los gestores en todo tipo de sistemas logísticos, tanto para Operadores Logísticos, Distribuidores Comerciales como Empresas Productoras.

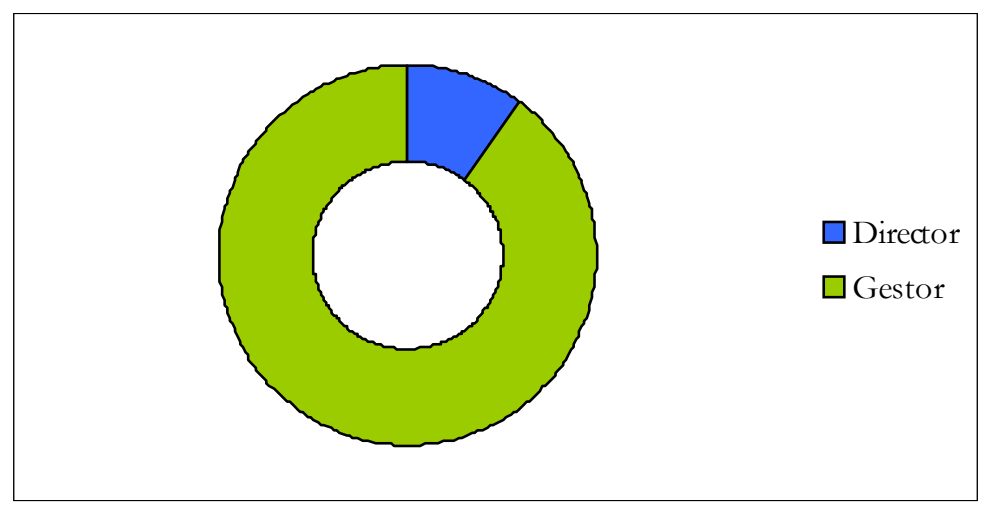

Ilustración 8. 11: Responsabilidad de revisión de tecnología

\section{Personal}

Finalmente y centrado en el elemento personal, la primera cuestión a analizar en las empresas estudiadas es el número de niveles jerárquicos existentes en los departamentos logísticos. 
El resultado obtenido fue que un 55\% de las empresas analizadas está constituido por tres niveles jerárquicos, mientras que solo un $45 \%$ de las empresas están constituidas por cuatro niveles jerárquicos, como muestra la Ilustración 8.12

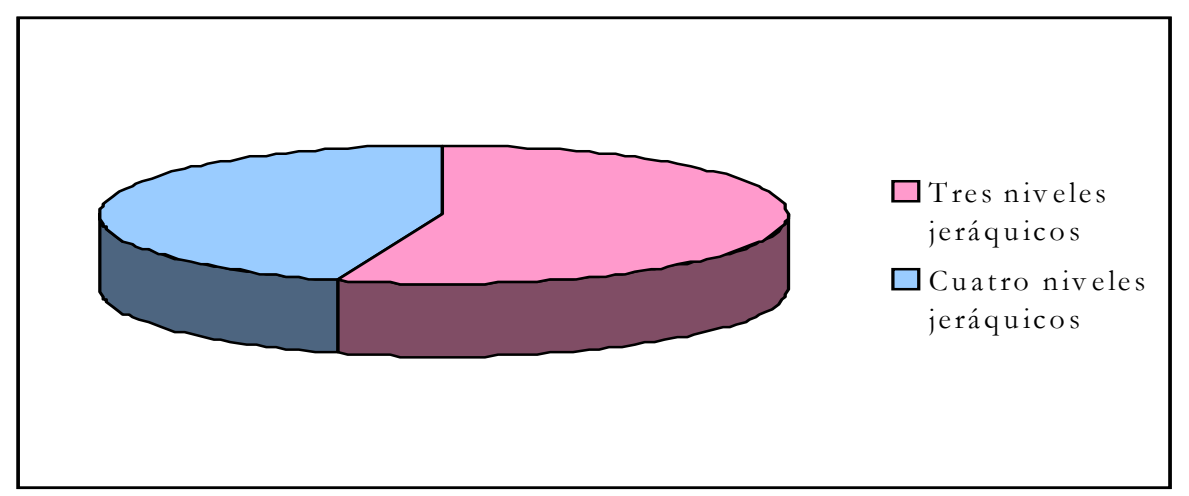

Ilustración 8. 12: Distribución según niveles jerárquicos de sistemas logísticos

De aquellas que constan de tres niveles se encuentran gran parte de las empresas productoras, mientras que solo la mitad de los operadores logísticos y distribuidores comerciales se situaron en tres niveles jerárquicos. De las situadas en cuatro niveles jerárquicos, se encontrarían por tanto la mitad de los operadores logísticos y de los distribuidores comerciales, lo que muestra la Ilustración 8. 13.

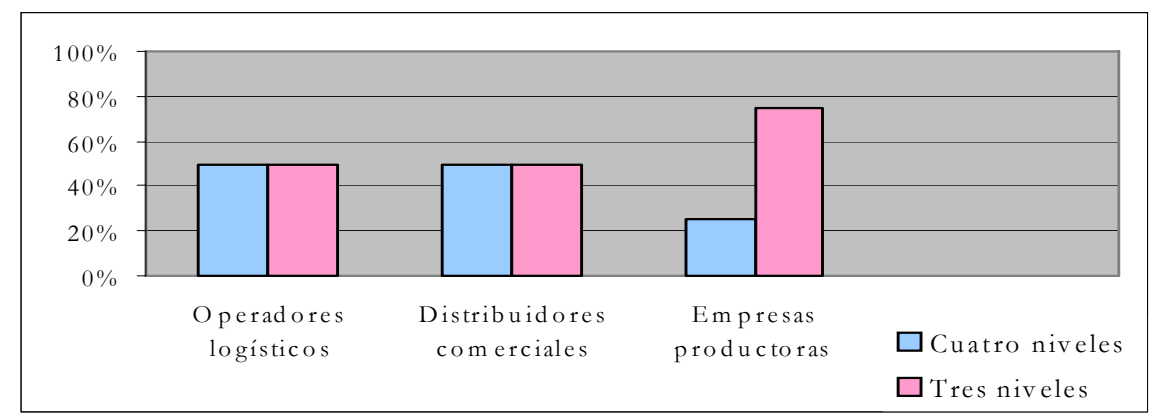

Ilustración 8. 13: Distribución de niveles jerárquicos según sistemas logísticos

Una vez conocida la distribución de los niveles jerárquicos existentes en las empresas, se analiza el perfil que han de tener esos puestos logísticos, atendiendo al nivel de estudios, conocimientos específicos, nivel de idiomas, habilidades, experiencia anterior y nivel de tecnología. 
Por tanto al analizar el nivel de estudios correspondiente a cada uno de los niveles presentados en el cuestionario, todas las empresas encuestadas señalaron que los puestos directivos debían de cumplir como requisito los estudios superiores, independientemente del tipo de sistema logísticos analizado. Para el puesto de gestor o manager, se requiere un perfil de estudios superiores o medios, dependiendo del tipo y categoría de empresa, siendo una media de un 55\% de las empresas las que señalaron como estudios superiores y un $65 \%$ señalaron como medios, por lo que distintas empresas señalaron ambos niveles indistintamente. Finalmente, el nivel de administrativo / operario tiende a ser ocupado por personas con nivel medio o básico. Generalmente el nivel de estudios medio tiende a ser medio para el personal de administración, pudiendo ser bajo, mientras que los operarios se sitúan habitualmente en el estrato más bajo de estudios, como muestra la Ilustración 8.14

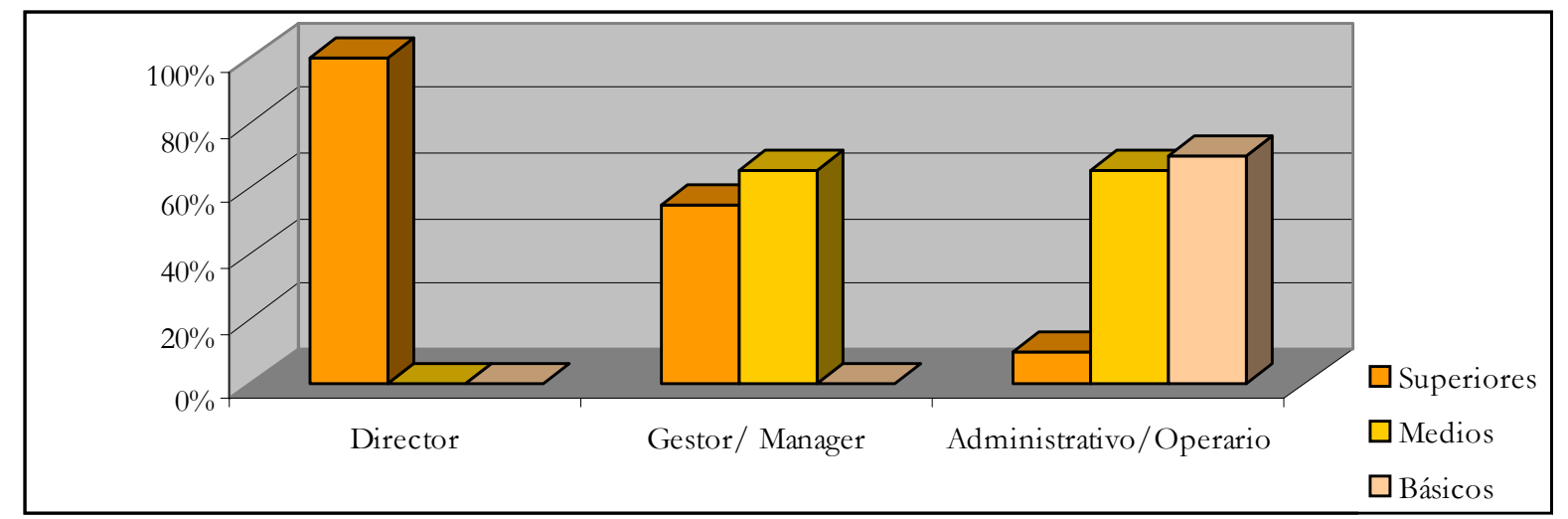

\section{Ilustración 8.14 : Nivel de estudios por puestos}

Una vez analizado el nivel de estudios por puestos de los sistemas logísticos, se plantea la necesidad de conocer el perfil requerido para cada uno de los puestos. Para ello, se ha preguntado a la empresa por aquellos conocimientos específicos dentro del área de la logística y de la dirección. Entre las opciones se señalan: logística, bases de datos, almacenes, transporte, recursos humanos, compras, ventas, planificación, supervisión, presupuestos, toma de decisiones y reuniones. 
El perfil que surge de este estudio hace especial énfasis en que el Director de una empresa o departamento logístico necesita conocimientos de logística, almacenes, planificación, supervisión, presupuestos, toma de decisión y reuniones principalmente, ya que todas las empresas optaron por esta opción. Un 65\% señaló como deseable conocimiento de transporte y Recursos Humanos, mientras que poco menos de la mitad señalaron deseables conocimientos en bases de datos, compras y ventas, ya que éstas son actividades que pueden ser desarrolladas por otros departamentos en las empresas.

Respecto al perfil de conocimientos deseados para el gestor se señalaron aquellos campos correspondientes a logística, almacenes, transportes, planificación y toma de decisión principalmente por casi todas las empresas, quedando como conocimientos secundarios los Recursos Humanos enfocados más bien al nivel de relación, la supervisión, y las reuniones, y siendo de menor importancia para este nivel de puesto los presupuestos, bases de datos y lo que menos se requiere habitualmente son conocimientos en compras y ventas por el motivo señalado en el perfil anterior ya que esta actividad puede venir desarrollada por otra área o departamento.

Finalmente para el perfil de los administrativos y operarios se requieren principalmente conocimientos específicos en almacenes y transportes, así como en casi la mitad de los casos entrevistados conocimientos de logística y bases de datos, sin que apenas sean destacables conocimientos en el resto de materias: como Recursos Humanos, compras, ventas, planificación, supervisión, presupuestos, toma de decisión y reuniones.

Los porcentajes obtenidos en el análisis de los resultados se muestran en la Tabla 8. 5 


\begin{tabular}{cccc}
\hline Logística & Director & Gestor & $\begin{array}{c}\text { Administrativo/ } \\
\text { Operario }\end{array}$ \\
\hline Base de datos & $45 \%$ & $100 \%$ & $45 \%$ \\
\hline Almacenes & $90 \%$ & $100 \%$ & $90 \%$ \\
\hline Transporte & $65 \%$ & $90 \%$ & $65 \%$ \\
\hline RRHH & $65 \%$ & $76 \%$ & $10 \%$ \\
\hline Compras & $45 \%$ & $33 \%$ & $20 \%$ \\
\hline Ventas & $45 \%$ & $33 \%$ & $20 \%$ \\
\hline Planificación & $100 \%$ & $90 \%$ & $20 \%$ \\
\hline Supervisión & $100 \%$ & $76 \%$ & $20 \%$ \\
\hline Presupuestos & $100 \%$ & $65 \%$ & $20 \%$ \\
\hline Toma de decisión & $100 \%$ & $90 \%$ & $33 \%$ \\
\hline Reuniones & $90 \%$ & $76 \%$ & $33 \%$ \\
\hline
\end{tabular}

Tabla 8. 5: Tabla de requisitos en conocimientos específicos del personal de los sistemas logísticos

Una vez presentada esta tabla de requisitos, en la Ilustración 8. 15 se muestran esos resultados gráficamente.

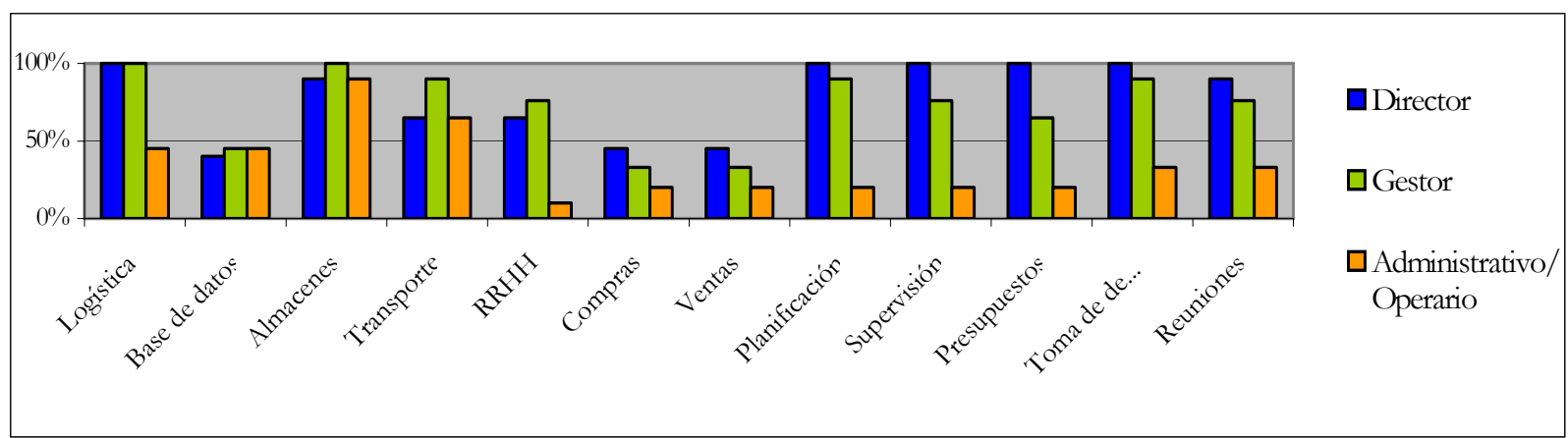

Ilustración 8. 15 : Conocimientos específicos del personal de los sistemas logísticos

Realizando el análisis según el tipo de sistema logístico de que se trate, se obtiene unos resultados muy uniformes en los puestos directivos, ya que casi todas las empresas encuestadas sea el tipo que sea, señalaron principalmente los mismos conocimientos fundamentales. 
En el caso de las empresas productoras con departamentos logísticos las que requieren conocimientos en logística, transporte planificación, supervisión, presupuestos, toma de decisiones y reuniones fundamentalmente para sus directores, apoyados de conocimientos en almacenes, Recursos Humanos, quedando los temas de bases de datos, compras y ventas en un segundo plano. Los gestores si que necesitan fundamente conocimientos en almacenes y Recursos Humanos en lo que a relaciones se refiere, así como planificación, toma de decisión y logística, quedando ya como conocimiento más profundo de los administrativos las bases de datos y logística como muestra en la Ilustración 8. 16.

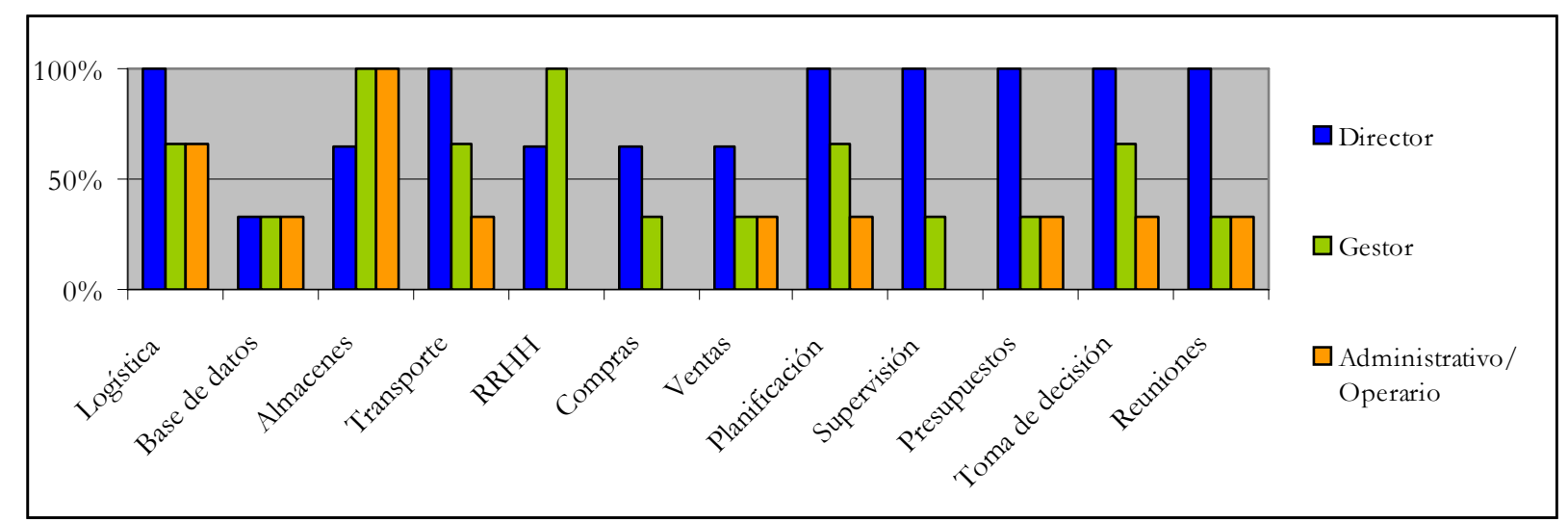

Ilustración 8. 16: Conocimientos específicos por puestos para el personal de las empresas productoras

Analizando el perfil requerido para el personal de las empresas de distribución comercial los directores han de poseer conocimientos en logística, almacenes, planificación, supervisión, presupuestos, toma de decisión y reuniones fundamentalmente, quedando como importantes a continuación el manejo de bases de datos y Recursos Humanos.

Los gestores necesitarán conocimientos de logística, almacenes, transportes, relación de personal, planificación, tomas de decisión, presupuestos, y reuniones. Y en menor medida las ventas y compras de las que se suelen encargar otras áreas de la empresa.

Finalmente, los administrativos y operarios han de cumplir el perfil de conocimientos en bases de datos, almacenes, transportes, y en algunos casos toma de decisión y reuniones, siendo estos casos en administrativos encargados de la realización de pedidos y en los que sea su responsabilidad. 


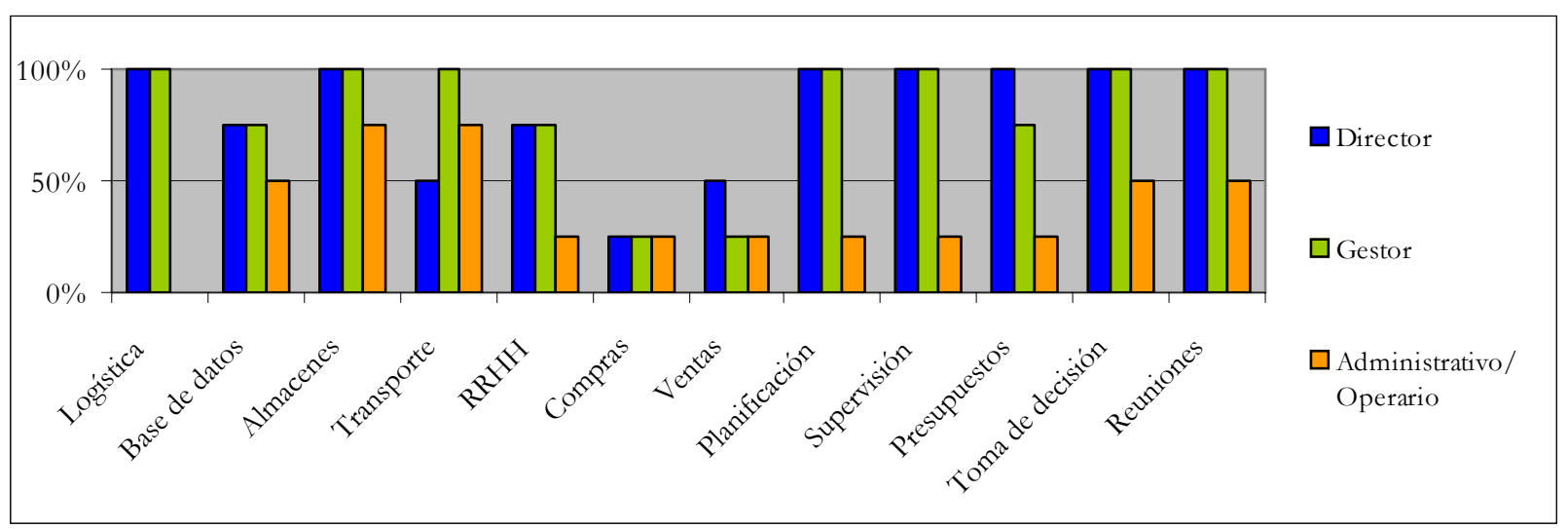

Ilustración 8. 17: Conocimientos específicos por puestos para el personal de las empresas de distribución comercial.

Para terminar este análisis de conocimientos específicos por puestos para el personal de los sistemas logísticos queda analizar los operadores logísticos. En este tipo de empresas, el perfil de los directores requiere como importante conocimientos de logística, planificación, supervisión, presupuestos, toma de decisiones y reuniones fundamentalmente, quedando en un segundo plano los conocimientos en Recursos Humanos, almacenes, transporte y por último compras.

Los gestores o managers apuntan a un perfil de conocimientos en logística, almacenes, transporte, planificación, supervisión, presupuestos, toma de decisiones, y reuniones. Y finalmente los administrativos necesitan conocimientos en logística, almacenes, transporte y en menor grado bases de datos y compras.

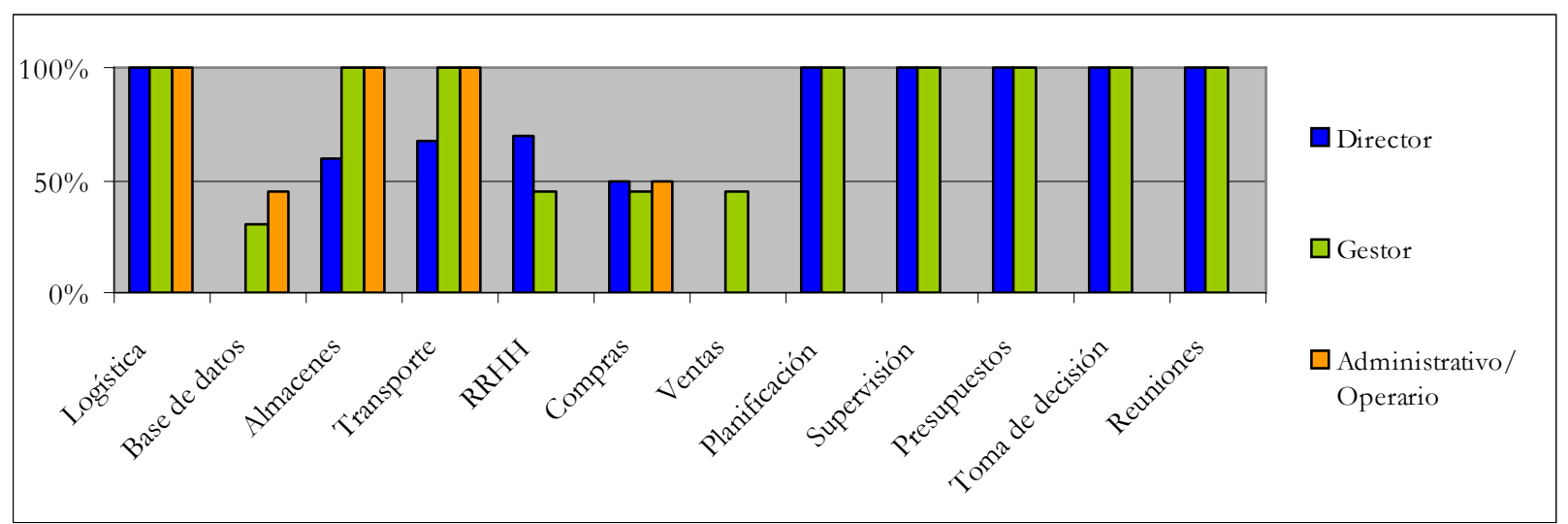

Ilustración 8. 18: Conocimientos específicos por puestos para el personal de los operadores logísticos 
El nivel de idiomas requerido según cada uno de los puestos se muestra en la Ilustración 8. 19, donde se observa como son los puestos directivos quienes necesitan mayor nivel de idiomas para su desarrollo, opción señalada por más del 50\%, mientras que aproximadamente el $45 \%$ se reparte aproximadamente por igual en el nivel medio o ninguno. Para el puesto de gestor, el nivel de idiomas está repartido llegando a ser una división muy aproximada de los tres niveles posibles, de forma que dependerá del tipo de empresa del que se trate, ya que puede ocurrir que sea una empresa internacional en la que si sea necesario un nivel de experto, o bien una empresa local donde no es necesario el uso de un idioma extranjero. Por último, el perfil del administrativo si que requiere un nivel de experto en aquellas empresas con departamentos de exportación donde se requieren niveles de experto, mientras que en otras empresas los niveles que se requieren son medios o ninguno, siendo este caso el de los operarios.

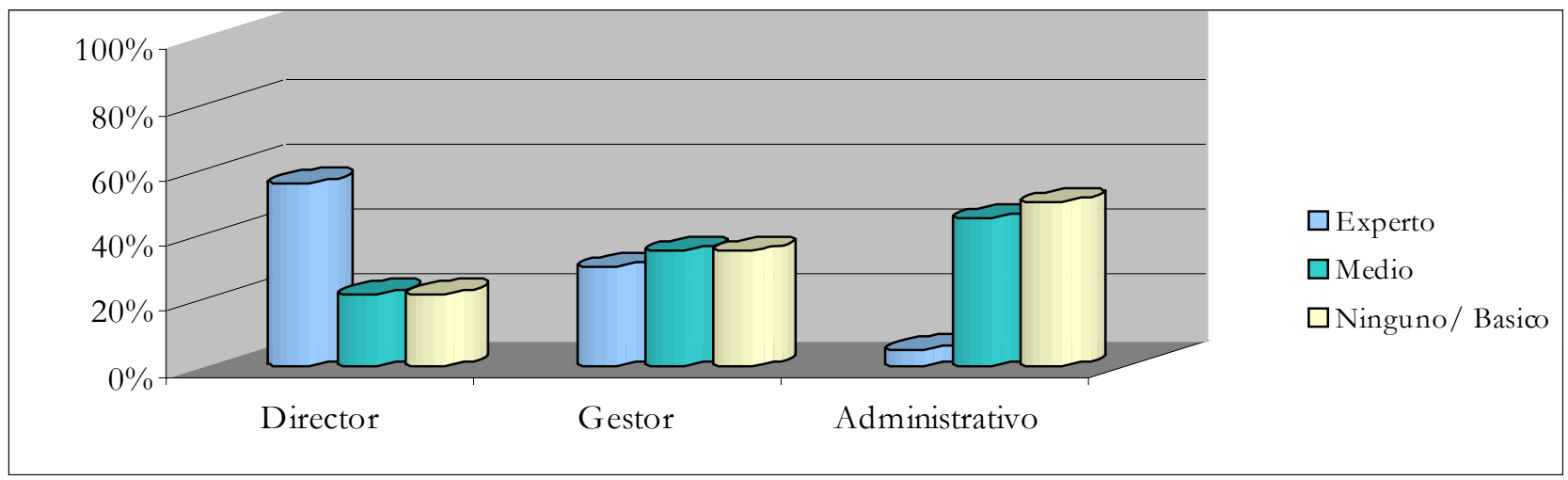

Ilustración 8. 19: Nivel de idiomas requeridos por puesto

Al cuestionar las habilidades requeridas para cada uno de los puestos propuestos, las empresas destacaron como una fundamental el trabajo en equipo, habilidad destacada por todas las empresas y prácticamente para todos los perfiles. El resto de habilidades: como la toma de decisión, liderazgo fidelidad, honestidad y responsabilidad son habilidades destacadas por una parte de las empresas. Destacando principalmente como se requiere la habilidad de liderazgo para los puestos de dirección y los gestores o managers, mientras que en ningún caso se requiere para los administrativos u operarios, como muestra la Ilustración 8. 20. 


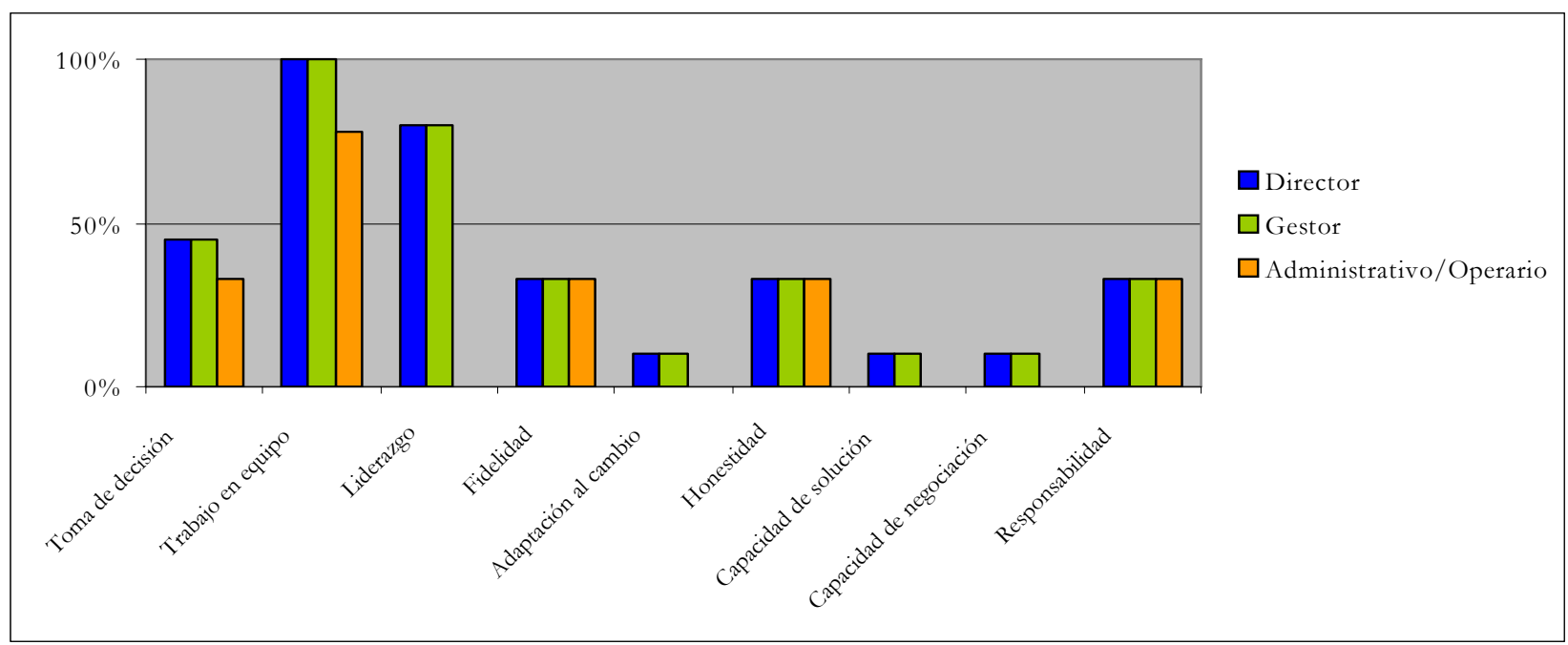

\section{Ilustración 8. 20 : Principales hablidades requeridas por puesto en los sistemas logísticos}

El último punto a estudiar respecto al perfil necesario para los puestos logísticos hace referencia al manejo de la tecnología informática. Cuestionando que tipo de tecnología se maneja, se obtiene que el uso de ordenadores como se comprobó anteriormente se realiza por todos los puestos y en todos los sistemas logísticos. El uso de bases de datos lo realizan en mayor medida los puestos de gestión y administrativos que en puestos de dirección.

El control informático de almacén corre a cargo principalmente de los operarios, y los gestores o managers, mientras que son únicamente los directivos de las empresas productoras las que en la mitad de los casos entrevistados declararon realizar esta operación.

Por último es destacable como la parte de telecomunicación está repartida en gestores y administrativos y la parte de manejo de códigos de barras la realizan únicamente los administrativos y operarios independientemente del tipo de sistema logístico analizado. 


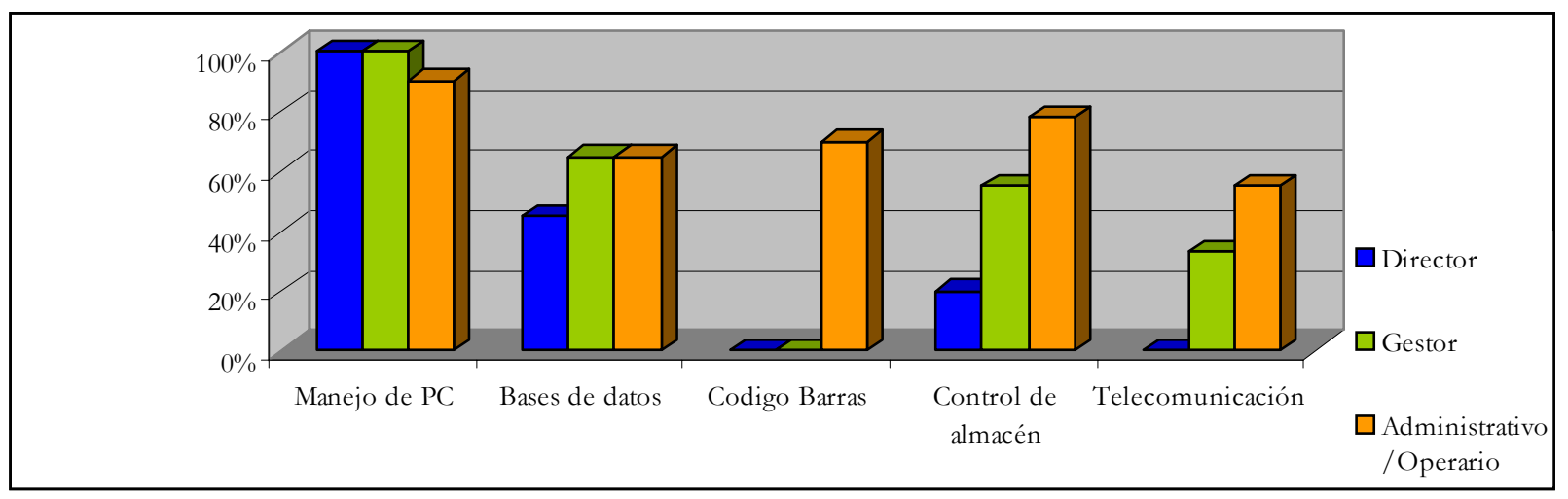

Ilustración 8. 21: Perfil del manejo de tecnología para puestos logísticos

Una vez explicadas las apreciaciones obtenidas en las visitas a las empresas respecto al perfil que han de cumplir sus distintos puestos, se analiza el funcionamiento de dichas áreas.

Todas las empresas encuestadas señalaron realizar planificación de los Recursos Humanos dedicados al departamento logístico. Pero al cuestionar quién es realmente encargado de realizar esa planificación, los Operadores Logísticos señalaron que es tarea de los directores, apoyados en algunos casos de los gestores, mientras que para las Empresas de Distribución Comercial, el 50\% de las mismas señalaron que es tarea del Director, y el otro 50\% que es tarea del Gestor. Finalmente, en las Empresas Productoras esta tarea suele venir realizada en un $70 \%$ por el director, salvo un $30 \%$ de las empresas entrevistadas, que señalaron que es tarea del gestor, sin que en ningún caso ni tipo de empresa sea una tarea desarrollada por administrativos, como se observa en la Ilustración 8. 22.

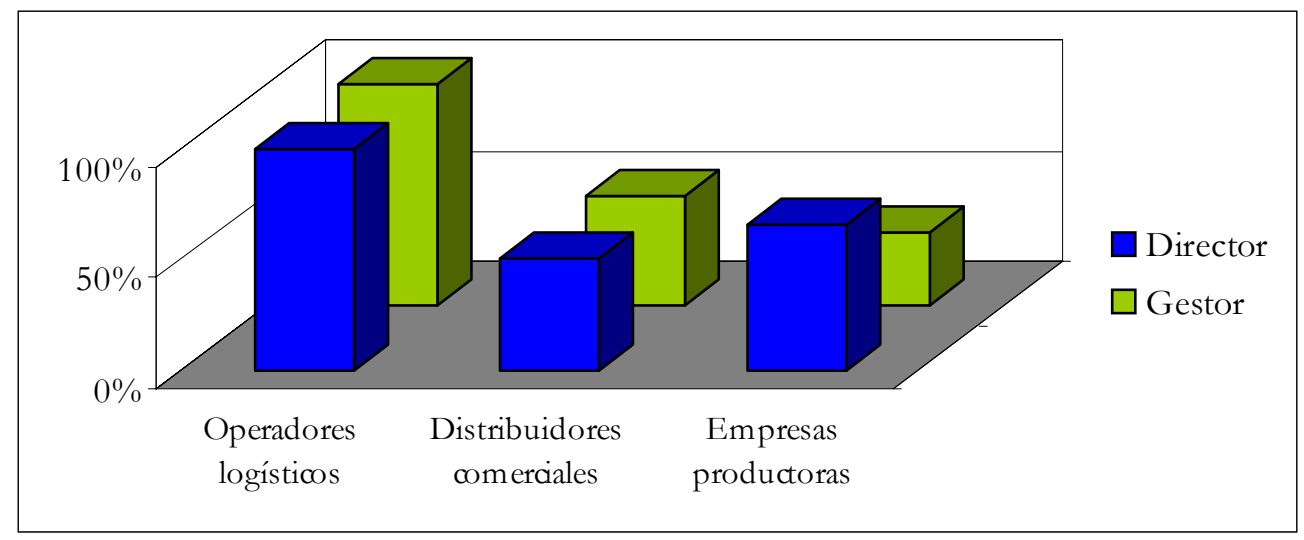

Ilustración 8. 22 : Encargados de realizar la planificación del sistema logístico 
Analizando quién es encargado de asignar personal a las tareas, el resultado obtenido supone que para los operadores logísticos es tarea de los gestores, al igual que para el 75\% de las empresas de distribución comercial entrevistadas, mientras que en el caso de las empresas productoras, la tendencia es mayor a que sea el director del área logística, como se muestra en la Ilustración 8. 23.

Por lo que, analizando quien es encargado de definir las tareas a realizar en cada uno de los puestos, las respuestas obtenidas son muy similares a las anteriores, debido a que suelen ser los directores del área logística quienes asignan personal a las tareas, a la vez que definen cuales son las tareas a realizar en dichos puestos. Cuando la asignación de personal a las tareas es realizada por el Gestor, se cumple que la definición de dichas tareas viene también definida por dicho director, lo que se muestra en la misma Ilustración 8. 23, debido a que no varía la figura de quién asigna personal y quién define que tareas se han de realizar.

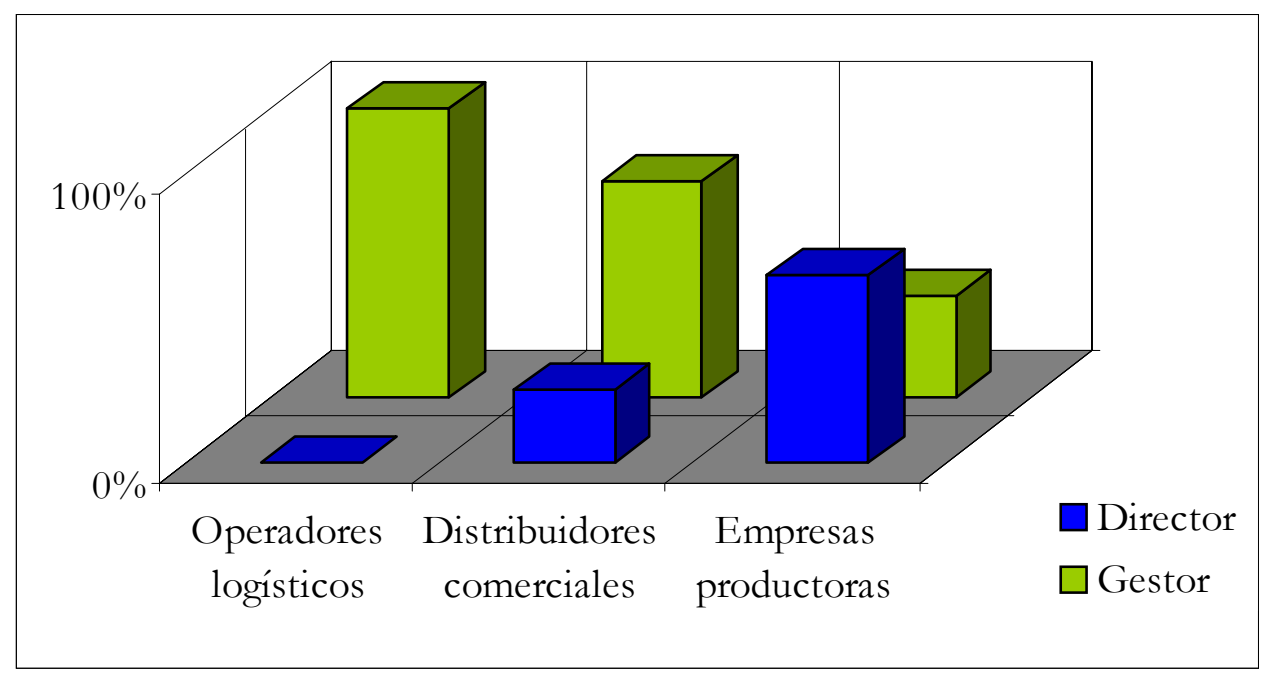

Ilustración 8. 23: Responsabilidad de asignación de personal a las tareas y definición de las mismas.

Lo que si es destacable, es la idea de que todas las empresas señalaron que todos sus empleados conocían que tareas habían de desarrollar, tanto al nivel de dirección, de gestión, como operarios, lo que lleva por tanto a la siguiente pregunta del cuestionario, sobre quién se encarga de explicar y describir como han de realizarse las tareas y actividades de los procesos logísticos. 
Ante esta cuestión, el reparto de esta actividad está muy igualado, ya que poco más del $50 \%$ de las empresas entrevistadas señaló que es tarea del director, mientras que el otro casi 50\% señaló que es tarea del gestor, incluso alguna empresa señaló ambos puestos como responsables de su realización junto con algún administrativo, siendo el caso de empresas de órganos colegiados, donde existe representación de todos los estratos en la gestión de la misma.

La realización de esta actividad de explicación y descripción de las actividades logísticas se suele realizar en la mayoría de empresas a través de manuales de procedimientos, para conseguir ciertos objetivos o en casos como los operadores logísticos junto a los clientes, para así diseñar cuales son las actividades principales que darán lugar a los procesos contratados. Además hay empresas que en su web corporativa han incorporado los procedimientos que ha de llevar a cabo cada uno de los puestos y finalmente habrá también que señalar, que siempre se recurre a la explicación de actividades de viva voz.

Este proceso de explicación de actividades se produce principalmente según las empresas entrevistadas a través de la recogida de información de puestos y elaboración de Manuales de Procedimientos. A su vez una parte de los operadores logísticos reconoció dar órdenes de viva voz, así como un mayor grupo de las empresas de distribución y todas las productoras. Solo los Operadores logísticos reconocieron actuar y explicar las actividades junto al cliente, ya que depende de los requisitos que éste solicite. Finalmente, hay que destacar que un 25\% de las Empresas de Distribución y un 35\% de las Productoras señalaron que la elaboración de los manuales y procedimientos se hacía en pro de conseguir la certificación ISO de Calidad. La representación gráfica se contempla en la Ilustración 8. 24. 


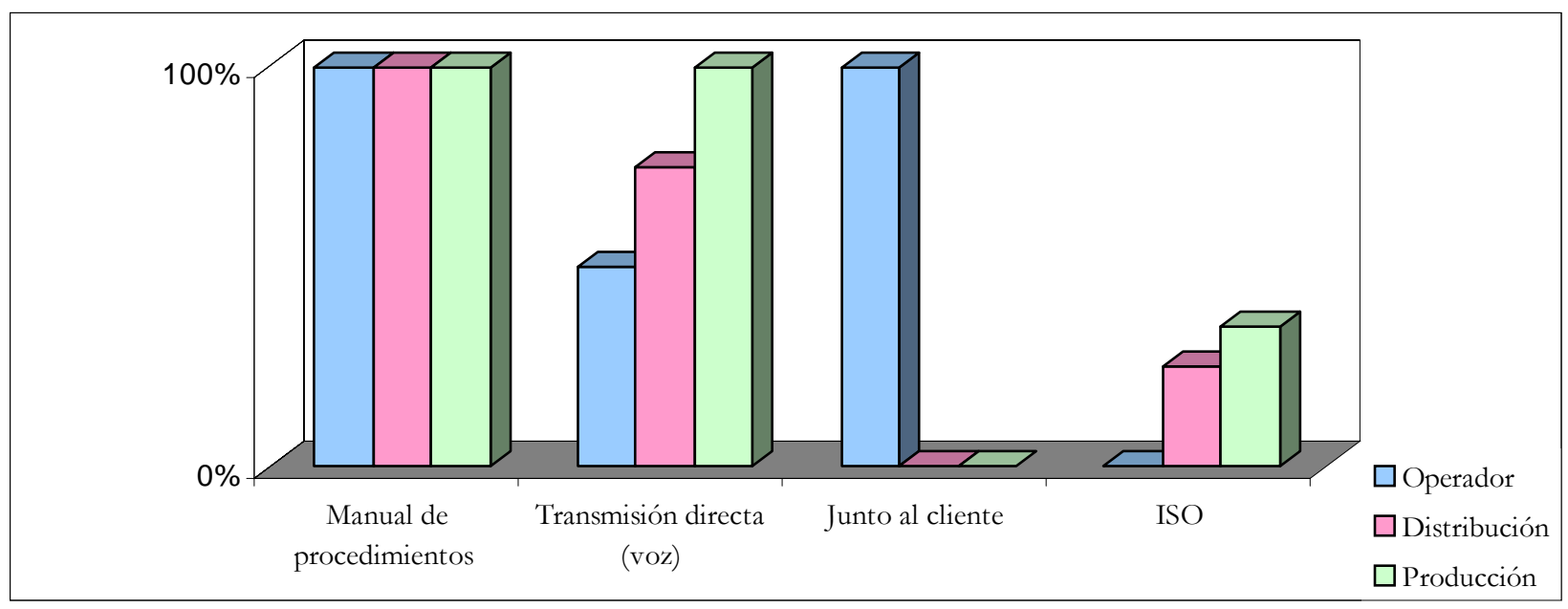

Ilustración 8. 24: Vías explicativas para las actividades logísticas según tipo de sistemas logísticos

En la Ilustración 8. 25 se muestra la periodicidad en la revisión y actualización de la explicación de las tareas a realizar por los sistemas logísticos. Los Operadores logísticos entrevistados señalaron que una parte de ellos los revisan cuando surge una nueva operativa, aunque verdaderamente la revisión realizada en este tipo de empresas se lleva a cabo al establecer junto a los clientes la definición de procesos que se llevarán a cabo para dicho cliente. En el caso de las distribuidoras comerciales, la mayoría de ellas realizan revisiones al cambiar las operativas, e incluso alguna señaló que son revisiones mensuales e incluso diarias. Para las empresas productoras son revisiones siempre que se produce una nueva operativa, o bien de tipo cuatrimestral y anual. 


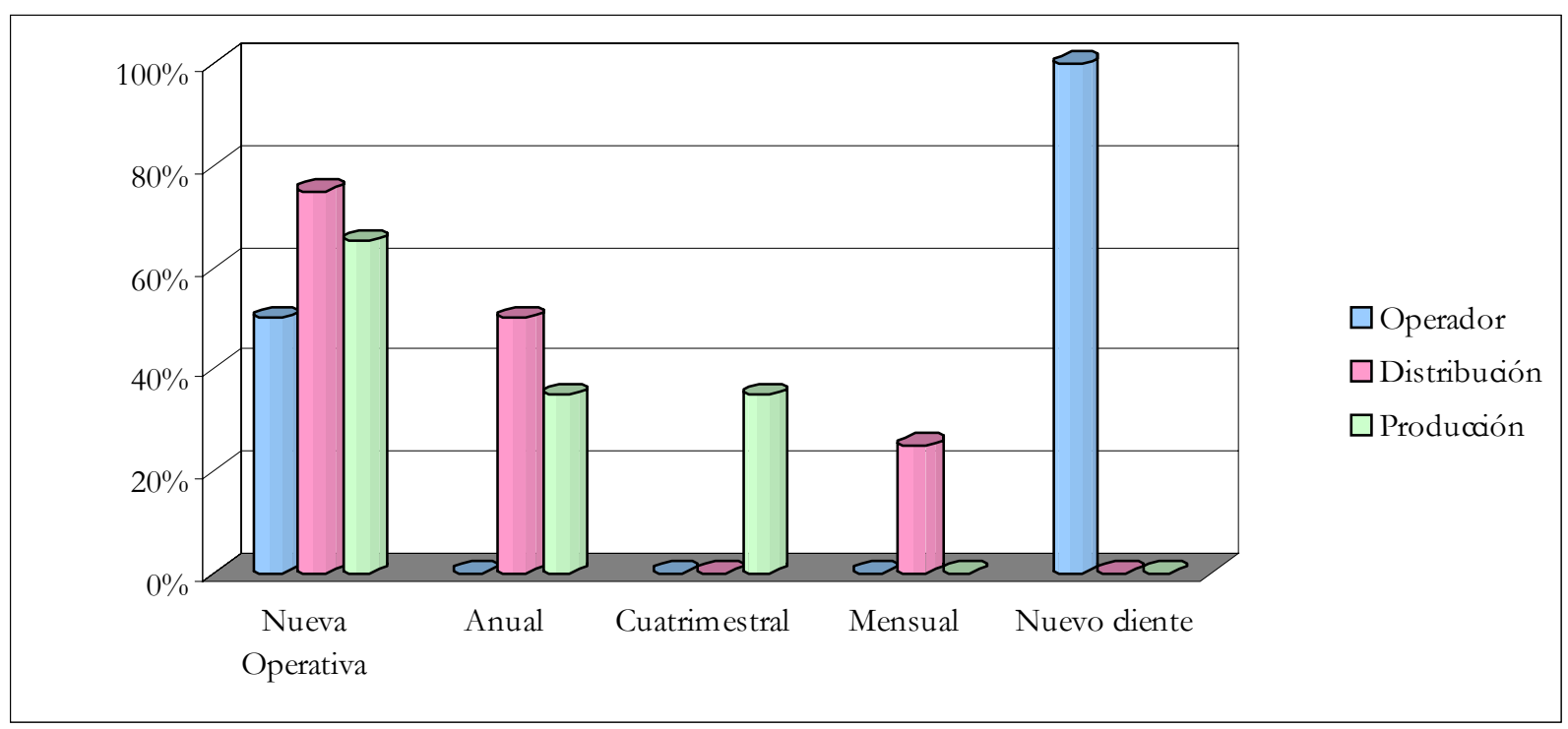

Ilustración 8. 25: Periodicidad de las explicaciones de actividades y tareas en los sistemas logísticos.

Finalmente, para terminar el análisis del cuestionario, se hace referencia a la formación impartida en las empresas analizadas. En una gran mayoría de ellas, se realiza formación por parte de la empresa en temas tanto de logística como de idiomas, e informática principalmente.

Los Operadores Logísticos invierten al menos entre 15 y 25 horas / año al menos en formación para sus directivos, y entre 25 y 50 en sus gestores, llegando en algunos casos donde se promueve mucho la formación hasta unas 100 horas formativas. Para los operarios la media es de 25 horas al año de formación. El tipo de formación realizada en empresas Operadores logísticos, es de tipo práctico y externa contratada.

Para las empresas de Distribución Comercial todas las analizadas señalaron realizar formación a sus empleados. La formación proporcionada es fundamentalmente práctica dentro de la empresa, y teórica tanto desde dentro de la empresa, como contratada para su impartición. En estas empresas, la realización de los cursos viene recomendada por un superior, además de por la solicitud del trabajador y siempre dependiendo del perfil del puesto debido a que no todos realizarán el mismo tipo de curso. Pudiendo incluso encontrar empresas donde no se imparta formación teórica desde la misma, sino que sean los proveedores quienes se encarguen de realizar la formación a los trabajadores, para que así conozcan el mejor uso y manejo de los materiales que proporcionan, e 
incluso esto llegue a suponer una preferencia de dichos productos por los trabajadores de la empresa.

Finalmente las Empresas Productoras, realizan en gran parte formación práctica y teórica. Siendo este tipo de formación teórica usualmente contratada, sobre todo en el ámbito directivo donde todo es contratado y con una media de 24 horas anuales.

\subsection{VALIDACIÓN DEL MODELO DE RECURSOS HUMANOS APLICADO A LOS SISTEMAS LOGÍSTICOS}

Una vez explicados en el apartado anterior los resultados obtenidos en las entrevistas realizadas a las empresas visitadas, hay que realizar la validación del modelo de Recursos Humanos Logístico propuesto en el capítulo séptimo de este trabajo con los resultados expuestos en el apartado 8.3.

Para ello, se realizará la comparación de las tareas propuestas en la tabla 7.1 del capítulo séptimo titulada: Presentación de las funciones del modelo de Recursos Humanos logístico. En dicha tabla aparecen las funciones propuestas para los puestos presentados en este trabajo, y por tanto en este apartado se trata de contrastar la información existente en las empresas con la presentada en dicha tabla.

En la citada tabla se presentan los puestos de Director general de la Empresa, Director de Logística, Analista Logístico, Ingeniero en Logística, Jefe Operativo Logístico y Operario Logístico. Estos puestos no coinciden directamente con los planteados en el cuestionario realizado a las empresas, debido a que en las empresas no se encuentra tal cantidad de puestos, por lo que en el cuestionario únicamente se presentan tres categorías: director, gestor / manager y administrativo/ operario. Estas categorías hay que casarlas para su validación con los puestos propuestos, haciendo esto en base a las funciones desarrolladas por cada uno de los puestos. Esto ocurre debido a que en las empresas no se encuentran cinco niveles sino que un $45 \%$ de las empresas encuestadas declararon tener cuatro niveles jerárquicos, mientras que un 55\% declaró poseer tres niveles jerárquicos, como se observa en la Ilustración 8. 12, observándose en la 
Ilustración 8. 13 como estos niveles suelen ser tres para empresas productoras, y repartidos aproximadamente al 50\% entre operadores y distribuidores logísticos.

Por tanto, se contrastarán los tres puestos propuestos con las tareas a validar de la Tabla 7.1 de los sistemas logísticos.

\section{Director}

Una vez realizados los cuestionarios y visitas in-situ a las empresas, se ha comprobado la gran importancia de los puestos directivos en éstas. Presentados aquí como un único bloque directivo que contempla los puestos propuestos en el modelo de Recursos Humanos Logísticos denominados bajo el nombre de: Director General de la empresa, Director de Logística y Analista Logístico. La inclusión de éstos, se debe a que en las empresas aparecen como un único puesto bajo la denominación de Dirección, pero realizándose bajo este las tareas que corresponden a los tres puestos presentados, tanto si es la dirección de una empresa productora, de distribución, como si es un operador logístico, caso en que la dirección de la empresa será una dirección logística.

Acudiendo a la descripción teórica de puestos realizada en el apartado 7. 4 de este trabajo, donde se expone que estos puestos son los encargados de proporcionar la lista de tareas fundamentales a realizar tanto por la empresa como por el modelo de negocio logístico y su funcionalidad, es decir, aquellas acciones de la cadena de suministro, con sus tareas, bajo el objetivo de hacer cumplir la visión, misión y objetivos correspondientes al aspecto logístico: tanto de forma contextual desde el director general, a través del modelo de negocio empresarial como por el Director Logístico, con modelos de negocio de forma rigurosa y técnica.

Así al repasar la Tabla 7.1 y justificar la definición del ¿Qué? realizada por los directores supondrá definir los elementos empresariales, es decir, los objetos físicos, conceptuales o de información, necesarios para establecer la cadena de suministro y las relaciones existentes entre empresas y clientes, así como su funcionalidad.

Por tanto para validar esta definición de elementos, habrá que acudir a los resultados obtenidos en las visitas a las empresas. Donde se comprueba tanto en la parte teórica (capítulo segundo) como en las contestaciones aportadas por las empresas que verdaderamente los elementos empresariales son: los procesos de la cadena de 
suministro, la información necesaria (Tabla 8. 2, Ilustración 8. 6 e Ilustración 8. 7), la tecnología (Ilustración 8. 10 y Tabla 8. 4) y personal (Ilustración 8. 14, Ilustración 8. 15, Ilustración 8. 19, Ilustración 8. 20 e Ilustración 8. 21).

Por ello, si se atiende a las respuestas proporcionadas en las empresas que han sido expuestas en el apartado anterior, se confirma que los directores son los encargados de describir las funciones de la cadena de suministro (Ilustración 8. 4), la información (Ilustración 8. 5), la decisión sobre la infraestructura (Ilustración 8. 9), y el personal (Ilustración 8. 22), aunque apoyados en gran medida de los gestores/managers.

Todo ello valida la cuestión del ¿Qué? y el ¿Cómo? correspondientes a los puestos de Director General de la empresa, Director de Logística y Analista Logístico respectivamente de la tabla 7.2.

Para justificar ¿Quién? está involucrado en el negocio logístico, los directivos proporcionarán las unidades logísticas participantes, como aquellas personas o equipos involucrados en la Cadena de Suministro, definiendo el organigrama funcional del personal y equipos. Esto se contempla en la Ilustración 8.22 e Ilustración 8. 23, donde se observa como los directores son quienes en más de la mitad de los casos se encargan de realizar la planificación del personal logístico, apoyados a su vez de los puestos de gestor /manager para realizar dicha planificación. Además, también definen las características de los equipos inteligentes, es decir, la infraestructura necesaria, justificado desde la Ilustración 8. 9 donde la dirección aparece como encargada de decidir la tecnología a utilizar en el proceso logístico, así como definiciones en el caso del Analista logístico como se observa en la Ilustración 8. 8.

Con todo ello se logra justificar el ¿Porqué? de la actuación de éstos puestos, ya que basándose en los objetivos y la misión de la empresa, los directivos son los responsables de desarrollar los objetivos estratégicos en el 100\% de los casos estudiados como se mostró gráficamente en la Ilustración 8. 2, realizando esta tarea anualmente. Además estos puestos directivos no se encargan únicamente del desarrollo de estos objetivos sino también en casi un 90\% de los casos realizan el control de los mismos, apoyados en la mitad de los casos por gestores/managers. 
En la Ilustración 8. 3, se muestra el motivo principal por el cual se desarrollan los objetivos logísticos en las empresas, justificado por que ayudan a cumplir los objetivos estratégicos de la empresa, y en un 90\% por ser más competitivos que la mayoría.

El perfil de directivo que las empresas dibujan es el de un profesional con estudios superiores en todos los casos, y con conocimientos en logística, almacenes, planificación, supervisión, presupuesto, toma de decisión y reuniones. Sólo un 45\% de los casos señalaron conocimientos en compras y ventas, y un $65 \%$ en conocimientos de transporte y Recursos Humanos.

El nivel de idiomas solicitado para el puesto directivo varía dependiendo del tipo de empresa y hacia que mercado trabaje, ya que un 56\% señaló un nivel experto, mientras que el nivel medio y básico fueron señalados por un $22 \%$ respectivamente.

Entre las habilidades destacadas para la figura del directivo se señalaron como fundamentales el trabajo en equipo, liderazgo (80\%) y toma de decisiones llegando ésta casi al 50\%. Únicamente un 33\% de las empresas visitadas señalaron la fidelidad, honestidad y responsabilidad, aunque alguna más señaló adaptación al cambio, capacidad de solución y capacidad de negociación. Respecto a la experiencia previa solicitada las empresas piden experiencia en los mismos conocimientos necesarios apuntados en el párrafo anterior y la tecnología que maneja cada uno de estos puestos es de oficina, con el uso de ordenadores y para un $45 \%$ de las empresas en bases de datos.

En la Tabla 8. 6, se observan las tareas que declararon ser realizadas por sus puestos directivos de las empresas visitadas, así como el porcentaje de las mismas que han afirmado realizar dichas tareas en esos puestos directivos. 


\begin{tabular}{llc}
\hline PUESTO & \multicolumn{1}{c}{ TAREAS } & \% \\
\hline \multirow{2}{*}{ Responsable de desarrollar el objetivo logístico } & 100 \\
& Control de cumplimiento del objetivo logístico & 89 \\
& Responsable de la gestión de la distribución & 33 \\
& Responsable del servicio al cliente & 45 \\
& Responsable de la gestión de Inventario y almacén & 33 \\
& Responsable de la gestión de compras & 33 \\
& Responsable de diseñar la Cadena de Suministro & \\
& Responsable de definir los procesos de la Cadena de & \\
Suministro & \\
Detalla las aplicaciones de la cadena de suministro & \\
Define las ubicaciones de la cadena de suministro & 90 \\
Decide la información a dar al personal de la empresa & 55 \\
& Decide la información a dar a proveedores \\
Decide la información a dar a clientes & 90 \\
Define la tecnología a utilizar en el proceso logístico & 66 \\
Decide la tecnología a utilizar & 100 \\
Realiza la planificación & 55 \\
Describe las tareas a realizar & 55 \\
Asigna personal a las tareas & 33 \\
\hline
\end{tabular}

Tabla 8. 6: Tabla de tareas del puesto de dirección logística en las empresas visitadas

\section{Gestor / Manager}

El puesto de Gestor / Manager es un puesto de apoyo fundamental para los puestos de dirección debido a que en muchos casos comparten las tareas a realizar con los puestos directivos y en otros casos las mismas tareas se desarrollan unas veces desde dirección y otras desde estos mandos intermedios.

El puesto denominado en el cuestionario por Gestor /Manager, abarca los puestos representados en el modelo de Recursos Humanos Logístico de la Tabla 7.1 correspondientes al Ingeniero en Logística y al Jefe Operativo. Acudiendo a las descripciones realizadas en dicha tabla, el puesto de Ingeniero en Logística, se encarga de definir los modelos tecnológicos y de infraestructura para operar los modelos 
proporcionados desde la dirección, mientras que el Jefe Operativo, ya que se encarga de definir representaciones detalladas de los modelos de forma específica.

Para ello definen la estructura de la cadena de suministro sobre la base de los elementos empresariales definidos desde la dirección, dándole robustez a las operaciones de cada uno de los elementos. Esto viene justificado con la participación de los Gestores /Managers en el diseño de la Cadena de Suministro, en la definición de la información necesaria (Ilustración 8. 5), la infraestructura (Ilustración 8. 8) y el personal (Ilustración 8. 23), en la cual participan activamente los gestores/managers.

Los gestores /managers describen puntualmente como se ejecuta cada una de las tareas para cada uno de los elementos: en los procesos se produce en el diseño de la Cadena de Suministro, la estructura y decisión de la información, realizada junto con dirección, ya que no se ha de proporcionar toda la información a los distintos colectivos (Ilustración 8. 6 e Ilustración 8. 7), quedando el gestor/manager como encargado de proporcionar información a los clientes en un 55\% de las empresas visitadas, aunque esta tarea se realiza a todos los niveles de la estructura jerárquica, como se comprobó en la Tabla 8. 3. Estructura de la infraestructura a utilizar, aunque viene definida en un $44 \%$ de los casos por los gestores, y en un 66\% los directivos como se observó en la Ilustración 8. 8, en las entrevistas realizadas se confirmó que aunque viene definida desde dirección, los gestores intervienen en dicha definición.

Ante la cuestión del ¿Cómo? el gestor/ manager describe como han de llevarse a cabo las actividades logísticas determinando puntualmente las funciones de cada puesto. Para ello en la Ilustración 8. 24 se muestran las distintas vías de explicativas que se utilizan en las empresas, siendo en la mayoría de casos el manual de procedimientos y la transmisión directa los más utilizados, quedando las normativas ISO en aquellas empresas que la tienen implantada o a implantar, y en los operadores logísticos se realizará esa descripción junto a los clientes.

Los gestores/ Managers serán los responsables de los procesos de gestión de pedidos, gestión de aprovisionamiento, planificación de la producción, gestión de la distribución, servicio al cliente, gestión de inventario y compras, siendo en más del 45\% de cada uno de ellos realizados por gestores / managers, llegando al 90\% en los casos de gestión de inventario y gestión de distribución y almacén, para ello intervienen junto con la 
dirección en el detalle de tareas de la Cadena de Suministro, basándose en el diseño y definición de procesos realizado por la dirección.

El ¿Quién? supondrá determinar puntualmente las funciones de cada puesto, asignando personal a las tareas y definiendo qué tareas han de llevarse a cabo. En la Ilustración 8. 23, se muestra como estas tareas las llevan a cabo los gestores /managers. Aunque existe una tendencia a que sean los gestores quienes se encarguen de ello (65\%), también existen empresas en las que estas tareas son realizadas desde dirección. El perfil de empresas en las que tiende a ser realizado por directores son las empresas productoras, mientras que son las de distribución comercial y los operadores logísticos quienes se decantan a que estas actividades sean realizadas por los gestores/ managers. Los gestores a su vez participan en las tareas de planificación del personal del departamento o área logística en el caso de las empresas productoras, y en igual y mayor para las distribuidoras comerciales y operadores logísticos, como se observó en la Ilustración 8. 22.

Lo que sí realizan en gran medida los gestores en un porcentaje del 85\% es la revisión tecnológica. En ella realizan un análisis del estado de la misma, así como las recomendaciones de mejora de ésta. Las actividades que aparecen en la Tabla 8. 7, corresponden a las tareas realizadas por los gestores y el porcentaje de las mismas en las empresas visitadas.

El perfil solicitado por las empresas para los gestores/managers requiere estudios superiores en un 55\% de los casos y un 65\% estudios medios, y con conocimientos en logística, almacenes, transporte, planificación y toma de decisión. Sólo un 33\% de los casos señalaron conocimientos en compras y ventas, y entre un 65- 75\% en conocimientos de Recursos Humanos (a nivel de relación), supervisión, presupuestos y reuniones.

El nivel de idiomas solicitado para el puesto de Gestor / Manager varía dependiendo del tipo de empresa y hacia que mercado trabaje, ya que un 30\% señaló un nivel experto, mientras que el nivel medio y básico fueron señalados por un 35\% respectivamente.

Entre las habilidades destacadas para la figura del Gestor / Manager se señalaron como fundamental el trabajo en equipo, liderazgo (80\%) y toma de decisiones llegando ésta 
casi al 50\%. Sólo un 33\% de las empresas visitadas señaló la fidelidad, honestidad y responsabilidad, aunque alguna más señaló adaptación al cambio, capacidad de solución y capacidad de negociación. Respecto a la experiencia previa solicitada las empresas piden experiencia en los mismos conocimientos necesarios apuntados en el párrafo anterior y la tecnología que maneja cada uno de estos puestos es tipo oficina, con el uso de ordenadores y para un 65\% de las empresas en bases de datos, el uso de métodos de control de almacén para un 55\% y uso de telecomunicación un 33\%.

\begin{tabular}{clc}
\hline PUESTO & \multicolumn{1}{c}{ TAREAS } & \% \\
\hline & $\begin{array}{l}\text { Responsable del control del cumplimiento de los } \\
\text { objetivos logísticos }\end{array}$ & 55 \\
& Responsable de la gestión de pedidos & 45 \\
& Responsable de la gestión de aprovisionamiento & 45 \\
& Responsable de la planificación de la producción & 45 \\
& Responsable de la gestión de distribución y almacén & 90 \\
Mestor / & Responsable del servicio al cliente & 55 \\
& Gestión de inventario y almacén & 90 \\
& Compras & 65 \\
& Decisión de dar información a clientes & 55 \\
& Define la tecnología a utilizar & 44 \\
& Realiza la revisión tecnológica & 85 \\
& Realiza la Planificación del departamento & 55 \\
& Asigna personal a tareas & 65 \\
& Define las tareas a realizar & 55 \\
& Describe como realizar las tareas & $?$ \\
\hline
\end{tabular}

Tabla 8. 7: Tabla de tareas del puesto de gestor/Manager logístico en las empresas visitadas

\section{Administrativo/ Operario}

En la explicación realizada en el capítulo séptimo referente a este puesto, se definió a los Operarios logísticos como aquellos trabajadores de la empresa encargados de ejecutar las tareas logísticas definidas por sus superiores con los elementos empresariales disponibles para el desarrollo del puesto. 
Para ello, han de situarse en las ubicaciones definidas por los superiores y llevar a cabo las tareas asignadas en el momento indicado.

En las empresas visitadas, éstos puestos han sido analizados desde el punto de vista más bien de administrativos que de operarios debido a que en muchos casos los almacenes y el personal de los mismos es subcontratado, como se demostró en la Tabla 8. 1, donde se dio la cifra de más de la mitad de los almacenes como subcontratados. Y a su vez, porque al ser estas encuestas realizadas a personal de oficina, al contestar lo han hecho de forma inconsciente pensando en el personal administrativo que les rodea, más que en el personal de los almacenes que no están situados en la mayor parte de las empresas en la misma ubicación.

Por tanto, los administrativos / Operarios realizan en su mayoría las funciones logísticas de gestión de pedidos, gestión de la distribución, servicio al cliente, gestión de inventarios y almacén, gestión de compras en aquellas empresas donde se realizan compras, en un 33\% de los casos deciden que información se puede dar a los clientes, siendo ésta como se mostró en la Ilustración 8. 6 de tipo: fechas de entrega, lugares de entrega, precios, tasas, disponibilidad de referencias y características de carga y descarga de los vehículos como muestra la Tabla 8. 8.

Esto validaría la suposición realizada en la parte teórica de este trabajo debido a que los administrativos operarios realizan las tareas encargadas a dichos puestos, situándose en los puestos requeridos y con la tecnología disponible para tal fin como se mostró en la Tabla 8. 4 e Ilustración 8. 10 sin tener que llevar a cabo más allá de la realización de dichas tareas.

El perfil de los administrativos/ operarios para ocupar estos puestos es de estudios de nivel medio o básico, con conocimientos y experiencia anterior habitualmente en almacenes y transporte, nociones de logística y bases de datos, sin que sea necesario el uso de idiomas extranjeros salvo para los administrativos de los departamentos de exportación donde si que puede pedirse un nivel de idioma hasta de experto.

Se requieren conocimientos de manejo de PC, bases de datos, y más orientado a almacén: control de almacén, manejo de código de barras y telecomunicación. 
Son puestos ocupados por personas con una gran capacidad de trabajo en equipo, y a quienes se les valora la fidelidad a la empresa la honestidad y la responsabilidad de acuerdo a las tareas que realiza.

\begin{tabular}{clc}
\hline \multicolumn{1}{c}{ PUESTO } & \multicolumn{1}{c}{ TAREAS } & $\mathbf{\%}$ \\
\hline & Gestión de pedidos & 55 \\
& Gestión de distribución & 40 \\
\multirow{2}{*}{$\begin{array}{c}\text { Administrativo / } \\
\text { Operario }\end{array}$} & Servicio al cliente & 65 \\
& Gestión de inventarios y almacén & 55 \\
& Compras & 33 \\
& Decisión de dar información a clientes & 33 \\
\hline
\end{tabular}

Tabla 8. 8: Tabla de tareas del puesto de Administrativo / Operario logístico en las empresas visitadas

Para finalizar se puede concluir que el planteamiento básico del Modelo de Recursos Humanos propuesto se cumple en las empresas, aunque con ciertas limitaciones debidas principalmente a la existencia de menores niveles jerárquicos en las empresas que en el modelo planteado, como se demostró en la Ilustración 8. 12.

Salvando esto, si que se puede afirmar la existencia de puestos directivos en las empresas que desarrollan las tareas aquí presentadas para los puestos de Director General de la Empresa, Director de Logística y Analista logísticos.

Los gestores / managers son puestos que aquí se relacionan con los Ingenieros en logística y los Jefes Operativos Logísticos. Este puesto es muy variable en las empresas, ya que unas veces realiza tareas muy cercanas a dirección, lo cual significaría el puestos de Ingeniero en logística, apoyando y desarrollando las tareas señaladas, y otras realiza tareas más operativas, lo que le aproxima al puesto de Jefe Operativo.

Finalmente el puesto de administrativo /operario, puede afirmarse que cumple los requisitos planteados en la parte teórica, aunque las empresas hayan validado estos puestos desde el punto de vista más administrativo que operario. 


\subsection{CONCLUSIONES DEL CAPITULO}

Una vez presentado en el capítulo séptimo el modelo de Recursos Humanos Logísticos, este capítulo entra en la validación del mismo. Para ello, partiendo de las etapas propuestas por Maholtra se aplica una a una para poder conseguir la información necesaria para dicha validación.

Una vez conocidos los pasos que hay que seguir para la obtención de la información, se realiza en el siguiente apartado una explicación de la estructura del cuestionario, así como del porqué de la misma.

Una vez realizada la explicación de lo que se va ha llevar a cabo, se analizan en el punto cuarto los resultados obtenidos una vez realizadas las visitas a las empresas. Para ello se han utilizado diversos gráficos donde se muestra de forma clara y concisa la situación actual de las empresas que aplican logística.

Finalmente el capítulo termina con la validación del modelo. Esta validación se realiza según los puestos analizados en la tabla 7.1 Presentación de las funciones del Modelo de Recursos Humanos Logístico, pero aplicando los resultados obtenidos en las vistas in situ.

\subsection{REFERENCIAS BIBLIOGRÁFICAS DEL CAPITULO}

Cabrero_Richa Cabrero García J., M. Richart Martínez. Metodología de la

rt Investigación I. Técnicas de recogida de datos.

http://perso.wanadoo.es/aniorte_nic/apunt_metod_investigac4_9.htm

Consultada el 05/03/02

CENReport19 CEN Report TC/ 273 "Some occupational profiles for Practitioners in

$98 \quad$ Logistics" European Logistics Association 1998.

De Rosnay J. De Rosnay. The macroscope, a new world scientific system. Web edition. Principia Cibernetica Web Project.

Http://pespmc1.vub.ac.be/ASC/UNCERT_PRINC.html Consultada el 27/02/2002

Domínguez200 Domínguez Torres, A. Cambio y conocimiento en los sistemas.

$0 \quad$ Editorial Galileo. México 2000.

DíazRamiro E. Díaz Ramiro. "Modelo de Evaluación de necesidades formativas basado en la evaluación de metas y objetivos" http://www.ucm.es/info/Psyap/jornadas/eva.htm Universidad

Complutense de Madrid. Facultad de Psicología. Departamento de 
Psicología diferencial y del trabajo. Somosaguas- Madrid. Consultada el 10/12/2001

González González, A.E.. Curso a distancia para la enseñanza de la Metodología de Investigación aplicada a la elaboración de Tesis de Grado. Unidad III. La Recolección de Datos. Sistema de Actualización docente de la Universidad Central de Venezuela.

http://www.aulavirtual.info.ve/m3recolecciondatos.html Consultada el 27/02/2002

Heylighen Heylighen, F. Principles of systems and cybernetics: an evolutionary perspective.

ftp://ftp.vub.ac.be/pub/projects/Principia_Cybernetica/Papers_Heyligh en/Systems_Principles.txt Consultada el 28/02/2002

INEI1997 INEI. Instituto Nacional de Estadística e Informática de Perú. Metodología para la elaboración de un sistema de información. Capítulo 4. http://www.inei.gob.pe/cpimapa/bancopub/libfree/lib606/CAP4-1.htm Consultada el 08/03/02

LeMay1999 Le May S., J.C. Carr. "The Growth and Development of Logistics Personnel". Mississippi State University. Council of Logistics Personnel. USA 1999

Malhotra1997 N. Malhotra. Investigación de Mercados. Un enfoque práctico. $2^{a}$ edición. PHH. Prentice Hall. 1997.México.

Model2000 M. Model. A Professional's Guide to Systems Analysis, Second Edition. www.dai-sho.com Martin Model 2000. Consultada el 25/02/2002

Morales $\quad$ M. Morales Caicedo. "Administración de Sistemas de Información". Basado en los libros: "Análisis de Sistemas de Información" de Kendall \& Kendall, "Análisis de Sistemas de Información" de J. A. Senn, y "Análisis de Sistemas de Información" de Whitten, Bentley y Barlow. Universidad Santiago de Cali. http://docentes.usaca.edu.co/marmol Consultada el 06/03/2002

SLC Sociedad Americana para la Calidad. Checklist para la Reunión de Datos (Data Gathering Checklist) http://www.calidad.org/s/datos.pdf .Consultada el 05/03/2002

Umpleby Umpleby. Principles of systems and cybernetics: an evolutionary perspective. http://pespmc1.vub.ac.be/ASC/PRINCI_SIMPL.html Consultada el 27/02/2002

Zachman Zachman. "The Zachman Framework " http://www.essentialstrategies.com/publications/methodology/zachma n.htm. Consultada el 26/02/2002 



\section{Capítulo 9.}

Conclusiones finales y líneas

futuras de Investigación 
CAPITULO 9

CONCLUSIONES FINALES Y LÍNEAS FUTURAS DE

INVESTIGACIÓN

\subsection{INTRODUCCIÓN}

Una vez expuestas en la primera parte de esta tesis doctoral las bases teóricas para el desarrollo del modelo de Recursos Humanos para la entidad de negocio expuesto en el capítulo quinto, y su aplicación a los sistemas logísticos en el capítulo séptimo, en el capítulo octavo se han mostrado sus resultados y la validez del modelo. Así, se llega al final de este trabajo obteniendo las conclusiones de lo expuesto, y realizando un planteamiento de líneas futuras de investigación que surgen del tema principal de este trabajo.

En el primer apartado del capítulo se presentan las conclusiones del trabajo, tanto a nivel del modelo obtenido a lo largo de la investigación, como de la información obtenida en las visitas a las empresas entrevistadas. Estas conclusiones recogen los resultados obtenidos una vez visitadas las empresas y comparada su situación con la propuesta por el modelo planteado para los Recursos Humanos en los sistemas logísticos. 
El segundo apartado plantea laexposición de las posibles líneas futuras de investigación. Líneas que surgen a lo largo de este trabajo como focos de atención, pero que no son objeto de investigación en este trabajo, sino motivo de investigación para futuros retos.

\subsection{CONCLUSIONES FINALES DE LA TESIS}

Una vez expuestos en el capítulo octavo los resultados de las respuestas proporcionadas por las empresas logísticas visitadas, y comprobada la validación del modelo en las empresas mismas, se llega a obtener las conclusiones finales de este trabajo. Estas conclusiones se dividen en dos bloques, las conclusiones del modelo en las que se analiza lo obtenido en la investigación teórica, y las conclusiones del proceso de validación, que comprueba la consistencia del modelo de Recursos Humanos propuesto a través de las respuestas obtenidas en las visitas y entrevistas con el personal logístico.

\section{Conclusiones del Modelo}

Tras realizar la identificación del Marco Teórico realizada en los cuatro primeros capítulos de este trabajo, que supuso una descripción en la que donde se desarrolló posteriormente el modelo de Recursos Humanos en su parte denominada Planteamiento del Modelo. Se llega en los últimos capítulos del trabajo, a realizar una aplicación a los sistemas logísticos, y una contrastación del mismo en empresas que realizan logística.

Ante esta situación, la primera apreciación que se plantea y afirma es la importancia de los Recursos Humanos en las organizaciones como se mostró tanto en el capítulo primero desde las arquitecturas de integración como en el cuarto desde la importancia del personal en las empresas, debido a que éstos son un factor fundamental y diferenciador de las mismas. Por ello es por lo que se ha planteado el trabajo y se ha justificado dicha importancia. 
El planteamiento del Personal como factor diferenciador y de vital importancia entre las organizaciones se ha demostrado desde dos enfoques: el enfoque de la integración empresarial mostrado en el capítulo primero y el enfoque de la Cadena de Valor de Porter del capítulo segundo.

Partiendo en el primer capítulo de varias de las principales arquitecturas existentes en la integración empresarial y mostrando sus principales características, tras el estudio de las mismas se puede concluir que todas ellas siguen una serie de pasos o etapas en sus metodologías de funcionamiento. PERA, GERAM, y IE-GIP comienzan con la etapa de la identificación, para pasar a continuación junto con la arquitectura de Zachman a la conceptualización y después a la etapa de definición o requisitos. Todas las arquitecturas recogen esta etapa, que se refleja en la etapa de diseño a la cual seguirá la implementación del mismo y la construcción u operación. Finalmente, excepto GRAI -GIM y Zachman el resto de arquitecturas habla de la etapa de desmantelación del sistema o bien del mantenimiento o actualización.

Partiendo de toda esta información de base, se desarrolla en el capítulo tercero la explicación de los ciclos de vida de los sistemas. Desde el enfoque proporcionado por el IE-GIP desarrollado por el Dr. Ortiz en la Universidad Politécnica de Valencia se estudian otros sistemas para finalmente proponer uno particular para el desarrollo los sistemas. Las etapas que componen el ciclo de vida propuesto son las siguientes:

Planificación: primera etapa en la cual hay que conocer las necesidades y prioridades del sistema, a través de un estudio de viabilidad o un análisis coste beneficio.

Análisis: conocidas las necesidades del sistema y el plan de trabajo hay que decidir que se va a hacer, como y cuando.

Diseño: etapa en la cual se diseña el nuevo sistema basado en los requisitos solicitados en las etapas anteriores. 
Implementación: etapa en la cual se toma el sistema diseñado bajo los requisitos solicitados en las etapas anteriores y se implementa.

Mantenimiento y Revisión: supone mantener y revisar posibles modificaciones del sistema

Desmantelamiento: eliminación de los sistemas si éstos han quedado obsoletos.

Una de las principales conclusiones que se obtiene al estudiar los ciclos de vida de los sistemas es que siempre se sigue una misma metodología, aunque existan autores que no denominen del mismo modo a las mismas etapas, o incluso autores que incluyan unas en otras.

Una vez conocidos los sistemas y su funcionamiento, y recogiendo las arquitecturas de integración del primer capítulo y comparados los elementos que las integran, se puede concluir que las organizaciones están formadas por cinco elementos básicos: los procesos, señalados por CIMOSA, OERA, GRAI , GERAM, Zachman y IE-GIP, la Información, destacada por CIMOSA, PERA, GERAM y Zachman, el Personal, señalado en CIMOSA, PERA, GRAI, Zachman y IE-GIP, la infraestructura nombrada por CIMOSA, PERA, GRAI Zachman y IE-GIP, y finalmente los productos o servicios señalados por GRAI, GERAM y Zachman.

Atendiendo desde el otro aspecto distinto a la Integración Empresarial, y tomando para ello la Cadena de Valor de Porter mostrada en el segundo capítulo, con sus actividades fundamentales (logística de entrada, operaciones, logística de salida, marketing, ventas, y servicio) y las de apoyo (infraestructura, recursos humanos, desarrollo de la tecnología y abastecimiento), en una abstracción de dichas actividades se ha obtenido que en cierta manera se pueden identificar con que los procesos pueden incluir las actividades de operaciones, logística de expedición, marketing, ventas y abastecimiento. La infraestructura identificada por Porter, se puede asociar a la tecnología y desarrollo de la tecnología, así como los servicios pasarán al grupo de productos y servicios, mientras que la gestión de los Recursos Humanos identificada por Porter, corresponderá al 
elemento Personal. Porter no hace referencia al elemento información, pero debido a la gran importancia de la misma en la sociedad actual, se incluye como otro elemento empresarial.

A su vez se puede observar que estos elementos no se encuentran aislados en las empresas debido a que entre ellos existe cierta relación, como se ha demostrado en el capítulo segundo, y esto sucede cuando se realiza una mejora en alguno de ellos y hay por tanto que reajustar los demás.

Obtenida toda esta justificación de los elementos empresariales, se procede al estudio del que aporta una mayor diferenciación entre las empresas, el Personal.

Realizando una aplicación de las etapas del ciclo de vida al elemento empresarial Personal en el capítulo tercero, se puede observar que al incorporar dicho elemento a la empresa, este pasa por una etapa de planificación de plantillas, análisis y descripción de puestos de trabajo, búsqueda y selección de personal, líneas de formación en la organización, evaluación de personas y finalmente la administración de la carrera del personal, todas estas etapas corresponden con las del ciclo de vida abstracto expuesto para los sistemas.

Al hacer alusión a los sistemas se está queriendo referenciar a las empresas o entidades de negocio, a las cuales hay que proporcionar la estructura de la que emanen tanto funciones como responsabilidades para sus integrantes, de forma que sirvan para orientar y canalizar las relaciones existentes entre la organización y los individuos.

Con ello surge la idea de crear en el capítulo quinto un modelo de Recursos Humanos basado en los procesos que llevan a cabo los participantes en la entidad de negocio. El modelo se ha creado siguiendo las etapas del ciclo de vida propuestas. Por ello, se comienza en la etapa de Planificación, siguiendo los requisitos de la creación del nuevo modelo, para lo que hay que conocer el modelo de partida y al que se quiere llegar. En la etapa de análisis, se identifican las diferencias entre los modelos de partida y el que se desea alcanzar, sus prioridades, transición, actuación, etc. que 
supondrá una ordenación jerárquica basada en la pirámide clásica pero siguiendo los procesos realizados a lo largo del ciclo de vida. Finalmente la etapa de diseño supone diseñar sobre la base de los requisitos definidos consolidando los requerimientos, comportamientos, operaciones, sistemas de información, recursos, infraestructuras y organización para la realización de las tareas.

Con esta operativa, y tomando como partida la pirámide jerárquica clásica de mando, se han ido añadiendo los elementos empresariales presentados en el primer y segundo capítulo. En el caso de los procesos se han asignado aquellos que se desarrollan en cada uno de los niveles propuestos en la pirámide y mostrados en el apartado 5.2.2, es decir, tareas fundamentalmente de planificación para la Alta Dirección, tareas fundamentalmente de Diseño para los Mandos Intermedios, y tareas fundamentalmente de Implementación para los Mandos Operativos y Operarios. Estos procesos los realizarán apoyándose en dos elementos empresariales principales: las infraestructuras y la información, que serán utilizados en su justa medida dependiendo del nivel jerárquico y puesto desarrollado, para con todo ello obtener el servicio o producto que genera la entidad de negocio. Desarrollando los procesos sobre la base del ciclo de vida expuesto en el capítulo tercero, surgen nuevos puestos asociados a cada etapa, ampliándose los puestos a: Director General, realizando tareas básicamente de Planificación, Analista para tareas de análisis, Ingeniero Diseñador realizando tareas de Diseño, Jefe Operativo y Operarios realizando tareas de implementación, mantenimiento y revisión.

Una vez obtenidos los puestos anteriormente citados se ha descrito en el apartado 5.5 el contenido de los puestos a través del ¿Qué?, ¿Cómo?, ¿Cuándo?, ¿Quién?, ¿Dónde? y ¿Porqué? de cada uno de los puestos propuestos en el modelo.

Una vez obtenido el modelo en el capítulo sexto se ha procedido a introducir el ámbito de los sistemas logísticos. Para ello se explica que es logística y basándose en la evolución histórica de la misma afirmar la importancia actual como ventaja competitiva. En el estudio de los sistemas logísticos se ha realizado un recorrido por las áreas principales de la logística: gestión de demanda, gestión de pedidos, gestión de 
aprovisionamiento, gestión de almacenes, gestión de stocks, gestión de distribución, llegando a la conclusión que el área de estudio en la cual se aplicará el modelo será uno de los eslabones que componen la cadena de suministro, es decir, entre cada proveedor y cliente que componen la cadena de suministro.

Aplicando el modelo de Recursos Humanos propuesto en el quinto capítulo al eslabón de la Cadena de Suministro que realizará el proceso logístico, surgen en el capítulo séptimo el Modelo de Recursos Humanos Logístico, en el que se identifican los puestos siguientes: Director General Logístico, Analista logístico, Diseñador Logístico, Jefe Operativo y Operarios Logísticos, apoyándose en los elementos empresariales correspondientes a la información e infraestructura logística, y obteniendo con todo ello un servicio logístico. Describiendo a su vez en el apartado 7.4 la información correspondiente al ¿Qué?, ¿Cómo?, ¿Cuándo?, ¿Quién?, ¿Dónde? y ¿Porqué? de cada uno de los puestos logísticos propuestos.

\section{Conclusiones de la Aplicación}

Con todo ello las conclusiones finales a las que se llega una vez analizados los resultados y contrastado el modelo en las empresas, se muestran en el capítulo octavo así como la validación del modelo propuesto. Las principales conclusiones de la aplicación son:

* Los niveles jerárquicos de los sistemas logísticos tienden a una horizontalización, debido a que el 55\% de las empresas visitadas tienen tres niveles jerárquicos, mientras que un $45 \%$ tiene cuatro niveles jerárquicos, como se muestra en el apartado 8.4 y en la Ilustración 8.12 .

* Esta tendencia a la horizontalización es más acusada en empresas productoras, que en el resto de empresas logísticas: operadores logísticos y distribuidores comerciales, donde la tendencia está muy igualada entre unos y otros, como se muestra en el apartado 8.4 y la Ilustración 8.13 
* El puesto de Director propuesto en el cuestionario abarca los puestos de Director General de la empresa, Director del Departamento y Analista logístico. Estos puestos son los encargados de proporcionar la lista de tareas fundamentales de la empresa y del departamento, del negocio logístico y su funcionalidad, con el objetivo de hacer cumplir la misión, visión y objetivos logísticos, como se propuso en el apartado 7.4 y la Tabla 7.1 e Ilustración 8.2

* Los directores y analistas definen los elementos empresariales, tanto físicos como conceptuales, así como la descripción del modelo logístico a seguir, como se propuso en el apartado 7.4, la Tabla 7.1 y se muestra en la Ilustración 8.4 para los procesos, la Ilustración 8.5 para la información, la Ilustración 8.9 para la infraestructura y la Ilustración 8.22 para el personal.

* Los directores y analistas proporcionan la lista de personal y equipos que intervienen, verificado con el resultado ya que definen el organigrama funcional de personas y equipos. Realizan la planificación junto a los gestores, como se propuso en el apartado 7.4, la Tabla 7.1 y se muestra en la Ilustración 8.4 para los procesos, la Ilustración 8.6 e Ilustración 8.7 para la información, la Tabla 8.4 para la infraestructura y la Tabla8.5, y desde la Ilustración 8.14 a Ilustración 8.21 para el personal

* Los directores y analistas definen las características de los equipos, es decir, el elemento infraestructura, y participan en la toma de decisión, como se propuso en el apartado 7.4, la Tabla 7.1 y se muestra en la Ilustración 8.8

* Los directores y analistas justifican su actuación debido a que esas tareas se realizan para cumplir con la misión y objetivos del departamento, como se propuso en el apartado 7.4, la Tabla 7.1 y se muestra en la Ilustración 8.2.

* El puesto de Gestor /Manager es un puesto de apoyo fundamental para los puestos de dirección, ya que en muchos casos no hay distinción entre las tareas 
realizadas por dirección y por gestión, como se propuso en el apartado 7.4, y la Tabla 7.1.

* Para las empresas en las que existen cuatro niveles, supondrá que el puesto de gestor/ Manager corresponde al Ingeniero logístico. Mientras que si la empresa consta de tres niveles jerárquicos, el puesto de Gestor/Manager estará compuesto por el Ingeniero Logístico y el Jefe Operativo Logístico, como se muestra en la Ilustración 8.12.

* Los Gestores/Managers proporcionan robustez a las operaciones con su participación en la Cadena de Suministro, en la definición de la información necesaria, la infraestructura y el personal necesarios, como se propuso en el apartado 7.4, la Tabla 7.1, y se muestra en las Ilustraciones 8.4 para los procesos, Ilustración 8.5 para la Información, y la Ilustración 8.8 para la infraestructura.

* Describen puntualmente como se ejecutan las tareas de los procesos de la Cadena de Suministro, la estructura y decisión de la información, ya que participan en la definición de las infraestructuras en un 44\%, como muestra la Ilustración 8.8 e Ilustración 8.22 .

* Los Gestores / Managers explican las tareas y su modo de realización, ya sea a través de manuales de procedimiento, transmisión directa de ordenes, siguiendo las normas ISO o junto a los clientes en el caso de los Operadores Logísticos, como se propuso en el apartado 7.4, la Tabla 7.1 y muestra la Ilustración 8.23 e Ilustración 8.24.

* Estos Gestores/Managers determinan en un 65\% de los casos las funciones puntuales de los puestos, aunque en un 35\% de los casos viene determinado desde dirección, como se propuso en el apartado 7.4, y la Tabla 7.1. 
* Los Gestores/Managers realizan en un $85 \%$ de los casos las revisiones tecnológicas, es decir, el análisis de estado de la infraestructura, así como las recomendaciones de mejora de la misma, como se propuso en el apartado 7.4, la Tabla 7.1 y muestra la Ilustración 8.11.

* Los Administrativos /Operarios, realizan las tareas encomendadas en áreas de gestión de pedidos, gestión de distribución, servicio al cliente, gestión de inventarios, almacén, y gestión de compras, como se propuso en el apartado 7.4, la Tabla 7.1 y se muestra en la Ilustración 8.4.

* En muy pocos casos, deciden que información dar a los clientes, siendo esta información referente a lugares de entrega, precios, tasas, disponibilidad de referencias, características de carga y descarga, como se muestra en la Ilustración 8.5.

* Lo que se puede confirmar que los puestos de administrativos/ operarios realizan las tareas para las que fueron contratados a lo largo de la Cadena de Suministro, como se propuso en el apartado 7.4, siguiendo las órdenes como muestra su perfil propuesto en la Tabla 8.5 y las habilidades de éstos puestos mostradas en la Ilustración 8.20.

\subsection{LÍNEAS FUTURAS DE INVESTIGACIÓN}

Debido al tipo de análisis realizado a lo largo de este trabajo, una vez conocida con profundidad la situación empresarial, se propone un cambio de técnica de investigación para con ello poder expandir el análisis a un mayor número de empresas.

Además de esta expansión puede enfocarse a su vez a profundizar la investigación del donde y cuando de los puestos presentados, debido a que en la actualidad las empresas no han facilitado información al respecto. 
Conocidos y estudiados los sistemas logísticos, se propone realizar un estudio del estado de los mismos en la logística actual española, para realizar con ello propuestas del perfil propio de operadores logísticos, distribuidores comerciales, responsables de logística en empresas productoras con áreas de logística, así como una propuesta de carreras logísticas basadas en los puestos propuestos y en las necesidades del sector.

Realización de estudios, descripciones de puestos y medida del rendimiento para los puestos de los sistemas logísticos, con objetivo de valorar dichos puestos, obteniendo con ello los requisitos mínimos de cada perfil tanto para la selección del personal como para la retribución de los mismos en los sistemas logísticos.

Entre las líneas futuras de investigación que propone este trabajo se destaca el estudio de otros elementos empresariales identificados en esta tesis. En el este trabajo se ha propuesto el estudio del elemento Personal, y se tiene conocimiento que dentro del grupo de investigación se está realizando un estudio del elemento Procesos.

El modelo de Recursos Humanos propuesto para una entidad de negocio se ha aplicado en este trabajo concreto a los sistemas logísticos, y por tanto es un modelo que puede aplicarse a cualquier ámbito, por lo que se propone como líneas futuras de investigación la aplicación del mismo a otros sectores empresariales.

Búsqueda, estudio y comparación de nuevos modelos para estudiar las capacidades de la organización. En este caso se propone el modelo de Capacitación de Madurez para el personal, realizado por Curtis et al. quedando abiertas nuevas vías de estudio de personal con modelos como el SPICE Europeo, EFQM, etc. 


\section{Bibliografía}




\title{
REFERENCIAS BIBLIOGRÁFICAS
}

\author{
Albizu \\ Albizu Gallastegi E. Y J. Landeta Rodríguez. "Contextualización de la función \\ e los Recursos Humanos". Capítulo correspondiente al libro "Dirección \\ stratégica de los Recursos Humanos" Ediciones Pirámide. España 2001 \\ Arenas \\ Arenas Herrera, J. "Glosario de Reingeniería" \\ http://www.alfinal.com/consultor/management/reingenieriaglosario.shtml \\ Consultada el 12/08/2002 \\ Arnedo92 Arnedo J.M. "Fabricación Asistida por ordenador (CIM)". Serie Productiva. \\ Marcombo 1992 \\ Ballou1991 Ballou, R.H. “Logística empresarial. Control y Planificación” Editorial Díaz de \\ Santos. España. 1991 \\ Bernus1996 Bernus P., Nemes L. Williams TJ "Architectures for Enterprise Integration" \\ Chapman\&Hall 1999 \\ Bueno1996 Bueno Campos, E. "Curso Básico de Economía. Un enfoque de Organización" \\ Editorial Pirámide. España 1996 \\ Cabrero_Richart Cabrero García J., M. Richart Martínez. Metodología de la Investigación I. \\ Técnicas de recogida de datos. \\ http://perso.wanadoo.es/aniorte_nic/apunt_metod_investigac4_9.htm \\ Consultada el 05/03/02 \\ Carrallo1978 Carrallo Méndez, A. “Logística Comercial”. Ediciones ESIC. Escuela Superior \\ de Gestión Comercial y Marketing. España. 1978. \\ CELConsorci200 Centro Español de Logística. El Consrci de la Zona Franca de Barcelona. La \\ 2 \\ CELFormación \\ CELPilot2001 \\ CENReport1998 \\ CLM2000 \\ Situación de la logística en España. Estudio de situación 2001.España 2002 \\ CEL- Formación. Formación en Logística Integral. Curso de Gestión de \\ Inventarios II. \\ CEL - Foro Pilot. "Estudio de situación logística en las empresas de Aragón \\ 2001". Centro Español de Logística. Mayo 2001. \\ CEN Report TC/ 273 "Some occupational profiles for Practitioners in Logistics" \\ European Logistics Association 1998. \\ Council of Logistics Management. "What is all about? Publicación del Council \\ of Logistics Management. USA. Año 2000
}


Cooper2002 Cooper M., A. Gillyard, A. Sandu. "2001 Career Patterns of Women in Logistics" http://www.clm1.org/career/downloads/2002WIL.pdf. Consultada en septiembre de 2002

Cotec Cotec: Fundación empresarial para el desarrollo del país mediante el fomento de la innovación tecnológica en la empresa y sociedad española. COTEC. Pautas metodológicas en Gestión de la Tecnología y de la Innovación para Empresas. Tomo 1. Cotec Innovation. España 1999.

CMM-P Curtis B., W.E. Heley, S. Miller. Overview of the People Capability Maturity Model September 1995.. http://phillips.rmc.ca/archive/cficse/resources/sei-pcmm-overview-mm001_95.pdf .Consultada el 15 de julio 2001

PCMMV2 Curtis B., W.E. Heley, S. Miller. Overview of the People Capability Maturity Model. Versión 2 http://www.sei.cmu.edu/cmmp/version2/part1.pdf. Consultada el 2 de noviembre de 2001

Dadzie1998 Dadzie K.Q. "Management education for physical distribution and logistics" International Journal of Physical Distribution \& Logisitcs Management. Vol 28. No 4, 1998 Pp: 259-271

Decenzo2001 DeCenzo D.A., S.P. Robins. "Administración de Recursos Humanos” Editorial Limusa S.A. de C.V. México. 2001

DeMiguel De Miguel. Introducción a la gestión (Management) I. $8^{\circ}$ Edición. Servicio de Publicaciones de la Universidad Politécnica de Valencia. España 1993

De Rosnay De Rosnay J.. The macroscope, a new world scientific system. Web edition. Principia Cibernetica Web Project. Http://pespmc1.vub.ac.be/ASC/UNCERT_PRINC.html Consultada el 27/02/2002

Dessler2001 Dessler G. “Administración del Personal” Octava Edición. Prentice Hall. México. 2001

DíazRamiro Díaz Ramiro, E.. "Modelo de Evaluación de necesidades formativas basado en la evaluación de metas y objetivos" http://www.ucm.es/info/Psyap/jornadas/eva.htm Universidad Complutense de Madrid. Facultad de Psicología. Departamento de Psicología diferencial y del trabajo. Somosaguas- Madrid. Consultada el 10/12/2001

Dolan1999 Dolan S., R. S. Schuler, R. Valle. "La Gestión de los Recursos Humanos" Mc Graw Hill. España 1999

DmachucaI1995 Domínguez Machuca J.A., M.A. Domínguez Machuca, S. García González, Al Ruiz Jimenez, M. J. Álvarez Gil. "Dirección de Operaciones. Aspectos tácticos y operativos en producción y servicios" Edición Mc Graw Hill. España 1995

Domínguez1999 Domínguez Torres, A. Modelos Curriculares de Postgrado en Informática/Computación, Soluciones Avanzadas, Año 7, Número 68, pp. 50-56, septiembre de 1999

Domínguez2000 Domínguez Torres, A. Cambio y conocimiento en los sistemas. Editorial Galileo. México 2000.

DTE Diccionario de Términos Económicos. Editorial Acento. España 1994

Elorduy Elorduy Mota, Juan Ignacio. "Estrategia de empresa y Recursos Humanos. Una visión dinámica de la empresa” Ediciones Mc Graw Hill. Serie Mc Graw Hill del Management. Instituto de Empresa. España 1997.

FdzGuerrero $\quad$ Fernández Guerrero R. , F. Balbastre Benavent, M ${ }^{\mathrm{a}} \mathrm{T}$. Canet Giner, A. Redondeo Cano, L. Revuelto Taboada. "Organización y Métodos de trabajo". Editorial Civitas. España 1998 
FORCEM2000 Fundación para la Formación Continua. Departamento de Organización Industrial y Gestión de Empresas de la Escuela Superior de Ingenieros de Sevilla, el Instituto de Formación y Estudios Sociales (IFES), la Asociación de Investigación y Cooperación Industrial de Andalucía (AICIA), PRINCA S. Coop. And., la Federación Regional de Transportes, Comunicaciones y Mar de la U.G.T. http://io.us.es/Formacion_Logistica.htm Consultada el 1 de octubre de 2002

Gan1995 Gan F., B. Alonso, E. De Francisco, S. Puyol. "Manual de técnicas e instrumentos de Formación en la empresa” Editorial Apóstrofe. España 1995

Gibson1998 Gibson B., M. Gibson, S.Runter. "Careers in Logistics" Georgia Southern University. Council of Logistics Management.1998.

http://www.clm1.org/career/downloads/careerstudy.pdf Consultada el 20 de agosto 2002

Gil1997 Gil I., Ruiz L., Ruiz J. “La nueva dirección de personas en la empresa” Mc Graw Hill. España 1997

Gil1998 Gil Pechúan I., J.J. Guarch Bertolín, D. Palacios Marqués. "Implantación de Sistemas y Tecnologías de Información en las Organizaciones" Servicio de Publicaciones de la Universidad Politécnica de Valencia. Colección Libro Docente. España1998.

GómezMejía2001 Gómez Mejía L. R., D. B. Balkin, R. L. Candy. “Dirección y Gestión de Recursos Humanos”. Editorial Prentice Hall. Tercera Edición. España 2001.

González2001 González, C. "Systems development life cycle". www.andrew.cmu.edu/user/conzalez/Teaching/ISW1/Lifecycle.html. Consultada 15/02/2001

González2002 González, A.E.. Curso a distancia para la enseñanza de la Metodología de Investigación aplicada a la elaboración de Tesis de Grado. Unidad III. La Recolección de Datos. Sistema de Actualización docente de la Universidad Central de Venezuela.

http://www.aulavirtual.info.ve/m3recolecciondatos.html Consultada el 27/02/2002

Goranson1997 Goranson H.T., F.Fox, B.Katzy, T.J. Williams and D. Wisnosky. "Human Factor and Enterprise Integration" Enterprise Engineering. Building International Consensus. ICEIMT 97. International Conference on Enterprise Integration and Modelling Technology . Torino Italia Octubre 1997.

Gutiérrez G Gutiérrez C. "Ensayos sobre el nuevo humanismo" http://cariari.ucr.ac.cr/ claudiog/El_genoma_25.html Consultada el $14 / 08 / 2002$

Guzman2002 Guzmán. J. "Desarrollo de un modelo de ciclo de vida para el desarrollo de proyectos de innovación en empresas extendidas" Propuesta de proyecto de fin de carrera 2002-2003. www.getec.etsit.upm.es Consultada el 20 de diciembre de 2002

Hammer Hammer M. y J. Champy " http://www.issa.int/span/domact/om/reengin.htm

Harvey2001

Harvey M.G., R. Glenn Richey. "Global supply chain management. The selection of globally competent managers" Journal of International Management. 7 año 2001. Páginas 105- 128

Heylighen Heylighen, F. Principles of systems and cybernetics: an evolutionary perspective.

ftp://ftp.vub.ac.be/pub/projects/Principia Cybernetica/Papers Heylighen/Sys tems_Principles.txt Consultada el 28/02/2002 
Hong1994 Hong, L., Williams T. "A Formalisation and Extension of the Purdue Enterprise Reference Architecture and the Purdue Methodology." Report 158. Purdue Laboratory for Applied Enterprise Control. http://iies.www.ecn.purdue.edu/IIES/PLAIC/PERA/Report158.pdf Consultada el 4/07/2002

Huse

Huse E.F., Bowditch J.L. "El comportamiento humano en la organización” Editorial Deusto. España 1986

ICEIMT1997 International Conference on Enterprise Integration Modelling Technology (ICEIMT) 1997. Enterprise Engineering. http://www.adn.com.mx/adn2/CIMOSA.htm Consultada 2/7/2002

INEI1997 INEI. Instituto Nacional de Estadística e Informática de Perú. Metodología para la elaboración de un sistema de información. Capítulo 4. http://www.inei.gob.pe/cpi-mapa/bancopub/libfree/lib606/CAP4-1.htm Consultada el 08/03/02

Kahn1996 Kahn K.B., Mentzer J.T. "Logistics and Interdepartmental Integration" International Journal of Physical distribution \& Logistics Management. Vol. 26. N No $_{\text {USA. University Press } 1996}$

Kersner Kersner, H.. Project Management. $7^{\text {a }}$ Edición. Editorial John Wiley. Año 2000. USA

Kirby2001 Kirby C, J.M. Planas. “Un caso de logística estratégica: ¿Cómo optimizar la red logística: centralizar o descentralizar”. Idom Ingeniería, Trace Logístics XXIII Jornadas de logística. Salón Internacional de la logística. Barcelona. Junio 2001

KohnMcGinnis19 Kohn J.W., M. A. McGinnis, "Advanced logistics organisation structures:

97

Kosanke

Kosanke1996

LaLonde2002

Lambert2001

LeMay1999

Lynch1998

Mabey1998

Malhotra1997 revisited" Journal of Business Logistics 1997, Vol 18. Issues2 P.147 16 p Kosanke, K. "Integración empresarial e industrial" http://www.millennium.com.br/cimosa.htm Consultada 30/6/2002

Kosanke, K. "Comparation of Modelling Methodologies". http://cimosa.cnt.pl/Docs/cmm.htm Consultada el 01/07/2002

La Londe B.J., J.L. Ginter. "2001 Survey of Career Patterns in Logistics" The Ohio State University.

http://www.clm1.org/career/downloads/2002careerpatterns.pdf Consultada el 15 junio 2002

Lambert DM (The Raymond E. Mason Chair in Transportation and Logistics. The Ohio State University). PF Osborn III (Eminent Scholar Chair in Logistics. University of North Florida). "Supply Chain Management”. XXIII Jornadas de Logística. Salón Internacional de Logística. Barcelona Junio 2001

Le May S.A, J.C. Carr, J.A. Periatt, R.D. McMahon.. "The Growth and Development of Logistics Personnel" Mississippi State University. Council of Logistics Management. 1999. USA

Lynch C.F. "Leadership in Logistics" Journal of Business Logistics 1998. Vol 19 Issue 2, pp 3-5.

Mabey C., G. Salaman, J. Storey. Human Resource Management. A strategic Introduction. $2^{\text {nd }}$ Edition. Ed. Blackwell Business. 1998 U.K.

Malhotra, N.. Investigación de Mercados. Un enfoque práctico. 2a edición. PHH. Prentice Hall. 1997.México. 
Maryland

Mayo

McConell

McIntryre2002

Menguzzato95

Model2000

Morales

Mullins2002

Murphy1998

Norris

O'Neill95

OpLogisticos27

Ortiz1997

Ortiz1998
Maryland Department Budget \& Management. Structured systems development life-cycle methodology Apendix A. www.dbm.state.md.us/mdplan/apdx-a.htm Consultada 15/02/2001

Mayo, J.C. "Cadena de Valor: El análisis de la Cadena de Valor, técnica de M. Porter para obtener ventaja competitiva". http:/www.gestiopolis.com/recursos/experto/catsexp/pagans/eco/no12/caden avalorporter.htm Consultada el 22/04/2002

McConnell. S. Desarrollo y Gestión de proyectos informáticos. Microsoft Press. MC Graw Hill. España 1997

McIntyre M.. "Today's Logistics Professional: It's not a Job - It's a carrer" Executive Vice President and Chief Operating Officer. 53 Annual Salzberg Medallion Lecture. 5/04/2002.

http://www.clm1.org/career/downloads/salzbergfull.pdf .Consultada el 1 de Octubre de 2002

Menguzzato M., J.J. Renau. "La dirección estratégica de la empresa. Un enfoque innovador del management". Ediciones Ariel Economía. $2^{\mathrm{a}}$ Reimpresión . España. 1995

Model M.. A Professional's Guide to Systems Analysis, Second Edition. www.dai-sho.com Martin Model 2000. Consultada el 25/02/2002

Morales Caicedo M., "Administración de Sistemas de Información". Basado en los libros: "Análisis de Sistemas de Información" de Kendall \& Kendall, "Análisis de Sistemas de Información" de J. A. Senn, y "Análisis de Sistemas de Información" de Whitten, Bentley y Barlow. Universidad Santiago de Cali. http://docentes.usaca.edu.co/marmol Consultada el 06/03/2002

Mullins L. J., "Management and organisational behaviour" $6^{\text {th }}$ Ed. Financial Times. Prentice Hall. 2002 UK

Murphy P.R., R. F. Poist Jr. "Skill requirements of senior-level logisticians" International Journal of Physical Distribution \& Logistics Management. Vol 28. N²4. p. 284-301. MCB University Press. 1998

Norris G., J.R. Hurley, K.M.Hartley, J.R. Dunleavy, J.D. Balls. "Del ERP al e-business. Transformando la empresa" Editorial Deusto S.A. Nueva Economía. PricewaterhouseCoopers Consulting. España 2001

O'Neill H. "Decision Support in the Extended Enterprise". PhD Cranfield University. Año 1995.

http://www.cranfield.ac.uk/sims/cim/research/publications/doctoral theses/p hd theses.htm. Consultada el 29 de enero de 2003

Operadores Logísticos Revista. № 27. Especial Manipulación y almacenaje. Año III. Junio 2002. BGO. Editores S.L.

Ortiz A. "Modelización en contexto CIMOSA. El caso de una Empresa de distribución" I Workshop International in Business Integration. Valencia 1997

Ortiz, A. "Propuesta para el desarrollo de programas de integración empresarial en empresas industriales. Aplicación a una empresa del sector cerámico." Tesis Doctoral. Universidad Politécnica de Valencia. Departamento de Organización de Empresas. Valencia. España. 1998. 
Pennsylvania

Peña1990

Pérez2001

Pérez1996

Persson1997

Phillips

Pina2000

PMI

Porter80

Prida

PwC2001

Rodríguez

Ross2000

Roux2002

RuizMandado

Rushton89

SanCristobal2001

SBarriga
Pennsylvania State University. Stages of the Systems Life Cycle. www.ist.psu.edu/courses/110 content/topic 10/lesson 04/10 04 02.html. Consultada el 27/02/2001

Peña Baztán, M. "Dirección de Personal en la Organización y técnicas” Colección ESADE. 6ª Edición. España 1990

Pérez, Carlos. "En un entorno cada vez más competitivo. La imprescindible figura del director logístico". Revista: Logística Profesional. Especial Operadores logísticos 2001. Grupo Tecnipublicaciones.

Pérez Fernández de Velasco, J.A. "Gestión de Procesos. Reingeniería y mejora de los procesos de empresa." Editorial ESIC (Escuela Superior de Gestión Comercial y Marketing) España. 1996

Person G., "Organisation design strategies for business logistics" International Journal of Physical Distribution \& Logistics Management" Vol. 27. No 5/6. 1997 p. 282-291. MCB University Press.

Phillis D. People, Process, and Product.. http://members.aol.com/dwaynephil/CutterPapers/ppp/ppp.htm Consultado el 24/05/2001

Pina Barrios, R. Director General de Shitake Corp. "Nuevas tecnologías para la automatización de almacenes". I Foro Logístico de la Región de Murcia. INFO - CEL. 2000

Project Management Institute. (PCI) USA. Chapter 10: Project

Communications Management. www.pmi.org Consultada el 10/04/2002

Porter. M.E. (1980) Competitive Strategy The Free Press, NY. Versión Española Estrategia Competitiva. CECSA México. 1982

Prida Romero B., G. Gutiérrez Casas. "Logística y aprovisionamiento". Mc Graw Hill de Management. España. 1996

PriceWaterhouseCoopers. Manual práctico de logística- Foro Pilot.

Zaragoza. España 2001

Rodríguez Cuadrado A., A. Márquez Serrano. Técnicas de Organización y Análisis de Sistemas. Organización de los servicios informáticos. Mc Graw Hill. España 1993

Ross, D.F. "Competing through Supply Chain Management: Creating Marketwinning strategies through Supply Chain Parternships" Materials Management. Logistics Series. Kluwer Academic Publishers $3^{\text {a }}$ Edición. USA año 2000

Roux M. "Manual de Logística para la Gestión de Almacenes". Edición Gestión 2000. Segunda Edición. España. Año 2002

Ruiz González M., E. Mandado Pérez. "La innovación tecnológica y su gestión" Serie Productica. Marcombo. Boixareu Editores. España 1989.

Rushton A., J. Oxley. "Handbook of Logistics and Distribution Management” Editorial Kogan Page. Reino Unido. 1989

San Cristóbal Espiga A., Director de Recursos Humanos SDF Ibérica S.A. Ponencia "Los Recursos Humanos de un Operador Logístico" II Foro Logístico de la Región de Murcia. Noviembre 2001 Sánchez Barriga F. Técnicas de Administración de RRHH. Editorial Limusa S.A. Grupo Noriega Editores. 3 Edición México. 1993. 
Schael97

Smart97

SLC

Soret97

Sundaresan

Thistle

Tissen2000

Tiwana

TQM_EFQM199 9

Umpleby

Werther 1991

West

Williams2002

Williams
Schael. T. "The Human Role in Enterprise Integration" Enterprise Engineering. Building International Consensus. ICEIMT 97. International Conference on Enterprise Integration and Modelling Technology . Torino Italia Octubre 1997.

Smart P.A., J.J.P. Ferreira, K. Kosanke, T. Sachael, M. Zelm. "Enterprise Modelling - User Semantics" ICEIMT 97. International Conference on Enterprise Integration and Modelling Technology . Torino Italia Octubre 1997.

Sociedad Americana para la Calidad. Checklist para la Reunión de Datos (Data Gathering Checklist) http://www.calidad.org/s/datos.pdf .Consultada el 05/03/2002

Soret los Santos, I. "Logística Comercial y Empresarial” Colección Universidad. ESIC (Escuela Superior de Gestión Comercial y Marketing). $2^{\circ}$ Edición. España 1997.

Sundaresan, S. Information systems processing and design. Systems development life cycle. http://www2.smeal.psu.edu/courses/mis430.sundaresan/protected/notes/sdlc_h o.pdf Consultada el 21/02/2001

Thistle, D.A. Systems development life cycle- SDLC. http://cs104cs.uwinsor.ca/develop.htm Consultada el 22/02/2001

Tissen R., D. Andriessen, F. Lekanne Deprez. "El valor del Conocimiento. Para aumentar el rendimiento en la empresa". Editorial Finanacial Times. Prentice Hall. España 2000.

Tiwana, A. The knowledge management toolkit. Practical techniques for building a knowledge management system. Ed. Prentice Hall PTR. USA 2000.

TQM-EFQM 1999. El Modelo EFQM de Excelencia.

http://www.tqm.es/TQM/ModEur/ModeloEuropeo.htm Consultada el 20 Noviembre 2002

Umpleby. Principles of systems and cybernetics: an evolutionary perspective. http://pespmc1.vub.ac.be/ASC/PRINCI SIMPL.html Consultada el 27/02/2002

Werther W.B., K. Davis. "Administración del Personal y Recursos Humanos" Mc Graw Hill. $3^{\text {a }}$ Edición . México 1991

West C. "SCM is about People, not Technology" Logistics Quarterly. Volume 7. Issue 3. Summer 2001. www.lq.ca/issues/fall2001/articles/article15.html Consultada el 30/05/2002

Williams L.R., T. L. Esper, J. Ozment. "The electronic Supply Chain. It's impact on the current and future structure of strategic alliances, parternships and logistics leadership" International Journal of Physical Distribution \& Logistics Management. Vol 32 Issue 8.

Williams. T.J. "PERA and GERAM- Enterprise Reference Arquitecturas for Enterprise Integration" Institute for Interdisciplinary Engineering Studies. Purdue University. http://iies.www.ecn.purdue.edu/IIES/PLAIC/PERAGERAM_10-98.pdf. Consultada el 9/07/2002 
Williams1994 Williams T.J. Editor “A Guide to Master Planning and Implementation for Enterprise Integration Programs, Technical Report 157, Purdue Laboratory for Applied Industrial Control Purdue University. West Lafayette, Indiana, June 1994

Williams1997 Williams T.J. "Pera Methodology" I Workshop International in Business Integration. Valencia 1997

Zachman Zachman. "The Zachman Framework "

http://www.essentialstrategies.com/publications/methodology/zachman.htm. Consultada el 26/02/2002

Zachman2 Zachman. Enterprise Architecture. A framework http://www.istis.unomaha.edu/isqa/vanvliet/arch/isa/isa-rows.htm Consultada el 19/09/2002

Zachman3

Zachman. Enterprise Architecture. A framework

http://www.zifa.com/zifajz02.htm. Consultada el 27/09/2001

Zelm95

Zelm M.; Vernadat F.; Kosanke K. "The CIMOSA Business Modelling

Process" Computers in Industry. Volume 27 n 2.1995 


\section{Anexo I}




\section{ANEXO I- DESCRIPCIÓN DE PUESTOS DE LOS SISTEMAS LOGÍsTICOS}

\section{A.I.1 Dirección Logística}

\section{A.I.1.1 Director General Logística}

- $\quad$ Objetivo general del puesto: Define los modelos de negocio a llevar a cabo en logística y el control sobre directores, supervisores, profesionales, y autoridad presupuestaria

- Denominación del puesto: Vice-Presidente de Operaciones Logísticas, Presidente Logístico, Director General en Logística, Vice-Presidente senior en logística

- Categoría profesional: Alta Dirección

- Dependencia jerárquica

Ascendente: Director General de la empresa

Descendente: analista logístico, ingeniero logístico, jefe operativo, operarios - empleados de operaciones logísticas, gestor y especialista en bases de datos, gestor y especialista en redes y comunicaciones.

Horizontal: resto de jefes de áreas como el jefe de marketing, jefe de producción, jefe comercial, finanzas, y jefe de compras

Relaciones internas: directores de medio nivel, alto administrativos y personal de apoyo. Supervisores de primera línea, profesionales y técnicos especialistas. 
Relaciones externas: directores, ejecutivos, proveedores, clientes, contratistas, solicitantes de empleo, y en menor grado: org. De caridad, inspecciones, prensa ...

- Órdenes:

Recibidas: de dirección, auditores e inspectores externos

Realizadas: supervisa a gerentes de nivel alto, medio, profesionales, y personal administrativo

\section{Descripción de tareas del puesto de Director General en Logística}

- Cotidianas:

- Define los procesos, el personal, la tecnología, la información y el servicio necesario para llevar a cabo la logística, estableciendo los componentes de la cadena de suministro y sus relaciones

- Supervisión y desarrollo del personal logístico

- Desarrollo de directivos y supervisores de oficinas, instalaciones, etc. relacionadas con la logística

- Toma de decisiones para la dirección de operaciones de almacén, control de inventarios, transporte, manufacturas, compras y otras áreas.

- Comunicación: oral y escrita de informes logísticos, tanto para la empresa, para el departamento, clientes, etc.

- Periódicas:

- Establecer metas logísticas, presupuestos

- Medida del rendimiento de las metas y objetivos logísticos

- Determinar el impacto de los cambios tecnológicos

- Ocasionales:

- Reclutamiento y selección de personal logístico

- Cambio de las relaciones interpersonales del área logística

- Establecimiento de los niveles de calidad, procedimientos y normas 


\section{Recursos utilizados en el puesto de Director General en Logística}

- Tecnología: informática, Internet

- Herramientas: teléfono, fax, calculadora, ordenador, agendas electrónicas

- Material: e-mail, notas, buzones de voz

\section{Requisitos del puesto}

Físicos:

- Vista: facilidad de análisis de modelos gráficos o dibujos, observación del comportamiento, observación de la maquinaria, equipos, percepción de cambios en el ambiente laboral, percepción de detalles a distancia, calidad de materiales, percibir cambios en formas y modelos, etc.

- Oído: Comprensión verbal alta, detectar cambios en el trabajo, diferenciar tonos y dirección del sonido.

- Destreza manual: Estar sentado mucho rato, andando mientras se trabaja, coordinación física

- Fuerza física: no requerida

- Intelectuales: Alto nivel de atención, alta discriminación visual, gran capacidad de memoria, fluidez verbal, alto nivel de toma de iniciativa, sociabilidad, rápido razonamiento

\section{Responsabilidades del puesto}

- Sobre equipo: Evalúa la efectividad de las operaciones, modifica y mejora las operaciones, establece metas a corto plazo, determina equipos y procesos.

- Sobre recursos financieros: establece y cambia los presupuestos asignados al área, compra material, compra equipos, dirige las inversiones y el dinero del departamento.

- Decisiones estratégicas: toma nuevos proyectos, establece los servicios ofrecidos a los clientes, decide sobre el abandono de proyectos, el comienzo de las operaciones y la adquisición de otros negocios.

- Sobre empleados: Siempre centrado en sus Recursos Humanos y sus empleados (es lo primero). Asigna responsabilidades a cada empleado, cambia líneas de autoridad, aumenta o disminuye el número de empleados, establece o cambia salarios (contribuye a la decisión) 


\section{Formación y experiencia requerida para el puesto de Director General}

\section{Logístico}

- Formación mínima: Recursos Humanos, informática (bases de datos), base de matemáticas y estadística, compras-ventas, presupuestos, contabilidad, control de almacenes, transporte, supervisión...

- Formación aconsejable: Conocimiento de idioma ingles, planes estratégicos, conocimiento del sector privado, público y empresarial, tablas de decisión, reuniones de dirección, redacción de informes.

- Experiencia: Negociación, reuniones de dirección, toma de decisiones, etc. 


\section{A.I.2 Sistema de Información Logística}

\section{A.I.2.1 Director del Sistema de Información Logística}

- Objetivo general del puesto: Toma de decisiones y responsabilidad para la implementación de sistemas de información logística. Para ello desarrolla una faceta de estrategia de RRHH y otra de especialista en cuestiones logísticas y tecnológicas.

- Denominación del puesto: Director de tecnología, Director de planificación de sistemas logísticos, director de arquitectura del sistema logístico, director del sistema logístico, director de proyecto del sistema logístico.

- Categoría profesional: Mando Intermedio

- Dependencia jerárquica

Ascendente: Director General de la empresa, Director General Logístico

Descendente: No especificada

Horizontal: No especificada

Relaciones internas: técnicos, especialistas, ejecutivos, administrativos, directivos intermedios, supervisores, personal de marketing y ventas,

Relaciones externas: clientes, proveedores, directores y ejecutivos externos.

- Órdenes:

Recibidas: supervisión regular de principales deberes y otros inferiores por parte del inmediato superior

Realizadas: supervisión regular de trabajos especialistas y profesionales, intercambio de información, establecimiento de políticas, resolución de problemas, evaluación, coordinación de trabajos 


\section{Descripción de tareas del puesto de Director del Sistema de Información Logística}

\section{- Cotidianas:}

- Mantiene el conocimiento logístico en la empresa, así como las prácticas llevadas a cabo.(Teoría y práctica)

- Mantiene la competencia en innovaciones tecnológicas, sobre todo en logística

- Coordinan sistemas logísticos de información para que sean exitosos: coordinación de trabajo, evaluación de proyectos, resolución de problemas, intercambio de información

- Utilizan la supervisión y formación para construir y mantener empleados eficaces y eficientes

\section{- Periódicas:}

- Toma decisiones muy frecuentes, que le ayudan a mejorar la función logística

- Dirigen y organizan reuniones para conseguir conocimiento y toma de decisiones efectivas.

- Ocasionales:

- Deciden sobre la adquisición de sistemas de información logística, su instalación y su implantación para mejorar la realización logística.

- Mantienen reuniones con consultores

\section{Recursos utilizados en el puesto de Director del Sistema de Información Logística}

- Tecnología: Ordenador personal, periféricos, redes, unidad central del ordenador

- Herramientas: Ordenadores, Internet, Impresoras, Bases de Datos, Hojas de Cálculo,etc.

- Material: equipo estándar de oficina

\section{Requisitos del puesto de Director del Sistema de Información Logística}

- Físicos: no especificados en vista, oído, destreza o fuerza física 
- Intelectuales: visual para dibujos, gráficos, modelos, observación de máquinas o equipos, abierto de ideas, extrovertido, decidido, realista, con visión analítica de la empresa

\section{Responsabilidades del puesto de Director del Sistema de Información Logística}

- $\quad$ Sobre equipo: Responsable de las decisiones del área de Información Logística

- $\quad$ Sobre recursos financieros: capacidad de retocar presupuestos y compras de equipos para la empresa

- Decisiones estratégicas: Toma nuevos proyectos, y respecto a decisiones de operación y producción, modifica o mejora operaciones estableciendo nuevas metas a corto y largo plazo, evalúa la efectividad de los equipos.

- $\quad$ Sobre empleados: Participa en la decisión de aumentar y disminuir el número de empleados, establece o cambia líneas de autoridad, participa de vez en cuando en el cambio de sueldos.

\section{Formación y experiencia requerida para el puesto de Director del}

\section{Sistema de Información Logística}

- Formación mínima: Conocimiento en dirección tecnológica e informática: bases de datos, cuestionarios, lenguajes informáticos, conocimiento y desarrollo de aplicaciones logísticas (control de inventarios, almacén y transporte), desarrollo de personal, idioma inglés (hablado y escrito)

- Formación aconsejable: Dirección de proyectos y organización de reuniones, equipos específicos (hardware y software de la empresa, así como disponibilidad de aplicaciones logísticas), movilidad interpersonal (dirección, estrés, supervisión, desarrollo empresarial, implementación de proyectos, reclutamiento), conocimiento (prácticas logísticas, dirección de operaciones logísticas)

- Experiencia: Dirección de proyectos 


\section{A.I.2.2 Técnico del Sistema de Información Logística}

- Objetivo general del puesto: Solucionar, programar e instalar sistemas, aportando apoyo, mantenimiento y lo necesario para el funcionamiento del sistema logístico

- Denominación del puesto: Especialista en Información logística, Diseñador de Sistemas de Información logística, Técnico de Sistemas y procesos, administrador de sistemas, Director de Servicio Técnico, programador.

- Categoría profesional: Mando Operativo/ Operario

- Dependencia jerárquica

Ascendente: Director General de la empresa, Director General Logístico

Descendente: no especificadas

Horizontal: no especificadas

Relaciones internas: Directivos intermedios, especialistas, técnicos, alta dirección, técnicos de primera línea de supervisión, administrativos

Relaciones externas: Proveedores, clientes, y en menor grado ejecutivos y consultores

- Órdenes:

Recibidas: Supervisión regular de las principales laborales y tareas menores por el inmediato superior

Realizadas: Ninguna 


\section{Descripción de tareas del puesto de Técnico en Sistemas de Información Logística}

\section{- Cotidianas:}

- Aplicar el conocimiento de software para dar solución a los problemas logísticos de la empresa y la cadena de suministro.

- Integra el conocimiento en los sistemas de información logística de los usuarios para anticiparse y evitar problemas logísticos

- Utiliza técnicas de dirección para resolver problemas según su importancia dentro de la empresa.

- Utiliza su preparación para el mantenimiento del hardware y software de los usuarios

\section{- Periódicas:}

- Mantiene entendimiento de las prácticas logística y su relación con los sistemas de información logística

- Mantiene el conocimiento de software, hardware y los sistemas que tienen que ver con la logística

- Ocasionales:

- Implanta nuevo software y hardware para las operaciones logísticas basado en la dirección de proyectos

\section{Recursos utilizados en el puesto de Técnico en Sistemas de}

\section{Información Logística}

- Tecnología: Ordenador personal, periféricos, redes, unidad central del ordenador

- Herramientas: Ordenadores, Internet, Impresoras, Bases de Datos, Hojas de Cálculo,etc.

- Material: equipo estándar de oficina

\section{Requisitos del puesto de Técnico en Sistemas de Información Logística}

- Físicos: Buena vista para la observación de pequeños detalles, observar el funcionamiento de las máquinas y cambios en los sucesos, trabajar sentado muchas horas

- Intelectuales: atención para percibir los cambios producidos en los sistemas, discriminación visual, razonamiento mecánico 


\section{Responsabilidades del puesto de Técnico en Sistemas de Información Logística}

- Sobre equipo: Mantenimiento de los equipos y Bases de datos, correspondientes a la información logística.

- Sobre recursos financieros: Elección de nuevos proyectos informáticos, y cuestiones de macros, y otros sistemas, y escasamente en compras (70.000 \$)

- Decisiones estratégicas: Sobre producción puede decidir en el cambio de operaciones, en la evaluación de la efectividad.

- Sobre empleados: Ninguna

\section{Formación y experiencia requerida para el puesto de Técnico en}

\section{Sistemas de Información Logística}

- Formación mínima: Alto nivel de informática, inglés hablado y escrito (para informes) utilización de bases de datos, Desarrollo e implementación de sistemas informáticos.

- Formación aconsejable: Logística

- Experiencia: En un puesto similar 


\section{A.I.3 Almacén}

\section{A.I.3.1 Director de Almacén}

- Objetivo general del puesto: Vigilar las facilidades que gobiernan la realización del sistema logístico. Su trabajo gira entorno a la toma de decisiones clave basadas en la información que se deriva del análisis, informes e interacción con sus empleados a todos los niveles: proveedores, clientes, clientes internos, altos directivos.

- Denominación del puesto: Supervisor de Distribución, Director de almacén y transporte, Director de producción de almacén, Director de recepción.

- Categoría profesional: Alta Dirección.

- Dependencia jerárquica

- $\quad$ Ascendente: Director General de la Empresa, Director de Logística

- Descendente: Planificador de Almacén, Administrativo de almacén, supervisor de almacén, Capataz y Operarios de Almacén

- Horizontal: Directores de Tráfico, Director CS, Director de Compras, Director de Servicio al Cliente, Director de Sistemas de Información Logística

- Relaciones internas: Supervisor de primera línea, alta dirección, administrativos, Directores intermedios, empleados.

- Relaciones externas: Altos directivos, proveedores, clientes.

- Órdenes:

- Recibidas: Supervisor de primera línea.

- Realizadas: Al personal operativo.

\section{Descripción de tareas del puesto de Director de Almacén}

- Cotidianas:

- Toma de decisiones operativas sobre información de análisis e informes, interacción con los subordinados a todos los niveles: clientes, proveedores, clientes internos.

- Supervisar a los operarios para que sean eficaces y eficientes. 
- Supervisar el flujo de papeleo/burocracia de almacén y asegurarse que no interfiera en el funcionamiento del almacén.

- Operar y vigilar el uso de máquinas y equipos.

- Periódicas:

- Aprender nuevos métodos bajo el concepto de seguridad y salud para bienes y materiales.

- Recibir retroalimentación y realizar comunicación con empleados, supervisores y directivos para establecer metas.

- Aplicar su conocimiento en Sistemas de Información Logística a decisiones de presupuestos, compras, contabilidad, transporte y telecomunicaciones.

- Ocasionales:

- Establecer procedimientos de trabajo.

- Determinar pagos a empleados.

- Cubrir el puesto de un empleado para entender su trabajo.

\section{Recursos utilizados en el puesto de Director de Almacén}

- Tecnología: Tablas, macros, programas informáticos, sobre todo control de almacén.

- Herramientas: PC's, periféricos, calculadoras, máquina de escribir, maquinaria de almacén(carretillas, elevadoras,...).

- Material: de oficina.

\section{Requisitos del puesto de Director de Almacén}

- Físicos:

- Vista: Dibujos, modelos, gráficos, funcionamiento de máquinas, cambios de eventos, comportamientos, calidad y cantidad de material, colores, facturas, copias, mapas, documentos.

- Oído: Apreciar cambios, entender.

- Destreza manual: Requerida para procesos manuales.

- Fuerza física: Para levantamientos y procesos. 
- Intelectuales (atención, discriminación visual, memoria, fluidez verbal, iniciativa, sociabilidad, razonamiento mecánico...). Fluidez verbal para lenguaje escrito y hablado.

\section{Responsabilidades del puesto de Director de Almacén}

- Sobre equipo: Conocimiento de equipos y maquinaria.

- Sobre recursos financieros: Compras de material, intervención en la realización de presupuestos.

- Decisiones estratégicas: Sobre los procedimientos de trabajo, cambios de metas y objetivos, evaluar la eficiencia-efectividad, nuevos proyectos . Decisiones para abordar nuevos proyectos o abandonar otros.

- Sobre empleados: Pagos y beneficios, supervisión, dirección, comunicación, asignar responsabilidades y trabajos, aumento o disminución de empleados de almacén.

\section{Formación y experiencia requerida para el puesto de Director de}

\section{Almacén}

- Formación mínima: Almacenes y control de almacén, distribución, compras, Recursos Humanos, Seguridad y Salud.

- Formación aconsejable: Supervisión, comunicación, escritura, presentación, presupuestos.

- Experiencia: Supervisión, toma de decisiones, reuniones, seguridad y salud

- Perfil deseable (edad, cercanía al puesto de trabajo, estado civil, sexo, iniciativa...): Contabilidad, auditoria, presupuestos, Recursos Humanos y otros temas relacionados, control de estrés, supervisión. 


\section{A.I.3.2 Planificador de Almacén}

- Objetivo general del puesto: Utilizar su capacidad analítica para hacer recomendaciones relacionadas con compras, presupuestos, operaciones y decisiones de Recursos Humanos. Asistir y dirigir reuniones y recopilar información para la toma de decisiones.

- Denominación del puesto: Director de Planificación Logística, Director de Calidad.

- Departamento/ Sección: Departamento Logístico.

- Categoría profesional: Alta Dirección.

- Dependencia jerárquica

- Ascendente: Director General de la empresa, Director de Logística, Director de Almacén

- Descendente: Administrativo, Supervisor, Capataz y Operarios de Almacén

- Horizontal: No especificado

- Relaciones internas: Directivos intermedios, supervisores, administrativos, profesionales con o sin decisiones de autoridad.

- Relaciones externas: Directivos, proveedores, otros empleados, contratistas.

- Órdenes:

- Recibidas: Supervisor de primera línea y por otros empleados.

- Realizadas: Supervisión a administrativos y personal de apoyo

\section{Descripción de tareas del puesto de Planificador de Almacén}

- Cotidianas:

- Manejar los procedimientos de oficina, trabajo, y presentaciones informáticas.

- Aplicar el conocimiento de compras, presupuestos, contabilidad, finanzas y de Recursos Humanos para desarrollar análisis de almacén. 
- Utilizar técnicas analíticas para desarrollar ideas, presentaciones documentos... que apoyen las decisiones de la dirección.

- Realiza reuniones y contactos para generar la información que apoye las decisiones.

- Periódicas:

- Utiliza presentaciones para comunicar resultados analíticos y en reuniones de directivos.

- Ocasionales:

- Asistir a Directores Generales y Logísticos para desarrollar metas a Largo y Corto Plazo.

\section{Recursos utilizados en el puesto de Planificador de Almacén}

- Tecnología: Software, Bases de Datos, macros, lenguajes informáticos.

- Herramientas: PC's y periféricos, conocimiento de las máquinas y equipos utilizados, calculadoras, máquinas de escribir.

- Material: Informático y de oficina.

\section{Requisitos del puesto de Planificador de Almacén}

- Físicos:

- Vista: Observar el funcionamiento las máquinas, equipos, colores, modelos y formas, calidad, cantidad, cambios en actividades y comportamientos.

- Oído: Entender cambios en actividades y cambios de la dirección del sonido.

- Destreza manual: Con los dedos, hablar mientas se anda.

- Fuerza física: No requerida para el puesto, permanecer sentado mucho tiempo.

- Intelectuales (atención, discriminación visual, memoria, fluidez verbal, iniciativa, sociabilidad, razonamiento mecánico...). Capacidad analítica muy desarrollada, capacidad matemática.

\section{Responsabilidades del puesto de Planificador de Almacén}

- Sobre equipo: Conocer el valor y uso del equipo utilizado.

- Sobre recursos financieros: Contribuir a la compra de material.

- Decisiones estratégicas: Sobre nuevos proyectos y mejoras de actividades, evalúa la efectividad de tareas, cambios de metas. 
- Sobre empleados: Incremento o disminución del número de empleados, asignar tareas, cambiar algunos procesos.

\section{Formación y experiencia requerida para el puesto de Planificador de}

\section{Almacén}

- Formación mínima: Escritura, presentaciones en reuniones, capacidad de análisis, conocimientos de métodos de transporte, telecomunicación, modelización, control, presupuestos, política de empresa.

- Formación aconsejable: Control de inventario, supervisión, relaciones personales.

- Experiencia: En dirección de proyectos y captación de requisitos.

- Perfil deseable (edad, cercanía al puesto de trabajo, estado civil, sexo, iniciativa...): Persona con amplios conocimientos logísticos y empresariales, así como planificación. 


\section{A.I.3.3 Capataz de Almacén}

- Objetivo general del puesto: Operaciones de almacén realizando más funciones de las propias de operarios, como reuniones y ejercicio de la prudencia y liderazgo como supervisor

- Denominación del puesto: Supervisor del equipo de almacén, supervisor de recepción/embarque de productos, jefe de equipo, líder de almacén, planificador de material.

- Categoría profesional: Mando Operativo

- Dependencia jerárquica

- Ascendente: Director de Almacén, Planificador de Almacén, Supervisor

- Descendente: Operarios y Administración

- Horizontal: Operarios

- Relaciones internas: Directivos intermedios, administrativos, supervisores, empleados de operaciones, trabajadores

- Relaciones externas: ninguna, y a lo sumo con clientes.

- Órdenes:

- Recibidas: supervisión en tareas principales y secundarias por un inmediato superior

- Realizadas: a sus operarios de almacén

\section{Descripción de tareas del puesto de Capataz de Almacén}

- Cotidianas:

- Resolución de problemas, conflictos, coordinación en el trabajo

- Tratar con los bienes de almacén e inventario según la política de la empresa

- Transportar carga, conocer donde cargar-descargar, las operaciones, subir, transportar y mover objetos manualmente.

- Grabaciones de datos de forma rápida mediante ordenadores y códigos de barras 


\section{- Periódicas:}

- Enseñanza e instrucción de nuevas tareas, operaciones y personal

- Realización de reuniones para comunicación a los empleados de instrucciones y metas a cumplir

- Ocasionales:

- Realización de reuniones para el intercambio de ideas, información ...

\section{Recursos utilizados en el puesto de Capataz de Almacén}

- Tecnología: Maquinarias elevadoras, carretillas,

- Herramientas: Ordenador, escáner, códigos de barras...

- Material: Material de almacén: etiquetas, materia prima, productos acabados, productos semiterminados

\section{Requisitos del puesto de Capataz de Almacén}

- Físicos:

- Vista: Para detectar la calidad del material, observar objetos, modelos, formas y colores, objetos a distancia, pequeños detalles cercanos a objetos...

- Oído: Distinguir sonidos a distancia, entender ordenes, percibir cambios...

- Destreza manual: alta para el manejo de elementos, trabajar y andar simultáneamente

- Fuerza física: alta, centrada en transporte, colocación, realizar trabajos de forma segura sin daño.

- Intelectuales (atención, discriminación visual, memoria, fluidez verbal, iniciativa, sociabilidad, razonamiento mecánico...)

\section{Responsabilidades del puesto de Capataz de Almacén}

- Sobre equipo: Asigna tareas a su equipo

- Sobre recursos financieros: No hay responsabilidad

- Decisiones estratégicas: No hay responsabilidad

- Sobre empleados: controla la paz laboral, aprende nuevas habilidades 


\section{Formación y experiencia requerida para el puesto de Capataz de}

\section{Almacén}

- Formación mínima: supervisión, reuniones, tareas de almacén, seguridad interna

- Formación aconsejable: Informática o proceso de datos con ordenador

- Experiencia: Carga y descarga de material

- Perfil deseable: experiencia previa en almacenes, preferiblemente hombre, con iniciativa y habilidad en el manejo de personal. 


\section{A.I.3.4 Operario de Almacén}

- Objetivo general del puesto: Trabajo centrado en operaciones con máquinas (carretillas, elevadoras...)

- Denominación del puesto: Trabajador de Muelle, asociado a carga, sostenedor de material, procesador de mercancías, equipo de almacén.

- Categoría profesional: Operario

- Dependencia jerárquica:

- Ascendente: Supervisores y capataces, supervisores de primera línea, directivos intermedios, administrativos

- Descendente: no existen

- Horizontal: entre compañeros, elevadores, transportadores, ...

- Relaciones internas: entre compañeros de almacén y resto de la empresa

- Relaciones externas: no existen

- Órdenes:

- Recibidas: supervisor de primera línea, para comprobar que realiza tanto las tareas principales, como las secundarias.

- Realizadas: a nadie

\section{Descripción de tareas del puesto de Operario de Almacén}

\section{- Cotidianas:}

- Recibir, dar de alta, almacenar, tratar con bienes de almacén, e inventario según la política de la empresa.

- Transportar la carga, conocer donde se puede cargar-descargar, conocer las operaciones, relaciones con operarios, subir, transportar, mover objetos manualmente.

- Realizar grabaciones de datos de forma rápida, operar con ordenadores, teclados y códigos de barras de forma eficiente.

- Operar con seguridad el material y equipo de mano de forma eficaz y eficiente 
- Periódicas:

- Comunicación con compañeros, supervisores y directores para conseguir metas a corto y largo plazo

- Ocasionales:

- Reuniones para el intercambio de información

\section{Recursos utilizados en el puesto de Operario de Almacén}

- Tecnología: Máquinas elevadoras, carretillas,

- Herramientas: Ordenador, escáner, códigos de barras

- Material: Etiquetas, materia prima, productos acabados, productos semiterminados...

\section{Requisitos del puesto de Operario de Almacén}

- Físicos:

- Vista: Diferenciar colores, observar el trabajo de las máquinas, objetos de poco peso, de mayor peso, objetos a distancia, interpretación de señales, calidad y cantidad de material

- Oído: entender órdenes, dirección del sonido, cambio de noticias...

- Destreza manual: alta para el manejo de elementos, trabajar y andar simultáneamente

- Fuerza física: alta, centrada en transporte, colocación, realizar trabajos de forma segura sin daño.

- Intelectuales (atención, discriminación visual, memoria, fluidez verbal, iniciativa, sociabilidad, razonamiento mecánico...): mantener la calma ante el cambio en demandas y otras situaciones.

\section{Responsabilidades del puesto de Operario de Almacén}

- Sobre equipo: Cumplir con su carga de trabajo

- Sobre recursos financieros: No hay responsabilidad

- Decisiones estratégicas: No hay responsabilidad

- Sobre empleados: No hay responsabilidad 


\section{Formación y experiencia requerida para el puesto de Operario de}

\section{Almacén}

- Formación mínima: Habilidad en el conocimiento numérico y escrito para la transmisión de datos, licencia de manejo de carretillas y alguna máquina

- Formación aconsejable: Informática o proceso de datos en el ordenador.

- Experiencia: Carga y descarga de material, pero no es imprescindible

- Perfil deseable: conocimientos en carga y descarga, preferiblemente hombre, disciplinado, con capacidad de asumir decisiones y trabajar en equipo 


\section{A.I.4 Transporte}

\section{A.I.4.1 Director de Tráfico}

- Objetivo general del puesto: Asumir la máxima responsabilidad de operaciones, Recursos Humanos, compres y decisiones presupuestarias. Dirigir las funciones de tráfico y transporte en la empresa.

- Denominación del puesto: Director de tránsito, Director de Servicios de Exportación e Importación.

- Categoría profesional: Mando Intermedio

- Dependencia jerárquica

- Ascendente: Director General de la Empresa, Director General Logístico

- Descendente: Cargadores, Mozos, carretilleros, etc.

- Horizontal: Director de Almacén, Director en Sistemas de Información Logística, Director de la Cadena de Suministro, Director de Compras, Director de Servicio al cliente.

- Relaciones internas: Personal Administrativo, superiores de Primera línea, Supervisores intermedios.

- Relaciones externas: Proveedores, clientes, directivos.

- Órdenes:

- Recibidas: Superior de Primera línea, para tareas principales como las secundarias.

- Realizadas: Seguimiento regular a las obligaciones laborales del personal de su departamento

\section{Descripción de tareas del puesto de Director de Tráfico}

- Cotidianas:

- Mantener el departamento de transporte organizado a través de la supervisión, desarrollo, reclutamiento y selección de habilidades de los Recursos Humanos. 
- Periódicas:

- Asistir a reuniones para resolver problemas, intercambio de información, coordinar actividades

- Ocasionales:

- Establecer políticas de transporte en la empresa.

\section{Recursos utilizados en el puesto de Director de Tráfico}

- Tecnología: Bases de Datos, macros...

- Herramientas: PC’s y periféricos, máquinas de escribir, calculadoras...

- Material: de oficina.

\section{Requisitos del puesto de Director de Tráfico}

- Físicos:

- Vista: Formas, dibujos, gráficos, cambio de actividades, observar objetos a distancia, mapas albaranes, comportamientos.

- Oído: Entender discursos.

- Intelectuales (atención, discriminación visual, memoria, fluidez verbal, iniciativa, sociabilidad, razonamiento mecánico...). Fluidez verbal (hablada y escrita), control del estrés, facilidad de realizar reuniones, facilidad en la toma de decisiones.

\section{Responsabilidades del puesto de Director de Tráfico}

- Sobre recursos financieros: Establecer y cambiar presupuestos, compra de material, adquirir vehículos, contratar personal operativo.

- Decisiones estratégicas: Evaluar la efectividad de los recursos y operaciones a Corto y Largo Plazo. Responsabilidad en la toma y abandono de nuevos productos.

- Sobre empleados: Cambiar procedimientos, asignar personal y responsabilidades. 


\section{Formación y experiencia requerida para el puesto de Director de}

\section{Tráfico}

- Formación mínima: Buen uso del lenguaje (hablado y escrito), uso de Bases de Datos, macros, operaciones con vehículos y mantenimiento, equipos de telecomunicación.

- Formación aconsejable: Toma de decisiones, trato con clientes.

- Experiencia: En transporte, telecomunicación, dirección de personal, logística, redes.

- Perfil deseable: Conocimiento del mercado, conocimiento de leyes y regulaciones de transporte, redes, etc. 


\section{A.I.4.2 Jefe de Expediciones}

- Objetivo general del puesto: Cargar vehículos y coordinar su movimiento para la mejor distribución de facilidades, asegurando que vaya al cliente correcto en vehículo correspondiente, en el paquete correcto y la cantidad indicada.

- Denominación del puesto: Especialista en operaciones de carga, planificador de carga, coordinador o especialista de embarque, Técnico de transporte.

- Categoría profesional: Mando Operativo.

- Dependencia jerárquica

- Ascendente: Director General de la empresa y de logística, Director de Tráfico

- Descendente: Cargadores, Mozos, Carretilleros, Elevadores, etc.

- Horizontal: Jefes de Almacén, Técnico en sistemas logísticos, etc.

- Relaciones internas: Directivos intermedios, superiores de Primera línea, trabajadores y administración.

- Relaciones externas: Clientes.

- Órdenes:

- Recibidas: Superior, para comprobar la realización de sus tareas principales y secundarias.

- Realizadas: Supervisión a los trabajadores de su área o departamento

\section{Descripción de tareas del puesto de Jefe de Expediciones}

- Cotidianas:

- Asegurar que las cargas realizadas cumplen las condiciones de seguridad, regulación, embalaje y requisitos de clientes.

- Ocasionales:

- Operar con material de mano de forma eficiente y segura.

- Utilizar la comunicación para planificar y completar las cargas según las necesidades de los clientes. 
- Mantener un control de inventario exacto utilizando las medidas correspondientes.

- Conocer los vehículos y las técnicas utilizadas en los centros de distribución, fábricas o almacenes que aseguren que encajan las cargas, inspección de vehículos.

\section{Recursos utilizados en el puesto de Jefe de Expediciones}

- Tecnología: PC's, fax, teléfono, periféricos

- Herramientas: Máquinas de oficina, máquinas de escribir, vehículos

- Material: de oficina.

\section{Requisitos del puesto de Jefe de Expediciones}

- Físicos:

- Vista: Observar la calidad y cantidad de los productos y pequeños detalles al respecto, observar el trabajo de máquinas o equipos, modelos, formas, gráficos.

- Oído: Apreciar cambios en eventos o localizar la dirección del sonido, distintos sonidos y tonos.

- Destreza manual: Requerida para el puesto.

- Fuerza física: Requerida para el puesto.

- Intelectuales (atención, discriminación visual, memoria, fluidez verbal, iniciativa, sociabilidad, razonamiento mecánico...). Control del estrés, negociación, “saber estar” en reuniones, comunicación.

\section{Responsabilidades del puesto de Jefe de Expediciones}

- Decisiones estratégicas: X, mejora en operaciones.

- Sobre empleados: Cambios en procedimientos de carga y asignación de responsabilidades.

\section{Formación y experiencia requerida para el puesto de Jefe de}

\section{Expediciones}

- Formación mínima: Carga y manejo manual de material, conocimiento de leyes y regulación de carga, procedimiento de carga. 
- Formación aconsejable: Tratamiento de datos de almacén, operativa de oficina, matemáticas básica.

- Perfil deseable: Conocimiento de las redes de los clientes, conocimiento de leyes y Regulación de transporte, Control de inventario y de gamas de productos, Políticas, procedimientos y prácticas empresariales. 


\section{A.I.4.3 Empleado de Transporte}

- Objetivo general del puesto: Realizar el transporte de mercancías

- Denominación del puesto: Enviador, conductor, transportista, inspector de transporte

- Categoría profesional: Operario

- Dependencia jerárquica

- Ascendente: Director de Tráfico, Jefe de Expediciones

- Descendente: No existen

- Horizontal: Operarios de almacén, empleados de control de inventario

- Relaciones internas: Personal Administrativo, superiores de Primera línea, Director-intermedio.

- Relaciones externas: Clientes, empleados no directivos.

- Órdenes:

- Recibidas: Superior de Primera línea, para comprobar que realiza tanto sus tareas principales como las secundarias.

- Realizadas: A nadie.

\section{Descripción de tareas del puesto de empleado de Transporte}

- Cotidianas:

- Mantener un entendimiento de las condiciones de entrega y características operativas en los almacenes de clientes.

- Operar con los medios de transporte correspondientes de forma que cumplan los requisitos de la Empresa y la ley, mientras se satisfacen las necesidades de los clientes y se minimizan costes.

- Utilizar las comunicaciones y sus habilidades para conocer las necesidades de los clientes.

- Periódicas:

- Renovar los conocimientos sobre leyes, normativas, velocidades, cargas,...

- Conocer las rutas, mejores horas de conducción. 
- Ocasionales:

- Mejorar información sobre los clientes, sus cambios y costumbres. Recibir retroalimentación de clientes y jefes.

\section{Recursos utilizados en el puesto de empleado de Transporte}

- Tecnología: Equipos de comunicación, calculadoras.

- Herramientas: Vehículos-camiones, balanzas, herramientas de manuales móviles, transportes pesados, herramientas manuales móviles.

- Material: de oficina estándar.

- Requisitos del puesto de empleado de Transporte - Físicos:

- Vista: Observar comportamientos, mapas, albaranes, cambios de eventos, observar la cantidad y calidad del material.

- Oído: Para la constante comunicación, cambio en la dirección del sonido, distintos sonidos y tonos.

- Destreza manual: Requerida para tratar el vehículo y los equipos.

- Fuerza física: Requerida para carga-descarga.

- Intelectuales (atención, discriminación visual, memoria, fluidez verbal, iniciativa, sociabilidad, razonamiento mecánico...). Sociabilidad.

\section{Responsabilidades del puesto de empleado de Transporte}

- Sobre equipo: Su cuidado y mantenimiento.

- Sobre recursos financieros: Nada.

- Decisiones estratégicas: Nada.

- Sobre empleados: Nada.

\section{Formación y experiencia requerida para el puesto de empleado de}

\section{Transporte}

- Formación mínima: Conocimientos de transporte: vehículos, su mantenimiento, inspección, Licencias de transporte, telecomunicación que le mantiene unido a la Central/Terminal, carga-descarga. 
- Formación aconsejable: Matemáticas básicas, habilidad social.

- Experiencia: En transporte y telecomunicación.

- Perfil deseable: estar en posesión de las licencias requeridas para poder conducir los vehículos requeridos, Experiencia, mantener el control en situaciones de estrés, etc. 


\section{A.I.5 Inventario}

\section{A.I.5.1 Director de la Cadena de Suministro}

- Objetivo general del puesto: Coordinar y dirigir la Cadena de Suministro.

- Denominación del puesto: Planificación de negocio de la Cadena de Suministro, Director de estrategia de la Cadena de Suministro e Inventario, Director del Control de Calidad de material. Director de Operaciones, Director de Producción.

- Categoría profesional: Alta Dirección/ Mando Intermedio

- Dependencia jerárquica

- Ascendente: Director General de la Empresa, Director de Logística

- Descendente: Jefe de Producción, Supervisor de Inventario, Empleados Inventario

- Horizontal: Director de Almacén, Director de tráfico, Director de sistemas de información logística, Director de servicio al cliente

- Relaciones internas: Alta dirección, administrativos, mandos intermedios, supervisores de primera línea.

- Relaciones externas: Representantes de ventas, proveedores, contratistas consultores.

- Órdenes:

- Recibidas: Supervisión de tareas principales y secundarias por un supervisor inmediato.

- Realizadas: Supervisión de tareas principales y secundarias a supervisores de primera línea.

\section{Descripción de tareas del puesto de la Cadena de Suministro}

- Cotidianas:

- Coordinar actividades, resolver conflictos, supervisar, evaluar, dar información especializada.

- Aplicar técnicas de dirección de proyectos y coordinación de recursos para aumentar la eficiencia de la organización y de la Cadena de Suministro. 
- Supervisan y se basan en empleados para construir y mantener una eficiencia laboral.

- Organizar, coordinar y dirigir reuniones para intercambiar información y conducir acuerdos necesarios para desarrollar una base de conocimiento común que ayude a esas decisiones.

- Periódicas:

- Establecer políticas, reglas, procedimientos y presentar información.

- Realizar reuniones múltiples para tomar decisiones y para obtener información.

- Ocasionales:

- Utiliza la decisión para identificar acuerdos que afectan a la competitividad de la Cadena de Suministro.

\section{Recursos utilizados en el puesto de la Cadena de Suministro}

- Tecnología: PC's, teclados, periféricos.

- Material: de oficina.

\section{Requisitos del puesto de la Cadena de Suministro}

- Físicos:

- Vista: Dibujos, fotos, gráficos, observar la calidad y cantidad de materiales, las acciones del personal, darse cuenta de eventos, diferencias en actividades, colores, pequeños detalles, copias, mapas, ver cosas con poca luz o con luz muy brillante.

- Oído: Entender discursos, identificar la dirección de los sonidos.

- Destreza manual: El tacto para evaluar objetos.

- Fuerza física: No es muy requerida para el puesto.

- Intelectuales (atención, discriminación visual, memoria, fluidez verbal, iniciativa, sociabilidad, razonamiento mecánico...). Pocos nerviosos, amenos.

\section{Responsabilidades del puesto de la Cadena de Suministro}

- Sobre recursos financieros: Compras de material, establecer presupuestos.

- Decisiones estratégicas: Cambio de metas a corto y largo plazo, evaluación de operaciones. Decisiones para tomar nuevos proyectos (falta algo) 
- Sobre empleados: Asignar responsabilidades a empleados, cambiar políticas o procedimientos, cambiar salarios, cambiar número de empleados o líneas de autoridad.

\section{Formación y experiencia requerida para el puesto de la Cadena de}

\section{Suministro}

- Formación mínima: Selección de empleados, supervisión, desarrollo, Dirección de producción, compras, matemáticas, estadísticas, comunicación, hablar en público, habilidad para mantener y dirigir reuniones. Toma de decisiones.

- Formación aconsejable:

- Experiencia:

- EQUIPOS: PC's, otros equipos, operaciones de máquinas y maquinaria de oficina.

- PERSONAL: Comunicación oral y escrita, hablar en público, conducir reuniones efectivas

- CONOCIMIENTO: Selección de empleados, Control de inventario y almacén, dirección de producción, planificación estratégica.

- Perfil deseable: Más de treinta años, experiencia anterior en puesto similar, independencia del sexo requerido, gran capacidad de dirección y organización, e iniciativa. 


\section{A.1.5.2 Director de Producción}

- Objetivo general del puesto:

- Coordinar el proceso de fabricación: tareas, productos y líneas de productos que satisfagan a los clientes con el mínimo coste.

- Se encargan de hacerse a cargo del inventario: entradas de materiales y su transformación en productos solicitados por los clientes.

- Participar en la coordinación logística principal.

- Identificar cómo las tareas de sus subordinados afectan la capacidad de satisfacer a los consumidores.

- Denominación del puesto: Director de producción, coordinador del proceso, Director de Control de Calidad, Director del programa de producción, Director Logístico al por menor.

- Categoría profesional: Alta Dirección

- Dependencia jerárquica

- Ascendente: Director General de la empresa, Director de Logística, Director de la CS

- Descendente: Supervisor de inventario y empleados

- Horizontal: Jefe de Expediciones, Planificador de almacén

- Relaciones internas: Dependerá de ejecutivos, mandos intermedios, supervisores de primera línea.

- Relaciones externas: Personal de ventas, representantes, proveedores, contratistas, subcontratistas o agentes.

- Órdenes:

- Recibidas: Supervisión infrecuente por parte del supervisor inmediato.

- Realizadas: Supervisión regular de las tareas principales de los administrativos, empleados profesionales. 


\section{Descripción de tareas del puesto de Producción}

- Cotidianas:

- Mantener un profundo conocimiento del proceso logístico y como se relaciona con el proceso productivo de la Empresa.

- Utilizar su habilidad de comunicación para dar información

- Utilizar supervisión y el desarrollo de empleados para crear y mantener unos trabajadores eficientes(desarrollando fortalezas en los individuos).

Periódicas:

- Utilizar la supervisión para anticiparse a problemas y desarrollar planes de contingencia

- Aplicar técnicas de dirección de proyectos y coordinación de recursos productivos para incrementar la eficiencia productiva.

- Establecer metas y localizar recursos.

Ocasionales:

- Organiza, coordina, dirige reuniones para intercambiar información y buscar el desarrollo de una base de conocimiento común (que evalúen las opciones, coordinen actividades, intercambien información, den instrucciones...).

\section{Recursos utilizados en el puesto de Producción}

- Tecnología: PC's, material informático, programas de producción, Base de Datos.

- Herramientas: Operaciones con máquinas.

- Material: de oficina.

\section{Requisitos del puesto de Producción}

- Físicos:

- Vista: Para comprobar el buen funcionamiento de las máquinas. Dibujos, modelos, cantidad y calidad del producto-material, comportamientos, eventos, mapas de ruta, albaranes,

- Oído: Escuchar instrucciones, cambios de eventos, dirección del sonido.

- Destreza manual: Tacto para percibir y evaluar objetos.

- Fuerza física: No requerida. 
- Intelectuales (atención, discriminación visual, memoria, fluidez verbal, iniciativa, sociabilidad, razonamiento mecánico...).Templados, orientados a la consecución de objetivos, amigables. Perciben a la Empresa como orientada al cliente.

\section{Responsabilidades del puesto de Producción}

- Sobre equipo:

- Sobre recursos financieros: Compras de materiales u ofertas.

- Decisiones estratégicas: Modificar o mejorar operaciones, procesos, metas, objetivos o políticas, nuevos productos, líneas de productos o proyectos.

- Sobre empleados: Asigna responsabilidad a los empleados, alguna vez puede participar en el cambio salarial o número de empleados.

\section{Formación y experiencia requerida para el puesto de Producción}

- Formación mínima: Auditoria y control de inventario, , operaciones productivas y transporte, coordinación de la cadena de suministro. En cuanto a los Recursos Humanos han de tener una formación en Selección, Supervisión y Desarrollo. Conocimiento de contabilidad, inventario, almacén, matemáticas (estadística), transporte y también en cuanto a la realización de Planes Estratégicos y Dirección de reuniones (fomentar la comunicación).

- Formación aconsejable:

- Experiencia: Han de reflejar la posición dentro de la empresa.

- EQUIPOS: Operación con máquinas y mantenimiento, PC's, periféricos, material de oficina

- PERSONAL: Comunicación oral y escrita, hablar en público, dirigir reuniones, toma de decisiones.

- CONOCIMIENTO: Operaciones, control de inventarios y archivos, contabilidad práctica, selección de formación de empleados y formas de transporte. 


\section{A.I.5.3 Supervisor de Inventario}

- Objetivo general del puesto: Supervisan el trabajo de los operarios de inventario. Entran entre los especialistas de inventario y los jefes de producción, realizan la supervisión última y decisiones de su área.

- Denominación del puesto: Supervisor de Inventario.

- Categoría profesional: Mando Operativo

- Dependencia jerárquica

- Ascendente: Director de Logística, Director de la CS, Jefe de Producción

- Descendente: Empleados operarios de control de inventario

- Horizontal: Supervisor de almacén, supervisor de Servicio al cliente

- Relaciones internas: Mandos intermedios, supervisores inmediatos, administrativos de producción.

- Relaciones externas: Clientes.

- Órdenes:

- Recibidas: Supervisión de tareas principales y secundarias por un supervisor inmediato.

- $\quad$ Realizadas: Sobre los operarios de inventario.

\section{Descripción de tareas del puesto de Supervisor de Inventario}

- Cotidianas:

- Hacer énfasis en la importancia de mantener la integridad de los datos.

- Coordinar la colocación del inventario para incrementar la eficiencia de la Empresa.

- Comprender profundamente las operaciones de manejo de material y las políticas de la Empresa para el mantenimiento de equipos.

- Periódicas:

- Evaluar situaciones para poder anticiparse a problemas y desarrollar planes de contingencia. 
- Utilizar supervisión y preparación para crear y mantener un control eficiente sobre los trabajadores.

- Ocasionales:

- Organizar, coordinar y dirigir reuniones de intercambio de información, llevando a cabo la formación necesaria que asegure que se comparte información.

\section{Recursos utilizados en el puesto de Supervisor de Inventario}

- Tecnología: Programas informáticos de base de datos

- Herramientas: Carretillas

- Material: Material de oficina.

\section{Requisitos del puesto de Supervisor de Inventario}

- Físicos:

- Vista: Para comprobar el buen funcionamiento de las máquinas. Dibujos, modelos, cantidad y calidad del producto-material, comportamientos, eventos, mapas de ruta, albaranes,

- Oído: Escuchar instrucciones, cambios de eventos, dirección del sonido.

- Destreza manual: Tacto para percibir y evaluar objetos.

- Fuerza física: Preferible en caso de movimiento de material.

- Intelectuales: Son los menos neuróticos y extrovertidos, abiertos, amenos. No se dejan influir por decisiones difíciles. Les gusta comprender como funcionan las cosas porque tienen orientación al cliente.

\section{Responsabilidades del puesto de Supervisor de Inventario}

- Sobre equipo: responsabilidad de mantenimiento de equipos

- Sobre recursos financieros: en algunos casos realizan funciones de compras y ventas de materiales

- Decisiones estratégicas: no realiza

- Sobre empleados: Supervisan tareas de empleados de inventario. 


\section{Formación y experiencia requerida para el puesto de Supervisor de}

\section{Inventario}

- Formación mínima: Matemáticas, supervisión, trato de personal, producción, informática para el manejo de Base de datos.

- Formación aconsejable: Recursos Humanos, producción y áreas operativas, inventarios, almacén, transporte, supervisión.

- Experiencia:

- EQUIPOS: PC's, periféricos, material de oficina estándar, operaciones con carretillas.

- PERSONALES: Supervisión, comunicación (oral y escrita), hablar en público, dirección de reuniones, dirección con estrés.

- CONOCIMIENTO: Producción, informática, Recursos Humanos, transporte, almacenes, seguridad, compras-ventas. 


\section{A.I.5.4 Empleado de Control de Inventario}

- Objetivo general del puesto: Recoger la carga-mercancía y entregar. Mayor rango de personal relacionado con movimientos de material. Mueven material dentro y fuera de la empresa, se escanea un código de barras y entra al sistema de inventario de la empresa (cantidad, control de calidad, lugar de la empresa). Colocan en un lugar del almacén, informando de su localización (informa al sistema de esa reubicación).

- Denominación del puesto: Empleados de Control de Material/Inventario. Administrador del control de inventario, Especialista en Control de Inventario, Supervisor de material.

- Categoría profesional: Operario.

- Dependencia jerárquica

- Ascendente: Director Logístico, Director de la Cadena de Suministro, Jefe de Producción, Supervisor de inventario

- Descendente: No existen

- Horizontal: Operarios de almacén, mozos, carretilleros, cargadores, etc.

- Relaciones internas: Mandos intermedios, supervisores inmediatos, Administrativos de producción.

- Relaciones externas:

- Órdenes:

- Recibidas: Supervisión de tareas principales y secundarias de un supervisor inmediato

- Realizadas: No hay.

\section{Descripción de tareas del puesto de Supervisor de Inventario}

- Cotidianas:

- Comprobar que los pedidos y cantidad recibida coincide con lo solicitado

- Realizar controles de calidad.

- Encontrar el lugar de destino en el almacén para la mercancía 
- Imprimir el informe de recibo

- Afectados por los cuellos de botella, agujeros negros.

- Movimiento de materiales dentro y fuera del almacén.

- Establece comunicación con los operarios para que el material se encuentre donde y cuando se quiera.

- Escaneo de los códigos de barras (entrada de datos al sistema), mantiene los datos actualizando los ficheros.

- Periódicas:

- $\quad$ Tomar tiempos de descanso entre tareas de gran esfuerzo físico.

- Ocasionales:

- Mantener reuniones de tipo informal para el intercambio de información.

\section{Recursos utilizados en el puesto de Supervisor de Inventario}

- Tecnología: PC's, programas de Base de Datos, teclados y periféricos.

- Herramientas: Carretillas, elevadoras.

- Material: utilizan ropa de trabajo, elementos para medir y pesar.

\section{Requisitos del puesto de Supervisor de Inventario}

- Físicos:

- Vista: Observar la calidad y cantidad del material y pequeños detalles al respecto, los modelos, formas o colores. Buena visión nocturna con poca iluminación.

- Oído: Dirección del sonido, los tonos, órdenes o reuniones.

- Destreza manual: para evaluar objetos

- Fuerza física: la requerida para el puesto, vorágine

- Intelectuales (atención, discriminación visual, memoria, fluidez verbal, iniciativa, sociabilidad, razonamiento mecánico...). Extrovertidos, abiertos de mente, calmados, amigables, amenos, escrupulosos con su trabajo.

\section{Responsabilidades del puesto de Supervisor de Inventario}

- Sobre equipo: Mantenimiento del material y herramientas utilizadas 
- Sobre recursos financieros: Ninguna, como mucho solicitar la compra de material.

- Decisiones estratégicas: Ninguna.

- Sobre empleados: Ninguna.

\section{Formación y experiencia requerida para el puesto de Supervisor de}

\section{Inventario}

- Formación mínima: Entrada de datos al sistema, preparación física, habilidad interpersonal. Operaciones con carretillas, grabación de datos

- Formación aconsejable: Procedimientos seguros de carga-descarga, habilidad para hablar y escribir.

- Experiencia: Certificado manejo de carretillas, cursos de informática. 


\section{A.I.6 Compras}

\section{A.I.6.1 Director de Compras}

- Objetivo general del puesto: Desarrollar la función de compras y coordinar y dirigir la cadena de suministros

- Denominación del puesto: Especialista de operaciones, agente de compras, coordinador de compras, Analista de la cadena de suministro, Director de conformidad de ventas.

- Categoría profesional: Mando Intermedio.

- Dependencia jerárquica

- Ascendente: Director General de la empresa, Director de logística

- Descendente: Agentes de compras

- Horizontal: Director de almacén, directo de servicio al cliente, director de información logística, director de tráfico, director de la cadena de suministro

- Relaciones internas: Administrativos y personal de apoyo, mandos intermedios, especialistas no supervisores, supervisores de primera línea, altos ejecutivos.

- Relaciones externas: Empleados de dirección, ejecutivos, contratistas, proveedores, representantes de ventas.

- Órdenes:

- Recibidas: Supervisión de tareas principales por su superior inmediato.

- Realizadas: Supervisión de tareas principales por especialistas técnicos o profesionales.

\section{Descripción de tareas del puesto de Director de Compras}

- Cotidianas:

- Coordinar recursos internos y externos utilizados para evaluar, seleccionar e implementar decisiones diseñadas para incrementar la Eficiencia de la Cadena de Suministro.

- Periódicas: 
- $\quad$ Organizar, coordinar y dirigir reuniones para intercambiar información necesaria para que la toma de decisiones tenga éxito.

- $\quad$ Utiliza la supervisión y la habilidad para el desarrollo de empleados para construir y mantener una eficaz y eficiente fuerza de compras.

- Ocasionales:

- Mantener el conocimiento de situaciones y acuerdos ambientales que identifiquen los efectos de prácticas de compras.

- Entender y emplear herramientas que identifiquen costes de comercio.

\section{Recursos utilizados en el puesto de Director de Compras}

- Tecnología: PC's, material informático y periféricos

- Material: Material de oficina estándar.

\section{Requisitos del puesto de Director de Compras}

- Físicos:

- Vista: Fotos, dibujos o gráficos, copias de mapas, observar el comportamiento y acciones de la gente, diferencias en colores, cantidad y calidad del material.

- Oído: Entender lo que dice la gente.

- Destreza manual: Tacto para percibir y evaluar objetos.

- Fuerza física: No requerida.

- Intelectuales: Templados, orientados a la consecución de objetivos, amigables. Perciben a la Empresa como orientada al cliente.

\section{Responsabilidades del puesto de Director de Compras}

- Sobre equipo: Cómo optimizar la toma de decisiones con ordenadores.

- Sobre recursos financieros: Compras de materiales a proveedores.

- Decisiones estratégicas: Puede intervenir a veces en el de objetivos o metas a Corto y Largo Plazo, nuevos proyectos (en un 71\%)

- Sobre empleados: Asignar cambios de responsabilidades, procedimientos de trabajo, políticas...

Formación y experiencia requerida para el puesto de Director de Compras 
- Formación mínima: DESARROLLO DE EMPLEADOS, SUPERVISIÓN, Selección, Compras, Planificación estratégica, Presupuestos, Bancos, acuerdos comerciales, acciones comerciales internacionales, búsqueda de operaciones, transporte, contabilidad, habilidad de comunicación oral y escrita, de organización y capacidad de negociación y aptitud numérica y técnica.

- Formación aconsejable: Programas informáticos.

- Experiencia: OJE, propia del trabajo desarrollado.

- Perfil deseable (edad, cercanía al puesto de trabajo, estado civil, sexo, iniciativa....):

Equipos específicos: operaciones con PC's, otros equipos y equipo de oficina

Habilidad personal: Dirección de proyectos, organización, técnicas de dirección con stress, supervisión y desarrollo de empleados.

Necesidades de conocimiento: Prácticas presupuestarias, Dirección de RRHH, comercio internacional, control de inventario y almacenes, transporte.

- Se incluyen en todos los aspectos de toma de decisiones

- Evolucionan desde la compra de la materia prima y dirección de proveedores a coordinar el diseño de recursos de la cadena de suministro para trasladar los deseos de los clientes en productos y servicios de gran valor.

- Su coordinación no es sólo interna, sino que toda la cadena de suministro se examina para definir la situación estratégica de recursos que resulte una consolidación de tareas.

- Mantienen diversas reuniones y dirigen qué abarcar desde clientes a proveedores.

- Coordina y dirige el proceso por la cantidad de participantes

- Internamente: Estar en contacto diario con producción y con dirección ejecutiva.

- Externamente: Hablar con clientes, gente del gobierno, proveedores para comprobar su proceso tiene fallos o es ético, reduce la eficiencia. 
Participan en Recursos Humanos, Dirección de la Cadena de Suministro y decisiones estratégicas. Además saben contabilidad para poder identificar como sus actividades contribuyen al incremento de valor de los productos y servicios.

\section{A.I.6.2 Agentes de Compras}

- Objetivo general del puesto: Coordinar el proceso de compra, generar información, desarrollar y evaluar alternativas (tras un proceso de selección, selecciona una alternativa y realiza la compra).

- Denominación del puesto: Compradores, Especialista en compras, Coordinador de Compras, Analistas de la Cadena de Suministro.

- Categoría profesional: Operarios.

- Dependencia jerárquica

- Ascendente: Director de Logística, Director de Compras

- Descendente: No existen

- Horizontal: Supervisores y Operarios

- Relaciones internas: Mandos intermedios, personal administrativo, supervisores de primera línea.

- Relaciones externas: Clientes, representantes de ventas, ejecutivos.

- Órdenes:

- Recibidas: Superior inmediato para comprobar la realización de sus tareas principales y secundarias.

- Realizadas:

\section{Descripción de tareas del puesto de Agente de compras}

- Cotidianas:

- Asimilar las prioridades de los clientes y un efecto sobre las prácticas logísticas (sobre las más valoradas y las que se suponen más consolidadas).

- Coordinar la comunicación entre individuos, Áreas Funcionales y Empresas (almacena y distribuye información entre el Centro de Compras y los miembros de la Cadena de Suministro). 
- Coordinar el proceso de compra.

- Aplicar la dirección del proyecto y técnicas interpersonales, desarrollar una base de conocimiento común y coordinar centros de compra y redes de comunicación.

- Periódicas:

- Eliminar actividades sin valor que requieren alguien que dirija.

- Ocasionales:

- Utilizar programas de Software para diseñar la comunicación interna y externa.

\section{Recursos utilizados en el puesto de Agente de Compras}

- Tecnología: PC’s, periféricos, programas.

- Material: Equipo estándar de oficina.

\section{Requisitos del puesto de Agente de Compras}

- Físicos:

- Vista: Cantidad y calidad del material, ofertas, dibujos, gráficos.

- Oído: Identificar discursos y charlas.

- Destreza manual: Con los dedos (alguna vez).

- Fuerza física: Sentado ratos grandes.

- Intelectuales: Templados, orientados a la consecución de objetivos, amigables. Perciben a la Empresa como orientada al cliente.

\section{Responsabilidades del puesto de Agente de Compras}

- Sobre equipo: no existen

- Sobre recursos financieros: Algunas compras de material.

- Decisiones estratégicas: Puede participar en la modificación o mejora de operaciones.

- Sobre empleados: no existen 


\section{Formación y experiencia requerida para el puesto de Agente de Compras}

- Formación mínima: Compras, control de inventario y almacén, nociones de informática, transporte, control de archivos, contabilidad, buen uso del lenguaje (oral y escrito), relaciones interpersonales, aptitud técnica y numérica, habilidad negociadora.

- Formación aconsejable: Capacidad de comunicación, comunicación electrónica (redes, internet, bases de datos y otras aplicaciones específicas).

- Experiencia:

- EQUIPOS: PC's, periféricos, material de oficina estándar.

- PERSONALES: Comunicación (oral y escrita), dirección de reuniones efectivas, técnicas de dirección con estrés.

- CONOCIMIENTO: Compras inventario, almacenes, transporte, control de archivos y mantenimiento de libros. 


\section{A.I.7 Servicio al cliente}

\section{A.I.7.1 Supervisor de Servicio al Cliente}

- Objetivo general del puesto: Dirigir el programa de servicio al cliente, supervisar que las solicitudes del cliente se convierten en servicios y productos.

- Denominación del puesto: Director de cuentas de clientes, Asistente de operaciones de servicio al cliente, Representante de productos de servicio al cliente, Supervisor de servicio logístico, Supervisor de operaciones.

- Categoría profesional: Mando Operativo/ Intermedio.

- Dependencia jerárquica

- Ascendente: Director General de la Empresa, Director General de logística

- Descendente: Supervisor de servicio al cliente y representantes

- Horizontal: Director de compras, director de tráfico, director de la CS, director de almacén, director en sistemas de información logística

- Relaciones internas: Personal de fabricación, administrativos.

- $\quad$ Relaciones externas: Clientes, Proveedores, personal no directivo.

- Órdenes:

- Recibidas: Supervisión regular recibida por un superior inmediato.

- Realizadas: Actividades directas de administración o personal de apoyo sobre sus tareas.

\section{Descripción de tareas del puesto de Supervisor de Servicio al cliente}

- Cotidianas:

- Aplicar su conocimiento de almacenes, control de inventario, transporte, fabricación, compras y otras tareas.

- Mantener reuniones para educar a los representantes de los consumidores. Recibir información de los representantes y comunicarla a los departamentos.

- Dan información para los usos. 
- Periódicas:

- Utilizar su habilidad de toma de decisiones para conseguir/dirigir los cambiantes deseos de los clientes. Hacer juicios sobre la demanda a Largo Plazo de un producto.

- Conducir reuniones operativas que desarrollen una base de conocimiento sin pérdidas de tiempo y siguiendo el orden del día.

- Ocasionales:

- Utilizar su preparación en supervisión y desarrollo para construir y mantener un servicio al cliente eficaz y efectivo.

\section{Recursos utilizados en el puesto de Supervisor de Servicio al cliente}

- Tecnología: PC’s, teclados periféricos

- Herramientas: Puede ser necesario que conozcan algunos vehículos de utilidad (carretillas) y de autopistas (camionetas).

- Material: Equipo estándar de oficina.

\section{Requisitos del puesto de Supervisor de Servicio al cliente}

- Físicos:

- Vista: Fotográficas, dibujos, modelos, gráficos, cambio de actividades, observar la calidad y cantidad del material, detalles de objetos u operaciones, observar el comportamiento del personal, formas o colores.

- Oído: Entender discursos, identificar la dirección del sonido, escuchar distintos tonos sonidos.

- Destreza manual: Movimientos -con dedos- rápidos.

- Fuerza física: Coordinación de ojos, oídos, manos y pies.

- Intelectuales: Disfrutar de la gente, tomar el liderazgo. Lograr que las cosas funcionen en lugar de tener que establecer acuerdos orientados a dicho logro cosas. Orientación al cliente.

\section{Responsabilidades del puesto de Supervisor de Servicio al cliente}

- Sobre equipo: responsabilidad sobre los equipos existentes y manejados

- Sobre recursos financieros: Pueden participar en establecer presupuestos o compras (50\%). 
- Decisiones estratégicas: Sobre operaciones evalúan y modifican o mejoran operaciones, cambios a Corto Plazo o incluso a Largo Plazo.

- Sobre empleados: Pueden decidir sobre el cambio de procedimientos e incluso (50\%) el número de empleados y la asignación de responsabilidades.

\section{Formación y experiencia requerida para el puesto de Supervisor de}

\section{Servicio al cliente}

- Formación mínima: Conocimiento de la función logística, Core-business, supervisión de empleados y desarrollo de los mismos. Excelente comunicación oral y escrita, habilidad en el manejo del material de oficina, capacidad para trabajar de forma independiente. Capacidad para trabajar en situaciones de estrés y aptitud matemática.

- Experiencia: En puestos de trabajo similares

- EQUIPOS: Pc's, periféricos, equipos estándar de oficina, equipos de telecomunicación

- PERSONAL: Desarrollo y Supervisión de empleados, habilidad directiva y comunicativa.

- CONOCIMIENTO: Marketing, llevar libros de empresa, operaciones informáticas, control de inventario, Seguridad y Salud, compras, Auditoría, presupuesto, ventas, búsqueda de información, contabilidad, análisis del trabajo, beneficios de empleados, selección de personal, Planificación estratégica. Español hablado y escrito correctamente, inglés, lenguajes informáticos. 


\section{A.I.7.2 Representante de Servicio al Cliente}

- Objetivo general del puesto: Relación con los clientes cuando una relación es mantenida, establecida o acabada para asegurar la satisfacción de clientes, contestar dudas, controlar estado del proceso.

- Denominación del puesto: Asistente administrativo.

- Categoría profesional: Operario

- Dependencia jerárquica

- Ascendente: Director de logística, Director de servicio al cliente, supervisor de servicio al cliente

- Descendente: no existe

- Horizontal: agentes de compras, supervisores, administrativos

- Relaciones internas: mandos intermedios, alta dirección o ejecutivos, empleados administrativos, personal de apoyo, personal de marketing.

- Relaciones externas: Proveedores y clientes, empleados de dirección, representantes de compras y ventas.

- Supervisión

- Recibidas: Supervisados por supervisor del área y otros empleados.

- Realizadas: no realizan

\section{Descripción de tareas del puesto de Representante de Servicio al cliente}

- Cotidianas:

- Utilizar recursos informáticos para dirigir las quejas, usos y cuestiones de los clientes: saber recoger toda la información posible y lo más rápido.

- Representar la imagen de la empresa a los clientes.

- Responder dudas, coordinar departamentos, resolver problemas gracias a la habilidad en comunicación.

- Aplicar técnicas de dirección de proyectos e interpesonales para desarrollar un conocimiento que coordine la red de comunicación entre empresas, compartir información con quién la necesite y también para tomar decisiones. 
- Periódicas:

- Mantener un conocimiento profundo del funcionamiento de la empresa y cómo afecta a los clientes.

- Ocasionales:

- Mantener la calma profesional frente a la adversidad y bajo condiciones diversas.

\section{Recursos utilizados en el puesto de Representante de Servicio al cliente}

- Tecnología: PC's, teclados y periféricos.

- Material: Material de oficina estándar.

\section{Requisitos del puesto de Representante de Servicio al cliente}

- Físicos:

- Vista: Fotografías, dibujos, modelos y gráficas, mapas o documentos similares, copias.

- Oído: Entender las instrucciones y darlas

- Destreza manual: Rápidos movimientos con dedos (entrada datos al sistema)

- Fuerza física: no requerida

- Intelectuales: Mantener la sangre fría ante las adversidades, ser educados y correctos, conservadores, bien organizados, orientado al logro de actividades, arreglar procesos y estudiar como funcionan.

\section{Responsabilidades del puesto de Representante de Servicio al cliente}

- $\quad$ Sobre equipo: sobre los equipos de trabajo.

- Sobre recursos financieros: No existen

- Decisiones estratégicas: Pueden cambiar o mejorar operaciones y añadir nuevos productos.

- Sobre empleados: En muy pocas ocasiones intervienen en cambios procedimientos. 


\section{Formación y experiencia requerida para el puesto de Representante de Servicio al cliente}

- Formación mínima: Formación oral y escrita, utilización de equipos de oficina estándar, nociones sobre informática y aptitud matemática.

- Formación aconsejable: Formación en informática para poder obtener toda la información de forma rápida

- Experiencia:

- Equipos específicos: PC's, otros equipos, equipos estándar de oficina, equipos de telecomunicación.

- Habilidad interpersonal: Dirección de proyectos, organización, pensamiento crítico, comunicación oral y escrita.

- Conocimiento: operaciones de transporte, geografía local y regional, prácticas de control de inventario, control de archivos y mantenimiento de libros, planificación estratégica, ambiente de marketing empresarial. 


\section{Anexo II}




\section{ANEXO II- ELABORACIÓN DE LOS CUESTIONARIOS}

En este Anexo II se incluye la metodología básica para la recopilación de datos que permitan verificar el Modelo propuesto de Recursos Humanos aplicado a los sistemas logísticos.

El Anexo II comienza con un repaso a la definición de entrevista y cuestionario, para pasar a estudiar las partes que componen una entrevista, las actitudes, pautas a aplicar en su puesta en marcha, errores a evitar, selección de entrevistados, y realizar la documentación. Se realiza también una comparativa entre los distintos tipos de entrevistas existentes: telefónica, in-situ, por correo y en grupo, examinando tanto sus ventajas como sus inconvenientes.

A continuación se fundamentará la filosofía que seguirán los cuestionarios que se realizarán en la entrevista, tanto para su diseño, como para clarificar los principios que los regirán.

El apartado siguiente aborda realmente la elaboración de los cuestionarios, desde como obtener unos cuestionarios iniciales, la depuración de los mismos, hasta la presentación de cuestionarios semi-elaborados para los puestos propuestos en el Modelo de Recursos Humanos aplicado a la Logística.

La evaluación de los cuestionarios pasará a su vez, por plantear los distintos tipos de sistemas logísticos que pueden encontrarse: ya que existen empresas productoras con departamentos logísticos, operadores logísticos o bien distribuidores comerciales. Tras explicar la evolución por la que han pasado los sistemas logísticos debido a la 
horizontalización de las estructuras de los sistemas empresariales, se optará por un único cuestionario adjuntado en la parte final del capítulo.

\section{A.II.1 METODOLOGÍA PARA LA RECOPILACIÓN DE DATOS}

Antes de llevar a cabo la realización de un cuestionario para una entrevista que se realizará posteriormente para la contrastación de datos, habrá que analizar los distintos tipos de recogida de información posibles, con sus ventajas e inconvenientes así como las partes en que se dividirá la misma, para con toda esta información diseñar la más adecuada para este tipo de trabajo.

Para proceder a la verificación del modelo de Recursos Humanos en los sistemas logísticos, ha de señalarse que la recogida de información de las empresas será de forma tal, que permita acercarse a la realidad y verificar el modelo, pudiendo ser de dos modos, a través de:

Observación: utilización de los sentidos orientados a la selección, captación de la realidad, observación de ambientes y comportamientos a estudiar del problema que se investiga

Entrevistas: suponen una interacción entre dos personas, una de las cuales (investigador- entrevistador) formula unas determinadas preguntas relativas al tema a investigar, mientras que la otra (el investigado o entrevistado) proporciona verbalmente o por escrito la información solicitada.

Existen otros medios de recolección de datos como los cuestionarios, tests, diagramas, escalas, etc. aunque todos ellos están de una u otra manera basados en los dos mencionados.

Ante esta situación, el método que se propone en la realización del presente trabajo es la entrevista en lugar de la observación. 


\section{A.II.1.1 Composición de las entrevistas}

El diccionario de la Real Academia Española, define entrevista como: "la conversación mantenida entre dos o más personas para tratar o resolver un tema o negocio”

El profesor A. González [González] en su Curso Virtual para la enseñanza de la Metodología de Investigación aplicada a la Elaboración de una Tesis de Grado (Unidad III) define entrevista como: "la técnica para recoger información confiable; basada en el arte de la interrogación directa a una o más personas, acerca de los indicadores de un tema previamente determinado".

M. Model [Model2000] tanto en su Libro (cap. 7) y página web define la entrevista como "la técnica primaria para la recolección de información en las fases de análisis de los sistemas durante el desarrollo de un proyecto". No sólo es importante la técnica utilizada para la recolección de información, sino también la habilidad y preparación del entrevistador, el cual debe determinar que información hay que recolectar, la calidad y la profundidad de dicha información, es decir, no sólo es importante la información en sí, sino que el modo de entrevistar, la observación y la búsqueda son también otras herramientas importantes para el análisis.

\section{Clasificación de las entrevistas}

Si se toma por tanto la entrevista como una forma de interacción entre dos individuos que recogen datos para un estudio, se observa que esa interacción puede ser de forma estructurada, cuando se predeterminen en cierta medida las respuestas, o no estructurada, cuando transcurren de forma más libre o espontánea.

- Las entrevistas no estructuradas: pueden a su vez subdividirse en

* Entrevista formal: conversación sobre el tema en estudio, haciendo hablar al entrevistado. Este tipo de entrevista es muy útil para fases iniciales de una investigación. 
* Entrevista focalizada: conversación que versa únicamente sobre un tema, de forma que cuando el entrevistado se desvía del tema principal, el entrevistador centra de nuevo la conversación sobre el asunto.

* Entrevista con pautas: conversación que sigue una serie de puntos durante la entrevista, que el entrevistador dirige para que se toquen todos ellos.

- Entrevistas Estructuradas: se subdividen en

* Abiertas: Son aquellas cuya variedad de respuesta es muy amplia, y hay que ser muy cuidadoso con ellas para evitar respuestas confusas.

* Cerradas: Otorgan al entrevistado la posibilidad de elegir entre el número de posibles respuestas.

Este tipo de entrevistas estructuradas utilizada como guía un listado concreto de preguntas denominado cuestionario.

Antes de poner en marcha la entrevista basada en el cuestionario confeccionado para tal fin, se realizará una prueba piloto como ensayo. Así, se conseguirán las alternativas más votadas y la seguridad de que el cuestionario es fácilmente comprensible.

Para decidirse por una entrevista estructurada o no estructurada será recomendable atender a las variables que a continuación se presentan sobre los beneficios que proporciona una u otra. Entre ellos se pueden destacar como la entrevista estructura es más fácil de evaluar, necesita menor tiempo, y menor entrenamiento para el entrevistador, teniendo éste mayor control sobre el entrevistado y mayor precisión y confiabilidad en los resultados. Mientras su parte más negativa viene de la poca espontaneidad y flexibilidad que permite, así como la poca posibilidad de perspicacia admitida por el entrevistador, quedando un resultado poco amplio y profundo. 
En el otro extremo, la entrevista no estructurada es más difícil de evaluar, y necesita una mayor cantidad de tiempo y entrenamiento, que con un alto grado de espontaneidad, flexibilidad y perspicacia proporcionan un alto grado en la profundidad y amplitud de resultados. Otros inconvenientes son el poco control que puede tenerse sobre los entrevistados, la precisión de los datos obtenidos y la baja fiabilidad.

Todas estas características tanto de las entrevistas estructuradas como de las no estructuradas se muestran la Tabla A-II. 1

\begin{tabular}{ccc}
\hline No estructurada & Variable & Estructurada \\
\hline Difícil & Evaluación & Fácil \\
\hline Alto & Cantidad de tiempo requerida & Bajo \\
\hline Muy necesario & Entrenamiento requerido & Limitado \\
\hline Mucho & Permite espontaneidad & Poco \\
\hline Mucha oportunidad & Perspicacia del entrevistado & Poca oportunidad \\
\hline Grande & Flexibilidad & Pequeña \\
\hline Bajo & Control del Entrevistado & Alto \\
\hline Bajo & Precisión & Alto \\
\hline Bajo & Confiabilidad & Alto \\
\hline Alto & Amplitud y profundidad & Bajo \\
\hline
\end{tabular}

Tabla A-II. 1: Comparación entre Entrevistas Estructuradas y No Estructuradas. Fuente Morales [Morales]

\section{Partes que componen una entrevista}

M. Morales [Morales] basándose en el análisis de los libros: "Análisis y Diseño de los sistemas de Información" de Kendall and Kendall, "Análisis y Diseño de los Sistemas de Información" de J.A. Senn y "Análisis y Diseño de los Sistemas de Información" de Whitten, Bentley y Barlow, propone como partes de una entrevista las siguientes:

- Selección de entrevistados: Para dicha selección es muy útil la ayuda de un organigrama que identifique a las personas y sus responsabilidades. Una vez seleccionada la persona a entrevistar, ha de tenerse en cuenta su posición y sus características, así como concertar una cita. Las citas tendrán una duración aproximada de media a una hora. y al concertarlas, deberá confirmarse el lugar donde se realizará la entrevista. 
- Preparación de una entrevista: Tanto por parte del entrevistado, haciéndole llegar el tema sobre el que versará la entrevista, cómo si fuera posible un guión de las preguntas a realizar. El entrevistador deberá tener un buen guión, que contenga preguntas de tipo quién, qué, cuándo, dónde, porqué y cuánto. Evitándose preguntas con segunda intención, preguntas dirigidas o con prejuicios. La preparación para el entrevistado supondrá lectura de material acerca de la empresa y el entrevistado, establecimiento de objetivos a lograr con la entrevista, decir qué tipos de preguntas se van a realizar.

- Inicio de la entrevista: Sirve para animar o motivar al entrevistado y a comunicarse con el mejor ambiente. Se notificará como se realizará el registro de la entrevista: si se hará uso de una grabadora o tomarán notas

- Cuerpo principal de la entrevista: En esta fase se obtienen las repuestas preparadas para preguntar al entrevistado. No solo ha de ajustarse a la entrevista, sino hay que escuchar y observar al entrevistado y tomar nota de sus actitudes verbales o no.

- Conclusión de la entrevista: Para finalizar, el entrevistador debe ofrecerse a contestar alguna de las preguntas que el entrevistado quiera formular, realizar un resumen y hacer saber las impresiones, así como informar sobre los pasos subsecuentes a tomar. Ha de agradecerse siempre la colaboración y el tiempo dedicado al entrevistado.

A su vez, puede comprobarse que estas etapas forman parte de un ciclo repetitivo para cada entrevista, que puede explicarse como sucesión de etapas con cierto orden que supone un ciclo de vida del proceso de la entrevista, al igual que los ciclos de vida expuestos en el capítulo tercero, ya que hay una planificación a la hora de realizar la selección de los entrevistados, un análisis y diseño al hacer la preparación de la entrevista y los cuestionarios, una implantación que supondrá la puesta en marcha de la entrevista, aunque esta tenga un inicio un cuerpo y una conclusión que se puede tomar como una etapa de comprobación o control. 
Estas etapas son recomendables para la buena realización de una entrevista, ya que saltarse alguna de ellas supone que aunque puedan obtenerse resultados de la entrevista, ésta no será tan productiva como en el caso de que se cuiden y cumplan todos los pasos.

\section{Pautas para la realización de una entrevista}

Dada la existencia de varias etapas y la variedad de metas de una entrevista, es evidente la importancia de realizar la entrevista de forma correcta. Puesto que la entrevista en sí, supone un intercambio de información entre dos o más personas, estableciéndose un sistema de pautas tanto para el entrevistador como para el entrevistado.

El entrevistador debe asegurar que nada interfiere en el objetivo que persigue, siendo para el INEI [INEI1997 Cap. 4] la recopilación de información de tipo tanto cualitativa (relacionada con opiniones, políticas y descripciones narrativas de actividades o problemas), como cuantitativa (suelen ser números, cantidades, frecuencias...), es decir, ha de recopilar información completa, y exacta. La entrevista supondrá una conversación, aunque realmente sea un proceso, con sus reglas y pautas que lo rigen. Estas pautas son para M.Model[Model2000]:

1. Establecer el tono de la entrevista: Especificando el tipo de entrevista a realizar: estructurada o no estructurada, preguntas detalladas inicialmente y posteriormente más generales (estructura de pirámide), o al revés como recomienda A. González [González] (estructura de embudo) o incluso ambas (estructura de rombo) propuestas todas por Morales [Morales]

2. Explicar al entrevistado el porqué de la entrevista y el motivo de su selección, denominado por A. González [González] "Romper el hielo" incluso se propone anticipar el tema de la entrevista y hasta los cuestionarios para su reflexión. El INEI [INEI1997] propone comenzar con una presentación subrayando el tema de la entrevista y estableciendo la naturaleza del trabajo que se está realizando. 
3. Hacer énfasis en la importancia del conocimiento y opiniones del entrevistado para el análisis final. A. González [González] señala esta parte como introducción a la entrevista.

4. Ganar la confianza y cooperación del entrevistado lo antes posible, y mantenerla a lo largo de la entrevista. A. González [González] apunta evitar preguntas delicadas, manipuladas o que generen antipatía.

5. Explicar qué sucederá con la información recopilada. El entrevistado se expresará más cómodamente si conoce con anterioridad el tratamiento se le dará a la información que aporte. Permitir al entrevistado saber que la sinceridad y la honradez serán valoradas y que no se publicará ni será filtrado nada hasta que no se haya repasado y verificado por el entrevistado.

6. Determinar las áreas confidenciales o de información restringida. Para evitar entrar en temas delicados, e intentar no hacer más preguntas de las estrictamente necesarias, y que éstas sean cortas, concretas, fáciles de recordar de principio a fin.

7. Aclarar que no existirán consecuencias negativas por el hecho de ser entrevistado, así como que no se remunerará económicamente al entrevistado como detalla A.González [AGonzález]

8. Maximizar el tiempo de la entrevista: no debe perderse el tiempo y para ello se recomienda que no excedan de entre cuarenta y cinco minutos y una hora. Si se exceden de tiempo se estará ante una perdida de trabajo tanto para entrevistado como para entrevistador como señala Morales [Morales]

9. Archivar una copia de la entrevista revisada por el entrevistado: esto se realiza con el fin de poder evitar posteriores reclamos. Para ello, debe resumirse la información recabada en la entrevista y enviar una copia al entrevistado para su 
aprobación. Dicha revisión es la que debe archivarse según señala el INEI [INEI1997]

\section{Actitudes ante una entrevista}

La Sociedad Latinoamericana para la Calidad [ㄴㄷ], Model [Model2000], Morales

[Morales], y el INEI [INEI1997] señalan una serie de actitudes muy recomendables para la realización de entrevistas. Éstas son las siguientes:

a. Definir el tipo de datos que se quiere reunir: teniendo bien claro el tipo de información que se busca y como se va a recoger (SLC)

b. Hacer buenas preguntas, a través de preguntas enfocadas a la obtención de información y de las que resulten datos fáciles y claros para reunir (SLC)

c. Ser imparcial en la recolección, y no manipular las respuestas del entrevistado.(SLC)

d. Utilizar formatos sencillos para la recopilación de datos, que puedan ser manejados sin problemas ni complicaciones.

e. Realizar pruebas piloto antes de realizar las entrevistas finales para que confirmen su adecuación. (SLC)

f. Mantener siempre una clara distinción entre hechos y opiniones del entrevistado, identificando en la documentación recogida lo que sean hechos y lo que sea opinión.

g. Seleccionar a los entrevistados a todos los niveles, es decir, que los entrevistados sean representativos de la población que se quiere analizar. (Morales). Para ello el INEI propone hacer una lista de todas las personas consideradas por su experiencia y conocimiento como claves para el desarrollo de las entrevistas.

h. Documentar todas las fuentes de información, sobre todo hechos y números.

i. Fechar toda la documentación, tanto la original como las futuras revisiones que se vayan generando, así como numerar todas las páginas de la documentación e incluir un índice donde o tabla de contenido y pueda localizarse cada sección. 
j. Recoger toda la información, aunque sea excesivamente extensa. Es mejor pecar de mucho que dejar fuera información relevante. Se recomienda que se comience a recabar antes de la entrevista para que el entrevistador informe sobre la organización y el entrevistado (Morales)

k. Utilizar terminología para aquellos a los que se dirija. Es decir, manejar el lenguaje utilizado por el personal del departamento u organización (Morales). A su vez debe incluirse en la documentación un glosario que defina estos términos especiales.

l. Incluir un resumen que contenga conclusiones, y recomendaciones, debiendo explicarse a fondo en los materiales de apoyo.

m. Utilizar cuadros, gráficos y diagramas, debido a lo explicativos, informativos y de fácil entendimiento. Deberá adjuntarse un listado de todos los cuadros, gráficos y diagramas.

n. Hacer uso de siglas, explicando éstas detalladamente en su primer empleo, e incluir un listado de estas siglas y sus significados.

o. Los documentos deben ser claros y legibles, recomendándose frases cortas, evitando la verbosidad y pomposidad. Esto ha de revisarse particularmente si el documento lo han escrito entre varias personas.

\section{Errores a evitar durante la realización de entrevistas}

Durante la entrevista han de evitarse errores del tipo de los señalados a continuación:

- Actitud expresa de ocultamiento de datos por parte del entrevistador, mentiras o invenciones

- Actitudes o ideas previas del entrevistador que impidan una visión objetiva de la situación problemática o que influyan en el desarrollo de la entrevista distorsionando la realidad.

- Situaciones de inhibición y bloqueo 
- La proyección de conflictos y frustraciones del entrevistador sobre el entrevistado.

- Influencia del entrevistador por su apariencia general o a través de rasgos de su personalidad.

- Utilizar refuerzos no apropiados o no reforzar suficientemente al entrevistado

- No llegar a definir la situación o problema por falta de datos

- No acertar en el grado de estructuración de la entrevista, como cuando se hace de forma demasiado cerrada, o impidiendo espontaneidad al sujeto

- Permitir que el entrevistado dirija la entrevista, evitando afrontar situaciones molestas.

- No abordar a fondo las situaciones o problemas por temor a que el entrevistado se vea inmerso en un estado de ansiedad o bloqueo

- Preguntar varias cosas de una vez, lo que crea confusión o bloqueo

- No atender a las comunicaciones no verbales del sujeto.

\section{Selección de los entrevistados}

Uno de los puntos fundamentales de las entrevistas es determinar quien será entrevistado en cada situación para lograr la correcta la recogida de datos. Esto implica realizar una selección de los posibles entrevistados o empresas elegidas, estudiar que se puede obtener de cada una de las entrevistas según el nivel de quien haya de ser entrevistado, verificar la información recibida de cada entrevista, y lo más importante, comprender el enfoque de la persona entrevistada.

En este trabajo, las entrevistas se realizarán dentro del departamento logístico de las empresas y se centrarán en los cinco niveles de puestos propuestos en el modelo de Recursos Humanos para los Sistemas Logísticos. 


\section{La documentación}

Para llevar a cabo una buena y eficaz documentación de cara a la realización de una buena entrevista es necesario conocer la información de carácter público que exista alrededor de la empresa o departamento.

Para ello, es necesario realizar una investigación previa de la empresa y conseguir folletos actuales, notas informativas, la publicidad emitida, etc. Esta información permitirá forjar un primer modelo de la actividad o actividades que realiza la empresa y como la lleva a cabo. La parte negativa de dicha documentación supone que la recopilación de datos puede convertirse en algo tedioso y aburrido, aunque debido a su importancia de cara al análisis es necesaria y por ello es fundamental su realización. Realizar una buena documentación puede resultar aburrido y tedioso, pero hay que tener en cuenta su importancia tanto para las personas que se reenganchen al proyecto, como para el éxito de fases posteriores.

A la hora de llevar a cabo las entrevistas, habrá que buscar documentación suficiente para que respalde esas entrevistas, así como estar pendientes de realizar observaciones, búsquedas y todo aquello que sirva para el análisis final de la información obtenida, analizada desde los principios que rigen la entrevista.

La buena documentación de una entrevista evita a su vez tener que repetirla, pudiendo ser revisada, hasta lograr una buena comprensión del tema tratado.

Por tanto, además de la preparación de la información previa que ha de estudiarse para realizar la entrevista, hay que determinar por adelantado que puntos deberán observarse, anotarse, y dar relevancia durante el desarrollo de la misma para obtener más información. Sobre la base del trabajo de M. Model [Model2000] se proponen como recomendables los siguientes puntos, para la realización de la entrevista:

1. Quien fue entrevistado: cargo, función del entrevistado, su inmediato superior, y quien realizó la entrevista: nombre y el cargo del entrevistador 
2. Fecha, duración, y lugar donde se realizó la entrevista

3. Objetivo de la entrevista

4. Trabajo del entrevistado (o descripción funcional)

5. Organigrama del entrevistado y descripción completa de hechos obtenidos durante la entrevista

6. Descripción completa de opiniones de los entrevistados: estas opiniones se recogerán a través de los cuestionarios.

7. Conclusiones de los hechos u opiniones emitidas

8. Anotar comentarios relevantes realizados por el entrevistado

9. Números, información importante para la distribución de tareas, de capacidad, de calidad, etc., obtenida durante la entrevista

Model [Model2000] señala una serie adicional de puntos a tener en cuenta como los posibles problemas existentes, diagramas de consecuencia de actuaciones, etc. pero este trabajo no los recoge debido a que el propósito perseguido es analizar la situación del modelo de Recursos Humanos en la empresa.

Cabrero y Richart [Cabrero_Richart] señalan que la calidad de los datos que se obtienen en una entrevista dependerá en gran medida de las aptitudes de relación interpersonal del entrevistador, quien debe procurar crear un clima agradable en la entrevista para entablar un buen nivel de comunicación. 
Tipos de entrevistas y sus principales ventajas e inconvenientes

A continuación se va a hacer un análisis sobre los distintos tipos de entrevistas existentes, así como sus ventajas e inconvenientes. Los tipos de entrevistas que se van a reflejar a continuación son: entrevista telefónica, encuesta por correo, entrevista en grupo, visitas in-situ

\section{Entrevista telefónica:}

Utilizadas para recabar respuestas de tipo si/no, o muy enfocadas a obtener una respuesta.

Características:

- El tamaño de la muestra relativamente es limitado.

- La tasa de respuesta es relativamente alta

- $\quad$ El tiempo de respuesta es muy rápido

- $\quad$ Tiene un coste moderado

- Bueno para recabar información relativamente simple 


\section{Ventajas}

Desventajas

- El entrevistador puede ayudar aclarando las - No se puede establecer relación con el preguntas si no se entienden entrevistado

- Es el método más rápido de recoger la información y con mejor tarifa de

- El alcance de la encuesta ha de ser respuesta que el envío por correo.

- Es el tipo de entrevista menos cara necesariamente limitado

- Los entrevistados se cansan

rápidamente

- Es difícil programar por adelantado entrevistas telefónicas

- Es muy difícil conseguir llamadas de vuelta

Tabla A-II. 2: Ventajas e Inconvenientes de la entrevista telefónica según Model

Para que una entrevista telefónica sea efectiva Model [Model2000] da los siguientes consejos:

- Desarrollar una escritura corta, concisa y clara

- Probar las preguntas que serán ejecutadas con miembros del proyecto y posibles entrevistados.

- Ponerse en contacto con el entrevistado antes de la entrevista.

- Establecer por adelantado un tiempo para la entrevista con entrevistado

- Entregar un cuestionario al entrevistado con el contenido de la entrevista para que disponga información de fondo y prepare la entrevista real.

- Intentar no desviar del formato predefinido. 
- Desarrollar un cuestionario con preguntas cortas, concisas, claras, que no sean susceptibles a respuestas ambiguas

- Probar las preguntas que serán ejecutadas con miembros del proyecto y posibles entrevistados.

- $\quad$ Ponerse en contacto el entrevistado antes y después de distribuir la encuesta.

- Hacer una encuesta rápida y fácil de completar (intentar que su respuesta no suponga más de 30 minutos)

- Incluir un sobre con franqueo pagado para la devolución del cuestionario

- Pedir permiso para realizar seguimiento de respuestas que sean confusas, pidiendo un número de contacto así como el mejor momento para contactar.

\section{Entrevista de grupo}

Cabrero y Richart, [Cabrero_Richart] proponen que las entrevistas de grupo se utilicen para conversar en grupo acerca de una serie temas que aparecen en una guía. Su importancia radica en la obtención de distintas reacciones diferentes frente a un asunto. Los grupos focales generan la sinergia entre los participantes que están en el mismo nivel técnico o de organización.

\section{Características:}

- El tamaño de la muestra es relativamente limitado

- La tasa de participación es relativamente buena

- El tiempo de respuesta es bueno 
- $\quad$ Tiene un coste de moderado a alto

- Buen sistema para recolectar tanto datos simples como sumamente detallados

\begin{tabular}{lc}
\hline \multicolumn{1}{c}{ Ventajas } & Desventajas \\
\hline - El entrevistador puede clarificar preguntas - El grupo fácilmente puede decir que no se \\
si las respuestas no se entienden & ha explicado correctamente \\
\hline - Esto puede ser usado para unir datos de & - Es difícil programar entrevistas \\
diversas fuentes simultáneamente & telefónicas por adelantado \\
\hline - La interacción de grupo proporciona una & - Es difícil conseguir devolución de \\
$\begin{array}{ll}\text { validación inmediata de los datos } \\
\text { recogidos }\end{array}$ & llamadas \\
\hline
\end{tabular}

Tabla A-II. 4: Ventajas e Inconvenientes del Entrevista de grupo según Model

Para que la entrevista de grupo sea efectiva Model [Model2000] proporciona los siguientes consejos:

- Distribuir el orden del día antes la reunión

- Pedir a los participantes su presentación

- Dar a los participantes una información concisa sobre el proyecto, comentándo porqué se cuenta con ellos y porqué se definen los objetivos de la reunión

- Empezar con asuntos y preguntas sencillas, hacia las más difíciles.

- Documente los procedimientos y saque una copia para todos los participantes

- Garantizar el anonimato de los participantes

\section{Visitas in Situ}

Se utilizan para obtener directamente información de primera mano de los procesos, actividades, el ambiente físico y condiciones de trabajo. 


\section{Características:}

- El tamaño de la muestra es relativamente limitado

- $\quad$ El tiempo de vuelta al servicio es muy lento

- Coste muy alto

- Bueno para reunión de datos sumamente detallados

\begin{tabular}{lc}
\hline \multicolumn{1}{c}{ Ventajas } & Desventajas \\
\hline $\begin{array}{l}\text { - Ayuda al entrevistador el entendimiento } \\
\text { del ambiente de trabajo del proyecto. }\end{array}$ & $\begin{array}{c}\text { - El equipo de miembros puede usarlo como } \\
\text { una oportunidad para un viaje de estudios } \\
\text { más bien que como recogida de datos. }\end{array}$ \\
\hline $\begin{array}{ll}\text { - Obtiene información que no podría ser } \\
\text { compartida durante las entrevistas }\end{array}$ & $\begin{array}{c}\text { - El número de los sitios a visitar puede ser } \\
\text { limitado. }\end{array}$ \\
\hline - Valida datos enlazados de otras fuentes & - Tiempo y consumo de recursos \\
\hline & - Programación muy cuidada \\
\hline & - Gran número de elementos \\
& distorsionadores \\
\hline
\end{tabular}

Tabla A-II. 5: Ventajas e inconvenientes de la entrevista In -Situ según Model [Model2000]

Para que la entrevista in situ sea efectiva Model [Model2000] proporciona los siguientes consejos:

- Prepararla con cuidado

- Asegurar que existe un orden del día claro y que todos los participantes lo conocen

- Verificar todas las citas por adelantado

- Adelantar la información de fondo sobre el proyecto, así como las cuestiones que se harán al entrevistado. Lo que ayudará a prepararse para la entrevista real 


\section{A.II.1.2 Filosofía y Principios sobre los que se rigen los cuestionarios}

Al comienzo de la pregunta anterior, se ha definido cuestionario como: "un conjunto formal de preguntas realizadas para obtener una información por parte de los entrevistados". De una u otra forma los autores coinciden al señalar dicha definición, y pudiendo concluirse con la definición aportada por Morales [Morales] como una "técnica de recopilación de información que permite a los analistas estudiar actitudes, creencias, comportamientos y características manifestadas por los encuestados a través de respuestas a preguntas realizadas"

Los objetivos que deben alcanzar los cuestionarios según dicho autor son:

* Traducir la información necesaria a un conjunto de preguntas específicas que los entrevistados puedan contestar.

* El cuestionario debe levantar la moral, motivar y alentar al entrevistado para que participe, coopere y termine la entrevista. De tal modo que al diseñar el cuestionario debe hacerse de modo que se minimice la fatiga, el aburrimiento y el esfuerzo del entrevistado, para evitar que se quede a medias o responda de forma incompleta.

* Un cuestionario debe minimizar el error de respuesta, evitando obtener respuestas incorrectas e inexactas.

\section{Proceso de diseño de los cuestionarios}

El diseño de un cuestionario supone la elaboración de las preguntas para obtener la información necesaria para el futuro análisis. La elaboración de un cuestionario supone un proceso en el que se siguen una serie de etapas mostradas en la Ilustración A-II. 1. La confección de los cuestionarios se plantea de forma tal, que recojan el mayor conocimiento posible, con el menor número de preguntas para cada uno de los entrevistados. 
Estas etapas comienzan con la especificación de la información que se está buscando y cómo se realizará la entrevista. Es fundamental cuestionar estos pasos antes de comenzar a redactar el formato de los cuestionarios, ya que es aquí donde se cuestiona la información que se está buscando y como se realizarán las entrevistas: si serán estructuradas o no estructuradas, y el medio elegido para su realización.

A continuación se determinará el contenido de las preguntas, buscando aquellas que sean necesarias y suficientes para obtener la información deseada: unas veces se utilizarán preguntas dobles, tratando de cubrir dos temas y otras preguntas de tipo directo, intentando ofrecer posibles soluciones que ayuden al entrevistado a contestar.

Las siguientes etapas a realizar corresponderán al diseño de las preguntas y su estructura, y la redacción, con el fin de obtener respuestas exactas o razonables, y superar la incapacidad de respuesta de algunos entrevistados. Han de ser cuestiones claras y fáciles de responder, utilizando palabras comunes, evitando palabras ambiguas, suposiciones, generalidades y preguntas tendenciosas.

A continuación se realizará la ordenación de las preguntas, teniendo siempre presente la estructura que se ha decidido seguir en el cuestionario. Malhotra [Malhotra97p. 335] recomienda comenzar con preguntas iniciales, sencillas, que sirvan para ganar la confianza y cooperación de los entrevistados. Esto conlleva a incluir los temas delicados más adelante en la secuencia. Dicha estrategia es denominada por Morales [Morales] como Estrategia de embudo.

Tras ello, queda reproducir el cuestionario lo que supone estudiar el formato. Según el tipo de entrevista que se haga, se utilizará un formato, papel, hojas grapadas, doble página, o incluso incluir cada pregunta en una sola página, etc. Finalmente hay que eliminar los problemas mediante la prueba previa, que identificará y eliminará los problemas esenciales tras la aplicación a una muestra reducida de entrevistados. 


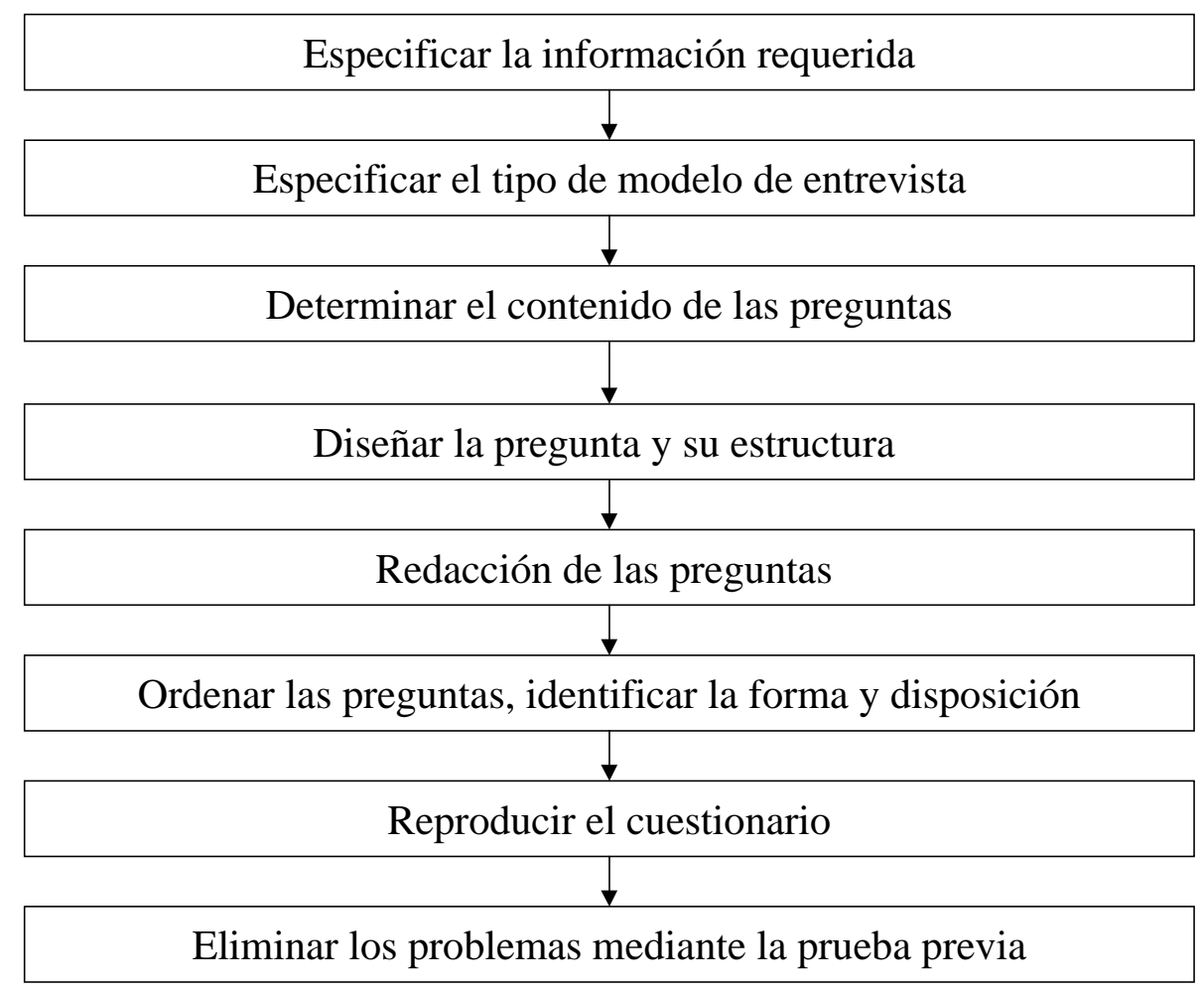

Ilustración A-II. 1: Proceso de diseño de cuestionarios. Basado en Malhotra

[Malhotra97p. 321]

Puede comprobarse como esta sucesión de etapas sigue también un ciclo de vida, como se estudió en el capítulo tercero de este trabajo. En este diseño de cuestionarios, se podría identificar un ciclo de vida con las siguientes etapas como muestra la Tabla A-II. 6 donde muestra como la etapa de Planificación de una entrevista supone especificar tanto la información requerida como el tipo de modelo de entrevista. En la etapa de Análisis, se determinará el contenido de las preguntas que compondrán la entrevista; mientras que la etapa de Diseño supondrá diseñar como van a ser las preguntas en base al tipo de entrevista que se realice, la información requerida y el contenido de las preguntas, por ello habrá que poner especial atención a la redacción y orden de las preguntas en el cuestionario o guión que se utilice en la visita. La implementación supondrá reproducir y realizar la entrevista en sí, y el control llevará a realizar pruebas del cuestionario y eliminar los posibles problemas que puedan surgir en este proceso. 


\begin{tabular}{cll}
\hline Etapa del ciclo de vida & & Etapa de diseño del cuestionario \\
\hline PLANIFICACIÓN & - & Especificar la información requerida \\
& - & Especificar el tipo de modelo de \\
& entrevista \\
\hline ANALISIS & - & Determinar el contenido de las preguntas \\
\hline DISEÑO & - & Diseño de las preguntas y su estructura \\
& - & Redacción de las preguntas \\
& - & Ordenar las preguntas \\
& - & Reproducir el cuestionario \\
\hline IMPLEMENTACIÓN & Eliminar problemas mediante pruebas \\
\hline CONTROL &
\end{tabular}

Tabla A-II. 6: Etapas de Ciclo de vida en la elaboración del cuestionario

Para Malhotra [Malhotra97 p. 320] la gran debilidad de los cuestionarios es la falta de teoría, puesto que no existe ningún principio científico que garantice un cuestionario óptimo o ideal.

\section{Principios que rigen los cuestionarios}

Los cuestionarios aquí planteados se van a regir por una serie de principios básicos sobre las empresas. Estos principios son los que a continuación se detallan: el Principio de Retención Selectiva, el Principio de Simplicidad, el Principio de Incertidumbre, el Principio de Oscuridad, el Principio de Variedad Obligada, que a continuación se detallan:

\section{Principio de Retención Selectiva}

El Principio de Retención Selectiva es enunciado por Domínguez [Domínguez2000 Principio $\mathrm{n}^{0} 12$ p.21] y por Heylighen [ configuraciones estables son retenidas, las inestables son eliminadas." 
La aplicación a la elaboración de cuestionarios es muy simple, ya que para su creación se tomarán aquellas preguntas que sean estables y busquen la máxima cantidad de información posible, eliminado aquellas que sean inconsistentes o que no proporcionen la debida información. De ahí procede a su vez la importancia de realizar las entrevistas piloto antes de comenzar a hacer las verdaderas entrevistas.

\section{Principio de Simplicidad}

El Principio de Simplicidad enunciado por Umpleby [Umpleby]: "Ha de elegirse siempre la explicación más simple de un fenómeno, es decir aquella que requiera los menores saltos de lógica"

Para los cuestionarios supone ir a lo más sencillo y más simple, preguntando siempre por explicaciones que requieran los menos desarrollos posibles, para evitar equivocar tanto al entrevistado como al entrevistador.

\section{Principio de Incertidumbre}

El Principio de Incertidumbre enunciado por Domínguez [Domínguez2000 Principio $\mathrm{n}^{\circ} 21$ p. 32] y por De Rosnay [De_Rosnay] supone: "Cualquier interacción entre el sistema y el entorno hace que cambien ambos. Entre más explore el sistema a su entorno, más difícil será para él obtener información acerca del estado inicial de lo que observa y sus observaciones estarán más contaminadas"

Aplicado a las entrevistas que se realizarán en las empresas que aplican logística, supone que cuando existan interacciones entre el entrevistador y la empresa, más cambios se irán produciendo, y por tanto será más difícil abstraer y estudiar la situación inicial existente.

Domínguez [Domínguez2000 p. 32] apunta que "si el Principio de Incertidumbre es válido, no habrá razón para observar el entorno, ya que nunca se podrá identificar la razón que originó el cambio. Sin embargo, se puede reducir al mínimo dicho error, maximizando la posible pérdida de información". 
Esto supone que si se van a realizar unas entrevistas en determinadas empresas, deberá procurarse la máxima información y documentación.

\section{Principio de la Oscuridad}

El Principio de Oscuridad enunciado por Domínguez [Domínguez2000 Principio nº24 p.35] supone: "A pesar de que un sistema no se puede conocer completamente, éste se puede administrar efectivamente".

Este principio supone que aunque no se conozca todo el conocimiento relativo a un tema, ha de procurarse a través de la transferencia de la información, es decir, sacar el máximo conocimiento a través de las entrevistas. Esto supondrá vencer barreras para sacar el conocimiento que poseen los entrevistados y de ahí abstraer dicho conocimiento para aplicarlo al modelo propuesto en este trabajo.

\section{$\underline{\text { Principio de Variedad Obligada }}$}

El Principio de Variedad Obligada lo enuncia Domínguez [Domínguez2000 Principio n 37 p.87]: "Entre mayor sea la variedad de acciones disponibles en un controlador más grande será la variedad de perturbaciones que le es posible compensar"

Dicho principio aplicado al estudio de un sistema logístico supondrá que cuantas más acciones tenga que llevar a cabo un puesto de trabajo, mayores serán las perturbaciones que puede recibir y por tanto solucionar.

\section{A.II.2 ELABORACIÓN DE LOS CUESTIONARIOS}

Una vez decidida la metodología a seguir para la obtención de los datos en las empresas. En este caso, corresponderá a las visitas in-situ, tras lo que se procederá a la elaboración de los cuestionarios que se utilizarán para dichas visitas. En este apartado se procede a explicar de la elaboración de los cuestionarios basándose en el modelo de Recursos Humanos propuesto en el capitulo séptimo. 


\section{A.II.2.1 Cuestionarios Iniciales}

Los cuestionarios van a ser la base para la obtención de información en las empresas a visitar. Dichos cuestionarios serán elaborados basándose en los distintos puestos propuestos en el modelo de Recursos Humanos propuesto para los Sistemas Logísticos del capítulo séptimo: Director General Logístico, Analista Logístico, Diseñador Logístico, Jefe Operativo y Operarios. Por lo tanto, dependiendo del puesto a entrevistar, las preguntas tendrán una u otra orientación, lo que supondrá realizar cuestiones de carácter más estratégico a los puestos directivos y de carácter más puntual a los operarios.

Una vez identificados aquellos que han de ser entrevistados, se procederá a analizar las áreas sobre las que se les realizarán preguntas consistentes. Éstas corresponderán a lo que a como afectan los elementos empresariales explicados en el capítulo segundo: procesos, productos (o servicios), infraestructura, información y personal, y respecto a todo ello, cuestionarán: ¿Qué?, ¿Cómo?, ¿Cuándo?, ¿Quién?, ¿Dónde? y ¿Porqué?.

Con todos estos elementos, se podría dibujar la situación de partida como la que muestra la Ilustración A-II. 2, donde aparecen reflejados en el eje horizontal los elementos empresariales presentados en el capítulo segundo: procesos, productos o servicios, infraestructura, información y personal, en el eje vertical los puestos logísticos obtenidos del Modelo de Recursos Humanos aplicado a los sistemas logísticos, y finalmente en un tercer eje situado a la izquierda, las preguntas sobre ¿Qué?, ¿Cómo?, ¿Cuándo?, ¿Quién?, ¿Dónde? y ¿Porqué?. 


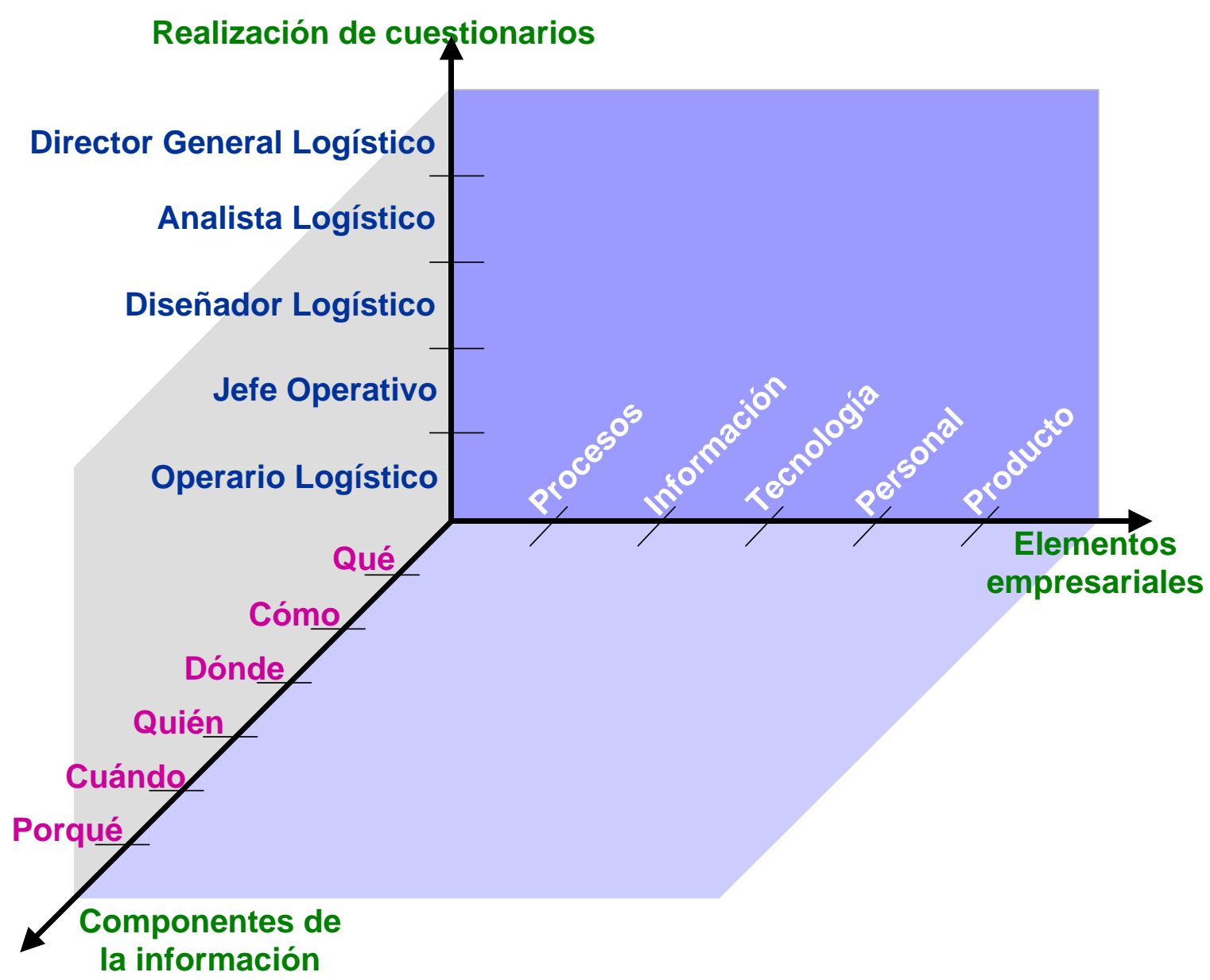

Ilustración A-II. 2: Elementos de partida para la elaboración de los cuestionarios. Fuente: Elaboración propia

La generación de los cuestionarios surgirá por una combinación de los tres ejes propuestos en la Ilustración A-II. 2, de forma que a cada uno de los puestos se les realicen preguntas que contengan información referente a los elementos empresariales, además de: Qué, Cómo, Quién, Dónde, Cuándo, Porqué, de cada elemento empresarial. Con ello se obtendría un cuestionario diferente para cada uno de los puestos como muestra la Ilustración A-II. 3, ya que no deben ser los mismos los cuestionarios realizados a los directivos logísticos debido que éstos realizarán tareas más bien de gestión y dirección como se explicó en el capítulo quinto (Ilustración 5.4), mientras que los cuestionarios que se realicen a los operarios harán más referencia a las operaciones puntuales que éstos llevan a cabo, y por tanto serán más específicos y puntuales en cuanto a esas operaciones. 


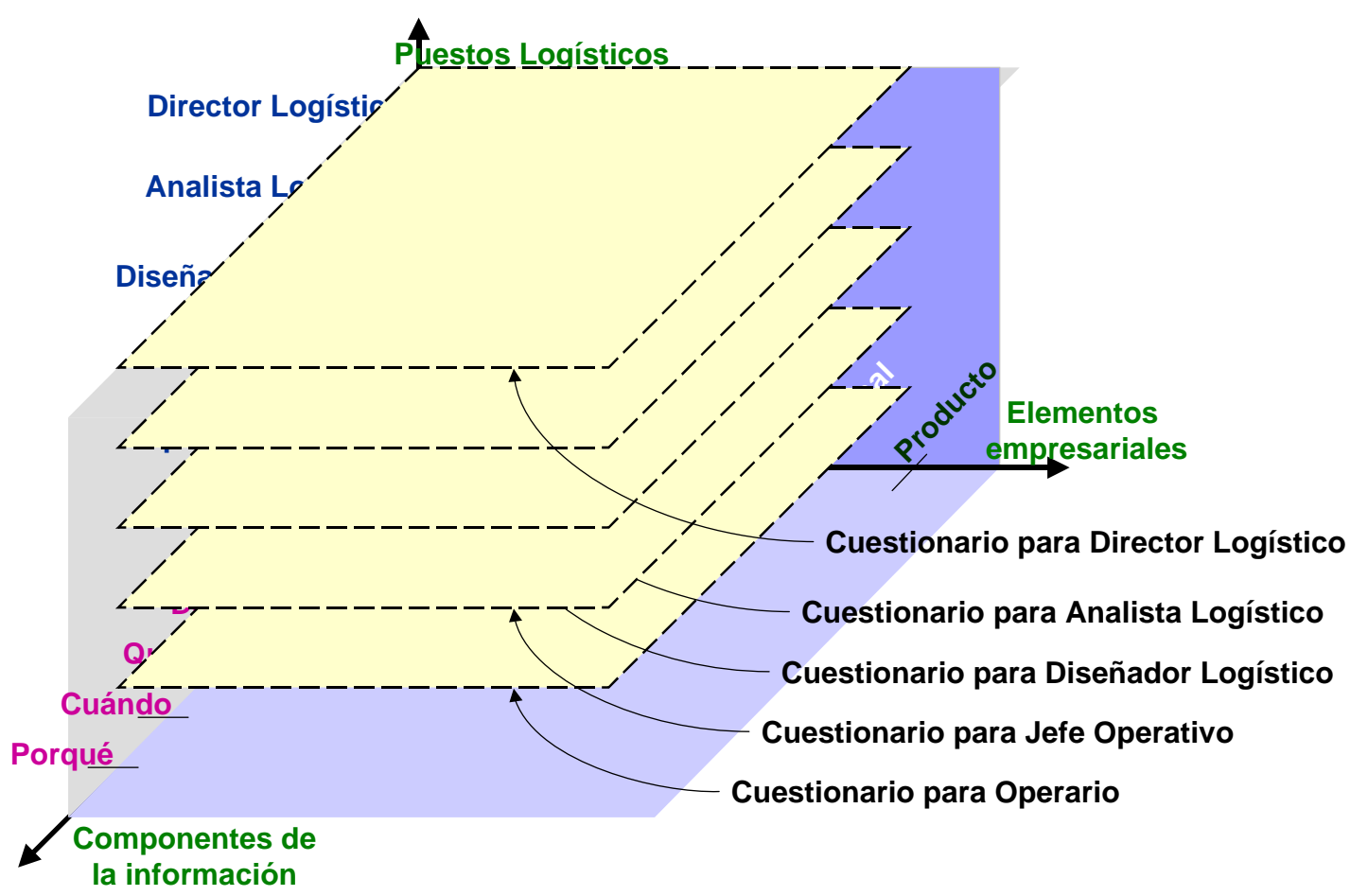

Ilustración A-II. 3: Obtención de los cuestionarios para los distintos puestos logísticos. Fuente: Elaboración propia

\section{A.Il.2.2 Depuración de los cuestionarios}

Una vez obtenidos los cuestionarios para los cinco puestos logísticos propuestos: Director Logístico, Analista Logístico, Diseñador Logístico, Jefe Operativo y Operarios Logísticos, habrá que proceder a realizar una depuración de los mismos, ya que existirán algunas cuestiones las cuales pueden ser poco concluyentes, excesivamente redundantes o no tengan excesivo sentido para las tareas que se realizan.

Por lo tanto, con el fin de no cansar y no hacer perder excesivo tiempo a aquellos trabajadores de los sistemas logísticos que vayan a ser entrevistados, se procederá a eliminar aquellas preguntas que no se encuentren adecuadas, o sean excesivamente complicadas o redundantes para los puestos.

Con esta filosofía surgen unos cuestionarios intermedios más depurados y más concretos que pueden realizarse a los distintos puestos logísticos identificados en el Modelo de Recursos Humanos aplicados a los sistemas logísticos.

Los cuestionarios depurados que surgen son los que se muestran a continuación: 


\section{CUESTIONARIO FINAL PARA EL DIRECTOR GENERAL EN LOGÍSTICA}

1. ¿Quién es responsable de desarrollar el objetivo logístico en la empresa?

2. ¿Porqué es importante desarrollar un Plan / objetivo logístico en la empresa?

3. ¿Quién lo planifica y cómo se controla que se han cumplido con los objetivos?

4. ¿Qué compone la Cadena de Suministro de su empresa? O lo que es lo mismo ¿Qué procesos componen y cómo se lleva a cabo el proceso logístico total de la empresa?

5. ¿Cómo se planifican los espacios donde se llevan a cabo los procesos logísticos? ¿Dónde se llevan a cabo?

6. ¿Qué información es necesaria para llevar a cabo el proceso logístico?

7. ¿ Dónde se encuentra esa información?

8. ¿Cada cuanto se obtiene esa información?

9. ¿Qué tecnología se utiliza para el proceso logístico? ¿Qué tipo de planificación tecnológica se realiza?

10. ¿Dónde se ubica la tecnología para maximizar el desarrollo del proceso logístico?

11. ¿Cada cuanto se hace una revisión de la tecnología y quién la realiza?

12. ¿Qué personal es necesario para el proceso logístico? ¿Qué planificación se realiza para el personal logístico?

13. ¿Están definidos los puestos necesarios para llevar a cabo los procesos de la Cadena de suministro?

14. ¿Qué características de formación y experiencia ha de cumplir el personal contratado?

15. ¿Qué personal recibe capacitación y cada cuanto tiempo?

16. ¿Qué procesos son necesarios que desarrollen nuestros clientes en su Cadena de Suministro?

17. ¿Qué información es necesaria para que los clientes desarrollen su CS?

18. ¿Qué infraestructura necesitan los clientes para desarrollar la CS?

19. ¿Qué personal y con que cualificación deben tener nuestros clientes para desarrollar la CS? 


\section{CUESTIONARIO PARA EL ANALÍSTA EN LOGISTICA}

1. ¿Cuales son los pasos - etapas de la Cadena de Suministro desarrollada por la empresa? ¿Cómo funciona la Cadena de Suministro (su ciclo de vida)?

2. ¿Cómo se obtiene la información? Y ¿Cómo se selecciona? (Cliente, proveedor, empresa?

3. ¿Porqué ha de generarse información?

4. ¿Cómo se usa esa información?

5. ¿Quién y cómo se analiza la puesta en marcha el proceso?

6. ¿Porqué es importante llevar a cabo la planificación del proceso (la demanda, producción, distribución, suministro, control)?

7. ¿Qué infraestructura es necesaria en cada puesto para poder llevar a cabo la cadena de suministro?

8. ¿Porqué se emplea esa infraestructura?

9. ¿Cómo se utiliza esa infraestructura?

10. ¿Cómo se controla la eficiencia de la infraestructura?

11. ¿Porqué se selecciona a ese personal con esas características y experiencia?

12. ¿Quién hace el análisis de la formación al personal, transmitiendo los objetivos empresariales para mejorar su eficiencia?

13. ¿Cómo se sabe cuanto y qué personal es necesario para realizar dichas tareas de forma eficiente?

14. ¿Porqué tiene que haber tal persona en tal puesto a tal turno?

15. ¿Qué información hay que dar a los clientes? ¿y a los proveedores? 


\section{CUESTIONARIO PARA EL DISEÑADOR LOGÍSTICO}

1. ¿Cuál es el proceso logístico de la empresa? ¿Cómo se diseña?

2. ¿Cómo se diseñan los pasos del proceso logístico?

3. ¿Cómo se diseñan los espacios físicos para llevar a cabo el proceso logístico?

4. ¿Quién participa en el proceso de diseño del proceso logístico?

5. ¿En que momento se pone en marcha el proceso?

6. ¿Cómo se diseña la infraestructura necesaria para llevar a cabo el proceso logístico?

7. ¿Cómo se organiza la infraestructura?

8. ¿Dónde ha de ubicarse la tecnología/ infraestructura para que el personal desarrolle su correcto funcionamiento?

9. ¿Qué personal estará encargado de manejar la infraestructura existente? ¿Cómo lo llevará a cabo?

10. ¿Cómo se realiza el diseño del personal necesario y las tareas que van a realizarse en la empresa?

11. ¿Qué personal interviene en cada uno de los procesos? ¿Cómo se estructura al personal?

12. ¿Dónde ha de ubicarse el personal para realizar cada uno de los procesos y tareas que ha de desempeñar?

13. ¿Cuánta gente hay por cada puesto? (mañana - tarde - noche)

14. ¿Dónde está la información más importante y necesaria para poder diseñar el proceso logístico?

15. ¿Qué información se necesita para diseñar el proceso?

16. ¿Cómo se organiza y estructura la información para poder diseñar el proceso logístico?

17. ¿Quién controla la información para poder diseñar el proceso logístico? ¿Quién selecciona la información para poder diseñar el proceso logístico? 


\section{CUESTIONARIO PARA EL JEFE OPERATIVO}

1. ¿Qué tareas componen los distintos procesos de la cadena de suministro? ¿Cómo se llevan a cabo los procesos de la cadena de suministro?

2. ¿Dónde se realiza cada una de las tareas del proceso logístico?

3. ¿Quién lleva a cabo la realización de cada proceso y en qué momento?

4. ¿Qué infraestructura / medios tecnológicos son necesarios para que puedan desarrollarse los trabajos? ¿Cómo ha de utilizarse la infraestructura existente?

5. ¿En qué momento ha de funcionar la tecnología/ infraestructura? (mañana - tarde- noche)

6. ¿Quién maneja la infraestructura /tecnología existente?

7. ¿Dónde ha de estar situada la infraestructura para que el personal la maximice?

8. ¿Qué personal se necesita para realizar las tareas del proceso?

9. ¿En que lugar ha de trabajar cada tarea/ se localizará cada puesto? ¿Dónde se sitúa el personal para realizar cada uno de los procesos?

10. ¿Cuándo ha de trabajar cada puesto? (mañana - tarde - noche)

11. ¿Qué tareas habituales realiza el personal en el desarrollo del proceso?

12. ¿Qué información es necesaria para poder poner en marcha el proceso logístico?

13. ¿Dónde se encuentra la información más importante y necesaria para poder desarrollar el proceso logístico?

14. ¿Quién se encarga de aportar la información necesaria?

15. ¿En que momento es necesaria información para que funcione el sistema? ¿Cómo se maneja la información? 


\section{CUESTIONES PARA EL OPERARIO LOGÍSTICO}

1. ¿Qué trabajo desempeña ud.? ¿Realiza Ud. un trabajo de tipo operativo, mando intermedio, toma de decisiones?

2. ¿Conoce exactamente que tareas hay que realizar en su puesto de trabajo? ¿Tiene claro que procesos realiza dentro de la Cadena de Suministro?

3. ¿Tiene claros los horarios en los que ha de desarrollar su trabajo? (mañana - tarde noche) ¿Desarrolla Ud. tareas que necesiten un horario preestablecido?

4. ¿Qué requisitos, habilidades, y capacitación son necesarios para desarrollar su puesto de trabajo y las tareas arriba mencionadas?

5. ¿Existen áreas o zonas definidas para realizar su trabajo?

6. ¿Qué infraestructura es necesaria para desarrollar su trabajo?

7. ¿Dónde se ubica la infraestructura necesaria para desarrollar cada puesto?

8. ¿Cómo se utiliza la infraestructura (tecnología y maquinaria) necesaria para realizar esas tareas?

9. ¿Que información es necesaria para desarrollar su trabajo?

10. ¿Donde se encuentra la información necesaria para el puesto a desarrollar?

11. ¿Quién decide la información a usar en cada proceso o tarea?

12. ¿Que información genera su trabajo? 
Para realizar un buen trabajo en la depuración y elaboración de cuestionarios, será necesario conocer el ambiente y entorno de un sistema logístico, es decir, tener conocimiento de los puestos, tareas y procesos que componen los sistemas logísticos. Para ello se realizó en el Apéndice I la elaboración análisis de puestos logísticos de los cuales se obtendrá información sobre los mismos para el conocimiento de sus tareas.

Dichos análisis se han realizado utilizando como base el modelo propuesto por la profesora Díaz de Ramiro [DíazRamiro] el cual sirve para realizar un completo análisis de cada puesto, con sus principales tareas, requisitos y habilidades necesarios, mientras que la base teórica de conocimiento de puestos procede del libro "The Growth and Development of Logistics Personnell" creado por el Council of Logistics Management y publicado por la Universidad del Estado de Mississppi [LeMay1999], donde se realiza un repaso de todos los puestos logísticos que puede haber en una empresa.

Basándose en esos puestos estudiados en el Apéndice I, que son puestos que como máximo pueden existir en los sistemas logísticos habrá que ubicar cada uno de ellos dentro del modelo propuesto, para conocer realmente como se encontrarían esos puestos en las empresas aplicando el modelo de Recursos Humanos aplicado para los sistemas Logísticos.

El puesto de Director General Logístico propuesto en el modelo, se correspondería prácticamente con la misma denominación al que se pueden llegar a encontrar en las empresas. El siguiente puesto propuesto en el modelo será el Analista Logístico, que se puede asimilar al Director de la Cadena de Suministro, que es quien analiza como está la situación y que requiere la Cadena de Suministro para poder ejecutarse correctamente. El puesto de Ingeniero Logístico puede encontrarse bajo la denominación de varios puestos como los de: Director de Producción, Director de Almacén, Director de Compras, o Director de Servicio al Cliente. El Jefe Operativo, corresponderá en las empresas a puestos de supervisión o encargado como lo son: Capataz de Almacén, al supervisor de inventario, al supervisor de servicio al cliente o al supervisor de producción. Finalmente, los operarios logísticos son quienes realizan las tareas del sistema logístico como los cargadores, operarios de producción, operarios de servicio al cliente o incluso administrativos de compras. 
La Tabla A-II. 7 muestra relación de puestos presentados en el Capítulo séptimo y Anexo I, asociados a cada uno de los puestos propuestos para el Modelo de Recursos Humanos aplicado a los Sistemas Logísticos.

\begin{tabular}{lll}
\hline Puesto Propuesto & Puesto Asimilado \\
\hline Director General Logístico & - & Director General en Logística \\
\hline Analista Logístico & - & Director de la Cadena de \\
& & Suministro \\
\hline Ingeniero Logístico & - & Director de Almacén \\
& - & Director de Producción \\
& - & Director de Compras \\
& - & Director de Servicio al Cliente \\
\hline Jefe Operativo & - & Capataz de Almacén \\
& - & Especialista- Supervisor de \\
& Inventario \\
& - & Supervisor de Servicio al cliente \\
& - & Supervisor de producción \\
\hline Operarios & Cargadores \\
& - & Operador de producción \\
& - & Operarios de Servicio al cliente \\
& - & Administrativos de Compras \\
\hline
\end{tabular}

Tabla A-II. 7 : Puestos propuestos y Puestos asimilados en la empresa. Fuente: Elaboración propia basada en Le May [LeMay1999]

En los puestos presentados se han incluido a su vez la información proporcionada en las descripciones de los puestos logísticos realizadas en el informe del proyecto FORCE 91/1/563 en el cual participaron miembros de la Asociación Europea de Logística (ELA).

El trabajo titulado "Some occupational profiles for practitioners in logistics" fue producir para CEN TC/273 (Logistics) [CENReport1998] bajo el programa europeo Leonardo una versión de perfiles logísticos comunes con el interés común de crear un grado de uniformidad entre los estados europeos miembros en lo que a carreras logísticas se refiere. Dicho informe recoge 32 perfiles logísticos, divididos en grupos 
como "Dirección", "Ventas", "Compras", "Desarrollo de producción", "Producción", "Distribución y Almacenes" y "Transporte" dividiendo cada uno de los niveles en cuatro tipos de puestos: director de área, gestor, supervisor y finalmente operario.

\section{A.Il.2.3 Evolución de los cuestionarios}

Una vez identificados en la Tabla A-II. 7 las denominaciones reales de los puestos existentes en los sistemas logísticos, y antes de proceder a confeccionar los cuestionarios definitivos, habrá que identificar ante que tipo de sistema logístico se enfrenta el cuestionario, ya que dependiendo del tipo de sistema logístico de que se trate habrá una u otra estructura, tamaño, u otra característica.

Al hacer referencia a los sistemas logísticos se está abarcando a tres grandes bloques de sistemas u organizaciones logísticas, que vendrán compuestas por: Operadores logísticos, los Distribuidores Comerciales y finalmente un tercer grupo que estará compuesto por empresas productoras con departamentos logísticos.

Los Operadores Logísticos son aquellas organizaciones que se encargan de la sincronización de los flujos en la cadena de suministro, incluyendo los mercados empresa a empresa (Business to Business b2b) y empresa a consumidor(Business to Consumer b2c).

Su gran importancia se debe al crecimiento que ha surgido en la subcontratación logística y el desarrollo de servicios logísticos a medida o servicios de outsourcing como ventaja estratégica para las empresas, adaptándose a las necesidades particulares de cada cliente, poniendo a su entera disposición todos los recursos tecnológicos, materiales y humanos disponibles del operador.

Estos servicios se basan en una alta especialización, donde las capacidades de distribución capilar e inversión tecnológica de cada operador ofrece una solución diferencial a cada uno de sus clientes. Los servicios que proporciona suelen ser actividades de almacenamiento, transporte, distribución, gestión de materiales promocionales. Asimismo, prestan servicios complementarios de valor añadido como 
son retractilados, envasados, enfudados y todo tipo de manipulaciones, entre las que se encuentran el ensobrado y envío de mailings.

Las tareas de un Operador Logístico pueden dividirse en dos grandes grupos: Logística Externa e Interna. En la primera, los clientes encargan la gestión de las entregas a los consumidores finales al Operador logístico, transfiriendo la responsabilidad de garantizar el niveles de servicio a través de la gestión e integración de los pedidos en tiempo real, gestión de almacenes (en temperatura ambiente o dirigida), gestión del transporte, soluciones múltiples de distribución capilar así como la logística inversa.

Por otro lado, la Logística Interna tratará la coordinación de todos los procesos logísticos a lo largo de la Cadena de producción como fuente de aportación de valor, generándose así la Gestión Integral individualizada de los distintos componentes de la cadena de suministro: desde el aprovisionamiento hasta la producción. El servicio prestado por un operador logístico se basa en una oferta diseñada para cada cliente/operación, para lo que hay que poner en marcha un proceso de equipo humano cualificado, una selecta comunidad de proveedores y el apoyo de tecnología de última generación.

Las Cadenas de Distribución Comercial son establecimientos que efectúan ventas minoristas, en varios locales de venta, perteneciendo a un mismo grupo económico, explotando firmas análogas, y con identidad del objeto económico. Habitualmente están encargadas de la distribución a grandes superficies comerciales: identificando entre ellas:

- Supermercados: establecimientos minoristas con superficie cubierta entre $1800 \mathrm{y}$ $2500 \mathrm{~m}^{2}$

- Hipermercados: establecimientos minoristas con superficie cubierta entre $1800 \mathrm{y}$ $5000 \mathrm{~m}^{2}$ 
- Megamercados: establecimientos minoristas con superficie cubierta de más de 5000 $\mathrm{m}^{2}$

Estos grupos suelen funcionar a través de plataformas logísticas gestionadas por ellas mismas, y así dando servicio a las empresas del grupo, aunque pueden incluirse empresa de transporte y distribución.

Las Empresas Productoras con departamentos de logística en sus estructuras, pueden realizar las tareas logísticas de forma total o parcial, debido a que tengan alguna parte de la misma subcontratada. Aun en éste caso, las tareas que se realizan desde estos departamentos son:

- Organización de la colaboración entre participantes y socios: independientemente del volumen y/o capacidad tecnológica que tengan y con cualquier tipo de ERP o sin él.

- Simplificar los procesos administrativos: a través de la eliminación de tareas que no aporten valor añadido y ejecutando tareas en origen y en su orden natural

- Establece procesos non-stop: eliminando intervenciones manuales y barreras tanto entre departamentos como entre compañías.

- Reduce los tiempos: en duración, tiempos muertos entre los procesos.

Así pues si se hace una reflexión sobre el tipo de sistema logístico donde se encontrará cada uno de los puestos mostrados en la Tabla A-II. 7. Se tendrá al puesto de Director General en Logística como un puesto que existe en todos los sistemas logísticos debido a que debe haber alguien que realice las funciones de responsabilidad de cualquier sistema logístico.

Habitualmente el puesto propuesto de Analista logístico desarrolla unas funciones fácilmente asimilables al Director General Logístico, por lo que a la hora de aplicar el 
modelo a la realidad de los sistemas logísticos, se asimilará este puesto al anterior, con lo que puede también encontrarse bajo la denominación de Director de la Cadena de Suministro. La persona que desarrolla las tareas correspondientes a ambos puestos realizará por tanto funciones de planificación y análisis de la Cadena de Suministro.

En el caso del puesto de Ingeniero en Logística puede ocurrir lo contrario al anterior, es decir, que en lugar de ser una persona la que desarrolla las funciones de dos de los puestos propuestos, sean varias personas desarrollando la función del puesto de diseñador logístico, ya que al mismo se asocian: el director de almacén, que suele existir en sistemas grandes como los distribuidores comerciales o los operadores logísticos, el Director de producción, en el caso de empresas productoras, el director de servicio al cliente, para el caso de productoras y operadores logísticos, y el director de compras, que si que existe en cualquiera de los sistemas propuestos.

Igualmente ocurre con el puesto de Jefe Operativo, donde aparece la figura del Capataz de almacén para los distribuidores comerciales y operadores logísticos, el supervisor de inventario para las productoras y la distribución comercial, el supervisor de Servicio al cliente existente en las productoras y operadores logísticos, así como un supervisor de producción que lógicamente existirá solo en empresas productoras.

Por último, entre los operarios logísticos también puede señalarse una gran variedad de puestos como los cargadores de los operadores logísticos y los distribuidores comerciales, los operarios de producción en las empresas productoras, los operarios de servicio al cliente de las productoras y operadores logísticos, y los administrativos, especialmente de compras que existen en todos los sistemas logísticos.

Los puestos propuestos por el Modelo de Recursos Humanos aplicado a los sistemas logísticos ordenados jerárquicamente, y sus correspondientes puestos existentes en las empresas (Tabla A-II. 7), se han identificado en la Tabla A-II. 8 con los sistemas logísticos donde pueden encontrarse cada uno de ellos. 


\begin{tabular}{|c|c|c|}
\hline Puesto Propuesto & Puesto Asimilado & Tipo de empresa \\
\hline $\begin{array}{l}\text { Director General } \\
\text { Logístico }\end{array}$ & $\begin{array}{l}\text { - Director General en } \\
\text { Logística }\end{array}$ & $\begin{array}{l}\text { Empresa productora/ Operador } \\
\text { Logístico/ Distribuidor Comercial }\end{array}$ \\
\hline Analista Logístico & $\begin{array}{l}\text { - Director de la Cadena } \\
\text { de Suministro }\end{array}$ & $\begin{array}{l}\text { Asimilado al Director General } \\
\text { Logístico }\end{array}$ \\
\hline $\begin{array}{l}\text { Ingeniero } \\
\text { Logístico }\end{array}$ & $\begin{array}{ll}\text { - } & \text { Director de Almacén } \\
\text { - } & \text { Director de Producción } \\
\text { - } & \text { Director de Compras } \\
\text { - } & \begin{array}{l}\text { Director de Servicio al } \\
\text { Cliente }\end{array}\end{array}$ & $\begin{array}{l}\text { Distribuidor Comercial/ Operador } \\
\text { Logístico } \\
\text { Empresa Productora } \\
\text { Empresa productora/ Operador } \\
\text { Logístico/ Distribuidor Comercial } \\
\text { Emp. Productora/ Operador Logístico }\end{array}$ \\
\hline Jefe Operativo & $\begin{array}{ll}\text { - } & \text { Capataz de Almacén } \\
\text { - } & \text { Especialista- } \\
& \text { Supervisor de } \\
& \text { Inventario } \\
\text { - } & \text { Supervisor de Servicio } \\
& \text { al cliente } \\
\text { - } & \text { Supervisor de } \\
& \text { producción }\end{array}$ & $\begin{array}{l}\text { Distribuidor Comercial/ Operador } \\
\text { Logístico } \\
\text { Empresa Productora/ Distribución } \\
\text { Comercial } \\
\text { Empresa Productora/ Operador } \\
\text { Logístico } \\
\text { Empresa Productora }\end{array}$ \\
\hline Operarios & $\begin{array}{ll}\text { - } & \text { Cargadores } \\
\text { - } & \text { Operador de } \\
\text { producción } \\
\text { - } & \begin{array}{l}\text { Operarios de Servicio } \\
\text { al cliente }\end{array} \\
\text { - } & \begin{array}{l}\text { Administrativos de } \\
\text { Compras }\end{array}\end{array}$ & $\begin{array}{l}\text { Operador Logístico/ Distribuidor } \\
\text { Comercial } \\
\text { Empresa productora } \\
\text { Empresa Productora /Operador } \\
\text { Logístico } \\
\text { Empresa Productiva/ Operador } \\
\text { Logístico/ Distribuidor comercial }\end{array}$ \\
\hline
\end{tabular}

Tabla A-II. 8: Tipos de perfiles según tipo de empresa. Fuente: Elaboración propia

El problema que surge a la hora de extrapolar estos puestos a las empresas, viene de que en la mayoría de sistemas logísticos, los puestos pueden dividirse en cuatro niveles jerárquicos como máximo. Esto es debido a la horizontalización de los organigramas y estructuras que se está produciendo en la sociedad actual. 
De modo que si el modelo de Recursos Humanos aplicado a los Sistemas Logísticos propone cinco niveles de puestos, lo máximo que se puede encontrar en los sistemas logísticos son cuatro niveles, y para prueba de ello el trabajo titulado "Some occupational profiles for practitioners in logistics" fue producir para CEN TC/273 (Logistics) [CENReport1998], donde ya se proponen cuatro niveles por área: director de área, gestor, supervisor y finalmente operario.

Si se recoge la información obtenida en la Tabla A-II. 8, y se suprime un nivel, daría como resultado la estructura de de director, gestor, jefe y operario. Como se ha explicado en la Tabla A-II. 7, existen puestos que pueden ser desarrollados por una misma persona, como es el caso del Director General logístico y el de la Cadena de Suministro, que pueden ser la misma persona. Por ello, se propone de cara a la elaboración de los cuestionarios, la unificación de los dos primeros niveles, quedando ambos bajo el nombre de Director, el diseñador en logística como gestor, manteniendo los puestos de Jefe Operativo y Operario en logística, como puede observarse en la Tabla A-II. 9.

Por lo tanto, si se ordenan jerárquicamente los puestos logísticos existentes según el sistema logístico correspondiente: empresa productora, operador logístico o distribuidor comercial, se obtiene: 


\begin{tabular}{|l|l|l|l|}
\hline & Empresa Productora & Operador Logístico & Distribución Comercial \\
\hline Director & Director Gral Logístico & Director Gral Logístico & Director Gral Logístico \\
\hline Gestor & $\begin{array}{l}\text { Director de Producción } \\
\text { Director de compras } \\
\text { Director de Servicio al } \\
\text { cliente }\end{array}$ & $\begin{array}{l}\text { Director de Almacén } \\
\text { Director de Compras } \\
\text { Director de Servicio al } \\
\text { cliente }\end{array}$ & $\begin{array}{l}\text { Director de Almacén } \\
\text { Director de compras }\end{array}$ \\
\hline Jefe & $\begin{array}{l}\text { Especialista en } \\
\text { Inventario } \\
\text { Supervisor de Servicio } \\
\text { al cliente } \\
\text { Supervisor de } \\
\text { producción }\end{array}$ & $\begin{array}{l}\text { Capataz de almacén } \\
\text { Supervisor de Servicio } \\
\text { al cliente }\end{array}$ & $\begin{array}{l}\text { Capataz de almacén } \\
\text { Especialista en Inventario }\end{array}$ \\
\hline Operarios & $\begin{array}{l}\text { Operador de } \\
\text { producción } \\
\text { Operario de Servicio al } \\
\text { cliente } \\
\text { Administrativo de } \\
\text { compras }\end{array}$ & $\begin{array}{l}\text { Operarios de Servicio } \\
\text { al cliente } \\
\text { Administrativo de } \\
\text { compras }\end{array}$ & $\begin{array}{l}\text { Cargadores } \\
\text { Administrativo de } \\
\text { compras }\end{array}$ \\
\hline
\end{tabular}

Tabla A-II. 9: Puestos logísticos por tipos de empresas que aplican logística.

Fuente: Elaboración propia

\section{A.II.2.4 Cuestionario Final}

Finalmente, se ha optado por realizar un único cuestionario, resultado de la depuración de los cuestionarios obtenidos para cada uno de los puestos propuestos. El cuestionario resultante se utilizará para cualquiera de los puestos existentes en el sistema logístico, contrastando mediante el mismo, las distintas visiones que aporta cada puesto dentro de la organización.

Al realizar un único cuestionario final, éste se ha elaborado de forma que se den opciones de respuesta a aquellos que sean entrevistados, por lo que se ofrecen como respuesta en diversas ocasiones los niveles jerárquicos identificados en las empresas para la mejor ubicación de aquellos que atiendan el cuestionario.

Por lo tanto, el cuestionario final quedará como se muestra a continuación: 


\subsubsection{CUESTIONARIO}

\section{OBJETIVOS LOGÍSTICOS}

1. ¿Quién es responsable de desarrollar el objetivo logístico en la empresa? (y CS)

\begin{tabular}{|l|l|l|}
\hline Director & Gestor/ Manager & Administrativo / Operario \\
\hline
\end{tabular}

2. ¿Quién controla el cumplimiento de dicho objetivo?

\begin{tabular}{|l|l|l|}
\hline Director & Gestor/ Manager & Administrativo / Operario \\
\hline
\end{tabular}

3. ¿Cada cuanto tiempo se desarrollan los objetivos logísticos?

\begin{tabular}{|l|l|l|}
\hline Entre 6 y 12 meses & Entre 12-18 meses & Más de 18 meses \\
\hline
\end{tabular}

4. ¿Porqué motivo es importante desarrollar los objetivos logísticos?
a) Ayudar a cumplir los objetivos estratégicos de la empresa
b) Ser más competitivos que la competencia
c) Entender la logística como modelo de lograr el crecimiento de la empresa.
d) Otros

\section{CADENA DE SUMINISTRO}

5. ¿Qué funciones de su C. Suministro engloba bajo su dirección? ¿Y quién las detalla (tiempo, lugar y empleado?

\begin{tabular}{|l|l|l|l|l|l|}
\hline ACTIVIDAD & SI/NO & Director & Gestor/Manager & $\begin{array}{l}\text { Administrativo/ } \\
\text { Operario }\end{array}$ & $\begin{array}{l}\mathrm{N}^{\circ} \\
\text { Empleados }\end{array}$ \\
\hline $\begin{array}{l}\text { a. Gestión de pedidos } \\
\text { aprovisionamiento de } \\
\text { materias primas/ } \\
\text { productos } \\
\text { empaquetados a } \\
\text { producción }\end{array}$ & & & & & \\
\hline $\begin{array}{l}\text { c. Planificación de la } \\
\text { producción }\end{array}$ & & & & & \\
\hline $\begin{array}{l}\text { d. Gestión de } \\
\text { distribución y } \\
\text { almacén }\end{array}$ & & & & & \\
\hline e. Servicio al cliente & & & & & \\
\hline $\begin{array}{l}\text { f. Gestión de } \\
\text { inventario }\end{array}$ & & & & & \\
\hline g. Compras & & & & & \\
\hline
\end{tabular}


TOTAL EMPLEADOS DEL DEPARTAMENTO DE LOGÍSTICA TOTAL EMPLEADOS DE LA EMPRESA

6. ¿Cómo se diseña la Cadena de Suministro?

\begin{tabular}{|l|l|l|l|l|}
\hline & $\begin{array}{l}\text { QUIÉN DISEÑA } \\
\text { LA CS }\end{array}$ & $\begin{array}{l}\text { QUIEN DEFINE } \\
\text { PROCESOS }\end{array}$ & $\begin{array}{l}\text { QUIEN DETALLA } \\
\text { TAREAS }\end{array}$ & $\begin{array}{l}\text { QUIEN DEFINE } \\
\text { UBICACIONES }\end{array}$ \\
\hline Propia empresa & & & & \\
\hline Consultora & & & & \\
\hline Seminarios & & & & \\
\hline Desde la Casa Madre & & & & \\
\hline Benchmarking & & & & \\
\hline Otros & & & & \\
\hline
\end{tabular}

7. ¿Cómo se lleva a cabo la distribución logística?

* Almacenes propios

* $\quad$ Flota propia

* Subcontratación de almacenes

* Subcontratación de transporte y flota

* Otros

\section{INFORMACIÓN}

8. ¿Qué información logística utilizan para llevar a cabo el proceso logístico?

* $\quad$ Niveles de inventarios

* Datos de demanda

* $\quad$ Datos de producción

* Datos de costes

* $\quad$ Bases de datos de clientes

* Bases de datos de proveedores

* Capacidades, producción, almacén, transporte *Rutas

* Datos de otras empresas

*Datos de embalaje

* Otros 
9. ¿Quién decide qué tipo de información dar a ...

\begin{tabular}{|l|l|l|l|}
\hline & Director & Gestor/Manager & $\begin{array}{l}\text { Administrativo/ } \\
\text { Operario }\end{array}$ \\
\hline PERSONAL DE LA EMPRESA & & & \\
\hline PROVEEDORES & & & \\
\hline CLIENTES & & & \\
\hline OTROS & & & \\
\hline
\end{tabular}

10. ¿Qué información considera necesario dar a sus clientes/ Proveedores?

\begin{tabular}{|l|l|}
\hline CLIENTES & PROVEEDORES \\
\hline Fechas de entrega de pedidos & Fechas de recepción de pedidos \\
\hline Lugares de entrega de pedidos & Lugares de recepción de pedidos \\
\hline Precios & Precios \\
\hline Tasas & Tasas \\
\hline Disponibilidad de referencias & Disponibilidad \\
\hline Tipo de compañía & Tipo de compañía \\
\hline Características de descarga/ vehículo & Características de descarga/ vehículo \\
\hline
\end{tabular}

TECNOLOGÍA

11. ¿Quién define y decide qué tecnología se utilizará en el proceso logístico?

\begin{tabular}{|l|l|l|l|}
\hline & Director & Gestor/ Manager & Administrativo / Operario \\
\hline Define & & & \\
\hline Decide & & & \\
\hline
\end{tabular}


12. ¿Qué tipo de tecnología se utiliza en el proceso?

\begin{tabular}{|l|l|l|l|}
\hline & Director & Jefe/ Manager & $\begin{array}{c}\text { Operario/ } \\
\text { Administrativo }\end{array}$ \\
\hline Ordenador / PC & & & \\
\hline Teléfono & & & \\
\hline Scaner & & & \\
\hline Intercomunicador & & & \\
\hline Fax & & & \\
\hline Redes de comunicaciones & & & \\
\hline Etiquetadoras & & & \\
\hline Ensacadoras/ Embaladoras & & & \\
\hline Vehículos & & & \\
\hline Remolques & & & \\
\hline Apiladoras & & & \\
\hline Carretillas & & & \\
\hline Transporte automático & & & \\
\hline
\end{tabular}

13. ¿Quién realiza la revisión tecnológica?

\begin{tabular}{|l|l|l|}
\hline Director & Gestor/ Manager & Administrativo / Operario \\
\hline PERSONAL &
\end{tabular}

14. ¿Cuántos niveles jerárquicos hay en su departamento logístico?

\begin{tabular}{|c|c|c|}
\hline Dos & Tres & Cuatro \\
\hline
\end{tabular}


15. ¿Qué perfil de Recursos Humanos se necesita para realizar los procesos logísticos?

\begin{tabular}{|c|c|c|c|}
\hline & Director & Gestor / Manager & $\begin{array}{c}\text { Administrativo/ } \\
\text { Operario }\end{array}$ \\
\hline $\begin{array}{l}\text { Estudios } \\
\text { Superiores (S) } \\
\text { Medios (M) } \\
\text { Básico (B) }\end{array}$ & & & \\
\hline $\begin{array}{l}\text { Conocimientos } \\
\text { específicos: } \\
\text { Logística (Log) } \\
\text { Bases Datos (BD) } \\
\text { Almacenes (Alm) } \\
\text { Transporte(Trans) } \\
\text { RRHH (RRHH) } \\
\text { Compras (C) } \\
\text { Ventas (V) } \\
\text { Planificación(Pln) } \\
\text { Supervisión (Spv) } \\
\text { Presupuestos(\$) } \\
\text { Toma de decisión } \\
\text { Reuniones (Mtng) }\end{array}$ & & & \\
\hline $\begin{array}{l}\text { Idiomas } \\
\text { Experto }(\mathrm{E}) \\
\text { Medio }(\mathrm{M}) \\
\text { Ninguno }(\mathrm{N}) \\
\end{array}$ & & & \\
\hline Habilidades & & & \\
\hline Competencias & & & \\
\hline $\begin{array}{c}\text { Experiencia anterior } \\
\text { Logística (Log) } \\
\text { Bases Datos (BD) } \\
\text { Almacenes (Alm) } \\
\text { Transporte(Trans) } \\
\text { RRHH (RRHH) } \\
\text { Compras (C) } \\
\text { Ventas (V) } \\
\text { Planificación(Pln) } \\
\text { Supervisión (Spv) } \\
\text { Presupuestos(\$) } \\
\text { Toma de decisión }\end{array}$ & & & \\
\hline $\begin{array}{l}\text { Informática } \\
\text { Manejo de PC } \\
\text { Bases de datos } \\
\text { Scanner }\end{array}$ & & & \\
\hline
\end{tabular}


Control almacén

Telecomunicación

16. ¿Se realiza una planificación de los RRHH dedicados al departamento logístico?

Si / No

17. ¿Quién se encarga de realizar la planificación?

\begin{tabular}{|l|l|l|}
\hline Director & Gestor/ Manager & Administrativo / Operario \\
\hline
\end{tabular}

18. ¿Quién es encargado de asignar personal a las tareas?

\begin{tabular}{|l|l|l|}
\hline Director & Gestor/ Manager & Administrativo / Operario \\
\hline
\end{tabular}

19. ¿Quién define las tareas a realizar en cada puesto?

\begin{tabular}{|l|l|l|}
\hline Director & Gestor/ Manager & Administrativo / Operario \\
\hline
\end{tabular}

20. ¿Conocen los empleados las tareas a desarrollar en sus puestos logísticos?

\begin{tabular}{|l|l|l|l|}
\hline & Director & Gestor/ Manager & Administrativo / Operario \\
\hline $\mathrm{Si}$ & & & \\
\hline No & & & \\
\hline
\end{tabular}

21. ¿Quién explica y describe cómo, cuando, donde y que tareas han de realizarse en las actividades de los procesos logísticos?

\begin{tabular}{|l|l|l|l|}
\hline & Director & Gestor/ Manager & Administrativo / Operario \\
\hline QUE & & & \\
\hline COMO & & & \\
\hline CUANDO & & & \\
\hline DONDE & & & \\
\hline
\end{tabular}

22. ¿Qué tipo de formación se imparte a los empleados logísticos?

\begin{tabular}{|l|l|l|l|l|c|}
\hline & $\begin{array}{l}\text { Duración de la } \\
\text { Formación }\end{array}$ & $\begin{array}{l}\text { Cada cuanto } \\
\text { tiempo }\end{array}$ & Práctica & $\begin{array}{l}\text { Teórica } \\
\text { en casa }\end{array}$ & $\begin{array}{c}\text { Teórica } \\
\text { contratada }\end{array}$ \\
\hline Director & & & & & \\
\hline Gestor/Manager & & & & & \\
\hline $\begin{array}{l}\text { Administrativo } \\
\text { /Operario }\end{array}$ & & & & & \\
\hline
\end{tabular}

\section{A.II.3 REFERENCIAS BIBLIOGRÁFICAS DEL ANEXO}

Cabrero_Richart Cabrero García J., M. Richart Martínez. Metodología de la Investigación I. Técnicas de recogida de datos.

http://perso.wanadoo.es/aniorte nic/apunt metod investigac4 9.htm Consultada el 05/03/02

CENReport1998 CEN Report TC/ 273 "Some occupational profiles for Practitioners in Logistics" European Logistics Association 1998. 
De Rosnay J. De Rosnay. The macroscope, a new world scientific system. Web edition. Principia Cibernetica Web Project.

Http://pespmc1.vub.ac.be/ASC/UNCERT PRINC.html Consultada el 27/02/2002

Domínguez2000 Domínguez Torres, A. Cambio y conocimiento en los sistemas. Editorial Galileo. México 2000.

DíazRamiro E. Díaz Ramiro. "Modelo de Evaluación de necesidades formativas basado en la evaluación de metas y objetivos" http://www.ucm.es/info/Psyap/jornadas/eva.htm Universidad Complutense de Madrid. Facultad de Psicología. Departamento de Psicología diferencial y del trabajo. Somosaguas- Madrid. Consultada el 10/12/2001

González González, A.E.. Curso a distancia para la enseñanza de la Metodología de Investigación aplicada a la elaboración de Tesis de Grado. Unidad III. La Recolección de Datos. Sistema de Actualización docente de la Universidad Central de Venezuela. http://www.aulavirtual.info.ve/m3recolecciondatos.html Consultada el 27/02/2002

Heylighen Heylighen, F. Principles of systems and cybernetics: an evolutionary perspective. ftp://ftp.vub.ac.be/pub/projects/Principia Cybernetica/Papers Heylighen/Systems Principles.txt Consultada el 28/02/2002

INEI1997 INEI. Instituto Nacional de Estadística e Informática de Perú. Metodología para la elaboración de un sistema de información. Capítulo 4.

http://www.inei.gob.pe/cpi-mapa/bancopub/libfree/lib606/CAP4-1.htm Consultada el 08/03/02

LeMay1999 Le May S., J.C. Carr. "The Growth and Development of Logistics Personnel". Mississippi State University. Council of Logistics Personnel. USA 1999

Malhotra1997 N. Malhotra. Investigación de Mercados. Un enfoque práctico. $2^{\mathrm{a}}$ edición. PHH. Prentice Hall. 1997.México.

Model2000 M. Model. A Professional's Guide to Systems Analysis, Second Edition. www.dai-sho.com Martin Model 2000. Consultada el 25/02/2002

Morales $\quad$ M. Morales Caicedo. "Administración de Sistemas de Información". Basado en los libros: "Análisis de Sistemas de Información" de Kendall \& Kendall, "Análisis de Sistemas de Información" de J. A. Senn, y "Análisis de Sistemas de Información" de Whitten, Bentley y Barlow. Universidad Santiago de Cali. http://docentes.usaca.edu.co/marmol Consultada el 06/03/2002

SLC Sociedad Americana para la Calidad. Checklist para la Reunión de Datos (Data Gathering Checklist) http://www.calidad.org/s/datos.pdf .Consultada el 05/03/2002

Umpleby Umpleby. Principles of systems and cybernetics: an evolutionary perspective. http://pespmc1.vub.ac.be/ASC/PRINCI_SIMPL.html Consultada el 27/02/2002

Zachman Zachman. "The Zachman Framework " http://www.essentialstrategies.com/publications/methodology/zachman.htm. Consultada el 26/02/2002 


\section{Anexo III}




\section{ANEXO III- RESULTADO DE LOS CUESTIONARIOS}

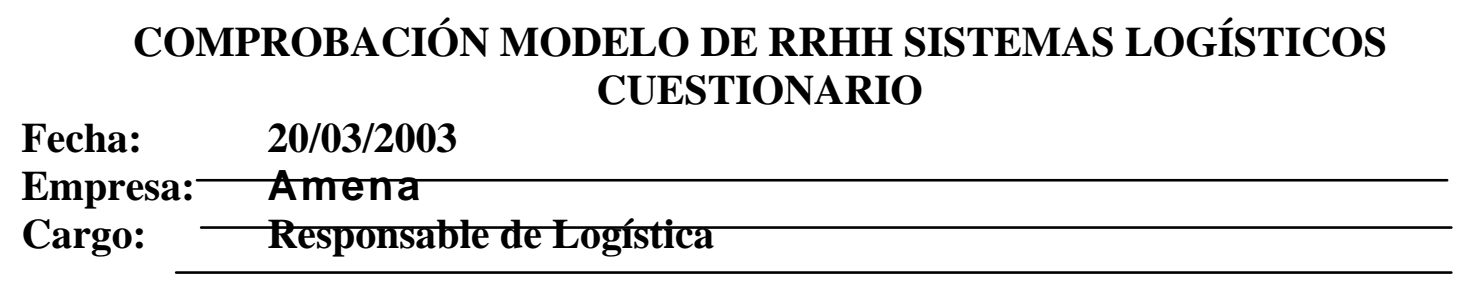

OBJETIVOS LOGÍSTICOS

23. ¿Quién es responsable de desarrollar el objetivo logístico en la empresa? (y CS)

\begin{tabular}{|l|l|l|}
\hline Director & Gestor/ Manager & Administrativo / Operario \\
\hline
\end{tabular}

24. ¿Quién controla el cumplimiento de dicho objetivo?

\begin{tabular}{|l|l|l|}
\hline Director & Gestor/ Manager & Administrativo / Operario \\
\hline
\end{tabular}

25. ¿Cada cuanto tiempo se desarrollan los objetivos logísticos?

\begin{tabular}{|l|l|l|}
\hline Entre 6 y 12 meses & Entre 12-18 meses & Más de 18 meses \\
\hline
\end{tabular}

26. ¿Porqué motivo es importante desarrollar los objetivos logísticos?

e) Ayudar a cumplir los objetivos estratégicos de la empresa 1

f) Ser más competitivos que la competencia 2

g) Entender la logística como modelo de lograr el crecimiento de la empresa.3

h) Otros 


\section{CADENA DE SUMINISTRO}

27. ¿Qué funciones de su C. Suministro engloba bajo su dirección? ¿Y quién las detalla (tiempo, lugar y empleado?

\begin{tabular}{|c|c|c|c|c|c|}
\hline ACTIVIDAD & $\mathrm{SI} / \mathrm{NO}$ & Director & $\begin{array}{l}\text { Gestor/ } \\
\text { Manager }\end{array}$ & $\begin{array}{l}\text { Administrativo/ } \\
\text { Operario }\end{array}$ & No Empleados \\
\hline a. Gestión de pedidos & SI & & & $\begin{array}{l}\text { Adm. Proceso } \\
\text { Pedido }\end{array}$ & \\
\hline $\begin{array}{l}\text { b. Gestión de } \\
\text { aprovisionamiento de } \\
\text { materias primas/ } \\
\text { productos empaquetados } \\
\text { a producción }\end{array}$ & SI & X & $\mathrm{X}$ & & \\
\hline $\begin{array}{l}\text { c. Planificación de la } \\
\text { producción }\end{array}$ & SI & & $\mathrm{X}$ & $\mathrm{X}$ & $\begin{array}{l}\text { Ensamblaje Op. } \\
\text { Log } \\
\text { Pack prepago } \\
\text { log }\end{array}$ \\
\hline $\begin{array}{l}\text { d. Gestión de } \\
\text { distribución (reparto) }\end{array}$ & SI & & $\begin{array}{l}\text { X Asigna } \\
\text { Mercancia } \\
\text { según canal }\end{array}$ & & \\
\hline $\begin{array}{l}\text { e. Servicio al cliente } \\
\text { Comercial } \\
\text { Atención al cliente }\end{array}$ & SI & & & $\begin{array}{l}X \\
X\end{array}$ & \\
\hline f. Gestión de inventario & SI & $\mathrm{X}$ & $X$ & $\mathrm{X}$ & \\
\hline g. Compras & SI & $\mathrm{X}$ & $\mathrm{X}$ & $\mathrm{x}$ & \\
\hline
\end{tabular}

TOTAL EMPLEADOS DEL DEPARTAMENTO DE LOGÍSTICA TOTAL EMPLEADOS DE LA EMPRESA

28. ¿Cómo se diseña la Cadena de Suministro?

\begin{tabular}{|l|l|l|l|l|}
\hline & $\begin{array}{l}\text { QUIÉN DISEÑA } \\
\text { LA CS }\end{array}$ & $\begin{array}{l}\text { QUIEN DEFINE } \\
\text { PROCESOS }\end{array}$ & $\begin{array}{l}\text { QUIEN DETALLA } \\
\text { TAREAS }\end{array}$ & $\begin{array}{l}\text { QUIEN DEFINE } \\
\text { UBICACIONES }\end{array}$ \\
\hline Propia empresa & \multicolumn{1}{|l}{ X } & X & X & X \\
\hline Consultora & & & & \\
\hline Seminarios & & & & \\
\hline Desde la Casa Madre & & & & \\
\hline Benchmarking & & & & \\
\hline Otros & & & & \\
\hline
\end{tabular}

29. ¿Cómo se lleva a cabo la distribución logística?

* Almacenes propios

* $\quad$ Flota propia

\section{Subcontratación de almacenes}


* Otros

\section{INFORMACIÓN}

30. ¿Qué información logística utilizan para llevar a cabo el proceso logístico?
Niveles de inventarios
Datos de demanda

Datos de producción

Datos de costes

Bases de datos de clientes

Bases de datos

proveedores

Capacidades, producción, almacén, transporte $\quad *$ RutasoPERADOR

Datos de otras empresas (IDEAS) $\quad * \quad$ Datos de embalaje

Otros (Actividades, Tco obj, entregas, canal (objetivos de ventas) entregas prepago)

31. ¿Quién decide que tipo de información dar a...?

\begin{tabular}{|l|c|c|c|}
\hline & Director & Gestor/Manager & $\begin{array}{l}\text { Administrativo/ } \\
\text { Operario }\end{array}$ \\
\hline PERSONAL DE LA EMPRESA & $\mathrm{X}$ & $\mathrm{X}$ & \\
\hline PROVEEDORES & $\mathrm{X}$ & $\mathrm{X}$ & $\mathrm{X}$ \\
\hline CLIENTES & $\mathrm{X}$ & $\mathrm{X}$ & \\
\hline OTROS & & & \\
\hline
\end{tabular}

32. ¿Qué información considera necesario dar a sus clientes/ Proveedores?

\begin{tabular}{|l|l|}
\hline CLIENTES & PROVEEDORES \\
\hline Fechas de entrega de pedidos & Fechas de recepción de pedidos \\
\hline Lugares de entrega de pedidos & Lugares de recepción de pedidos \\
\hline Precios $x$ & Precios van en los precontratos \\
\hline Tasas & Tasas \\
\hline Disponibilidad de referencias & Disponibilidad \\
\hline Tipo de compañía & Tipo de compañía \\
\hline Características de descarga/ vehículo & Características de descarga/ vehículo \\
\hline
\end{tabular}

TECNOLOGÍA

33. ¿Quién define y decide qué tecnología se utilizará en el proceso logístico?

\begin{tabular}{|l|l|l|l|}
\hline & Director & Gestor/ Manager & Administrativo / Operario \\
\hline Define SAP & X y Cia & & \\
\hline Decide & X y Cia & & \\
\hline
\end{tabular}


34. ¿Qué tipo de tecnología se utiliza en el proceso?

\begin{tabular}{|c|c|c|c|}
\hline & Director & Gestor/ Manager & $\begin{array}{c}\text { Operario/ } \\
\text { Administrativo }\end{array}$ \\
\hline Ordenador / PC & $X$ & $\mathrm{X}$ & $\mathrm{X}$ \\
\hline Teléfono & $X$ & $\mathrm{X}$ & $\mathrm{X}$ \\
\hline Scaner & & & $\mathrm{X}$ \\
\hline \multicolumn{4}{|l|}{ Intercomunicador } \\
\hline Fax & $\mathrm{X}$ & $\mathrm{X}$ & $\mathrm{X}$ \\
\hline Redes de comunicaciones & $X$ & $X$ & $\mathrm{X}$ \\
\hline \multicolumn{4}{|l|}{ Etiquetadoras } \\
\hline \multicolumn{4}{|l|}{ Ensacadoras/ Embaladoras } \\
\hline \multicolumn{4}{|l|}{ Vehículos } \\
\hline \multicolumn{4}{|l|}{ Remolques } \\
\hline \multicolumn{4}{|l|}{ Apiladoras } \\
\hline \multicolumn{4}{|l|}{ Carretillas } \\
\hline Transporte automático & & & \\
\hline
\end{tabular}

35. ¿Quién realiza la revisión tecnológica? Control de calidad en recepciones

\begin{tabular}{|l|l|l|}
\hline Director & Gestor/ Manager & Administrativo / Operario \\
\hline
\end{tabular}

\section{PERSONAL}

36. ¿Cuántos niveles jerárquicos hay en su departamento logístico?

\begin{tabular}{|c|c|c|}
\hline Dos & Tres & Cuatro \\
\hline
\end{tabular}

37. ¿Qué perfil de Recursos Humanos se necesita para realizar los procesos logísticos?

\begin{tabular}{|l|c|c|c|}
\hline & Director & Gestor / Manager & $\begin{array}{c}\text { Administrativo/ } \\
\text { Operario }\end{array}$ \\
\hline
\end{tabular}




\begin{tabular}{|c|c|c|c|}
\hline $\begin{array}{l}\text { Estudios } \\
\text { Superiores (S) } \\
\text { Medios (M) } \\
\text { Básicos (B) }\end{array}$ & $\begin{array}{l}\text { Superiores (S) } \\
\text { Medios (M) } \\
\text { Básicos (B) }\end{array}$ & $\begin{array}{l}\text { Superiores (S) } \\
\text { Medios (M) } \\
\text { Básicos (B }\end{array}$ & $\begin{array}{l}\text { Superiores (S) } \\
\text { Medios (M) } \\
\text { Básicos (B) }\end{array}$ \\
\hline $\begin{array}{l}\text { Conocimientos } \\
\text { específicos: } \\
\text { Logística (Log) } \\
\text { Bases Datos (BD) } \\
\text { Almacenes (Alm) } \\
\text { Transporte(Trans) } \\
\text { RRHH (RRHH) } \\
\text { Compras (C) } \\
\text { Ventas (V) } \\
\text { Planificación(Pln) } \\
\text { Supervisión (Spv) } \\
\text { Presupuestos(\$) } \\
\text { Toma de decisión } \\
\text { Reuniones (Mtng) }\end{array}$ & $\begin{array}{l}\text { Logística } 1 \\
\text { Bases Datos } \\
\text { Almacenes } \\
\text { Transporte } \\
\text { RRHH 4 } \\
\text { Compras } 2 \\
\text { Ventas } \\
\text { Planificación } \\
\text { Supervisión } \\
\text { Presupuestos } 3 \\
\text { Toma de decisión } \\
\text { Reuniones }\end{array}$ & $\begin{array}{l}\text { Logística } \\
\text { Bases Datos } \\
\text { Almacenes } \\
\text { Transporte } \\
\text { RRHH Relación } \\
\text { Compras No } \\
\text { Ventas Comercial } \\
\text { Planificación } \\
\text { Supervisión } \\
\text { Presupuestos } \\
\text { Toma de decisión } \\
\text { Reuniones }\end{array}$ & $\begin{array}{l}\text { Logística } \\
\text { Bases Datos } \\
\text { Almacenes } \\
\text { Transporte } \\
\text { RRHH } \\
\text { Compras } \\
\text { Ventas } \\
\text { Planificación } \\
\text { Supervisión } \\
\text { Presupuestos } \\
\text { Toma de decisión } \\
\text { Reuniones }\end{array}$ \\
\hline $\begin{array}{l}\text { Idiomas } \\
\text { Experto }(\mathrm{E}) \\
\text { Medio }(\mathrm{M}) \\
\text { Ninguno }(\mathrm{N})\end{array}$ & $\begin{array}{l}\text { Idiomas } \\
\text { Experto (E) } \\
\text { Medio (M) } \\
\text { Ninguno (N) }\end{array}$ & $\begin{array}{l}\text { Idiomas } \\
\text { Experto (E) } \\
\text { Medio (M) } \\
\text { Ninguno (N) }\end{array}$ & $\begin{array}{l}\text { Idiomas } \\
\text { Experto (E) } \\
\text { Medio (M) } \\
\text { Ninguno (N) }\end{array}$ \\
\hline $\begin{array}{l}\text { Habilidades } \\
\text { Trabajo en equipo } \\
\text { Colaboración } \\
\text { Honradez } \\
\text { Cumplimiento } \\
\text { Capacidad de liderazgo }\end{array}$ & $\begin{array}{l}X \\
X \\
X \\
X \\
X\end{array}$ & $\begin{array}{l}X \\
X \\
X \\
X \\
X\end{array}$ & $\begin{array}{l}X \\
X \\
X \\
X\end{array}$ \\
\hline $\begin{array}{l}\text { Conocimientos } \\
\text { específicos: } \\
\text { Logística (Log) } \\
\text { Bases Datos (BD) } \\
\text { Almacenes (Alm) } \\
\text { Transporte(Trans) } \\
\text { RRHH (RRHH) } \\
\text { Compras (C) } \\
\text { Ventas (V) } \\
\text { Planificación(Pln) } \\
\text { Supervisión (Spv) } \\
\text { Presupuestos(\$) } \\
\text { Toma de decisión } \\
\text { Reuniones (Mtng) }\end{array}$ & $\begin{array}{l}\text { Logística } 1 \\
\text { Bases Datos } \\
\text { Almacenes } \\
\text { Transporte } \\
\text { RRHH 4 } \\
\text { Compras } 2 \\
\text { Ventas } \\
\text { Planificación } \\
\text { Supervisión } \\
\text { Presupuestos } 3 \\
\text { Toma de decisión } \\
\text { Reuniones }\end{array}$ & $\begin{array}{l}\text { Logística } \\
\text { Bases Datos } \\
\text { Almacenes } \\
\text { Transporte } \\
\text { RRHH Relación } \\
\text { Compras No } \\
\text { Ventas Comercial } \\
\text { Planificación } \\
\text { Supervisión } \\
\text { Presupuestos } \\
\text { Toma de decisión } \\
\text { Reuniones }\end{array}$ & $\begin{array}{l}\text { Logística } \\
\text { Bases Datos } \\
\text { Almacenes } \\
\text { Transporte } \\
\text { RRHH } \\
\text { Compras } \\
\text { Ventas } \\
\text { Planificación } \\
\text { Supervisión } \\
\text { Presupuestos } \\
\text { Toma de decisión } \\
\text { Reuniones }\end{array}$ \\
\hline $\begin{array}{l}\text { Informática } \\
\text { Manejo de PC } \\
\text { Bases de datos } \\
\text { Scanner } \\
\text { Control almacén } \\
\text { Telecomunicación }\end{array}$ & $\begin{array}{l}\text { Informática } \\
\text { Manejo de PC } \\
\text { Bases de datos } \\
\text { Scanner } \\
\text { Control almacén } \\
\text { Telecomunicación }\end{array}$ & $\begin{array}{l}\text { Informática } \\
\text { Manejo de PC } \\
\text { Bases de datos } \\
\text { Scanner } \\
\text { Control almacén } \\
\text { Telecomunicación }\end{array}$ & $\begin{array}{l}\text { Informática } \\
\text { Manejo de PC } \\
\text { Bases de datos } \\
\text { Scanner } \\
\text { Control almacén } \\
\text { Telecomunicación }\end{array}$ \\
\hline
\end{tabular}


38. ¿Se realiza una planificación de los RRHH dedicados al departamento logístico?

Si / No

39. ¿Quién se encarga de realizar la planificación?

\begin{tabular}{|l|l|l|}
\hline Director & Gestor/ Manager (Almacén) & Administrativo / Operario \\
\hline
\end{tabular}

40. ¿Quién se encarga de asignar personal a las tareas? Jefe de Almacén para Operador

\begin{tabular}{|l|l|l|}
\hline Director para Administración & Gestor/ Manager & Administrativo / Operario
\end{tabular}

41. ¿Quién define las tareas a realizar en cada puesto?

\begin{tabular}{|l|l|l|}
\hline Director & Gestor/ Manager & Administrativo / Operario
\end{tabular}

42. ¿Conocen los empleados las tareas a desarrollar en sus puestos logísticos?

\begin{tabular}{|l|c|c|c|}
\hline & Director & Gestor/ Manager & Administrativo / Operario \\
\hline $\mathrm{Si}$ & $\mathrm{X}$ & $\mathrm{X}$ & $\mathrm{X}$ \\
\hline $\mathrm{No}$ & & & \\
\hline
\end{tabular}

43. ¿Quién explica y describe cómo, cuando, donde y que tareas han de realizarse en las actividades de los procesos logísticos?

\begin{tabular}{|l|l|l|l|}
\hline & Director & Gestor/ Manager & Administrativo / Operario \\
\hline QUE & $\mathrm{X}$ & & \\
\hline COMO & $\begin{array}{c}\text { Manual de } \\
\text { procedimientos }\end{array}$ & & \\
\hline CUANDO & $\begin{array}{c}\text { Variación Signific } \\
\text { Certificado ISO } \\
\text { Nueva Operarativa }\end{array}$ & & \\
\hline DONDE & & & \\
\hline
\end{tabular}

44. ¿¿ué tipo de formación se imparte a los empleados logísticos?

\begin{tabular}{|l|l|l|l|c|c|}
\hline & $\begin{array}{l}\text { Duración de la } \\
\text { Formación }\end{array}$ & $\begin{array}{l}\text { Cada cuanto } \\
\text { tiempo }\end{array}$ & Práctica & $\begin{array}{c}\text { Teórica } \\
\text { en casa }\end{array}$ & $\begin{array}{c}\text { Teórica } \\
\text { contratada }\end{array}$ \\
\hline Director & SI & & NO & & X \\
\hline Gestor/Manager & SI & & NO & & X \\
\hline $\begin{array}{l}\text { Administrativo } \\
\text { /Operario }\end{array}$ & SI & NO & & $X$ \\
\hline
\end{tabular}

Planificación de la formación anual específica oportuna: logística, idiomas.... 


\section{COMPROBACIÓN MODELO DE RRHH SISTEMAS LOGÍSTICOS CUESTIONARIO}

Fecha: $\quad 20 / 03 / 2003$

Empresa:- Bruño Editorial

Cargo: Directora de Logística y Distribución

OBJETIVOS LOGÍSTICOS

1. ¿ ¿Quién es responsable de desarrollar el objetivo logístico en la empresa? (y CS)

\begin{tabular}{|l|l|l}
\hline Director & Gestor/ Manager & Administrativo / Operario
\end{tabular}

2. ¿¿uién controla el cumplimiento de dicho objetivo?

\begin{tabular}{|l|l|l|}
\hline Director & Gestor/ Manager & Administrativo / Operario \\
\hline
\end{tabular}

3. ¿Cada cuanto tiempo se desarrollan los objetivos logísticos?

\begin{tabular}{|l|l|l|}
\hline Entre 6 y 12 meses & Entre 12-18 meses & Más de 18 meses \\
\hline
\end{tabular}

4. ¿'Porqué motivo es importante desarrollar los objetivos logísticos?

\section{a) Ayudar a cumplir los objetivos estratégicos de la empresa 1}

b) Ser más competitivos que la competencia

\section{Entender la logística como modelo de lograr el crecimiento de la empresa.2}

d) Otros 


\section{CADENA DE SUMINISTRO}

5. ¿Qué funciones de su C. Suministro engloba bajo su dirección? ¿Y quién las detalla (tiempo, lugar y empleado?

\begin{tabular}{|c|c|c|c|c|c|}
\hline ACTIVIDAD & SI/NO & Director & $\begin{array}{l}\text { Gestor/ } \\
\text { Manager }\end{array}$ & $\begin{array}{l}\text { Administrativo/ } \\
\text { Operario }\end{array}$ & $\begin{array}{l}\mathrm{N}^{\mathrm{o}} \\
\text { Empleados }\end{array}$ \\
\hline a. Gestión de pedidos & SI & & & $\begin{array}{l}\text { Adm. Vtas } \\
\text { Logística }\end{array}$ & \\
\hline $\begin{array}{l}\text { b. Gestión de } \\
\text { aprovisionamiento de } \\
\text { materias primas/ } \\
\text { productos } \\
\text { empaquetados a } \\
\text { producción }\end{array}$ & $\mathrm{NO}$ & & & & \\
\hline $\begin{array}{l}\text { c. Planificación de la } \\
\text { producción }\end{array}$ & $\begin{array}{l}\text { No } \\
\text { Produc }\end{array}$ & & & & \\
\hline $\begin{array}{l}\text { d. Gestión de } \\
\text { distribución } \\
\text { (reparto) }\end{array}$ & $\begin{array}{l}\text { SI } \\
\text { Manda } \\
\text { comerc }\end{array}$ & & $\mathrm{X}$ & & \\
\hline $\begin{array}{l}\text { e. Servicio al cliente } \\
\text { Comercial } \\
\text { Atención al cliente }\end{array}$ & SI & & & $\begin{array}{l}X \\
X\end{array}$ & \\
\hline $\begin{array}{l}\text { f. Gestión de } \\
\text { inventario }\end{array}$ & SI & & $\mathrm{X}$ & & \\
\hline g. Compras & $\begin{array}{l}\text { Compr } \\
\text { as }\end{array}$ & & $\mathrm{X}$ & & \\
\hline
\end{tabular}


6. ¿Cómo se diseña la Cadena de Suministro?

\begin{tabular}{|l|l|l|l|l|}
\hline & $\begin{array}{l}\text { QUIÉN DISEÑA } \\
\text { LA CS }\end{array}$ & $\begin{array}{l}\text { QUIEN DEFINE } \\
\text { PROCESOS }\end{array}$ & $\begin{array}{l}\text { QUIEN DETALLA } \\
\text { TAREAS }\end{array}$ & $\begin{array}{l}\text { QUIEN DEFINE } \\
\text { UBICACIONES }\end{array}$ \\
\hline Propia empresa & \multicolumn{1}{|l|}{ X } & $\mathrm{X}$ & $\mathrm{X}$ & $\mathrm{X}$ \\
\hline Consultora & & & & \\
\hline Seminarios & & & & \\
\hline Desde la Casa Madre & & & & \\
\hline Benchmarking & & & & \\
\hline Otros & & & & \\
\hline
\end{tabular}

7. ¿Cómo se lleva a cabo la distribución logística?

\section{Almacenes propios}

* $\quad$ Flota propia

* Subcontratación de almacenes

Subcontratación de transporte y flota

* Otros

\section{INFORMACIÓN}

8. ¿Qué información logística utilizan para llevar a cabo el proceso logístico?

Niveles de inventarios

Datos de producción

Bases de datos de clientes

proveedores

Capacidades, producción, almacén, transporte

Datos de otras empresas (IDEAS)

\section{Datos de demanda}

Datos de costes

Bases de datos de

Otros

\section{Rutas}

Datos de embalaje 
9. ¿¿uién decide que tipo de información dar a...?

\begin{tabular}{|l|c|l|l|}
\hline & Director & Gestor/Manager & $\begin{array}{l}\text { Administrativo/ } \\
\text { Operario }\end{array}$ \\
\hline PERSONAL DE LA EMPRESA & $\mathrm{X}$ & & \\
\hline PROVEEDORES & $\mathrm{X}$ & & \\
\hline CLIENTES & $\mathrm{X}$ & & \\
\hline OTROS & & & \\
\hline
\end{tabular}

10. ¿Qué información considera necesario dar a sus clientes/ Proveedores?

\begin{tabular}{|l|l|}
\hline CLIENTES & PROVEEDORES \\
\hline Fechas de entrega de pedidos & Fechas de recepción de pedidos \\
\hline Lugares de entrega de pedidos & Lugares de recepción de pedidos \\
\hline Precios & Precios van en los precontratos \\
\hline Tasas & Tasas \\
\hline Disponibilidad de referencias & Disponibilidad \\
\hline Tipo de compañía (Grupo Achet) & Tipo de compañía \\
\hline Características de descarga/ vehículo & Características de descarga/ vehículo \\
\hline
\end{tabular}

TECNOLOGÍA

11. ¿Quién define y decide qué tecnología se utilizará en el proceso logístico?

\begin{tabular}{|l|l|l|l|}
\hline & Director & Gestor/ Manager & Administrativo / Operario \\
\hline $\begin{array}{l}\text { Define } \\
\text { CONSULTORES }\end{array}$ & & & \\
\hline Decide & $\mathrm{X}$ & & \\
\hline
\end{tabular}

12. ¿Qué tipo de tecnología se utiliza en el proceso?

\begin{tabular}{|l|c|c|c|}
\hline & Director & Gestor/ Manager & $\begin{array}{c}\text { Operario/ } \\
\text { Administrativo }\end{array}$ \\
\hline Ordenador / PC & $\mathrm{X}$ & $\mathrm{X}$ & $\mathrm{X}$ \\
\hline Teléfono & $\mathrm{X}$ & $\mathrm{X}$ \\
\hline Scaner & & $\mathrm{X}$ & \\
\hline Intercomunicador & $\mathrm{X}$ & $\mathrm{X}$ & $\mathrm{X}$ \\
\hline Fax & $\mathrm{X}$ & & $\mathrm{X}$ \\
\hline Redes de comunicaciones & & & \\
\hline Etiquetadoras & & & \\
\hline
\end{tabular}




\begin{tabular}{|l|l|l|c|}
\hline Ensacadoras/ Embaladoras & & & \\
\hline Vehículos & & & $\mathrm{X}$ \\
\hline Remolques & & & $\mathrm{X}$ \\
\hline Apiladoras & & & $\mathrm{X}$ \\
\hline Carretillas & & & $\mathrm{X}$ \\
\hline Transporte automático & & & $\mathrm{X}$ \\
\hline
\end{tabular}

13. ¿Quién realiza la revisión tecnológica?

\begin{tabular}{|l|l|l|}
\hline Director & Gestor/ Manager & Administrativo / Operario \\
\hline
\end{tabular}

PERSONAL

14. ¿Cuántos niveles jerárquicos hay en su departamento logístico?

\begin{tabular}{|c|c|c|}
\hline Dos & Tres & Cuatro \\
\hline
\end{tabular}

15. ¿Qué perfil de Recursos Humanos se necesita para realizar los procesos logísticos?

\begin{tabular}{|c|c|c|c|}
\hline & Director & Gestor / Manager & $\begin{array}{c}\text { Administrativo } \\
\text { Operario }\end{array}$ \\
\hline $\begin{array}{l}\text { Estudios } \\
\text { Superiores (S) } \\
\text { Medios (M) } \\
\text { Básicos (B) }\end{array}$ & $\begin{array}{l}\text { Superiores (S) } \\
\text { Medios (M) } \\
\text { Básicos (B) }\end{array}$ & $\begin{array}{l}\text { Superiores (S) } \\
\text { Medios (M) } \\
\text { Básicos (B }\end{array}$ & $\begin{array}{l}\text { Superiores (S) } \\
\text { Medios (M) } \\
\text { Básicos (B) }\end{array}$ \\
\hline $\begin{array}{l}\text { Conocimientos } \\
\text { específicos: } \\
\text { Logística (Log) } \\
\text { Bases Datos (BD) } \\
\text { Almacenes (Alm) } \\
\text { Transporte(Trans) } \\
\text { RRHH (RRHH) } \\
\text { Compras (C) } \\
\text { Ventas (V) } \\
\text { Planificación(Pln) } \\
\text { Supervisión (Spv) } \\
\text { Presupuestos(\$) } \\
\text { Toma de decisión } \\
\text { Reuniones (Mtng) }\end{array}$ & $\begin{array}{l}\text { Logística 1 } \\
\text { Bases Datos } \\
\text { Almacenes } \\
\text { Transporte } \\
\text { RRHH } \\
\text { Compras No } \\
\text { Ventas } \\
\text { Planificación } 2 \\
\text { Supervisión 4 } \\
\text { Presupuestos 3 } \\
\text { Toma de decisión } \\
\text { Reuniones }\end{array}$ & $\begin{array}{l}\text { Logística } 1 \\
\text { Bases Datos } \\
\text { Almacenes } 4 \\
\text { Transporte } \\
\text { RRHH Relación2 } \\
\text { Compras No } \\
\text { Ventas Comercial } \\
\text { Planificación } \\
\text { Supervisión } \\
\text { Presupuestos } \\
\text { Toma de decisión } 3 \\
\text { Reuniones }\end{array}$ & $\begin{array}{l}\text { Logística } \\
\text { Bases Datos } \\
\text { Almacenes } \\
\text { Transporte } \\
\text { RRHH } \\
\text { Compras } \\
\text { Ventas } \\
\text { Planificación } \\
\text { Supervisión } \\
\text { Presupuestos } \\
\text { Toma de decisión } \\
\text { Reuniones }\end{array}$ \\
\hline $\begin{array}{l}\text { Idiomas } \\
\text { Experto (E) } \\
\text { Medio (M) } \\
\text { Ninguno }(\mathrm{N}) \\
\end{array}$ & $\begin{array}{l}\text { Idiomas } \\
\text { Experto (E) } \\
\text { Medio (M) } \\
\text { Ninguno (N) } \\
\end{array}$ & $\begin{array}{l}\text { Idiomas } \\
\text { Experto (E) } \\
\text { Medio (M) } \\
\text { Ninguno (N) } \\
\end{array}$ & $\begin{array}{l}\text { Idiomas } \\
\quad \text { Experto (E) } \\
\text { Medio (M) } \\
\text { Ninguno (N) } \\
\end{array}$ \\
\hline
\end{tabular}




\begin{tabular}{|c|c|c|c|}
\hline $\begin{array}{l}\text { Habilidades } \\
\text { Trabajo en equipo } \\
\text { Colaboración } \\
\text { Honradez } \\
\text { Cumplimiento } \\
\text { Capacidad de liderazgo }\end{array}$ & $\begin{array}{l}X \\
X \\
X \\
X \\
X\end{array}$ & $\begin{array}{l}X \\
X \\
X \\
X \\
X\end{array}$ & $\begin{array}{l}X \\
X \\
X \\
X\end{array}$ \\
\hline \multicolumn{4}{|l|}{ Experiencia anterior } \\
\hline Logística (Log) & Logística 1 & Logística 1 & Logística \\
\hline Bases Datos (BD) & Bases Datos & Bases Datos & Bases Datos \\
\hline Almacenes (Alm) & Almacenes & Almacenes 4 & Almacenes \\
\hline Transporte(Trans) & Transporte & Transporte & Transporte \\
\hline RRHH (RRHH) & RRHH & RRHH Relación2 & RRHH \\
\hline Compras (C) & Compras No & Compras No & Compras \\
\hline Ventas (V) & Ventas & Ventas Comercial & Ventas \\
\hline Planificación(Pln) & Planificación 2 & Planificación & Planificación \\
\hline Supervisión (Spv) & Supervisión 4[ & Supervisión & Supervisión \\
\hline Presupuestos(\$) & Presupuestos 3 & Presupuestos & Presupuestos \\
\hline Toma de decisión & Toma de decisión & Toma de decisión 3 & Toma de decisión \\
\hline Reuniones (Mtng) & Reuniones & Reuniones & Reuniones \\
\hline Informática & Informática & Informática & Informática \\
\hline Manejo de PC & Manejo de PC & Manejo de PC & Manejo de PC \\
\hline Bases de datos & Bases de datos & Bases de datos & Bases de datos \\
\hline Scanner & Scanner & Scanner & Scanner \\
\hline Control almacén & Control almacén & Control almacén & Control almacén \\
\hline Telecomunicación & Telecomunicación & Telecomunicación & Telecomunicación \\
\hline
\end{tabular}

16. ¿Se realiza una planificación de los RRHH dedicados al departamento logístico?

Si / No

17. ¿Quién se encarga de realizar la planificación?

\begin{tabular}{|l|l|l|}
\hline Director & Gestor/ Manager & Administrativo / Operario \\
\hline
\end{tabular}

18. ¿Quién se encarga de asignar personal a las tareas?

\begin{tabular}{|l|l|l|}
\hline Director & Gestor/ Manager & Administrativo / Operario \\
\hline
\end{tabular}

19. ¿Quién define las tareas a realizar en cada puesto?

\begin{tabular}{|l|l|l|}
\hline Director & Gestor/ Manager & Administrativo / Operario
\end{tabular}

20. ¿Conocen los empleados las tareas a desarrollar en sus puestos logísticos?

\begin{tabular}{|l|c|c|c|}
\hline & Director & Gestor/ Manager & Administrativo / Operario \\
\hline Si & $\mathrm{X}$ & $\mathrm{X}$ & $\mathrm{X}$ \\
\hline No & & & \\
\hline
\end{tabular}


21. ¿Quién explica y describe cómo, cuando, donde y que tareas han de realizarse en las actividades de los procesos logísticos?

\begin{tabular}{|l|c|l|l|}
\hline & Director & Gestor/ Manager & Administrativo / Operario \\
\hline QUE & $\mathrm{X}$ & & \\
\hline COMO & $\begin{array}{l}\text { Manual de } \\
\text { procedimientos }\end{array}$ & & \\
\hline CUANDO & $\begin{array}{c}3-4 \text { meses } \\
\text { Nuevo proceso }\end{array}$ & & \\
\hline DONDE & & & \\
\hline
\end{tabular}

22. ¿Qué tipo de formación se imparte a los empleados logísticos?

\begin{tabular}{|l|l|l|c|c|c|}
\hline & $\begin{array}{l}\text { Duración de la } \\
\text { Formación }\end{array}$ & $\begin{array}{l}\text { Cada cuanto } \\
\text { tiempo }\end{array}$ & Práctica & $\begin{array}{c}\text { Teórica } \\
\text { en casa }\end{array}$ & $\begin{array}{c}\text { Teórica } \\
\text { contratada }\end{array}$ \\
\hline Director & SI & & $\mathrm{X}$ & & Francés \\
\hline Gestor/Manager & SI & & $\mathrm{X}$ & & \\
\hline $\begin{array}{l}\text { Administrativo } \\
\text { /Operario }\end{array}$ & SI & & $\begin{array}{c}\mathrm{X} \\
\text { Interna }\end{array}$ & & \\
\hline
\end{tabular}

Enseñanza de nuevos procesos al personal 


\section{COMPROBACIÓN MODELO DE RRHH SISTEMAS LOGÍSTICOS CUESTIONARIO}

Fecha: $\quad$ 19/03/2003

Empresa: Carreras

Cargo: Director/(División de Amacén y Distribución)

OBJETIVOS LOGÍSTICOS

1. ¿Quién es responsable de desarrollar el objetivo logístico en la empresa? (y CS)

\begin{tabular}{|l|l|l}
\hline Director & Gestor/ Manager & Administrativo / Operario
\end{tabular}

2. ¿¿uién controla el cumplimiento de dicho objetivo?

\begin{tabular}{|l|l|l|}
\hline Director & Gestor/ Manager & Administrativo / Operario \\
\hline
\end{tabular}

3. ¿Cada cuanto tiempo se desarrollan los objetivos logísticos?

\begin{tabular}{|l|l|l|}
\hline Entre 6 y 12 meses & Entre 12-18 meses & Más de 18 meses \\
\hline
\end{tabular}

4. ¿Porqué motivo es importante desarrollar los objetivos logísticos?

\section{a) Ayudar a cumplir los objetivos estratégicos de la empresa 1}

b) Ser más competitivos que la competencia 2

c) Entender la logística como modelo de lograr el crecimiento de la empresa.

d) Otros 


\section{CADENA DE SUMINISTRO}

5. ¿Qué funciones de su C. Suministro engloba bajo su dirección? ¿Y quién las detalla (tiempo, lugar y empleado?

\begin{tabular}{|c|c|c|c|c|c|}
\hline ACTIVIDAD & $\mathrm{SI} / \mathrm{NO}$ & Director & $\begin{array}{l}\text { Gestor/ } \\
\text { Manager }\end{array}$ & $\begin{array}{c}\text { Administrativo/ } \\
\text { Operario }\end{array}$ & $\begin{array}{c}\mathrm{N}^{\mathrm{o}} \\
\text { Empleados }\end{array}$ \\
\hline \multicolumn{6}{|l|}{ a. Gestión de pedidos } \\
\hline \multicolumn{6}{|l|}{$\begin{array}{l}\text { b. Gestión de } \\
\text { aprovisionamiento de } \\
\text { materias primas/ } \\
\text { productos } \\
\text { empaquetados a } \\
\text { producción }\end{array}$} \\
\hline \multicolumn{6}{|l|}{$\begin{array}{l}\text { c. Planificación de la } \\
\text { producción }\end{array}$} \\
\hline $\begin{array}{l}\text { d. Gestión de } \\
\text { distribución } \\
\text { (reparto) }\end{array}$ & SI & & $\begin{array}{c}\text { Dept. } \\
\text { Operacione } \\
\text { s } \\
\end{array}$ & & \\
\hline $\begin{array}{l}\text { e. Servicio al cliente } \\
\text { Comercial } \\
\text { Atención al cliente }\end{array}$ & SI & $\mathrm{X}$ & & & \\
\hline $\begin{array}{l}\text { f. Gestión de } \\
\text { inventario y almacén }\end{array}$ & SI & & & $\begin{array}{c}\text { Administrativo/ } \\
\text { Operario } \\
\end{array}$ & \\
\hline g. Compras & SI & & $\mathrm{X}$ & & \\
\hline
\end{tabular}

TOTAL EMPLEADOS DEL DEPARTAMENTO DE LOGÍSTICA

TOTAL EMPLEADOS DE LA EMPRESA 
6. ¿Cómo se diseña la Cadena de Suministro?

\begin{tabular}{|l|l|l|l|l|}
\hline & $\begin{array}{l}\text { QUIÉN DISEÑA } \\
\text { LA CS }\end{array}$ & $\begin{array}{l}\text { QUIEN DEFINE } \\
\text { PROCESOS }\end{array}$ & $\begin{array}{l}\text { QUIEN DETALLA } \\
\text { TAREAS }\end{array}$ & $\begin{array}{l}\text { QUIEN DEFINE } \\
\text { UBICACIONES }\end{array}$ \\
\hline Propia empresa & \multicolumn{1}{|l|}{ X } & $\mathrm{X}$ & $\mathrm{X}$ & $\mathrm{X}$ \\
\hline Consultora & & & & \\
\hline Seminarios & & & & \\
\hline Desde la Casa Madre & & & & \\
\hline Benchmarking & & & & \\
\hline Otros & & & & \\
\hline
\end{tabular}

7. ¿Cómo se lleva a cabo la distribución logística?

\section{Almacenes propios}

* $\quad$ Flota propia

* Subcontratación de almacenes

\section{Subcontratación de transporte y flota}

* Otros

\section{INFORMACIÓN}

8. ¿Qué información logística utilizan para llevar a cabo el proceso logístico?

* $\quad$ Niveles de inventarios

* Datos de producción

* $\quad$ Bases de datos de clientes

proveedores
* $\quad$ Datos de demanda

* $\quad$ Datos de costes

* Bases de datos de

\section{* Capacidades, producción, almacén, transporte * Rutas}

* Datos de otras empresas $\quad * \quad$ Datos de embalaje

* Otros

9. ¿ ¿Quién decide qué tipo de información dar a ...?

\begin{tabular}{|l|c|l|l|}
\hline & Director & $\begin{array}{l}\text { Gestor/ } \\
\text { Manager }\end{array}$ & $\begin{array}{l}\text { Administrativo/ } \\
\text { Operario }\end{array}$ \\
\hline PERSONAL DE LA EMPRESA & $\mathrm{X}$ & & \\
\hline PROVEEDORES & & $\mathrm{X}$ & \\
\hline CLIENTES & $\mathrm{X}$ & $\mathrm{X}$ & \\
\hline OTROS & & & \\
\hline
\end{tabular}

10. ¿Qué información considera necesario dar a sus clientes/ Proveedores? 


\begin{tabular}{|l|l|}
\hline CLIENTES & PROVEEDORES \\
\hline Fechas de entrega de pedidos & Fechas de recepción de pedidos \\
\hline Lugares de entrega de pedidos & Lugares de recepción de pedidos \\
\hline Precios & Precios \\
\hline Tasas & Tasas \\
\hline Disponibilidad de referencias & Disponibilidad \\
\hline Tipo de compañía & Tipo de compañía \\
\hline Características de descarga/ vehículo & Características de descarga/ vehículo \\
\hline
\end{tabular}

TECNOLOGÍA

11. ¿Quién define y decide qué tecnología se utilizará en el proceso logístico?

\begin{tabular}{|l|r|l|l|}
\hline & Director & Gestor/ Manager & Administrativo / Operario \\
\hline Define & $\mathrm{X}$ & & \\
\hline Decide & $\mathrm{X}$ & & \\
\hline
\end{tabular}

12. ¿Qué tipo de tecnología se utiliza en el proceso?

\begin{tabular}{|l|c|c|c|}
\hline & Director & Gestor/ Manager & $\begin{array}{c}\text { Operario/ } \\
\text { Administrativo }\end{array}$ \\
\hline Ordenador / PC & $\mathrm{X}$ & $\mathrm{X}$ & $\mathrm{X}$ \\
\hline Teléfono & $\mathrm{X}$ & $\mathrm{X}$ & $\mathrm{X}$ \\
\hline Scaner & & & $\mathrm{X}$ \\
\hline Intercomunicador & & $\mathrm{X}$ & $\mathrm{X}$ \\
\hline Fax & $\mathrm{X}$ & $\mathrm{X}$ & $\mathrm{X}$ \\
\hline Redes de comunicaciones & & & $\mathrm{X}$ \\
\hline Etiquetadoras & & & $\mathrm{X}$ \\
\hline Ensacadoras/ Embaladoras & & & $\mathrm{X}$ \\
\hline Vehículos & & & \\
\hline Remolques & & & \\
\hline Apiladoras & & & \\
\hline Carretillas & & & \\
\hline Transporte automático & & & \\
\hline
\end{tabular}


13. ¿Quién realiza la revisión tecnológica?

\begin{tabular}{|l|l|l|}
\hline Director & Gestor/ Manager & Administrativo / Operario \\
\hline
\end{tabular}

PERSONAL

14. ¿Cuántos niveles jerárquicos hay en su departamento logístico?

\begin{tabular}{|l|l|l} 
Dos & Tres & Cuatro \\
\hline
\end{tabular}

15. ¿Qué perfil de Recursos Humanos se necesita para realizar los procesos logísticos?

\begin{tabular}{|c|c|c|c|}
\hline & Director & Gestor / Manager & $\begin{array}{c}\text { Administrativo/ } \\
\text { Operario }\end{array}$ \\
\hline $\begin{array}{l}\text { Estudios } \\
\text { Superiores (S) } \\
\text { Medios (M) } \\
\text { Básicos (B) }\end{array}$ & $\begin{array}{l}\text { Superiores (S) } \\
\text { Medios (M) } \\
\text { Básicos (B) }\end{array}$ & $\begin{array}{l}\text { Superiores (S) } \\
\text { Medios (M) } \\
\text { Básicos (B }\end{array}$ & $\begin{array}{l}\text { Superiores (S) } \\
\text { Medios (M) } \\
\text { Básicos (B) }\end{array}$ \\
\hline $\begin{array}{l}\text { Conocimientos } \\
\text { específicos: } \\
\text { Logística (Log) } \\
\text { Bases Datos (BD) } \\
\text { Almacenes (Alm) } \\
\text { Transporte(Trans) } \\
\text { RRHH (RRHH) } \\
\text { Compras (C) } \\
\text { Ventas (V) } \\
\text { Planificación(Pln) } \\
\text { Supervisión (Spv) } \\
\text { Presupuestos(\$) } \\
\text { Toma de decisión } \\
\text { Reuniones (Mtng) }\end{array}$ & $\begin{array}{l}\text { Logística } \\
\text { Bases Datos } \\
\text { Almacenes Poco } \\
\text { Transporte } \\
\text { RRHH } \\
\text { Compras No } \\
\text { Ventas Comercial } \\
\text { Planificación } \\
\text { Supervisión } \\
\text { Presupuestos } \\
\text { Toma de decisión } \\
\text { Reuniones }\end{array}$ & $\begin{array}{l}\text { Logística } \\
\text { Bases Datos } \\
\text { Almacenes 1 } \\
\text { Transporte 2 } \\
\text { RRHH Relación } \\
\text { Compras No } \\
\text { Ventas Comercial } \\
\text { Planificación 4 } \\
\text { Supervisión 3 } \\
\text { Presupuestos } \\
\text { Toma de decisión } \\
\text { Reuniones }\end{array}$ & $\begin{array}{l}\text { Logística } \\
\text { Bases Datos } \\
\text { Almacenes } \\
\text { Transporte } \\
\text { RRHH } \\
\text { Compras } \\
\text { Ventas } \\
\text { Planificación } \\
\text { Supervisión } \\
\text { Presupuestos } \\
\text { Toma de decisión } \\
\text { Reuniones }\end{array}$ \\
\hline $\begin{array}{l}\text { Idiomas } \\
\text { Experto (E) } \\
\text { Medio }(\mathrm{M}) \\
\text { Ninguno }(\mathrm{N})\end{array}$ & $\begin{array}{l}\text { Idiomas } \\
\text { Experto (E) } \\
\text { Medio (M) } \\
\text { Ninguno (N) }\end{array}$ & $\begin{array}{l}\text { Idiomas } \\
\text { Experto (E) } \\
\text { Medio (M) } \\
\text { Ninguno (N) }\end{array}$ & $\begin{array}{l}\text { Idiomas } \\
\text { Experto (E) de } \\
\text { Cara Europa } \\
\text { Medio (M) } \\
\text { Ninguno (N) }\end{array}$ \\
\hline $\begin{array}{l}\text { Habilidades } \\
\text { Liderazgo } \\
\text { Trabajo en equipo } \\
\text { Responsabilidad } \\
\text { Compromiso con la } \mathrm{E}^{\mathrm{a}}\end{array}$ & $\begin{array}{l}\text { Liderazgo } \\
\text { Trabajo en equipo } \\
\text { Responsabilidad } \\
\text { Compromiso con Ea }\end{array}$ & $\begin{array}{l}\text { Liderazgo } \\
\text { Trabajo en equipo } \\
\text { Responsabilidad } \\
\text { Compromiso con } \mathrm{E}^{\mathrm{a}}\end{array}$ & $\begin{array}{l}\text { Liderazgo } \\
\text { Trabajo en equipo } \\
\text { Responsabilidad } \\
\text { Compromiso con } \mathrm{E}^{\mathrm{a}}\end{array}$ \\
\hline $\begin{array}{c}\text { Experiencia Anterior } \\
\text { Logística (Log) } \\
\text { Bases Datos (BD) } \\
\text { Almacenes (Alm) } \\
\text { Transporte(Trans) } \\
\text { RRHH (RRHH) } \\
\text { Compras (C) } \\
\text { Ventas (V) } \\
\text { Planificación(Pln) }\end{array}$ & $\begin{array}{l}\text { Logística } \\
\text { Bases Datos } \\
\text { Almacenes Poco } \\
\text { Transporte } \\
\text { RRHH } \\
\text { Compras No } \\
\text { Ventas Comercial } \\
\text { Planificación }\end{array}$ & $\begin{array}{l}\text { Logística } \\
\text { Bases Datos } \\
\text { Almacenes } 1 \\
\text { Transporte 2 } \\
\text { RRHH Relación } \\
\text { Compras No } \\
\text { Ventas Comercial } \\
\text { Planificación 4 }\end{array}$ & $\begin{array}{l}\text { Logística } \\
\text { Bases Datos } \\
\text { Almacenes } \\
\text { Transporte } \\
\text { RRHH } \\
\text { Compras } \\
\text { Ventas } \\
\text { Planificación }\end{array}$ \\
\hline
\end{tabular}




\begin{tabular}{|c|c|c|c|}
\hline $\begin{array}{l}\text { Supervisión (Spv) } \\
\text { Presupuestos(\$) } \\
\text { Toma de decisión } \\
\text { Reuniones (Mtng) }\end{array}$ & $\begin{array}{l}\text { Supervisión } \\
\text { Presupuestos } \\
\text { Toma de decisión } \\
\text { Reuniones }\end{array}$ & $\begin{array}{l}\text { Supervisión } 3 \\
\text { Presupuestos } \\
\text { Toma de decisión } \\
\text { Reuniones }\end{array}$ & $\begin{array}{l}\text { Supervisión } \\
\text { Presupuestos } \\
\text { Toma de decisión } \\
\text { Reuniones }\end{array}$ \\
\hline $\begin{array}{l}\text { Informática } \\
\text { Manejo de PC } \\
\text { Bases de datos } \\
\text { Scanner } \\
\text { Control almacén } \\
\text { Telecomunicación }\end{array}$ & $\begin{array}{l}\text { Manejo de PC } \\
\text { Bases de datos } \\
\text { Scanner/Cod.Barr } \\
\text { Control almacén } \\
\text { Telecomunicación }\end{array}$ & $\begin{array}{l}\text { Manejo de PC } \\
\text { Bases de datos } \\
\text { Scanner/Cod.Barr } \\
\text { Control almacén } \\
\text { Telecomunicación }\end{array}$ & $\begin{array}{l}\text { Manejo de PC } \\
\text { Bases de datos } \\
\text { Scanner/Cod.Barr } \\
\text { Control almacén } \\
\text { Telecomunicación }\end{array}$ \\
\hline
\end{tabular}

16. ¿Se realiza una planificación de los RRHH dedicados al departamento logístico?

Si / No

17. ¿Quién se encarga de realizar la planificación?

\begin{tabular}{|l|l|l|}
\hline Director & Gestor/ Manager & Administrativo / Operario \\
\hline
\end{tabular}

18. ¿Quién se encarga de asignar personal a las tareas?

\begin{tabular}{|l|l|l|}
\hline Director & Gestor/ Manager & Administrativo / Operario \\
\hline
\end{tabular}

19. ¿Quién define las tareas a realizar en cada puesto?

\begin{tabular}{|l|l|l}
\hline Director & Gestor/ Manager & Administrativo / Operario \\
\hline
\end{tabular}

20. ¿Conocen los empleados las tareas a desarrollar en sus puestos logísticos?

\begin{tabular}{|l|c|c|c|}
\hline & Director & Gestor/ Manager & Administrativo / Operario \\
\hline $\mathrm{Si}$ & $\mathrm{X}$ & $\mathrm{X}$ & $\mathrm{X}$ \\
\hline No & & & \\
\hline
\end{tabular}


21. ¿Quién explica y describe cómo, cuando, donde y que tareas han de realizarse en las actividades de los procesos logísticos?

\begin{tabular}{|l|l|l|l|}
\hline & Director & Gestor/ Manager & Administrativo / Operario \\
\hline QUE & & \multicolumn{1}{|c|}{ X } & \\
\hline COMO & & $\begin{array}{l}\text { Manuales de procedimiento } \\
\text { Web corporativa } \\
\text { Por cliente } \\
\text { Viva voz }\end{array}$ & Web corporativa \\
\hline CUANDO & $\begin{array}{l}\text { Al cambiar la operativa de } \\
\text { los clientes } \\
\text { Depto Calidad ISO 9002 } \\
\text { trasp }\end{array}$ & \\
\hline DONDE & & \\
\hline
\end{tabular}

22. ¿Qué tipo de formación se imparte a los empleados logísticos?

\begin{tabular}{|c|l|l|c|c|c|}
\hline & $\begin{array}{l}\text { Duración de la } \\
\text { Formación }\end{array}$ & $\begin{array}{l}\text { Cada cuanto } \\
\text { tiempo }\end{array}$ & Práctica & $\begin{array}{c}\text { Teórica } \\
\text { en casa }\end{array}$ & $\begin{array}{c}\text { Teórica } \\
\text { contratada }\end{array}$ \\
\hline Director & & & $\mathrm{X}$ & - & $\mathrm{X}$ \\
\hline $\begin{array}{c}\text { Gestor/Manager } \\
\text { 1 vez año }\end{array}$ & $\begin{array}{l}\text { Informes } \\
\text { Control }\end{array}$ & $\mathrm{X}$ & $\mathrm{X}$ & $\mathrm{X}$ \\
\hline $\begin{array}{c}\text { Administrativo } \\
\text { /Operario }\end{array}$ & $\begin{array}{c}\text { Carretilleros } \\
\text { Manip. Almac }\end{array}$ & & $\mathrm{X}$ & $\mathrm{X}$ & $\mathrm{X}$ \\
\hline
\end{tabular}




\section{COMPROBACIÓN MODELO DE RRHH SISTEMAS LOGÍSTICOS CUESTIONARIO}

Fecha: $\quad$ 18/03/2003

Empresa: DIA

Cargo: JEFE DEL DEPARTAMENTO DE IMPORTACIÓN

OBJETIVOS LOGÍSTICOS

1. ¿ ¿Quién es responsable de desarrollar el objetivo logístico en la empresa? (y CS)

\begin{tabular}{|l|l|l}
\hline Director & Gestor/ Manager & Administrativo / Operario
\end{tabular}

2. ¿Quién controla el cumplimiento de dicho objetivo?

\begin{tabular}{|l|l|l|}
\hline Director & Gestor/ Manager & Administrativo / Operario \\
\hline
\end{tabular}

3. ¿Cada cuanto tiempo se desarrollan los objetivos logísticos?

\begin{tabular}{|l|l|l|}
\hline Entre 6 y 12 meses & Entre 12-18 meses & Más de 18 meses
\end{tabular}

4. ¿Porqué motivo es importante desarrollar los objetivos logísticos?

a) Ayudar a cumplir los objetivos estratégicos de la empresa 1-2

b) Ser más competitivos que la competencia 1-2

Entender la logística como modelo de lograr el crecimiento de la empresa. 3

d) Otros 


\section{CADENA DE SUMINISTRO}

5. ¿Qué funciones de su C. Suministro engloba bajo su dirección? ¿Y quién las detalla (tiempo, lugar y empleado?

\begin{tabular}{|c|c|c|c|c|c|}
\hline ACTIVIDAD & $\mathrm{SI} / \mathrm{NO}$ & Director & $\begin{array}{l}\text { Gestor/ } \\
\text { Manager }\end{array}$ & $\begin{array}{l}\text { Administrativo/Ope } \\
\text { rario }\end{array}$ & $\begin{array}{l}\mathrm{N}^{\mathrm{o}} \\
\text { Empleados }\end{array}$ \\
\hline $\begin{array}{l}\text { a. Gestión de } \\
\text { pedidos }\end{array}$ & SI & Decisión & & $\begin{array}{c}\text { Realización } \\
\text { Pedidos, Control de } \\
\text { stock }\end{array}$ & \\
\hline $\begin{array}{l}\text { b. Gestión de } \\
\text { aprovisionami } \\
\text { de materias } \\
\text { primas/ produ } \\
\text { empaquetados } \\
\text { producción }\end{array}$ & & & & & \\
\hline $\begin{array}{l}\text { c. Planificació } \\
\text { la producción }\end{array}$ & & & & & \\
\hline $\begin{array}{l}\text { d. Gestión de } \\
\text { distribución y } \\
\text { almacén }\end{array}$ & SI & $\mathrm{X}$ & $\mathrm{X}$ & $\mathrm{X}$ & \\
\hline $\begin{array}{l}\text { e. Servicio al } \\
\text { cliente }\end{array}$ & SI & & Dept & $\mathrm{X}$ & \\
\hline $\begin{array}{l}\text { f. Gestión de } \\
\text { inventario }\end{array}$ & SI & & $\mathrm{X}$ & $\mathrm{X}$ & \\
\hline g. Compras & SI & & Dept & & \\
\hline
\end{tabular}


6. ¿Cómo se diseña la Cadena de Suministro?

\begin{tabular}{|l|l|l|l|l|}
\hline & $\begin{array}{l}\text { QUIÉN DISEÑA } \\
\text { LA CS }\end{array}$ & $\begin{array}{l}\text { QUIEN DEFINE } \\
\text { PROCESOS }\end{array}$ & $\begin{array}{l}\text { QUIEN DETALLA } \\
\text { TAREAS }\end{array}$ & $\begin{array}{l}\text { QUIEN DEFINE } \\
\text { UBICACIONES }\end{array}$ \\
\hline Propia empresa & \multicolumn{1}{|l|}{ X } & $\mathrm{X}$ & $\mathrm{X}$ & $\mathrm{X}$ \\
\hline Consultora & & & & \\
\hline Seminarios & & & & \\
\hline Desde la Casa Madre & & & & \\
\hline Benchmarking & & & & \\
\hline Otros & & & & \\
\hline
\end{tabular}

7. ¿Cómo se lleva a cabo la distribución logística?

\section{Almacenes propios}

* $\quad$ Flota propia

* Subcontratación de almacenes

\section{Subcontratación de transporte y flota}

* Otros

\section{INFORMACIÓN}

8. ¿Qué información logística utilizan para llevar a cabo el proceso logístico?

* $\quad$ Niveles de inventarios

* $\quad$ Datos de producción Dem)

* $\quad$ Bases de datos de clientes proveedores

\section{* Capacidades, producción, almacén, transporte}

* $\quad$ Datos de otras empresas

* Otros

\section{* $\quad$ Datos de embalaje}

* Datos de demanda

* Datos de costes (incl Prev

* Bases de datos de

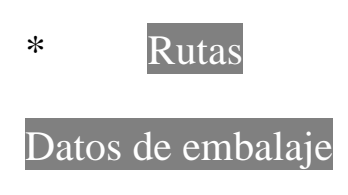


9. ¿Quién decide qué tipo de información dar a ...?

\begin{tabular}{|l|c|l|l|}
\hline & Director & Gestor/Manager & $\begin{array}{l}\text { Administrativ } \\
\text { o/ Operario }\end{array}$ \\
\hline PERSONAL DE LA EMPRESA & $\mathrm{X}$ & & \\
\hline PROVEEDORES & $\mathrm{X}$ & & \\
\hline CLIENTES & & & \\
\hline OTROS & & & \\
\hline
\end{tabular}

10. ¿Qué información considera necesario dar a sus clientes/ Proveedores?

\begin{tabular}{|l|l|}
\hline CLIENTES & PROVEEDORES \\
\hline Fechas de entrega de pedidos & Fechas de recepción de pedidos \\
\hline Lugares de entrega de pedidos & Lugares de recepción de pedidos \\
\hline Precios & Precios contrato previo \\
\hline Tasas & Tasas \\
\hline Disponibilidad de referencias & Disponibilidad De Proveedores a Dia \\
\hline Tipo de compañía & Tipo de compañía \\
\hline Características de descarga/ vehículo & $\begin{array}{l}\text { Características de descarga/ vehículo Def } \\
\text { Com. Aut. }\end{array}$ \\
\hline
\end{tabular}

\section{TECNOLOGÍA}

11. ¿Quién define y decide qué tecnología se utilizará en el proceso logístico?

\begin{tabular}{|l|c|c|c|}
\hline & Director & Gestor/ Manager & Administrativo / Operario \\
\hline Define & & Equipo Trabajo & \\
\hline Decide & $\mathrm{X}$ & & \\
\hline
\end{tabular}

12. ¿Qué tipo de tecnología se utiliza en el proceso?

\begin{tabular}{|l|c|c|c|}
\hline & Director & Gestor/ Manager & $\begin{array}{c}\text { Operario/ } \\
\text { Administrativo }\end{array}$ \\
\hline Ordenador / PC & $\mathrm{X}$ & $\mathrm{X}$ & $\mathrm{X}$ \\
\hline Teléfono & $\mathrm{X}$ & $\mathrm{X}$ & $\mathrm{X}$ \\
\hline Scaner & & $\mathrm{X}$ & $\mathrm{X}$ \\
\hline Intercomunicador & $\mathrm{X}$ & $\mathrm{X}$ & $\mathrm{X}$ \\
\hline Fax & $\mathrm{X}$ & $\mathrm{X}$ & $\mathrm{X}$ \\
\hline Redes de comunicaciones & $\mathrm{X}$ & & $\mathrm{X}$ \\
\hline Etiquetadoras & & & $\mathrm{X}$ \\
\hline
\end{tabular}




\begin{tabular}{|l|l|l|c|}
\hline Ensacadoras/ Embaladoras & & & \\
\hline Vehículos & & & $\mathrm{X}$ \\
\hline Remolques & & & $\mathrm{X}$ \\
\hline Apiladoras & & & $\mathrm{X}$ \\
\hline Carretillas & & & $\mathrm{X}$ \\
\hline Transporte automático & & & \\
\hline
\end{tabular}

13. ¿Quién realiza la revisión tecnológica?

\begin{tabular}{|l|l|l|}
\hline Director & Gestor/ Manager & Administrativo / Operario \\
\hline
\end{tabular}

PERSONAL

14. ¿Cuántos niveles jerárquicos hay en su departamento logístico?

\begin{tabular}{|c|c|c|}
\hline Dos & Tres & Cuatro \\
\hline
\end{tabular}

15. ¿Qué perfil de Recursos Humanos se necesita para realizar los procesos logísticos?

\begin{tabular}{|c|c|c|c|}
\hline & Director & Gestor / Manager & $\begin{array}{c}\text { Administrativo/ } \\
\text { Operario }\end{array}$ \\
\hline $\begin{array}{l}\text { Estudios } \\
\text { Superiores (S) } \\
\text { Medios (M) } \\
\text { Ninguno (N) }\end{array}$ & $\begin{array}{l}\text { Superiores (S) } \\
\text { Medios (M) } \\
\text { Ninguno (N) }\end{array}$ & $\begin{array}{l}\text { Superiores (S) } \\
\text { Medios (M) } \\
\text { Ninguno (N) }\end{array}$ & $\begin{array}{l}\text { Superiores (S) } \\
\text { Medios (M) } \\
\text { Ninguno (N) }\end{array}$ \\
\hline $\begin{array}{l}\text { Conocimientos } \\
\text { específicos: } \\
\text { Logística (Log) } \\
\text { Bases Datos (BD) } \\
\text { Almacenes (Alm) } \\
\text { Transporte(Trans) } \\
\text { RRHH (RRHH) } \\
\text { Compras (C) } \\
\text { Ventas (V) } \\
\text { Planificación(Pln) } \\
\text { Supervisión (Spv) } \\
\text { Presupuestos(\$) } \\
\text { Toma de decisión } \\
\text { Reuniones (Mtng) }\end{array}$ & $\begin{array}{l}\text { Logística } 1 \\
\text { Bases Datos } \\
\text { Almacenes } 4 \\
\text { Transporte } \\
\text { RRHH } \\
\text { Compras } \\
\text { Ventas } \\
\text { Planificación } 4 \\
\text { Supervisión } \\
\text { Presupuestos } 2 \\
\text { Toma de decisión3 } \\
\text { Reuniones }\end{array}$ & $\begin{array}{l}\text { Logística } \\
\text { Bases Datos } \\
\text { Almacenes } 1 \\
\text { Transporte2 } \\
\text { RRHH Relación } \\
\text { Compras } \\
\text { Ventas } \\
\text { Planificación } \\
\text { Supervisión } 4 \\
\text { Presupuestos } 2 \\
\text { Toma de decisión3 } \\
\text { Reuniones } \\
\end{array}$ & $\begin{array}{l}\text { Logística } 3 \\
\text { Bases Datos } \\
\text { Almacenes } 1 \\
\text { Transporte2 } \\
\text { RRHH } \\
\text { Compras Cuanto } \\
\text { Ventas } \\
\text { Planificación } \\
\text { Supervisión } \\
\text { Presupuestos } \\
\text { Toma de decisión } \\
\text { Reuniones }\end{array}$ \\
\hline $\begin{array}{l}\text { Idiomas } \\
\text { Experto (E) } \\
\text { Medio }(\mathrm{M}) \\
\text { Ninguno }(\mathrm{N})\end{array}$ & $\begin{array}{l}\text { Idiomas } \\
\text { Experto (E) } \\
\text { Medio (M) } \\
\text { Ninguno (N) }\end{array}$ & $\begin{array}{l}\text { Idiomas } \\
\text { Experto (E) } \\
\text { Medio }(\mathrm{M}) \\
\text { Ninguno }(\mathrm{N})\end{array}$ & $\begin{array}{l}\text { Idiomas } \\
\text { Experto (E) } \\
\text { Medio (M) } \\
\text { Ninguno (N) }\end{array}$ \\
\hline
\end{tabular}

\section{Habilidades}




\begin{tabular}{|c|c|c|c|}
\hline $\begin{array}{l}\text { Trabajo en equipo } \\
\text { Toma de decisiones } \\
\text { Responsabilidad } \\
\text { Liderazgo } \\
\text { Negociación interna- } \\
\text { externa }\end{array}$ & $\begin{array}{l}\text { Trabajo en equipo } \\
\text { Toma de decisiones } \\
\text { Responsabilidad } \\
\text { Liderazgo } \\
\text { Negociación interna- } \\
\text { externa }\end{array}$ & $\begin{array}{l}\text { Trabajo en equipo } \\
\text { Toma de decisiones } \\
\text { Responsabilidad } \\
\text { Liderazgo } \\
\text { Negociación interna- } \\
\text { externa }\end{array}$ & $\begin{array}{l}\text { Trabajo en equipo } \\
\text { Toma de decisiones } \\
\text { Responsabilidad } \\
\text { Liderazgo } \\
\text { Negociación interna- } \\
\text { externa }\end{array}$ \\
\hline $\begin{array}{l}\text { Experiencia anterior } \\
\text { Logística (Log) } \\
\text { Bases Datos (BD) } \\
\text { Almacenes (Alm) } \\
\text { Transporte(Trans) } \\
\text { RRHH (RRHH) } \\
\text { Compras (C) } \\
\text { Ventas (V) } \\
\text { Planificación(Pln) } \\
\text { Supervisión (Spv) } \\
\text { Presupuestos(\$) } \\
\text { Toma de decisión }\end{array}$ & $\begin{array}{l}\text { RECIÉN } \\
\text { LICENCIADOS } \\
\text { Logística } \\
\text { Bases Datos } \\
\text { Almacenes } \\
\text { Transporte } \\
\text { RRHH } \\
\text { Compras } \\
\text { Ventas } \\
\text { Planificación } \\
\text { Supervisión } \\
\text { Presupuestos } \\
\text { Toma de decisión }\end{array}$ & $\begin{array}{l}\text { SIN } \\
\text { EXPERIENCIA } \\
\text { Logística } \\
\text { Bases Datos } \\
\text { Almacenes } \\
\text { Transporte } \\
\text { RRHH } \\
\text { Compras } \\
\text { Ventas } \\
\text { Planificación } \\
\text { Supervisión } \\
\text { Presupuestos } \\
\text { Toma de decisión }\end{array}$ & $\begin{array}{l}\text { Logística } \\
\text { Bases Datos } \\
\text { Almacenes } \\
\text { Transporte } \\
\text { RRHH } \\
\text { Compras } \\
\text { Ventas } \\
\text { Planificación } \\
\text { Supervisión } \\
\text { Presupuestos } \\
\text { Toma de decisión }\end{array}$ \\
\hline $\begin{array}{l}\text { Informática } \\
\text { Manejo de PC } \\
\text { Bases de datos } \\
\text { Scanner } \\
\text { Control almacén } \\
\text { Telecomunicación }\end{array}$ & $\begin{array}{l}\text { Manejo de PC } \\
\text { Bases de datos } \\
\text { Scanner/Cod.Barr } \\
\text { Control almacén } \\
\text { Telecomunicación }\end{array}$ & $\begin{array}{l}\text { Manejo de PC } \\
\text { Bases de datos } \\
\text { Scanner/Cod.Barr } \\
\text { Control almacén } \\
\text { Telecomunicación }\end{array}$ & $\begin{array}{l}\text { Manejo de PC } \\
\text { Bases de datos } \\
\text { Scanner/Cod.Barr } \\
\text { Control almacén } \\
\text { Telecomunicación }\end{array}$ \\
\hline
\end{tabular}

16. ¿Se realiza una planificación de los RRHH dedicados al departamento logístico? Si /

No

\section{Marcada por la Companía}

17. ¿Quién se encarga de realizar la planificación?

\begin{tabular}{|l|l|l|}
\hline Director & Gestor/ Manager & Administrativo / Operario \\
\hline
\end{tabular}

18. ¿Quién se encarga de asignar personal a las tareas?

\begin{tabular}{|l|l|l|}
\hline Director & Gestor/ Manager & Administrativo / Operario \\
\hline
\end{tabular}

19. ¿Quién define las tareas a realizar en cada puesto?

\begin{tabular}{|l|l|l|}
\hline Director & Gestor/ Manager & Administrativo / Operario \\
\hline
\end{tabular}

20. ¿Conocen los empleados las tareas a desarrollar en sus puestos logísticos?

\begin{tabular}{|l|c|c|c|}
\hline & Director & Gestor/ Manager & Administrativo / Operario \\
\hline $\mathrm{Si}$ & $\mathrm{X}$ & $\mathrm{X}$ & $\mathrm{X}$ \\
\hline No & & & \\
\hline
\end{tabular}


21. ¿Quién explica y describe cómo, cuando, donde y que tareas han de realizarse en las actividades de los procesos logísticos?

\begin{tabular}{|l|c|c|c|}
\hline & Director & Gestor/ Manager & Administrativo / Operario \\
\hline QUE & & $\mathrm{X}$ & \\
\hline COMO & & Manuales & \\
\hline CUANDO & & Transmisión directa & \\
\hline DONDE & & Luriamente & \\
\hline
\end{tabular}

22. ¿Qué tipo de formación se imparte a los empleados logísticos?

\begin{tabular}{|l|l|l|c|c|c|}
\hline & $\begin{array}{l}\text { Duración de la } \\
\text { Formación }\end{array}$ & $\begin{array}{l}\text { Cada cuanto } \\
\text { tiempo }\end{array}$ & Práctica & $\begin{array}{c}\text { Teórica } \\
\text { en casa }\end{array}$ & $\begin{array}{c}\text { Teórica } \\
\text { contratada }\end{array}$ \\
\hline Director & & & $\mathrm{X}$ & $\mathrm{X}$ & \\
\hline Gestor/Manager & & & $\mathrm{X}$ & $\mathrm{X}$ & \\
\hline $\begin{array}{l}\text { Administrativo } \\
\text { /Operario }\end{array}$ & & & $\mathrm{X}$ & $\mathrm{X}$ & \\
\hline
\end{tabular}

Cambio de tareas y Responsabilidades

Presupuestos de cursos y reuniones 


\section{COMPROBACIÓN MODELO DE RRHH SISTEMAS LOGÍSTICOS CUESTIONARIO}

Fecha: $\quad 18 / 03 / 2003$

Empresa: Procter \& Gamble

Cargo: Jefe de Logística (Customer Logistics Manager)

OBJETIVOS LOGÍSTICOS

1. ¿ ¿Quién es responsable de desarrollar el objetivo logístico en la empresa? (y CS)

\begin{tabular}{|l|l|l|}
\hline Director Europeo & Gestor/ Manager & Administrativo / Operario \\
\hline
\end{tabular}

2. ¿¿uién controla el cumplimiento de dicho objetivo?

\begin{tabular}{|l|l|l|}
\hline Director País & Gestor/ Manager & Administrativo / Operario \\
\hline
\end{tabular}

3. ¿Cada cuanto tiempo se desarrollan los objetivos logísticos?

\begin{tabular}{|l|l|l|}
\hline Entre 6 y 12 meses Anual & Entre 12-18 meses & Más de 18 meses
\end{tabular}

4. ¿Porqué motivo es importante desarrollar los objetivos logísticos?

\section{a) Ayudar a cumplir los objetivos estratégicos de la empresa 1}

\section{b) Ser más competitivos que la competencia 2}

c) Entender la logística como modelo de lograr el crecimiento de la empresa. Superado

d) Otros 


\section{CADENA DE SUMINISTRO}

5. ¿ ¿Qué funciones de su C. Suministro engloba bajo su dirección? ¿Y quién las detalla (tiempo, lugar y empleado?

\begin{tabular}{|l|c|l|l|l|l|}
\hline ACTIVIDAD & SI/NO & Director & $\begin{array}{l}\text { Gestor/ } \\
\text { Manager }\end{array}$ & $\begin{array}{l}\text { Administrativo/ } \\
\text { Operario }\end{array}$ & $\begin{array}{l}\mathrm{N}^{\circ} \\
\text { Empleados }\end{array}$ \\
\hline $\begin{array}{l}\text { a. Gestión de pedidos } \\
\text { b. Gestión de } \\
\text { aprovisionamiento de } \\
\text { materias primas/ } \\
\text { productos empaquetados } \\
\text { a producción }\end{array}$ & $\begin{array}{c}\text { Planta } \\
\text { Produc }\end{array}$ & & X & & \\
\hline $\begin{array}{l}\text { c. Planificación de la } \\
\text { producción }\end{array}$ & SI & & X & & \\
\hline $\begin{array}{l}\text { d. Gestión de } \\
\text { distribución } \\
\text { (reparto) }\end{array}$ & SI & & & & \\
\hline $\begin{array}{l}\text { e. Servicio al cliente } \\
\text { Comercial } \\
\text { Atención Cliente }\end{array}$ & SI & & & & \\
\hline $\begin{array}{l}\text { f. Gestión de inventario } \\
\text { y almacén }\end{array}$ & SI & & X & & \\
\hline g. Compras & NO & & & & \\
\hline
\end{tabular}

TOTAL EMPLEADOS DEL DEPARTAMENTO DE LOGÍSTICA España

6. TOTAL EMPLEADOS DE LA EMPRESA 
6. ¿Cómo se diseña la Cadena de Suministro?

\begin{tabular}{|l|c|c|c|c|}
\hline & $\begin{array}{c}\text { QUIÉN DISEÑA } \\
\text { LA CS }\end{array}$ & $\begin{array}{c}\text { QUIEN DEFINE } \\
\text { PROCESOS }\end{array}$ & $\begin{array}{c}\text { QUIEN DETALLA } \\
\text { TAREAS }\end{array}$ & $\begin{array}{c}\text { QUIEN DEFINE } \\
\text { UBICACIONES }\end{array}$ \\
\hline Propia empresa & PG Europa & $\mathrm{X}$ & $\mathrm{X}$ & $\mathrm{X}$ \\
\hline Consultora & & & & \\
\hline Seminarios & & & & $\mathrm{X}$ \\
\hline Desde la Casa Madre & $\mathrm{X}$ & $\mathrm{X}$ & & \\
\hline Benchmarking & & & & \\
\hline Otros & & & & \\
\hline
\end{tabular}

7. ¿Cómo se lleva a cabo la distribución logística?

* Almacenes propios

* $\quad$ Flota propia

Subcontratación de almacenes

Subcontratación de transporte y flota

* Otros

\section{INFORMACIÓN}

8. ¿Qué información logística utilizan para llevar a cabo el proceso logístico?

* $\quad$ Niveles de inventarios

* $\quad$ Datos de producción

* $\quad$ Bases de datos de clientes proveedores(planta)
* $\quad$ Datos de demanda

* $\quad$ Datos de costes

Bases de datos de

* Capacidades, producción, almacén, transporte * Rutas

* Datos de otras empresas(Benchamark) * Datos de embalaje/ Prep Pedidos

Otros 
9. ¿ ¿Quién decide qué tipo de información dar a ...?

\begin{tabular}{|l|l|c|c|}
\hline & Director & Gestor/Manager & $\begin{array}{l}\text { Administrativ } \\
\text { o/ Operario }\end{array}$ \\
\hline PERSONAL DE LA EMPRESA & & $\mathrm{X}$ & X ALTO \\
\hline PROVEEDORES (no maneja) & & & \\
\hline CLIENTES & & $\mathrm{X}$ & \\
\hline OTROS & & & \\
\hline
\end{tabular}

10. ¿Qué información considera necesario dar a sus clientes/ Proveedores?

\begin{tabular}{|l|l|}
\hline CLIENTES & PROVEEDORES \\
\hline Fechas de entrega de pedidos & Fechas de recepción de pedidos \\
\hline Lugares de entrega de pedidos & Lugares de recepción de pedidos \\
\hline Precios & Precios \\
\hline Tasas & Tasas \\
\hline Disponibilidad de referencias & Disponibilidad \\
\hline Tipo de compañía & Tipo de compañía \\
\hline Características de descarga/ vehículo & Características de descarga/ vehículo \\
\hline
\end{tabular}

TECNOLOGÍA

11. ¿Quién define y decide qué tecnología se utilizará en el proceso logístico?

\begin{tabular}{|l|c|c|c|}
\hline & Director & Gestor/ Manager & Administrativo / Operario \\
\hline Define & $\mathrm{X}$ & $\mathrm{X}$ & \\
\hline Decide & $\mathrm{X}$ & $\mathrm{X}$ & \\
\hline
\end{tabular}

12. ¿Qué tipo de tecnología se utiliza en el proceso?

\begin{tabular}{|l|c|c|c|}
\hline & Director & Jefe/ Manager & $\begin{array}{c}\text { Operario/ } \\
\text { Administrativo }\end{array}$ \\
\hline Ordenador / PC & $\mathrm{X}$ & $\mathrm{X}$ & $\mathrm{X}$ \\
\hline Teléfono & $\mathrm{X}$ & $\mathrm{X}$ & ALMACEN \\
\hline Scaner & & $\mathrm{X}$ & ALMACEN \\
\hline Intercomunicador & & $\mathrm{X}$ & ALMACEN \\
\hline Fax & $\mathrm{X}$ & & ALMACEN \\
\hline Redes de comunicaciones & $\mathrm{X}$ & & ALMACEN \\
\hline Etiquetadoras & & & \\
\hline Ensacadoras/ Embaladoras & & & \\
\hline
\end{tabular}




\begin{tabular}{|l|l|l|l|}
\hline Vehículos & & & ALMACEN \\
\hline Remolques & & & ALMACEN \\
\hline Apiladoras & & & ALMACEN \\
\hline Carretillas & & & ALMACEN \\
\hline Transporte automático & & & ALMACEN \\
\hline
\end{tabular}

13. ¿Quién realiza la revisión tecnológica?

\begin{tabular}{|l|l|l|}
\hline Director & Gestor/ Manager & Administrativo / Operario \\
\hline
\end{tabular}

14. ¿Cuántos niveles jerárquicos hay en su departamento logístico?

\begin{tabular}{|c|c|c|}
\hline Dos & Tres & Cuatro \\
\hline
\end{tabular}

15. ¿Qué perfil de Recursos Humanos se necesita para realizar los procesos logísticos?

\begin{tabular}{|c|c|c|c|}
\hline & Director & Gestor / Manager & $\begin{array}{c}\text { Administrativo/ } \\
\text { Operario }\end{array}$ \\
\hline $\begin{array}{l}\text { Estudios } \\
\text { Superiores (S) } \\
\text { Medios (M) } \\
\text { Básico (B) } \\
\end{array}$ & $\begin{array}{l}\text { Estudios } \\
\text { Superiores (S) } \\
\text { Medios (M) } \\
\text { Básico (B) }\end{array}$ & \begin{tabular}{|l} 
Estudios \\
Superiores (S) \\
Medios (M) \\
Básico (B) \\
\end{tabular} & $\begin{array}{l}\text { Estudios } \\
\text { Superiores (S) } \\
\text { Medios (M) } \\
\text { Básico (B) } \\
\end{array}$ \\
\hline $\begin{array}{l}\text { Conocimientos } \\
\text { específicos: (ordenar) } \\
\text { Logística (Log) } \\
\text { Bases Datos (BD) } \\
\text { Almacenes (Alm) } \\
\text { Transporte(Trans) } \\
\text { RRHH (RRHH) } \\
\text { Compras (C) } \\
\text { Ventas (V) } \\
\text { Planificación(Pln) } \\
\text { Supervisión (Spv) } \\
\text { Presupuestos(\$) } \\
\text { Toma de decisión } \\
\text { Reuniones (Mtng) }\end{array}$ & $\begin{array}{l}\text { Logística } \\
\text { Bases Datos } \\
\text { Almacenes } \\
\text { Transporte } \\
\text { RRHH 4 } \\
\text { Compras } \\
\text { Ventas } \\
\text { Planificación } 3 \\
\text { Supervisión (-) } \\
\text { Presupuestos } 2 \\
\text { Toma de decisión1 } \\
\text { Reuniones }\end{array}$ & $\begin{array}{l}\text { Logística } \\
\text { Bases Datos } \\
\text { Almacenes } \\
\text { Transporte } \\
\text { RRHH 4 } \\
\text { Compras } \\
\text { Ventas } \\
\text { Planificación } 3 \\
\text { Supervisión (+) } \\
\text { Presupuestos 2 } \\
\text { Toma de decisión1 } \\
\text { Reuniones }\end{array}$ & $\begin{array}{l}\text { Logística 3 } \\
\text { Bases Datos } 4 \\
\text { Almacenes 1 } \\
\text { Transporte2 } \\
\text { RRHH } \\
\text { Compras } \\
\text { Ventas } \\
\text { Planificación } \\
\text { Supervisión } \\
\text { Presupuestos } \\
\text { Toma de decisión } \\
\text { Reuniones }\end{array}$ \\
\hline $\begin{array}{l}\text { Idiomas } \\
\text { Experto (E) } \\
\text { Medio }(\mathrm{M}) \\
\text { Ninguno }(\mathrm{N}) \\
\end{array}$ & $\begin{array}{l}\text { Idiomas } \\
\text { Experto (E) } \\
\text { Medio (M) } \\
\text { Ninguno (N) } \\
\end{array}$ & $\begin{array}{l}\text { Idiomas } \\
\text { Experto (E) } \\
\text { Medio (M) } \\
\text { Ninguno }(\mathrm{N}) \\
\end{array}$ & $\begin{array}{l}\text { Idiomas } \\
\text { Experto (E) } \\
\text { Medio (M) } \\
\text { Ninguno (N) } \\
\end{array}$ \\
\hline
\end{tabular}




\begin{tabular}{|c|c|c|c|}
\hline Habilidades & & & \\
\hline Trabajo en equipo & Trabajo en equipo & Trabajo en equipo & Trabajo en equipo \\
\hline Comunicación & Comunicación & Comunicación & Comunicación \\
\hline Solucionar temas & Solucionar temas & Solucionar temas & Solucionar temas \\
\hline Liderazgo & Liderazgo & Liderazgo & Liderazgo \\
\hline Toma de decisión & Toma de decisión & Toma de decisión & Toma de decisión \\
\hline Experiencia Anterior & & & \\
\hline Logística (Log) & Logística & Logística & Logística 3 \\
\hline Bases Datos (BD) & Bases Datos & Bases Datos & Bases Datos 4 \\
\hline Almacenes (Alm) & Almacenes & Almacenes & Almacenes 1 \\
\hline Transporte(Trans) & Transporte & Transporte & Transporte2 \\
\hline RRHH (RRHH) & RRHH 4 & RRHH 4 & RRHH \\
\hline Compras (C) & Compras & Compras & Compras \\
\hline Ventas (V) & Ventas & Ventas & Ventas \\
\hline Planificación(Pln) & Planificación 3 & Planificación 3 & Planificación \\
\hline Supervisión (Spv) & Supervisión (-) & Supervisión $(+)$ & Supervisión \\
\hline Presupuestos(\$) & Presupuestos 2 & Presupuestos 2 & Presupuestos \\
\hline Toma de decisión & Toma de decisión1 & Toma de decisión1 & Toma de decisión \\
\hline Reuniones (Mtng) & Reuniones & Reuniones & Reuniones \\
\hline Informática & & & \\
\hline Manejo de PC & Manejo de PC & Manejo de PC & Manejo de PC \\
\hline Bases de datos & Bases de datos & Bases de datos & Bases de datos \\
\hline Scanner/Cod.Barr & Scanner/Cod.Barr & Scanner/Cod.Barr & Scanner/Cod.Barn \\
\hline Control almacén & Control almacén & Control almacén & Control almacén \\
\hline Telecomunicación & Telecomunicación & Telecomunicación & Telecomunicación \\
\hline
\end{tabular}

16. ¿Se realiza una planificación de los RRHH dedicados al departamento logístico? Si /

No

17. ¿Quién se encarga de realizar la planificación?

\begin{tabular}{|l|l|l}
\hline Director & Gestor/ Manager & Administrativo / Operario
\end{tabular}

18. ¿Quién se encarga de asignar personal a las tareas?

\begin{tabular}{|l|l|l}
\hline Director & Gestor/ Manager & Administrativo / Operario
\end{tabular}

19. ¿Quién define las tareas a realizar en cada puesto?

\begin{tabular}{|l|l|l|}
\hline Director & Gestor/ Manager & Administrativo / Operario \\
\hline
\end{tabular}

20. ¿Conocen los empleados las tareas a desarrollar en sus puestos logísticos?

\begin{tabular}{|l|c|c|c|}
\hline & Director & Gestor/ Manager & Administrativo / Operario \\
\hline $\mathrm{Si}$ & $\mathrm{X}$ & $\mathrm{X}$ & $\mathrm{X}$ \\
\hline $\mathrm{No}$ & & & \\
\hline
\end{tabular}


21. ¿Quién explica y describe cómo, cuando, donde y que tareas han de realizarse en las actividades de los procesos logísticos?

\begin{tabular}{|l|c|c|c|}
\hline & Director & Gestor/ Manager & Administrativo / Operario \\
\hline QUE & & $\mathrm{X}$ & \\
\hline COMO & Job Descriptions & Job Descriptions & Job Descriptions \\
Informes, & Objetivos anuales & Objetivos anuales & Objetivos anuales \\
Notas & Manuales & Manuales & Manuales \\
Ordenes & & Anual & Anual \\
\hline CUANDO & Anual & & \\
Mensual & & & \\
Semanal & & & \\
Diario & & & \\
\hline DONDE & & & \\
\hline
\end{tabular}

22. ¿Qué tipo de formación se imparte a los empleados logísticos?

\begin{tabular}{|l|c|c|c|c|c|}
\hline & $\begin{array}{l}\text { Duración de } \\
\text { la Formación }\end{array}$ & $\begin{array}{c}\text { Cada X } \\
\text { tiempo }\end{array}$ & Práctica & $\begin{array}{c}\text { Teórica } \\
\text { en casa }\end{array}$ & $\begin{array}{c}\text { Teórica } \\
\text { contratada }\end{array}$ \\
\hline Director & $3 \times 1$ dia & Anual & $\mathrm{X}$ & $\mathrm{X}$ & $\mathrm{X}$ \\
\hline Gestor/Manager & $3 \times 1$ dia & Anual & $\mathrm{X}$ & $\mathrm{X}$ & $\mathrm{X}$ \\
\hline $\begin{array}{l}\text { Administrativo } \\
\text { /Operario }\end{array}$ & $3 \times 1$ dia & Anual & $\mathrm{X}$ & $\mathrm{X}$ & $\mathrm{X}$ \\
\hline
\end{tabular}




\section{COMPROBACIÓN MODELO DE RRHH SISTEMAS LOGÍSTICOS CUESTIONARIO}

Fecha: $\quad$ 19/03/2003

Empresa: SABECO

Cargo: Director de Logística

OBJETIVOS LOGÍSTICOS

1. ¿ ¿Quién es responsable de desarrollar el objetivo logístico en la empresa? (y CS)

\begin{tabular}{|l|l|l|l|}
\hline Director Estratégico & Gestor/ Manager Operaciones & $\begin{array}{l}\text { Administrativo por Pto y } \\
\text { producto / Operario }\end{array}$
\end{tabular}

2. ¿Quién controla el cumplimiento de dicho objetivo?

\begin{tabular}{|l|l|l|}
\hline Director & Gestor/ Manager Mens. & Administrativo / Operario \\
\hline
\end{tabular}

3. ¿Cada cuanto tiempo se desarrollan los objetivos logísticos?

\begin{tabular}{|l|l|l|}
\hline Entre 6 y 12 meses Mensual & Entre 12-18 meses & Más de 18 meses \\
\hline
\end{tabular}

4. ¿Porqué motivo es importante desarrollar los objetivos logísticos?

1. Ayudar a cumplir los objetivos estratégicos de la empresa

2. Ser más competitivos que la competencia

3. Entender la logística como modelo de lograr el crecimiento de la empresa.

4. Otros 


\section{CADENA DE SUMINISTRO}

5. ¿ ¿Qué funciones de su C. Suministro engloba bajo su dirección? ¿Y quién las detalla (tiempo, lugar y empleado?

\begin{tabular}{|l|c|c|l|l|l|}
\hline ACTIVIDAD & SI/NO & Director & $\begin{array}{l}\text { Gestor/ } \\
\text { Manager }\end{array}$ & $\begin{array}{l}\text { Administrativo/ } \\
\text { Operario }\end{array}$ & $\begin{array}{l}\mathrm{N}^{0} \\
\text { Empleados }\end{array}$ \\
\hline $\begin{array}{l}\text { a. Gestión de pedidos } \\
\text { b. Gestión de } \\
\text { aprovisionamiento de } \\
\text { materias primas/ } \\
\text { productos } \\
\text { empaquetados a } \\
\text { producción }\end{array}$ & SI & X & & & \\
\hline $\begin{array}{l}\text { c. Planificación de la } \\
\text { producción }\end{array}$ & Conjunto & $\mathrm{X}$ & $\mathrm{X}$ & & \\
\hline $\begin{array}{l}\text { d. Gestión de } \\
\text { distribución } \\
\text { (reparto) }\end{array}$ & SI & Politicas & Planes & & \\
\hline $\begin{array}{l}\text { e. Servicio al cliente } \\
\text { Comercial } \\
\text { Atención al cliente }\end{array}$ & $\mathrm{X}$ & $\mathrm{X}$ & & & \\
\hline $\begin{array}{l}\text { f. Gestión de } \\
\text { inventario }\end{array}$ & SI & & & & \\
\hline \begin{tabular}{l} 
g. Compras \\
\hline
\end{tabular}
\end{tabular}

TOTAL EMPLEADOS DEL DEPARTAMENTO DE LOGÍSTICA TOTAL EMPLEADOS DE LA EMPRESA 
6. ¿Cómo se diseña la Cadena de Suministro?

\begin{tabular}{|l|c|c|l|c|}
\hline & $\begin{array}{l}\text { QUIÉN DISEÑA } \\
\text { LA CS }\end{array}$ & $\begin{array}{l}\text { QUIEN DEFINE } \\
\text { PROCESOS }\end{array}$ & $\begin{array}{l}\text { QUIEN DETALLA } \\
\text { TAREAS }\end{array}$ & $\begin{array}{l}\text { QUIEN DEFINE } \\
\text { UBICACIONES }\end{array}$ \\
\hline Propia empresa & $\mathrm{X}$ & $\mathrm{X}$ & $\mathrm{X}$ & $\mathrm{X}$ \\
\hline Consultora & & & & \\
\hline Seminarios & & & & \\
\hline Desde la Casa Madre & & & & \\
\hline Benchmarking & & & & \\
\hline Otros & & & & \\
\hline
\end{tabular}

7. ¿Cómo se lleva a cabo la distribución logística?

* $\quad$ Almacenes propios 95\%

* $\quad$ Flota propia

* $\quad$ Subcontratación de almacenes $5 \%$ y Operación

* Subcontratación de transporte y flota 100\%

* Otros

\section{INFORMACIÓN}

8. ¿Qué información logística utilizan para llevar a cabo el proceso logístico?

* $\quad$ Niveles de inventarios

* $\quad$ Datos de producción

* $\quad$ Bases de datos de clientes(interno/tienda)

* Capacidades, producción, almacén, transporte

* $\quad$ Datos de otras empresas

* Otros
* Datos de demanda

* Datos de costes

Bases de datos de proveedores

*Rutas (son fijas)

*Datos de embalajePesos, Vol, med 
9. ¿Quién decide qué tipo de información dar a...?

\begin{tabular}{|l|c|c|c|}
\hline & Director & Gestor/Manager & $\begin{array}{l}\text { Administrativ } \\
\text { o/ Operario }\end{array}$ \\
\hline PERSONAL DE LA EMPRESA & $\mathrm{X}$ & $\mathrm{X}$ & \\
\hline PROVEEDORES & $\mathrm{X}$ & & \\
\hline CLIENTES (Internos: tiendas) & $\mathrm{X}$ & $\mathrm{X}$ & $\mathrm{X}$ \\
\hline OTROS & & & \\
\hline
\end{tabular}

10. ¿Qué información considera necesario dar a sus clientes/ Proveedores?

\begin{tabular}{|l|l|}
\hline CLIENTES & PROVEEDORES \\
\hline Fechas de entrega de pedidos FIJO & Fechas de recepción de pedidos \\
\hline Lugares de entrega de pedidos FIJO & Lugares de recepción de pedidos Hora \\
\hline Precios NO LOGISTICA & Precios NO \\
\hline Tasas & Tasas NO \\
\hline Disponibilidad de referencias NO & Disponibilidad NO \\
\hline Tipo de compañía & Tipo de compañía \\
\hline Características de descarga/ vehículo FIJO & $\begin{array}{l}\text { Características de descarga/ vehículo } \\
\text { PALET FIJO }\end{array}$ \\
\hline
\end{tabular}

TECNOLOGÍA

11. ¿Quién define y decide qué tecnología se utilizará en el proceso logístico?

\begin{tabular}{|l|c|c|c|}
\hline & Director & Gestor/ Manager & Administrativo / Operario \\
\hline Define EQUIPO & Def Politica & Colegiado & Colegiado \\
\hline Decide & $\mathrm{X}$ & $\mathrm{X}$ & \\
\hline
\end{tabular}

12. ¿Qué tipo de tecnología se utiliza en el proceso?

\begin{tabular}{|l|c|c|c|}
\hline & Director & Gestor/ Manager & $\begin{array}{c}\text { Operario/ } \\
\text { Administrativo }\end{array}$ \\
\hline Ordenador / PC & $\mathrm{X}$ & $\mathrm{X}$ & $\mathrm{X}$ \\
\hline Teléfono & $\mathrm{X}$ & $\mathrm{X}$ & $\mathrm{X}$ \\
\hline Scaner & & $\mathrm{X}$ & $\mathrm{X}$ \\
\hline Intercomunicador & $\mathrm{X}$ & $\mathrm{X}$ & $\mathrm{X}$ \\
\hline Fax & $\mathrm{X}$ & $\mathrm{X}$ & \\
\hline Redes de comunicaciones & & & \\
\hline
\end{tabular}




\begin{tabular}{|l|l|l|c|}
\hline Etiquetadoras & & & $\mathrm{X}$ \\
\hline Ensacadoras/ Embaladoras & & & $\mathrm{X}$ \\
\hline Vehículos & & & $\mathrm{X}$ \\
\hline Remolques & & & $\mathrm{X}$ \\
\hline Apiladoras & & & $\mathrm{X}$ \\
\hline Carretillas & & & $\mathrm{X}$ \\
\hline Transporte automático & & & $\mathrm{X}$ \\
\hline
\end{tabular}

13. ¿Quién realiza la revisión tecnológica?

\begin{tabular}{|l|l|l}
\hline Director & Gestor/ Manager & Administrativo / Operario \\
\hline
\end{tabular}

\section{PERSONAL}

14. ¿Cuántos niveles jerárquicos hay en su departamento logístico?

\begin{tabular}{|c|c|c|}
\hline Dos & Tres & Cuatro \\
\hline
\end{tabular}

15. ¿Qué perfil de Recursos Humanos se necesita para realizar los procesos logísticos?

\begin{tabular}{|c|c|c|c|}
\hline & Director & Gestor / Manager & $\begin{array}{c}\text { Administrativo/ } \\
\text { Operario }\end{array}$ \\
\hline $\begin{array}{l}\text { Estudios } \\
\text { Superiores (S) } \\
\text { Medios (M) } \\
\text { Básicos (B) } \\
\end{array}$ & $\begin{array}{l}\text { Superiores (S) } \\
\text { Medios (M) } \\
\text { Básicos (B) } \\
\end{array}$ & $\begin{array}{l}\text { Superiores (S) } \\
\text { Medios (M) } \\
\text { Básicos (B) }\end{array}$ & $\begin{array}{l}\text { Superiores (S) } \\
\text { Medios (M) } \\
\text { Básicos (B) }\end{array}$ \\
\hline 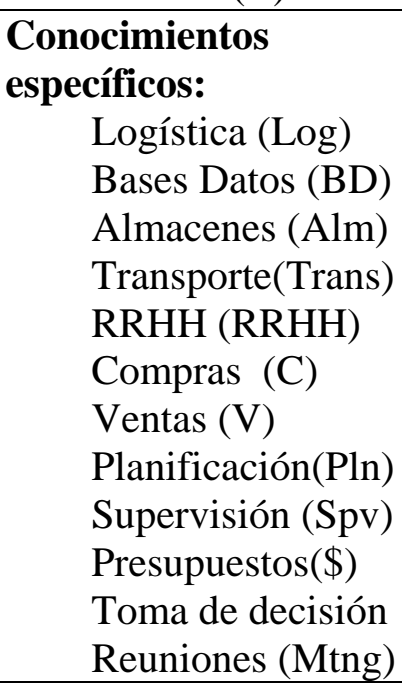 & $\begin{array}{l}\text { Logística } \\
\text { Bases Datos } \\
\text { Almacenes } \\
\text { Transporte X } \\
\text { RRHH } \\
\text { Compras } \\
\text { Ventas } \\
\text { Planificación } 1 \\
\text { Supervisión } \\
\text { Presupuestos } 2 \\
\text { Toma de decisión3 } \\
\text { Reuniones }\end{array}$ & $\begin{array}{l}\text { Logística } \\
\text { Bases Datos } \\
\text { Almacenes } \\
\text { Transporte4 } \\
\text { RRHH Relación } \\
\text { Compras (Convine) } \\
\text { Ventas (Conocer) } \\
\text { Planificación 1 } \\
\text { Supervisión } 2 \\
\text { Presupuestos } \\
\text { Toma de decisión3 } \\
\text { Reuniones }\end{array}$ & $\begin{array}{l}\text { Depende Perfil } \\
\text { Logística Func } \\
\text { Bases Datos } \\
\text { Almacenes Op1 } \\
\text { Transporte } \\
\text { RRHH } \\
\text { Compras } \\
\text { Ventas } \\
\text { Planificación } \\
\text { Supervisión } \\
\text { Presupuestos } \\
\text { Toma de decisión A1 } \\
\text { Reuniones }\end{array}$ \\
\hline $\begin{array}{l}\text { Idiomas } \\
\text { Experto (E) } \\
\text { Medio }(\mathrm{M}) \\
\text { Ninguno }(\mathrm{N})\end{array}$ & $\begin{array}{l}\text { Experto (E) } \\
\text { Medio (M) } \\
\text { Ninguno (N) }\end{array}$ & $\begin{array}{l}\text { Experto (E) } \\
\text { Medio (M) } \\
\text { Ninguno (N) }\end{array}$ & $\begin{array}{l}\text { Experto (E) } \\
\text { Medio (M) } \\
\text { Ninguno (N) }\end{array}$ \\
\hline
\end{tabular}




\begin{tabular}{|c|c|c|c|}
\hline $\begin{array}{l}\text { Habilidades } \\
\text { Toma de decisiones } \\
\text { Trabajo en equipo } \\
\text { Fidelidad y Honestidad } \\
\text { Liderazgo }\end{array}$ & $\begin{array}{l}X \\
X \\
X \\
X\end{array}$ & $\begin{array}{l}\mathrm{X} \\
\mathrm{X} \\
\mathrm{X} \\
\mathrm{X}\end{array}$ & $\begin{array}{l}X \\
X \\
X\end{array}$ \\
\hline $\begin{array}{l}\text { Experiencia anterior } \\
\text { Logística (Log) } \\
\text { Bases Datos (BD) } \\
\text { Almacenes (Alm) } \\
\text { Transporte(Trans) } \\
\text { RRHH (RRHH) } \\
\text { Compras (C) } \\
\text { Ventas (V) } \\
\text { Planificación(Pln) } \\
\text { Supervisión (Spv) } \\
\text { Presupuestos(\$) } \\
\text { Toma de decisión } \\
\end{array}$ & $\begin{array}{l}\text { Logística } \\
\text { Bases Datos } \\
\text { Almacenes } \\
\text { Transporte } \\
\text { RRHH }\end{array}$ & $\begin{array}{l}\text { - Nivel } \\
\text { Logística } \\
\text { Bases Datos } \\
\text { Almacenes } \\
\text { Transporte } \\
\text { RRHH } \\
\text { Compras } \\
\text { Ventas } \\
\text { Planificación } \\
\text { Supervisión } \\
\text { Presupuestos } \\
\text { Toma de decisión }\end{array}$ & $\begin{array}{l}\text { Experto en } 1 \text { solo } \\
\text { Logística } \\
\text { Bases Datos } \\
\text { Almacenes } \\
\text { Transporte } \\
\text { RRHH } \\
\text { Compras } \\
\text { Ventas } \\
\text { Planificación } \\
\text { Supervisión } \\
\text { Presupuestos } \\
\text { Toma de decisión }\end{array}$ \\
\hline $\begin{array}{l}\text { Informática } \\
\text { Manejo de PC } \\
\text { Bases de datos } \\
\text { Scanner } \\
\text { Control almacén } \\
\text { Telecomunicación }\end{array}$ & $\begin{array}{l}\text { Manejo de PC } \\
\text { Bases de datos } \\
\text { Scanner } \\
\text { Control almacén } \\
\text { Telecomunicación }\end{array}$ & $\begin{array}{l}\text { Manejo de PC } \\
\text { Bases de datos } \\
\text { Scanner } \\
\text { Control almacén } \\
\text { Telecomunicación }\end{array}$ & $\begin{array}{l}\text { Manejo de PC (A) } \\
\text { Bases de datos } \\
\text { Scanner } \\
\text { Control almacén } \\
\text { Operarios } \\
\text { Telecomunicación } \\
\text { Operarios }\end{array}$ \\
\hline
\end{tabular}

16. ¿ Se realiza una planificación de los RRHH dedicados al departamento logístico?

Si / No

17. ¿Quién se encarga de realizar la planificación?

\begin{tabular}{|l|l|l}
\hline Director & Gestor/ Manager & Administrativo / Operario
\end{tabular}

18. ¿Quién se encarga de asignar personal a las tareas?

\begin{tabular}{|l|l|l}
\hline Director & Gestor/ Manager & Administrativo / Operario
\end{tabular}

19. ¿Quién define las tareas a realizar en cada puesto?

\begin{tabular}{|l|l|l|}
\hline $\begin{array}{l}\text { Director } \\
\text { Diseño }\end{array}$ & $\begin{array}{l}\text { Gestor/ Manager } \\
\text { Diseño Implem }\end{array}$ & $\begin{array}{l}\text { Administrativo / Operario } \\
\text { Implementación y Mejora }\end{array}$ \\
\hline
\end{tabular}

20. ¿Conocen los empleados las tareas a desarrollar en sus puestos logísticos?

\begin{tabular}{|l|c|c|c|}
\hline & Director & Gestor/ Manager & Administrativo / Operario \\
\hline $\mathrm{Si}$ & $\mathrm{X}$ & $\mathrm{X}$ & $\mathrm{X}$ \\
\hline $\mathrm{No}$ & & & \\
\hline
\end{tabular}


21. ¿Quién explica y describe cómo, cuando, donde y que tareas han de realizarse en las actividades de los procesos logísticos?

\begin{tabular}{|l|l|l|c|}
\hline & Director & Gestor/ Manager & Administrativo / Operario \\
\hline QUE & Global & \multicolumn{1}{|c|}{ Global } & X \\
\hline COMO & & Manual de procedim & \\
\hline CUANDO & & $\begin{array}{l}\text { No hay revisión oblig } \\
\text { Anual }\end{array}$ & \\
\hline DONDE & & & \\
\hline
\end{tabular}

22. ¿Qué tipo de formación se imparte a los empleados logísticos?

\begin{tabular}{|l|l|l|c|c|c|}
\hline & $\begin{array}{l}\text { Duración de la } \\
\text { Formación }\end{array}$ & $\begin{array}{l}\text { Cada cuanto } \\
\text { tiempo }\end{array}$ & Práctica & $\begin{array}{c}\text { Teórica } \\
\text { en casa } \\
\text { Mayor }\end{array}$ & $\begin{array}{c}\text { Teórica } \\
\text { contratada } \\
\text { Menor }\end{array}$ \\
\hline Director & $\mathrm{X}$ & & $\mathrm{X}$ & $\mathrm{X}$ & $\mathrm{X}$ \\
\hline Gestor/Manager & $\mathrm{X}$ & & $\mathrm{X}$ & $\mathrm{X}$ & $\mathrm{X}$ \\
\hline $\begin{array}{l}\text { Administrativo } \\
\text { /Operario }\end{array}$ & $\mathrm{X}$ & & $\mathrm{X}$ & $\mathrm{X}$ & $\mathrm{X}$ \\
\hline
\end{tabular}

Formación de Acceso para los nuevos

Después de 6 meses se hacen contratos Indefinidos, y se ofrece ser accionista.

Existe un catalogo de cursos, una serie de ellos recomendados por los superiores y otros solicitados

Producto- Oficio: los puestos de almacén dependen del perfil del operario, como por ejemplo los carretilleros. 


\section{COMPROBACIÓN MODELO DE RRHH SISTEMAS LOGÍSTICOS CUESTIONARIO}

Fecha:

$14 / 3 / 03$

Empresa:-Grupo Logístico Santos

Cargo:

DTRA. DE RECURSOS HUMANOS

\section{OBJETIVOS LOGÍSTICOS}

1. ¿ ¿Quién es responsable de desarrollar el objetivo logístico en la empresa? (y CS)

\begin{tabular}{|l|c|c|} 
Director & Gestor/ Manager & Administrativo / Operario \\
\hline
\end{tabular}

2. ¿¿uién controla el cumplimiento de dicho objetivo?

\begin{tabular}{|l|c|c|} 
Director & Gestor/ Manager & Administrativo / Operario \\
\hline
\end{tabular}

3. ¿Cada cuanto tiempo se desarrollan los objetivos logísticos?

\begin{tabular}{l|l|l} 
Entre 6 y 12 meses & Entre 12-18 meses & Más de 18 meses
\end{tabular}

4. ¿Porqué motivo es importante desarrollar los objetivos logísticos?

a. Ayudar a cumplir los objetivos estratégicos de la empresa

b. Ser más competitivos que la competencia

c. Entender la logística como modelo de lograr el crecimiento de la empresa.

d. Otros 


\section{CADENA DE SUMINISTRO}

5. ¿Qué funciones de su C. Suministro engloba bajo su dirección? ¿Y quién las detalla (tiempo, lugar y empleado?

\begin{tabular}{|c|c|c|c|c|c|}
\hline ACTIVIDAD & $\mathrm{SI} / \mathrm{NO}$ & Director & $\begin{array}{l}\text { Gestor/ } \\
\text { Manager }\end{array}$ & $\begin{array}{l}\text { Administrativo/ } \\
\text { Operario }\end{array}$ & $\begin{array}{l}\mathrm{N}^{\mathrm{o}} \\
\text { Empleados }\end{array}$ \\
\hline a. Gestión de pedidos & SI & NO & SI & NO & 30 \\
\hline $\begin{array}{l}\text { b. Gestión de } \\
\text { aprovisionamiento de } \\
\text { materias primas/ } \\
\text { productos } \\
\text { empaquetados a } \\
\text { producción }\end{array}$ & SI & NO & NO & NO & 30 \\
\hline $\begin{array}{l}\text { c. Planificación de la } \\
\text { producción }\end{array}$ & SI & NO & SI & NO & 5 \\
\hline $\begin{array}{l}\text { d. Gestión de } \\
\text { distribución y } \\
\text { almacén }\end{array}$ & SI & SI & SI & NO & 2 \\
\hline e. Servicio al cliente & SI & SI & SI & $\mathrm{NO}$ & 2 \\
\hline $\begin{array}{l}\text { f. Gestión de } \\
\text { inventario }\end{array}$ & SI & SI & SI & NO & 3 \\
\hline g. Compras & $\mathrm{NO}$ & $\mathrm{NO}$ & SI & $\mathrm{NO}$ & 2 \\
\hline
\end{tabular}


6. ¿Cómo se diseña la Cadena de Suministro?

\begin{tabular}{|l|l|l|l|l|}
\hline & $\begin{array}{l}\text { QUIÉN DISEÑA } \\
\text { LA CS }\end{array}$ & $\begin{array}{l}\text { QUIEN DEFINE } \\
\text { PROCESOS }\end{array}$ & $\begin{array}{l}\text { QUIEN DETALLA } \\
\text { TAREAS }\end{array}$ & $\begin{array}{l}\text { QUIEN DEFINE } \\
\text { UBICACIONES }\end{array}$ \\
\hline Propia empresa & NO & NO & SI & SI \\
\hline Consultora & NO & NO & NO & NO \\
\hline Seminarios & NO & NO & NO & NO \\
\hline Desde la Casa Madre & NO & NO & NO & NO \\
\hline Benchmarking & NO & NO & NO & NO \\
\hline Otros & EL CLIENTE & EL CLIENTE & EL CLIENTE & \\
\hline
\end{tabular}

7. ¿Cómo se lleva a cabo la distribución logística?

Almacenes propios

Flota propia

* Subcontratación de almacenes

Subcontratación de transporte y flota

* Otros

\section{INFORMACIÓN}

8. ¿Qué información logística utilizan para llevar a cabo el proceso logístico?

* $\quad$ Niveles de inventarios

Datos de demanda

* $\quad$ Datos de producción

*Datos de costes

* $\quad$ Bases de datos de clientes

*Bases de datos de proveedores

* $\quad$ Capacidades, producción, almacén, transporte *Rutas

* $\quad$ Datos de otras empresas

*Datos de embalaje

* Otros

9. ¿QQuién decide qué tipo de información dar a ...?

\begin{tabular}{|l|c|c|l|}
\hline & Director & Gestor/Manager & $\begin{array}{l}\text { Administrativo/ } \\
\text { Operario }\end{array}$ \\
\hline PERSONAL DE LA EMPRESA & $\mathrm{X}$ & $\mathrm{X}$ & \\
\hline PROVEEDORES & & $\mathrm{X}$ & \\
\hline CLIENTES & $\mathrm{X}$ & $\mathrm{X}$ & \\
\hline OTROS & & & \\
\hline
\end{tabular}

10. ¿Qué información considera necesario dar a sus clientes/ Proveedores?

\begin{tabular}{|l|l|}
\hline CLIENTES & PROVEEDORES \\
\hline Fechas de entrega de pedidos & Fechas de recepción de pedidos \\
\hline
\end{tabular}




\begin{tabular}{|l|l|}
\hline Lugares de entrega de pedidos & Lugares de recepción de pedidos \\
\hline Precios & Precios \\
\hline Tasas & Tasas \\
\hline Disponibilidad de referencias & Disponibilidad \\
\hline Tipo de compañía & Tipo de compañía \\
\hline Características de descarga/ vehículo & Características de descarga/ vehículo \\
\hline
\end{tabular}

TECNOLOGÍA

11. ¿Quién define y decide qué tecnología se utilizará en el proceso logístico?

\begin{tabular}{|l|r|l|l|}
\hline & Director & Gestor/ Manager & Administrativo / Operario \\
\hline Define & $\mathrm{X}$ & & \\
\hline Decide & $\mathrm{X}$ & & \\
\hline
\end{tabular}

12. ¿Qué tipo de tecnología se utiliza en el proceso?

\begin{tabular}{|l|c|c|c|}
\hline & Director & Gestor/ Manager & $\begin{array}{c}\text { Operario/ } \\
\text { Administrativo }\end{array}$ \\
\hline Ordenador / PC & $\mathrm{X}$ & $\mathrm{X}$ & $\mathrm{X}$ \\
\hline Teléfono & $\mathrm{X}$ & $\mathrm{X}$ & $\mathrm{X}$ \\
\hline Scaner & $\mathrm{X}$ & $\mathrm{X}$ & $\mathrm{X}$ \\
\hline Intercomunicador & $\mathrm{X}$ & $\mathrm{X}$ & $\mathrm{X}$ \\
\hline Fax & $\mathrm{X}$ & & $\mathrm{X}$ \\
\hline Redes de comunicaciones & & & $\mathrm{X}$ \\
\hline Etiquetadoras & & & $\mathrm{X}$ \\
\hline Ensacadoras/ Embaladoras & & & $\mathrm{X}$ \\
\hline Vehículos & & & $\mathrm{X}$ \\
\hline Remolques & & & \\
\hline Apiladoras & & & \\
\hline Carretillas & & & \\
\hline Transporte automático & & & \\
\hline
\end{tabular}

13. ¿Quién realiza la revisión tecnológica? 


\begin{tabular}{|c|c|c|}
\hline Director & Gestor/ Manager & Administrativo / Operario \\
\hline PERSONAL
\end{tabular}

14. ¿Cuántos niveles jerárquicos hay en su departamento logístico?

\begin{tabular}{|c|c|c|}
\hline Dos & Tres & Cuatro \\
\hline
\end{tabular}

15. ¿Qué perfil de Recursos Humanos se necesita para realizar los procesos logísticos?

\begin{tabular}{|c|c|c|c|}
\hline & Director & Gestor / Manager & $\begin{array}{c}\text { Administrativo/ } \\
\text { Operario }\end{array}$ \\
\hline $\begin{array}{l}\text { Estudios } \\
\text { Superiores (S) } \\
\text { Medios (M) } \\
\text { Ninguno (N) }\end{array}$ & $\begin{array}{l}\text { Superiores } \\
\text { Medios } \\
\text { Básicos } \\
\end{array}$ & $\begin{array}{l}\text { Superiores } \\
\text { Medios } \\
\text { Básicos }\end{array}$ & $\begin{array}{l}\text { Superiores } \\
\text { Medios } \\
\text { Básicos }\end{array}$ \\
\hline $\begin{array}{l}\text { Conocimientos } \\
\text { específicos: } \\
\text { Logística (Log) } \\
\text { Bases Datos (BD) } \\
\text { Almacenes (Alm) } \\
\text { Transporte(Trans) } \\
\text { RRHH (RRHH) } \\
\text { Compras (C) } \\
\text { Ventas (V) } \\
\text { Planificación(Pln) } \\
\text { Supervisión (Spv) } \\
\text { Presupuestos(\$) } \\
\text { Toma de decisión } \\
\text { Reuniones (Mtng) }\end{array}$ & $\begin{array}{l}\text { Logística } \\
\text { Bases de datos } \\
\text { Almacenes } \\
\text { Transportes } \\
\text { Recursos Humanos } \\
\text { Compras } \\
\text { Ventas } \\
\text { Planificación } \\
\text { Supervisión } \\
\text { Presupuestos } \\
\text { Toma de decisión } \\
\text { Reuniones }\end{array}$ & $\begin{array}{l}\text { Logística } \\
\text { Bases de datos } \\
\text { Almacenes } \\
\text { Transportes } \\
\text { Recursos Humanos } \\
\text { Compras } \\
\text { Ventas } \\
\text { Planificación } \\
\text { Supervisión } \\
\text { Presupuestos } \\
\text { Toma de decisión } \\
\text { Reuniones }\end{array}$ & $\begin{array}{l}\text { Logística } \\
\text { Bases de datos } \\
\text { Almacenes } \\
\text { Transportes } \\
\text { Recursos Humanos } \\
\text { Compras } \\
\text { Ventas } \\
\text { Planificación } \\
\text { Supervisión } \\
\text { Presupuestos } \\
\text { Toma de decisión } \\
\text { Reuniones }\end{array}$ \\
\hline $\begin{array}{l}\text { Idiomas } \\
\text { Experto (E) } \\
\text { Medio }(\mathrm{M}) \\
\text { Ninguno }(\mathrm{N}) \\
\end{array}$ & $\begin{array}{l}\text { Experto (E) } \\
\text { Medio (M) } \\
\text { Ninguno (N) }\end{array}$ & $\begin{array}{l}\text { Experto (E) } \\
\text { Medio (M) } \\
\text { Ninguno (N) }\end{array}$ & $\begin{array}{l}\text { Experto (E) } \\
\text { Medio (M) } \\
\text { Ninguno (N) }\end{array}$ \\
\hline Habilidades & & & \\
\hline $\begin{array}{c}\text { Experiencia anterior } \\
\text { Logística (Log) } \\
\text { Bases Datos (BD) } \\
\text { Almacenes (Alm) } \\
\text { Transporte(Trans) } \\
\text { RRHH (RRHH) } \\
\text { Compras (C) } \\
\text { Ventas (V) } \\
\text { Planificación(Pln) } \\
\text { Supervisión (Spv) } \\
\text { Presupuestos(\$) } \\
\text { Toma de decisión } \\
\end{array}$ & $\begin{array}{l}\text { Logística } \\
\text { Bases de datos } \\
\text { Almacenes } \\
\text { Transportes } \\
\text { Recursos Humanos } \\
\text { Compras } \\
\text { Ventas } \\
\text { Planificación } \\
\text { Supervisión } \\
\text { Presupuestos } \\
\text { Toma de decisión } \\
\end{array}$ & $\begin{array}{l}\text { Logística } \\
\text { Bases de datos } \\
\text { Almacenes } \\
\text { Transportes } \\
\text { Recursos Humanos } \\
\text { Compras } \\
\text { Ventas } \\
\text { Planificación } \\
\text { Supervisión } \\
\text { Presupuestos } \\
\text { Toma de decisión } \\
\end{array}$ & $\begin{array}{l}\text { Logística } \\
\text { Bases de datos } \\
\text { Almacenes } \\
\text { Transportes } \\
\text { Recursos Humanos } \\
\text { Compras } \\
\text { Ventas } \\
\text { Planificación } \\
\text { Supervisión } \\
\text { Presupuestos } \\
\text { Toma de decisión } \\
\end{array}$ \\
\hline $\begin{array}{l}\text { Informática } \\
\text { Manejo de PC }\end{array}$ & Manejo de PC & Manejo de PC & Manejo de PC \\
\hline
\end{tabular}




\begin{tabular}{l|l|l|l|} 
Bases de datos & Bases de datos & Bases de datos & Bases de datos \\
Scanner & Scanner & Scanner & Scanner \\
Control almacén & Control almacén & Control almacén & Control almacén \\
Telecomunicación & Telecomunicación & Telecomunicación & Telecomunicación \\
\hline
\end{tabular}

16. ¿Se realiza una planificación de los RRHH dedicados al departamento logístico?

Si / No

17. ¿Quién se encarga de realizar la planificación?

\begin{tabular}{|l|l|l|}
\hline Director & Gestor/ Manager & Administrativo / Operario \\
\hline
\end{tabular}

18. ¿Quién se encarga de asignar personal a las tareas?

\begin{tabular}{|l|l|l|}
\hline Director & Gestor/ Manager & Administrativo / Operario \\
\hline
\end{tabular}

19. ¿Quién define las tareas a realizar en cada puesto?

\begin{tabular}{|l|l|l|}
\hline Director & Gestor/ Manager & Administrativo / Operario \\
\hline
\end{tabular}

20. ¿Conocen los empleados las tareas a desarrollar en sus puestos logísticos?

\begin{tabular}{|l|l|c|c|}
\hline & Director & Gestor/ Manager & Administrativo / Operario \\
\hline $\mathrm{Si}$ & SI & SI & SI \\
\hline No & & & \\
\hline
\end{tabular}

21. ¿Quién explica y describe cómo, cuando, donde y que tareas han de realizarse en las actividades de los procesos logísticos?

\begin{tabular}{|l|c|l|l|}
\hline & Director & Gestor/ Manager & Administrativo / Operario \\
\hline QUE & $\mathrm{X}$ & & \\
\hline COMO & $\mathrm{X}$ & & \\
\hline CUANDO & $\mathrm{X}$ & & \\
\hline DONDE & $\mathrm{X}$ & & \\
\hline
\end{tabular}

22. ¿Qué tipo de formación se imparte a los empleados logísticos?

\begin{tabular}{|l|l|c|c|c|c|}
\hline & $\begin{array}{l}\text { Duración de la } \\
\text { Formación }\end{array}$ & $\begin{array}{l}\text { Cada cuanto } \\
\text { tiempo }\end{array}$ & Práctica & $\begin{array}{c}\text { Teórica } \\
\text { en casa }\end{array}$ & $\begin{array}{c}\text { Teórica } \\
\text { contratada }\end{array}$ \\
\hline Director & $\begin{array}{l}\text { RRHH 16 HS } \\
\text { 2/AÑO }\end{array}$ & & & \\
\hline Gestor/Manager & $\begin{array}{c}\text { RRH, LOG, } \\
\text { 20 HS }\end{array}$ & 3/AÑO & & & \\
\hline $\begin{array}{l}\text { Administrativo } \\
\text { /Operario }\end{array}$ & $\begin{array}{c}\text { INFORMATI } \\
\text { CA }\end{array}$ & 2/AÑO & & & \\
\hline
\end{tabular}




\section{COMPROBACIÓN MODELO DE RRHH SISTEMAS LOGÍSTICOS CUESTIONARIO}

Fecha: $\quad 13$ Marzo 2003

Empresa:- Silvestre Autobat (Distribución Comercial)

Cargo: Director de Recursos Humanos.

OBJETIVOS LOGÍSTICOS

1. ¿ ¿Quién es responsable de desarrollar el objetivo logístico en la empresa? (y CS)

$$
\text { Director }
$$

Gestor/ Manager

Administrativo / Operario

2. ¿Quién controla el cumplimiento de dicho objetivo?

\begin{tabular}{|l|l|l|}
\hline Director & Gestor/ Manager & Administrativo / Operario \\
\hline
\end{tabular}

3. ¿Cada cuanto tiempo se desarrollan los objetivos logísticos?

\begin{tabular}{|l|l|l|}
\hline Entre 6 y 12 meses & Entre 12-18 meses & Más de 18 meses \\
\hline
\end{tabular}

4. ¿Porqué motivo es importante desarrollar los objetivos logísticos?

a. Ayudar a cumplir los objetivos estratégicos de la empresa

b. Ser más competitivos que la competencia

\section{Entender la logística como modelo de lograr el crecimiento de la empresa.}

d. Otros 


\section{CADENA DE SUMINISTRO}

5. ¿ ¿Qué funciones de su C. Suministro engloba bajo su dirección? ¿Y quién las detalla (tiempo, lugar y empleado?

\begin{tabular}{|c|c|c|c|c|c|}
\hline ACTIVIDAD & $\mathrm{SI} / \mathrm{NO}$ & Director & $\begin{array}{l}\text { Gestor/ } \\
\text { Manager }\end{array}$ & $\begin{array}{l}\text { Administrativo/ } \\
\text { Operario }\end{array}$ & $\begin{array}{l}\mathrm{N}^{\circ} \\
\text { Empleados }\end{array}$ \\
\hline a. Gestión de pedidos & Si & $\begin{array}{l}\text { Negociaci } \\
\text { ón anual }\end{array}$ & 1 & 1 & 2 \\
\hline $\begin{array}{l}\text { b. Gestión de } \\
\text { aprovisionamiento de } \\
\text { materias primas/ } \\
\text { productos empaquetados } \\
\text { a producción }\end{array}$ & No & & & & \\
\hline $\begin{array}{l}\text { c. Planificación de la } \\
\text { producción }\end{array}$ & No & & & & \\
\hline $\begin{array}{l}\text { d. Gestión de } \\
\text { distribución } \\
\text { (reparto) }\end{array}$ & $\mathrm{Si}$ & & $\begin{array}{l}1 \text { Central } \\
1 \times 35 \\
\text { sucursal }\end{array}$ & 3 & \\
\hline $\begin{array}{l}\text { e. Servicio al cliente } \\
\text { Comercial } \\
\text { Atención Cliente }\end{array}$ & $\mathrm{Si}$ & $1+2$ asist & $\begin{array}{l}1 \mathrm{C} 1 \times 35 \mathrm{~S} \\
2 \mathrm{C} 1 \times 35 \mathrm{~S}\end{array}$ & $\begin{array}{ll}1 \mathrm{C} & 0 \mathrm{~S} \\
1 \mathrm{C} & 1 \times 35 \mathrm{~S}\end{array}$ & \\
\hline $\begin{array}{l}\text { f. Gestión de inventario } \\
\text { y almacén }\end{array}$ & Si & & $1 \mathrm{C} 1 \times 35 S$ & $\begin{array}{l}6 \text { (3entrada } \\
\text { 3salida) } \\
\text { 1pto x tareas } \\
\end{array}$ & \\
\hline g. Compras & Si & 1 & 1 Respons & 2 Administr & Centralizado \\
\hline
\end{tabular}

TOTAL EMPLEADOS DEL DEPARTAMENTO DE LOGÍSTICA

TOTAL EMPLEADOS DE LA EMPRESA 210 
¿Cómo se diseña la Cadena de Suministro?

\begin{tabular}{|l|c|c|c|c|}
\hline & $\begin{array}{c}\text { QUIÉN DISEÑA } \\
\text { LA CS }\end{array}$ & $\begin{array}{c}\text { QUIEN DEFINE } \\
\text { PROCESOS }\end{array}$ & $\begin{array}{c}\text { QUIEN DETALLA } \\
\text { TAREAS }\end{array}$ & $\begin{array}{c}\text { QUIEN DEFINE } \\
\text { UBICACIONES }\end{array}$ \\
\hline Propia empresa & Dirección & Dirección & Dirección & Dirección \\
\hline Consultora & & & & \\
\hline Seminarios & & & & \\
\hline Desde la Casa Madre & & & & \\
\hline Benchmarking & & & & \\
\hline Otros & & & & \\
\hline
\end{tabular}

6. ¿Cómo se lleva a cabo la distribución logística?

\section{Almacenes propios}

\section{Flota propia}

* Subcontratación de almacenes

\section{Subcontratación de transporte y flota}

* Otros

\section{INFORMACIÓN}

7. ¿Qué información logística utilizan para llevar a cabo el proceso logístico?

\section{* $\quad$ Niveles de inventarios}

* $\quad$ Datos de producción

* $\quad$ Bases de datos de clientes proveedores

* Capacidades, producción, almacén, transporte * Rutas

* Datos de otras empresas * $\quad * \quad$ Datos de embalaje

* Otros

8. ¿ ¿Quién decide qué tipo de información dar a ...?

\begin{tabular}{|l|l|l|l|}
\hline & Director & Gestor/Manager & $\begin{array}{l}\text { Administrativo/ } \\
\text { Operario }\end{array}$ \\
\hline PERSONAL DE LA EMPRESA & Director & & \\
\hline PROVEEDORES & Director & & \\
\hline CLIENTES & Director & & \\
\hline OTROS & Director & & \\
\hline
\end{tabular}

9. ¿Qué información considera necesario dar a sus clientes/ Proveedores? 


\begin{tabular}{|l|l|}
\hline CLIENTES & PROVEEDORES \\
\hline Fechas de entrega de pedidos & Fechas de recepción de pedidos \\
\hline Lugares de entrega de pedidos & Lugares de recepción de pedidos \\
\hline Precios & Precios \\
\hline Tasas (transporte) & Tasas \\
\hline Disponibilidad de referencias & Disponibilidad \\
\hline Tipo de compañía & Tipo de compañía \\
\hline Características de descarga/ vehículo & Características de descarga/ vehículo \\
\hline
\end{tabular}

TECNOLOGÍA

10. ¿Quién define y decide qué tecnología se utilizará en el proceso logístico?

\begin{tabular}{|l|l|l|l|}
\hline & Director & Gestor/ Manager & Administrativo / Operario \\
\hline Define & Dirección & & \\
\hline Decide & Dirección & & \\
\hline
\end{tabular}

11. ¿Qué tipo de tecnología se utiliza en el proceso?

\begin{tabular}{|l|c|c|c|}
\hline & Director & Jefe/ Manager & $\begin{array}{c}\text { Operario/ } \\
\text { Administrativo }\end{array}$ \\
\hline Ordenador / PC & $\mathrm{X}$ & $\mathrm{X}$ & $\mathrm{X}$ \\
\hline Teléfono & $\mathrm{X}$ & $\mathrm{X}$ & $\mathrm{X}$ \\
\hline Scaner & & $\mathrm{X}$ & $\mathrm{X}$ \\
\hline Intercomunicador & $\mathrm{X}$ & $\mathrm{X}$ & $\mathrm{X}$ \\
\hline Fax & $\mathrm{X}$ & & $\mathrm{X}$ \\
\hline Redes de comunicaciones & & & $\mathrm{X}$ \\
\hline Etiquetadoras & & & $\mathrm{X}$ \\
\hline Ensacadoras/ Embaladoras & & & $\mathrm{X}$ \\
\hline Vehículos & & & $\mathrm{X}$ \\
\hline Remolques & & & \\
\hline Apiladoras & & & \\
\hline Carretillas & & & \\
\hline Transporte automático & & & \\
\hline
\end{tabular}


12. ¿Quién realiza la revisión tecnológica?

\begin{tabular}{|c|c|c|}
\hline \begin{tabular}{|l|l} 
Director \\
\end{tabular} & Gestor/ Manager & Administrativo / Operario \\
\hline \multicolumn{3}{|l|}{ PERSONAL } \\
\hline \multicolumn{3}{|c|}{ 13. ¿Cuántos niveles jerárquicos hay en su departamento logístico? } \\
\hline Dos & Tres & Cuatro \\
\hline
\end{tabular}

14. ¿Qué perfil de Recursos Humanos se necesita para realizar los procesos logísticos?

\begin{tabular}{|c|l|l|l|}
\hline Estudios & Director & Gestor / Manager & $\begin{array}{c}\text { Administrativo/ } \\
\text { Operario }\end{array}$ \\
$\begin{array}{c}\text { Superiores (S) } \\
\text { Medios (M) }\end{array}$ & Superiores (S) & $\begin{array}{l}\text { Superiores (S) } \\
\text { Bedico (B) }\end{array}$ & $\begin{array}{l}\text { Superiores (S) } \\
\text { Medios (M) }\end{array}$ \\
\hline $\begin{array}{c}\text { Conocimientos } \\
\text { específicos: (ordenar) }\end{array}$ & Básico (B) & Básico (B) & \\
Logística (Log) & Logística & Logística & \\
Bases Datos (BD) & Bases Datos & Bases Datos & Logística \\
Almacenes (Alm) & Almacenes & Almacenes & Bases Datos \\
Transporte(Trans) & Transporte & Transporte & Transpones \\
RRHH (RRHH) & RRHH & RRHH (relaciones) & RRHH \\
Compras (C) & Compras & Compras & Compras \\
Ventas (V) & Ventas & Ventas & Ventas \\
Planificación(Pln) & Planificación & Planificación & Planificación \\
Supervisión (Spv) & Supervisión & Supervisión & Supervisión \\
Presupuestos(\$) & Presupuestos & Presupuestos & Presupuestos \\
Toma de decisión & Toma de decisión & Toma de decisión & Toma de decisión \\
Reuniones (Mtng) & Reuniones & Reuniones & Reuniones \\
\hline Idiomas & Idiomas & Idiomas & Idiomas \\
Experto (E) & Experto (E) & Experto (E) & Experto (E) \\
Medio (M) & Medio (M) & Medio (M) & Medio (M) \\
Ninguno (N) & Ninguno (N) & Ninguno (N) & Ninguno (N) \\
\hline
\end{tabular}




\begin{tabular}{|c|c|c|c|}
\hline Habilidades (0-6) & $\begin{array}{l}\text { Organización } 6 \\
\text { Liderazgo6 } \\
\text { Cap. Análisis6 } 6 \\
\text { Autoridad 6 } \\
\text { Acept. Cambio } 6 \\
\text { Relaciones } 5\end{array}$ & $\begin{array}{l}\text { Organización } 4 \\
\text { Liderazgo5 } \\
\text { Cap. Análisis } 4 \\
\text { Autoridad } 3 \\
\text { Acept. Cambio } 5 \\
\text { Relaciones } 5\end{array}$ & $\begin{array}{l}\text { Organización } 1 \\
\text { Liderazgo } 0 \\
\text { Cap. Análisis } 0 \\
\text { Autoridad } 0 \\
\text { Acept. Cambio } 3 \\
\text { Relaciones } 2\end{array}$ \\
\hline \multicolumn{4}{|l|}{ Experiencia anterior } \\
\hline Logística (Log) & Logística & Logística & Logística \\
\hline Bases Datos (BD) & Bases Datos & Bases Datos & Bases Datos \\
\hline Almacenes (Alm) & Almacenes & Almacenes & Almacenes \\
\hline Transporte(Trans) & Transporte & Transporte & Transporte \\
\hline RRHH (RRHH) & RRHH & RRHH (relaciones) & RRHH \\
\hline Compras (C) & Compras & Compras & Compras \\
\hline Ventas (V) & Ventas & Ventas & Ventas \\
\hline Planificación(Pln) & Planificación & Planificación & Planificación \\
\hline Supervisión (Spv) & Supervisión & Supervisión & Supervisión \\
\hline Presupuestos(\$) & Presupuestos & Presupuestos & Presupuestos \\
\hline Toma de decisión & Toma de decisión & Toma de decisión & Toma de decisión \\
\hline \multicolumn{4}{|l|}{ Informática } \\
\hline Manejo de PC & Manejo de PC & Manejo de PC & Manejo de PC \\
\hline Bases de datos & Bases de datos & Bases de datos & Bases de datos \\
\hline Scanner/Cod.Barr & Scanner/Cod.Barr & Scanner/Cod.Barr & Scanner/Cod.Barr \\
\hline Control almacén & Control almacén & Control almacén & Control almacén \\
\hline Telecomunicación & Telecomunicación & Telecomunicación & Telecomunicación \\
\hline
\end{tabular}

15. ¿Se realiza una planificación de los RRHH dedicados al departamento logístico? Si / No

16. ¿Quién se encarga de realizar la planificación?

\begin{tabular}{|l|l|l|}
\hline Director & Gestor/ Manager & Administrativo / Operario
\end{tabular}

17. ¿Quién se encarga de asignar personal a las tareas?

\begin{tabular}{|l|l|l|}
\hline Director & Gestor/ Manager & Administrativo / Operario \\
\hline
\end{tabular}

18. ¿Quién define las tareas a realizar en cada puesto?

\begin{tabular}{|l|l|l|}
\hline Director & Gestor/ Manager & Administrativo / Operario \\
\hline
\end{tabular}

19. ¿Conocen los empleados las tareas a desarrollar en sus puestos logísticos?

\begin{tabular}{|l|l|l|l|}
\hline & Director & Gestor/ Manager & Administrativo / Operario \\
\hline Si & Director & Gestor/Managener & Administrativo/ Operario \\
\hline No & & & \\
\hline
\end{tabular}


20. ¿Quién explica y describe cómo, cuando, donde y que tareas han de realizarse en las actividades de los procesos logísticos?

\begin{tabular}{|l|c|l|l|}
\hline & Director & Gestor/ Manager & Administrativo / Operario \\
\hline QUE & Director & & \\
\hline COMO & Director & & \\
\hline CUANDO & Director & & \\
\hline DONDE & Director & & \\
\hline
\end{tabular}

21. ¿Qué tipo de formación se imparte a los empleados logísticos?

\begin{tabular}{|l|l|l|l|l|l|}
\hline & $\begin{array}{l}\text { Duración de } \\
\text { la Formación }\end{array}$ & $\begin{array}{l}\text { Cada X } \\
\text { tiempo }\end{array}$ & Práctica & $\begin{array}{l}\text { Teórica } \\
\text { en casa }\end{array}$ & $\begin{array}{c}\text { Teórica } \\
\text { contratada }\end{array}$ \\
\hline Director & & & Desde la Ea & Lecturas & \\
\hline Gestor/Manager & & & $\begin{array}{l}\text { Desde dentro } \\
\text { de la } \\
\text { Empresa }\end{array}$ & $\begin{array}{l}\text { Por } \\
\text { proveedores } \\
\text { (autofinan) }\end{array}$ \\
\hline $\begin{array}{l}\text { Administrativo } \\
\text { /Operario }\end{array}$ & & & Desde la E & & \\
\hline
\end{tabular}




\section{COMPROBACIÓN MODELO DE RRHH SISTEMAS LOGÍSTICOS CUESTIONARIO}

Fecha: $\quad 17 / 03 / 2003$

Empresa: SLI (Servicios Logísticos Integrados)

Cargo: Director de Recursos Humanos

OBJETIVOS LOGÍSTICOS

1. ¿Quién es responsable de desarrollar el objetivo logístico en la empresa? (y CS)

\begin{tabular}{|l|l|l}
\hline Director & Gestor/ Manager & Administrativo / Operario
\end{tabular}

2. ¿¿uién controla el cumplimiento de dicho objetivo?

\begin{tabular}{|l|l|l|}
\hline Director & Gestor/ Manager & Administrativo / Operario \\
\hline
\end{tabular}

3. ¿Cada cuanto tiempo se desarrollan los objetivos logísticos?

\begin{tabular}{|l|l|l|}
\hline Entre 6 y 12 meses Anual & Entre 12-18 meses & $\begin{array}{l}\text { Más de } 18 \text { meses } \\
\text { Largo Plazo: } 3 \text { años }\end{array}$ \\
\hline
\end{tabular}

4. ¿Porqué motivo es importante desarrollar los objetivos logísticos?

a. Ayudar a cumplir los objetivos estratégicos de la empresa

b. Ser más competitivos que la competencia

Entender la logística como modelo de lograr el crecimiento de la empresa.

d. Otros 


\section{CADENA DE SUMINISTRO}

5. ¿Qué funciones de su C. Suministro engloba bajo su dirección? ¿Y quién las detalla (tiempo, lugar y empleado?

\begin{tabular}{|l|c|l|c|l|l|}
\hline ACTIVIDAD & SI/NO & Director & $\begin{array}{l}\text { Gestor/ } \\
\text { Manager }\end{array}$ & $\begin{array}{l}\text { Administrativo/ } \\
\text { Operario }\end{array}$ & $\begin{array}{l}\mathrm{N}^{\circ} \\
\text { Empleados }\end{array}$ \\
\hline a. Gestión de pedidos & SI & & $\mathrm{X}$ & & \\
\hline $\begin{array}{l}\text { b. Gestión de } \\
\text { aprovisionamiento de } \\
\text { materias primas/ } \\
\text { productos } \\
\text { empaquetados a } \\
\text { producción }\end{array}$ & SI & & $\mathrm{X}$ & & \\
\hline $\begin{array}{l}\text { c. Planificación de la } \\
\text { producción }\end{array}$ & SI & & $\mathrm{X}$ & & \\
\hline $\begin{array}{l}\text { d. Gestión de } \\
\text { distribución y } \\
\text { almacén }\end{array}$ & SI & & $\mathrm{X}$ & & \\
\hline e. Servicio al cliente & SI & & $\mathrm{X}$ & & \\
\hline $\begin{array}{l}\text { f. Gestión de } \\
\text { inventario }\end{array}$ & SI & & $\mathrm{X}$ & & \\
\hline g. Compras & SI & & $\mathrm{X}$ & & \\
\hline
\end{tabular}

TOTAL EMPLEADOS DEL DEPARTAMENTO DE LOGÍSTICA

TOTAL EMPLEADOS DE LA EMPRESA

Planificación de la demanda SI

Servicios Generales 20\% 
6. ¿Cómo se diseña la Cadena de Suministro?

\begin{tabular}{|l|c|l|l|c|}
\hline & $\begin{array}{l}\text { QUIÉN } \\
\text { DISEÑA } \\
\text { LA CS }\end{array}$ & $\begin{array}{l}\text { QUIEN } \\
\text { DEFINE } \\
\text { PROCESOS }\end{array}$ & $\begin{array}{l}\text { QUIEN } \\
\text { DETALLA } \\
\text { TAREAS }\end{array}$ & $\begin{array}{l}\text { QUIEN DEFINE } \\
\text { UBICACIONES }\end{array}$ \\
\hline $\begin{array}{l}\text { Propia empresa + } \\
\text { CLIENTE /consultora }\end{array}$ & $\mathbb{X}$ & $\mathbb{X}$ & $\mathbb{X}$ \\
\hline Consultora & & & & \\
\hline Seminarios & & & & \\
\hline Desde la Casa Madre & & & & \\
\hline Benchmarking & & & & \\
\hline Otros & & & & \\
\hline
\end{tabular}

6. ¿Cómo se lleva a cabo la distribución logística?

* $\quad$ Almacenes propios

* $\quad$ Flota propia

\section{Subcontratación de almacenes}

\section{Subcontratación de transporte y flota}

* Otros

\section{INFORMACIÓN}

7. ¿Qué información logística utilizan para llevar a cabo el proceso logístico?

* $\quad$ Niveles de inventarios

* Datos de demanda

* Datos de producción

\section{* Datos de costes}

* Bases de datos de clientes (distribución) * Bases de datos de proveedores

* Capacidades, producción, almacén, transporte $\quad * \quad$ Rutas

* Datos de otras empresas $\quad * \quad$ Datos de embalaje

* Otros 
8. ¿Quién decide qué tipo de información dar a .... ?

\begin{tabular}{|l|c|c|c|}
\hline & Director & $\begin{array}{l}\text { Gestor/ } \\
\text { Manager }\end{array}$ & $\begin{array}{l}\text { Administrativo/ } \\
\text { Operario }\end{array}$ \\
\hline PERSONAL DE LA EMPRESA & $\mathrm{X}$ & & \\
\hline PROVEEDORES & & $\mathrm{X}$ & $\mathrm{X}$ \\
\hline CLIENTES & $\mathrm{X}$ & $\mathrm{X}$ & \\
\hline OTROS & & & \\
\hline
\end{tabular}

9. ¿Qué información considera necesario dar a sus clientes/ Proveedores?

\begin{tabular}{|l|l|}
\hline CLIENTES & PROVEEDORES \\
\hline Fechas de entrega de pedidos & Fechas de recepción de pedidos \\
\hline Lugares de entrega de pedidos (ellos) & Lugares de recepción de pedidos \\
\hline Precios & Precios \\
\hline Tasas & Tasas \\
\hline Disponibilidad de referencias & Disponibilidad \\
\hline Tipo de compañía & Tipo de compañía \\
\hline Características de descarga/ vehículo & Características de descarga/ vehículo \\
\hline
\end{tabular}

TECNOLOGÍA

10. ¿Quién define y decide qué tecnología se utilizará en el proceso logístico?

\begin{tabular}{|l|l|c|c|}
\hline & Director & Gestor/ Manager & Administrativo / Operario \\
\hline Define & & $\mathrm{X}$ & \\
\hline Decide & $\mathrm{X}$ & & \\
\hline
\end{tabular}

11. ¿Qué tipo de tecnología se utiliza en el proceso?

\begin{tabular}{|l|c|c|c|}
\hline & Director & Jefe/ Manager & $\begin{array}{c}\text { Operario/ } \\
\text { Administrativo }\end{array}$ \\
\hline Ordenador / PC & $\mathrm{X}$ & $\mathrm{X}$ & $\mathrm{X}$ \\
\hline Teléfono & $\mathrm{X}$ & $\mathrm{X}$ & $\mathrm{X}$ \\
\hline Scaner & & & $\mathrm{X}$ \\
\hline Intercomunicador & & $\mathrm{X}$ & $\mathrm{X}$ \\
\hline Fax & $\mathrm{X}$ & $\mathrm{X}$ & $\mathrm{X}$ \\
\hline Redes de comunicaciones & $\mathrm{X}$ & & $\mathrm{X}$ \\
\hline Etiquetadoras & & & $\mathrm{X}$ \\
\hline Ensacadoras/ Embaladoras & & & \\
\hline
\end{tabular}




\begin{tabular}{|l|l|l|c|}
\hline Vehículos & & & $\mathrm{X}$ \\
\hline Remolques & & & $\mathrm{X}$ \\
\hline Apiladoras & & & $\mathrm{X}$ \\
\hline Carretillas & & & $\mathrm{X}$ \\
\hline Transporte automático & & & $\mathrm{X}$ \\
\hline
\end{tabular}

12. ¿Quién realiza la revisión tecnológica?

\begin{tabular}{|l|l|l|}
\hline Director (aprueba) & Gestor/ Manager (propone) & Administrativo / Operario \\
\hline
\end{tabular}

\section{PERSONAL}

13. ¿Cuántos niveles jerárquicos hay en su departamento logístico?

\begin{tabular}{|c|c|c|}
\hline Dos & Tres & Cuatro \\
\hline
\end{tabular}

14. ¿Qué perfil de Recursos Humanos se necesita para realizar los procesos logísticos?

\begin{tabular}{|c|c|c|c|}
\hline & Director & Gestor / Manager & $\begin{array}{c}\text { Administrativo/ } \\
\text { Operario }\end{array}$ \\
\hline $\begin{array}{l}\text { Estudios } \\
\text { Superiores (S) } \\
\text { Medios (M) } \\
\text { Ninguno (N) }\end{array}$ & $\begin{array}{l}\text { Estudios } \\
\text { Superiores (S) } \\
\text { Medios (M) } \\
\text { Ninguno (N) }\end{array}$ & $\begin{array}{l}\text { Estudios } \\
\text { Superiores (S) } \\
\text { Medios (M) } \\
\text { Ninguno (N) }\end{array}$ & $\begin{array}{l}\text { Estudios } \\
\text { Superiores (S) } \\
\text { Medios (M) } \\
\text { Ninguno }(\mathrm{N})\end{array}$ \\
\hline $\begin{array}{l}\text { Conocimientos } \\
\text { específicos: } \\
\text { Logística (Log) } \\
\text { Bases Datos (BD) } \\
\text { Almacenes (Alm) } \\
\text { Transporte(Trans) } \\
\text { RRHH (RRHH) } \\
\text { Compras (C) } \\
\text { Ventas (V) } \\
\text { Planificación(Pln) } \\
\text { Supervisión (Spv) } \\
\text { Presupuestos(\$) } \\
\text { Toma de decisión } \\
\text { Reuniones (Mtng) }\end{array}$ & $\begin{array}{l}\text { Logística } \\
\text { Bases Datos } \\
\text { Almacenes } \\
\text { Transporte } \\
\text { RRHH 4 } \\
\text { Compras } \\
\text { Ventas } \\
\text { Planificación } 1 \\
\text { Supervisión } \\
\text { Presupuestos } 2 \\
\text { Toma de decisión3 } \\
\text { Reuniones }\end{array}$ & $\begin{array}{l}\text { Logística 1 } \\
\text { Bases Datos } \\
\text { Almacenes } 2 \\
\text { Transporte3 } \\
\text { RRHH } \\
\text { Compras } 4 \\
\text { Ventas } \\
\text { Planificación } \\
\text { Supervisión } \\
\text { Presupuestos } \\
\text { Toma de decisión } 3 \\
\text { Reuniones }\end{array}$ & $\begin{array}{l}\text { Logística } \\
\text { Bases Datos } \\
\text { Almacenes } \\
\text { Transporte } \\
\text { RRHH } \\
\text { Compras } \\
\text { Ventas } \\
\text { Planificación } \\
\text { Supervisión } \\
\text { Presupuestos } \\
\text { Toma de decisión } \\
\text { Reuniones }\end{array}$ \\
\hline $\begin{array}{l}\text { Idiomas } \\
\text { Experto (E) } \\
\text { Medio (M) } \\
\text { Ninguno }(\mathrm{N})\end{array}$ & $\begin{array}{l}\text { Idiomas } \\
\text { Experto (E) } \\
\text { Medio (M) } \\
\text { Ninguno (N) }\end{array}$ & $\begin{array}{l}\text { Idiomas } \\
\text { Experto (E) } \\
\text { Medio (M) } \\
\text { Ninguno (N) }\end{array}$ & $\begin{array}{l}\text { Idiomas } \\
\text { Experto (E) } \\
\text { Medio (M) Adm } \\
\text { Ninguno (N) } \\
\text { Operarios }\end{array}$ \\
\hline
\end{tabular}




\begin{tabular}{|c|c|c|c|}
\hline $\begin{array}{l}\text { Habilidades } \\
\text { Responsabilidad I } \\
\text { Trato humano con } \\
\text { clientes } \\
\text { Trabajo en equipo }\end{array}$ & $\mathrm{X}$ & $\begin{array}{l}X \\
X \\
X\end{array}$ & $\begin{array}{l}X \\
X \\
X\end{array}$ \\
\hline \multicolumn{4}{|l|}{ Experiencia Anterior } \\
\hline Logística (Log) & Logística & Logística 1 & Logística \\
\hline Bases Datos (BD) & Bases Datos & Bases Datos & Bases Datos \\
\hline Almacenes (Alm) & Almacenes & Almacenes 2 & Almacenes \\
\hline Transporte(Trans) & Transporte & Transporte3 & Transporte \\
\hline RRHH (RRHH) & RRHH 4 & RRHH & RRHH \\
\hline Compras (C) & Compras & Compras 4 & Compras \\
\hline Ventas (V) & Ventas & Ventas & Ventas \\
\hline Planificación(Pln) & Planificación 1 & Planificación & Planificación \\
\hline Supervisión (Spv) & Supervisión & Supervisión & Supervisión \\
\hline Presupuestos(\$) & Presupuestos 2 & Presupuestos & Presupuestos \\
\hline Toma de decisión & Toma de decisión3 & Toma de decisión 3 & Toma de decisión \\
\hline Reuniones (Mtng) & Reuniones & Reuniones & Reuniones \\
\hline \multicolumn{4}{|l|}{ Informática } \\
\hline Manejo de PC & Manejo de PC & Manejo de PC & Manejo de PC \\
\hline Bases de datos & Bases de datos & Bases de datos & Bases de datos \\
\hline Scanner & Scanner/Cod Barr & Scanner/Cod Barr & Scanner/Cod Barr \\
\hline Control almacén & Control almacén & Control almacén & Control almacén \\
\hline Telecomunicación & Telecomunicación & Telecomunicación & Telecomunicación \\
\hline
\end{tabular}

15. ¿ Se realiza una planificación de los RRHH dedicados al departamento logístico?

Si / No

16. ¿Quién se encarga de realizar la planificación?

\begin{tabular}{|l|l|l|}
\hline Director & Gestor/ Manager & Administrativo / Operario \\
\hline
\end{tabular}

17. ¿Quién se encarga de asignar personal a las tareas?

\begin{tabular}{|l|l|l|}
\hline Director & Gestor/ Manager & Administrativo / Operario \\
\hline
\end{tabular}

18. ¿Quién define las tareas a realizar en cada puesto?

\begin{tabular}{|l|l|l|}
\hline Director & Gestor/ Manager & Administrativo / Operario \\
\hline
\end{tabular}

19. ¿Conocen los empleados las tareas a desarrollar en sus puestos logísticos?

\begin{tabular}{|l|c|c|c|}
\hline & Director & Gestor/ Manager & Administrativo / Operario \\
\hline Si & $\mathrm{X}$ & $\mathrm{X}$ & $\mathrm{X}$ \\
\hline No & & & \\
\hline
\end{tabular}


20. ¿Quién explica y describe cómo, cuando, donde y que tareas han de realizarse en las actividades de los procesos logísticos?

\begin{tabular}{|l|l|l|l|}
\hline & Director & Gestor/ Manager & Administrativo / Operario \\
\hline QUE & & \multicolumn{1}{|c|}{ X } & \\
\hline COMO & & $\begin{array}{l}\text { Proceso SPIC } \\
\text { Definir con cliente } \\
\text { Firma y Actualizar }\end{array}$ & \\
\hline CUANDO & & $\begin{array}{l}\text { Actualizar datos a diario } \\
\text { Revisión mensual } \\
\text { Acc Internet }\end{array}$ & \\
\hline DONDE & & Junto al cliente & \\
\hline
\end{tabular}

21. ¿Qué tipo de formación se imparte a los empleados logísticos?

\begin{tabular}{|l|l|l|c|c|c|}
\hline & $\begin{array}{l}\text { Duración de la } \\
\text { Formación }\end{array}$ & $\begin{array}{l}\text { Cada cuanto } \\
\text { tiempo }\end{array}$ & Práctica & $\begin{array}{c}\text { Teórica } \\
\text { en casa } \\
\text { Interna }\end{array}$ & $\begin{array}{c}\text { Teórica } \\
\text { contratada }\end{array}$ \\
\hline Director & Min 25 hrs año & & $\mathrm{X}$ & $\mathrm{X}$ & $\mathrm{X}$ \\
\hline Gestor/Manager & $\begin{array}{l}\text { Min 25 hrs año } \\
80-100 \text { aprox }\end{array}$ & & $\mathrm{X}$ & $\mathrm{X}$ & $\mathrm{X}$ \\
\hline $\begin{array}{l}\text { Administrativo } \\
\text { /Operario }\end{array}$ & Min 25 hrs año & & $\mathrm{X}$ & $\mathrm{X}$ & $\mathrm{X}$ \\
\hline
\end{tabular}

